\title{
Earnings dynamics in Europe
}

Citation for published version (APA):

Sologon, D. M. (2010). Earnings dynamics in Europe. [Doctoral Thesis, Maastricht University]. Boekenplan Maastricht. https://doi.org/10.26481/dis.20100604ds

Document status and date:

Published: 01/01/2010

DOI:

$10.26481 /$ dis.20100604ds

Document Version:

Publisher's PDF, also known as Version of record

\section{Please check the document version of this publication:}

- A submitted manuscript is the version of the article upon submission and before peer-review. There can be important differences between the submitted version and the official published version of record.

People interested in the research are advised to contact the author for the final version of the publication, or visit the DOI to the publisher's website.

- The final author version and the galley proof are versions of the publication after peer review.

- The final published version features the final layout of the paper including the volume, issue and page numbers.

Link to publication

\footnotetext{
General rights rights.

- You may freely distribute the URL identifying the publication in the public portal. please follow below link for the End User Agreement:

www.umlib.nl/taverne-license

Take down policy

If you believe that this document breaches copyright please contact us at:

repository@maastrichtuniversity.nl

providing details and we will investigate your claim.
}

Copyright and moral rights for the publications made accessible in the public portal are retained by the authors and/or other copyright owners and it is a condition of accessing publications that users recognise and abide by the legal requirements associated with these

- Users may download and print one copy of any publication from the public portal for the purpose of private study or research.

- You may not further distribute the material or use it for any profit-making activity or commercial gain

If the publication is distributed under the terms of Article $25 \mathrm{fa}$ of the Dutch Copyright Act, indicated by the "Taverne" license above, 
EARNINGS DYNAMICS IN EUROPE 
(C) 2010 Denisa Maria Sologon

All rights reserved. No part of this publication may be reproduced, stored in a retrieval system, or transmitted in any form, or by any means, electronic, mechanical, photocopying, recording or otherwise, without the prior permission in writing, from the author.

ISBN 9789086661442

Cover picture by Denisa Maria Sologon

Published by Boekenplan, Maastricht 


\section{EARNINGS DYNAMICS IN EUROPE}

\section{DISSERTATION}

PROEFSCHRIFT

To obtain the degree of Doctor at the Maastricht University, on the authority of the Rector Magnificus Prof. Dr. G.P.M.F. Mols, in accordance with the decision of the Board of Deans, to be defended in public on 4 June 2010, at 10:00 hours

$$
\text { by }
$$

\section{Denisa Maria Sologon}


Promoter:

Supervisors:

Assessment Committee:
Prof. Dr. Chris de Neubourg

Dr. Cathal O'Donoghue, Teagasc Rural Economy Research Centre; NUI Galway; IZA and ULB

Dr. Raymond Wagener, Inspection Générale De La Sécurité Sociale (IGSS), Luxembourg

Prof. Dr. Lex Borghans (Chairman)

Prof. Dr. Hans Heijke

Dr. Erik de Regt

Prof. Dr. Gary Solon, Michigan State University (USA)

Dr. Philippe Van Kerm, CEPS/INSTEAD

(Luxembourg), Institute for Social and Economic

Research, University of Essex (UK), University of

Namur (Belgium) 
In loving remembrance of my mother, Lia 


\section{Acknowledgements}

This book is dedicated to my beloved parents and grandparents, whose love and sustained support made this accomplishment possible. There are no words to capture my love and my gratitude for all their sacrifices.

I thank Victor for his love and for being my pillar of strength through the hardest moments of my life. We started our Master together and now we are finishing our PhDs together: thank you for making these challenging years a beautiful, happy and enriching experience.

My deepest gratitude goes towards my supervisors, Dr. Cathal O'Donoghue and Dr. Raymond Wagener, whose kind and fruitful guidance led my steps towards obtaining my PhD. I learned tremendously from working with you and I am so grateful for the stimulating working environment you have created for me. Thank you for being so supportive, for believing in me and for the amazing opportunities you have opened to me. You hold a very special place in my heart.

I would like to thank the reading committee members, Prof. Dr. Lex Borghans, Prof. Dr. Hans Heijke, Dr. Erik de Regt, Prof. Dr. Gary Solon and Dr. Philippe Van Kerm for their useful comments in finalizing this manuscript.

My PhD developed within a unique place - Maastricht Graduate School of Governance - created with a unique vision. I thank our promoter Chris de Neubourg and his team - Annemarie Rima, Mindel van de Laar, Franziska Gassmann, Mieke Drossaert, Celine Duijsens and Susan Roggen - for creating not only an amazing educational environment, but also a real family. This School has become home for many of us, extremely rewarding and motivating those far away from their homes. My PhD years have been the best years of my life. And this was due to the School and my dear colleagues, who became cherished lifetime friends. We share so many memories...from the stressful moments and the amazing PhD parties, to the great joy of the four marriages and four PhD babies - Paola, Farouk, Izzy and Calvin. Yes, we have been very productive! Thank you, my dear friends for the unforgettable moments we have shared!

Zina - we started this road together sharing the same office and we grew into more than friends. I am so grateful to have met somebody as special as you. Thank you for being there with your love, friendship and wisdom! You have enriched my life in so many ways! 
Melissa - you won my heart with your delicious lactose-free brownies in the first year! There are so many memories I cherish... Thank you for the memorable "ladies nights", the great parties, brunches, and diners you hosted... but for them, these years wouldn't have been as much fun. I thank you and Flo for visiting my family in Romania and for the nice vacations we spent together.

Britta - one of the warmest and sincere hearts I have ever met! Thank you for being there during tough times and for the wonderful moments we have shared!

Jessica - you are our "Superwoman": three adorable, smart babies and a PhD. I thank you, Alex and Paola for visiting my family in Romania and for the precious memories.

Jinjing - there are so many memories that bond us and I cherish them all...Thank you for being there both during tough and good times, and for visiting my family in Romania.

Frieda - unique Frieda... our French "touch". Liege has stolen you from Maastricht, but not from my heart.

Metka - I will always remember our cosy girly movie evenings. Not to mention the great parties, brunches, dinners at your house...great memories!

The Mexicans Paty and David- one of my regrets is missing your great wedding! Thank you for always making me laugh and for the great parties, brunches and chats we had!

Robert - thank you for your help during my first year in Maastricht...it helped me make Maastricht my home. Lina - we share nice memories from the summer school in Palma de Mallorca and our visits in Luxembourg.

Carlos, Eze, Irina, Ilire, Luciana, Jasmin, Nevena, Seda- thank you for the nice parties, chats, brunches, lunches and dinners we had together.

These years were also a culinary delight. I thank Sonila and Florian for sharing with us the great Albanian cuisine; Maha and Cheng for the amazing Asian diners; Ana Maria for the delicious pizza moments; Carlos and Carolina for the exquisite Columbian dishes; and Jinjing for opening the doors to the diverse Chinese cuisine.

I thank Bart, Keetie, Kristine, and Mindel for helping me with the Dutch translation. It was not an easy job and I am very grateful.

Thank you to my other friends at the School, Bianca, Christiane, Geranda, Hao, Judith, Julie, Keetie, Marina, Michal, Mirtha, Pascal, and Renée for their friendship and the nice moments we shared. 
My PhD project developed within a larger project - The Coherence of Social Transfer Policies and Microsimulation - REDIS - initiated by the Inspection Générale de la Sécurité Sociale (Luxembourg) in cooperation with CEPS/ INSTEAD (Luxembourg) and Cathal O'Donoghue (Teagasc Rural Economy Research Centre; NUI Galway; IZA and ULB). I would like to thank all team members of the REDIS project - Raymond Wagener, Isabelle Debourg, Tom Dominique, Thierry Mazoyer, Frédéric Berger, Philippe Liegeois, Nizamul Islam - who created a pleasant and stimulating working environment.

I thank the Harvard Kennedy School of Government, Harvard University, for accepting me as a visiting research fellow. It was an amazing experience which enriched both my personal and my professional development. I would like to thank Gerardo for his useful comments and his friendship during our research visit at Harvard University.

I thank the Marie Curie Fellowship and the Fonds National de la Recherche (Luxembourg) who funded my PhD research fellow work contract at Maastricht University, and without whom this PhD would not have been possible.

I thank Mihai Focsa, Adrian Postelnicu and Prof. Tutuianu Ion, who cultivated my passion for Mathematics, which proved to be of invaluable help for my thesis.

I thank Gabi and Roger - my Luxembourgish family - for their love and enthusiastic support.

Last but not least I thank the rest of my family and my oldest friends from Romania - Corina, Cristi, Levi, Roxana, Silvia, Silviu and Stefan who always believed in me. 


\section{Table of Contents}

Preface

iv

1. Introduction 1

1.1. Objective and relevance 3

$\begin{array}{ll}\text { 1.2. Structure of the study } & 7\end{array}$

2. Increased opportunity to move up the economic ladder? Earnings mobility in the EU: 1994-2001

2.1. Introduction 11

2.2. Literature review 12

2.3. Methodology 13

2.3.1. Transition matrix approach to mobility 14

2.3.2. Alternative approach to mobility (Dickens 2000a) 15

2.4. Data 16

2.5. Changes in the cross-section earnings distribution over time 17

2.6. Linking earnings inequality and mobility: individual movements within the distribution over time $\quad 25$

2.6.1. Mobility among labour market states 25

2.6.2. The transition matrix approach to mobility among income quintiles 27

2.6.3. Alternative approach to mobility (Dickens 2000a) 37

2.7. Linking mobility and inequality 47

2.7.1. Short-term mobility and yearly inequality $\quad 47$

2.7.2. Long-term mobility and yearly inequality 49

2.8. Concluding remarks 50

2.9. Annex 55

3. Equalizing or disequalizing lifetime earnings differentials? Earnings mobility in the EU: 1994-2001

$\begin{array}{ll}\text { 3.1. Introduction } & 77\end{array}$

$\begin{array}{ll}\text { 3.2. } & 79\end{array}$

3.3. Methodology 81

3.3.1. Shorrocks $\quad 81$

3.3.2. Fields $\quad 83$

3.4. Data 84 
3.5. Changes in earnings inequality $\quad 85$

3.5.1. Changes in the cross-section earnings distribution over time 85

3.5.2. Changes in the earnings distribution over the lifecycle: short versus long-term income inequality

3.6. Mobility profile $\quad 99$

3.6.1. Stability profile - Shorrocks 99

3.6.2. Mobility Profile - as equalizer on long-term earnings inequality 109

3.6.3. The evolution of mobility over time 122

$\begin{array}{ll}\text { 3.7. Concluding remarks } & 125\end{array}$

$\begin{array}{ll}\text { 3.8. Annex } & 129\end{array}$

4. Earnings dynamics and inequality in EU, 1994-2001 137

$\begin{array}{lll}\text { 4.1. Introduction } & 138\end{array}$

4.2. Literature review 139

4.3. Theoretical model of the determinants of wage differentials 141

4.3.1. Determinants of earnings inequality 141

4.3.2. Alternative model specifications for the permanent and transitory components 142

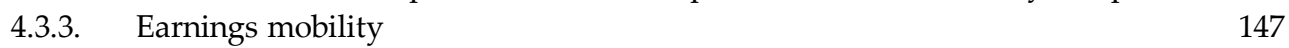

$\begin{array}{lll}\text { 4.4. Data } & 148\end{array}$

4.5 Econometric specification and estimation method of covariance structures 150

$\begin{array}{lll}\text { 4.5.1. } & \text { Econometric earnings specification } & 151\end{array}$

4.5.2. Specification of the covariance structure of earnings 153

$\begin{array}{lll}\text { 4.5.3. } & \text { Estimation of covariance structures } & 154\end{array}$

4.6. Strategy for model specification $\quad 157$

4.7. The dynamic autocovariance structure of hourly earnings 158

4.8. Results of covariance structure estimation 163

4.8.1. Error component model estimation results 163

4.9. Inequality decomposition into permanent and transitory inequality 175

4.9.1. Absolute decomposition 175

4.9.2. Relative decomposition - structure of inequality 181

4.10. Concluding remarks 190

4.11. Annex 193

5. Policy, institutional factors and earnings mobility 203

5.1. Introduction 204

5.2. Theoretical model of the determinants of wage differentials 207

$\begin{array}{lll}\text { 5.2.1. } & \text { Literature review } & 207\end{array}$

5.2.2. Determinants of earnings inequality 207

5.2.3. Permanent and transitory components of earnings inequality 209

$\begin{array}{lll}\text { 5.3. Data } & 225\end{array}$

5.4. Econometric specifications and estimation methods 228

5.4.1. Econometric specifications and estimation methods of covariance structures 228 
5.4.2. Estimation of the links between policy, institutions and outcomes 232

5.5. Results - descriptive 234

5.5.1. The dynamic autocovariance structure of hourly earnings 234

5.5.2. The evolution of the main labour market and institutional factors 236

5.6. Results of covariance structure estimation 239

$\begin{array}{lll}\text { 5.6.1. } & \text { Estimation results } & 239\end{array}$

5.6.2. Inequality decomposition into permanent and transitory inequality 243

5.7. Linking policy with outcomes 256

5.7.1. Explaining the changes and differences 257

$\begin{array}{ll}\text { 5.7.2. Correlations } & 259\end{array}$

$\begin{array}{lll}\text { 5.7.3. } & \text { Estimation } & 262\end{array}$

5.8. Concluding remarks 278

5.9. Annex 281

6. Earnings dynamics and inequality among men in Luxembourg, 1988-2004: evidence from administrative data 291

6.1. Introduction 292

6.2. Literature review 294

6.3. Theoretical model of the determinants of wage differentials 297

6.3.1. Determinants of earnings inequality 297

$\begin{array}{lll}\text { 6.3.2. } & \text { Earnings mobility } & 302\end{array}$

6.4. Data 304

6.5. Econometric specification and estimation method of covariance structures 310

6.5.1. Econometric earnings specification 310

6.5.2. Specification of the covariance structure of earnings 313

$\begin{array}{lll}\text { 6.5.3. } & \text { Estimation of covariance structures } & 314\end{array}$

6.5.4. Strategy for model specification 318

6.6. The dynamic autocovariance structure of hourly earnings 319

6.7. Results of Covariance Structure Estimation 324

6.7.1. Error component model estimation results 338

6.7.2. Inequality Decomposition into Permanent and Transitory Inequality 338

6.8. Concluding remarks 360

6.9. Annex 363

7. Conclusions and forward looking 365

Bibliography $\quad 378$

Samenvatting $\quad 385$

Curriculum Vitae $\quad 389$

Maastricht Graduate School of Governance Dissertation Series 394 


\section{Preface}

This dissertation is a collection of five articles written as standalone papers included as separate chapters. Given the strong link between the articles due to the common theme and in some cases common methodology, this dissertation includes a certain degree of duplication. I summarize below the overlapping parts between the five papers, together with the working papers these chapters are based on.

Chapter 2 - Increased opportunity to move up the economic ladder? Earnings mobility in the EU: 1994-2001 - is based on Sologon and O'Donoghue (2009d).

Chapter 3 - Equalizing or disequalizing lifetime earnings differentials? Earnings mobility in the EU: 1994-2001 - is based on Sologon and O'Donoghue (2009c). The information in section 3.4 and 3.5.1 has already been discussed in section 2.4 and 2.5 .

Chapter 4 - Earnings dynamics and inequality in EU, 1994-2001 - is based on Sologon and O'Donoghue (2009a, 2009b). Part of the information in section 4.4 has been discussed in section 2.4 and 3.4. This version benefitted from the valuable comments received from Gary Solon, University of Michigan, Christopher Jencks, Harvard University, and Peter Gottschalk, Boston College.

Chapter 5 - Policy, institutional factors and earnings mobility - is based on Sologon and O'Donoghue (2009e). It builds on the results obtained by Sologon and O'Donoghue (2009a, 2009b) discussed in Chapter 4: using the predicted components from the error component models estimated in Chapter 4 and the OECD data, we estimate the relationship between the three labour market outcomes - permanent inequality, transitory inequality and earnings immobility and the labour market policy and institutional factors. Since this Chapter is written as a standalone paper, the information in sections 5.2.3.1, 5.2.3.2, 5.4.1, 5.5.1, 5.6 summarises the core aspects of Chapter 4: the econometric specification and estimation method of the covariance earnings structure, the dynamic autocovariance structure of hourly earnings, and the results of the covariance structure estimation for each country.

Chapter 6 - Earnings dynamics and inequality among men in Luxembourg, 19882004: evidence from administrative data - is based on Sologon (2009). The information in section 6.2, 6.3, 6.5.3, and 6.5.4 has been discussed in Chapter 4. 


\section{List of Figures}

Figure 2.1. Epanechinov Kernel Density Estimates for Selected Years - EU 15. .18

Figure 2.2. Percentage Change in Mean Hourly Earnings by Percentiles Over The Sample

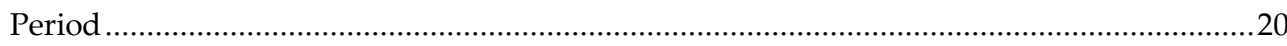

Figure 2.3. Ratio between Mean Earnings at the 9th Decile and the 1st Decile......................21

Figure 2.4. Relative Change in Inequality over Time - Gini, Theil, Atkinson(1), D9/D1 ........24

Figure 2.5. Immobility Ratio for One-Year Transitions between Earnings Quintiles over Time

Figure 2.6. Average Jump for One-Year Transitions between Earnings Quintiles over Time 30 Figure 2.7. Relative Change over Time in Short-Term Immobility Ratio (IR) and Average Jump (AJ) 30

Figure 2.8. Relative Difference between Long and Short-term Immobility Ratio and Average

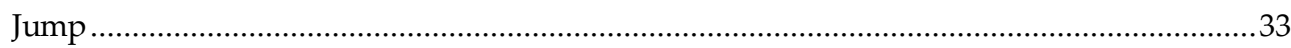

Figure 2.9. Short and Long Term Immobility Ratio and Average Jump................................35

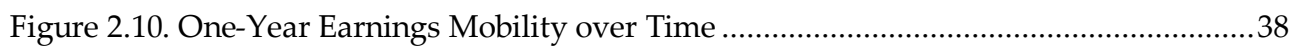

Figure 2.11. One-Year and Seven-Year Period Earnings Mobility: 1994-1995; 1994-2001 ....... 39

Figure 2.12. Dickens Mobility Index for Different Time Horizons the Sample Period

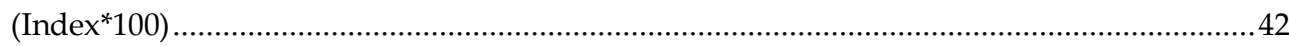

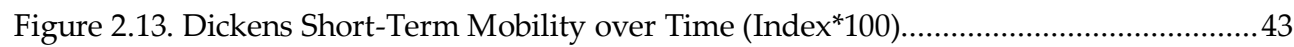

Figure 2.14. Relative Change in Short-term Mobility Measured by the Dickens Index..........44

Figure 2.15. Relative Difference between Long and Short-term Mobility Measured by the

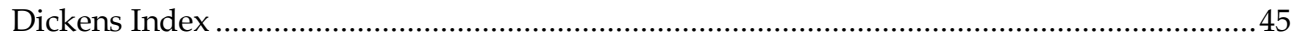

Figure 2.16. Short (1994/1995) and Long Term (1994/2001) Mobility Measured by the Dickens Index

Figure 2.17. Relative Difference between Long-Term and Cross-sectional Earnings Inequality

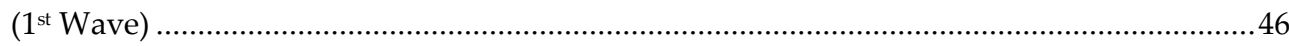

Figure 2.18. Link between Short-Term Mobility and Cross-Sectional Inequality: ..................4 48 Figure 2.19. Relative Change in Cross-Sectional Inequality and Short-Term Mobility Over

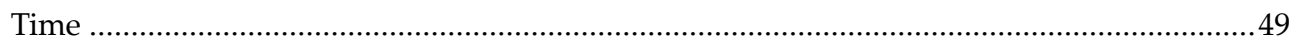

Figure 2.20. Long-Term Mobility and Cross-Sectional Inequality .........................................50

Figure 3.1 Percentage Change in Mean Hourly Earnings by Percentiles Over The Sample

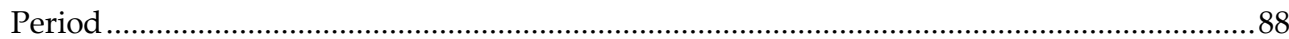

Figure 3.2 Ratio between Mean Earnings at the 9th Decile and the 1st Decile......................89

Figure 3.3.Relative Change in Inequality over Time - Gini, Theil, Atkinson(1), D9/D1 .........92

Figure 3.4. Short and Long Term Income Inequality and their Relative Difference ...............94 
Figure 3.5. Stability Profiles for Male Earnings by Selected Countries (based on Theil) -

Balanced vs Unbalanced

Figure 3.6. Stability Profiles for Male Earnings for Selected Countries (based on Theil) -

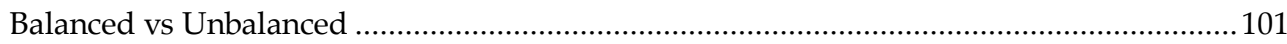

Figure 3.7. Long-Term Earnings Mobility based on the Shorrocks Index ............................... 108

Figure 3.8. Mobility Profile based on the Fields Index ......................................................112

Figure 3.9. Mobility Profile based on the Fields Index ....................................................... 113

Figure 3.10. Long-Term Earnings Mobility (Fields)..............................................................116

Figure 3.11. Scatter plot of 6-year and 7-year period mobility: Shorrocks vs. Fields ............118

Figure 3.12. Scatter plot of 8-year period mobility: Shorrocks vs. Fields..............................119

Figure 3.13. The Evolution of 2-Year Period Mobility ......................................................... 123

Figure 3.14. The Evolution of Long-Term Mobility Over Time ..........................................125

Figure 3-A-1. Epanechinov Kernel Density Estimates for Selected Years - EU 15...............136

Figure 4.1. Overall Autocovariance Structure of Hourly Earnings: Years 1994-2001 ...........160

Figure 4.2. Permanent and Transitory Variance for Selected Cohorts in 2001 .....................178

Figure 4.3. Actual and Predicted Variance of Earnings with Permanent and Transitory

Predicted Components for Selected Cohorts: 1994-2001 .......................................................179

Figure 4.4. Predicted Permanent and Transitory Variance as \% of Predicted Overall Variance

for Selected Cohorts: 1994-2001 .............................................................................................. 182

Figure 4.5. Ratio between Permanent Variance and Transitory Variance over Time for

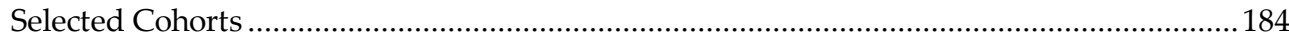

Figure 4.6. Permanent Inequality - \% of the Overall Inequality and Earnings Immobility for

Selected Cohorts over Time 185

Figure 4.7. Average Earnings Immobility - Ratio between Average Permanent Variance and

Average Transitory Variance over Time. 188

Figure 4.8. Average Earnings Inequality and Average Earnings Immobility Ratio in 2001 .189 Figure 4-A-1. Autocovariance Structure of Hourly Earnings for Selected Cohorts: years 19942001

Figure 4-A-2. Lifecycle Autocovariances for Selected Years: First and Last Wave, by Country

Figure 5.1. Determinants of Permanent and Transitory Inequality and Earnings Mobility. 217 Figure 5.2. Labour Market Evolution: Union Density, EPL, PMR, Tax Wedge, , EPLT, EPLR,

Degree of Corporatism, Bargaining Coverage..................................................................237

Figure 5.3.Actual and Predicted Variance of Earnings with Permanent and Transitory

Predicted Components for Selected Cohorts: 1994-2001 245

Figure 5.4. Predicted Permanent and Transitory Variance as \% of Predicted Overall Variance for Selected Cohorts: 1994-2001 247 
Figure 5.5. Ratio Between Permanent Variance and Transitory Variance Over Time For

Selected Cohorts

Figure 5.6. Permanent Inequality - \% of the Overall Inequality and Earnings Immobility for

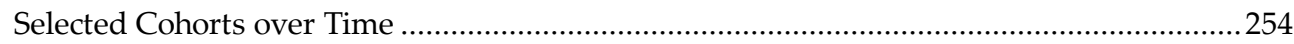

Figure 5-A-1. Overall Autocovariance Structure of Hourly Earnings: Years 1994-2001 ....... 289

Figure 5-A-2. Evolution of Macroeconomic Shocks..............................................................290

Figure 6.1. The variance and mean of log hourly earnings, 1988-2004 ................................306

Figure 6.2. The evolution of the labour market structure by occupational status in the sample in 1988, 1996 and 2004.

Figure 6.3. The evolution of the labour market structure by sector in the sample in 1988, 1996

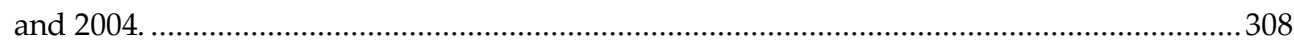

Figure 6.4. The evolution of the age structure of the active population in the sample.........309

Figure 6.5. Autocovariance Structure of Earnings for Selected Cohorts: 1940 - 1975 ...........321

Figure 6.6. Lifecycle Autocovariances for Selected Years : 1988, 1992, 1996, 2000, 2004....... 323

Figure 6.7. The pattern of the permanent component without time and cohort loading

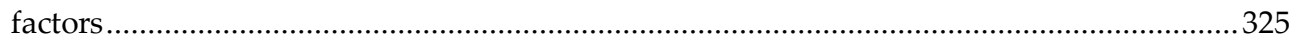

Figure 6.8. Year-specific factor loadings on the persistent and transitory components .......325

Figure 6.9. Cohort-specific loading factors on the permanent and transitory components.. 326

Figure 6.10. Cohort-specific initial transitory variances ..................................................... 327

Figure 6.11. The age profile of the variance of the transitory innovation, base model .........328

Figure 6.12. Actual and Predicted Variance of Earnings with Permanent and Transitory

Predicted Components for Selected Cohorts: 1940-1975 ....................................................341

Figure 6.13. Predicted Permanent and Transitory Variance as \% of Predicted Overall

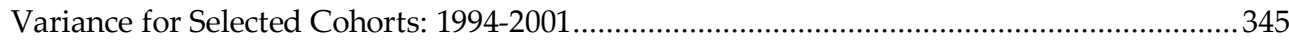

Figure 6.14. Earnings immobility for men by cohort over time - base model.......................347

Figure 6.15. Cross-sectional age profile of the permanent and transitory variance for selected

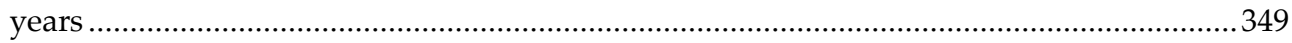

Figure 6.16. Cross-sectional age profile of the share of the permanent component from the

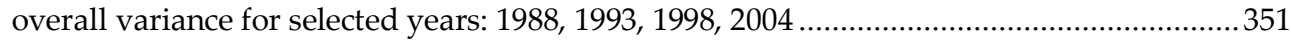

Figure 6.17. The cross-sectional age - immobility profile for selected years 1988, 1993, 1998, 2004

Figure 6.18. A decomposition of the variance of log hourly earnings for men, 40 years old:

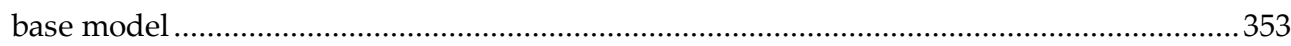

Figure 6.19. Earnings immobility for men of age 30,40 and 50 - base model .......................355

Figure 6.20. Earnings immobility for men of age 20, 25, 30, 35, 40, 45, 50, 55 - base model. 356 Figure 6.21. A decomposition of the variance of log hourly earnings for men, 40 years old: restricted model. 359 
Figure 6-A-1. The evolution of the labour market structure by occupation status in Luxembourg in 1988, 1996 and 2004.

Figure 6-A-2. The evolution of the labour market structure by sector of activity in Luxembourg in 1988, 1996 and 2004 .363

Figure 6-A-3. The evolution of the age structure in Luxembourg in 1988, 1996 and 2004 ...364 


\section{List of Tables}

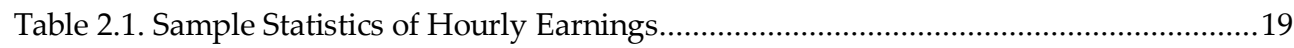

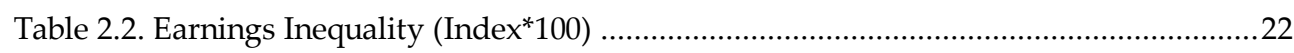

Table 2.3. Immobility Ratio (IR) and Average Jump (AJ) for 1-year and 7-year Transition

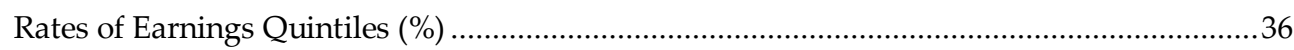

Table 2.4. Mobility Index for different time horizons over time: year 1994-2001 (Index¹00)

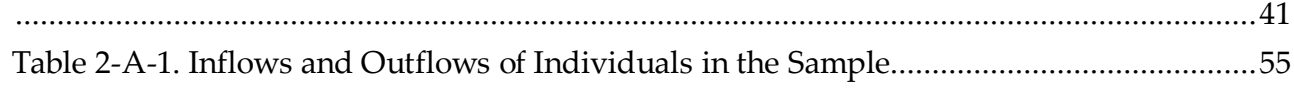

Table 2-A-2. Short-Term Transition Rates Among Labour Market States ..............................62

Table 2-A-3. Long-Term Transition Rates Among Labour Market States ...............................67

Table 2-A-4. Short-Term Transition Rates Among Income Quintiles ......................................70

Table 2-A-5. Long-Term Transition Rates Among Income Quintiles ....................................74

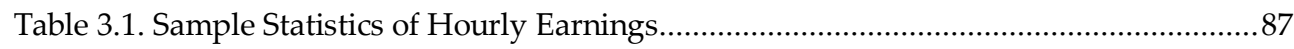

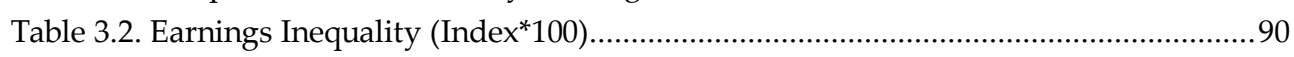

Table 3.3. Earnings Inequality (Theil) for Different Time Horizons - Balanced sample over

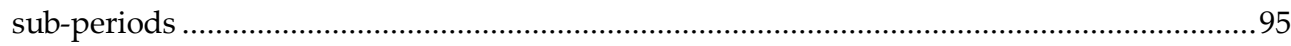

Table 3.4. Earnings Inequality (Theil) for Different Time Horizons - Unbalanced sample over

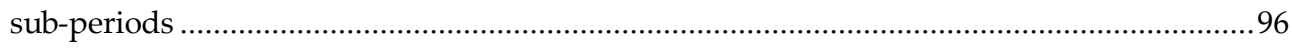

Table 3.5. Shorrocks Mobility based on Theil for Different Time Horizons - Balanced sample

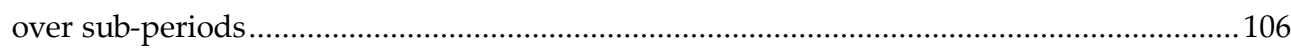

Table 3.6. Shorrocks Mobility based on Theil for Different Time Horizons - Unbalanced

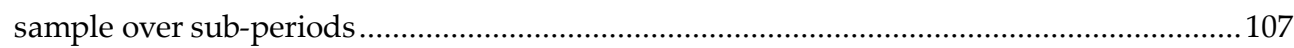

Table 3.7. Fields Mobility based on Theil for Different Time Horizons - Balanced sample

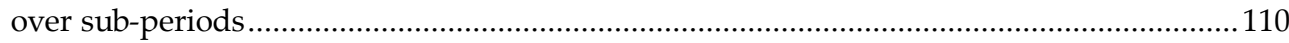

Table 3.8. Fields Mobility based on Theil for Different Time Horizons - Unbalanced sample over sub-periods.

Table 3.9. Dominance relations in long term earnings mobility: Shorrocks and Fields Index

Table 3-A-1. Inflows and Outflows of Individuals in the Sample. 129

Table 4.1. Mean hourly earnings ( Euro) and number of individuals with positive earnings 
Table 4.2. Error-Components Models for Log Real Hourly Earnings

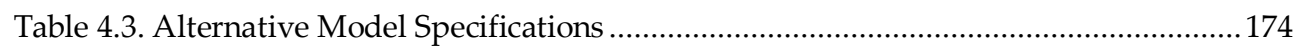

Table 4-A-1. Inflows and Outflows of Individuals in the Sample......

Table 5.1. Mean hourly earnings and number of individuals with positive earnings 226

Table 5.2. Summary of the evolution of the actual inequality, permanent and transitory inequality, the permanent inequality as \% of predicted overall variance, and the immobility ratio, by cohorts: $1994-2001$ 250

Table 5.3. Summary of the evolution of the average actual inequality, average permanent and transitory inequality, and the average immobility ratio : 1994-2001

Table 5.4. Pair wise Correlations Between the Labour Market Outcomes, Labour Market

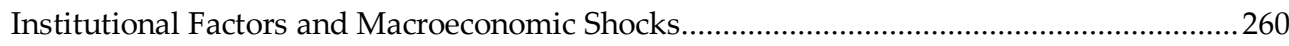

Table 5.5. Model 1 - Systemic Effects across Institutions......................................................264

Table 5.6. Models with cross-interactions between institutions and macroeconomic shocks,

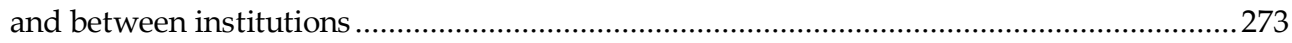

Table 5.7. Summary results for permanent variance ........................................................... 275

Table 5.8. Summary results for transitory variance ............................................................ 276

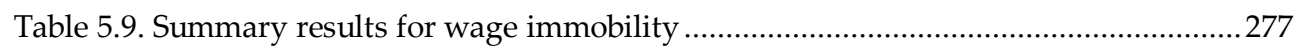

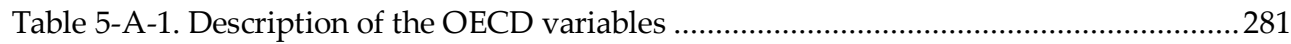

Table 5-A-2. Institutional Variables - Summary Statistics ..................................................... 282

Table 5-A-3. The Evolution of the labour market policy and institutional factors: 1994-2001

Table 5-A-4. Share of employees by educational level, by sector, by type of contract, by employment status, by occupation - for selected cohorts based on ECHP...........................228

Table 5-A-5. Error-Components Models for Log Real Hourly Earnings ............................... 285

Table 6.1. Cohorts Included in the Working Sample .............................................................305

Table 6.2. Wald tests of model restrictions in the base model..............................................329

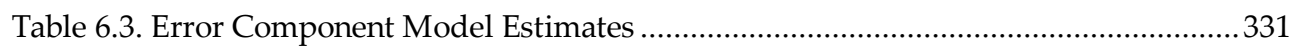

Table 6.4. Trend and cyclical variation of the persistent and transitory components, base and

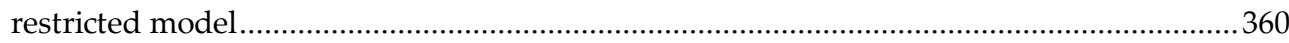


1. INTRODUCTION 
Nearly half a century ago Milton Friedman (1962) called attention to the importance of mobility in understanding inequality:

"A major problem in interpreting evidence on the distribution of income is the need to distinguish two basically different kinds of inequality: temporary, short-run differences in income, and differences in long-run income status. Consider two societies that have the same distribution of annual income. In one there is great mobility and change so that the position of particular families in the income hierarchy varies widely from year to year. In the other, there is great rigidity so that each family stays in the same position year after year. Clearly, in any meaningful sense, the second would be the more unequal society. The one kind of inequality is a sign of dynamic change, social mobility, equality of opportunity; the other of a status society."

Interest in the extent of mobility in individual earnings over time has increased greatly in recent years and was fuelled mainly by the rise in earnings inequality experienced by many developed countries during the 1980s and 1990s, which triggered a strong debate with respect to the driving factors and the implications of this increase.

Some analysts argue that rising annual inequality does not necessarily have negative implications. This statement relies on the "offsetting mobility" argument, which states that if there has been a sufficiently large simultaneous increase in mobility, the inequality of income measured over a longer period of time, such as lifetime income or "permanent" income - can be lower despite the rise in annual inequality, with a positive impact on social welfare. This statement, however, holds only under the assumption that individuals are not averse to income variability, future risk or multi-period inequality (Creedy and Wilhelm, 2002; Gottschalk and Spolaore, 2002). Therefore, there is not a complete agreement in the literature on the value judgement of income mobility (Atkinson, Bourguignon, and Morrisson, 1992).

Those that value income mobility positively perceive it in two ways: as a goal in its own right or as an instrument to another end. The goal of having a mobile society is linked to the goal of securing equality of opportunity in the labour market and of having a more flexible and efficient economy (Friedman, 1962; Atkinson et al., 1992). The instrumental justification for mobility takes place in the context of 
achieving distributional equity: lifetime equity depends on the extent of movement up and down the earnings distribution over the lifetime (Atkinson et al., 1992).

In this line of thought, Friedman (1962) underlined the role of social mobility in reducing lifetime earnings differentials between individuals, by allowing them to change their position in the income distribution over time. Thus earnings mobility is perceived in the literature as a way out of poverty. In the absence of mobility the same individuals remain stuck at the bottom of the earnings distribution, hence annual earnings differentials are transformed into lifetime differentials.

Hence the scarcity of data on lifetime earnings motivated the study of economic mobility, viewed as the link between short and long-term earnings differentials: a cross-sectional snapshot of income distribution overstates lifetime inequality to a degree that depends on the degree of earnings mobility (Lillard, 1977; Atkinson et al., 1992; Creedy, 1998). If countries have different earnings mobility levels, then single-year inequality country rankings may lead to a misleading picture of longterm inequality ranking. To support this statement, Creedy (1998), conducted a simulation study to examine the relationship between cross-sectional and lifetime income distributions. His conclusion was that simple inferences about lifetime income distributions cannot be made on the basis of cross-sectional distributions alone, thus the need for information on earnings mobility.

In order to understand fully the evolution of economic inequality and opportunity, it is crucial to combine the analysis of earnings inequality with the analysis of earnings mobility.

\subsection{Objective and relevance}

This dissertation explores the dynamics of individual male earnings in order to explain what is happening behind the changes in the distribution of labour market income across $14 \mathrm{EU}$ countries. In the study of earnings, the treatment of dynamics has become increasingly sophisticated. The same strategy is applied here. The objective of this dissertation is twofold.

\section{$1^{\text {st }}$ Objective: Cross-national EU comparative studies on earnings dynamics}

As a first objective, I conduct four cross-national comparative studies on earnings dynamics at the EU level between 1994 and 2001, to answer the following research questions aimed to cover complementary parts of the inequality-mobility story and to fill part of the research gap on mobility at the EU level: 
(1) Do EU citizens have an increased opportunity to improve their position in the distribution of earnings over time?

Earnings mobility is evaluated using rank measures which capture positional movements in the distribution of earnings.

(2) Do EU citizens have an increased opportunity to improve their position in the distribution of lifetime earnings? To what extent does earnings mobility work to equalize/disequalize longer-term earnings relative to cross-sectional inequality and how does it differ across the EU?

Earnings mobility is evaluated using measures as equalizer of long-term earnings differentials.

(3) To what extent do changes in cross-sectional earnings inequality reflect transitory or permanent components of individual lifecycle earnings variation?

This question is answered using the most complex models of earnings dynamics: starting with the US and Canada, followed by the UK and Europe, recent studies on earnings dynamics stressed the importance of decomposing the growth in earnings inequality into permanent and transitory components, due to their implications for long-run differentials.

Following the terminology introduced by Friedman and Kuznets (1954), individual earnings are composed of a permanent and a transitory component, assumed to be independent of each other. The permanent component of earnings reflects personal characteristics, education, training and other persistent elements. The transitory component captures the chance and other factors influencing earnings in a particular period and is expected to average out over time. Following the structure of individual earnings, overall inequality at any point in time is composed from inequality in the transitory component and inequality in the permanent component of earnings. An increase in cross-sectional earnings inequality triggered by an increase in the permanent component signals an increase in lifetime earnings differentials, suggesting a worsening of the relative lifetime earnings position of the chronically poor. An increase in cross-sectional earnings differentials triggered by an increase in earnings instability signals an increase in earnings mobility, implying an increased opportunity for the poor to improve their relative income position in a lifetime perspective. 
(4) What are the labour market policy and institutional driving factors behind the evolution of the three labour market outcomes - permanent inequality, transitory inequality and earnings mobility?

The answers to the first three questions bring complementary pieces of information regarding the evolution of earnings mobility, the evolution of cross-sectional earnings inequality, its permanent and transitory components, and their implications for lifetime earnings inequality across the EU. So far, at the EU level, no study attempted to analyse and to understand these issues in a comparative manner.

The forth question puts forward an issue neglected so far by the empirical literature on earnings dynamics: the role of labour market policy and institutional factors in explaining cross-national differences in the evolution of permanent inequality, transitory inequality and earnings mobility.

These questions are highly relevant in the context of the changes that took place in the EU labour market policy framework after 1995 under the incidence of the 1994 OECD Jobs Strategy and the 2000 Lisbon Agenda, which recommended policies to increase wage flexibility, lower non-wage labour costs and allow relative wages to better reflect individual differences in productivity and local labour market conditions. Before 1995, Europe could have been described as making labour more expensive, accompanied by a decline in employment and an increase in productivity. Starting at different dates for different policies, Europe began the process of shifting toward making labour less expensive, accompanied by higher employment per capita but lower average productivity per hour. Moreover, all OECD countries moved towards greater decentralization, which could result in greater inter-firm wage differentials. These trends appear to have worsened the apparent trade-off between a strong employment performance and a more equal distribution of earnings, consistent with relative labour demand having shifted towards high-skilled workers (OECD, 2004; Dew-Becker and Gordon, 2008).

As pointed out by Dew-Becker and Gordon (2008) and OECD (2004), the most notable change after 1995 in Europe has been increased country heterogeneity. I investigate how this heterogeneity translates itself in the level and components of the cross-sectional earnings inequality and earnings mobility.

Understanding wage dynamics and the driving factors behind these labour market outcomes - permanent inequality, transitory inequality and earnings mobility - is vitally important from a welfare perspective, particularly given the large variation in the evolution of cross-sectional wage inequality across the EU. It is highly relevant to understand what the source of this variation is. Did the increase in 
cross-sectional wage inequality observed in some countries result from greater transitory fluctuations in earnings and individuals facing a higher degree of earnings mobility? Or is this rise reflecting increasing permanent differences between individuals with mobility remaining constant or even falling? What about countries that recorded a decrease in cross-sectional earnings inequalities, what lessons can we learn from them? Can increased mobility be a factor behind shrinking earnings differentials? In some countries, earnings distribution might not change to a large extent over a period of one or two years, and the core question is what happens in different parts of the distribution. Are the same people stuck at the bottom of the earnings distribution or are low earnings largely transitory? How mobile are people in the earnings distribution over different time horizons? Did mobility patterns change over time? Is mobility equalizing or disequalizing lifetime earnings inequality compared with annual inequality? Are there common trends in earnings inequality and mobility across different countries? What lessons can we learn from the different mobility approaches? What are the possible labour market policy and institutional factors that can explain these trends in permanent and transitory differentials, and earnings mobility?

These questions have a twofold importance. One the one hand, understanding the contributions of the changes in permanent and transitory components of earnings variation to the changes in cross-sectional earnings inequality, and the possible link with earnings mobility is very useful in the evaluation of alternative hypotheses for wage structure changes and for determining the potential welfare consequences of rising inequality (Katz and Autor, 1999).

On the other hand, understanding the driving factors behind the changes in permanent and transitory inequality and earnings mobility is very useful for the design of policies and labour market institutions. Understanding the factors that enhance earnings mobility, represents a step forward towards designing policies and institutions that enable low-wage workers to escape low-wage trap and improve their position in the distribution of lifetime earnings.

\section{$2^{\text {nd }}$ Objective: Zooming in - earnings dynamics in Luxembourg}

As a second objective, in the fifth study, I zoom in and explore earnings dynamics in the EU country which underwent the most dramatic labour market structural changes during the last decades - Luxembourg. Starting with the late 1970s and intensifying after early 1990s, Luxembourg evolved from an industrial economy to an economy dominated by the tertiary sector, which relies heavily on the crossborder workforce. Moreover, Luxembourg recorded a large increase in the number of active population, both residents and cross-borders, which more than doubled 
in 2004 compared with 1988. The change in the structure of the labour market reveals an increase in the share of white collars and civil servants in the detriment of the share of blue collars, an increase in the share of the service sector in the detriment of the share of the industry sector. The evolution of the labour market age distribution reveals a clear shift in men's labour market behaviour due to the education system: the share of people present in the labour market until age 25 is almost double in 1988 compared with 2004. Following these changes crosssectional earnings inequality increased.

(5) What are the implications of these changes for the structure of earnings inequality and for earnings mobility? To what extent do changes in crosssectional earnings inequality in Luxembourg between 1988 and 2004 reflect changes in the transitory or permanent components of earnings?

Using 17 years of longitudinal earnings information drawn from the administrative data on the professional career, I decompose Luxembourg's growth in earnings inequality into persistent and transitory components and conclude about their evolution.

The contribution of this study to the literature on earnings dynamics and inequality is twofold. First, it aims to expand the research regarding the possible implications of the labour market structural changes on the structure of earnings inequality and on earnings mobility. Second, I exploit my extraordinary dataset on Luxembourg to achieve some methodological advances at the EU level. The limited scale of most European panels has forced EU researchers to rely on simple country models, which impose economically implausible restrictions. Due to my long panel, I am able to estimate much richer models that nest the various specifications used in the US, Canadian and European literature up to date.

\subsection{Structure of the study}

The dissertation is structured as a collection of five articles comprised in separate chapters, which answer the research questions stated above. The next four chapters explore the evolution of earnings mobility, permanent and transitory inequality in the context of the EU labour market changes after 1995, and the role of the labour market policy and institutional factors in explaining the evolution of the three labour market outcomes across the $14 \mathrm{EU}$ countries. These chapters use the European Community Household Panel across 14 EU countries between 1994 and 2001. Following the tradition of previous studies I focus only on men to avoid the problems of selection bias characterising female earnings. 


\section{Chapter 2. Increased opportunity to move up the economic ladder? Earnings}

mobility in the EU: 1994-2001

Chapter 2 explores whether the EU citizens have an increased opportunity to improve their position in the distribution of earnings over time. This question is answered by exploring short and long-term wage mobility, evaluated using two types of rank measures which capture positional movements in the distribution of earnings. The first one is derived from the transition matrix approach between income quintiles, and the second is based on individual ranks, as derived by Dickens (2000a).

\section{Chapter 3. Equalizing or disequalizing lifetime earnings differentials? Earnings mobility in the EU: 1994-2001}

Chapter 3 explores whether EU citizens have an increased opportunity to improve their position in the distribution of lifetime earnings, and whether earnings mobility works towards equalizing/disequalizing lifetime earnings relative to cross-sectional inequalities. Our basic assumption is that mobility measured over a horizon of 8 years is a good proxy for lifetime mobility. These questions are answered by using the Shorrocks (1978) and the Fields (2008) indices. Moreover, I explored the impact of differentials attrition on the study of earnings mobility as equalizer of longer-term earnings.

\section{Chapter 4. Earnings dynamics and inequality in EU, 1994-2001}

Chapter 4 explores the dynamic structure of earnings and the extent to which changes in cross-sectional earnings inequality across the $14 \mathrm{EU}$ countries reflect transitory or permanent components of individual lifecycle earnings variation. Equally weighted minimum distance methods are used to estimate the covariance structure of earnings, decompose earnings inequality into a permanent and a transitory component, and estimate earnings immobility.

\section{Chapter 5. Policy, institutional factors and earnings mobility}

Chapter 5 builds on the estimation results from Chapter 4 and the OECD data for the $14 \mathrm{EU}$ countries to explore the role of the labour market factors in explaining cross-national differences in the dynamic structure of earnings. The predicted labour market outcomes from Chapter 4 - permanent inequality, transitory inequality and earnings immobility - together with the institutional OECD data are used in a non-linear least squares setting to estimate the relationship between the 
three labour market outcomes, and the labour market policy and institutional factors.

Chapter 6. Earnings dynamics and inequality among men in Luxembourg, 19882004: evidence from administrative data

In Chapter 6, using an extraordinary longitudinal dataset drawn from administrative records on professional career, I decompose Luxembourg's growth in earnings inequality into persistent and transitory components, and assess the evolution of the inequality structure and earnings mobility following the dramatic labour market structural changes characterising the transition from an industrial economy to an economy dominated by the tertiary sector, which relies heavily on the cross-border workforce.

Chapter 7 concludes and sets the next steps. 
2. INCREASED OPPORTUNITY TO MOVE UP THE ECONOMIC LADDER? EARNINGS MOBILITY IN THE EU: 1994-2001 


\subsection{Introduction}

Do EU citizens have an increased opportunity to improve their position in the distribution of earnings over time? This question is relevant in the context of the EU labour market policy changes that took place after 1995 under the incidence of the 1994 OECD Jobs Strategy, which recommended policies to increase wage flexibility, lower non-wage labour costs and allow relative wages to reflect better individual differences in productivity and local labour market conditions (OECD, 2004). Following these reforms, the labour market performance improved in some countries and deteriorated in others, with heterogeneous consequences for crosssectional earnings inequality and earnings mobility. Averaged across OECD, however, gross earnings inequality increased after 1994 (OECD, 2006).

Some people argue that rising annual inequality does not necessarily have negative implications. This statement relies on the "offsetting mobility" argument, which states that if there has been a sufficiently large simultaneous increase in mobility, the inequality of income measured over a longer period of time, such as lifetime income or permanent income - can be lower despite the rise in annual inequality, with a positive impact on social welfare. This statement, however, holds only under the assumption that individuals are not averse to income variability, future risk or multi-period inequality (Creedy and Wilhelm, 2002; Gottschalk and Spolaore, 2002). Therefore, there is not a complete agreement in the literature on the value judgement of income mobility (Atkinson et al., 1992).

Those that value income mobility positively perceive it in two ways: as a goal in its own right or as an instrument to another end. The goal of having a mobile society is linked to the goal of securing equality of opportunity in the labour market and of having a more flexible and efficient economy (Friedman, 1962; Atkinson et al., 1992). The instrumental justification for mobility takes place in the context of achieving distributional equity: lifetime equity depends on the extent of movement up and down the earnings distribution over the lifetime (Atkinson et al., 1992). In this line of thought, Friedman (1962) underlined the role of social mobility in reducing lifetime earnings differentials between individuals, by allowing them to change their position in the income distribution over time. Thus earnings mobility is perceived in the literature as a way out of poverty. In the absence of mobility the same individuals remain stuck at the bottom of the earnings distribution, hence annual earnings differentials are transformed into lifetime differentials.

This paper explores earnings mobility across 14 EU countries over the period 19942001 using the European Community Household Panel (ECHP) to identify the possible consequences of the labour market changes occurred across Europe after 
1995. We are interested in mobility as the degree of opportunity to better ones position in the earnings distribution over time. The second aspect of mobility mentioned above - as equalizer of lifetime earnings differentials - is left for future research. The comparative perspective aims to shed light on the link between the evolution of earnings mobility and cross-sectional earnings inequality.

The question regarding the degree of wage mobility is vitally important from a welfare perspective, particularly given the large variation in the evolution of crosssectional wage inequality across Europe over the period 1994-2001. It is highly relevant to understand what the source of this variation is. Did the increase in cross-sectional wage inequality observed in some countries result from greater transitory fluctuations in earnings and individuals facing a higher degree of earnings mobility? Or is this rise reflecting increasing permanent differences between individuals with mobility remaining constant or even falling? What about countries which recorded a decrease in cross-sectional earnings inequality? Can increased mobility be a factor behind shrinking earnings differentials? In some countries, earnings distribution might not change to a large extent over a period of one or two years, and the core question is what happens in different parts of the distribution. Are the same people stuck at the bottom of the earnings distribution or are low earnings largely transitory? How mobile are people in earnings distribution over different time horizons? Did mobility patterns change over time? Are there common trends in earnings inequality and mobility across different countries? What lessons can we learn from the different mobility approaches?

Mobility is measured using two approaches based on rank measures which capture positional movements in the distribution of earnings. The first one is based on estimating transition probabilities between earnings quintiles, and the second one on the changes in the individual ranks in the earnings distribution between different time periods.

\subsection{Literature review}

The number of comparative studies on earnings mobility is limited because of the lack of sufficiently comparable panel cross-country data. Most of the existing studies focus on the comparison between the US and a small number of European countries.

Aaberge, Bjorklund, Jantti, Palme, Pedersen, Smith, and Wannemo (2002) compared income (family income, disposable income and earnings) inequality and mobility in the Scandinavian countries and the US during 1980-1990. They measured mobility as the proportionate reduction of inequality when the 
accounting period of income is extended and found low mobility levels for all countries. Independent of the accounting period, they found that earnings inequality is higher in the US than in the Scandinavian countries. Mobility is higher for the US only for long accounting periods. They also found evidence of greater dispersion of first differences of relative earnings and income in the United States.

Brukhauser and Poupore (1997) and Brukhauser, Holtz-Eakin, and Rhody (1998) found that, the US, in spite of having a higher earnings or disposable income dispersion than Germany, its mobility is similar with Germany between 1983 and 1988.

Fritzell (1990) studied mobility in Sweden using mobility tables from 1973 and 1980 and compared them with Duncan and Morgan (1981) for the US for the period 1971 and 1978, and found remarkable similarities between the two countries.

OECD $(1996,1997)$ presented a variety of comparisons of earnings inequality and mobility across OECD countries over the period 1986-1991. The results vary depending on the definition and measure of mobility.

At the EU level, no study attempted to analyse and to understand in a comparative manner earnings mobility and its link with earnings inequality over a more recent period and covering a longer time frame than six years. By exploiting the eight years of panel in ECHP, our paper aims to fill part of this gap and to make a substantive contribution to the literature on cross-national comparisons of mobility at the EU level.

\subsection{Methodology}

There are many approaches to measuring mobility.(Fields and Ok, 1999; Fields, Leary, and Ok, 2003) We focus on two rank measures, which capture positional movements in the distribution of earnings. The first one is derived from the transition matrix approach between income quintiles and other labour market states, and the second one is based on individual ranks, as derived by Dickens (2000a).

We estimate two types of mobility measures:

- short-term mobility $\mathrm{M}(\mathrm{t}, \mathrm{t}+1)$ - defined as mobility between periods one year apart, meaning between year $t$ and year $t+1$. This is used to 
assess the pattern of short-term mobility over time, between M(1994, 1995) and $\mathrm{M}(2000,2001)$.

- $\quad$ longer period mobility $\mathrm{M}(\mathrm{t}, \mathrm{t}+7)$ - defined as mobility between periods seven $^{1}$ years apart, meaning between year $t$ and year $t+7$. This will be compared with short-term mobility to assess the extent to which mobility increases with the time span.

Finally, we explore the link between short and long-term mobility and the evolution of yearly inequality: first, the link between the relative change in shortterm mobility $M(t, t+1)^{2}$ and in yearly inequality $I(t+1)^{3}$ over the sample period; second the link between the relative difference between mobility in the first and last wave, $\mathrm{M}(\mathrm{t}, \mathrm{t}+7)$, and the relative change in inequality between the first and last wave ${ }^{4}$.

\subsubsection{Transition matrix approach to mobility}

Mobility measures derived from transition probabilities between different earnings ranges (e.g. quintiles) or between different labour market states are purely relative. For example, in the case of earnings transition probabilities, in a country with a low level of cross-sectional earnings inequality, a modest increase in earnings could cause a large change in an individual's relative position. The same quintile transition in a second country, with high cross-sectional inequality, would require a larger percentage increase in earnings. Thus, equal transition probabilities indicate similar relative mobility, meaning that the frequency of changes in the earnings rankings is the same in both countries, but earnings volatility is higher in the second country. The extent of relative mobility has important implication for long-period or lifetime inequality (OECD, 1996).

The information contained in the transition matrices can be summarized by several immobility indices, which allows one to create mobility rankings. Two of them are selected for summarizing the transitions between the earnings quintiles: the immobility ratio and the average jump (Atkinson et al., 1992).

The immobility ratio measures the percentage of people staying in the same quintile or entering the quintile immediately above/below. Because the immobility ratio focuses on the near-diagonal entries, it is insensitive to the movement outside the diagonal (Atkinson et al., 1992). One popular alternative which circumvents

\footnotetext{
16 for Luxembourg and Austria and 5 for Finland.

${ }^{2} \mathrm{M}(1994,1995)$ to $\mathrm{M}(2000,2001)$

${ }^{3} \mathrm{I}(1995)$ to $\mathrm{I}(2001)$

4 The link between $\mathrm{M}(1994,2001)$ and the relative difference between $\mathrm{I}(1994)$ and $\mathrm{I}(2001)$
} 
this problem is the average jump (AJ), which captures the degree of movement in a transition matrix:

$$
A J=\frac{\sum_{i=1}^{q} \sum_{j=1}^{q}|i-j| \cdot p_{i j}}{q}
$$

where $q$ is the number of quintiles, $p_{i j}$ is the transition rate located in row $i$ and column $j$. AJ represents the expected jumps in terms of quintiles. One drawback of the $\mathrm{AJ}$ is that it is insensitive to purely exchange mobility.

In order to be interpretable, these measures of immobility need to be compared with the degree of mobility achieved under "perfect mobility", meaning where the probability of occupying each rank is independent of the starting point (Atkinson et al., 1992). For a transition matrix defined in terms of quintiles, perfect mobility means that the probability of moving into a particular rank from one period to the next is 0.2 . The immobility ratio under the assumption of perfect mobility for a transition matrix defined in terms of quintiles equals $0.52^{5}$. The expected AJ under the assumption of perfect mobility for a quintile transition matrix equals 1.6. Therefore, the value of the immobility ratio should be compared with $52 \%$ (base line for perfect mobility) and the value of the AJ should be compared with 1.6 (base line for perfect mobility).

\subsubsection{Alternative approach to mobility (Dickens 2000a)}

The main limitation of the transition matrix approach to mobility is that it fails to capture the movement within each earnings quintile or income group. An alternative approach to the quintile transition matrices presented above is to compute the ranking of the individuals in the wage distribution for each year and examine the degree of movement in percentile ranking from one year to the next (Dickens, 2000a). For each mobility comparison only individuals that have earnings in both periods are considered.

One way to give an indication of the level of mobility is to plot the percentile rankings for pairs of years. If there is no mobility, meaning that each individual preserves his/her rank in the income distribution from one period to the next, then the plot looks like a 45-degree line that starts at the origin. If there is no association between earnings from different years, then one would expect a random scatter.

$5\left(2 * 0.2+3^{*} 0.2+3^{*} 0.2+3 * 0.2+2 * 0.2\right) / 5=0.52$ 
Following Dickens (2000a), the percentile rankings can be used to construct a measure of mobility based on the degree of change in ranking from one year to the other. The measure of mobility between year $t$ and year $s$ is:

$$
M=\frac{2 \cdot \sum_{i=1}^{N}\left|F\left(w_{i t}\right)-F\left(w_{i s}\right)\right|}{N}
$$

where $F\left(w_{i t}\right)$ and $F\left(w_{i s}\right)$ are the cumulative distribution function for earnings in year $\mathrm{t}$ and year $\mathrm{s}$ and $\mathrm{N}$ is the number of individuals that record positive earnings in both year $t$ and year $s$. Based on this measure, the degree of mobility equals twice the average absolute change in percentile ranking between year $t$ and year $s$. When there is no mobility and people hold their position in the income distribution from year $t$ to year $s$, the difference between $F\left(w_{i t}\right)$ and $F\left(w_{i s}\right)$ is equal to 0 for all individuals, and therefore $M$ is equal to 0 . The index takes a maximum value of 1 if earnings in the two years are perfectly negatively correlated, meaning that in the second period there is a complete reversal of ranks, and the value $2 / 3$ if earnings in the two periods are independent. The robustness of this measure of mobility was discussed in Dickens (2000a).

\subsection{Data}

The study is conducted using the European Community Household Panel (ECHP) ${ }^{6}$ over the period 1994-2001 for 14 EU countries. Not all countries are present for all waves. Luxembourg and Austria are observed over a period of 7 waves (1995-2001) and Finland over a period of 6 waves (1996-2001). Following the tradition of previous studies, the analysis focuses only on men.

A special problem with panel data is that of attrition over time, as individuals are lost at successive dates causing the panel to decline in size and raising the problem of representativeness. Several papers analysed the extent and the determinants of panel attrition in ECHP. A. Behr, E. Bellgardt, U. Rendtel (2005) found that the extent and the determinants of panel attrition vary between countries and across waves within one country, but these differences do not bias the analysis of income or the ranking of the national results. L.Ayala, C. Navrro, M.Sastre (2006) assessed the effects of panel attrition on income mobility comparisons for some EU countries from ECHP. The results show that ECHP attrition is characterized by a

\footnotetext{
${ }^{6}$ The European Community Household Panel provided by Eurostat via the Department of Applied Economics at the Université Libre de Bruxelles.
} 
certain degree of selectivity, but only affecting some variables and some countries. Moreover, the income mobility indicators show certain sensitivity to the weighting system.

In this paper, we use the weighting system recommended by Eurostat, namely using the "base weights" of the last wave observed for each individual, bounded between 0.25 and 10 . The dataset is scaled up to a multiplicative constant ${ }^{7}$ of the base weights of the last year observed for each individual.

For this study we use real net ${ }^{8}$ hourly wage adjusted for consumer price index (CPI) of male workers aged 20 to 57, born between 1940 and 1981. Only observations with hourly wage lower than 50 Euros and higher than 1 Euro were considered in the analysis. The resulting sample for each country is an unbalanced panel. Details on the number of observations, inflows and outflows of the sample by cohort over time for each country are provided in Table 2-A-1 (Annex).

\subsection{Changes in the cross-section earnings distribution over time}

This section presents the changing shape of the cross-sectional distribution of earnings for men over time. Figure 2.1 illustrates the frequency density estimates for the first wave', 1998 and 2001 earnings distributions, and Table 2.1 illustrates the evolution of the other moments of the earnings distribution over time. The evolution of mean net hourly wage shows that men got richer over time in most countries, except Austria. Net hourly earnings became more dispersed in most countries, except Austria, France and Denmark.

\footnotetext{
7 The multiplicative constant equals e.g. $\mathrm{p}^{*}$ (Population above 16/Sample Population). The ratio $\mathrm{p}$ varies across countries so that sensible samples are obtained. It ranges between 0.001-0.01.

${ }^{8}$ Except for France, where wage is in gross amounts

${ }^{9}$ For Luxembourg and Austria, the first wave was recorded in 1995, whereas for Finland in 1996.
} 

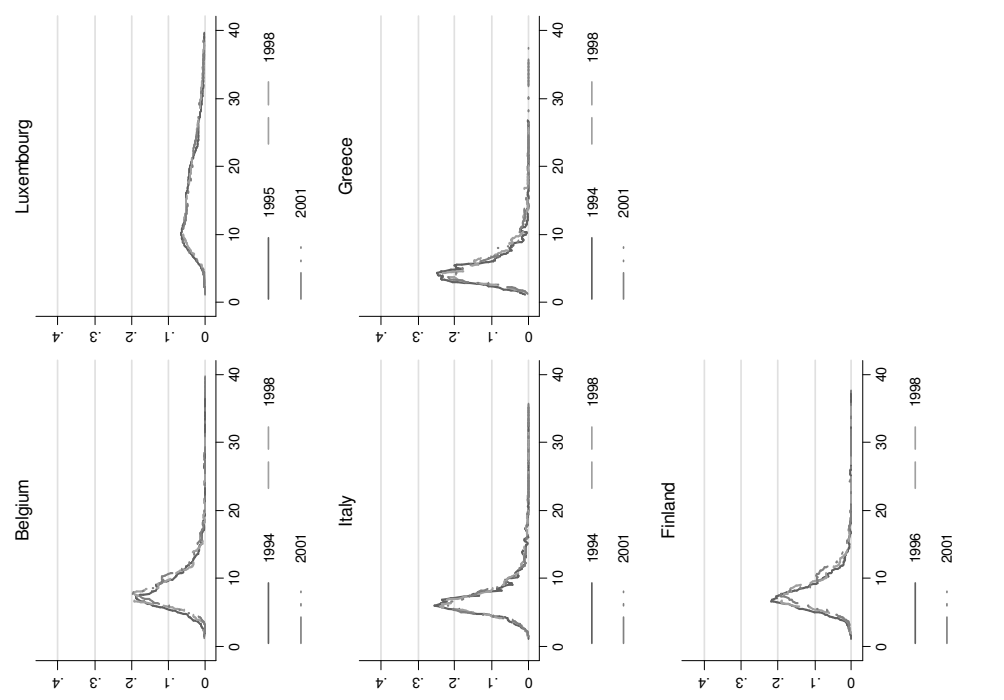

10

密
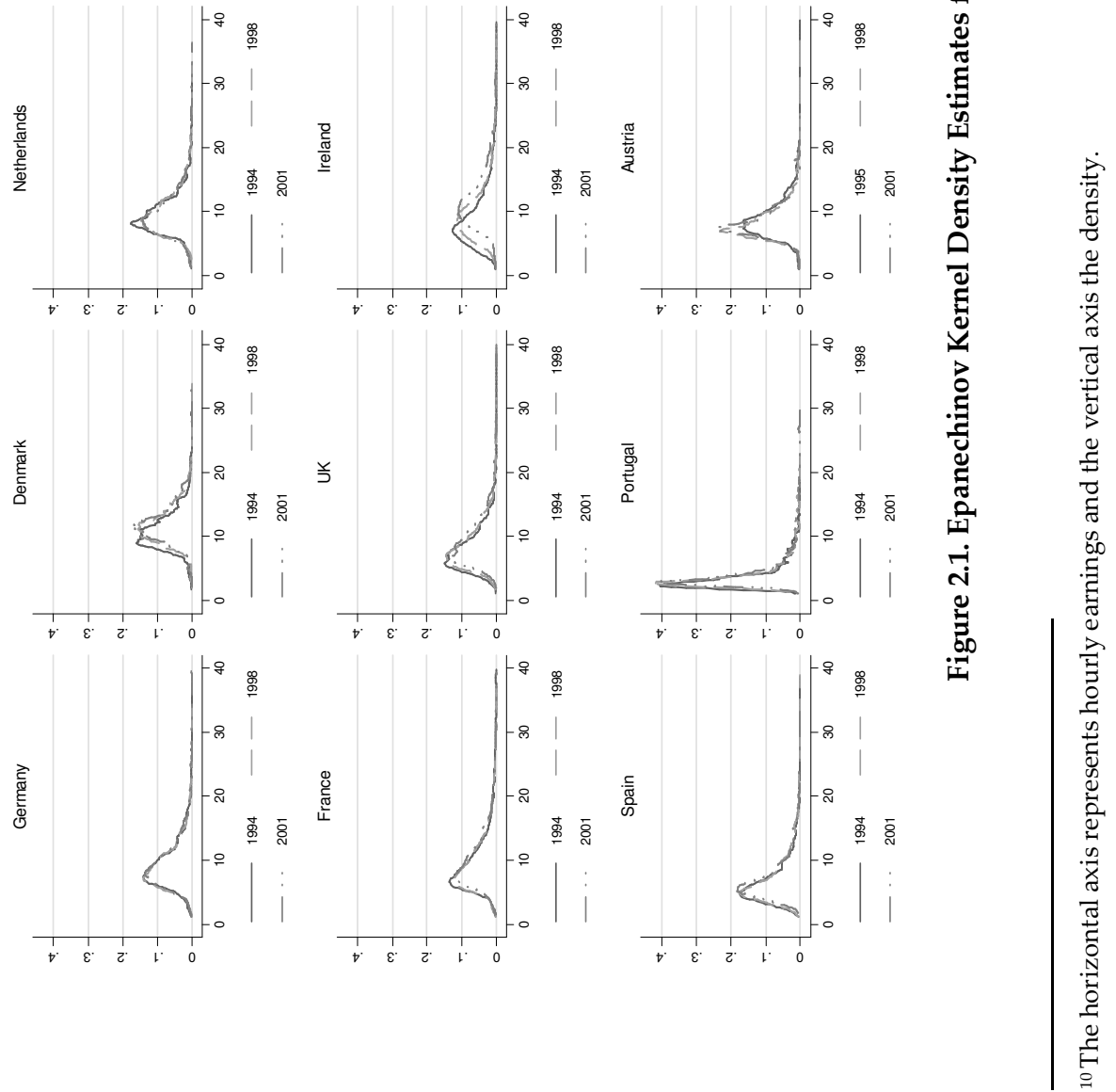
Table 2.1. Sample Statistics of Hourly Earnings

\begin{tabular}{|c|c|c|c|c|c|c|c|c|c|}
\hline & Year & 1994 & 1995 & 1996 & 1997 & 1998 & 1999 & 2000 & 2001 \\
\hline \multirow{3}{*}{ Germany } & Mean & 9.43 & 9.49 & 9.61 & 9.52 & 9.57 & 9.48 & 9.60 & 9.72 \\
\hline & Median & 8.65 & 8.68 & 8.78 & 8.84 & 8.70 & 8.65 & 8.75 & 8.82 \\
\hline & Standard Deviation & 4.00 & 4.17 & 4.09 & 4.01 & 4.39 & 4.32 & 4.39 & 4.37 \\
\hline \multirow{3}{*}{ Denmark } & Mean & 10.89 & 11.40 & 11.58 & 11.61 & 11.86 & 11.85 & 12.02 & 12.08 \\
\hline & Median & 10.36 & 10.76 & 10.96 & 11.14 & 11.46 & 11.36 & 11.77 & 11.50 \\
\hline & Standard Deviation & 3.23 & 3.31 & 3.52 & 3.54 & 3.13 & 3.31 & 3.43 & 3.20 \\
\hline \multirow{3}{*}{ Netherlands } & Mean & 9.69 & 9.56 & 9.59 & 9.70 & 10.02 & 9.88 & 10.04 & 9.91 \\
\hline & Median & 9.11 & 9.07 & 9.01 & 9.10 & 9.27 & 9.18 & 9.32 & 9.23 \\
\hline & Standard Deviation & 3.39 & 3.37 & 3.55 & 3.56 & 3.64 & 3.40 & 3.48 & 3.95 \\
\hline \multirow{3}{*}{ Belgium } & Mean & 8.48 & 8.82 & 8.71 & 8.75 & 8.81 & 8.83 & 8.92 & 9.10 \\
\hline & Median & 7.86 & 8.17 & 7.99 & 8.09 & 8.08 & 8.34 & 8.25 & 8.30 \\
\hline & Standard Deviation & 3.17 & 3.08 & 3.02 & 3.09 & 2.97 & 2.94 & 3.00 & 3.21 \\
\hline \multirow{3}{*}{ Luxembourg } & Mean & & 16.18 & 15.81 & 16.73 & 17.39 & 17.15 & 17.22 & 17.10 \\
\hline & Median & & 14.90 & 14.52 & 15.31 & 15.72 & 15.60 & 15.65 & 15.29 \\
\hline & Standard Deviation & & 7.50 & 7.19 & 7.77 & 8.21 & 8.38 & 8.37 & 8.22 \\
\hline \multirow{3}{*}{ France $^{11}$} & Mean & 10.23 & 9.92 & 9.87 & 10.05 & 10.33 & 10.60 & 10.55 & 10.87 \\
\hline & Median & 8.56 & 8.57 & 8.53 & 8.53 & 8.84 & 9.04 & 9.06 & 9.48 \\
\hline & Standard Deviation & 5.82 & 5.33 & 5.17 & 5.65 & 5.62 & 5.78 & 5.51 & 5.72 \\
\hline \multirow{3}{*}{ UK } & Mean & 8.16 & 8.11 & 8.22 & 8.34 & 8.68 & 9.01 & 9.21 & 9.68 \\
\hline & Median & 7.30 & 7.29 & 7.51 & 7.52 & 7.67 & 8.00 & 8.22 & 8.68 \\
\hline & Standard Deviation & 3.99 & 3.95 & 3.80 & 3.79 & 4.01 & 4.13 & 4.24 & 4.49 \\
\hline \multirow{3}{*}{ Ireland } & Mean & 9.30 & 9.54 & 9.76 & 10.02 & 10.43 & 10.84 & 11.69 & 12.44 \\
\hline & Median & 8.06 & 8.44 & 8.84 & 8.86 & 9.33 & 9.73 & 10.25 & 11.36 \\
\hline & Standard Deviation & 5.14 & 4.99 & 4.85 & 4.98 & 5.17 & 5.02 & 5.24 & 5.15 \\
\hline \multirow{3}{*}{ Italy } & Mean & 7.16 & 6.91 & 6.96 & 7.05 & 7.29 & 7.37 & 7.28 & 7.32 \\
\hline & Median & 6.65 & 6.32 & 6.43 & 6.48 & 6.69 & 6.76 & 6.59 & 6.67 \\
\hline & Standard Deviation & 2.77 & 2.59 & 2.67 & 2.68 & 3.01 & 3.00 & 2.99 & 3.04 \\
\hline \multirow{3}{*}{ Greece } & Mean & 4.95 & 5.03 & 5.23 & 5.59 & 5.63 & 5.85 & 5.70 & 5.77 \\
\hline & Median & 4.49 & 4.41 & 4.53 & 4.90 & 4.91 & 4.99 & 4.89 & 4.99 \\
\hline & Standard Deviation & 2.33 & 2.42 & 2.43 & 2.91 & 2.87 & 3.14 & 3.07 & 3.21 \\
\hline \multirow{3}{*}{ Spain } & Mean & 6.83 & 6.95 & 7.09 & 6.89 & 7.18 & 7.37 & 7.45 & 7.42 \\
\hline & Median & 5.86 & 5.82 & 5.92 & 5.72 & 6.04 & 6.15 & 6.29 & 6.33 \\
\hline & Standard Deviation & 3.81 & 3.86 & 4.00 & 3.92 & 4.06 & 4.15 & 4.07 & 3.87 \\
\hline \multirow{3}{*}{ Portugal } & Mean & 3.70 & 3.74 & 3.84 & 3.92 & 3.99 & 4.08 & 4.31 & 4.46 \\
\hline & Median & 2.92 & 2.82 & 2.98 & 3.03 & 3.05 & 3.08 & 3.29 & 3.34 \\
\hline & Standard Deviation & 2.34 & 2.45 & 2.54 & 2.65 & 2.81 & 2.82 & 3.16 & 3.33 \\
\hline \multirow{3}{*}{ Austria } & Mean & & 9.08 & 8.33 & 8.37 & 8.49 & 8.55 & 8.55 & 8.54 \\
\hline & Median & & 8.51 & 7.64 & 7.63 & 7.84 & 7.82 & 7.86 & 7.93 \\
\hline & Standard Deviation & & 3.52 & 3.00 & 3.07 & 2.95 & 2.89 & 2.84 & 2.82 \\
\hline \multirow{3}{*}{ Finland } & Mean & & & 7.89 & 8.01 & 8.41 & 8.45 & 8.66 & 8.86 \\
\hline & Median & & & 7.48 & 7.57 & 7.85 & 7.90 & 8.18 & 7.97 \\
\hline & Standard Deviation & & & 2.70 & 2.77 & 2.92 & 2.91 & 2.93 & 3.29 \\
\hline
\end{tabular}

11 Gross Amounts 
Plotting the percentage change in mean hourly earnings between the beginning of the sample period and 2001 at each point of the distribution for each country (Figure 2.2), revealed that, in most countries, the relationship between the quantile ${ }^{12}$ rank and growth in real earnings is negative and nearly monotonic: the higher the rank, the smaller the increase in earnings. This shows that in most countries, over time, the situation of the low paid people improved to a larger extent than for the better off ones. In Austria, people at the top of the distribution experience a decrease in mean hourly wage over time, which might explain the decrease in the overall mean.

Netherlands, Germany, Greece and Finland diverge in their pattern from the other EU countries experiencing a higher relative increase in earnings the higher the rank. Netherlands is the only country where men at the bottom of the income distribution recorded a deterioration of their work pay. For these countries, the increase in mean earnings might be the result of an increase in the earnings position of the better off individuals, not the low paid.

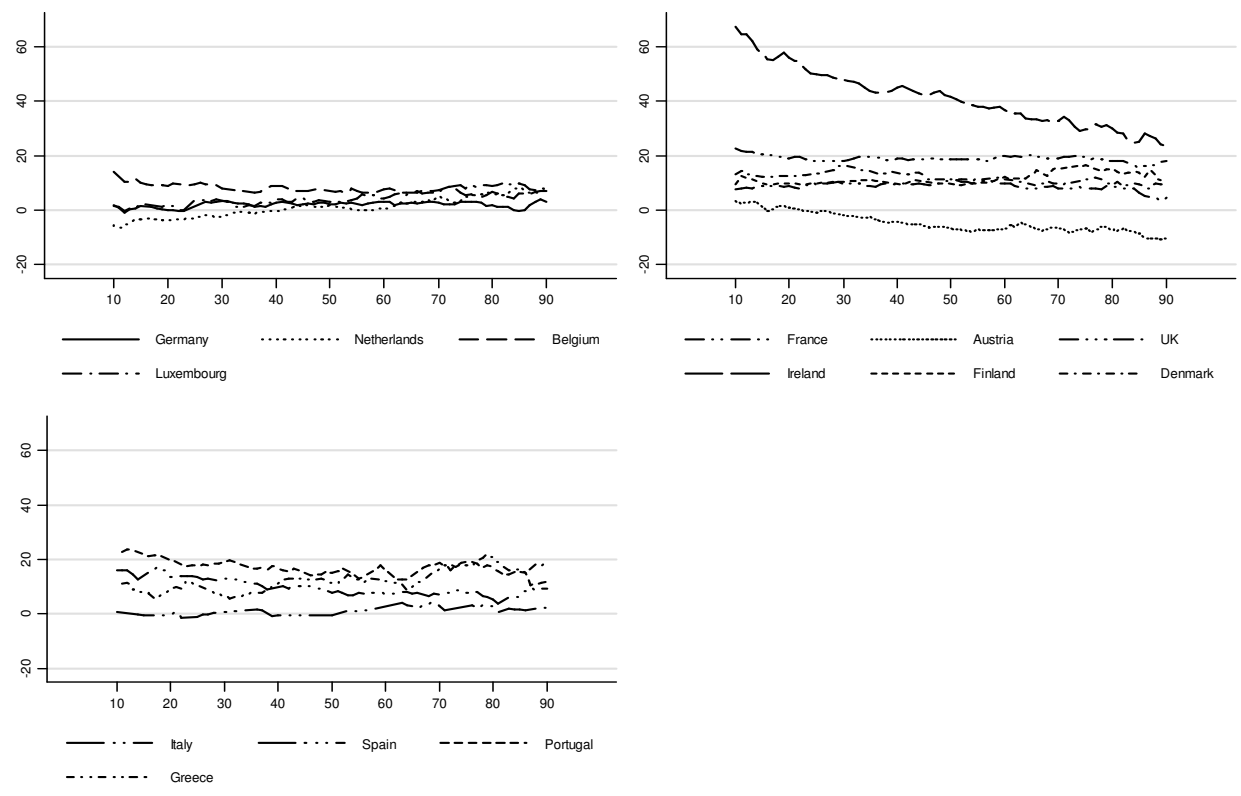

Figure 2.2. Percentage Change in Mean Hourly Earnings by Percentiles Over The Sample Period

Note: Vertical axis - the percentage change in mean hourly earnings; Horizontal axis - percentiles.

12100 Quantiles 
To complete the descriptive picture of the cross-sectional earnings distribution over time, we provide also inequality measures. Inequality indices differ with respect to their sensitivity to income differences in different parts of the distribution. Therefore they illustrate different sides of the earnings distribution. The year-to-year changes in earnings inequality are captured by computing the ratio between the mean earnings in the 9th decile and the 1st decile (Figure 2.3), the Gini index, the GE indices - the Theil Index (GE(1)) -, and the Atkinson inequality index evaluated at an the aversion parameter equal to 1 (Table 2.2). ${ }^{13}$

The ratio between the mean earnings in the 9th decile and the 1st deciles focuses only on the two ends of the distribution. The Gini index is most sensitive to income differences in the middle of the distribution (more precisely, the mode). The GE with a negative parameter is sensitive to income differences at the bottom of the distribution and the sensitivity increases the more negative the parameter is. The GE with a positive parameter is sensitive to income differences at the top of the distribution and it becomes more sensitive the more positive the parameter is. For the Atkinson inequality indices, the more positive the "inequality aversion parameter" is, the more sensitive the index is to income differences at the bottom of the distribution.
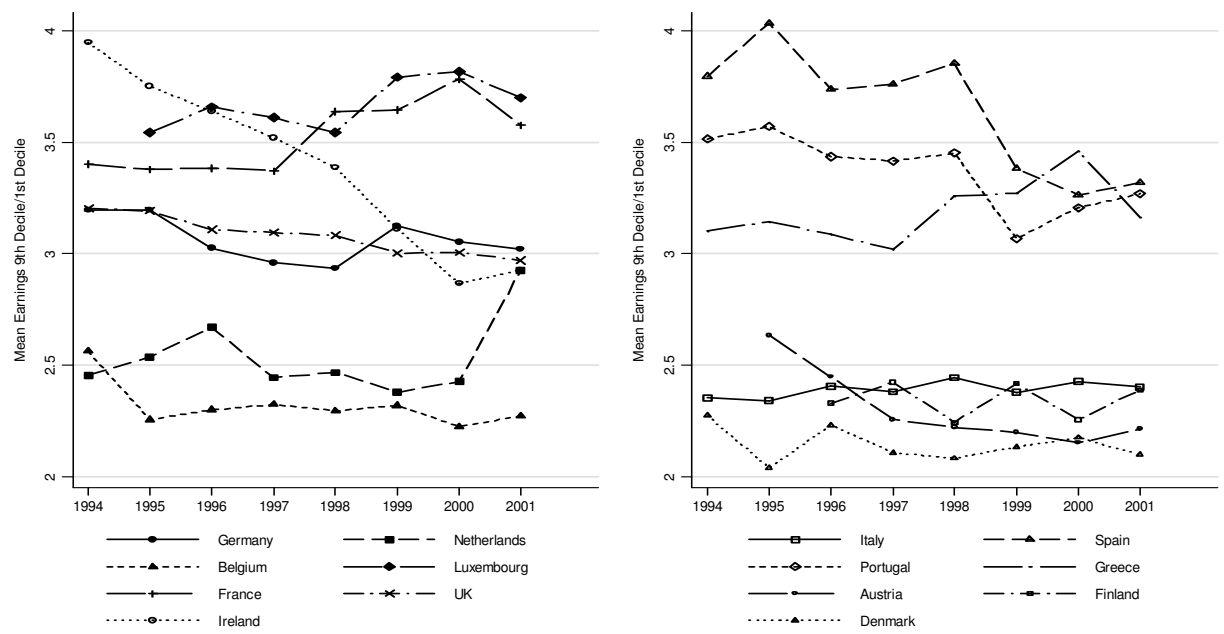

Figure 2.3. Ratio between Mean Earnings at the 9th Decile and the 1st Decile Note: Vertical axis - Mean earnings in the $9^{\text {th }}$ decile /Mean earnings in the $1^{\text {st }}$

\footnotetext{
${ }^{13}$ Besides these indices, several others were computed (GE(-1); GE(0), GE(2), Atkinson evaluated at different values of the aversion parameter) and can be provided upon request from the authors. They support the findings shown by the reported indices.
} 
Table 2.2. Earnings Inequality (Index ${ }^{*}$ 100)

\begin{tabular}{|c|c|c|c|c|c|c|c|c|c|}
\hline & & 1994 & 1995 & 1996 & 1997 & 1998 & 1999 & 2000 & 2001 \\
\hline \multirow{3}{*}{ Germany } & Gini & 22.15 & 22.34 & 22.04 & 21.89 & 22.58 & 22.81 & 22.75 & 22.54 \\
\hline & Theil & 8.22 & 8.61 & 8.23 & 8.06 & 8.85 & 8.96 & 8.92 & 8.72 \\
\hline & $\mathrm{A}(1)$ & 8.08 & 8.38 & 8.04 & 7.84 & 8.12 & 8.53 & 8.41 & 8.17 \\
\hline \multirow{3}{*}{ Denmark } & Gini & 15.76 & 15.26 & 15.52 & 15.21 & 14.24 & 14.68 & 14.94 & 14.05 \\
\hline & Theil & 4.22 & 3.92 & 4.23 & 4.15 & 3.37 & 3.73 & 3.83 & 3.35 \\
\hline & $\mathrm{A}(1)$ & 4.26 & 3.78 & 4.10 & 3.96 & 3.37 & 3.76 & 3.78 & 3.33 \\
\hline \multirow{3}{*}{ Netherlands } & Gini & 18.07 & 18.37 & 19.19 & 18.80 & 18.93 & 17.92 & 18.18 & 20.67 \\
\hline & Theil & 5.63 & 5.76 & 6.32 & 6.07 & 5.96 & 5.40 & 5.56 & 7.25 \\
\hline & $\mathrm{A}(1)$ & 5.56 & 5.77 & 6.33 & 5.90 & 5.65 & 5.18 & 5.44 & 7.08 \\
\hline \multirow{3}{*}{ Belgium } & Gini & 19.10 & 17.71 & 17.64 & 18.13 & 17.53 & 17.33 & 17.13 & 17.85 \\
\hline & Theil & 6.23 & 5.37 & 5.35 & 5.58 & 5.15 & 5.11 & 5.04 & 5.48 \\
\hline & $\mathrm{A}(1)$ & 5.92 & 4.95 & 5.04 & 5.24 & 4.85 & 4.92 & 4.69 & 5.14 \\
\hline \multirow{3}{*}{ Luxembourg } & Gini & & 25.23 & 24.74 & 25.41 & 25.62 & 26.58 & 26.50 & 26.32 \\
\hline & Theil & & 10.09 & 9.85 & 10.24 & 10.37 & 11.19 & 11.15 & 10.89 \\
\hline & $\mathrm{A}(1)$ & & 9.88 & 10.00 & 10.16 & 10.02 & 10.95 & 11.09 & 10.66 \\
\hline \multirow{3}{*}{ France } & Gini & 27.62 & 26.47 & 26.26 & 27.23 & 27.28 & 27.41 & 26.83 & 26.49 \\
\hline & Theil & 13.21 & 12.04 & 11.63 & 12.88 & 12.58 & 12.65 & 11.94 & 11.87 \\
\hline & $\mathrm{A}(1)$ & 11.64 & 10.88 & 10.58 & 11.41 & 11.54 & 11.59 & 11.17 & 10.98 \\
\hline \multirow{3}{*}{ UK } & Gini & 24.26 & 24.22 & 23.35 & 23.36 & 23.54 & 23.25 & 23.35 & 23.51 \\
\hline & Theil & 10.08 & 10.01 & 9.20 & 9.05 & 9.24 & 9.08 & 9.16 & 9.29 \\
\hline & $\mathrm{A}(1)$ & 9.25 & 9.19 & 8.57 & 8.46 & 8.55 & 8.32 & 8.46 & 8.51 \\
\hline \multirow{3}{*}{ Ireland } & Gini & 27.59 & 26.87 & 25.76 & 25.47 & 25.00 & 23.39 & 22.77 & 21.70 \\
\hline & Theil & 12.87 & 11.97 & 11.00 & 10.83 & 10.60 & 9.31 & 8.78 & 7.85 \\
\hline & $\mathrm{A}(1)$ & 11.84 & 11.21 & 10.50 & 10.14 & 9.85 & 8.66 & 8.15 & 7.64 \\
\hline \multirow{3}{*}{ Italy } & Gini & 19.16 & 18.47 & 19.02 & 18.93 & 19.85 & 19.72 & 19.78 & 19.90 \\
\hline & Theil & 6.51 & 6.08 & 6.42 & 6.29 & 7.13 & 7.01 & 7.08 & 7.19 \\
\hline & $\mathrm{A}(1)$ & 5.99 & 5.58 & 5.91 & 5.78 & 6.41 & 6.30 & 6.33 & 6.39 \\
\hline \multirow{3}{*}{ Greece } & Gini & 23.62 & 24.37 & 23.80 & 25.55 & 25.66 & 26.98 & 26.51 & 26.37 \\
\hline & Theil & 9.51 & 9.97 & 9.44 & 11.23 & 11.09 & 12.20 & 11.93 & 12.17 \\
\hline & $\mathrm{A}(1)$ & 8.77 & 9.13 & 8.70 & 9.97 & 9.99 & 10.97 & 10.68 & 10.55 \\
\hline \multirow{3}{*}{ Spain } & Gini & 27.87 & 28.27 & 28.19 & 28.71 & 28.37 & 26.99 & 26.36 & 26.07 \\
\hline & Theil & 13.08 & 13.22 & 13.36 & 13.67 & 13.47 & 12.69 & 12.09 & 11.47 \\
\hline & $\mathrm{A}(1)$ & 11.84 & 12.13 & 11.94 & 12.33 & 12.17 & 11.07 & 10.60 & 10.28 \\
\hline \multirow{3}{*}{ Portugal } & Gini & 30.05 & 31.14 & 30.66 & 30.85 & 31.13 & 30.11 & 31.32 & 31.72 \\
\hline & Theil & 15.79 & 16.93 & 16.76 & 17.27 & 18.01 & 17.21 & 18.86 & 19.27 \\
\hline & $\mathrm{A}(1)$ & 13.23 & 14.16 & 13.80 & 14.05 & 14.37 & 13.55 & 14.60 & 14.92 \\
\hline \multirow{3}{*}{ Austria } & Gini & & 19.49 & 18.34 & 18.34 & 17.39 & 17.07 & 16.72 & 16.85 \\
\hline & Theil & & 6.67 & 5.84 & 5.90 & 5.27 & 5.10 & 4.93 & 4.97 \\
\hline & $\mathrm{A}(1)$ & & 6.44 & 5.62 & 5.52 & 4.87 & 4.80 & 4.67 & 4.82 \\
\hline \multirow{3}{*}{ Finland } & Gini & & & 17.32 & 17.80 & 17.30 & 17.81 & 17.10 & 18.50 \\
\hline & Theil & & & 5.22 & 5.46 & 5.23 & 5.38 & 5.08 & 5.98 \\
\hline & $\mathrm{A}(1)$ & & & 4.94 & 5.29 & 4.83 & 5.19 & 4.76 & 5.53 \\
\hline
\end{tabular}

The level and pattern of inequality over time as measured by the ratio between the mean earnings in the 9th decile and the 1st decile differs to a large extent between the EU14 countries. Two clusters can be identified. The first one is comprised of Netherlands, Begium, Italy, Finland, Austria and Denmark and is characterized by a small relative distance between the bottom and top of the distribution. The other cluster identifies countries with a higher level of inequality, with ratios between 2.75 and 4 . 
In 1994, based on the Gini index, Portugal is the most unequal, followed by Spain, France, Ireland, UK, Greece, Germany, Italy, Belgium, Netherlands and Denmark. In general, the other two indices confirm this ranking. However, using the Theil index, France appears to be more unequal than Spain, whereas using the Atkinson index, Ireland appears to be more unequal than France and as equal as Spain.

In 2001, based on the Gini index, Portugal is still the most unequal, followed by France, Greece, Luxembourg, Spain, UK, Germany, Ireland, Netherlands, Italy, Finland, Belgium, Austria and Denmark. In general, the other two indices confirm this ranking. Based on Theil, however, Greece is more unequal than France, and Spain than Luxembourg. Based on Atkinson, Luxembourg is more unequal than Greece.

For most countries, all indices show a consistent story regarding the evolution of inequality over the sample period, except for Germany, France and Portugal, where the evolution of the Gini, Theil and Atkinson index is opposite to the one observed for the D9/D1. Based on Gini, Theil and Atkinson, Netherlands, Greece, Finland, Portugal, Luxembourg, Italy and Germany recorded an increase in yearly inequality, and the rest a decrease.

The relative evolution over the sample period is captured in Figure 2.4, which illustrates for each country, the change in inequality as measured by Gini, Theil, Atkinson index and the D9/D1. Based on Gini, the highest increase in inequality was recorded by Netherlands (around 15\%), followed by Greece, Finland, Portugal, Luxembourg, Italy and Germany. The highest decrease was recorded in Ireland (around 20\%), followed by Austria, Denmark, Belgium, Spain, France and UK. Based on the Theil index, Portugal records a higher increase than Finland, Italy a higher increase than Luxembourg and Spain a higher decrease than Belgium. Based on Atkinson index, Portugal records a higher increase than Finland and UK a higher decrease than France.

For Netherlands, Finland and Greece the increase in the distance between the top and bottom of the distribution and in the overall level of inequality can be explained by the improved earnings position of the better off individuals. Hence in these countries, the economic growth benefitted the high income people and led to an increase in earnings inequality.

Luxembourg and Italy recorded an increase in inequality based on all indices, but the situation at the bottom improved to a larger extent than for the top. Thus the increase in inequality might be the result of other forces affecting the distribution, such as mobility in the bottom and top deciles. 


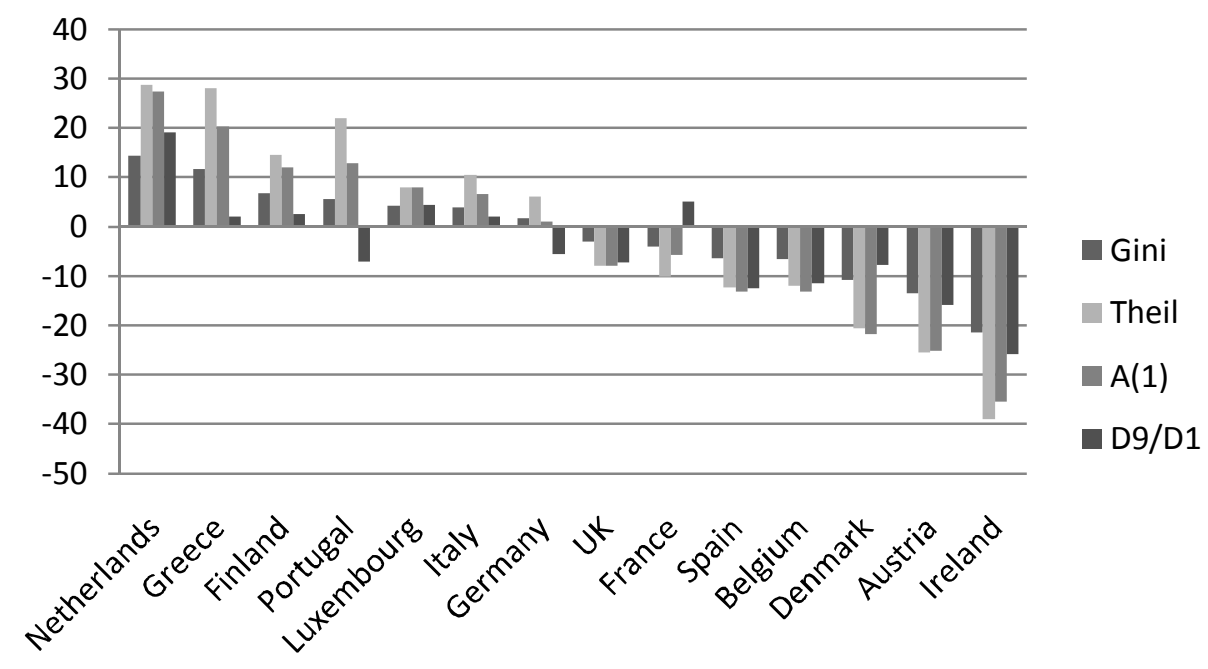

Figure 2.4. Relative Change in Inequality over Time - Gini, Theil, Atkinson(1), D9/D1 ${ }^{14}$

For France, the relative distance between the top and the bottom 10\% appears to increase over time, in spite of a higher relative increase in mean earnings at the bottom of the distribution compared with the top. This discrepancy could be explained by the presence of earnings mobility in the bottom and top $10 \%$ of the earnings distribution. The improved conditions for people in the bottom of the distributions could explain the decrease in earnings inequality as displayed by the other three indices.

Germany records opposite trends from France: the situation of the better off individuals improved to a larger extent than for low paid ones, which explains the increase in the overall inequality as captured by the Gini, Theil and Atkinson indices. The evolution of the ratio between mean earnings at the top and the bottom deciles is opposite to what was expected: the decrease might suggest that there are other forces at work, such as mobility in the top part of the distribution, which determined mean earnings to decrease for this group.

Portugal records similar trends with Germany, except for the negative correlation between the rank in the earnings distribution and the growth in earnings. Thus, the fact that low paid individuals improved their earnings position to a higher extent relative to high paid individuals, lowering the distance between the bottom and

${ }^{14}$ Countries are ranked based on Gini index. 
the top deciles of the earnings distribution did not have the expected effect of lowering overall earnings inequality as measured by the Gini, Theil and Atkinson indices. Mobility is expected to be the factor counteracting all these movements.

For the rest of the countries, the increase in the overall mean, coupled with the higher relative increase in the earnings position of the low paid individuals compared with high earnings individuals can be an explanation for their decrease in inequality.

Besides the direction of evolution, also the magnitude of the change records differences among inequality indices. In general, the magnitude of the change is the highest for the index that is most sensitive to the income differences at the top of the distribution, followed by bottom and middle sensitive one, sign that most of the major changes happened at the top and the bottom of the distribution. There are a few exceptions. In UK, Spain, Belgium and Denmark the magnitude of the evolution is the highest for the bottom sensitive one, followed by the top and middle ones.

\subsection{Linking earnings inequality and mobility: individual movements within the distribution over time}

When analysing the change in the distribution of earnings, one has to pay attention to two basic characteristics. First, how far apart are individuals in terms of their wage and to what extent does the ranking of each individual change from one period to the next. Section 2.5 offered a broad overview of the first characteristic. This section focuses on the second one and analyses the intra-distributional mobility of earnings over the period $1994-2001$.

\subsubsection{Mobility among labour market states}

To understand mobility patterns over time, it is informative to inspect mobility both within the wage distribution and into and out of the distribution to other employment states. For this purpose, we compute the quintiles of the wage distribution and present short-term and long-term transitions both between quintiles and to other employment states. ${ }^{15}$

Table 2-A-2 (Annex) presents one-year period transition matrices for men between the first and second wave and between 2000 and 2001. For all countries, one-year

\footnotetext{
${ }^{15}$ Short-term transitions are defined as transitions from one year to the next. Long-term transitions are defined as transitions from the first to the last wave.
} 
labour market transition matrices portray a picture of persistence, with little shortterm mobility. The diagonal elements of these matrices are much higher than the off-diagonal elements, suggesting a low degree of mobility from one period to the next, both in terms of quintiles of the earnings distribution and in states outside of employment. The concentration around the diagonal decreases the further one moves from the diagonal, indicating that those individuals that do change their labour market position from one period to the next, do not move very far.

In most countries, individuals in the lowest two quintiles are more likely to enter unemployment and inactivity compared with the rest of the distribution. Netherlands is an exception, where the top and the bottom of the distribution have similar high rates of entering unemployment and inactivity. Similarly, those unemployed and inactive that manage to get a job in the next period are more likely to enter the lower quintiles of the distribution. These findings are consistent with previous findings, for example Dickens (2000a) for UK over the period 19751994.

In the beginning of the sample period, the highest short-term persistence in unemployment was recorded in Ireland, Luxembourg, Italy, Finland, Belgium and Austria where between $62.45 \%$ and $50.63 \%$ kept their status from one year to the next, followed by Spain and Netherlands with $46 \%$ and $42.92 \%$, and Germany, UK, Greece, Portugal, France and Denmark with rates between $39.42 \%$ and $34 \%$. The highest persistency in inactivity was recorded in France, Belgium, Ireland and Portugal where more than half kept the same status in 1995. Over time, short-term mobility out of unemployment increased in Luxembourg, Ireland, Italy, Spain, Portugal, Austria and Finland, whereas short-term mobility out of inactivity increased only in Belgium, France and UK.

Looking at the pattern of mobility over a longer time span (Table 2-A-3, Annex), mobility measured over the whole sample period is higher than one-period mobility: the concentration along the diagonal is much less than when measured over one year. These trends are consistent with previous findings. (Atkinson et al., 1992; OECD, 1996; Dickens, 2000a) The highest long-term persistency in unemployment is found in Belgium, UK, Italy, Germany and Spain, where between $23 \%$ and $12 \%$ maintained their status in 2001. The highest persistency in inactivity is in France, Belgium, Portugal, Spain, Netherlands and Ireland with rates between $29 \%$ and $23 \%$. 


\subsubsection{The transition matrix approach to mobility among income quintiles}

Having introduced the general picture of mobility between different labour market states, the next step is to explore short and long-term mobility between income classes, as well as how short-term earnings mobility patterns changed over time.

Short-term earnings transition matrices (Table 2-A-4, Annex) portray a picture of persistence, with little mobility over a one-year period: the diagonal elements of these matrices are much higher than the off-diagonal elements. All rows display high predictability and origin dependence (the transition probabilities are not equal) meaning that the position in the earnings distribution in the next period depends heavily on the initial state. The concentration around the diagonal decreases the further one moves from the diagonal, indicating that those individuals that do change their income position from one period to the next, do not move very far. For all countries, short-term persistency appears to be the highest for the top quintile, followed by the bottom and middle ones.

Of those in the lowest quintile in the first wave, the highest percentage of people that are still in the lowest quintile one year later is recorded in Luxembourg $(76.59 \%)$, followed by Germany $(71.28 \%)$, Italy, France, Finland, Netherlands and Ireland, with values between $60 \%$ and $70 \%$, and Portugal, Austria, UK, Denmark, Spain, Belgium and Greece, with values between $50 \%$ and $60 \%$.

For the middle quintile, in the first wave, the highest mobility is observed in Austria, where $27.53 \%$ maintained their state from one year to the next, followed by Denmark (32.22\%), Greece, Finland, Spain, Italy, Belgium, Ireland and Germany with a persistency between $40 \%$ and $50 \%$, France, UK and Portugal with values between $50 \%$ and $55 \%$, and finally Luxembourg, where $68.15 \%$ of those in the middle quintile in the first wave maintained their earnings position in the next period.

For the top quintile, Portugal, followed by Germany, UK, Netherlands, Ireland, Spain record the highest persistency in the first wave, with a probability of over $80 \%$ of remaining in the same state one year later. Next follow Luxembourg, Belgium, Italy, France and Finland, with a probability between $80 \%$ and $70 \%$, Austria, Denmark and Greece, with a probability between $70 \%$ and $60 \%$.

Over time, short-term income mobility for individuals belonging to the first quintile decreased in all countries, with three exceptions: Luxembourg, Spain and Finland. This decrease in short-term mobility over time suggests that in 2000-2001, low paid individuals find more difficult to move up the income distribution 
compared with the first two waves. For the middle quintile, mobility increased only in Belgium and UK. Short-term mobility increased for the top quintile in Germany, Netherlands, UK, Ireland, Spain and Portugal, and decreased in the other countries.

In 2000-2001, for the bottom quintile the highest persistency was recorded in Portugal, Germany, Austria, Belgium, Netherlands and Luxembourg where between $78 \%$ and $70 \%$ remained in the same income group, followed by Greece, France, Ireland, Denmark with probabilities between $69 \%$ and $60 \%$, and UK, Finland, Italy and Spain with rates between $59 \%$ and $49 \%$. For the middle quintile, the persistency is high in Luxembourg, Netherlands, Greece, Portugal, France, Austria, Germany, UK, Italy, and Denmark with rates between $69 \%$ and $50 \%$, and the rest with rates between $49 \%$ (Ireland) and $43 \%$ (Belgium). For the top quintile, all countries have a high persistency: between $87 \%$ (Luxembourg) and $73 \%$ (Finland) remained in the same earnings group.

As expected, for most countries and most income quintiles, long-term mobility (Table 2-A-5, Annex) is higher compared with short-term mobility, but the persistency is still very high. The concentration along the diagonal is less than when measured over just one year.

For those in the bottom quintile in the first wave, the degree of long-term persistency is the highest in Germany, Austria, Finland, Portugal and France, where between $49 \%$ and $41 \%$ remained in the same earnings quintile in 2001, followed by Luxembourg, Netherlands, Spain, Belgium, Italy, Denmark, UK, Greece and Ireland, with values between $40 \%$ and $23 \%$. The mobility of the bottom quintile is higher than the mobility of the middle quintile in Denmark, Luxembourg, UK, Ireland and Greece. From those in the middle quintile in the first wave, between $21 \%$ (Austria) and $45 \%$ (Luxembourg) are still in the middle quintile in the last wave. For those in the top quintile, the persistency is much higher, ranging between $88 \%$ and $71 \%$ for Spain, Luxembourg, Portugal, Netherlands, Ireland, Germany, UK and Italy, and between $70 \%$ and $57 \%$ for Belgium, France, Finland, Austria, Greece and Denmark.

The decreasing degree of persistence with the time span is consistent with previous research, which proved that the transitory component of earnings dies off after a certain number of years. The effects of the transitory shocks which might have affected earnings in one year are expected to diminish with time, determining people that experienced the transitory shocks to regain their pre-shock position in the earnings distribution. Exceptions from this trend are observed for the top quintile in Luxembourg and Greece, where long-term mobility is roughly equal to short-term mobility, suggesting the existence of high permanent differences 
between individual earnings, and in Spain, where long-term mobility decreased compared to short-term mobility.

The information in the transition matrices can be summarized by the immobility ratio (IR) and the average jump (AJ). Figure 2.5, Figure 2.6 and Table 2.3 illustrate the short and long-term immobility ratio and average jump for the earnings quintiles transition matrices, both in absolute values and relative to the case of perfect mobility. For the interpretation, we use the ones relative to the case of perfect mobility.
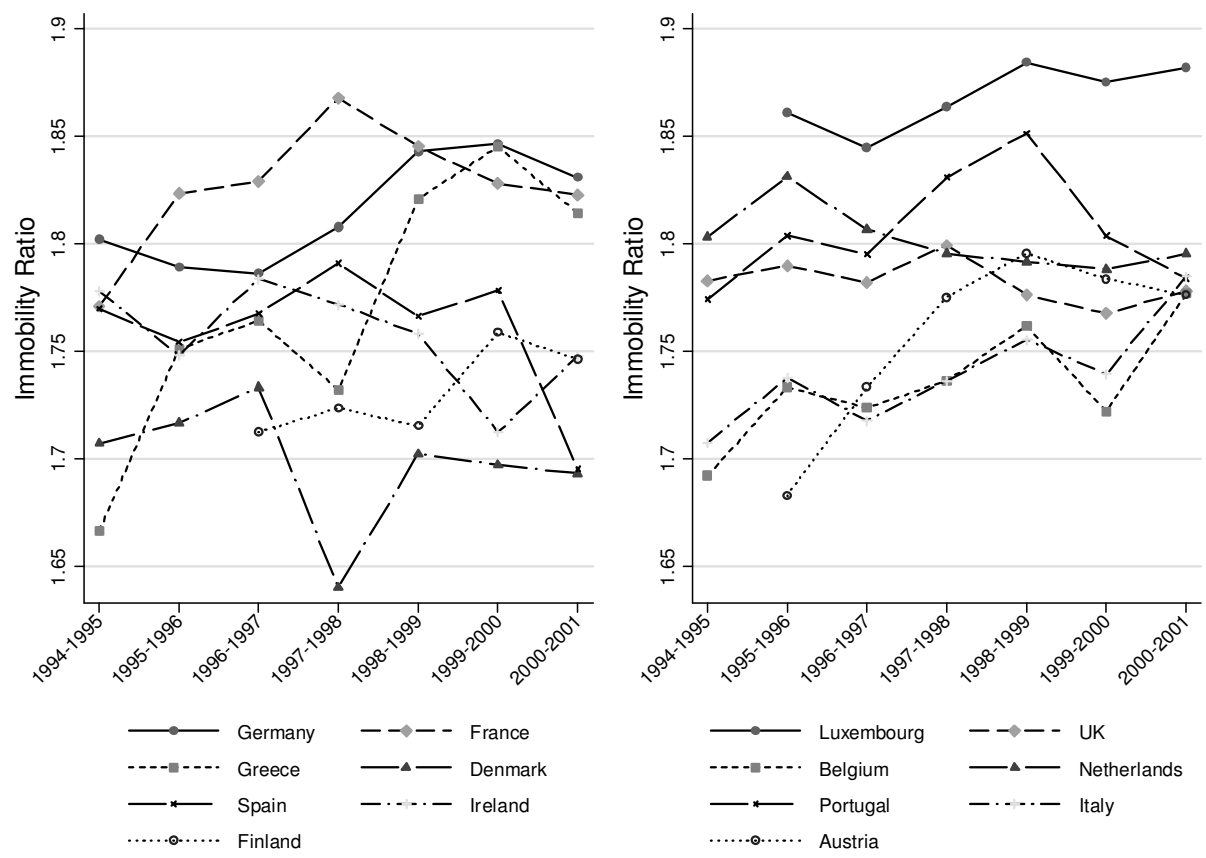

Figure 2.5. Immobility Ratio for One-Year Transitions between Earnings Quintiles over Time

Short-term immobility ratios for all countries over time (Figure 2.5) have values roughly between 1.6 and 1.9 times the immobility ratio for the case of perfect mobility, suggesting a very high degree of persistency on or close the diagonal from one year to the next. In the first wave, Greece has the lowest persistency, followed by Austria, Belgium, Denmark, Italy and Finland, and, at a higher level, by Spain, France, Portugal, Ireland, UK, Germany, Netherlands and Luxembourg. 

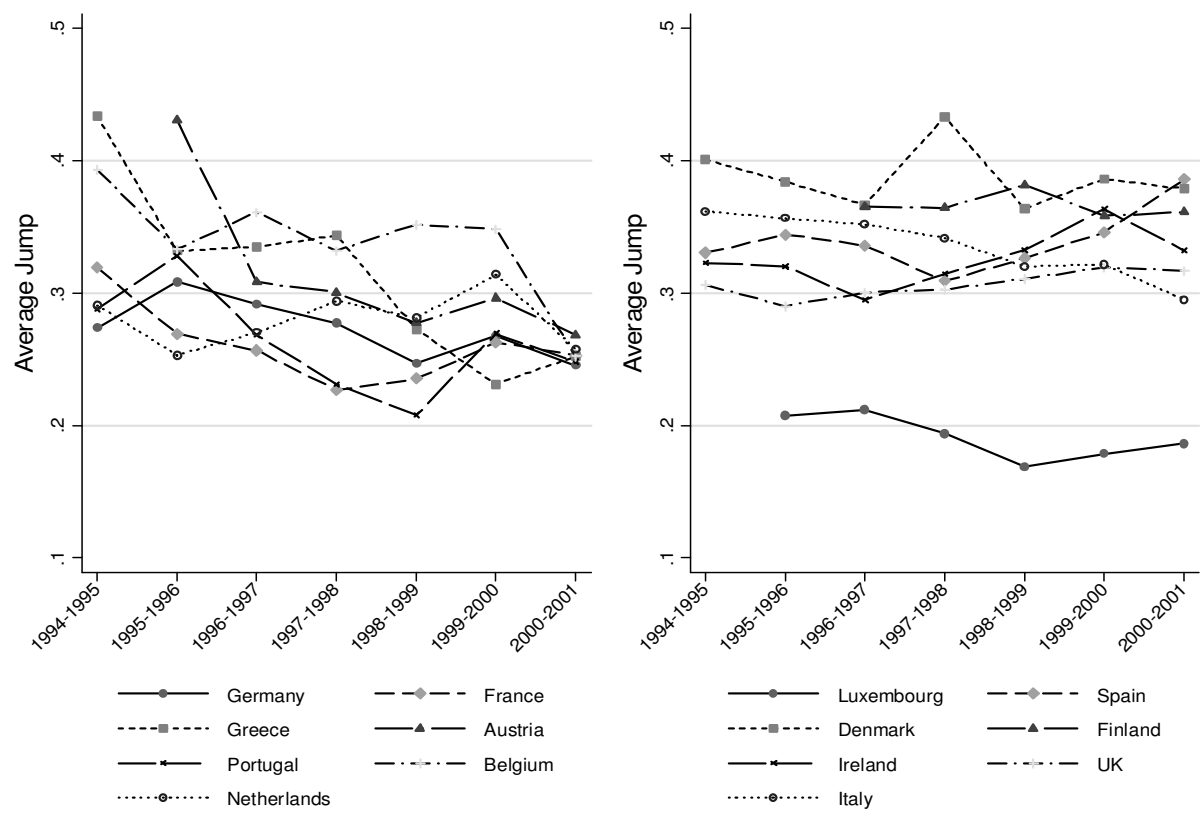

Figure 2.6. Average Jump for One-Year Transitions between Earnings Quintiles over Time
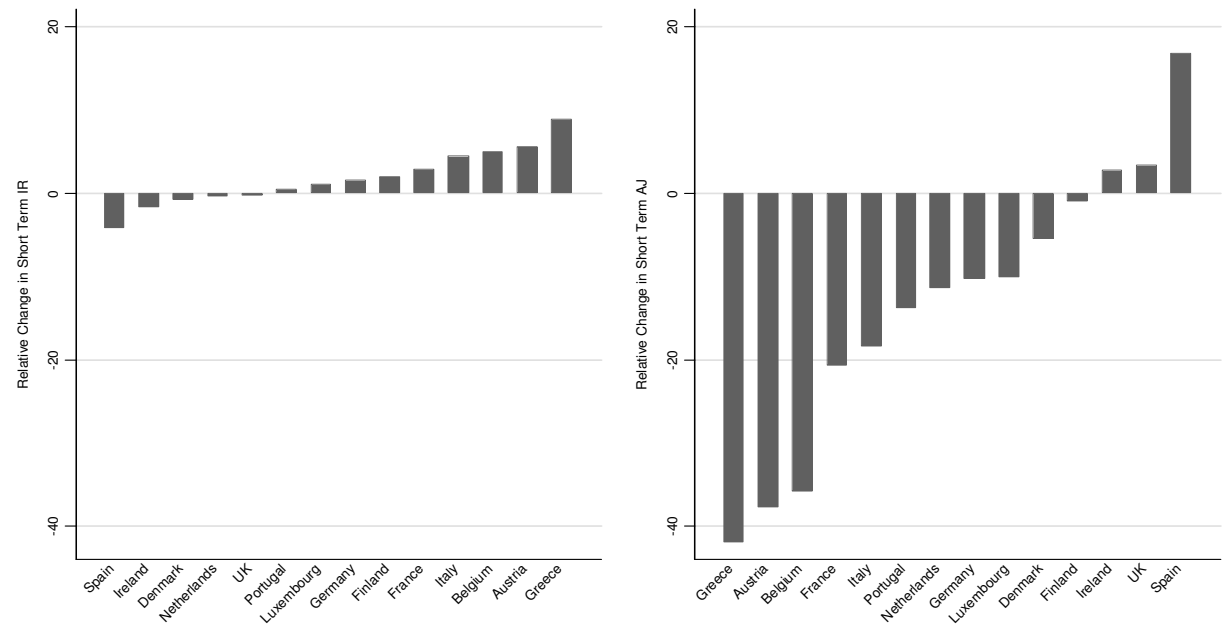

Figure 2.7. Relative Change over Time in Short-Term Immobility Ratio (IR) and Average Jump (AJ)

Short-term average jump over time (Figure 2.6) records values roughly between 0.15 and 0.45 of the value under perfect mobility, suggesting a low to moderate 
degree of mobility outside the diagonal for all countries. In the first wave, the lowest average jump is recorded in Luxembourg (above 0.2), followed by Germany, Portugal and Netherlands (with values close to 0.3), UK, France, Ireland, Spain, Italy, Finland, and Belgium (with values between 0.3 and 0.4), and Denmark, Austria and Greece (with values greater than 0.4).( Figure 2.6 and Table 2.3)

As illustrated in Figure 2.5 and Figure 2.6, some countries recorded a decrease and others an increase in short-term mobility over time. In general, over time, the evolution of the immobility ratio is negatively associated with the evolution of the average jump: the larger the decrease in the share of individuals staying in the same quintile or entering the quintile immediately above/below (decrease in the immobility ratio), the larger the increase in mobility away from the diagonal (increase in average jump), and vice versa.

Greece, Austria, Belgium, France, Italy, Portugal, Germany, Luxembourg and Finland recorded a decrease in the average jump and an increase in the immobility ratio, suggesting that over time the degree of movement in the earnings distribution decreased leading to a high concentration on and close to the main diagonal. As captured in Figure 2.7, the magnitude of the evolution is the highest in the first five countries, ranging between $9 \%$ and 3\% for the immobility ratio, and $41 \%$ and $18 \%$ for the average jump.

The relative decrease in mobility as measured by the average jump is higher than the relative decrease in mobility as measured by the immobility ratio, suggesting that the degree of movement away from the initial earnings position decreased to a higher extent than the increase in the share of individuals who maintained their earnings status or moved in the position immediately above/below. Thus the offdiagonal transition probabilities are shrinking towards the main diagonal at a higher rate than captured by the immobility ratio, signalling an increase in the share of individuals who maintained their status from one period to the next. An exception is Finland, where the relative decrease in the average jump is low, and slightly smaller than the relative increase in the immobility ratio, sign of a small increase in the share of individuals which maintained their income class from one period to the next between $1^{\text {st }}$ wave $-2^{\text {nd }}$ wave and 2000-2001.

Among the countries recording an increase in earnings mobility, Spain has the largest decrease in the immobility ratio $(4 \%)$ and the largest increase in average jump $(16.8 \%)$, sign of increased mobility throughout the earnings distribution. In the same category we find Ireland and UK, but with a lower magnitude of the evolution (around $0.3 \%-1 \%$ for the immobility ratio and 3\%-4\% for AJ). The relative increase in the average jump is higher than the relative decrease in the 
immobility ratio, sign of increased quintile jumps far from the initial state, ignored by the immobility ratio. (Figure 2.7)

Denmark and Netherlands are exceptions, recording both a decrease in the average jump (Denmark 5\% and Netherlands 11\%) and a slight decrease in the immobility ratio, meaning that both the degree of movement in the earnings distribution and the share of individuals maintaining the income position or moving in the position immediately below/above decreased. This might be due to an increase in earnings persistency on the main diagonal accompanied by a decrease in the cumulative shares of individuals keeping the same status or moving on the immediate position, and by an increase - of the same magnitude with the decrease in the cumulative share - in the share of individuals moving further up in the earnings distribution. The increased persistency reduces the average jump, as the index does not incorporate the share of individuals maintaining the same rank, and the reduction in the cumulative share of the individuals keeping the same status or moving on the immediate position reduces the immobility ratio. (Figure 2.7)

The immobility ratio appears to converge over time in five clusters (Figure 2.5): first, Luxembourg which records the highest immobility ratio in 2000-2001; second, Germany, France and Greece; third, UK, Belgium, Netherlands, Portugal, Italy and Austria; forth, Ireland and Finland, and lastly, with the lowest immobility ratio, Denmark and Spain.

Similarly, mobility away from the diagonal appears to converge over time in four clusters (Figure 2.6): first, Luxembourg - the lowest average jump in 2000-2001; second, Germany, France, Austria, Netherlands, Belgium, Greece, and Portugal; third, Italy, UK and Ireland; and lastly, Finland, Spain and Denmark, with the highest mobility away from the diagonal in 2000-2001. Overall, Luxembourg appears to diverge from the other EU countries.

In line with previous studies, the longer the period over which mobility is measured the higher the earnings mobility. (Table 2.3) The long-term immobility ratio records values roughly between 1.4 and 1.7 of the value under perfect mobility, whereas the long-term average jump is roughly between 0.3 and 0.6 of the jump under perfect mobility, indicating a high degree of persistency.

Figure 2.8 illustrates the relative difference between long and short-term mobility, based on the immobility ratio and the average jump. For all countries, the relative decrease in the immobility ratio with the time span is lower than the relative increase in the average jump with the time span, suggesting that, as the time span over which mobility is measured is extended, mobility away from the diagonal increases, and part of it is ignored by the immobility ratio as this index focuses 
only on the near-diagonal entries. Thus the longer the time period, the more likely it is that people move away from their initial state, and the degree of movement among the income quintiles increases to a larger extent than the relative reduction in the share of individuals maintaining the same status or moving in the position immediately below/above.

The ranking of the countries based on the relative difference between long and short-term mobility reveals that the relative change in the average jump with the time horizon is negatively associated with the relative change in the immobility ratio with the time horizon.
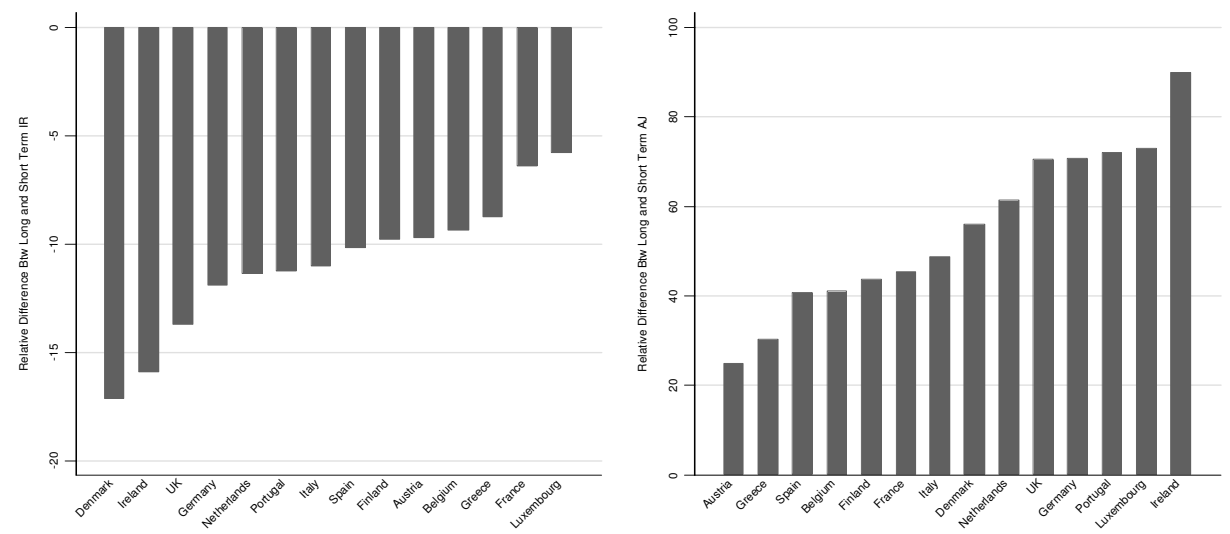

Figure 2.8. Relative Difference between Long and Short-term Immobility Ratio and Average Jump

The first six countries which record the highest drop in the immobility ratio with the time horizon are among the first seven countries with the highest increase in the average jump. It is the case of Denmark, Ireland, UK, Germany, Netherlands and Portugal. Denmark appears to record the highest decrease in persistency close to the main diagonal (approximately 17\%), whereas the increase in mobility away from the diagonal is of almost $55 \%$. Ireland, which has a similar decrease in the immobility ratio, has the highest increase in the average jump, almost $90 \%$. UK, Germany, Portugal and Netherlands record a relatively smaller reduction in the immobility ratio (between $11 \%$ and $14 \%$ ) than Denmark and Ireland, and a higher increase in the average jump (over 60\%) than Denmark, but lower than Ireland. Thus this countries record the largest relative increases in the degree of movement in the earnings distribution and the largest relative decreases in the degree of persistency on and close to the diagonal as the horizon over which mobility is measured is extended. 
These countries are followed by Italy, Spain, Finland, Belgium, Greece and France, which record a smaller decrease in the immobility ratio (between $6 \%$ and $11 \%$ ) and a smaller increase of in the average jump (roughly between $40 \%$ and $50 \%$ ). Thus these countries exhibit a higher degree of earnings persistency compared with the previous country cluster. Austria records the lowest increase in the average jump (around 25\%) and the $5^{\text {th }}$ decrease in the immobility ratio (around 9\%). Luxembourg stands out, recording the lowest decrease (around 6\%) in the longterm immobility ratio relative to the short-term immobility ratio, and among the highest increases (over 70\%) in the long-term average jump relative to the shortterm average jump, suggesting that when the horizon is extended, the share of individuals who "escape" their rank moving further away from it increases to a much smaller extent compared with the relative increase in their degree of movement. Thus, long-term, there are slightly more people that move further away from their initial position, but their degree of movement in the earnings distribution is relatively much higher compared with short-term.

In the long run (Figure 2.9), Luxembourg and France appear to be the least mobile, and Denmark and Ireland the most mobile, confirmed by both indices. In between, in ascending order based on the average jump we find Spain, Germany, Netherlands, Portugal, UK, Finland, Austria, Italy, Belgium and Greece. The longterm immobility ratios have similar values among countries, whereas for the average jump more heterogeneity is observed. Overall, we observed less heterogeneity with respect to long-term mobility rates compared with short-term rates, suggesting that over the lifetime earnings mobility rates are expected to converge to similar levels in most countries. The convergence is expected to be more evident for the immobility ratio than for the average jump. (Figure 2.9) 

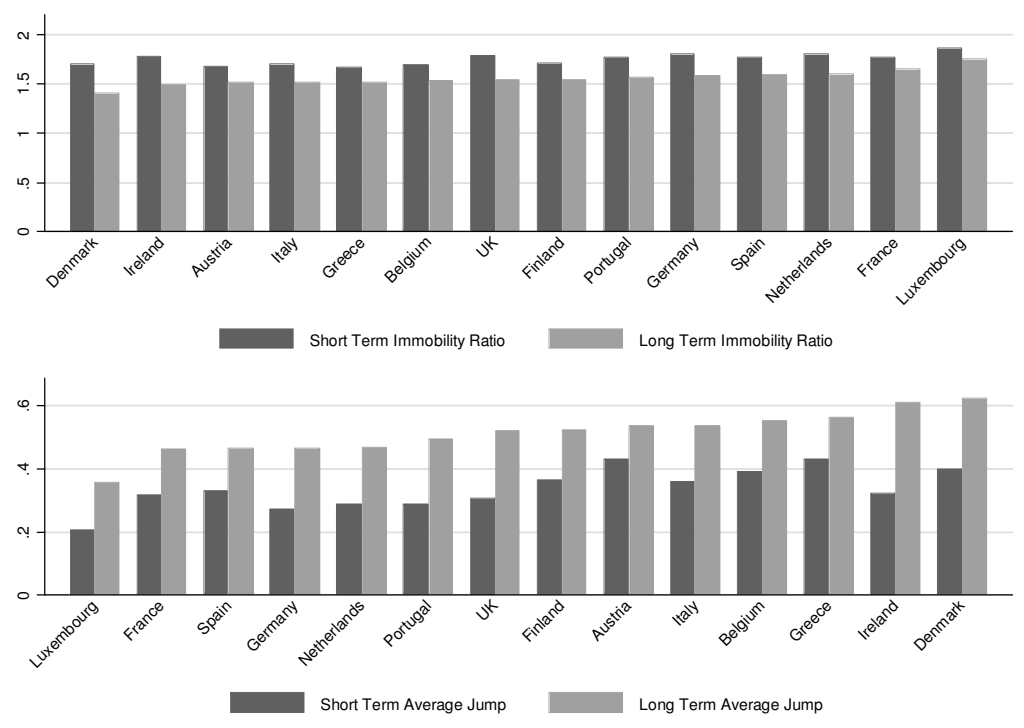

Figure 2.9. Short and Long Term Immobility Ratio and Average Jump

Note: The value for Luxembourg and Austria illustrate mobility over a period of 6 years, and for Finland over 5 years. 
Table 2.3. Immobility Ratio (IR) and Average Jump (AJ) for 1-year and 7-year Transition Rates of Earnings Quintiles (\%)

\begin{tabular}{|c|c|c|c|c|c|c|}
\hline Country & & Period & IR & $\begin{array}{c}\text { IR/ } \\
\text { IR(perfect mobility) }\end{array}$ & AJ & $\begin{array}{c}\mathrm{AJ} / \\
\mathrm{AJ}(\text { perfect mobility) }\end{array}$ \\
\hline \multirow{3}{*}{ Germany } & \multirow{2}{*}{ 1-year } & 1994-1995 & 0.937 & 1.802 & 0.438 & 0.274 \\
\hline & & $2000-2001$ & 0.952 & 1.831 & 0.392 & 0.245 \\
\hline & 8-year & $1994-2001$ & 0.825 & 1.587 & 0.747 & 0.467 \\
\hline \multirow{3}{*}{ Denmark } & \multirow{2}{*}{ 1-year } & 1994-1995 & 0.888 & 1.707 & 0.641 & 0.401 \\
\hline & & $2000-2001$ & 0.880 & 1.693 & 0.606 & 0.379 \\
\hline & 8-year & 1994-2001 & 0.735 & 1.414 & 1.000 & 0.625 \\
\hline \multirow{3}{*}{ Netherlands } & \multirow{2}{*}{ 1-year } & 1994-1995 & 0.938 & 1.803 & 0.465 & 0.291 \\
\hline & & 2000-2001 & 0.934 & 1.795 & 0.412 & 0.257 \\
\hline & 8-year & $1994-2001$ & 0.831 & 1.598 & 0.751 & 0.469 \\
\hline \multirow{3}{*}{ Belgium } & \multirow{2}{*}{ 1-year } & 1994-1995 & 0.880 & 1.692 & 0.629 & 0.393 \\
\hline & & $2000-2001$ & 0.924 & 1.777 & 0.403 & 0.252 \\
\hline & 8-year & $1994-2001$ & 0.797 & 1.533 & 0.888 & 0.555 \\
\hline \multirow{3}{*}{$\underset{*}{\text { Luxembourg }}$} & \multirow{2}{*}{ 1-year } & 1995-1996 & 0.968 & 1.861 & 0.332 & 0.207 \\
\hline & & $2000-2001$ & 0.979 & 1.882 & 0.298 & 0.186 \\
\hline & 8-year & $1995-2001$ & 0.911 & 1.753 & 0.574 & 0.359 \\
\hline \multirow{3}{*}{ France } & \multirow{2}{*}{ 1-year } & 1994-1995 & 0.921 & 1.771 & 0.511 & 0.319 \\
\hline & & 2000-2001 & 0.948 & 1.823 & 0.405 & 0.253 \\
\hline & 8-year & 1994-2001 & 0.861 & 1.657 & 0.742 & 0.464 \\
\hline \multirow{3}{*}{ UK } & \multirow{2}{*}{ 1-year } & 1994-1995 & 0.927 & 1.783 & 0.490 & 0.306 \\
\hline & & 2000-2001 & 0.925 & 1.778 & 0.506 & 0.317 \\
\hline & 8-year & 1994-2001 & 0.800 & 1.538 & 0.836 & 0.522 \\
\hline \multirow{3}{*}{ Ireland } & \multirow{2}{*}{ 1-year } & 1994-1995 & 0.925 & 1.778 & 0.516 & 0.323 \\
\hline & & $2000-2001$ & 0.909 & 1.748 & 0.531 & 0.332 \\
\hline & 8-year & 1994-2001 & 0.777 & 1.495 & 0.980 & 0.613 \\
\hline \multirow{3}{*}{ Italy } & \multirow{2}{*}{ 1-year } & 1994-1995 & 0.888 & 1.708 & 0.579 & 0.362 \\
\hline & & 2000-2001 & 0.928 & 1.785 & 0.472 & 0.295 \\
\hline & 8-year & $1994-2001$ & 0.790 & 1.519 & 0.860 & 0.538 \\
\hline \multirow{3}{*}{ Greece } & \multirow{2}{*}{ 1-year } & 1994-1995 & 0.867 & 1.667 & 0.694 & 0.434 \\
\hline & & $2000-2001$ & 0.943 & 1.814 & 0.403 & 0.252 \\
\hline & 8 -year & 1994-2001 & 0.790 & 1.520 & 0.904 & 0.565 \\
\hline \multirow{3}{*}{ Spain } & \multirow{2}{*}{ 1-year } & 1994-1995 & 0.920 & 1.770 & 0.528 & 0.330 \\
\hline & & $2000-2001$ & 0.882 & 1.695 & 0.617 & 0.386 \\
\hline & 8-year & 1994-2001 & 0.826 & 1.589 & 0.744 & 0.465 \\
\hline \multirow{3}{*}{ Portugal } & \multirow{2}{*}{ 1-year } & 1994-1995 & 0.923 & 1.774 & 0.460 & 0.288 \\
\hline & & 2000-2001 & 0.928 & 1.784 & 0.397 & 0.248 \\
\hline & 8 -year & 1994-2001 & 0.819 & 1.574 & 0.792 & 0.495 \\
\hline & 1-vear & $1995-1996$ & 0.875 & 1.683 & 0.689 & 0.431 \\
\hline Austria & 1-year & 2000-2001 & 0.924 & 1.776 & 0.429 & 0.268 \\
\hline & 7-year & 1995-2001 & 0.790 & 1.519 & 0.861 & 0.538 \\
\hline & 1-year & 1996-1997 & 0.891 & 1.713 & 0.584 & 0.365 \\
\hline Finland & & 2000-2001 & 0.908 & 1.746 & 0.578 & 0.361 \\
\hline & 6-year & 1996-2001 & 0.803 & 1.544 & 0.840 & 0.525 \\
\hline
\end{tabular}




\subsubsection{Alternative approach to mobility (Dickens 2000a)}

To circumvent the main limitation of the transition matrix approach - it fails to capture the movement within each earnings quintile, and thus underestimates the true degree of mobility - we explore earnings mobility using the approach introduced by Dickens (2000a), which accounts for the individual earnings ranks.

Similar to the transition matrix approach, we look first at short-term mobility and then at long-term mobility. Figure 2.10 presents plots of percentile rankings of male earnings in 1994/1995 and 2000/2001, and. Figure 2.11 percentile plots for 1994/1995 and 1994/2001.

For the pair of years situated at 1 year time horizon (Figure 2.10) a high earnings persistency is observed for all countries: most of the individuals are concentrated in a band around the 45-degree line, at different degrees across countries. The highest concentration is observed at the two extremes of the distribution, meaning that individuals situated at the bottom and the top of the earnings distribution have a lower mobility compared to the ones in the middle of the distribution, which is in line with the findings from the transition matrix approach.

In the beginning of the sample period, the countries with the lowest overall shortterm mobility (highest concentration along the 45-degree line) appear to be Germany, Netherlands, Luxembourg, France, UK, Ireland, Italy, Spain and Portugal. The most mobile appear to be Denmark, Belgium, Greece, Austria and Finland.

In order to understand better how the pattern of mobility changed over time we look at pairs of earnings rankings situated at the same time horizon (Figure 2.10). The concentration along the 45-degree line appears to increase over time, suggesting a decreasing degree of mobility from one year to the next, for most countries. Denmark, UK, Ireland, Spain represent an exception, recording an apparent diminishing concentration along the 45-degree line and therefore an increase in mobility. If one looks at the different parts of the distribution, diverging patterns appear.

There are a few individuals that record a huge jump in their rank from one year to the next: some that start at the bottom and jump to the top in the next period, and vice versa. This indicates the presence of a limited measurement error in hourly earnings in all countries. 

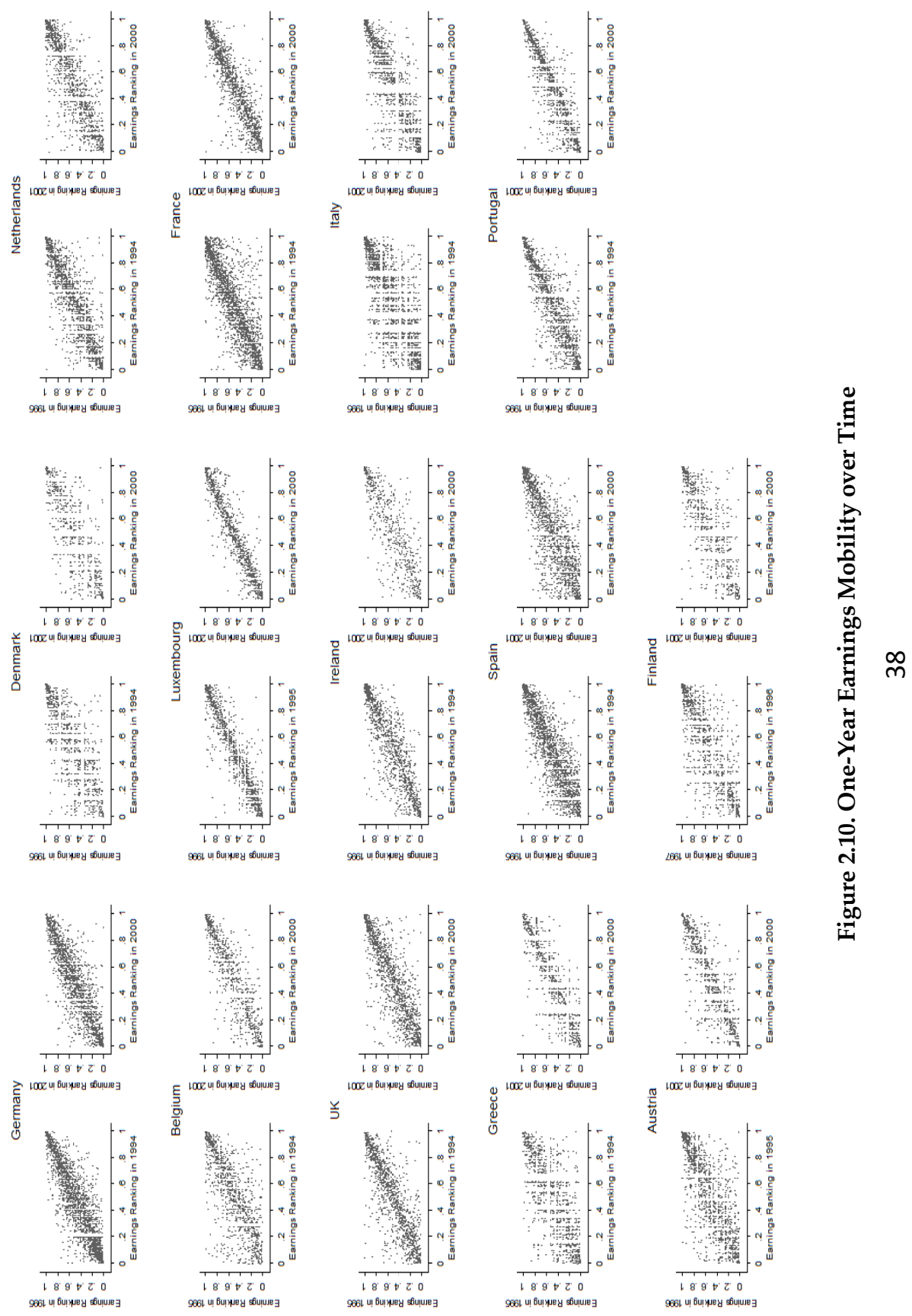

亏

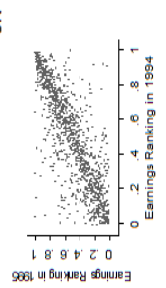

趌
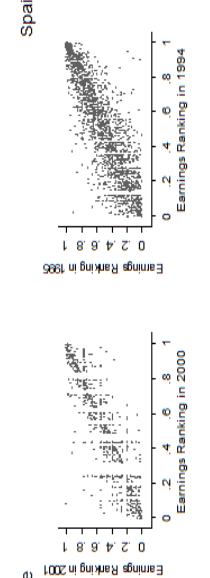

迩
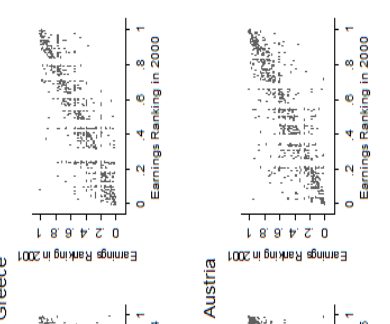

$\frac{5}{\frac{5}{4}}$
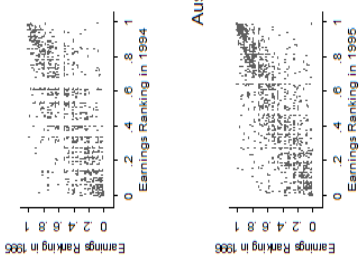

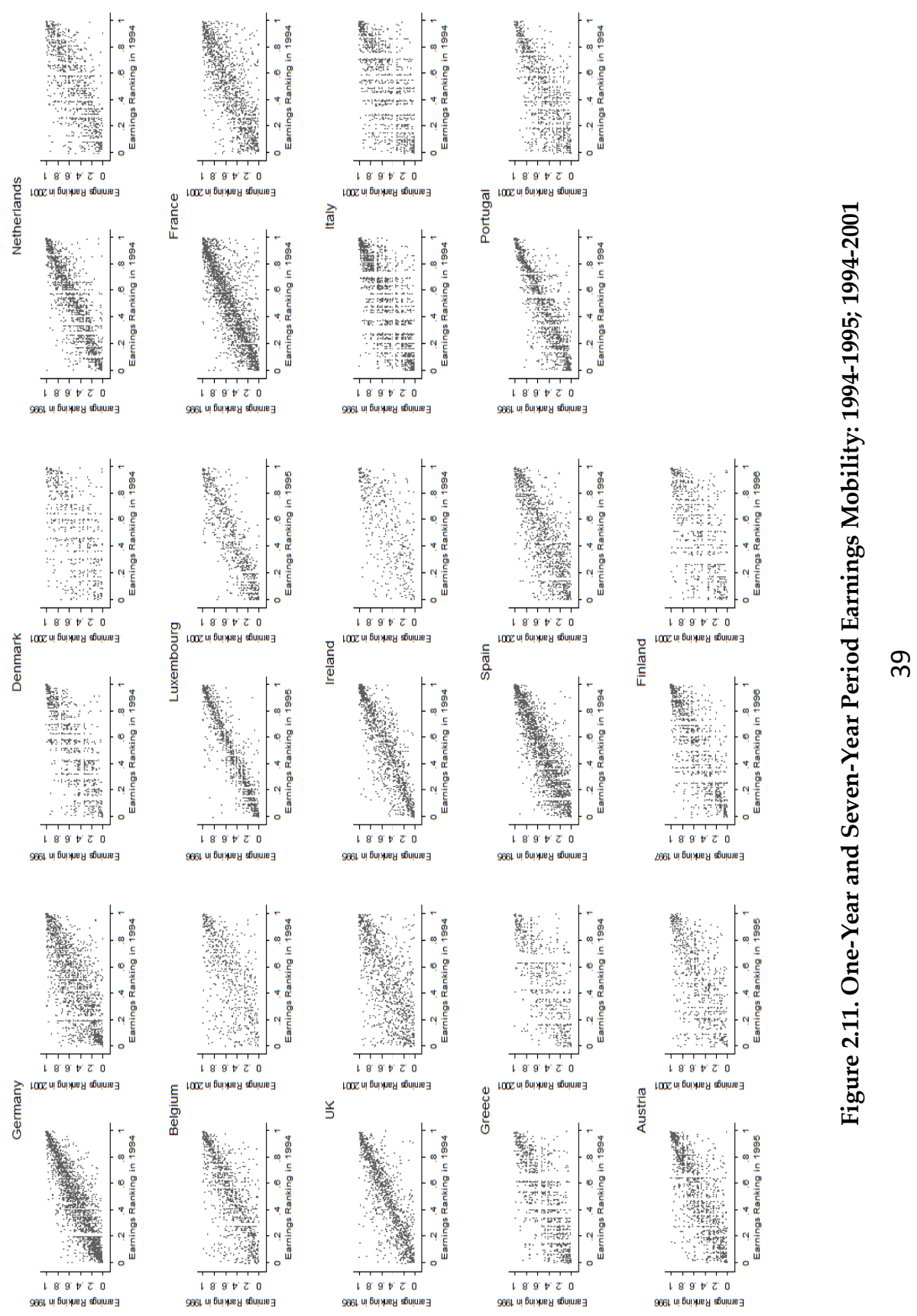
Looking at mobility across different time horizons (Figure 2.11), we observe that the longer the time span between the pair of earnings rankings, the less concentrated the scatter becomes along the 45-degree line, suggesting an increase in mobility with the time span. This trend is valid for all years and for all countries, and reconfirms previous findings.

The information in the rank scatter plots is summarised by the mobility index in (2.2). Figure 2.12 and Table 2.4 illustrate the evolution of the mobility index in (2.2) for different time horizons over the sample period for all countries. The values from all time horizons are below the value expected if earnings were independent in both years.

Figure 2.13 illustrates the evolution of the short-term mobility over time for all countries. Short-term mobility in the beginning of the sample period was the highest in Greece, followed by Austria, Belgium, Denmark and Finland with values over 0.25 . Next follows Italy, France, Spain, Ireland, UK and Portugal with values between 0.2 and 0.25 . The lowest mobility is observed in Luxembourg, Germany and Netherlands, with values lower than 0.2. This ranking is in general confirmed by the ranking based on the immobility ratio and the average jump.

The evolution of short-term mobility over time differs across countries. Except Spain, Ireland, UK and Denmark, all other countries record a decrease in the degree of mobility from one year to the next, which is in general consistent with the evolution of the immobility ratio and average jump. Exceptions are Denmark where the average jump decreased - and Netherlands - where the immobility ratio decreased. The change in mobility using Dickens, however, is very small in Denmark and Netherlands.

These mobility trends correspond to years 1994 to 2000. Linking these trends in mobility with the evolution of inequality over the period 1994-2000 (Table 2.2), we conclude that in 2000 men were: better off both in terms of their relative wage and opportunity to escape low pay in the next period in Denmark, UK, Ireland, and Spain; better off in terms of their relative wage, but worst off in terms of their chance to escape low pay in Belgium, France and Austria; and worst off in terms of both in Germany, Netherlands, Luxembourg, Italy, Greece, Finland and Portugal. 


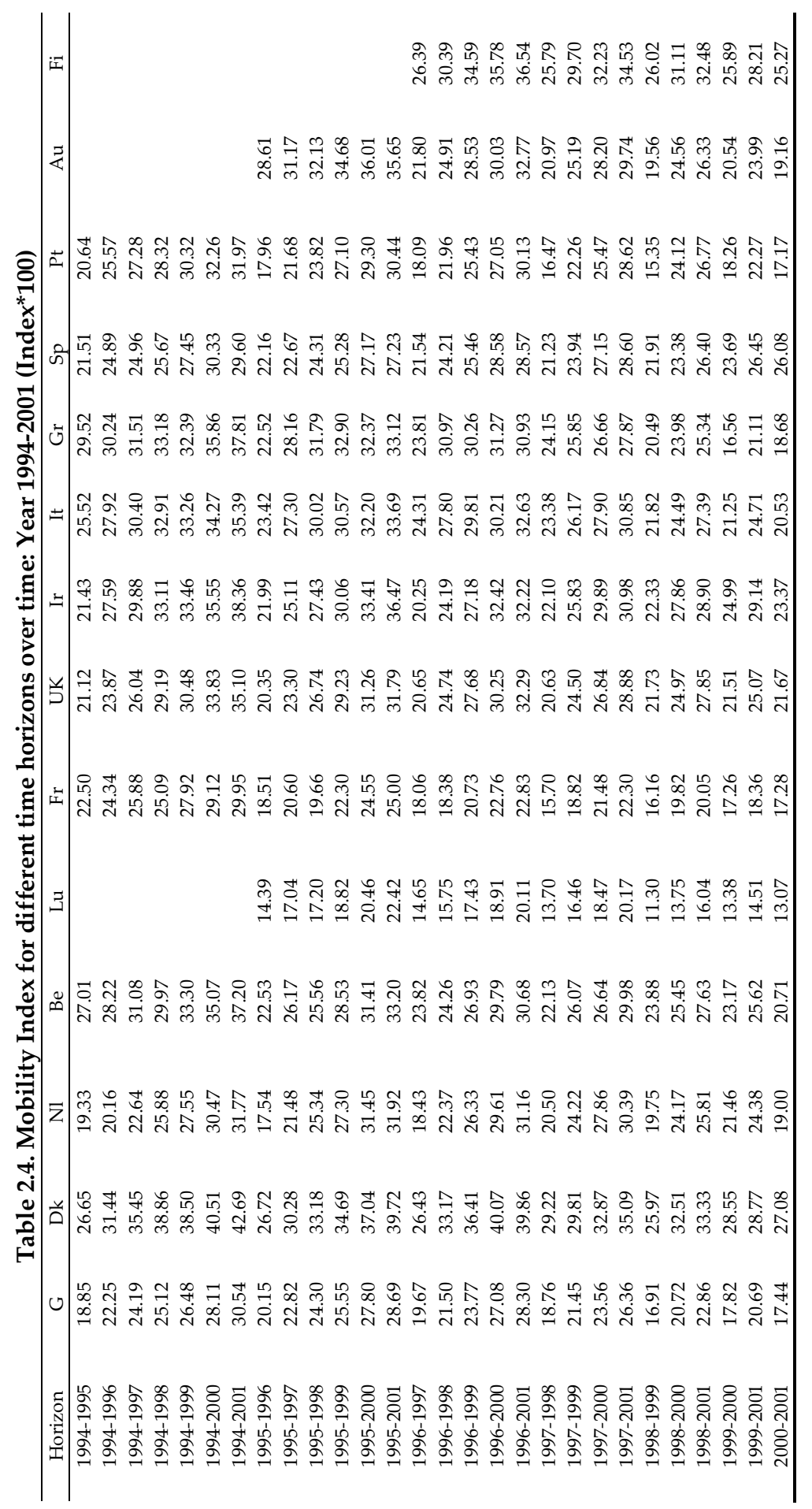



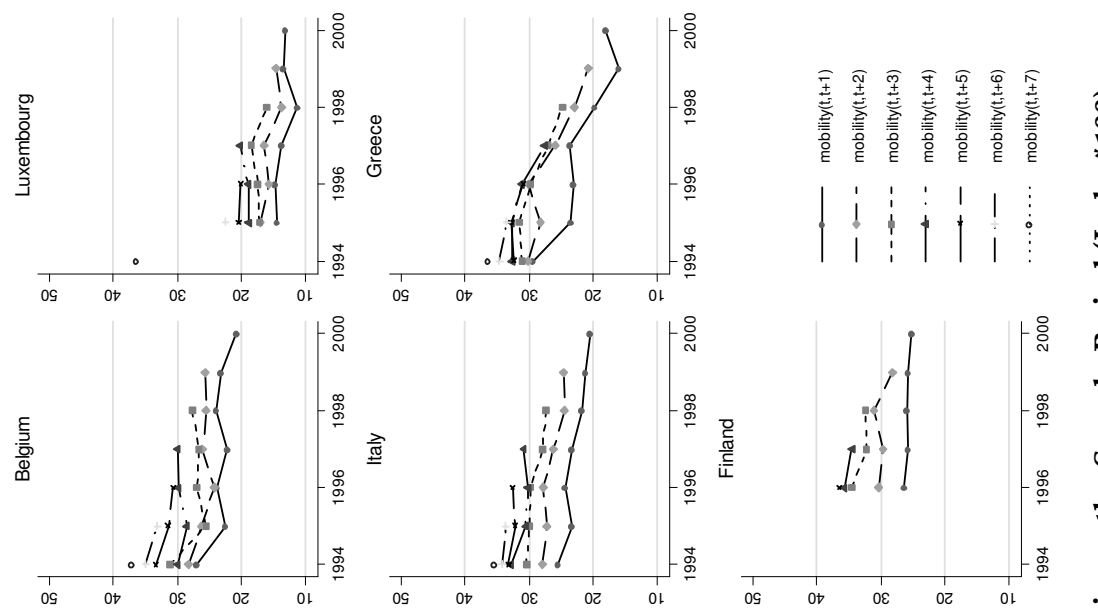

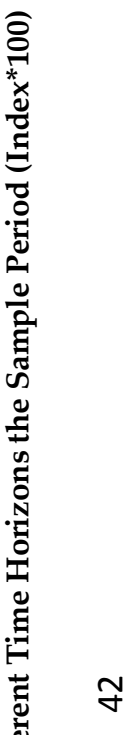
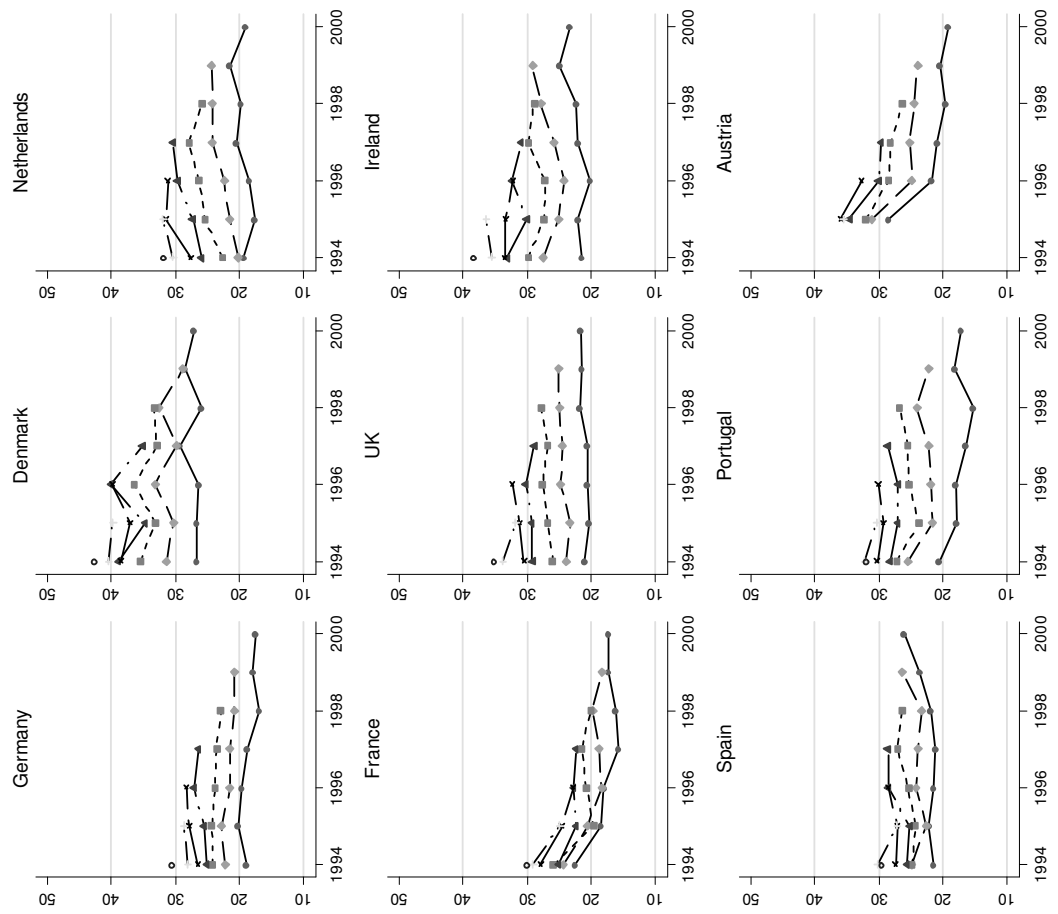

ํㅗㄹ 

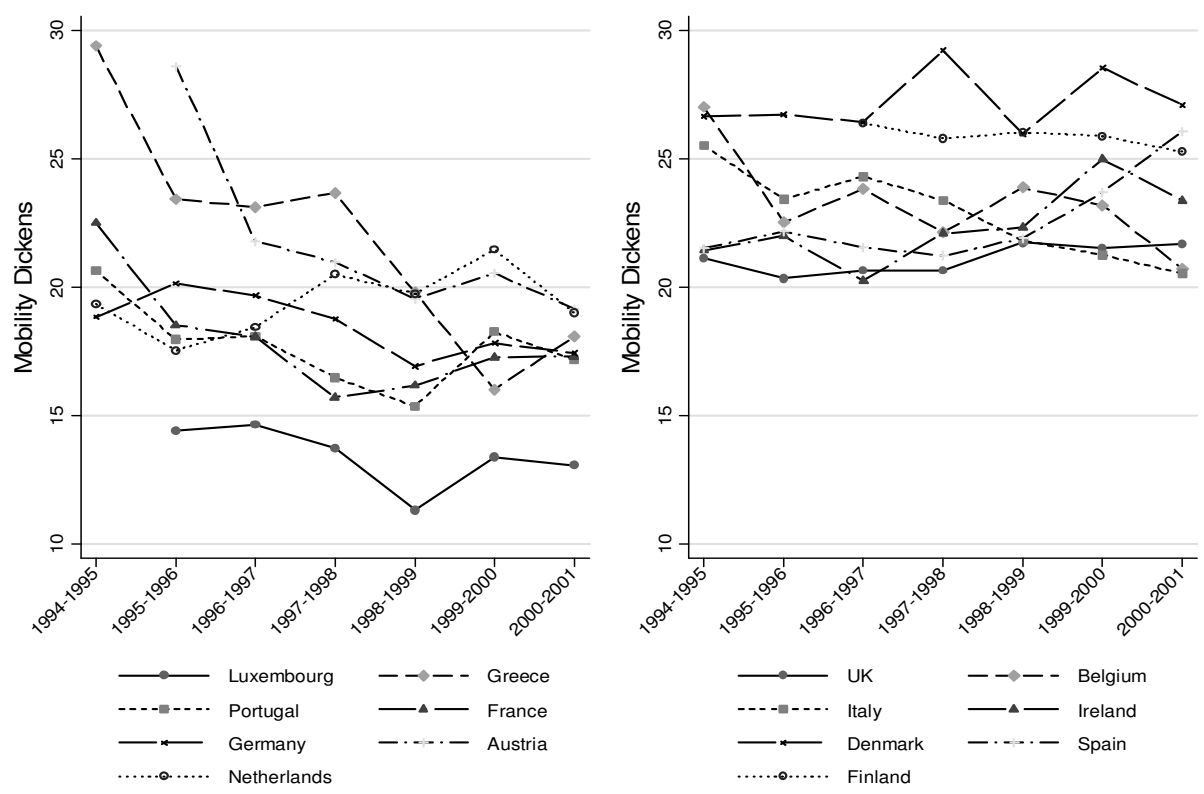

Figure 2.13. Dickens Short-Term Mobility over Time (Index $\left.{ }^{*} 100\right)$

In 2000-2001 a convergence in mobility rates is observed for four country clusters. (Figure 2.13) Luxembourg, which records the lowest mobility, and Denmark, which records the highest mobility, have a singular evolution. Spain and Finland converge towards a lower mobility than Denmark, followed by Ireland, which also has a singular evolution. The next cluster in terms of mobility is formed by UK, Italy and Belgium. The last two clusters are Austria and Netherlands, and Greece, Portugal, France and Germany. This ranking is in general confirmed by the ranking based on the average jump and the immobility ratio.

Figure 2.14 summarizes the relative change in short-term mobility for all countries. The largest decrease in mobility is recorded by Greece (almost $40 \%$ ), followed by Austria, with a reduction of more than 30\%, Belgium and France over 20\%, Italy and Portugal between 15\% and 20\%, and Luxembourg, Germany, Finland and Netherlands with a reduction lower than $10 \%$. Spain records the highest increase in short-term mobility with a rate of over $20 \%$, followed by Ireland, UK and Denmark, with a rate below $10 \%$.

The ranking, the magnitude and the direction of the relative change in short-term mobility based on Dickens index are, in general, similar with those based on the average jump. (Figure 2.7 and Figure 2.14). A big discrepancy is observed in the direction of evolution for Denmark: based on average jump mobility decreased 
with almost $10 \%$, whereas based on Dickens index it increases with almost $2 \%$. Differences in the magnitude of the evolution are observed for Netherlands, Germany, Luxembourg and Finland, where the increase in mobility was higher as measured by the average jump than by the Dickens index.

The difference in the ranking, magnitude and the direction of evolution of shortterm mobility might be explained by the limitations of using quintile transition matrices to look at mobility, particularly when looking at changes in mobility over time. If the earnings distribution has widened over time, then the size of the quintiles has also increased, so it might be that the movement across quintiles decreased. However, it might also be the case that mobility within quintiles has increased, which cannot be captured by the transition matrix approach.

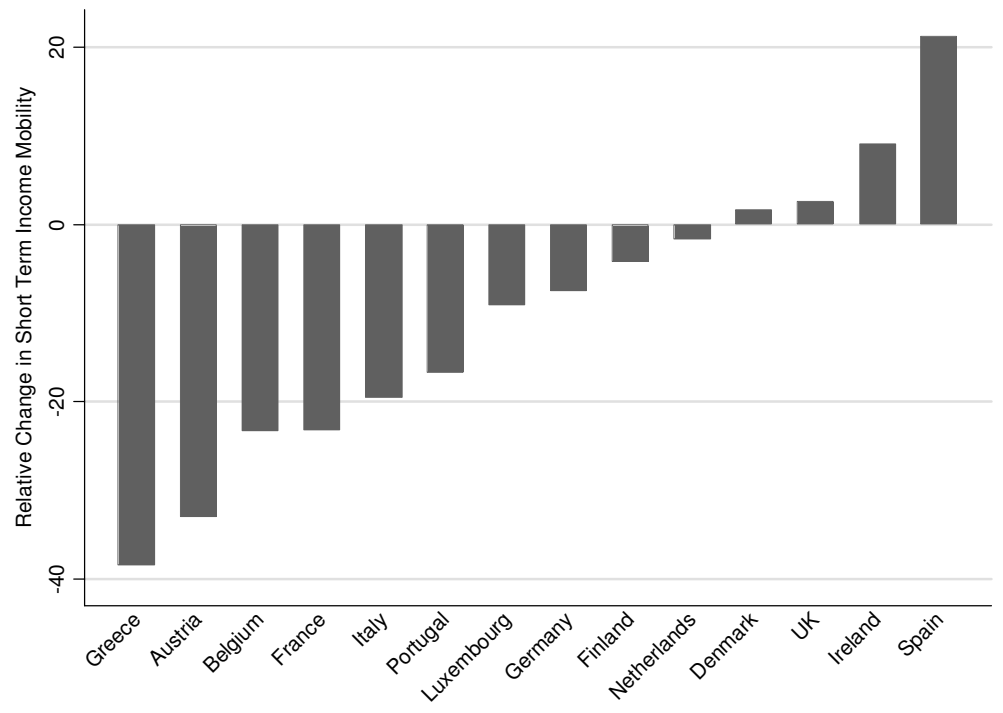

Figure 2.14. Relative Change in Short-term Mobility Measured by the Dickens Index

Consistent with the transition matrix approach and previous studies, long-term mobility is higher than short-term mobility and the trend is valid across countries. The relative increase in long term mobility relative to short-term mobility is summarized in Figure 2.15. The highest relative increase in mobility with the time span is recorded in Ireland with a value of almost $80 \%$, followed by UK, Netherlands, Germany, Denmark, Luxembourg and Portugal with values between $50 \%$ and $70 \%$. The other countries record values between $20 \%$ and $40 \%$. 


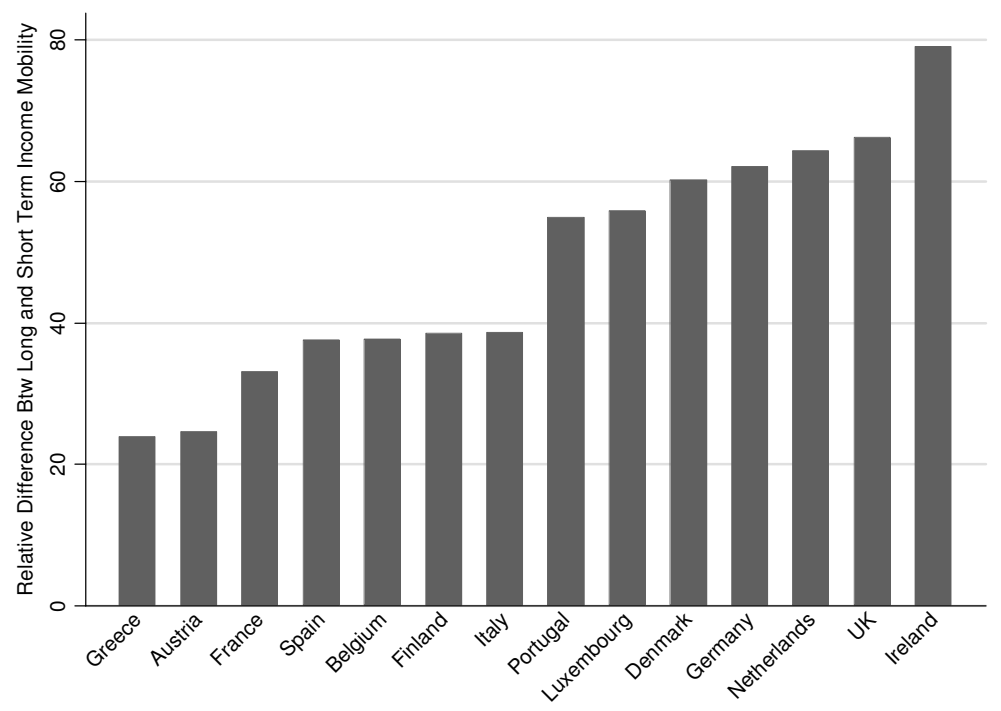

Figure 2.15. Relative Difference between Long and Short-term Mobility Measured by the Dickens Index

This evolution triggered a re-ranking of the countries with respect to their longterm mobility.(Figure 2.16) Luxembourg appears to have the lowest earnings mobility also in the long run, followed by Spain, France and Germany which record similar values, Netherlands, and Portugal, UK, Italy and Austria, Greece, Finland, Belgium and Ireland, and the highest Denmark. This ranking coincides in general with the one from the transition matrix approach.

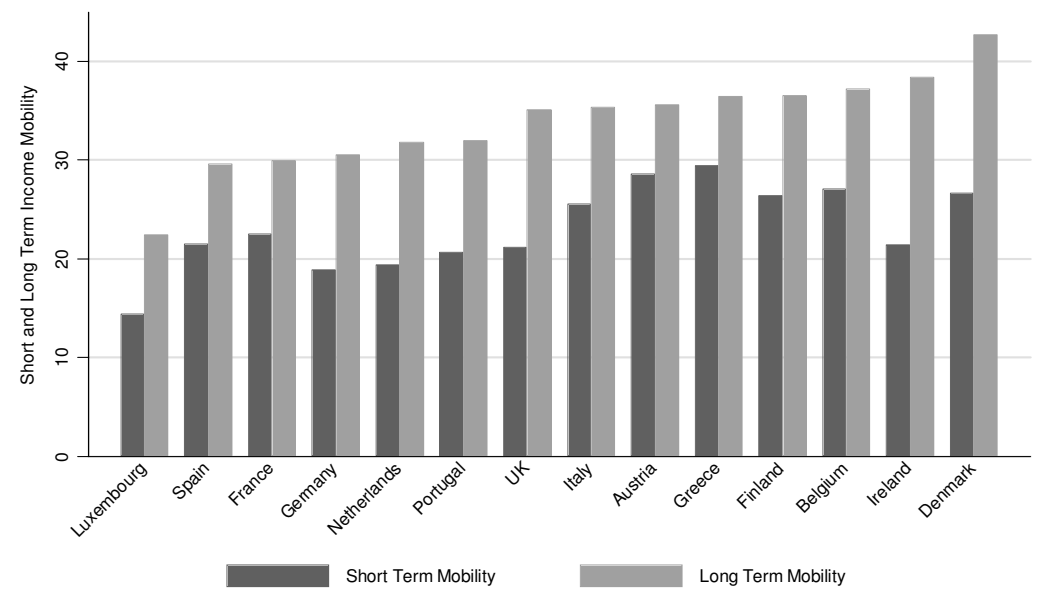

Figure 2.16. Short (1994/1995) and Long Term (1994/2001) Mobility Measured by the Dickens Index 
Judging whether this mobility is high or low depends on the question being asked. Long term mobility is certainly high enough to make the point that people are not stuck at the bottom top of the earnings distribution. The degree of mobility, however, is too low to wash out the effect of the yearly inequality. Even when earnings are summed over the sample period, a substantial inequality remains, signalling the presence of a substantial inequality in the "permanent" component of earnings.

Figure 2.17 shows the reduction in long-term inequality - measured by the Theil index for individual hourly earnings summed over the sample period - relative to cross-sectional inequality in the first wave - measured by the Theil index. These rates, however, overestimate the true values because cross-sectional inequality is based on all positive earnings, whereas longer-term inequality is based on a balanced panel. The rate of decrease ranges from 50\%-35\% for Denmark, Austria, Ireland, UK, Belgium, France, Luxembourg and Finland, to $30 \%-10 \%$ for Netherlands, Spain, Germany, Greece, Italy and Portugal, which provides a first clue that the first cluster of countries has a higher chance in reducing lifetime earnings differentials compared with the second one. This conclusion, however, needs to be explored further by estimating appropriate indicators that measure mobility as equalizer/disequalizer of longer term incomes, which represents a topic for future research.

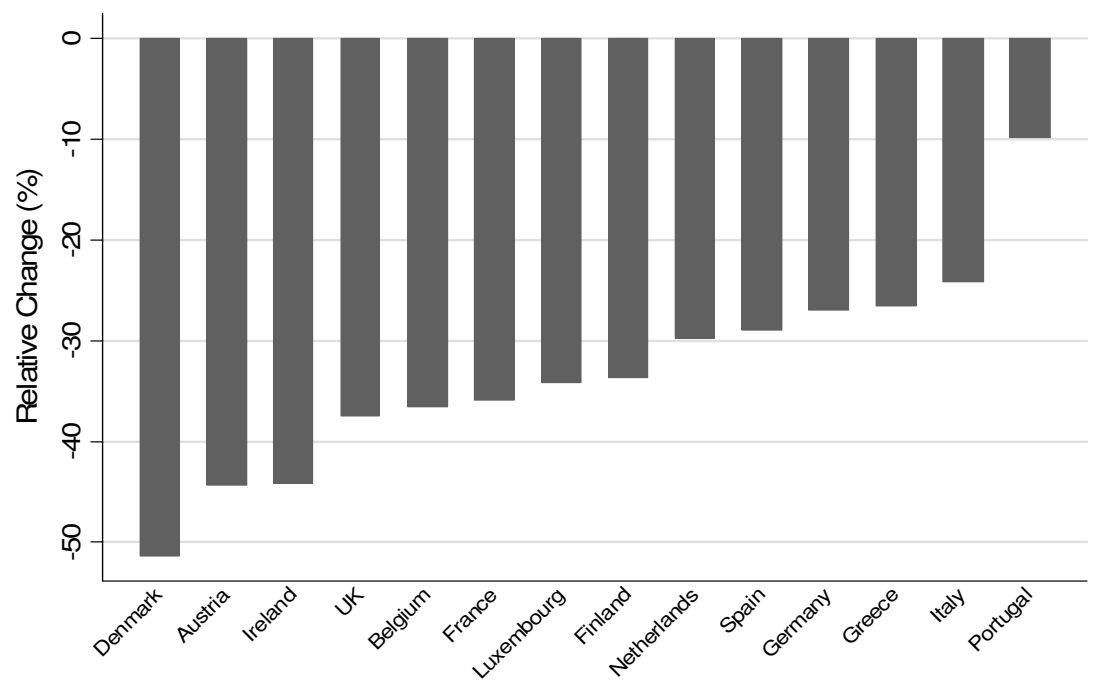

Figure 2.17. Relative Difference between Long-Term and Cross-sectional Earnings Inequality ( $1^{\text {st }}$ Wave) 


\subsection{Linking mobility and inequality}

Next we aim to link the patterns in short and long-term mobility with yearly inequality. This requires a backward looking approach. In interpreting the figures one has to pay attention to the difference in samples in computing inequality and mobility. The inequality measures are based on all individuals with positive earnings. The mobility measures refer to balanced 2-year panels, meaning individuals that recorded positive earnings in both years. We chose an unbalanced panel for inequality to avoid underestimating the degree of dispersion. When interpreting the results, however, we have to bear in mind that the degree of inequality in period $t$ depends also on the inflows and outflows of the sample in period $t$, not only on the degree of mobility from one period.

\subsubsection{Short-term mobility and yearly inequality}

Inequality in time $\mathrm{t}$ depends on inequality in time $\mathrm{t}-1$, mobility between $\mathrm{t}$ and $\mathrm{t}-1$ and individuals entering and exiting the sample between period $t-1$ and $t$. Thus inequality in the $2^{\text {nd }}$ wave depends on inequality in the $1^{\text {st }}$ wave, and the mobility between the $1^{\text {st }}$ wave and the $2^{\text {nd }}$ wave. Similarly, inequality in 2001 depends on inequality in 2000 and mobility between 2000 and 2001.

To shed some light on the potential link between short-term mobility and yearly inequality we look comparatively at the evolution of short term mobility between the $1^{\text {st }}$ wave/2nd wave, and 2000/2001, and the evolution of yearly inequality between the $2^{\text {nd }}$ wave and 2001. Figure 2.18 - left panel - ranks the countries with respect to their mobility between the $1^{\text {st }}$ wave and the $2^{\text {nd }}$ wave and the inequality in the $2^{\text {nd }}$ wave. The same is done in the right panel for inequality in 2001 and mobility in 2000-2001

Overall, it appears that the higher the inequality in year $t$, the lower the mobility between year $\mathrm{t}-1$ and $\mathrm{t}$. The ranking, however, has some exceptions. For example, in 1995, Greece ranks among the countries with the highest mobility and the highest inequality, suggesting that earnings mobility 1994-1995 might have had a disequalizing impact on earnings inequality in 1995. Similarly for Spain, which in 2001 ranks among the countries with the highest mobility and the highest inequality. These exceptions indicate that there are cases when earnings (part of) mobility might have a disequalizing impact on cross-sectional earnings inequality. 

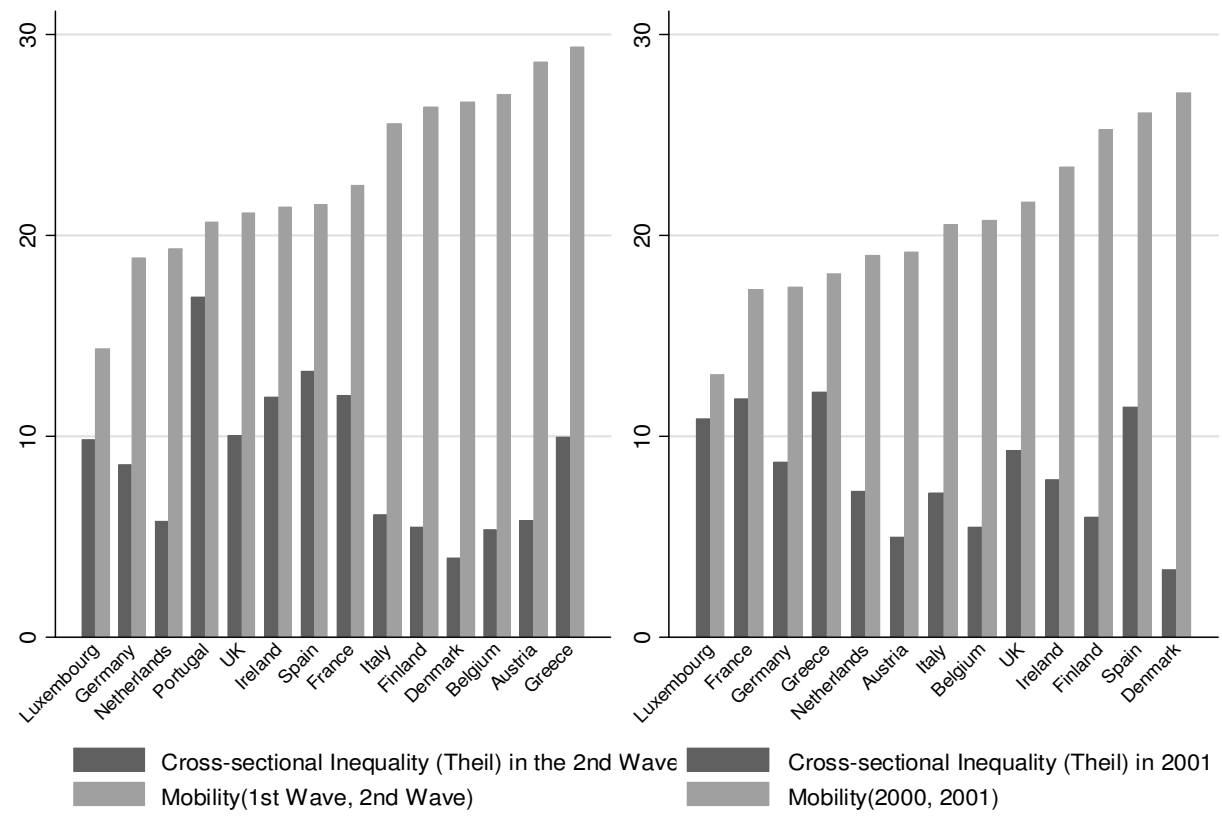

Figure 2.18. Link between Short-Term Mobility and Cross-Sectional Inequality: Mobility (1 ${ }^{\text {st }}$ Wave, $2^{\text {nd }}$ Wave $)->$ Inequality (2nd Wave) Mobility (2000, 2001) -> Inequality (2001)

Looking at the relative change in cross-sectional inequality and short-term mobility over the sample period, the picture is not clear-cut. (Figure 2.19) Most countries recording a decrease in short-term mobility, record also an increase in crosssectional inequality. Exceptions are Austria and France, where both decrease. One possible explanation is that the decrease in mobility was due to a decrease in the disequalizing part of mobility, which led to a decrease in inequality.

All countries recording an increase in short-term mobility over time - Denmark, UK, Spain and Ireland - record a decrease in cross-sectional inequality between 1995 and 2001, signalling a reducing effect of short-term mobility on yearly inequality. (Figure 2.19)

The ranking, however, is ambiguous. The countries with the smallest (Netherlands) and the largest (Greece) reduction in short-term mobility have the highest increase in cross-sectional inequality over time. Similarly, the countries with the lowest (UK) and the largest (Spain) increase in mobility do not have the largest reduction in inequality. These exceptions reinforce the argument that mobility can have both equalizing and disequalizing impacts on inequality, and 
the change in inequality depends on which facet of mobility changes with a dominating effect.

In general, it appears that short-term mobility has a reducing effect on yearly inequality, but the exceptions signal that mobility is not always beneficial.

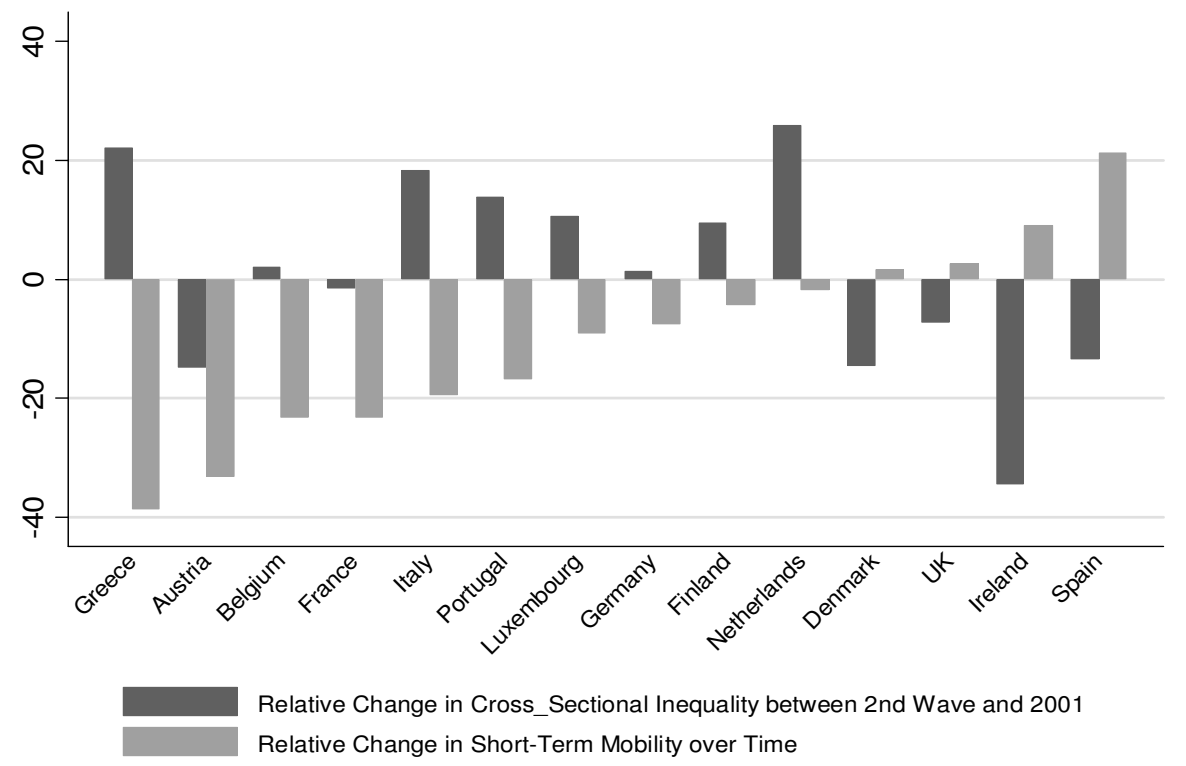

Figure 2.19. Relative Change in Cross-Sectional Inequality and Short-Term Mobility Over Time

Note: Inequality - between the $2^{\text {nd }}$ and the last wave; Mobility between $1^{\text {st-2 }} 2^{\text {nd }}$ wave and $2000-2001$

\subsubsection{Long-term mobility and yearly inequality}

Extending the time frame, inequality in time $t$ depends on inequality in time t-s and mobility between $t$ and $t-s$. Figure 2.20 ranks the 14 countries in terms of their long term mobility displaying at the same time the cross-sectional inequality in 2001 and the relative change in cross-sectional inequality between the $1^{\text {st }}$ wave and 2001 for each country.

On average it appears that a higher long-term mobility is associated with a lower cross-sectional inequality in 2001, but the ranking in the two measures is not consistent. The highest long-term mobility is present in Denmark, which records also the lowest inequality in 2001, but the highest inequality (Portugal) does not 
have the lowest mobility. Thus in Portugal, part of long-term earnings mobility is disequalizing yearly inequality.

The link between long-term mobility and the relative change in inequality is ambiguous. Mobility rates are similar, but the relative change in inequality is very heterogeneous, with no visible pattern. A possible explanation for the ambiguity in the mobility-inequality story relates to the nature of mobility: long-term mobility might have an equalizing effect on cross-sectional inequality in Denmark, Ireland, Belgium, Austria, UK, France, and Spain, and a disequalizing impact in the other countries.
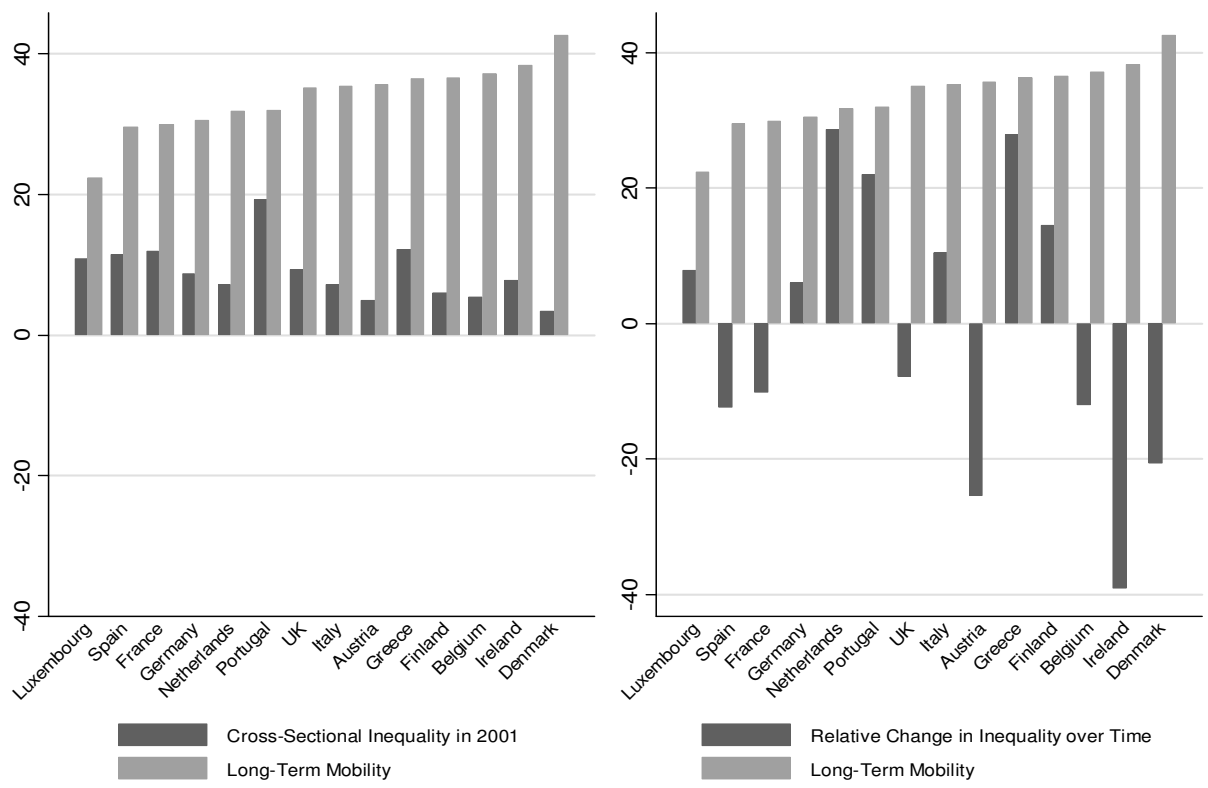

Figure 2.20. Long-Term Mobility and Cross-Sectional Inequality

\subsection{Concluding remarks}

In this paper we explored wage mobility for males across $14 \mathrm{EU}$ countries between 1994 and 2001 using ECHP. We used two types of rank measures, which capture positional movements in the distribution of earnings. The first one is derived from the transition matrix approach between income quintiles and other labour market states, and the second one is based on individual earnings ranks, as derived by Dickens (2000a). 
Starting with the transition matrices among labour market states, we find considerable levels of short-term immobility in all countries, with high shares of individuals staying in the same earnings quintile from one period to the next. Individuals situated in the bottom of the distribution are more likely to enter unemployment and inactivity compared with the rest of the distribution. Moreover, those that manage to get a job in the next period are more likely to enter the bottom of the earnings distribution. Mobility over the sample period is higher than one-period mobility, suggesting that the longer the period, the higher the opportunity to escape the initial state. The highest persistency in unemployment is found in Belgium, UK, Italy, Germany and Spain, and in inactivity in France, Belgium, Spain, Netherlands and Ireland.

Looking at the transition matrices among the income quintiles, we find a high level of persistency from one period to the next in all countries. Moreover, individuals that change their income position from one period to the next do not move very far. Individuals situated at the top of the distribution are less mobile than people at the bottom, which in turn are less mobile than the middle of the distribution. Longterm mobility is higher than short-term mobility, suggesting that the longer the period, the higher the opportunity to escape the initial earnings state.

Over time, short-term income mobility for individuals belonging to the first quintile decreased in all countries, except Luxembourg, Spain and Finland. In 20002001 the highest persistency for low-earnings individuals is in Portugal, Germany, Austria, Belgium, Netherlands and Luxembourg where between $78 \%$ and $70 \%$ remained in the same income group, followed by Greece, France, Ireland, Denmark with probabilities between $69 \%$ and $60 \%$, and UK, Finland, Italy and Spain with rates between $59 \%$ and $49 \%$.

Long-term mobility is higher than short-term mobility, but the persistency is still high: in Germany, Austria, Finland, Portugal and France, between $49 \%$ and $41 \%$ remained in bottom quintile in 2001, followed by Luxembourg, Netherlands, Spain, Belgium, Italy, Denmark, UK, Greece and Ireland, with values between $40 \%$ and $23 \%$.

Most countries that recorded an increase in cross-sectional earnings inequality between the 2nd wave and 2001, recorded also a decrease in short-term mobility over time, supported both by the increase in the share of individuals maintaining their state or moving to the closest state from one period to the next, and by the decrease in the degree of movement far away from the initial state. Netherlands is an exception, recording a decrease in the share of individuals maintaining their state or moving in the immediate income group. 
The decrease in cross-sectional earnings inequality between the $2^{\text {nd }}$ wave and 2001 was accompanied by a decrease in short-term mobility - captured by an increase in the share of individuals maintaining their state or moving in the income state immediately below/above and by a decrease in the degree of movement - in France and Austria, and by the opposite in UK, Spain, and Ireland. In Denmark, the decrease in inequality was accompanied by a decrease in the share of individuals who maintained their income state or moved in the one immediately below/above, and by a decrease in the average quintile jump.

The short-term immobility ratio converges over time in five clusters: first, Luxembourg which records the highest immobility ratio in 2000-2001; second, Germany, France and Greece; third, UK, Belgium, Netherlands, Portugal, Italy and Austria; forth, Ireland and Finland, and lastly, with the lowest immobility ratios, Denmark and Spain. Similarly, short-term mobility away from the diagonal converges over time in four clusters: first, Luxembourg - the lowest average jump in 2000-2001; second, Germany, France, Austria, Netherlands, Belgium, Greece, and Portugal; third, Italy, UK and Ireland; and lastly, Finland, Spain and Denmark, with the highest mobility away from the diagonal in 2000-2001. Overall, Luxembourg appears to diverge from the other EU countries.

In the long-run, Luxembourg and France appear to be the least mobile, and Denmark and Ireland the most mobile, confirmed by both indices. In between, in ascending order based on the average jump we find Spain, Germany, Netherlands, Portugal, UK, Finland, Austria, Italy, Belgium and Greece. The long-term immobility ratios have similar values among countries, whereas for the average jump more heterogeneity is observed. Overall, we observe less heterogeneity with respect to long-term mobility rates compared with short-term rates, suggesting that, over the lifetime, earnings mobility rates are expected to converge to similar levels in most countries. The convergence is expected to be more evident for the immobility ratio than for the average jump.

To overcome the main drawbacks of the transition matrix approach, we looked at the actual percentile rankings of workers within the wage distribution and computed a measure of mobility following Dickens (2000a). This approach reconfirmed most of the findings above.

Based on the proposed index, all countries recording an increase in cross-sectional inequality between the $2^{\text {nd }}$ wave and 2001 recorded also a decrease in short-term mobility. Among the countries where inequality decreased, earnings mobility increased in UK, Spain, Denmark and Ireland, and decreased in France and Austria. The trend in the Dickens mobility index is consistent with the trend in the 
average jump in all countries except Denmark, and with the trend in the immobility ratio in all countries except Netherlands.

What are the welfare implications of these trends in short-term mobility? In Netherlands, Greece, Finland, Portugal, Luxembourg, Italy, Germany, and Belgium, individuals find it harder in 2000-2001 to better their position in the earnings distribution short-term compared with the $1^{\text {st }} 2^{\text {nd }}$ wave, factor which might have contributed to the increase in earnings differentials between the $2^{\text {nd }}$ wave and 2001. Moreover, the decrease in mobility rates might signal an increase in permanent earning differentials.

In France and Austria, despite the decrease in cross-sectional earnings differentials between the $2^{\text {nd }}$ wave and 2001, individuals have a decreased opportunity in 20002001 to better their position in the earnings distribution compared with the $1^{\text {st }} 2^{\text {nd }}$ wave. In the UK, Spain, Denmark, and Ireland individuals have an increased opportunity in 2000 to improve their earnings position short-term compared with 1994, which might have contributed to reduce cross-sectional differentials over time.

Short-term mobility rates converge towards 2001 in four country clusters. Luxembourg - the lowest mobility in 2001 - and Denmark - the highest mobility in 2001 - have a singular evolution. Spain and Finland converge towards a lower mobility than Denmark, followed by Ireland, with a singular evolution. Next, UK, Italy and Belgium converge towards a lower level than Ireland. The last two clusters are Austria and Netherlands, and Greece, Portugal, France and Germany. This ranking is in general confirmed by the ranking based on the immobility ratio and the average jump.

The lowest opportunity of improving the earnings position in the long run is found in Luxembourg followed by four clusters which record similar values: first, Spain, France and Germany; second, Netherlands and Portugal; third, UK, Italy and Austria; forth Greece, Finland, Belgium and Ireland. Finally, men in Denmark have the highest opportunity of improving their income position in the long run.

We also tried to link the patterns in short and long-term mobility with yearly inequality. Overall, it appears that the higher the inequality in the $2^{\text {nd }}$ wave, the lower the mobility between the $1^{\text {st }}$ and $2^{\text {nd }}$ wave. Similarly, a higher long-term mobility (between the $1^{\text {st }}$ wave and 2001) is associated with a lower cross-sectional inequality in 2001.The rankings, however, has some exceptions, indicating that there are cases when (part of earnings) mobility might have a disequalizing impact on cross-sectional earnings inequality. These factors reinforce the belief that mobility is not always beneficial. 
A topic for further research is to explore the implications of the long-term mobility rates for lifetime inequality. 


\subsection{Annex}

Table 2-A-1. Inflows and Outflows of Individuals in the Sample - Germany

\begin{tabular}{|c|c|c|c|c|c|c|c|c|}
\hline & 1994 & 1995 & 1996 & 1997 & 1998 & 1999 & 2000 & 2001 \\
\hline $\begin{array}{l}\text { Number of individuals with } \\
\text { positive earnings }\end{array}$ & 25018 & 26059 & 25806 & 24889 & 23290 & 22955 & 21909 & 20703 \\
\hline \multicolumn{9}{|c|}{$\begin{array}{c}\text { Absolute number and proportion of individuals who report positive earnings in current year conditional on being in } \\
\text { the sample in previous year }\end{array}$} \\
\hline & Frequencies & 23956 & 25224 & 24197 & 22814 & 22321 & 21290 & 20107 \\
\hline & $\%$ & 66.99 & 67.37 & 66.2 & 63.01 & 64.84 & 64.86 & 64.39 \\
\hline \multicolumn{9}{|c|}{$\begin{array}{c}\text { Absolute number and proportion of individuals who report no earnings in current year conditional on being in the } \\
\text { sample in the previous year }\end{array}$} \\
\hline Unemployed & Frequencies & 3448 & 3461 & 4119 & 3932 & 3055 & 2787 & 2766 \\
\hline Inactive & $\%$ & 9.64 & 9.24 & 11.27 & 10.86 & 8.87 & 8.49 & 8.86 \\
\hline \multirow{2}{*}{ Attrition } & Frequencies & 1885 & 2182 & 1892 & 3280 & 2951 & 2924 & 2830 \\
\hline & $\%$ & 5.27 & 5.83 & 5.18 & 9.06 & 8.57 & 8.91 & 9.06 \\
\hline \multirow{2}{*}{ Missing Wage } & Frequencies & 6470 & 6576 & 6345 & 6180 & 6100 & 5826 & 5524 \\
\hline & $\%$ & 18.09 & 17.56 & 17.36 & 17.07 & 17.72 & 17.75 & 17.69 \\
\hline \multirow[t]{2}{*}{ Total } & Frequencies & 35759 & 37443 & 36553 & 36206 & 34427 & 32827 & 31227 \\
\hline & $\%$ & 100 & 100 & 100 & 100 & 100 & 100 & 100 \\
\hline
\end{tabular}

Table 2-A-1. Inflows and Outflows of Individuals in the Sample - Denmark

\begin{tabular}{|c|c|c|c|c|c|c|c|c|}
\hline & 1994 & 1995 & 1996 & 1997 & 1998 & 1999 & 2000 & 2001 \\
\hline $\begin{array}{l}\text { Number of individuals with } \\
\text { positive earnings }\end{array}$ & 20899 & 20399 & 19190 & 19062 & 17321 & 16235 & 15678 & 15380 \\
\hline \multicolumn{9}{|c|}{$\begin{array}{l}\text { Absolute number and proportion of individuals who report positive earnings in current year conditional on being in the } \\
\text { sample in previous year }\end{array}$} \\
\hline & Frequencies & 19854 & 18527 & 18110 & 16442 & 15334 & 14865 & 14642 \\
\hline & $\%$ & 68.74 & 66.59 & 69.43 & 66.23 & 67.41 & 69.6 & 71.6 \\
\hline \multicolumn{9}{|c|}{$\begin{array}{l}\text { Absolute number and proportion of individuals who report no earnings in current year conditional on being in the } \\
\text { sample in the previous year }\end{array}$} \\
\hline Unemployed & Frequencies & 1535 & 1744 & 951 & 899 & 732 & 658 & 958 \\
\hline Inactive & $\%$ & 5.31 & 6.27 & 3.65 & 3.62 & 3.22 & 3.08 & 4.68 \\
\hline \multirow{2}{*}{ Attrition } & Frequencies & 2440 & 3096 & 2914 & 3603 & 2922 & 2133 & 1775 \\
\hline & $\%$ & 8.45 & 11.13 & 11.17 & 14.51 & 12.85 & 9.99 & 8.68 \\
\hline \multirow{2}{*}{ Missing Wage } & Frequencies & 5054 & 4454 & 4110 & 3881 & 3759 & 3703 & 3074 \\
\hline & $\%$ & 17.5 & 16.01 & 15.76 & 15.63 & 16.53 & 17.34 & 15.03 \\
\hline \multirow[t]{2}{*}{ Total } & Frequencies & 28883 & 27821 & 26085 & 24825 & 22747 & 21359 & 20449 \\
\hline & $\%$ & 100 & 100 & 100 & 100 & 100 & 100 & 100 \\
\hline
\end{tabular}


Table 2-A-1. Inflows and Outflows of Individuals in the Sample - Netherlands

\begin{tabular}{|c|c|c|c|c|c|c|c|c|}
\hline & 1994 & 1995 & 1996 & 1997 & 1998 & 1999 & 2000 & 2001 \\
\hline $\begin{array}{l}\text { Number of individuals with } \\
\text { positive earnings }\end{array}$ & 20221 & 22100 & 22892 & 22753 & 22863 & 23233 & 24065 & 24130 \\
\hline \multicolumn{9}{|c|}{$\begin{array}{l}\text { Absolute number and proportion of individuals who report positive earnings in current year conditional on being in the } \\
\text { sample in previous year }\end{array}$} \\
\hline & Frequencies & 20578 & 21328 & 21221 & 21055 & 20545 & 21026 & 21341 \\
\hline & $\%$ & 69.07 & 71.37 & 68.68 & 67.52 & 67.24 & 68.56 & 69.59 \\
\hline \multicolumn{9}{|c|}{$\begin{array}{c}\text { Absolute number and proportion of individuals who report no earnings in current year conditional on being in the } \\
\text { sample in the previous year }\end{array}$} \\
\hline Unemployed & Frequencies & 2418 & 2356 & 2536 & 2120 & 1984 & 1840 & 1689 \\
\hline Inactive & $\%$ & 8.12 & 7.88 & 8.21 & 6.8 & 6.49 & 6 & 5.51 \\
\hline \multirow{2}{*}{ Attrition } & Frequencies & 2941 & 1889 & 2591 & 3562 & 3984 & 4301 & 4891 \\
\hline & $\%$ & 9.87 & 6.32 & 8.39 & 11.42 & 13.04 & 14.02 & 15.95 \\
\hline \multirow{2}{*}{ Missing Wage } & Frequencies & 3857 & 4310 & 4550 & 4448 & 4042 & 3502 & 2745 \\
\hline & $\%$ & 12.95 & 14.42 & 14.73 & 14.26 & 13.23 & 11.42 & 8.95 \\
\hline \multirow[t]{2}{*}{ Total } & Frequencies & 29794 & 29883 & 30898 & 31185 & 30555 & 30669 & 30666 \\
\hline & $\%$ & 100 & 100 & 100 & 100 & 100 & 100 & 100 \\
\hline
\end{tabular}

Table 2-A-1. Inflows and Outflows of Individuals in the Sample - Belgium

\begin{tabular}{|c|c|c|c|c|c|c|c|c|}
\hline & 1994 & 1995 & 1996 & 1997 & 1998 & 1999 & 2000 & 2001 \\
\hline $\begin{array}{l}\text { Number of individuals with } \\
\text { positive earnings }\end{array}$ & 35342 & 34367 & 33280 & 32378 & 31129 & 29414 & 28087 & 26538 \\
\hline \multicolumn{9}{|c|}{$\begin{array}{c}\text { Absolute number and proportion of individuals who report positive earnings in current year conditional on being in the } \\
\text { sample in previous year }\end{array}$} \\
\hline & Frequencies & 33277 & 32384 & 31564 & 30575 & 28731 & 27460 & 25790 \\
\hline & $\%$ & 63.43 & 63.65 & 64.38 & 63.88 & 64.28 & 65.15 & 64.38 \\
\hline \multicolumn{9}{|c|}{$\begin{array}{c}\text { Absolute number and proportion of individuals who report no earnings in current year conditional on being in the } \\
\text { sample in the previous year }\end{array}$} \\
\hline Unemployed & Frequencies & 3810 & 5127 & 4378 & 3601 & 3040 & 3090 & 2540 \\
\hline Inactive & $\%$ & 7.26 & 10.08 & 8.93 & 7.52 & 6.8 & 7.33 & 6.34 \\
\hline \multirow{2}{*}{ Attrition } & Frequencies & 4145 & 3798 & 3473 & 4803 & 4421 & 3851 & 4930 \\
\hline & $\%$ & 7.9 & 7.46 & 7.08 & 10.04 & 9.89 & 9.14 & 12.31 \\
\hline \multirow{2}{*}{ Missing Wage } & Frequencies & 11228 & 9573 & 9614 & 8882 & 8504 & 7748 & 6798 \\
\hline & $\%$ & 21.4 & 18.81 & 19.61 & 18.56 & 19.03 & 18.38 & 16.97 \\
\hline \multirow[t]{2}{*}{ Total } & Frequencies & 52460 & 50882 & 49029 & 47861 & 44696 & 42149 & 40058 \\
\hline & $\%$ & 100 & 100 & 100 & 100 & 100 & 100 & 100 \\
\hline
\end{tabular}


Table 2-A-1. Inflows and Outflows of Individuals in the Sample - Luxembourg

\begin{tabular}{|c|c|c|c|c|c|c|c|c|}
\hline & 1994 & 1995 & 1996 & 1997 & 1998 & 1999 & 2000 & 2001 \\
\hline $\begin{array}{l}\text { Number of individuals with } \\
\text { positive earnings }\end{array}$ & & 15829 & 13695 & 14489 & 13403 & 14075 & 12667 & 12992 \\
\hline \multicolumn{9}{|c|}{$\begin{array}{l}\text { Absolute number and proportion of individuals who report positive earnings in current year conditional on being in the } \\
\text { sample in previous year }\end{array}$} \\
\hline & Frequencies & & 13417 & 12498 & 13190 & 12257 & 12402 & 11457 \\
\hline & $\%$ & & 64.75 & 69.48 & 69.33 & 69.81 & 68.71 & 70.39 \\
\hline \multicolumn{9}{|c|}{$\begin{array}{c}\text { Absolute number and proportion of individuals who report no earnings in current year conditional on being in the } \\
\text { sample in the previous year }\end{array}$} \\
\hline Unemployed & Frequencies & & 1765 & 1559 & 1505 & 1408 & 1246 & 954 \\
\hline Inactive & $\%$ & & 8.52 & 8.67 & 7.91 & 8.02 & 6.9 & 5.86 \\
\hline \multirow{2}{*}{ Attrition } & Frequencies & & 3423 & 1663 & 2109 & 1913 & 2346 & 1940 \\
\hline & $\%$ & & 16.52 & 9.25 & 11.09 & 10.9 & 13 & 11.92 \\
\hline \multirow{2}{*}{ Missing Wage } & Frequencies & & 2116 & 2267 & 2220 & 1980 & 2057 & 1926 \\
\hline & $\%$ & & 10.21 & 12.6 & 11.67 & 11.28 & 11.4 & 11.83 \\
\hline \multirow{3}{*}{ Total } & & & & & & & 1805 & \\
\hline & Frequencies & & 20721 & 17987 & 19024 & 17558 & 1 & 16277 \\
\hline & $\%$ & 100 & 100 & 100 & 100 & 100 & 100 & 100 \\
\hline
\end{tabular}

Table 2-A-1. Inflows and Outflows of Individuals in the Sample - France

\begin{tabular}{|c|c|c|c|c|c|c|c|c|}
\hline & 1994 & 1995 & 1996 & 1997 & 1998 & 1999 & 2000 & 2001 \\
\hline $\begin{array}{l}\text { Number of individuals with } \\
\text { positive earnings }\end{array}$ & 20137 & 19270 & 19042 & 17906 & 14467 & 14012 & 13760 & 14212 \\
\hline \multicolumn{9}{|c|}{$\begin{array}{c}\text { Absolute number and proportion of individuals who report positive earnings in current year conditional on being in the } \\
\text { sample in previous year }\end{array}$} \\
\hline & Frequencies & 19143 & 18197 & 17243 & 14014 & 12209 & 12080 & 12468 \\
\hline & $\%$ & 62.47 & 64.76 & 62 & 52.08 & 54.24 & 55.54 & 60.8 \\
\hline
\end{tabular}

Absolute number and proportion of individuals who report no earnings in current year conditional on being in the

\begin{tabular}{ccccccccc}
\multicolumn{10}{c}{ sample in the previous year } \\
\hline Unemployed & Frequencies & 3259 & 3042 & 3426 & 3006 & 2607 & 2072 & 1995 \\
Inactive & $\%$ & 10.64 & 10.83 & 12.32 & 11.17 & 11.58 & 9.53 & 9.73 \\
& Frequencies & 3371 & 2213 & 2785 & 5584 & 3531 & 3786 & 2658 \\
Attrition & $\%$ & 11 & 7.88 & 10.01 & 20.75 & 15.69 & 17.41 & 12.96 \\
& Frequencies & 4871 & 4646 & 4358 & 4304 & 4162 & 3811 & 3385 \\
Missing Wage & $\%$ & 15.9 & 16.53 & 15.67 & 16 & 18.49 & 17.52 & 16.51 \\
& Frequencies & 30644 & 28098 & 27812 & 26908 & 22509 & 21749 & 20506 \\
Total & $\%$ & 100 & 100 & 100 & 100 & 100 & 100 & 100 \\
& & & &
\end{tabular}


Table 2-A-1. Inflows and Outflows of Individuals in the Sample - UK

\begin{tabular}{|c|c|c|c|c|c|c|c|c|}
\hline & 1994 & 1995 & 1996 & 1997 & 1998 & 1999 & 2000 & 2001 \\
\hline $\begin{array}{l}\text { Number of individuals with } \\
\text { positive earnings }\end{array}$ & 24949 & 25329 & 25495 & 26010 & 26145 & 25750 & 25674 & 25264 \\
\hline \multicolumn{9}{|c|}{$\begin{array}{l}\text { Absolute number and proportion of individuals who report positive earnings in current year conditional on being in the } \\
\text { sample in previous year }\end{array}$} \\
\hline & Frequencies & 24511 & 24848 & 25303 & 25278 & 25006 & 24881 & 24467 \\
\hline & $\%$ & 64.59 & 66.31 & 67.06 & 67.04 & 67.36 & 68.33 & 68.58 \\
\hline \multicolumn{9}{|c|}{$\begin{array}{c}\text { Absolute number and proportion of individuals who report no earnings in current year conditional on being in the } \\
\text { sample in the previous year }\end{array}$} \\
\hline Unemployed & Frequencies & 4712 & 5053 & 4663 & 4140 & 3941 & 3607 & 3595 \\
\hline Inactive & $\%$ & 12.42 & 13.48 & 12.36 & 10.98 & 10.62 & 9.91 & 10.08 \\
\hline \multirow{2}{*}{ Attrition } & Frequencies & 1836 & 966 & 1169 & 2073 & 1919 & 2153 & 2105 \\
\hline & $\%$ & 4.84 & 2.58 & 3.1 & 5.5 & 5.17 & 5.91 & 5.9 \\
\hline \multirow{2}{*}{ Missing Wage } & Frequencies & 6888 & 6605 & 6597 & 6213 & 6257 & 5774 & 5510 \\
\hline & $\%$ & 18.15 & 17.63 & 17.48 & 16.48 & 16.85 & 15.86 & 15.44 \\
\hline \multirow[t]{2}{*}{ Total } & Frequencies & 37947 & 37472 & 37732 & 37704 & 37123 & 36415 & 35677 \\
\hline & $\%$ & 100 & 100 & 100 & 100 & 100 & 100 & 100 \\
\hline
\end{tabular}

Table 2-A-1. Inflows and Outflows of Individuals in the Sample - Ireland

\begin{tabular}{|c|c|c|c|c|c|c|c|c|}
\hline & 1994 & 1995 & 1996 & 1997 & 1998 & 1999 & 2000 & 2001 \\
\hline $\begin{array}{l}\text { Number of individuals with } \\
\text { positive earnings }\end{array}$ & 13937 & 13221 & 12590 & 12515 & 12435 & 12091 & 10745 & 9727 \\
\hline \multicolumn{9}{|c|}{$\begin{array}{l}\text { Absolute number and proportion of individuals who report positive earnings in current year conditional on being in the } \\
\text { sample in previous year }\end{array}$} \\
\hline & Frequencies & 12750 & 12217 & 12212 & 12020 & 11668 & 10236 & 9507 \\
\hline & $\%$ & 49.99 & 50.04 & 52.41 & 53.13 & 54.1 & 51.63 & 54.65 \\
\hline \multicolumn{9}{|c|}{$\begin{array}{l}\text { Absolute number and proportion of individuals who report no earnings in current year conditional on being in the } \\
\text { sample in the previous year }\end{array}$} \\
\hline Unemployed & Frequencies & 4930 & 4723 & 4254 & 3374 & 2905 & 2185 & 2307 \\
\hline Inactive & $\%$ & 19.33 & 19.35 & 18.26 & 14.91 & 13.47 & 11.02 & 13.26 \\
\hline \multirow{2}{*}{ Attrition } & Frequencies & 2167 & 2115 & 1600 & 1936 & 2516 & 3288 & 2362 \\
\hline & $\%$ & 8.5 & 8.66 & 6.87 & 8.56 & 11.66 & 16.59 & 13.58 \\
\hline \multirow{2}{*}{ Missing Wage } & Frequencies & 5656 & 5359 & 5235 & 5292 & 4480 & 4116 & 3220 \\
\hline & $\%$ & 22.18 & 21.95 & 22.47 & 23.39 & 20.77 & 20.76 & 18.51 \\
\hline \multirow[t]{2}{*}{ Total } & Frequencies & 25503 & 24414 & 23301 & 22622 & 21569 & 19825 & 17396 \\
\hline & $\%$ & 100 & 100 & 100 & 100 & 100 & 100 & 100 \\
\hline
\end{tabular}


Table 2-A-1. Inflows and Outflows of Individuals in the Sample - Italy

\begin{tabular}{|c|c|c|c|c|c|c|c|c|}
\hline & 1994 & 1995 & 1996 & 1997 & 1998 & 1999 & 2000 & 2001 \\
\hline $\begin{array}{l}\text { Number of individuals with } \\
\text { positive earnings }\end{array}$ & 32633 & 32236 & 32111 & 29661 & 28865 & 26993 & 26912 & 25170 \\
\hline \multicolumn{9}{|c|}{$\begin{array}{l}\text { Absolute number and proportion of individuals who report positive earnings in current year conditional on being in the } \\
\text { sample in previous year }\end{array}$} \\
\hline & Frequencies & 30946 & 31028 & 28717 & 27188 & 25717 & 25348 & 24139 \\
\hline & $\%$ & 51.58 & 51.19 & 47.18 & 47.34 & 46.87 & 48.73 & 48.86 \\
\hline \multicolumn{9}{|c|}{$\begin{array}{c}\text { Absolute number and proportion of individuals who report no earnings in current year conditional on being in the } \\
\text { sample in the previous year }\end{array}$} \\
\hline Unemployed & Frequencies & 7900 & 7799 & 7670 & 6627 & 6890 & 5662 & 5027 \\
\hline Inactive & $\%$ & 13.17 & 12.87 & 12.6 & 11.54 & 12.56 & 10.88 & 10.18 \\
\hline \multirow{2}{*}{ Attrition } & Frequencies & 3175 & 2947 & 5922 & 6030 & 5941 & 5399 & 5920 \\
\hline & $\%$ & 5.29 & 4.86 & 9.73 & 10.5 & 10.83 & 10.38 & 11.98 \\
\hline \multirow{2}{*}{ Missing Wage } & Frequencies & 17978 & 18836 & 18559 & 17585 & 16325 & 15610 & 14315 \\
\hline & $\%$ & 29.96 & 31.08 & 30.49 & 30.62 & 29.75 & 30.01 & 28.98 \\
\hline \multirow[t]{2}{*}{ Total } & Frequencies & 59999 & 60610 & 60868 & 57430 & 54873 & 52019 & 49401 \\
\hline & $\%$ & 100 & 100 & 100 & 100 & 100 & 100 & 100 \\
\hline
\end{tabular}

Table 2-A-1. Inflows and Outflows of Individuals in the Sample - Greece

\begin{tabular}{|c|c|c|c|c|c|c|c|c|}
\hline & 1994 & 1995 & 1996 & 1997 & 1998 & 1999 & 2000 & 2001 \\
\hline $\begin{array}{l}\text { Number of individuals with } \\
\text { positive earnings }\end{array}$ & 27974 & 27654 & 26150 & 24865 & 22675 & 22001 & 21335 & 21929 \\
\hline \multicolumn{9}{|c|}{$\begin{array}{l}\text { Absolute number and proportion of individuals who report positive earnings in current year conditional on being in the } \\
\text { sample in previous year }\end{array}$} \\
\hline & Frequencies & 26868 & 25946 & 24385 & 21815 & 20357 & 20443 & 21342 \\
\hline & $\%$ & 45.83 & 45.69 & 44.98 & 42.09 & 43.52 & 46.06 & 49.72 \\
\hline \multicolumn{9}{|c|}{$\begin{array}{l}\text { Absolute number and proportion of individuals who report no earnings in current year conditional on being in the } \\
\text { sample in the previous year }\end{array}$} \\
\hline Unemployed & Frequencies & 7537 & 6813 & 6419 & 4523 & 4489 & 4427 & 3858 \\
\hline Inactive & $\%$ & 12.86 & 12 & 11.84 & 8.73 & 9.6 & 9.97 & 8.99 \\
\hline \multirow{2}{*}{ Attrition } & Frequencies & 4417 & 4392 & 4347 & 7892 & 6222 & 4159 & 2363 \\
\hline & $\%$ & 7.53 & 7.73 & 8.02 & 15.23 & 13.3 & 9.37 & 5.5 \\
\hline \multirow{2}{*}{ Missing Wage } & Frequencies & 19802 & 19640 & 19068 & 17599 & 15707 & 15352 & 15365 \\
\hline & $\%$ & 33.78 & 34.58 & 35.17 & 33.96 & 33.58 & 34.59 & 35.79 \\
\hline \multirow[t]{2}{*}{ Total } & Frequencies & 58624 & 56791 & 54219 & 51829 & 46775 & 44381 & 42928 \\
\hline & $\%$ & 100 & 100 & 100 & 100 & 100 & 100 & 100 \\
\hline
\end{tabular}


Table 2-A-1. Inflows and Outflows of Individuals in the Sample - Spain

\begin{tabular}{|c|c|c|c|c|c|c|c|c|}
\hline & 1994 & 1995 & 1996 & 1997 & 1998 & 1999 & 2000 & 2001 \\
\hline $\begin{array}{l}\text { Number of individuals with } \\
\text { positive earnings }\end{array}$ & 22559 & 21863 & 21296 & 20975 & 20371 & 20580 & 19898 & 20185 \\
\hline \multicolumn{9}{|c|}{$\begin{array}{l}\text { Absolute number and proportion of individuals who report positive earnings in current year conditional on being in the } \\
\text { sample in previous year }\end{array}$} \\
\hline & Frequencies & 21460 & 20521 & 20329 & 19456 & 19679 & 19167 & 19352 \\
\hline & $\%$ & 47.6 & 48.29 & 48.49 & 48.63 & 52.13 & 52.12 & 56.06 \\
\hline \multicolumn{9}{|c|}{$\begin{array}{l}\text { Absolute number and proportion of individuals who report no earnings in current year conditional on being in the } \\
\text { sample in the previous year }\end{array}$} \\
\hline Unemployed & Frequencies & 8419 & 8230 & 7353 & 5970 & 5083 & 4512 & 4761 \\
\hline Inactive & $\%$ & 18.67 & 19.37 & 17.54 & 14.92 & 13.46 & 12.27 & 13.79 \\
\hline \multirow{2}{*}{ Attrition } & Frequencies & 4467 & 3000 & 4120 & 4327 & 3188 & 3922 & 3052 \\
\hline & $\%$ & 9.91 & 7.06 & 9.83 & 10.81 & 8.44 & 10.66 & 8.84 \\
\hline \multirow{2}{*}{ Missing Wage } & Frequencies & 10741 & 10742 & 10121 & 10259 & 9802 & 9176 & 7357 \\
\hline & $\%$ & 23.82 & 25.28 & 24.14 & 25.64 & 25.96 & 24.95 & 21.31 \\
\hline \multirow{3}{*}{ Total } & & & & & & 3775 & 3677 & \\
\hline & Frequencies & 45087 & 42493 & 41923 & 40012 & 2 & 7 & 34522 \\
\hline & $\%$ & 100 & 100 & 100 & 100 & 100 & 100 & 100 \\
\hline
\end{tabular}

Table 2-A-1. Inflows and Outflows of Individuals in the Sample - Portugal

\begin{tabular}{|c|c|c|c|c|c|c|c|c|}
\hline & 1994 & 1995 & 1996 & 1997 & 1998 & 1999 & 2000 & 2001 \\
\hline $\begin{array}{l}\text { Number of individuals with } \\
\text { positive earnings }\end{array}$ & 14653 & 15450 & 15379 & 15087 & 14837 & 14569 & 14604 & 14550 \\
\hline \multicolumn{9}{|c|}{$\begin{array}{c}\text { Absolute number and proportion of individuals who report positive earnings in current year conditional on being in the } \\
\text { sample in previous year }\end{array}$} \\
\hline & Frequencies & 13892 & 14538 & 14321 & 13977 & 13921 & 13952 & 13942 \\
\hline & $\%$ & 57.84 & 57.5 & 57.32 & 56.98 & 59.12 & 60.83 & 62.16 \\
\hline \multicolumn{9}{|c|}{$\begin{array}{c}\text { Absolute number and proportion of individuals who report no earnings in current year conditional on being in the } \\
\text { sample in the previous year }\end{array}$} \\
\hline Unemployed & Frequencies & 2187 & 2264 & 2396 & 2019 & 2067 & 1843 & 1702 \\
\hline Inactive & $\%$ & 9.11 & 8.95 & 9.59 & 8.23 & 8.78 & 8.04 & 7.59 \\
\hline \multirow{2}{*}{ Attrition } & Frequencies & 1701 & 1908 & 1918 & 2346 & 1956 & 1617 & 1575 \\
\hline & $\%$ & 7.08 & 7.55 & 7.68 & 9.56 & 8.31 & 7.05 & 7.02 \\
\hline \multirow{2}{*}{ Missing Wage } & Frequencies & 6236 & 6573 & 6350 & 6189 & 5602 & 5525 & 5211 \\
\hline & $\%$ & 25.97 & 26 & 25.42 & 25.23 & 23.79 & 24.09 & 23.23 \\
\hline \multirow[t]{2}{*}{ Total } & Frequencies & 24016 & 25283 & 24985 & 24531 & 23546 & 22937 & 22430 \\
\hline & $\%$ & 100 & 100 & 100 & 100 & 100 & 100 & 100 \\
\hline
\end{tabular}


Table 2-A-1. Inflows and Outflows of Individuals in the Sample - Austria

\begin{tabular}{|c|c|c|c|c|c|c|c|c|}
\hline & 1994 & 1995 & 1996 & 1997 & 1998 & 1999 & 2000 & 2001 \\
\hline $\begin{array}{l}\text { Number of individuals with } \\
\text { positive earnings }\end{array}$ & & 17944 & 17789 & 17199 & 16209 & 15162 & 13816 & 13056 \\
\hline \multicolumn{9}{|c|}{$\begin{array}{l}\text { Absolute number and proportion of individuals who report positive earnings in current year conditional on being in the } \\
\text { sample in previous year }\end{array}$} \\
\hline & Frequencies & & 16472 & 16384 & 15634 & 14551 & 13403 & 12601 \\
\hline & $\%$ & & 67.96 & 68.2 & 67.49 & 67.2 & 66.51 & 68.21 \\
\hline \multicolumn{9}{|c|}{$\begin{array}{l}\text { Absolute number and proportion of individuals who report no earnings in current year conditional on being in the } \\
\text { sample in the previous year }\end{array}$} \\
\hline Unemployed & Frequencies & & 1209 & 1231 & 906 & 790 & 803 & 843 \\
\hline Inactive & $\%$ & & 4.99 & 5.12 & 3.91 & 3.65 & 3.98 & 4.56 \\
\hline \multirow{2}{*}{ Attrition } & Frequencies & & 2195 & 2080 & 2435 & 2470 & 2409 & 1794 \\
\hline & $\%$ & & 9.06 & 8.66 & 10.51 & 11.41 & 11.95 & 9.71 \\
\hline \multirow{2}{*}{ Missing Wage } & Frequencies & & 4361 & 4330 & 4189 & 3842 & 3538 & 3235 \\
\hline & $\%$ & & 17.99 & 18.02 & 18.08 & 17.74 & 17.56 & 17.51 \\
\hline \multirow[t]{2}{*}{ Total } & Frequencies & & 24237 & 24025 & 23164 & 21653 & 20153 & 18473 \\
\hline & $\%$ & & 100 & 100 & 100 & 100 & 100 & 100 \\
\hline
\end{tabular}

Table 2-A-1. Inflows and Outflows of Individuals in the Sample - Finland

\begin{tabular}{|c|c|c|c|c|c|c|c|}
\hline & & 1996 & 1997 & 1998 & 1999 & 2000 & 2001 \\
\hline $\begin{array}{l}\text { Number of individuals with } \\
\text { positive earnings }\end{array}$ & & 15811 & 15845 & 15895 & 15546 & 13329 & 13057 \\
\hline \multicolumn{8}{|c|}{$\begin{array}{l}\text { Absolute number and proportion of individuals who report positive earnings in current year conditional on being in the } \\
\text { sample in previous year }\end{array}$} \\
\hline & Frequencies & & 15246 & 15345 & 14753 & 12756 & 12588 \\
\hline & $\%$ & & 55.95 & 57.2 & 59.29 & 53.83 & 64.16 \\
\hline \multicolumn{8}{|c|}{$\begin{array}{l}\text { Absolute number and proportion of individuals who report no earnings in current year conditional on being in the } \\
\text { sample in the previous year }\end{array}$} \\
\hline Unemployed & Frequencies & & 3446 & 2327 & 1657 & 1326 & 1267 \\
\hline Inactive & $\%$ & & 12.65 & 8.67 & 6.66 & 5.6 & 6.46 \\
\hline \multirow{2}{*}{ Attrition } & Frequencies & & 1933 & 3219 & 2658 & 5219 & 1708 \\
\hline & $\%$ & & 7.09 & 12 & 10.68 & 22.02 & 8.71 \\
\hline \multirow{2}{*}{ Missing Wage } & Frequencies & & 6623 & 5937 & 5814 & 4398 & 4057 \\
\hline & $\%$ & & 24.31 & 22.13 & 23.37 & 18.56 & 20.68 \\
\hline \multirow[t]{2}{*}{ Total } & Frequencies & & 27248 & 26828 & 24882 & 23699 & 19620 \\
\hline & $\%$ & & 100 & 100 & 100 & 100 & 100 \\
\hline
\end{tabular}


Table 2-A-2.Short-Term Transition Rates Among Labour Market States

\begin{tabular}{|c|c|c|c|c|c|c|c|c|c|c|}
\hline \multirow{18}{*}{ 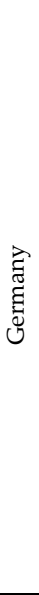 } & & State in 1995 & $1^{\text {st }} \mathrm{Q}$ & $2^{\text {nd }} Q$ & $3^{\text {rd }} Q$ & $4^{\text {th }} \mathrm{Q}$ & $5^{\text {th }} \mathrm{Q}$ & Unempl. & Inactiv. & Missing* \\
\hline & \multirow{17}{*}{ 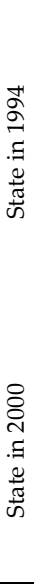 } & $1^{\text {st }}$ Quintile & 56.21 & 17.05 & 4.73 & 0.86 & 0 & 6.81 & 1.58 & 12.76 \\
\hline & & $2^{\text {nd }}$ Quintile & 13.66 & 47.58 & 17.52 & 6.19 & 0.84 & 6.31 & 0.76 & 7.13 \\
\hline & & $3^{\text {rd }}$ Quintile & 3.6 & 17 & 42.71 & 20.28 & 3.14 & 2.2 & 0.56 & 10.44 \\
\hline & & $4^{\text {th }}$ Quintile & 0.43 & 4.48 & 18.92 & 51.67 & 17.33 & 1.55 & 1.44 & 4.17 \\
\hline & & $5^{\text {th }}$ Quintile & 0 & 0.46 & 2.36 & 11.86 & 77.28 & 0.93 & 0.97 & 6.14 \\
\hline & & Unemployed & 19.35 & 10.13 & 4.95 & 1.2 & 0.08 & 39.72 & 1.95 & 22.62 \\
\hline & & Inactive & 3.5 & 4.56 & 2.12 & 0.53 & 2.01 & 20.25 & 27.47 & 39.55 \\
\hline & & Missing Wage* & 6.29 & 3.93 & 2.78 & 1.58 & 1.89 & 5.55 & 4.32 & 73.67 \\
\hline & & State in 2001 & $1^{\text {st }} \mathrm{Q}$ & $2^{\text {nd }} Q$ & $3^{\text {rd }} Q$ & $4^{\text {th }} \mathrm{Q}$ & $5^{\text {th }} \mathrm{Q}$ & Unempl. & Inactiv. & Missing* \\
\hline & & $1^{\text {st }}$ Quintile & 54.96 & 12.34 & 2.99 & 0.52 & 0.16 & 9.31 & 1.98 & 17.73 \\
\hline & & $2^{\text {nd }}$ Quintile & 14.92 & 48.06 & 17.06 & 3.65 & 0.34 & 3.97 & 0.64 & 11.36 \\
\hline & & $3^{\text {rd }}$ Quintile & 3.3 & 20 & 47.65 & 18.01 & 1 & 1.55 & 0.89 & 7.91 \\
\hline & & $4^{\text {th }}$ Quintile & 0.53 & 2.31 & 13.86 & 58.68 & 12.4 & 0.48 & 0.53 & 11.23 \\
\hline & & $5^{\text {th }}$ Quintile & 0.53 & 2.31 & 2.63 & 13.49 & 71.68 & 0.5 & 0.57 & 8.27 \\
\hline & & Unemployed & 14.83 & 2.71 & 5.93 & 1.1 & 0.08 & 46.44 & 2.37 & 26.53 \\
\hline & & Inactive & 8.46 & 0 & 2.57 & 1.65 & 1.47 & 8.09 & 45.77 & 31.99 \\
\hline & & Missing & 2.51 & 2.03 & 1.35 & 0.72 & 1.09 & 2.11 & 0.89 & 89.3 \\
\hline \multirow{18}{*}{ 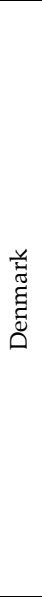 } & \multirow{18}{*}{ 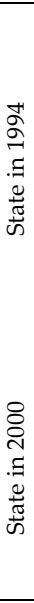 } & State in 1995 & $1^{\text {st }} \mathrm{Q}$ & $2^{\text {nd }} Q$ & $3^{\text {rd }} Q$ & $4^{\text {th }} \mathrm{Q}$ & $5^{\text {th }} \mathrm{Q}$ & Unempl. & Inactiv. & Missing* \\
\hline & & $1^{\text {st }}$ Quintile & 41.28 & 19.41 & 9.96 & 1.7 & 1.98 & 4.61 & 0 & 21.06 \\
\hline & & $2^{\text {nd }}$ Quintile & 21.45 & 40.87 & 14.52 & 7.36 & 1.07 & 3.69 & 0.79 & 10.26 \\
\hline & & $3^{\text {rd }}$ Quintile & 6.28 & 30 & 28.78 & 17.72 & 6.16 & 2.02 & 0 & 8.66 \\
\hline & & $4^{\text {th }}$ Quintile & 0.78 & 6.91 & 22.95 & 43.62 & 14.92 & 1.07 & 0 & 9.74 \\
\hline & & $5^{\text {th }}$ Quintile & 2.25 & 1.06 & 1.69 & 25.86 & 61.83 & 0.48 & 0 & 6.83 \\
\hline & & Unemployed & 12.86 & 15.85 & 6.16 & 3.25 & 2.87 & 34.02 & 0.25 & 24.75 \\
\hline & & Inactive & 4.55 & 0 & 0 & 0 & 0 & 26.14 & 0 & 69.32 \\
\hline & & Missing Wage & 8.82 & 1.39 & 0.29 & 0.94 & 4.4 & 1.86 & 1.19 & 81.1 \\
\hline & & State in 2001 & $1^{\text {st }} \mathrm{Q}$ & $2^{\text {nd }} Q$ & $3^{\text {rd }} Q$ & $4^{\text {th }} \mathrm{Q}$ & $5^{\text {th }} \mathrm{Q}$ & Unempl. & Inactiv. & Missing* \\
\hline & & $1^{\text {st }}$ Quintile & 48.61 & 16.15 & 12.74 & 1.74 & 0.7 & 2.09 & 3.63 & 14.35 \\
\hline & & $2^{\text {nd }}$ Quintile & 24.64 & 35.88 & 18.56 & 3 & 4.81 & 4.93 & 0 & 8.18 \\
\hline & & $3^{\text {rd }}$ Quintile & 5.88 & 21 & 45.01 & 14.56 & 3.05 & 0.14 & 0 & 10.83 \\
\hline & & $4^{\text {th }}$ Quintile & 4.39 & 8.29 & 21.01 & 39.61 & 17.96 & 2.43 & 0 & 6.31 \\
\hline & & $5^{\text {th }}$ Quintile & 0.57 & 0.67 & 5.59 & 13.02 & 66.9 & 1.95 & 0.38 & 10.92 \\
\hline & & Unemployed & 7.9 & 3.71 & 2.9 & 3.71 & 0 & 41.77 & 0 & 40 \\
\hline & & Inactive & 41.46 & 0 & 0 & 0 & 0 & 7.32 & 51.22 & 0 \\
\hline & & Missing & 3.11 & 1.81 & 2.24 & 1.09 & 0.76 & 0.9 & 0.05 & 90.03 \\
\hline \multirow{18}{*}{ 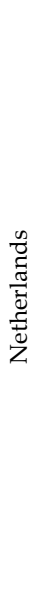 } & \multirow{18}{*}{ 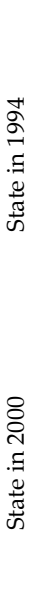 } & State in 1995 & $1^{\text {st }} \mathrm{Q}$ & $2^{\text {nd }} Q$ & $3^{\text {rd }} Q$ & $4^{\text {th }} \mathrm{Q}$ & $5^{\text {th }} \mathrm{Q}$ & Unempl. & Inactiv. & Missing* \\
\hline & & $1^{\text {st }}$ Quintile & 47.57 & 22.85 & 4.74 & 1.65 & 0.07 & 2.25 & 1.3 & 19.57 \\
\hline & & $2^{\text {nd }}$ Quintile & 11.35 & 44.68 & 24.03 & 5.72 & 1.45 & 0.66 & 0.71 & 11.41 \\
\hline & & $3^{\text {rd }}$ Quintile & 2.96 & 14 & 45.96 & 22.65 & 3.07 & 0.4 & 1.03 & 9.62 \\
\hline & & $4^{\text {th }}$ Quintile & 0.51 & 2.67 & 13.11 & 52.7 & 18.97 & 2.21 & 0.78 & 9.04 \\
\hline & & $5^{\text {th }}$ Quintile & 0.91 & 0.51 & 2.35 & 13.61 & 73.84 & 1.85 & 0.46 & 6.48 \\
\hline & & Unemployed & 15.02 & 5.69 & 6.81 & 2.47 & 3 & 42.92 & 8.05 & 16.04 \\
\hline & & Inactive & 8.1 & 1.49 & 2.79 & 3.45 & 1.12 & 22.44 & 47.49 & 13.13 \\
\hline & & Missing Wage* & 13.79 & 6.97 & 4.49 & 5.99 & 4.77 & 2.85 & 0.8 & 60.34 \\
\hline & & State in 2001 & $1^{\text {st }} \mathrm{Q}$ & $2^{\text {nd }} Q$ & $3^{\text {rd }} Q$ & $4^{\text {th }} \mathrm{Q}$ & $5^{\text {th }} \mathrm{Q}$ & Unempl. & Inactiv. & Missing* \\
\hline & & $1^{\text {st }}$ Quintile & 53.88 & 15.15 & 3.56 & 2.7 & 0.45 & 0.29 & 0.31 & 23.66 \\
\hline & & $2^{\text {nd }}$ Quintile & 7.82 & 49.78 & 18.96 & 6.14 & 1.31 & 0.57 & 0.17 & 15.25 \\
\hline & & $3^{\text {rd }}$ Quintile & 4.74 & 7 & 52.65 & 16.22 & 4.42 & 0.89 & 0.32 & 13.42 \\
\hline & & $4^{\text {th }}$ Quintile & 0.85 & 1.15 & 15.05 & 52.18 & 12.51 & 1.06 & 0.61 & 16.59 \\
\hline & & $5^{\text {th }}$ Quintile & 0 & 0.71 & 1.19 & 15.11 & 65.95 & 0.27 & 0 & 16.78 \\
\hline & & Unemployed & 7.2 & 1.83 & 0.54 & 0 & 2.47 & 46.13 & 18.6 & 23.23 \\
\hline & & Inactive & 4.96 & 1.6 & 0.8 & 0 & 1.77 & 4.96 & 59.75 & 26.15 \\
\hline & & Missing & 3.78 & 1.92 & 0.82 & 1.34 & 1.06 & 0.38 & 0.45 & 90.24 \\
\hline
\end{tabular}




\begin{tabular}{|c|c|c|c|c|c|c|c|c|c|c|}
\hline \multirow{18}{*}{$\underset{D}{D}$} & \multirow{18}{*}{ 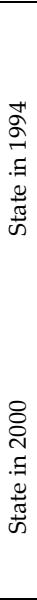 } & State in 1995 & $1^{\text {st }} \mathrm{Q}$ & $2^{\text {nd }} Q$ & $3^{\text {rd }} Q$ & $4^{\text {th }} Q$ & $5^{\text {th }} \mathrm{Q}$ & Unempl. & Inactive & Missing* \\
\hline & & $1^{\text {st }}$ Quintile & 44.95 & 16.63 & 10.1 & 6.77 & 4.15 & 4.39 & 0.25 & 12.76 \\
\hline & & $2^{\text {nd }}$ Quintile & 24.75 & 37.63 & 16.29 & 6.7 & 1.36 & 0.83 & 0 & 12.45 \\
\hline & & $3^{\text {rd }}$ Quintile & 5.29 & 25 & 43.1 & 11.4 & 4 & 0.53 & 0.53 & 10.18 \\
\hline & & $4^{\text {th }}$ Quintile & 3.35 & 5.11 & 21.81 & 45.16 & 15.11 & 0.89 & 0 & 8.57 \\
\hline & & $5^{\text {th }}$ Quintile & 0.64 & 1.51 & 2.78 & 16.61 & 68.27 & 1.84 & 0.24 & 8.13 \\
\hline & & Unemployed & 13.03 & 11.53 & 0 & 0.76 & 1.24 & 54.21 & 1.22 & 18 \\
\hline & & Inactive & 0 & 0.81 & 0 & 0 & 0 & 13.67 & 64.89 & 20.63 \\
\hline & & Missing Wage* $^{*}$ & 6.09 & 2.75 & 1.97 & 0.66 & 0.66 & 2.67 & 0.72 & 84.49 \\
\hline & & State in 2001 & 1st Q & 2nd Q & 3rd Q & 4th Q & 5th Q & Unempl. & Inactive & Missing* \\
\hline & & $1^{\text {st }}$ Quintile & 62.45 & 15.38 & 7.37 & 0.34 & 0.3 & 0.44 & 0 & 13.72 \\
\hline & & $2^{\text {nd }}$ Quintile & 10.49 & 45.04 & 19.82 & 5.54 & 1.73 & 1.71 & 0 & 15.68 \\
\hline & & $3^{\text {rd }}$ Quintile & 5.34 & 17 & 36.25 & 22.99 & 2.37 & 0.97 & 0 & 15.19 \\
\hline & & $4^{\text {th }}$ Quintile & 0.89 & 5.95 & 20.93 & 50.18 & 13.53 & 0.55 & 0 & 7.95 \\
\hline & & $5^{\text {th }}$ Quintile & 0 & 1.3 & 1.6 & 16.38 & 70.82 & 0.45 & 0 & 9.45 \\
\hline & & Unemployed & 16.9 & 0 & 2.74 & 0 & 0 & 58.62 & 0.99 & 20.75 \\
\hline & & Inactive & 0 & 3.42 & 0 & 0 & 0 & 0 & 62.86 & 33.72 \\
\hline & & Missing & 1.37 & 1.13 & 1.62 & 0.7 & 0.46 & 0.78 & 0.64 & 93.3 \\
\hline \multirow{18}{*}{ 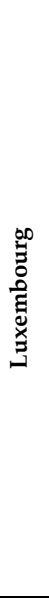 } & \multirow{18}{*}{$\begin{array}{l}\stackrel{2}{2} \\
\sigma \\
\Xi \\
\frac{\pi}{0} \\
\frac{\pi}{\omega}\end{array}$} & State in 1996 & 1st Q & 2nd Q & 3rd Q & 4th Q & 5 th Q & Unempl. & Inactiv. & Miss. $^{*}$ \\
\hline & & $1^{\text {st }}$ Quintile & 57.09 & 14.93 & 1.06 & 0.65 & 0.81 & 3.09 & 0.34 & 22.03 \\
\hline & & $2^{\text {nd }}$ Quintile & 12.92 & 54.54 & 14.01 & 0.19 & 0.22 & 1.18 & 0 & 16.92 \\
\hline & & $3^{\text {rd }}$ Quintile & 2.36 & 12.16 & 57.08 & 8.76 & 3.39 & 0.58 & 0.36 & 15.31 \\
\hline & & $4^{\text {th }}$ Quintile & 0.2 & 0.56 & 17.68 & 51.76 & 10.24 & 0.16 & 0 & 19.39 \\
\hline & & $5^{\text {th }}$ Quintile & 0.25 & 0 & 3.45 & 14.19 & 65.8 & 0 & 0 & 16.31 \\
\hline & & Unemployed & 5.3 & 1.32 & 0.55 & 1.54 & 0 & 59.62 & 2.98 & 28.68 \\
\hline & & Inactive & 15 & 0 & 0 & 0 & 0 & 8 & 24 & 53 \\
\hline & & Missing Wage $^{*}$ & 8.08 & 2.83 & 1.62 & 1.83 & 4.54 & 11.37 & 1.8 & 67.94 \\
\hline & & State in 2001 & 1st Q & 2nd Q & 3rd Q & 4th Q & 5 th $Q$ & Unempl. & Inactiv. & Miss. $^{*}$ \\
\hline & & $1^{\text {st }}$ Quintile & 58.16 & 22.08 & 1.44 & 0.51 & 0 & 1.17 & 0 & 16.64 \\
\hline & & $2^{\text {nd }}$ Quintile & 9.98 & 58.63 & 16.61 & 1.52 & 0.56 & 0.16 & 0 & 12.54 \\
\hline & & $3^{\text {rd }}$ Quintile & 2.53 & 5.53 & 60.67 & 18.54 & 0.75 & 0 & 0 & 11.98 \\
\hline & & $4^{\text {th }}$ Quintile & 0.28 & 1.26 & 9.48 & 63.97 & 17.43 & 0 & 0 & 7.59 \\
\hline & & $5^{\text {th }}$ Quintile & 0 & 0.2 & 0.28 & 10.4 & 74.12 & 0 & 0 & 15.01 \\
\hline & & Unemployed & 13.93 & 5.57 & 3.54 & 0 & 0 & 55.5 & 3.61 & 17.85 \\
\hline & & Inactive & 0 & 0 & 0 & 0 & 0 & 9.76 & 66.67 & 23.58 \\
\hline & & Missing & 0.72 & 0.7 & 0.35 & 0.1 & 0.75 & 0.29 & 0.22 & 96.87 \\
\hline \multirow{18}{*}{ 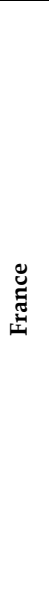 } & \multirow{18}{*}{ 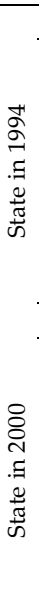 } & State in 1995 & 1st Q & 2nd $Q$ & 3rd Q & 4th Q & 5th Q & Unempl. & Inactiv. & Miss.* \\
\hline & & $1^{\text {st }}$ Quintile & 50.21 & 19.57 & 5.51 & 0.92 & 0.55 & 5.26 & 1.36 & 16.62 \\
\hline & & $2^{\text {nd }}$ Quintile & 12.37 & 45.38 & 20.14 & 3.2 & 0.76 & 2.79 & 1.39 & 13.98 \\
\hline & & $3^{\text {rd }}$ Quintile & 4.28 & 15 & 45.24 & 21.12 & 2.67 & 0.55 & 0.28 & 10.58 \\
\hline & & $4^{\text {th }}$ Quintile & 2.29 & 4.5 & 14.03 & 48.05 & 19.62 & 0.97 & 0.4 & 10.15 \\
\hline & & $5^{\text {th }}$ Quintile & 2.81 & 2.36 & 3.8 & 14.76 & 64.82 & 0.15 & 0.37 & 10.93 \\
\hline & & Unemployed & 14.52 & 4.34 & 3.68 & 3.73 & 4.44 & 35.24 & 3.94 & 30.11 \\
\hline & & Inactive & 0 & 0.93 & 3.59 & 0 & 0.93 & 2.66 & 76.1 & 15.8 \\
\hline & & Missing Wage* $^{*}$ & 5.16 & 2.62 & 1.82 & 2.96 & 1.95 & 7.24 & 2.55 & 75.71 \\
\hline & & State in 2001 & 1 st $Q$ & 2nd $Q$ & 3rd Q & 4th Q & 5 th Q & Unempl. & Inactiv. & Miss. $^{*}$ \\
\hline & & 1st Quintile & 48.37 & 16.06 & 5.75 & 1.99 & 0.54 & 6.84 & 1.09 & 19.36 \\
\hline & & 2nd Quintile & 16.79 & 46.58 & 16.86 & 3.13 & 0.29 & 2.88 & 0.44 & 13.04 \\
\hline & & 3rd Quintile & 2.14 & 15 & 49.2 & 16.06 & 0.91 & 1.34 & 0.55 & 14.83 \\
\hline & & 4th Quintile & 0.58 & 3.24 & 12.43 & 56.16 & 14.94 & 0.95 & 0.25 & 11.45 \\
\hline & & 5th Quintile & 0.44 & 0.18 & 1.53 & 11.03 & 71.68 & 0.18 & 0.18 & 14.78 \\
\hline & & Unemployed & 16.43 & 8.43 & 2.81 & 1.06 & 0.69 & 49.78 & 1.75 & 19.05 \\
\hline & & Inactive & 8.81 & 0 & 1.04 & 0 & 0 & 3.88 & 73.58 & 12.69 \\
\hline & & Missing & 3.07 & 2.12 & 2.28 & 2.17 & 2.01 & 2.1 & 0.5 & 85.75 \\
\hline
\end{tabular}




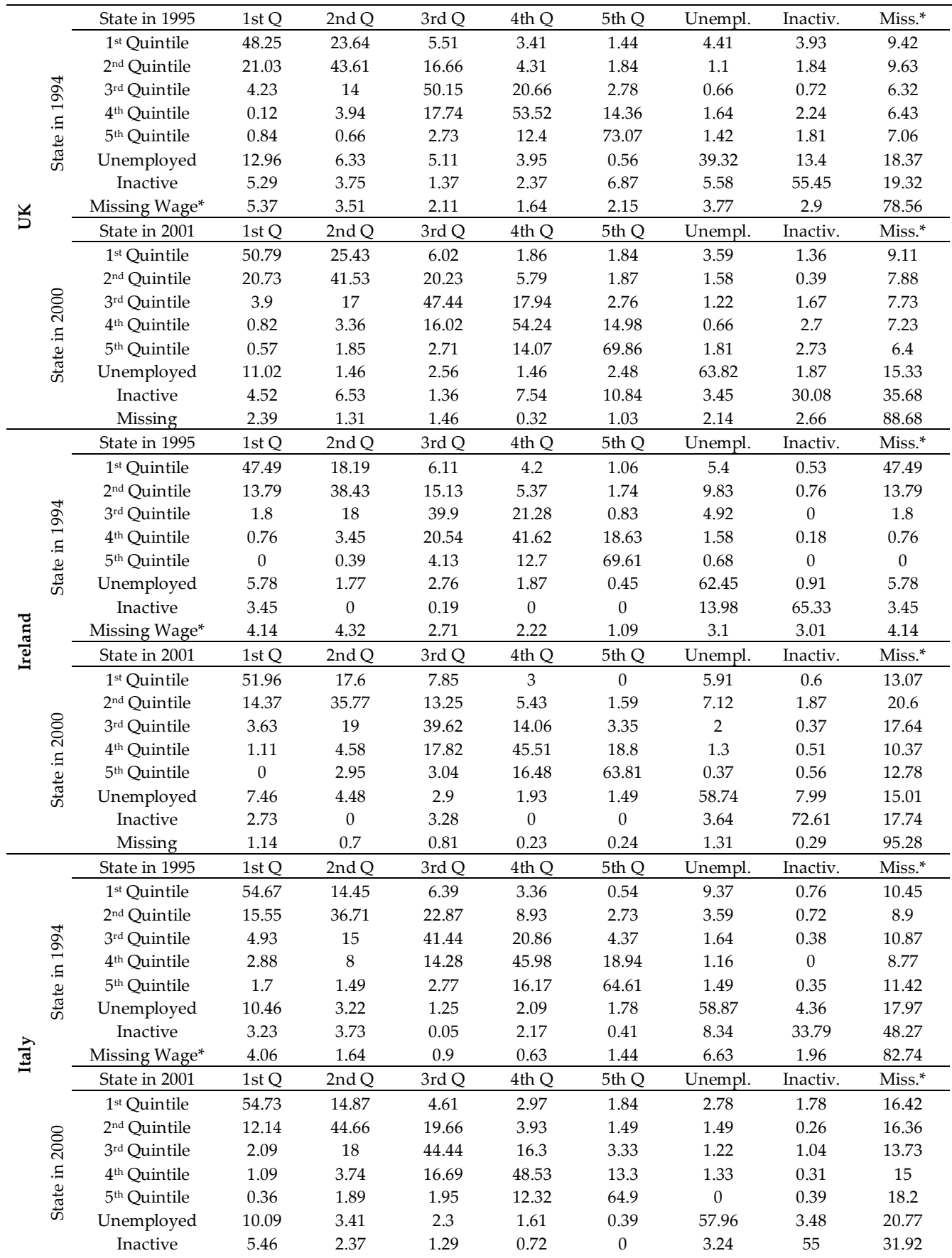




\begin{tabular}{|c|c|c|c|c|c|c|c|c|c|c|}
\hline & & Missing & 1.17 & 1.23 & 0.81 & 1.12 & 0.88 & 1.78 & 0.48 & 92.52 \\
\hline \multirow{18}{*}{ 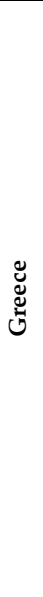 } & \multirow{9}{*}{ 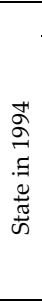 } & State in 1995 & 1st Q & 2nd Q & 3rd Q & 4th Q & 5th Q & Unempl. & Inactive & Missing ${ }^{*}$ \\
\hline & & 1st Quintile & 39.99 & 20.39 & 9.28 & 2.09 & 1.84 & 7.28 & 0.91 & 18.23 \\
\hline & & 2nd Quintile & 16.5 & 28.77 & 25.81 & 4.87 & 4.05 & 6.05 & 0.13 & 13.82 \\
\hline & & 3rd Quintile & 4.81 & 17 & 35.22 & 19.86 & 5.99 & 1.56 & 0.39 & 14.95 \\
\hline & & 4th Quintile & 2.94 & 6.44 & 20.1 & 36.09 & 18.06 & 2.13 & 0 & 14.24 \\
\hline & & 5th Quintile & 0.7 & 3.13 & 7.73 & 18.06 & 56.56 & 0.46 & 0.25 & 13.11 \\
\hline & & Unemployed & 15.29 & 6.95 & 5.53 & 1.4 & 1.74 & 36.37 & 9.35 & 23.38 \\
\hline & & Inactive & 6.74 & 2.58 & 0.52 & 0 & 0.63 & 19.07 & 44.73 & 25.73 \\
\hline & & Missing Wage* & 3.68 & 3.03 & 1.79 & 0.92 & 1.5 & 7.48 & 4.83 & 76.77 \\
\hline & \multirow{9}{*}{ 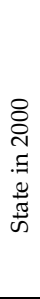 } & State in 2001 & 1st Q & 2nd Q & 3rd Q & 4th Q & 5th Q & Unempl. & Inactiv. & Miss. ${ }^{*}$ \\
\hline & & 1st Quintile & 57.69 & 19.5 & 4.41 & 1.08 & 0.37 & 6.24 & 1.19 & 9.51 \\
\hline & & 2nd Quintile & 10.75 & 52.41 & 20.83 & 6.52 & 0.82 & 2.18 & 0 & 6.49 \\
\hline & & 3rd Quintile & 4.26 & 14 & 55.8 & 13.9 & 2.45 & 1.59 & 0 & 7.76 \\
\hline & & 4th Quintile & 0 & 2.19 & 17.84 & 52.7 & 19.34 & 1.32 & 0.23 & 6.38 \\
\hline & & 5th Quintile & 0 & 0.5 & 2.58 & 10.8 & 76.59 & 1.57 & 0.95 & 7 \\
\hline & & Unemployed & 16.89 & 8.83 & 7.46 & 5.7 & 0 & 39.23 & 9.5 & 12.39 \\
\hline & & Inactive & 8.28 & 4.42 & 0.75 & 0 & 1.05 & 5.37 & 53.51 & 26.61 \\
\hline & & Missing & 0.98 & 1.03 & 0.6 & 0.36 & 0.38 & 0.79 & 1.05 & 94.8 \\
\hline \multirow{18}{*}{$\begin{array}{l}\text { ส } \\
\text { के }\end{array}$} & \multirow{9}{*}{ 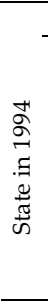 } & State in 1995 & 1st Q & 2nd Q & 3rd Q & 4th Q & 5th Q & Unempl. & Inactiv. & Miss. ${ }^{*}$ \\
\hline & & 1st Quintile & 38.99 & 21.45 & 9.27 & 1.57 & 0.18 & 10.95 & 2.06 & 15.55 \\
\hline & & 2nd Quintile & 14.17 & 31.82 & 22.21 & 5.62 & 0.78 & 7.95 & 0.71 & 16.74 \\
\hline & & 3rd Quintile & 4.64 & 13 & 33.48 & 20.93 & 2.92 & 8.16 & 0.52 & 16.66 \\
\hline & & 4th Quintile & 0.37 & 2.65 & 11.34 & 49.61 & 21.04 & 2.03 & 1.64 & 11.32 \\
\hline & & 5th Quintile & 0.4 & 0.24 & 1.22 & 14.67 & 69.13 & 1.94 & 0.33 & 12.06 \\
\hline & & Unemployed & 13.21 & 8.97 & 7.79 & 2.17 & 0.52 & 46 & 3.27 & 18.06 \\
\hline & & Inactive & 6.08 & 3.77 & 2.03 & 0.6 & 0.21 & 19.96 & 40.77 & 26.59 \\
\hline & & Missing Wage* & 3.92 & 3.63 & 1.91 & 0.55 & 0.95 & 7.02 & 4.85 & 77.18 \\
\hline & \multirow{9}{*}{ 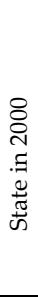 } & State in 2001 & 1st Q & 2nd Q & 3rd Q & 4th Q & 5th Q & Unempl. & Inactiv. & Miss. ${ }^{*}$ \\
\hline & & 1st Quintile & 38.28 & 23.31 & 8.71 & 6.47 & 0.38 & 11.92 & 0.78 & 10.16 \\
\hline & & 2nd Quintile & 21.29 & 34.57 & 18.5 & 10.27 & 0.28 & 6.04 & 0.68 & 8.38 \\
\hline & & 3rd Quintile & 7.61 & 17 & 38.97 & 14.88 & 3.67 & 3.94 & 0.32 & 13.4 \\
\hline & & 4th Quintile & 3.5 & 4.99 & 18.15 & 40.77 & 16.36 & 2.5 & 1.19 & 12.53 \\
\hline & & 5th Quintile & 0 & 1.29 & 1.11 & 15.31 & 69.04 & 0.68 & 0.38 & 12.2 \\
\hline & & Unemployed & 14.22 & 10.02 & 7.66 & 3.72 & 0.77 & 39.71 & 7.62 & 16.28 \\
\hline & & Inactive & 2.14 & 0.35 & 0.25 & 0.15 & 0.35 & 10.74 & 68.39 & 17.64 \\
\hline & & Missing & 2.15 & 1.57 & 0.99 & 1.51 & 1.56 & 1.48 & 1.4 & 89.34 \\
\hline \multirow{18}{*}{ 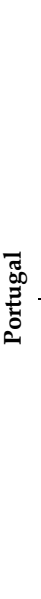 } & \multirow{9}{*}{ 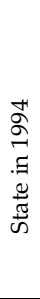 } & State in 1995 & 1st Q & 2nd Q & 3rd Q & 4th Q & 5th Q & Unempl. & Inactiv. & Miss. $^{*}$ \\
\hline & & 1st Quintile & 51.15 & 23.41 & 8.84 & 2.5 & 0.17 & 4.76 & 0.2 & 8.97 \\
\hline & & 2nd Quintile & 16.63 & 43.8 & 22.63 & 4.26 & 0 & 2.62 & 0.07 & 9.99 \\
\hline & & 3rd Quintile & 5.1 & 12 & 45.81 & 19.03 & 1.86 & 4.21 & 3.72 & 8.14 \\
\hline & & 4th Quintile & 2 & 6.32 & 12.94 & 53.79 & 9.81 & 3.23 & 0.75 & 11.17 \\
\hline & & 5th Quintile & 0.03 & 0.21 & 1.72 & 8.8 & 71.88 & 3.85 & 0 & 13.51 \\
\hline & & Unemployed & 18.83 & 7.45 & 9.93 & 1.79 & 0 & 36 & 6.41 & 19.59 \\
\hline & & Inactive & 4.84 & 2.67 & 0.2 & 4.15 & 1.28 & 5.53 & 50.35 & 31 \\
\hline & & Missing Wage* & 4.42 & 2.31 & 2.22 & 2.08 & 2.95 & 2.2 & 2.4 & 81.41 \\
\hline & \multirow{9}{*}{ 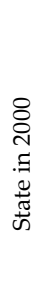 } & State in 2001 & 1st Q & 2nd Q & 3rd Q & 4th Q & 5th Q & Unempl. & Inactiv. & Miss. ${ }^{*}$ \\
\hline & & 1st Quintile & 68.37 & 10.58 & 4.28 & 2.31 & 1.71 & 2.9 & 1.32 & 8.53 \\
\hline & & 2nd Quintile & 13.53 & 50.22 & 21.93 & 3.24 & 0.09 & 3.78 & 0.16 & 7.05 \\
\hline & & 3rd Quintile & 4.82 & 10 & 52.41 & 15.01 & 6.42 & 2.72 & 0.18 & 8.66 \\
\hline & & 4th Quintile & 0.07 & 6.08 & 17.34 & 58.25 & 6.85 & 1.91 & 0.85 & 8.65 \\
\hline & & 5th Quintile & 0 & 0.48 & 2.43 & 10.25 & 76.13 & 0.51 & 0.07 & 10.12 \\
\hline & & Unemployed & 10.98 & 7.94 & 15.07 & 1.05 & 2.1 & 34.7 & 4.44 & 23.71 \\
\hline & & Inactive & 4.05 & 0 & 0 & 0 & 0.85 & 0.28 & 73.47 & 21.35 \\
\hline & & Missing & 1.42 & 0.53 & 0.96 & 1.31 & 1.46 & 0.83 & 0.71 & 92.78 \\
\hline
\end{tabular}




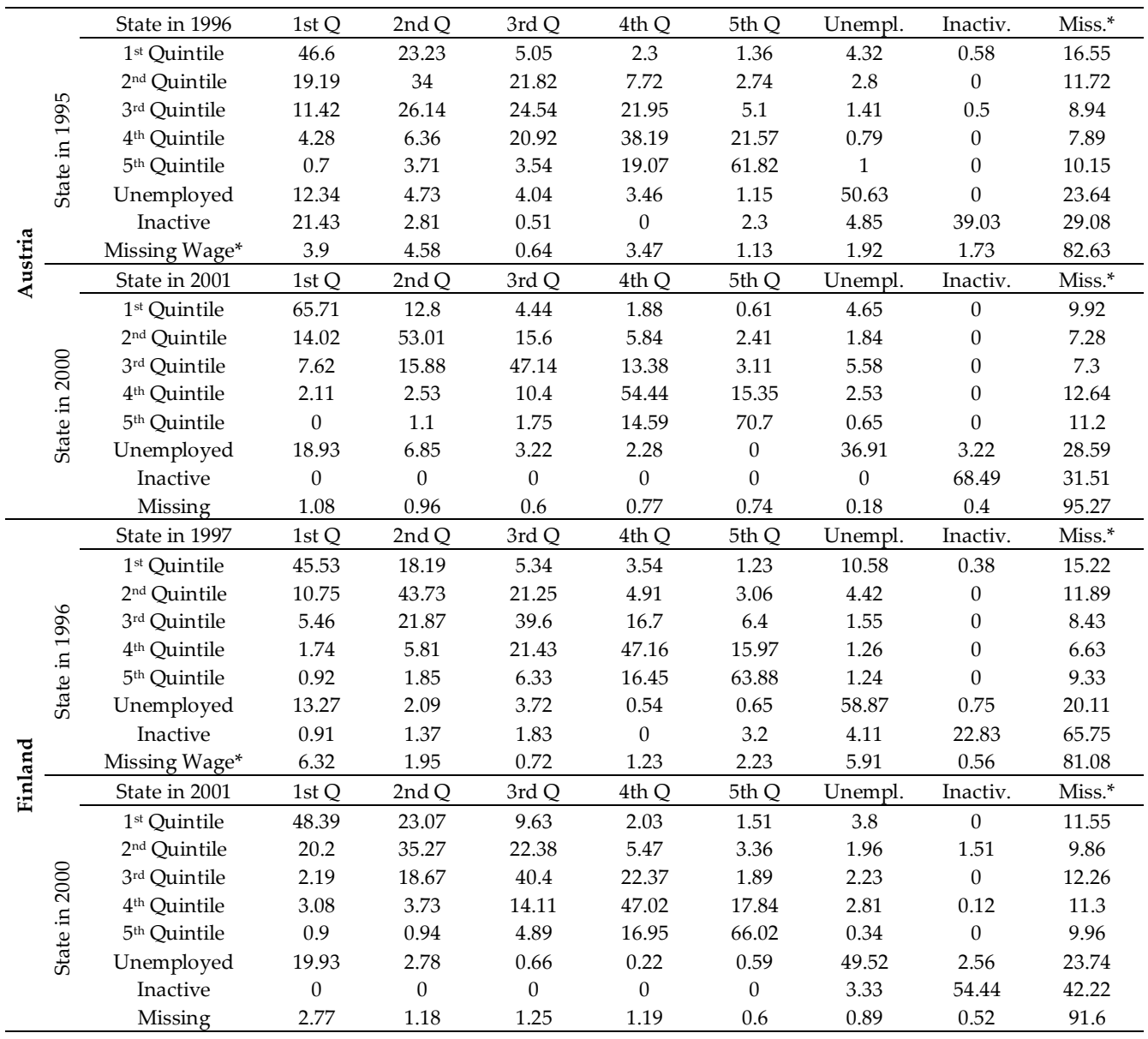

* Missing Wage refers to individuals with missing wage in the first wave and Missing refers to individuals with missing wage, self-employed, retired, not in formal employment and those that dropped from the survey in the previous year 
Table 2-A-3. Long-Term Transition Rates Among Labour Market States

\begin{tabular}{|c|c|c|c|c|c|c|c|c|c|c|}
\hline \multirow{9}{*}{$\begin{array}{l}\text { ટ્ } \\
\text { हूँ } \\
\text { Uू }\end{array}$} & & State in 2001 & 1 st $Q$ & 2nd Q & 3rd Q & 4th Q & 5 th Q & Unemp. & Inactiv. & Miss. ${ }^{*}$ \\
\hline & \multirow{8}{*}{ 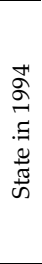 } & $1^{\text {st }}$ Quintile & 24.7 & 13.38 & 8.87 & 2.4 & 0.88 & 10.62 & 1.84 & 37.32 \\
\hline & & $2^{\text {nd }}$ Quintile & 10.35 & 21.27 & 13.02 & 12.84 & 2.98 & 4.69 & 0.14 & 34.7 \\
\hline & & $3^{\text {rd }}$ Quintile & 5.97 & 11.48 & 17.89 & 17.2 & 4.6 & 4.95 & 1.17 & 36.74 \\
\hline & & $4^{\text {th }}$ Quintile & 1.32 & 5.8 & 11.66 & 25.46 & 16.74 & 2.19 & 1.38 & 35.45 \\
\hline & & $5^{\text {th }}$ Quintile & 0.52 & 0.91 & 2.6 & 10.65 & 44.21 & 0.48 & 0.4 & 40.22 \\
\hline & & Unemployed & 16.84 & 6.38 & 5.36 & 6.53 & 3.34 & 14.37 & 1.84 & 45.35 \\
\hline & & Inactive & 7.95 & 1.91 & 7.85 & 0.21 & 2.55 & 3.82 & 8.7 & 67.02 \\
\hline & & Missing Wage $^{*}$ & 8.66 & 5.78 & 7.98 & 6.26 & 3.29 & 3.13 & 2.42 & 62.48 \\
\hline \multirow{9}{*}{ 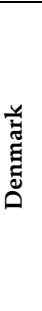 } & \multirow{9}{*}{ 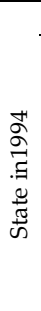 } & State in 2001 & 1st Q & 2nd Q & 3rd Q & 4th Q & 5th Q & Unemp. & Inactiv. & Miss. * \\
\hline & & 1st Quintile & 16.67 & 9.31 & 14.33 & 5.83 & 2.48 & 4.89 & 2.24 & 44.25 \\
\hline & & 2nd Quintile & 24.11 & 17.35 & 12.64 & 2.17 & 7.36 & 0.14 & 0 & 36.23 \\
\hline & & 3rd Quintile & 6.56 & 11.35 & 18.59 & 7.29 & 8.58 & 1.08 & 0.36 & 46.19 \\
\hline & & 4th Quintile & 2.85 & 12.07 & 12.07 & 16.37 & 12.66 & 1.45 & 0 & 42.53 \\
\hline & & 5th Quintile & 2.29 & 2.22 & 3.6 & 14.22 & 30.78 & 1.52 & 0 & 45.36 \\
\hline & & Unemployed & 5.94 & 10.58 & 2.99 & 4.38 & 8.47 & 7.21 & 0.67 & 59.74 \\
\hline & & Inactive & 21.59 & 0 & 0 & 0 & 0 & 0 & 0 & 78.41 \\
\hline & & Missing & 6.21 & 4.56 & 8.31 & 5.05 & 3.82 & 3.19 & 0.16 & 68.7 \\
\hline \multirow{9}{*}{ 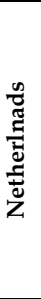 } & \multirow{9}{*}{ 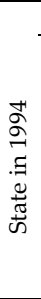 } & State in 2001 & 1st Q & 2nd Q & 3rd Q & 4th Q & 5th Q & Unemp. & Inactiv. & Miss.* \\
\hline & & $1^{\text {st }}$ Quintile & 18.3 & 12.93 & 8.78 & 6.36 & 1.63 & 0.88 & 1.11 & 50.01 \\
\hline & & $2^{\text {nd }}$ Quintile & 6.14 & 19.42 & 15.38 & 8.01 & 1.74 & 1.08 & 1.5 & 46.73 \\
\hline & & $3^{\text {rd }}$ Quintile & 1.19 & 9.3 & 19.44 & 16.57 & 9.04 & 0.56 & 0.45 & 43.45 \\
\hline & & $4^{\text {th }}$ Quintile & 0.24 & 2.48 & 9.98 & 23.29 & 12.55 & 0.81 & 1.19 & 49.46 \\
\hline & & $5^{\text {th }}$ Quintile & 0.33 & 0.46 & 2.86 & 10.32 & 43.37 & 0.08 & 0.53 & 42.05 \\
\hline & & Unemployed & 9.87 & 9.39 & 2.15 & 3.59 & 2.15 & 9.6 & 7.3 & 55.95 \\
\hline & & Inactive & 3.54 & 0 & 1.4 & 0.84 & 5.49 & 9.31 & 26.82 & 52.61 \\
\hline & & Missing Wage $^{*}$ & 9.07 & 7 & 8.73 & 9.56 & 4.76 & 0.55 & 1.08 & 59.24 \\
\hline \multirow{9}{*}{ 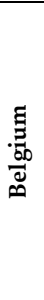 } & \multirow{9}{*}{ 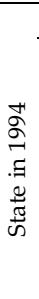 } & State in 2001 & 1 st $Q$ & 2nd Q & 3rd Q & 4 th $Q$ & 5th Q & Unemp. & Inactiv. & Miss.* \\
\hline & & $1^{\text {st }}$ Quintile & 19.91 & 13.81 & 10.73 & 7.76 & 3.8 & 2.53 & 0.72 & 40.74 \\
\hline & & $2^{\text {nd }}$ Quintile & 15.53 & 16.71 & 11.06 & 8.06 & 4.29 & 2.76 & 0.9 & 40.7 \\
\hline & & $3^{\text {rd }}$ Quintile & 7.53 & 17.91 & 15.34 & 12.69 & 5.46 & 0.7 & 0.62 & 39.76 \\
\hline & & $4^{\text {th }}$ Quintile & 2.14 & 2.8 & 13.85 & 23.12 & 13.15 & 0.68 & 0 & 44.26 \\
\hline & & $5^{\text {th }}$ Quintile & 0.8 & 2.16 & 1.79 & 12.41 & 39.45 & 0.97 & 0.68 & 41.74 \\
\hline & & Unemployed & 4.13 & 7.04 & 8.34 & 1.53 & 0.48 & 22.39 & 0.99 & 55.12 \\
\hline & & Inactive & 0.81 & 0 & 2.9 & 0 & 0 & 0 & 28.78 & 67.51 \\
\hline & & Missing & 6.79 & 4.18 & 6.34 & 5.72 & 1.94 & 1.93 & 1.53 & 71.56 \\
\hline \multirow{9}{*}{ 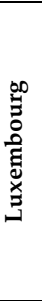 } & \multirow{9}{*}{ 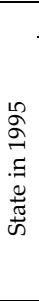 } & State in 2001 & 1 st Q & 2nd Q & 3rd Q & 4 th Q & 5th Q & Unemp. & Inactiv. & Miss. ${ }^{*}$ \\
\hline & & $1^{\text {st }}$ Quintile & 17.82 & 19.54 & 5.58 & 1 & 0.87 & 0.5 & 0.81 & 53.88 \\
\hline & & $2^{\text {nd }}$ Quintile & 4.64 & 23.77 & 16.99 & 4.93 & 0 & 0 & 0 & 49.68 \\
\hline & & $3^{\text {rd }}$ Quintile & 1.06 & 4.12 & 25.04 & 18.88 & 6.24 & 0 & 0 & 44.65 \\
\hline & & $4^{\text {th }}$ Quintile & 0 & 0.92 & 6.29 & 28.65 & 18.6 & 0 & 0 & 45.54 \\
\hline & & $5^{\text {th }}$ Quintile & 0 & 0.25 & 1.36 & 9.85 & 42.91 & 0 & 0 & 45.63 \\
\hline & & Unemployed & 2.98 & 3.47 & 11.42 & 7 & 2.26 & 4.58 & 1.99 & 66.3 \\
\hline & & Inactive & 0 & 20 & 0 & 0 & 0 & 0 & 9 & 71 \\
\hline & & Missing Wage $^{*}$ & 5.9 & 4.26 & 1.71 & 0.53 & 3.51 & 2.14 & 2.49 & 79.47 \\
\hline \multirow{9}{*}{ 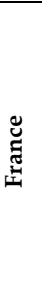 } & \multirow{9}{*}{ 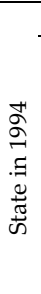 } & State in 2001 & 1st Q & 2nd Q & 3rd Q & 4th Q & 5 th $Q$ & Unemp. & Inactiv. & Miss. ${ }^{*}$ \\
\hline & & $1^{\text {st }}$ Quintile & 19.2 & 18.63 & 6.8 & 1.61 & 0.57 & 4.07 & 1.71 & 47.41 \\
\hline & & $2^{\text {nd }}$ Quintile & 8.33 & 14.69 & 16.79 & 5.79 & 1.32 & 4.55 & 1.05 & 47.48 \\
\hline & & $3^{\text {rd }}$ Quintile & 1.59 & 6.45 & 18.62 & 20.01 & 4.89 & 1.79 & 0.68 & 45.97 \\
\hline & & $4^{\text {th }}$ Quintile & 2.36 & 3.21 & 7.68 & 20.62 & 18.73 & 1.12 & 0.72 & 45.56 \\
\hline & & $5^{\text {th }}$ Quintile & 0.99 & 1.32 & 4.22 & 10.29 & 38.46 & 0.75 & 0.42 & 43.55 \\
\hline & & Unemployed & 10.84 & 6.27 & 3.55 & 3.66 & 2.67 & 8.96 & 3.12 & 60.93 \\
\hline & & Inactive & 1.86 & 1.06 & 0 & 4.25 & 0.66 & 1.33 & 29.88 & 60.96 \\
\hline & & Missing & 4.69 & 5.81 & 4.03 & 4.52 & 2.12 & 4.23 & 1.61 & 73 \\
\hline
\end{tabular}




\begin{tabular}{|c|c|c|c|c|c|c|c|c|c|c|}
\hline \multirow{9}{*}{$\stackrel{\breve{b}}{5}$} & \multirow{9}{*}{ 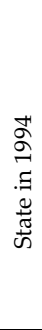 } & State in 2001 & $1^{\text {st }} Q$ & $2^{\text {nd }} Q$ & $3^{\text {rd }} Q$ & $4^{\text {th }} \mathrm{Q}$ & $5^{\text {th }} \mathrm{Q}$ & Unempl. & Inactive & Missing* \\
\hline & & $1^{\text {st }}$ Quintile & 20.32 & 19.25 & 15.53 & 6.11 & 2.99 & 5.31 & 3.11 & 27.39 \\
\hline & & $2^{\text {nd }}$ Quintile & 13.82 & 22.88 & 15.82 & 10.43 & 3.37 & 0.48 & 1.4 & 31.8 \\
\hline & & $3^{\text {rd }}$ Quintile & 6.95 & 11.35 & 24.86 & 17.05 & 10.17 & 1.35 & 0 & 28.27 \\
\hline & & $4^{\text {th }}$ Quintile & 2.38 & 4.81 & 11.71 & 29.82 & 22.79 & 0.84 & 3.14 & 24.51 \\
\hline & & $5^{\text {th }}$ Quintile & 1.63 & 0.42 & 2.15 & 12.96 & 45.2 & 1.87 & 2.29 & 33.49 \\
\hline & & Unemployed & 11.92 & 7.52 & 7.67 & 6.3 & 3.18 & 16.2 & 5.32 & 41.9 \\
\hline & & Inactive & 6.74 & 5.62 & 4.33 & 3.54 & 4.04 & 24.9 & 7.41 & 43.42 \\
\hline & & $\begin{array}{l}\text { Missing } \\
\text { Wage* }^{*}\end{array}$ & 5.64 & 5.65 & 7.37 & 5.61 & 4.2 & 3.26 & 3.81 & 64.45 \\
\hline \multirow{9}{*}{ 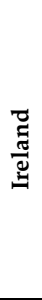 } & \multirow{9}{*}{ 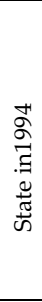 } & State in 2001 & 1st Q & 2nd Q & 3rd Q & 4th Q & 5th Q & Unemp. & Inactiv. & Miss. ${ }^{*}$ \\
\hline & & $1^{\text {st }}$ Quintile & 10.49 & 11.65 & 8.72 & 8.33 & 5.97 & 2.05 & 0 & 52.79 \\
\hline & & $2^{\text {nd }}$ Quintile & 9 & 6.2 & 10.05 & 7.22 & 1.63 & 2.1 & 2.9 & 60.89 \\
\hline & & $3^{\text {rd }}$ Quintile & 1.94 & 9.74 & 13.55 & 9.06 & 8.12 & 0 & 0.54 & 57.05 \\
\hline & & $4^{\text {th }}$ Quintile & 0.76 & 0.76 & 8.42 & 11.8 & 18.09 & 1.15 & 0.32 & 58.71 \\
\hline & & $5^{\text {th }}$ Quintile & 0.65 & 0.83 & 1.18 & 7 & 29.17 & 0.72 & 0 & 60.46 \\
\hline & & Unemployed & 5.7 & 6.28 & 7 & 1.91 & 0.35 & 13.89 & 5.72 & 59.14 \\
\hline & & Inactive & 6.52 & 0 & 1.12 & 0 & 0 & 9.04 & 23.86 & 59.46 \\
\hline & & Missing & 2.57 & 2.71 & 1.89 & 4.85 & 0.85 & 0.76 & 3.89 & 82.48 \\
\hline \multirow{9}{*}{$\frac{\vec{\pi}}{\Xi}$} & \multirow{9}{*}{ 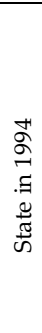 } & State in 2001 & 1 st $Q$ & 2nd $Q$ & 3rd Q & 4th Q & 5 th $\mathrm{Q}$ & Unemp. & Inactiv. & Miss. ${ }^{*}$ \\
\hline & & $1^{\text {st }}$ Quintile & 17.46 & 16.67 & 9.27 & 5.29 & 2.29 & 3.9 & 0.61 & 44.5 \\
\hline & & $2^{\text {nd }}$ Quintile & 4.97 & 14.49 & 16.73 & 10.58 & 3.66 & 2.23 & 0.49 & 46.85 \\
\hline & & $3^{\text {rd }}$ Quintile & 3 & 7.93 & 16.19 & 14.2 & 7.53 & 1.29 & 1.67 & 48.19 \\
\hline & & $4^{\text {th }}$ Quintile & 1.01 & 5.38 & 8.97 & 21.99 & 16.94 & 0.37 & 1.27 & 44.07 \\
\hline & & $5^{\text {th }}$ Quintile & 0.17 & 1.79 & 3.23 & 9.01 & 34.99 & 0.29 & 0.58 & 49.93 \\
\hline & & Unemployed & 13.24 & 7.71 & 4.45 & 3.44 & 2.09 & 16.22 & 2.84 & 50 \\
\hline & & Inactive & 3.87 & 1.98 & 3.04 & 1.71 & 1.34 & 6.69 & 11.3 & 70.08 \\
\hline & & $\begin{array}{c}\text { Missing } \\
\text { Wage* }^{*}\end{array}$ & 4.15 & 2.61 & 3.03 & 3.17 & 2.16 & 3.93 & 1.67 & 79.29 \\
\hline \multirow{9}{*}{$\begin{array}{l}\stackrel{\Xi}{\Xi} \\
\text { Uूँ }\end{array}$} & \multirow{9}{*}{ 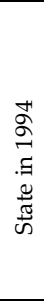 } & State in 2001 & 1st Q & 2nd Q & 3rd Q & 4th Q & 5th Q & Unemp. & Inactiv. & Miss.* \\
\hline & & $1^{\text {st }}$ Quintile & 15.45 & 13.37 & 11.53 & 5.46 & 3.26 & 2.21 & 0.7 & 48.02 \\
\hline & & $2^{\text {nd }}$ Quintile & 7.72 & 10.31 & 15.43 & 10.12 & 2.98 & 1.41 & 0.26 & 51.79 \\
\hline & & $3^{\text {rd }}$ Quintile & 1.42 & 4.84 & 17.51 & 18.75 & 4.45 & 0.23 & 0.66 & 52.13 \\
\hline & & $4^{\text {th }}$ Quintile & 3.16 & 2.9 & 11.96 & 19.13 & 12.53 & 0.68 & 0 & 49.63 \\
\hline & & $5^{\text {th }}$ Quintile & 0 & 2.7 & 3 & 12.27 & 34.75 & 0 & 0.57 & 46.71 \\
\hline & & Unemployed & 8.11 & 12.07 & 6.86 & 3.69 & 1.57 & 8.09 & 3.16 & 56.44 \\
\hline & & Inactive & 6.62 & 6.3 & 3.01 & 4.44 & 0.59 & 1.59 & 16.18 & 61.26 \\
\hline & & Missing & 3.3 & 4.17 & 3.56 & 1.11 & 2.28 & 2.75 & 2.27 & 80.57 \\
\hline \multirow{9}{*}{$\begin{array}{l}\text { कू } \\
\text { के }\end{array}$} & \multirow{9}{*}{ 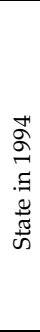 } & State in 2001 & 1st Q & 2nd Q & 3rd Q & 4th Q & 5th Q & Unemp. & Inactiv. & Miss. $^{*}$ \\
\hline & & $1^{\text {st }}$ Quintile & 18.47 & 14.53 & 9.31 & 5.33 & 1.33 & 3.98 & 2.01 & 45.05 \\
\hline & & $2^{\text {nd }}$ Quintile & 5.49 & 15.59 & 12.21 & 6.62 & 2.18 & 2.53 & 1.04 & 54.34 \\
\hline & & $3^{\text {rd }}$ Quintile & 6.01 & 6.16 & 17.34 & 15.75 & 5.62 & 2.83 & 1.61 & 44.67 \\
\hline & & $4^{\text {th }}$ Quintile & 1.51 & 1.39 & 5.89 & 23.28 & 19.72 & 2.33 & 3.33 & 42.56 \\
\hline & & $5^{\text {th }}$ Quintile & 0 & 1.25 & 1.29 & 3.56 & 44.87 & 0.51 & 2.49 & 46.03 \\
\hline & & Unemployed & 10.5 & 8.75 & 8.53 & 7.49 & 0.91 & 12.46 & 2.96 & 48.39 \\
\hline & & Inactive & 3.85 & 4.55 & 4.91 & 2 & 0.78 & 6.91 & 24.74 & 52.26 \\
\hline & & $\begin{array}{l}\text { Missing } \\
\text { Wage* }^{*}\end{array}$ & 4.87 & 4.48 & 3.64 & 4.86 & 4.3 & 2.62 & 2.52 & 72.7 \\
\hline \multirow{8}{*}{ 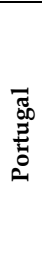 } & \multirow{8}{*}{ 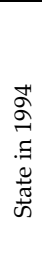 } & State in 2001 & 1 st $Q$ & 2nd Q & 3rd Q & 4th Q & 5th Q & Unemp. & Inactiv. & Miss. ${ }^{*}$ \\
\hline & & $1^{\text {st }}$ Quintile & 25.3 & 18.35 & 9.01 & 7.83 & 0.67 & 3.1 & 0.64 & 35.09 \\
\hline & & $2^{\text {nd }}$ Quintile & 11.42 & 16.67 & 18.81 & 9.58 & 1.36 & 1.47 & 1.74 & 38.96 \\
\hline & & $3^{\text {rd }}$ Quintile & 6.27 & 13.65 & 16.61 & 15.99 & 6.34 & 2.79 & 2.38 & 35.95 \\
\hline & & $4^{\text {th }}$ Quintile & 3.43 & 3.94 & 8.49 & 22.34 & 14.43 & 1.05 & 0.48 & 45.84 \\
\hline & & $5^{\text {th }}$ Quintile & 0.07 & 0.07 & 3.85 & 7.18 & 40.43 & 1.31 & 0.14 & 46.96 \\
\hline & & Unemployed & 9.66 & 14.07 & 8.34 & 3.1 & 3.45 & 4.69 & 9.66 & 47.03 \\
\hline & & Inactive & 11.06 & 1.68 & 3.06 & 1.78 & 1.09 & 2.96 & 28.43 & 49.95 \\
\hline
\end{tabular}




\begin{tabular}{|c|c|c|c|c|c|c|c|c|c|c|}
\hline & & Missing & 3.2 & 2.67 & 4.49 & 4.34 & 7.07 & 1.49 & 1.27 & 75.48 \\
\hline \multirow{9}{*}{ 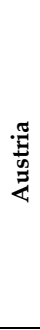 } & \multirow{9}{*}{ 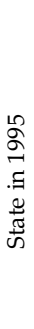 } & State in 2001 & 1st Q & 2nd Q & 3rd Q & 4th Q & 5th Q & Unemp. & Inactiv. & Miss.* \\
\hline & & $1^{\text {st }}$ Quintile & 23.54 & 16.86 & 7.6 & 3.13 & 1.94 & 2.25 & 0.39 & 44.3 \\
\hline & & $2^{\text {nd }}$ Quintile & 10.63 & 14.49 & 17.77 & 11.53 & 2.8 & 3.11 & 0 & 39.68 \\
\hline & & $3^{\text {rd }}$ Quintile & 8.85 & 12.93 & 11.45 & 14.4 & 5.82 & 4.3 & 0.41 & 41.84 \\
\hline & & $4^{\text {th }}$ Quintile & 0.62 & 5.86 & 7.46 & 24.87 & 13.32 & 1.24 & 0.59 & 46.04 \\
\hline & & $5^{\text {th }}$ Quintile & 1.51 & 3.15 & 3.85 & 8.84 & 35.19 & 1.14 & 0 & 46.32 \\
\hline & & Unemployed & 10.27 & 1.15 & 3.58 & 1.73 & 2.08 & 19.03 & 0 & 62.17 \\
\hline & & Inactive & 14.29 & 0 & 2.81 & 6.63 & 2.3 & 0.51 & 9.18 & 64.29 \\
\hline & & $\begin{array}{l}\text { Missing } \\
\text { Wage* }^{*}\end{array}$ & 4.91 & 3.65 & 3.63 & 1.3 & 3.4 & 0.17 & 0.14 & 82.81 \\
\hline \multirow{9}{*}{$\underset{\text { 疍 }}{\stackrel{\Xi}{\Xi}}$} & \multirow{9}{*}{ 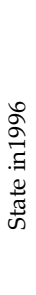 } & State in 2001 & 1st Q & 2nd Q & 3rd Q & 4th Q & 5th Q & Unemp. & Inactiv. & Miss.* \\
\hline & & $1^{\text {st }}$ Quintile & 20.59 & 11.87 & 7.01 & 6.76 & 2.68 & 2.12 & 0.6 & 48.37 \\
\hline & & $2^{\text {nd }}$ Quintile & 7.29 & 19.15 & 19.27 & 10.53 & 1.95 & 0.56 & 0.28 & 40.98 \\
\hline & & $3^{\text {rd }}$ Quintile & 5.07 & 10.82 & 21.71 & 14.7 & 8.04 & 2 & 0 & 37.66 \\
\hline & & $4^{\text {th }}$ Quintile & 0.69 & 4.32 & 10.95 & 20.96 & 17.83 & 1.64 & 0 & 43.59 \\
\hline & & $5^{\text {th }}$ Quintile & 1.72 & 0.95 & 3.88 & 10.79 & 35.23 & 0.67 & 0.29 & 46.47 \\
\hline & & Unemployed & 14.51 & 9.58 & 5.16 & 3.49 & 1.45 & 12.88 & 0.83 & 52.1 \\
\hline & & Inactive & 0 & 0 & 4.57 & 2.74 & 0 & 6.39 & 0 & 86.3 \\
\hline & & Missing & 5.66 & 4.51 & 4.35 & 5.08 & 4.25 & 3.17 & 1.81 & 71.16 \\
\hline
\end{tabular}

${ }^{*}$ Missing Wage refers to individuals with missing wage in the first wave and Missing refers to individuals with missing wage, self-employed, retired, not in formal employment and those that dropped from the survey in the previous year. 
Table 2-A-4. Short-Term Transition Rates Among Income Quintiles

\begin{tabular}{|c|c|c|c|c|c|c|}
\hline \multirow{14}{*}{ 己 } & & \multicolumn{5}{|c|}{ State in 1995} \\
\hline & State in 1994 & 1st Quintile & 2nd Quintile & 3rd Quintile & 4th Quintile & 5th Quintile \\
\hline & 1st Quintile & 71.28 & 21.63 & 6 & 1.09 & 0 \\
\hline & 2nd Quintile & 15.93 & 55.46 & 20.42 & 7.22 & 0.98 \\
\hline & 3rd Quintile & 4.15 & 19.68 & 49.2 & 23.36 & 3.62 \\
\hline & 4th Quintile & 0.47 & 4.82 & 20.38 & 55.66 & 18.67 \\
\hline & 5th Quintile & 0 & 0.5 & 2.56 & 12.9 & 84.03 \\
\hline & \multicolumn{6}{|c|}{ State in 2001} \\
\hline & State in 2000 & 1st Quintile & 2nd Quintile & 3rd Quintile & 4th Quintile & 5th Quintile \\
\hline & 1st Quintile & 77.43 & 17.39 & 4.21 & 0.74 & 0.23 \\
\hline & 2nd Quintile & 17.75 & 57.19 & 20.3 & 4.34 & 0.41 \\
\hline & 3rd Quintile & 3.68 & 21.97 & 53.15 & 20.09 & 1.12 \\
\hline & 4th Quintile & 0.6 & 2.63 & 15.79 & 66.86 & 14.13 \\
\hline & 5th Quintile & 0.58 & 2.55 & 2.91 & 14.89 & 79.08 \\
\hline \multirow{14}{*}{ ڤ્ટ } & \multicolumn{6}{|c|}{ State in 1995} \\
\hline & State in 1994 & 1st Quintile & 2nd Quintile & 3rd Quintile & 4th Quintile & 5th Quintile \\
\hline & 1st Quintile & 55.54 & 26.12 & 13.4 & 2.28 & 2.67 \\
\hline & 2nd Quintile & 25.15 & 47.93 & 17.03 & 8.63 & 1.26 \\
\hline & 3rd Quintile & 7.03 & 34.02 & 32.22 & 19.84 & 6.89 \\
\hline & 4th Quintile & 0.88 & 7.75 & 25.73 & 48.91 & 16.73 \\
\hline & 5th Quintile & 2.42 & 1.15 & 1.82 & 27.9 & 66.71 \\
\hline & \multicolumn{6}{|c|}{ State in 2001} \\
\hline & State in 2000 & 1st Quintile & 2nd Quintile & 3rd Quintile & 4th Quintile & 5th Quintile \\
\hline & 1st Quintile & 60.81 & 20.21 & 15.94 & 2.17 & 0.87 \\
\hline & 2nd Quintile & 28.36 & 41.29 & 21.36 & 3.45 & 5.54 \\
\hline & 3rd Quintile & 6.61 & 23.05 & 50.56 & 16.36 & 3.42 \\
\hline & 4th Quintile & 4.81 & 9.09 & 23.02 & 43.4 & 19.68 \\
\hline & 5th Quintile & 0.66 & 0.77 & 6.44 & 15.01 & 77.12 \\
\hline \multirow{14}{*}{ 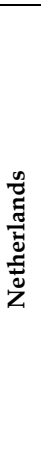 } & \multicolumn{6}{|c|}{ State in 1995} \\
\hline & State in 1994 & 1st Quintile & 2nd Quintile & 3rd Quintile & 4th Quintile & 5th Quintile \\
\hline & 1st Quintile & 61.88 & 29.72 & 6.16 & 2.14 & 0.09 \\
\hline & 2nd Quintile & 13.02 & 51.22 & 27.54 & 6.55 & 1.66 \\
\hline & 3rd Quintile & 3.33 & 16.08 & 51.68 & 25.46 & 3.45 \\
\hline & 4th Quintile & 0.58 & 3.04 & 14.91 & 59.91 & 21.56 \\
\hline & 5th Quintile & 1 & 0.55 & 2.58 & 14.92 & 80.94 \\
\hline & \multicolumn{6}{|c|}{ State in 2001} \\
\hline & State in 2000 & 1st Quintile & 2nd Quintile & 3rd Quintile & 4th Quintile & 5th Quintile \\
\hline & 1st Quintile & 71.13 & 20.01 & 4.7 & 3.56 & 0.6 \\
\hline & 2nd Quintile & 9.31 & 59.25 & 22.57 & 7.3 & 1.56 \\
\hline & 3rd Quintile & 5.55 & 8.59 & 61.68 & 19 & 5.18 \\
\hline & 4th Quintile & 1.04 & 1.41 & 18.41 & 63.84 & 15.3 \\
\hline & 5th Quintile & 0 & 0.85 & 1.43 & 18.22 & 79.5 \\
\hline \multirow{11}{*}{ 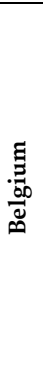 } & \multicolumn{6}{|c|}{ State in 1995} \\
\hline & State in 1994 & 1st Quintile & 2nd Quintile & 3rd Quintile & 4th Quintile & 5th Quintile \\
\hline & 1st Quintile & 54.42 & 20.13 & 12.22 & 8.2 & 5.03 \\
\hline & 2nd Quintile & 28.54 & 43.39 & 18.78 & 7.72 & 1.57 \\
\hline & 3rd Quintile & 5.96 & 28.14 & 48.55 & 12.84 & 4.51 \\
\hline & 4th Quintile & 3.7 & 5.64 & 24.09 & 49.88 & 16.68 \\
\hline & 5th Quintile & 0.71 & 1.68 & 3.09 & 18.49 & 76.02 \\
\hline & \multicolumn{6}{|c|}{ State in 2001} \\
\hline & State in 2000 & 1st Quintile & 2nd Quintile & 3rd Quintile & 4th Quintile & 5th Quintile \\
\hline & 1st Quintile & 72.75 & 17.92 & 8.59 & 0.39 & 0.35 \\
\hline & 2nd Quintile & 12.7 & 54.52 & 23.99 & 6.7 & 2.09 \\
\hline
\end{tabular}




\begin{tabular}{|c|c|c|c|c|c|c|}
\hline & 3rd Quintile & 6.37 & 20.15 & 43.23 & 27.42 & 2.82 \\
\hline & 4th Quintile & 0.98 & 6.51 & 22.88 & 54.85 & 14.79 \\
\hline & 5th Quintile & 0 & 1.44 & 1.78 & 18.18 & 78.6 \\
\hline \multirow{14}{*}{ 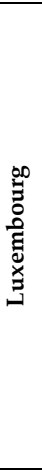 } & \multicolumn{6}{|c|}{ State in 1996} \\
\hline & State in 1995 & 1st Quintile & 2nd Quintile & 3rd Quintile & 4th Quintile & 5th Quintile \\
\hline & 1st Quintile & 76.59 & 20.03 & 1.42 & 0.88 & 1.09 \\
\hline & 2nd Quintile & 15.78 & 66.6 & 17.11 & 0.23 & 0.27 \\
\hline & 3rd Quintile & 2.82 & 14.51 & 68.15 & 10.46 & 4.05 \\
\hline & 4th Quintile & 0.25 & 0.7 & 21.98 & 64.35 & 12.73 \\
\hline & 5th Quintile & 0.3 & 0 & 4.12 & 16.95 & 78.62 \\
\hline & & & State & 2001 & & \\
\hline & State in 2000 & 1st Quintile & 2nd Quintile & 3rd Quintile & 4th Quintile & 5th Quintile \\
\hline & 1st Quintile & 70.77 & 26.87 & 1.75 & 0.61 & 0 \\
\hline & 2nd Quintile & 11.44 & 67.15 & 19.03 & 1.74 & 0.64 \\
\hline & 3rd Quintile & 2.87 & 6.29 & 68.93 & 21.06 & 0.85 \\
\hline & 4th Quintile & 0.3 & 1.36 & 10.26 & 69.22 & 18.86 \\
\hline & 5th Quintile & 0 & 0.23 & 0.33 & 12.24 & 87.2 \\
\hline \multirow{14}{*}{ 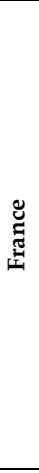 } & \multicolumn{6}{|c|}{ State in 1995} \\
\hline & State in 1994 & 1st Quintile & 2nd Quintile & 3rd Quintile & 4th Quintile & 5th Quintile \\
\hline & 1st Quintile & 65.42 & 25.5 & 7.18 & 1.2 & 0.71 \\
\hline & 2nd Quintile & 15.11 & 55.45 & 24.6 & 3.91 & 0.93 \\
\hline & 3rd Quintile & 4.84 & 17.24 & 51.07 & 23.84 & 3.02 \\
\hline & 4th Quintile & 2.59 & 5.09 & 15.85 & 54.3 & 22.18 \\
\hline & 5th Quintile & 3.17 & 2.67 & 4.29 & 16.67 & 73.2 \\
\hline & \multicolumn{6}{|c|}{ State in 2001} \\
\hline & State in 2000 & 1st Quintile & 2nd Quintile & 3rd Quintile & 4th Quintile & 5th Quintile \\
\hline & 1st Quintile & 66.52 & 22.09 & 7.91 & 2.74 & 0.75 \\
\hline & 2nd Quintile & 20.07 & 55.68 & 20.16 & 3.74 & 0.35 \\
\hline & 3rd Quintile & 2.57 & 17.98 & 59.08 & 19.28 & 1.09 \\
\hline & 4th Quintile & 0.67 & 3.7 & 14.23 & 64.29 & 17.1 \\
\hline & 5th Quintile & 0.51 & 0.21 & 1.8 & 13 & 84.47 \\
\hline \multirow{14}{*}{ 光 } & \multicolumn{6}{|c|}{ State in 1995} \\
\hline & State in 1994 & 1st Quintile & 2nd Quintile & 3rd Quintile & 4th Quintile & 5th Quintile \\
\hline & 1st Quintile & 58.66 & 28.75 & 6.7 & 4.14 & 1.75 \\
\hline & 2nd Quintile & 24.05 & 49.87 & 19.05 & 4.93 & 2.1 \\
\hline & 3rd Quintile & 4.58 & 15.68 & 54.34 & 22.38 & 3.01 \\
\hline & 4th Quintile & 0.13 & 4.4 & 19.78 & 59.68 & 16.01 \\
\hline & 5th Quintile & 0.94 & 0.74 & 3.04 & 13.82 & 81.46 \\
\hline & \multicolumn{6}{|c|}{ State in 2001} \\
\hline & State in 2000 & 1st Quintile & 2nd Quintile & 3rd Quintile & 4th Quintile & 5th Quintile \\
\hline & 1st Quintile & 59.09 & 29.59 & 7 & 2.17 & 2.15 \\
\hline & 2nd Quintile & 23 & 46.06 & 22.44 & 6.43 & 2.08 \\
\hline & 3rd Quintile & 4.37 & 19.4 & 53.07 & 20.07 & 3.08 \\
\hline & 4th Quintile & 0.92 & 3.76 & 17.91 & 60.66 & 16.75 \\
\hline & 5th Quintile & 0.64 & 2.08 & 3.04 & 15.79 & 78.44 \\
\hline \multirow{11}{*}{ 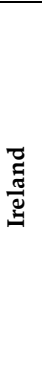 } & \multicolumn{6}{|c|}{ State in 1995} \\
\hline & State in 1994 & 1st Quintile & 2nd Quintile & 3rd Quintile & 4th Quintile & 5th Quintile \\
\hline & 1st Quintile & 61.64 & 23.6 & 7.93 & 5.45 & 1.37 \\
\hline & 2nd Quintile & 18.52 & 51.61 & 20.32 & 7.21 & 2.34 \\
\hline & 3rd Quintile & 2.2 & 21.77 & 48.92 & 26.09 & 1.01 \\
\hline & 4th Quintile & 0.89 & 4.06 & 24.16 & 48.96 & 21.92 \\
\hline & 5th Quintile & 0 & 0.45 & 4.75 & 14.63 & 80.17 \\
\hline & \multicolumn{6}{|c|}{ State in 2001} \\
\hline & State in 2000 & 1st Quintile & 2nd Quintile & 3rd Quintile & 4th Quintile & 5th Quintile \\
\hline & 1st Quintile & 64.62 & 21.88 & 9.76 & 3.73 & 0 \\
\hline & 2nd Quintile & 20.41 & 50.8 & 18.82 & 7.71 & 2.26 \\
\hline
\end{tabular}









\begin{tabular}{|c|c|c|c|c|c|c|}
\hline & 2nd Quintile & 15.2 & 56.42 & 24.64 & 3.64 & 0.11 \\
\hline & 3rd Quintile & 5.45 & 11.07 & 59.26 & 16.97 & 7.25 \\
\hline & 4th Quintile & 0.08 & 6.86 & 19.58 & 65.75 & 7.73 \\
\hline & 5th Quintile & 0 & 0.54 & 2.73 & 11.48 & 85.25 \\
\hline \multirow{14}{*}{$\frac{\stackrel{\pi}{E}}{\stackrel{n}{0}}$} & \multicolumn{6}{|c|}{ State in 1995} \\
\hline & State in 1994 & 1st Quintile & 2nd Quintile & 3rd Quintile & 4th Quintile & 5th Quintile \\
\hline & 1st Quintile & 59.34 & 29.58 & 6.42 & 2.93 & 1.73 \\
\hline & 2nd Quintile & 22.45 & 39.77 & 25.53 & 9.03 & 3.21 \\
\hline & 3rd Quintile & 12.81 & 29.32 & 27.53 & 24.62 & 5.72 \\
\hline & 4th Quintile & 4.69 & 6.97 & 22.91 & 41.81 & 23.62 \\
\hline & 5th Quintile & 0.78 & 4.17 & 3.99 & 21.47 & 69.59 \\
\hline & \multicolumn{6}{|c|}{ State in 2001} \\
\hline & State in 2000 & 1st Quintile & 2nd Quintile & 3rd Quintile & 4th Quintile & 5th Quintile \\
\hline & 1st Quintile & 76.91 & 14.99 & 5.19 & 2.2 & 0.72 \\
\hline & 2nd Quintile & 15.42 & 58.33 & 17.17 & 6.42 & 2.66 \\
\hline & 3rd Quintile & 8.74 & 18.23 & 54.11 & 15.35 & 3.57 \\
\hline & 4th Quintile & 2.48 & 2.98 & 12.26 & 64.18 & 18.1 \\
\hline & 5th Quintile & 0 & 1.25 & 1.99 & 16.55 & 80.21 \\
\hline \multirow{14}{*}{ 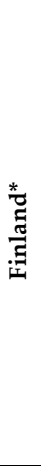 } & \multicolumn{6}{|c|}{ State in 1997} \\
\hline & State in 1996 & 1st Quintile & 2nd Quintile & 3rd Quintile & 4th Quintile & 5th Quintile \\
\hline & 1st Quintile & 61.68 & 24.64 & 7.23 & 4.79 & 1.67 \\
\hline & 2nd Quintile & 12.84 & 52.25 & 25.39 & 5.87 & 3.65 \\
\hline & 3rd Quintile & 6.06 & 24.29 & 43.99 & 18.55 & 7.1 \\
\hline & 4th Quintile & 1.88 & 6.31 & 23.27 & 51.2 & 17.34 \\
\hline & 5th Quintile & 1.03 & 2.06 & 7.08 & 18.4 & 71.42 \\
\hline & \multicolumn{6}{|c|}{ State in 2001} \\
\hline & State in 2000 & 1st Quintile & 2nd Quintile & 3rd Quintile & 4th Quintile & 5th Quintile \\
\hline & 1st Quintile & 57.17 & 27.26 & 11.38 & 2.4 & 1.79 \\
\hline & 2nd Quintile & 23.31 & 40.69 & 25.82 & 6.31 & 3.88 \\
\hline & 3rd Quintile & 2.56 & 21.84 & 47.24 & 26.16 & 2.21 \\
\hline & 4th Quintile & 3.59 & 4.35 & 16.45 & 54.82 & 20.8 \\
\hline & 5th Quintile & 1.01 & 1.05 & 5.45 & 18.9 & 73.6 \\
\hline
\end{tabular}


Table 2-A-5. Long-Term Transition Rates Among Income Quintiles

\begin{tabular}{|c|c|c|c|c|c|c|}
\hline \multirow{7}{*}{ 己 } & \multicolumn{6}{|c|}{ State in 2001} \\
\hline & State in 1994 & 1st Quintile & 2nd Quintile & 3rd Quintile & 4th Quintile & 5th Quintile \\
\hline & 1st Quintile & 49.18 & 26.64 & 17.65 & 4.77 & 1.75 \\
\hline & 2nd Quintile & 17.11 & 35.18 & 21.54 & 21.24 & 4.92 \\
\hline & 3rd Quintile & 10.45 & 20.09 & 31.31 & 30.1 & 8.06 \\
\hline & 4th Quintile & 2.17 & 9.51 & 19.12 & 41.76 & 27.45 \\
\hline & 5th Quintile & 0.89 & 1.54 & 4.41 & 18.09 & 75.07 \\
\hline \multirow{7}{*}{ ڤั } & \multicolumn{6}{|c|}{ State in 2001} \\
\hline & State in 1994 & 1st Quintile & 2nd Quintile & 3rd Quintile & 4th Quintile & 5th Quintile \\
\hline & 1st Quintile & 34.28 & 19.16 & 29.47 & 11.98 & 5.11 \\
\hline & 2nd Quintile & 37.9 & 27.27 & 19.87 & 3.4 & 11.56 \\
\hline & 3rd Quintile & 12.53 & 21.67 & 35.49 & 13.91 & 16.39 \\
\hline & 4th Quintile & 5.09 & 21.54 & 21.54 & 29.22 & 22.6 \\
\hline & 5th Quintile & 4.32 & 4.18 & 6.77 & 26.77 & 57.95 \\
\hline \multirow{7}{*}{ 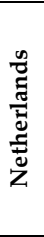 } & \multicolumn{6}{|c|}{ State in 2001} \\
\hline & State in 1994 & 1st Quintile & 2nd Quintile & 3rd Quintile & 4th Quintile & 5th Quintile \\
\hline & 1st Quintile & 38.12 & 26.95 & 18.29 & 13.26 & 3.39 \\
\hline & 2nd Quintile & 12.11 & 38.31 & 30.35 & 15.8 & 3.43 \\
\hline & 3rd Quintile & 2.14 & 16.75 & 35 & 29.83 & 16.27 \\
\hline & 4th Quintile & 0.5 & 5.11 & 20.57 & 47.97 & 25.85 \\
\hline & 5th Quintile & 0.57 & 0.79 & 4.99 & 18.01 & 75.64 \\
\hline \multirow{7}{*}{ 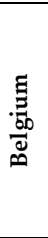 } & \multicolumn{6}{|c|}{ State in 2001} \\
\hline & State in 1994 & 1st Quintile & 2nd Quintile & 3rd Quintile & 4th Quintile & 5th Quintile \\
\hline & 1st Quintile & 35.55 & 24.66 & 19.16 & 13.85 & 6.79 \\
\hline & 2nd Quintile & 27.91 & 30.03 & 19.87 & 14.48 & 7.71 \\
\hline & 3rd Quintile & 12.77 & 30.39 & 26.03 & 21.53 & 9.27 \\
\hline & 4th Quintile & 3.89 & 5.09 & 25.16 & 41.98 & 23.88 \\
\hline & 5th Quintile & 1.41 & 3.82 & 3.17 & 21.92 & 69.68 \\
\hline \multirow{7}{*}{ 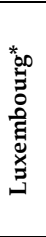 } & \multicolumn{6}{|c|}{ State in 2001} \\
\hline & State in 1995 & 1st Quintile & 2nd Quintile & 3rd Quintile & 4th Quintile & 5th Quintile \\
\hline & 1st Quintile & 39.78 & 43.6 & 12.45 & 2.23 & 1.95 \\
\hline & 2nd Quintile & 9.22 & 47.23 & 33.76 & 9.79 & 0 \\
\hline & 3rd Quintile & 1.92 & 7.45 & 45.24 & 34.12 & 11.28 \\
\hline & 4th Quintile & 0 & 1.69 & 11.55 & 52.6 & 34.16 \\
\hline & 5th Quintile & 0 & 0.47 & 2.5 & 18.11 & 78.92 \\
\hline \multirow{7}{*}{ 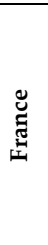 } & \multicolumn{6}{|c|}{ State in 2001} \\
\hline & State in 1994 & 1st Quintile & 2nd Quintile & 3rd Quintile & 4th Quintile & 5th Quintile \\
\hline & 1st Quintile & 41.02 & 39.8 & 14.52 & 3.44 & 1.22 \\
\hline & 2nd Quintile & 17.76 & 31.3 & 35.78 & 12.34 & 2.81 \\
\hline & 3rd Quintile & 3.08 & 12.51 & 36.12 & 38.81 & 9.48 \\
\hline & 4th Quintile & 4.49 & 6.1 & 14.61 & 39.2 & 35.6 \\
\hline & 5th Quintile & 1.8 & 2.38 & 7.64 & 18.61 & 69.57 \\
\hline \multirow{7}{*}{ 光 } & \multicolumn{6}{|c|}{ State in 2001} \\
\hline & State in 1994 & 1st Quintile & 2nd Quintile & 3rd Quintile & 4th Quintile & 5th Quintile \\
\hline & 1st Quintile & 31.65 & 29.99 & 24.19 & 9.52 & 4.65 \\
\hline & 2nd Quintile & 20.84 & 34.5 & 23.85 & 15.73 & 5.08 \\
\hline & 3rd Quintile & 9.87 & 16.13 & 35.33 & 24.23 & 14.45 \\
\hline & 4th Quintile & 3.33 & 6.72 & 16.38 & 41.7 & 31.87 \\
\hline & 5th Quintile & 2.61 & 0.68 & 3.44 & 20.79 & 72.49 \\
\hline \multirow{5}{*}{ 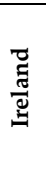 } & \multicolumn{6}{|c|}{ State in 2001} \\
\hline & State in 1994 & 1st Quintile & 2nd Quintile & 3rd Quintile & 4th Quintile & 5th Quintile \\
\hline & 1st Quintile & 23.22 & 25.8 & 19.31 & 18.45 & 13.21 \\
\hline & 2nd Quintile & 26.38 & 18.19 & 29.47 & 21.17 & 4.79 \\
\hline & 3rd Quintile & 4.58 & 22.97 & 31.95 & 21.36 & 19.15 \\
\hline
\end{tabular}




\begin{tabular}{|c|c|c|c|c|c|c|}
\hline & 4th Quintile & 1.9 & 1.9 & 21.14 & 29.63 & 45.44 \\
\hline & 5th Quintile & 1.66 & 2.13 & 3.05 & 18.02 & 75.14 \\
\hline \multirow{7}{*}{$\frac{\lambda}{\pi}$} & \multicolumn{6}{|c|}{ State in 2001} \\
\hline & State in 1994 & 1st Quintile & 2nd Quintile & 3rd Quintile & 4th Quintile & 5th Quintile \\
\hline & 1st Quintile & 34.25 & 32.69 & 18.18 & 10.38 & 4.5 \\
\hline & 2nd Quintile & 9.86 & 28.73 & 33.17 & 20.98 & 7.26 \\
\hline & 3rd Quintile & 6.14 & 16.23 & 33.14 & 29.08 & 15.41 \\
\hline & 4th Quintile & 1.85 & 9.92 & 16.51 & 40.51 & 31.21 \\
\hline & 5th Quintile & 0.34 & 3.64 & 6.57 & 18.32 & 71.12 \\
\hline \multirow{7}{*}{$\begin{array}{l}\text { Uूँ } \\
\text { Uँّ }\end{array}$} & \multicolumn{6}{|c|}{ State in 2001} \\
\hline & State in 1994 & 1st Quintile & 2nd Quintile & 3rd Quintile & 4th Quintile & 5th Quintile \\
\hline & 1st Quintile & 31.48 & 27.25 & 23.5 & 11.12 & 6.65 \\
\hline & 2nd Quintile & 16.57 & 22.14 & 33.15 & 21.74 & 6.4 \\
\hline & 3rd Quintile & 3.02 & 10.31 & 37.28 & 39.92 & 9.47 \\
\hline & 4th Quintile & 6.35 & 5.85 & 24.07 & 38.51 & 25.23 \\
\hline & 5th Quintile & 0 & 5.12 & 5.7 & 23.27 & 65.91 \\
\hline \multirow{7}{*}{$\begin{array}{l}\text { हू } \\
\text { के }\end{array}$} & \multicolumn{6}{|c|}{ State in 2001} \\
\hline & State in 1994 & 1st Quintile & 2nd Quintile & 3rd Quintile & 4th Quintile & 5th Quintile \\
\hline & 1st Quintile & 37.71 & 29.67 & 19.02 & 10.89 & 2.71 \\
\hline & 2nd Quintile & 13.03 & 37.04 & 29.02 & 15.73 & 5.17 \\
\hline & 3rd Quintile & 11.81 & 12.1 & 34.08 & 30.96 & 11.05 \\
\hline & 4th Quintile & 2.91 & 2.69 & 11.37 & 44.95 & 38.08 \\
\hline & 5th Quintile & 0 & 2.45 & 2.53 & 6.99 & 88.03 \\
\hline \multirow{7}{*}{ 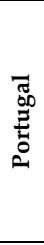 } & \multicolumn{6}{|c|}{ State in 2001} \\
\hline & State in 1994 & 1st Quintile & 2nd Quintile & 3rd Quintile & 4th Quintile & 5th Quintile \\
\hline & 1st Quintile & 41.37 & 30.01 & 14.73 & 12.8 & 1.1 \\
\hline & 2nd Quintile & 19.74 & 28.82 & 32.53 & 16.56 & 2.36 \\
\hline & 3rd Quintile & 10.66 & 23.19 & 28.22 & 27.17 & 10.77 \\
\hline & 4th Quintile & 6.52 & 7.48 & 16.13 & 42.45 & 27.42 \\
\hline & 5th Quintile & 0.13 & 0.13 & 7.46 & 13.92 & 78.35 \\
\hline \multirow{7}{*}{$\frac{\pi}{\stackrel{\pi}{ \pm}}$} & \multicolumn{6}{|c|}{ State in 2001} \\
\hline & State in 1994 & 1st Quintile & 2nd Quintile & 3rd Quintile & 4th Quintile & 5th Quintile \\
\hline & 1st Quintile & 44.36 & 31.77 & 14.32 & 5.9 & 3.66 \\
\hline & 2nd Quintile & 18.58 & 25.33 & 31.05 & 20.15 & 4.89 \\
\hline & 3rd Quintile & 16.56 & 24.2 & 21.41 & 26.93 & 10.89 \\
\hline & 4th Quintile & 1.19 & 11.24 & 14.32 & 47.7 & 25.55 \\
\hline & 5th Quintile & 2.87 & 6 & 7.32 & 16.83 & 66.99 \\
\hline \multirow{7}{*}{ 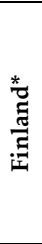 } & \multicolumn{6}{|c|}{ State in 2001} \\
\hline & State in 1996 & 1st Quintile & 2nd Quintile & 3rd Quintile & 4th Quintile & 5th Quintile \\
\hline & 1st Quintile & 42.09 & 24.27 & 14.33 & 13.82 & 5.49 \\
\hline & 2nd Quintile & 12.53 & 32.91 & 33.12 & 18.1 & 3.34 \\
\hline & 3rd Quintile & 8.4 & 17.93 & 35.97 & 24.36 & 13.33 \\
\hline & 4th Quintile & 1.27 & 7.9 & 20 & 38.27 & 32.56 \\
\hline & 5th Quintile & 3.27 & 1.82 & 7.38 & 20.52 & 67.01 \\
\hline
\end{tabular}


3. EQUALIZING OR DISEQUALIZING LIFETIME EARNINGS DIFFERENTIALS? EARNINGS MOBILITY IN THE EU: 1994-2001 


\subsection{Introduction}

Do EU citizens have an increased opportunity to improve their position in the distribution of lifetime earnings? To what extent does earnings mobility work to equalize/disequalize longer-term earnings relative to cross-sectional inequality and how does it differ across the EU?

These questions are relevant in the context of the EU labour market policy changes that took place after 1995 under the incidence of the 1994 OECD Jobs Strategy, which recommended policies to increase wage flexibility, lower non-wage labour costs and allow relative wages to reflect better individual differences in productivity and local labour market conditions (OECD, 2004). Following these reforms, the labour market performance improved in some countries and deteriorated in others, with heterogeneous consequences for cross-sectional earnings inequality and earnings mobility. Averaged across the OECD, however, gross earnings inequality increased after 1994 (OECD, 2006).

To explore the possible lifetime inequality consequences of these labour market changes, one has to expand the typical cross-sectional view usually taken in crossnational comparisons of earnings distribution because a simple cross-sectional picture of earnings inequality is inadequate in capturing the true degree of inequality faced by individuals during their lifetime. The welfare implications of any labour market changes should to be analysed in a lifetime perspective because lifetime earnings reflect to a larger extent the differences in the opportunities faced by individuals.

The lifetime approach faces a huge impediment: the scarcity of data on lifetime earnings. This motivated the study of economic mobility, viewed as the link between short and long-term earnings differentials: a cross-sectional snapshot of income distribution overstates lifetime inequality to a degree that depends on the degree of earnings mobility (Lillard, 1977; Atkinson et al., 1992; Creedy, 1998). If countries have different earnings mobility levels, then single-year inequality country rankings may lead to a misleading picture of long-term inequality ranking. To support this statement, Creedy (1998), conducted a simulation study to examine the relationship between cross-sectional and lifetime income distributions. His conclusion was that simple inferences about lifetime income distributions cannot be made on the basis of cross-sectional distributions alone, dismissing the conclusions drawn by the OECD (1996) report.

Some people argue that rising annual inequality does not necessarily have negative implications. This statement relies on the "offsetting mobility" argument, which 
states that if there has been a sufficiently large simultaneous increase in mobility, the inequality of income measured over a longer period of time, such as lifetime income or permanent income - can be lower despite the rise in annual inequality, with a positive impact on social welfare. This statement, however, holds only under the assumption that individuals are not averse to income variability, future risk or multi-period inequality (Creedy and Wilhelm, 2002; Gottschalk and Spolaore, 2002). Therefore, there is not a complete agreement in the literature on the value judgement of income mobility (Atkinson et al., 1992).

Those that value income mobility positively perceive it in two ways: as a goal in its own right or as an instrument to another end. The goal of having a mobile society is linked to the goal of securing equality of opportunity in the labour market and of having a more flexible and efficient economy (Friedman, 1962; Atkinson et al., 1992). The instrumental justification for mobility takes place in the context of achieving distributional equity: lifetime equity depends on the extent of movement up and down the earnings distribution over the lifetime (Atkinson et al., 1992). In this line of thought, Friedman (1962) underlined the role of social mobility in reducing lifetime earnings differentials between individuals, by allowing them to change their position in the income distribution over time.

Thus earnings mobility is perceived in the literature as a way out of poverty. In the absence of mobility the same individuals remain stuck at the bottom of the earnings distribution, hence annual earnings differentials are transformed into lifetime differentials.

Using ECHP over the period 1994-2001, we explore earnings mobility across 14 EU countries to identify whether mobility operates as an equalizer or disequalizer of lifetime earnings differentials, a question much neglected at the EU level. Our paper contributes to the existing literature in three ways. First, by exploring a different facet of mobility - as an equalizer or disequalizer of lifetime earnings differentials -, we complement Sologon and O'Donoghue (2009d) findings on the evolution of earnings mobility over time across the EU, thus filling part of the gap in the study of earnings mobility at the EU level. Second, we apply a new class of measures of mobility as an equalizer of longer-term incomes - developed by Fields (2008) - in comparison to the well-known measure developed by Shorrocks (1978).

Third, unlike previous studies that rely on a fully balanced sample to explore mobility (only those individuals that record positive earnings independent of the sub-period), we extend the analysis by including the results for the unbalanced sample over different sub-periods. By doing so, we want to explore mobility as equalizer of longer term incomes not only for the people that remain employed over the entire sample period, but also for those that move into and out of 
employment. Focusing only on the fully balanced sample might bias the estimation of mobility due to the overestimation of earnings persistency. Moreover, besides the employment status, there are other factors determining panel attrition. All in all, this exercise provides is an interesting check of the impact of differential attrition on the study of earnings mobility as equalizer of longer term differentials using the Shorrock and the Fields index.

\subsection{Literature review}

The concept of mobility as an equalizer of longer term income is an old one, complementing mobility-as-time-independence, positional movement, share movement, non-directional income movement, and directional income movement. (Fields, 2008) The number of comparative studies on earnings mobility as a source of equalization of longer term income is limited because of the lack of sufficiently long comparable panel cross-country data. To investigate the link between longitudinal earnings mobility and the reduction in long-term earnings inequality most studies used the Shorrocks index (Shorrocks, 1978). One of the main critiques regarding this index is that it treats equalizing and disequalizing changes in essentially identical fashion (Benabou and Ok, 2001; Fields, 2008).

Most of the existing studies focus on the comparison between the US and a small number of European countries. OECD $(1996,1997)$ presented a variety of comparisons of earnings inequality and mobility across the OECD countries over the period 1986-1991. They included also the Shorrocks mobility index and concluded that the results vary depending on the inequality index used for computing the Shorrocks index. This sensitivity was investigated more in depth by Jarvis and Jenkins (1998), which concluded that measures focusing on the tails of the distribution (e.g. Theil) shows greater mobility compared with the situation when more weight is given to the middle of the distribution (e.g. Gini).

Burkhauser and Poupore (1997), using GSOEP between 1983 and 1988, compared long-term inequality in Germany and the US. To evaluate the extent to which mobility reduces longer term differentials, they used the Shorrocks(1978) index based on the Theil index. Their findings identified a higher mobility in Germany than in the US for all time periods.

Aaberge, Bjorklund, Jantti, Palme, Pedersen, Smith, and Wannemo (2002) compared income (family income, disposable income and earnings) inequality and mobility in the Scandinavian countries and the United Stated during 1980-1990. They used the Shorrocks (1978) index based on the Gini index and found low mobility levels for all countries, with higher values for the US only for long 
accounting periods. Despite the higher mobility, independent of the accounting period, they found that earnings inequality is higher in the US than in the Scandinavian countries.

Hofer and Weber (2002) looked at mobility in Austria between 1986-1991 using among other indices also the Shorrocks index calculated using the Gini, the Theil and Mean log deviation index. They compared their results with the OECD (1996, 1997). In Austria they found a weak equalization effect of long-term mobility over the selected period compared with Denmark, France, Germany, Italy, the UK and the US. Moreover they underlined that "except the Austrian case, country rankings in this panel depends on the chosen inequality index and there emerges no clear picture which countries are the most mobile or the most immobile".

Gregg and Vittori (2008), starting from the approach proposed by Schluter and Trede (2003) developed a continuous alternative measure of "Shorrocks" mobility which first, allows to identify mobility over different parts of the earnings distribution and second, to distinguish between mobility that tends to reduce or increase the level of permanent or long-term inequality. They used the ECHP data on annual earnings for four countries - Denmark, Germany, Spain and the UK. Mobility was found to equalize long-term differentials. Denmark had the highest mobility, steaming mainly from the middle and top parts of the distribution, whereas the lowest was found in Germany.

Most recently, Fields (2008) developed a new index to explore mobility as an equalizer of longer term income, which unlike Shorrocks index, is able to identify whether longitudinal mobility is equalizing or disequalizing long-term earnings differentials. The results for the United States and France showed that the new index picks up different trends compared with the Shorrocks index. Income mobility was found to equalize longer-term incomes among U.S. men in the 1970s but not in the 1980s and 1990s. In France, income mobility has been equalizing since the late 1960s, with a higher degree of equalization in more recent years.

At the EU level, no study explored in a comparative setting earnings mobility as an equalizer of longer-term inequality using a panel longer than six years. Moreover, except for the short exercise in Fields (2008), The Fields index, has not been applied in any other European country or in a comparative setting at the EU level. We argue that the Fields and the Shorrocks indices provide complementary pieces of information regarding the link between longitudinal mobility and long-term earnings differentials. By exploiting the 8 years of panel in ECHP, and coupling the information provided by the two indices, our paper aims to fill part of that gap and make a substantive contribution to the literature on cross-national comparisons of longitudinal mobility at the EU level. Moreover, the balanced and unbalanced 
approach allows identifying the impact of differential attrition on measuring longterm mobility, and which of the two indices is the most sensitive.

\subsection{Methodology}

It is recognized in the literature that a snapshot of the distribution exaggerates the true degree of inequality to a degree that depends on the mobility of earnings. (Atkinson et al., 1992) The core question that arises is whether low pay is persistent, meaning that the same people are stuck at the bottom of the income distribution, or there is a transitory component, meaning that people change their position in the income distribution over time. To answer this question, we focus on a balanced panel for all countries over the sample period, meaning men with positive earnings over the entire period. This will be referred to as the "balanced" approach.

To check for the impact of differentials attrition, we consider also unbalanced panels across different sub-periods. For example, the mobility index for 1994-1998 is based on individuals with positive earnings in each year between 1994 and 1998, whereas the mobility index for 1994-2001 uses the balanced sample between 1994 and 2001. This will be referred to as the "unbalanced" approach.

\subsubsection{Shorrocks}

As noted also by Pen (1971), for a thorough understanding of the personal income distribution it is necessary to have an insight into the vertical mobility. One way to create a bridge between vertical mobility and personal income distribution is to measure the extent of mobility in terms of the proportion to which it reduces lifetime earnings inequality compared with annual inequality (Atkinson et al., 1992). For this purpose, Shorrocks (1978) proposes the following indicator ${ }^{16}$ :

$$
0 \leq R_{T}=\frac{I\left(\sum_{t=1}^{T} y_{i t}\right)}{\sum_{t=1}^{T} w_{t} I\left(y_{i t}\right)} \leq 1
$$

where $y_{i t}$ represents individual annual earnings, $t$ time $t=1, \ldots, T, I$ is an inequality index that is a strictly convex function of incomes relative to the mean ${ }^{17}$,

\footnotetext{
${ }^{16}$ The formula applies for a cohort of constant size.

17 This is the condition that must be fulfilled by the inequality index for the inequality (Atkinson et al., 1992) to hold.
} 
$I\left(\sum_{t=1}^{T} y_{i t}\right)$ the inequality of lifetime income, $w_{t}$ the share of earnings in year $t$ of the total earnings over a $\mathrm{T}$ year period and $I\left(y_{i t}\right)$ the cross-sectional annual inequality. $R_{T}$ ranges from 0 (perfect mobility) to 1 (complete rigidity). ${ }^{18}$ There is complete income rigidity if lifetime inequality is equal to the weighted sum of individual period income inequalities, meaning that everybody holds their position in the income distribution from period to period. Perfect mobility is achieved when everybody has the same average lifetime income, meaning that there is a complete reversal of positions in the income distribution. The degree of mobility can be computed as follows:

$$
M_{T}=1-R_{T}
$$

Under Shorrocks (1978)'s definition, mobility is regarded as the degree to which equalisation occurs as the observation period is extended. This definition is very important from an economic point of view because it provides a way of identifying those countries that exhibit a high annual income inequality, but fares better when a longer period of time is considered. If a country $\mathrm{A}$ has both greater annual inequality and greater rigidity than country $B$, it will be more unequal than $B$ whatever period is chosen for comparison. But if A exhibits more mobility, this may be sufficient to change the rankings when longer periods are considered (Shorrocks, 1978).

Because our data covers only eight years, the full equalising effect of mobility over the working lifetime is not captured. Some conclusions, however, can be drawn based on a horizon of 8 years.

The measures of earnings mobility are closely related to the importance of the permanent and transitory components of earnings. Following the terminology introduced by Friedman and Kuznets (1954), individual earnings are composed of a permanent and a transitory component, assumed to be independent of each other. The permanent component of earnings reflects personal characteristics, education, training and other persistent elements. The transitory component captures the chance and other factors influencing earnings in a particular period and is expected to average out over time. Following the structure of individual earnings, overall inequality at any point in time is composed from inequality in the transitory component and inequality in the permanent component of earnings. The evolution of the overall earnings inequality is determined by the cumulative changes in the two inequality components.

${ }^{18}$ To compute this index only individuals that are present in all years are considered. 
An increase in the cross-sectional earnings inequality could reflect a rise in the permanent and/or transitory component of earnings inequality. The rise in the inequality in the permanent component of earnings may be consistent with increasing returns to education, on-the-job training and other persistent abilities that are among the main determinants of the permanent component of earnings (Mincer, 1957, 1958, 1962, 1974; Hause, 1980). The increase in the inequality in the transitory component of earnings may be attributed to the weakening of the labour market institutions (e.g. unions, government wage regulation, internal labour markets) which increases earnings exposion to shocks. Overall, the increase in the return to persistent skills is expected to have a much larger impact on long-run earnings inequality than an increase in the transitory component of earnings (Katz and Autor, 1999).

In order to make inferences concerning the sources of mobility, meaning whether income changes were determined by large variations in transitory earnings and small variations in permanent earnings or vice-versa, we construct the stability profile or the rigidity curve, which plots the rigidity measure $R_{T}$ against different time horizons. A mobile earnings structure is represented by a stability profile that declines with time away from the immobility horizontal line, where $R_{T}=1$. If incomes changes are purely due to transitory effects, relative incomes will rapidly approach their permanent values and there will then be no substantial further equalisation. The stability profile will therefore tend to become horizontal after the first few years. If income changes are due to more mobility in permanent incomes, the stability profile will continue to decline as the aggregation period is extended (Shorrocks, 1978).

\subsubsection{Fields}

To recall, Shorrocks (1978) conceptualized income mobility as the opposite of income rigidity. As highlighted by Benabou and Ok (2001) and Fields (2008), the main limitation of this measure was that it does not quantify the direction and the extent of the difference between inequality of longer-term income and inequality of base year income, meaning that it treats equalizing and disequalizing changes in essentially identical fashion. Fields (2008) explained with the following example, which uses Gini as the inequality index. The mobility index, $M_{T}$, for a "Gatesgains" mobility process $(100,200,20000) \rightarrow(100,200,30000)$ equals $4.99 \cdot 10^{-5}, 5.91$ $10^{-5}$ for a "Gates-loses" mobility process and 0 for "no change". The ranking in mobility is "Gates-loses", "Gates-gains" and "no change", but neither the sign nor 
the relative magnitude of $M_{T}$ conveys any information whether mobility is equalizing or disequalizing in a lifetime perspective.

Fields (2008) developed a mobility measure which circumvents this limitations, capturing mobility as an equalizer/disequalizer of longer-tern incomes:

$$
\varepsilon=1-\frac{I(a)}{I(y l)}
$$

where $a$ a is the vector of average incomes, $y l$ is the vector of base-year incomes, and $\mathrm{I}($.$) is a Lorentz-consistent inequality measure such as the Gini coefficient or$ the Theil index. A positive/negative value of $\mathcal{E}$ indicates that average incomes, $a$, are more/less equally distributed than the base-year incomes, $y l$, and a 0 value that $a$ and $y l$ are distributed equally unequally.

Applying this measure to the hypothetical situations introduced above, results in a value of $-3.9 \cdot 10^{-3}$ for the "Gates-gains" and of $+6.6 \cdot 10^{-3}$ for the "Gates-loses", suggesting that the "Gates-loses" process is equalizing and "Gates-gains" is disequalizing (Fields, 2008). For a complete description of the properties of the Fields index please refer to Fields (2008).

By applying these two indices, we first assess the degree of long-term earnings mobility across 14 EU countries, and second we establish whether this mobility is equalizing or disequalizing long-term earnings differentials. We chose to work with the mobility index based on the Theil index, but the other indices can be provided upon request from the authors.

\subsection{Data ${ }^{19}$}

The study uses the European Community Household Panel (ECHP) $)^{20}$ over the period 1994-2001 for 14 EU countries. Not all countries are present in all waves. Luxembourg and Austria are observed over a period of 7 waves (1995-2001) and Finland over a period of 6 waves (1996-2001). Following the tradition of previous studies, the analysis focuses only on men.

A special problem with panel data is that of attrition over time, as individuals are lost at successive dates causing the panel to decline in size and raising the problem

\footnotetext{
${ }^{19}$ The information in section 3.4 has already been discussed in section 2.4.

${ }^{20}$ The European Community Household Panel provided by Eurostat via the Department of Applied Economics at the Université Libre de Bruxelles.
} 
of representativeness. Several papers analysed the extent and the determinants of panel attrition in ECHP. A. Behr, E. Bellgardt, U. Rendtel (2005) found that the extent and the determinants of panel attrition vary between countries and across waves within one country, but these differences do not bias the analysis of income or the ranking of the national results. L.Ayala, C. Navrro, M.Sastre (2006) assessed the effects of panel attrition on income mobility comparisons for some EU countries from ECHP. The results show that ECHP attrition is characterized by a certain degree of selectivity, but only affecting some variables and some countries. Moreover, the income mobility indicators show certain sensitivity to the weighting system.

In this paper, we applied the weighting system recommended by Eurostat, namely using the "base weights" of the last wave observed for each individual, bounded between 0.25 and 10. The dataset is scaled up to a multiplicative constant ${ }^{21}$ of the base weights of the last year observed for each individual.

For this study we use real net ${ }^{22}$ hourly wage adjusted for CPI of male workers aged 20 to 57, born between 1940 and 1981. Only observations with hourly wage lower than 50 Euros and higher than 1 Euro were considered in the analysis. The resulting sample for each country is an unbalanced panel. Details on the number of observations, inflows and outflows of the sample by cohort over time for each country are provided in Table 3-A-1 (Annex).

\subsection{Changes in earnings inequality}

Before exploring earnings mobility at the EU level, as a first step we describe the evolution of the earnings distribution both over time and across different time horizons.

\subsubsection{Changes in the cross-section earnings distribution over time ${ }^{23}$}

This section presents the changing shape of the cross-sectional distribution of earnings for men over time. Figure 3-A-1 illustrates the frequency density estimates for the first wave ${ }^{24}, 1998$ and 2001 earnings distributions, and Table 3.1

\footnotetext{
${ }^{21}$ The multiplicative constant equals $\mathrm{p}^{*}$ (Population above 16/Sample Population). The ratio $\mathrm{p}$ varies across countries so that sensible samples are obtained. It ranges between 0.001-0.01.

22 Except for France, where wage is in gross amounts

${ }^{23}$ The information in section 3.5.1 has already been discussed in section 2.5.

${ }^{24}$ For Luxembourg and Austria, the first wave was recorded in 1995, whereas for Finland in 1996.
} 
illustrates the evolution of the other moments of the earnings distribution over time. The evolution of mean net hourly wage shows that men in most countries got richer over time, except Austria. Net hourly earnings became more dispersed in most countries, except Austria, France and Denmark. 
Table 3.1. Sample Statistics of Hourly Earnings

\begin{tabular}{|c|c|c|c|c|c|c|c|c|c|}
\hline & Year & 1994 & 1995 & 1996 & 1997 & 1998 & 1999 & 2000 & 2001 \\
\hline \multirow[t]{3}{*}{ Germany } & Mean & 9.43 & 9.49 & 9.61 & 9.52 & 9.57 & 9.48 & 9.60 & 9.72 \\
\hline & Median & 8.65 & 8.68 & 8.78 & 8.84 & 8.70 & 8.65 & 8.75 & 8.82 \\
\hline & Standard Deviation & 4.00 & 4.17 & 4.09 & 4.01 & 4.39 & 4.32 & 4.39 & 4.37 \\
\hline \multirow[t]{3}{*}{ Denmark } & Mean & 10.89 & 11.40 & 11.58 & 11.61 & 11.86 & 11.85 & 12.02 & 12.08 \\
\hline & Median & 10.36 & 10.76 & 10.96 & 11.14 & 11.46 & 11.36 & 11.77 & 11.50 \\
\hline & Standard Deviation & 3.23 & 3.31 & 3.52 & 3.54 & 3.13 & 3.31 & 3.43 & 3.20 \\
\hline \multirow[t]{3}{*}{ Netherlands } & Mean & 9.69 & 9.56 & 9.59 & 9.70 & 10.02 & 9.88 & 10.04 & 9.91 \\
\hline & Median & 9.11 & 9.07 & 9.01 & 9.10 & 9.27 & 9.18 & 9.32 & 9.23 \\
\hline & Standard Deviation & 3.39 & 3.37 & 3.55 & 3.56 & 3.64 & 3.40 & 3.48 & 3.95 \\
\hline \multirow[t]{3}{*}{ Belgium } & Mean & 8.48 & 8.82 & 8.71 & 8.75 & 8.81 & 8.83 & 8.92 & 9.10 \\
\hline & Median & 7.86 & 8.17 & 7.99 & 8.09 & 8.08 & 8.34 & 8.25 & 8.30 \\
\hline & Standard Deviation & 3.17 & 3.08 & 3.02 & 3.09 & 2.97 & 2.94 & 3.00 & 3.21 \\
\hline \multirow[t]{3}{*}{ Luxembourg } & Mean & & 16.18 & 15.81 & 16.73 & 17.39 & 17.15 & 17.22 & 17.10 \\
\hline & Median & & 14.90 & 14.52 & 15.31 & 15.72 & 15.60 & 15.65 & 15.29 \\
\hline & Standard Deviation & & 7.50 & 7.19 & 7.77 & 8.21 & 8.38 & 8.37 & 8.22 \\
\hline \multirow[t]{3}{*}{ France $^{25}$} & Mean & 10.23 & 9.92 & 9.87 & 10.05 & 10.33 & 10.60 & 10.55 & 10.87 \\
\hline & Median & 8.56 & 8.57 & 8.53 & 8.53 & 8.84 & 9.04 & 9.06 & 9.48 \\
\hline & Standard Deviation & 5.82 & 5.33 & 5.17 & 5.65 & 5.62 & 5.78 & 5.51 & 5.72 \\
\hline \multirow[t]{3}{*}{ UK } & Mean & 8.16 & 8.11 & 8.22 & 8.34 & 8.68 & 9.01 & 9.21 & 9.68 \\
\hline & Median & 7.30 & 7.29 & 7.51 & 7.52 & 7.67 & 8.00 & 8.22 & 8.68 \\
\hline & Standard Deviation & 3.99 & 3.95 & 3.80 & 3.79 & 4.01 & 4.13 & 4.24 & 4.49 \\
\hline \multirow[t]{3}{*}{ Ireland } & Mean & 9.30 & 9.54 & 9.76 & 10.02 & 10.43 & 10.84 & 11.69 & 12.44 \\
\hline & Median & 8.06 & 8.44 & 8.84 & 8.86 & 9.33 & 9.73 & 10.25 & 11.36 \\
\hline & Standard Deviation & 5.14 & 4.99 & 4.85 & 4.98 & 5.17 & 5.02 & 5.24 & 5.15 \\
\hline \multirow[t]{3}{*}{ Italy } & Mean & 7.16 & 6.91 & 6.96 & 7.05 & 7.29 & 7.37 & 7.28 & 7.32 \\
\hline & Median & 6.65 & 6.32 & 6.43 & 6.48 & 6.69 & 6.76 & 6.59 & 6.67 \\
\hline & Standard Deviation & 2.77 & 2.59 & 2.67 & 2.68 & 3.01 & 3.00 & 2.99 & 3.04 \\
\hline \multirow[t]{3}{*}{ Greece } & Mean & 4.95 & 5.03 & 5.23 & 5.59 & 5.63 & 5.85 & 5.70 & 5.77 \\
\hline & Median & 4.49 & 4.41 & 4.53 & 4.90 & 4.91 & 4.99 & 4.89 & 4.99 \\
\hline & Standard Deviation & 2.33 & 2.42 & 2.43 & 2.91 & 2.87 & 3.14 & 3.07 & 3.21 \\
\hline \multirow[t]{3}{*}{ Spain } & Mean & 6.83 & 6.95 & 7.09 & 6.89 & 7.18 & 7.37 & 7.45 & 7.42 \\
\hline & Median & 5.86 & 5.82 & 5.92 & 5.72 & 6.04 & 6.15 & 6.29 & 6.33 \\
\hline & Standard Deviation & 3.81 & 3.86 & 4.00 & 3.92 & 4.06 & 4.15 & 4.07 & 3.87 \\
\hline \multirow[t]{3}{*}{ Portugal } & Mean & 3.70 & 3.74 & 3.84 & 3.92 & 3.99 & 4.08 & 4.31 & 4.46 \\
\hline & Median & 2.92 & 2.82 & 2.98 & 3.03 & 3.05 & 3.08 & 3.29 & 3.34 \\
\hline & Standard Deviation & 2.34 & 2.45 & 2.54 & 2.65 & 2.81 & 2.82 & 3.16 & 3.33 \\
\hline \multirow[t]{3}{*}{ Austria } & Mean & & 9.08 & 8.33 & 8.37 & 8.49 & 8.55 & 8.55 & 8.54 \\
\hline & Median & & 8.51 & 7.64 & 7.63 & 7.84 & 7.82 & 7.86 & 7.93 \\
\hline & Standard Deviation & & 3.52 & 3.00 & 3.07 & 2.95 & 2.89 & 2.84 & 2.82 \\
\hline \multirow[t]{3}{*}{ Finland } & Mean & & & 7.89 & 8.01 & 8.41 & 8.45 & 8.66 & 8.86 \\
\hline & Median & & & 7.48 & 7.57 & 7.85 & 7.90 & 8.18 & 7.97 \\
\hline & Standard Deviation & & & 2.70 & 2.77 & 2.92 & 2.91 & 2.93 & 3.29 \\
\hline
\end{tabular}

${ }^{25}$ Gross Amounts 
Plotting the percentage change in mean hourly earnings between the beginning of the sample period and 2001 at each point of the distribution for each country (Figure 3.1), revealed that, in most countries, the relationship between the quantile ${ }^{26}$ rank and the growth in real earnings is negative and nearly monotonic: the higher the rank, the smaller the increase in earnings. This shows that in most countries, over time, the situation of the low paid people improved to a larger extent than for the better off ones. In Austria, people at the top of the distribution experienced a decrease in mean hourly wage over time, which might explain the decrease in the overall mean.

Netherlands, Germany, Greece and Finland diverge in their pattern from the other EU countries experiencing a higher relative increase in earnings the higher the rank. Netherlands is the only country where men at the bottom of the income distribution recorded a deterioration of their work pay. For these countries, the increase in the overall mean might be the result of an increase in the earnings position of the better off individuals, not the low paid ones.
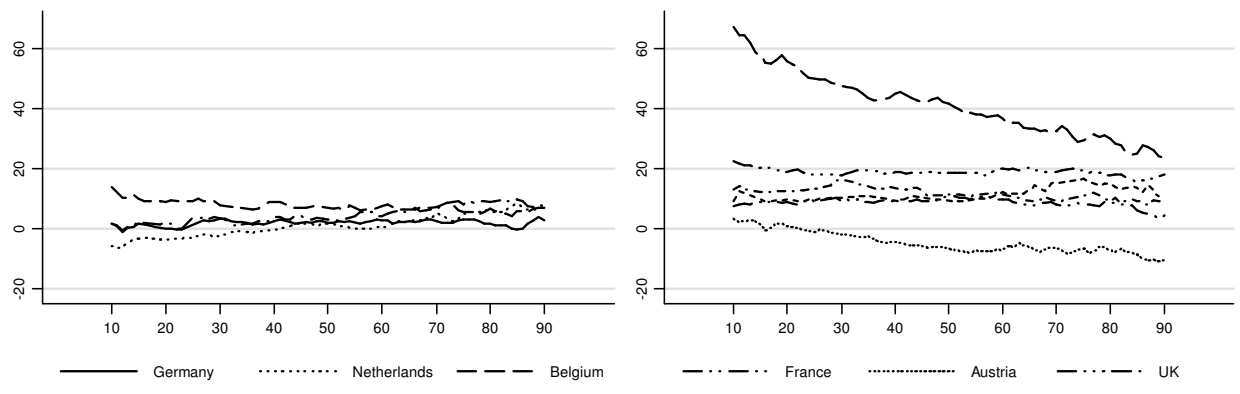

$-\cdots-\cdots$ France

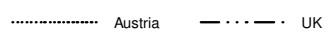

$-\cdot-$ Luxembourg
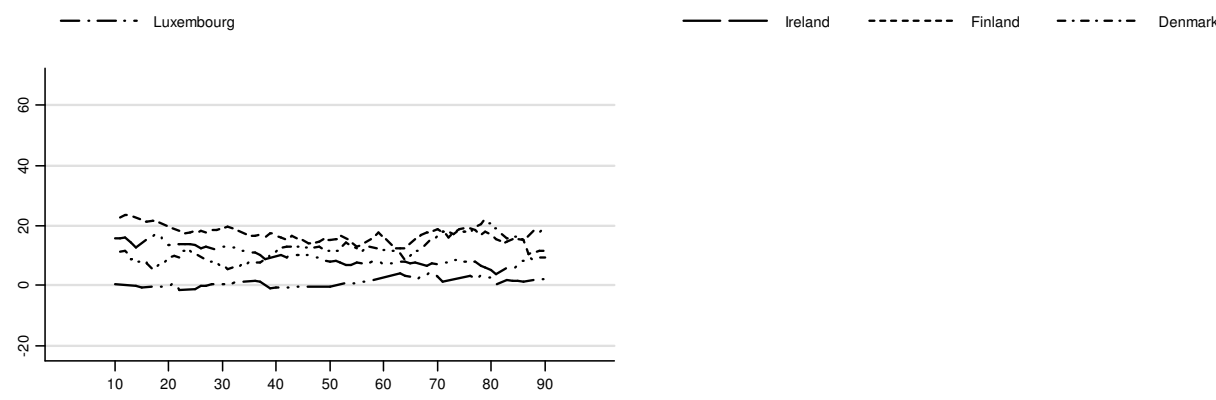

$\cdots-$ Italy
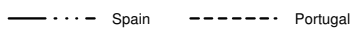

-....... Greece

Figure 3.1 Percentage Change in Mean Hourly Earnings by Percentiles Over The Sample Period

Note: Vertical axis - the percentage change in mean hourly earnings; Horizontal axis - percentiles. 
To complete the descriptive picture of the cross-sectional earnings distribution over time, we provide also inequality measures. Inequality indices differ with respect to their sensitivity to income differences in different parts of the distribution. Therefore they illustrate different sides of the earnings distribution. The year-to-year changes in earnings inequality are captured by computing the ratio between mean earnings in the $9^{\text {th }}$ decile and the $1^{\text {st }}$ decile (Figure 3.2), the Gini index, the GE indices - the Theil Index (GE(1)) -, and the Atkinson inequality index evaluated at an the aversion parameter equal to 1 (Table 3.2).27
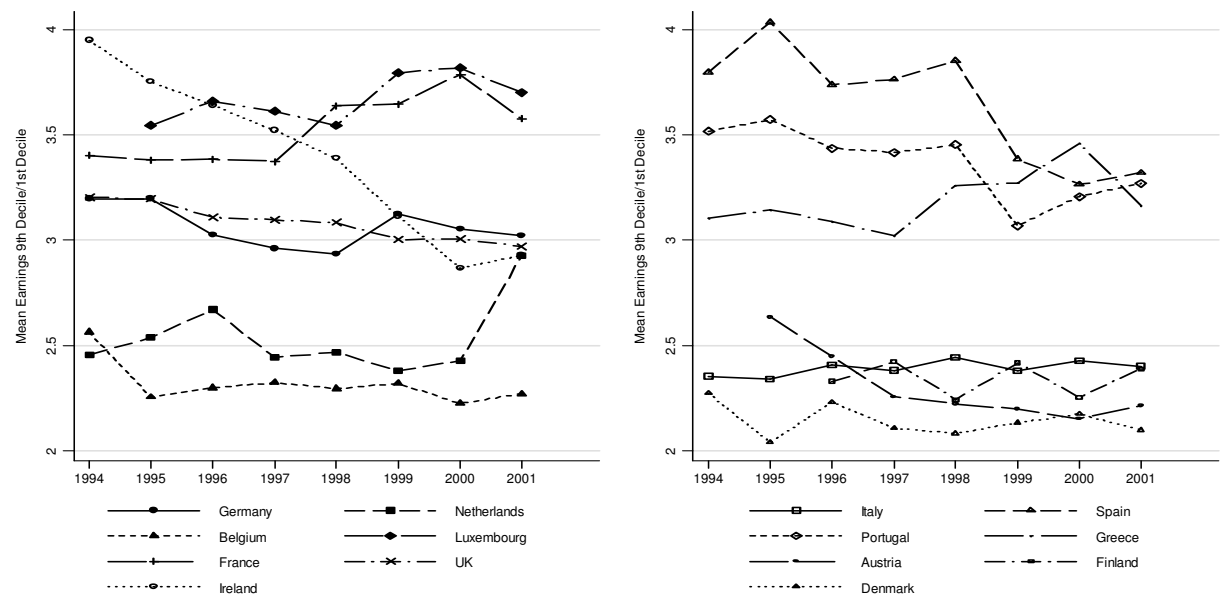

Figure 3.2 Ratio between Mean Earnings at the $9^{\text {th }}$ Decile and the $1^{\text {st }}$ Decile

The ratio between the mean earnings in the 9th decile and the 1st deciles focuses only on the two ends of the distribution. The Gini index is most sensitive to income differences in the middle of the distribution (more precisely, the mode). The GE with a negative parameter is sensitive to income differences at the bottom of the distribution and the sensitivity increases the more negative the parameter is. The GE with a positive parameter is sensitive to income differences at the top of the distribution and it becomes more sensitive the more positive the parameter is. For the Atkinson inequality indices, the more positive the "inequality aversion parameter" is, the more sensitive the index is to income differences at the bottom of the distribution.

\footnotetext{
${ }^{27}$ Besides these indices, several others were computed (GE(-1); GE(0), GE(2), Atkinson evaluated at different values of the aversion parameter) and can be provided upon request from the authors. They support the findings shown by the reported indices.
} 
Table 3.2. Earnings Inequality (Index ${ }^{*}$ 100)

\begin{tabular}{|c|c|c|c|c|c|c|c|c|c|}
\hline & & 1994 & 1995 & 1996 & 1997 & 1998 & 1999 & 2000 & 2001 \\
\hline \multirow{3}{*}{ Germany } & Gini & 22.15 & 22.34 & 22.04 & 21.89 & 22.58 & 22.81 & 22.75 & 22.54 \\
\hline & Theil & 8.22 & 8.61 & 8.23 & 8.06 & 8.85 & 8.96 & 8.92 & 8.72 \\
\hline & $\mathrm{A}(1)$ & 8.08 & 8.38 & 8.04 & 7.84 & 8.12 & 8.53 & 8.41 & 8.17 \\
\hline \multirow{3}{*}{ Denmark } & Gini & 15.76 & 15.26 & 15.52 & 15.21 & 14.24 & 14.68 & 14.94 & 14.05 \\
\hline & Theil & 4.22 & 3.92 & 4.23 & 4.15 & 3.37 & 3.73 & 3.83 & 3.35 \\
\hline & $\mathrm{A}(1)$ & 4.26 & 3.78 & 4.10 & 3.96 & 3.37 & 3.76 & 3.78 & 3.33 \\
\hline \multirow{3}{*}{ Netherlands } & Gini & 18.07 & 18.37 & 19.19 & 18.80 & 18.93 & 17.92 & 18.18 & 20.67 \\
\hline & Theil & 5.63 & 5.76 & 6.32 & 6.07 & 5.96 & 5.40 & 5.56 & 7.25 \\
\hline & $\mathrm{A}(1)$ & 5.56 & 5.77 & 6.33 & 5.90 & 5.65 & 5.18 & 5.44 & 7.08 \\
\hline \multirow{3}{*}{ Belgium } & Gini & 19.10 & 17.71 & 17.64 & 18.13 & 17.53 & 17.33 & 17.13 & 17.85 \\
\hline & Theil & 6.23 & 5.37 & 5.35 & 5.58 & 5.15 & 5.11 & 5.04 & 5.48 \\
\hline & $\mathrm{A}(1)$ & 5.92 & 4.95 & 5.04 & 5.24 & 4.85 & 4.92 & 4.69 & 5.14 \\
\hline \multirow{3}{*}{ Luxembourg } & Gini & & 25.23 & 24.74 & 25.41 & 25.62 & 26.58 & 26.50 & 26.32 \\
\hline & Theil & & 10.09 & 9.85 & 10.24 & 10.37 & 11.19 & 11.15 & 10.89 \\
\hline & $\mathrm{A}(1)$ & & 9.88 & 10.00 & 10.16 & 10.02 & 10.95 & 11.09 & 10.66 \\
\hline \multirow{3}{*}{ France } & Gini & 27.62 & 26.47 & 26.26 & 27.23 & 27.28 & 27.41 & 26.83 & 26.49 \\
\hline & Theil & 13.21 & 12.04 & 11.63 & 12.88 & 12.58 & 12.65 & 11.94 & 11.87 \\
\hline & $\mathrm{A}(1)$ & 11.64 & 10.88 & 10.58 & 11.41 & 11.54 & 11.59 & 11.17 & 10.98 \\
\hline \multirow{3}{*}{ UK } & Gini & 24.26 & 24.22 & 23.35 & 23.36 & 23.54 & 23.25 & 23.35 & 23.51 \\
\hline & Theil & 10.08 & 10.01 & 9.20 & 9.05 & 9.24 & 9.08 & 9.16 & 9.29 \\
\hline & $\mathrm{A}(1)$ & 9.25 & 9.19 & 8.57 & 8.46 & 8.55 & 8.32 & 8.46 & 8.51 \\
\hline \multirow{3}{*}{ Ireland } & Gini & 27.59 & 26.87 & 25.76 & 25.47 & 25.00 & 23.39 & 22.77 & 21.70 \\
\hline & Theil & 12.87 & 11.97 & 11.00 & 10.83 & 10.60 & 9.31 & 8.78 & 7.85 \\
\hline & $\mathrm{A}(1)$ & 11.84 & 11.21 & 10.50 & 10.14 & 9.85 & 8.66 & 8.15 & 7.64 \\
\hline \multirow{3}{*}{ Italy } & Gini & 19.16 & 18.47 & 19.02 & 18.93 & 19.85 & 19.72 & 19.78 & 19.90 \\
\hline & Theil & 6.51 & 6.08 & 6.42 & 6.29 & 7.13 & 7.01 & 7.08 & 7.19 \\
\hline & $\mathrm{A}(1)$ & 5.99 & 5.58 & 5.91 & 5.78 & 6.41 & 6.30 & 6.33 & 6.39 \\
\hline \multirow{3}{*}{ Greece } & Gini & 23.62 & 24.37 & 23.80 & 25.55 & 25.66 & 26.98 & 26.51 & 26.37 \\
\hline & Theil & 9.51 & 9.97 & 9.44 & 11.23 & 11.09 & 12.20 & 11.93 & 12.17 \\
\hline & $\mathrm{A}(1)$ & 8.77 & 9.13 & 8.70 & 9.97 & 9.99 & 10.97 & 10.68 & 10.55 \\
\hline \multirow{3}{*}{ Spain } & Gini & 27.87 & 28.27 & 28.19 & 28.71 & 28.37 & 26.99 & 26.36 & 26.07 \\
\hline & Theil & 13.08 & 13.22 & 13.36 & 13.67 & 13.47 & 12.69 & 12.09 & 11.47 \\
\hline & $\mathrm{A}(1)$ & 11.84 & 12.13 & 11.94 & 12.33 & 12.17 & 11.07 & 10.60 & 10.28 \\
\hline \multirow{3}{*}{ Portugal } & Gini & 30.05 & 31.14 & 30.66 & 30.85 & 31.13 & 30.11 & 31.32 & 31.72 \\
\hline & Theil & 15.79 & 16.93 & 16.76 & 17.27 & 18.01 & 17.21 & 18.86 & 19.27 \\
\hline & $\mathrm{A}(1)$ & 13.23 & 14.16 & 13.80 & 14.05 & 14.37 & 13.55 & 14.60 & 14.92 \\
\hline \multirow{3}{*}{ Austria } & Gini & & 19.49 & 18.34 & 18.34 & 17.39 & 17.07 & 16.72 & 16.85 \\
\hline & Theil & & 6.67 & 5.84 & 5.90 & 5.27 & 5.10 & 4.93 & 4.97 \\
\hline & $\mathrm{A}(1)$ & & 6.44 & 5.62 & 5.52 & 4.87 & 4.80 & 4.67 & 4.82 \\
\hline \multirow{3}{*}{ Finland } & Gini & & & 17.32 & 17.80 & 17.30 & 17.81 & 17.10 & 18.50 \\
\hline & Theil & & & 5.22 & 5.46 & 5.23 & 5.38 & 5.08 & 5.98 \\
\hline & $\mathrm{A}(1)$ & & & 4.94 & 5.29 & 4.83 & 5.19 & 4.76 & 5.53 \\
\hline
\end{tabular}

The level and pattern of inequality over time as measured by the ratio between the mean earnings in the 9th decile and the 1st decile differs to a large extent between the EU14 countries. Two clusters can be identified. The first one is comprised of Netherlands, Begium, Italy, Finland, Austria and Denmark and is characterized by a small relative distance between the bottom and top of the distribution. The other 
cluster identifies countries with a higher level of inequality, with ratios between 2.75 and 4 .

In 1994, based on the Gini index, Portugal is the most unequal, followed by Spain, France, Ireland, UK, Greece, Germany, Italy, Belgium, Netherlands and Denmark. In general, the other two indices confirm this ranking. However, using the Theil index, France appears to be more unequal than Spain, whereas using the Atkinson index, Ireland appears to be more unequal than France and as equal as Spain.

In 2001, based on the Gini index, Portugal is still the most unequal, followed by France, Greece, Luxembourg, Spain, UK, Germany, Ireland, Netherlands, Italy, Finland, Belgium, Austria and Denmark. In general, the other two indices confirm this ranking. Based on Theil, however, Greece is more unequal than France, and Spain than Luxembourg. Based on Atkinson, Luxembourg is more unequal than Greece.

For most countries, all indices show a consistent story regarding the evolution of inequality over the sample period, except for Germany, France and Portugal, where the evolution of the Gini, Theil and Atkinson index is opposite to the one observed for the D9/D1. Based on Gini, Theil and Atkinson, Netherlands, Greece, Finland, Portugal, Luxembourg, Italy and Germany recorded an increase in yearly inequality, and the rest a decrease. The trends for Denmark, UK, Spain and Germany are consistent with Gregg and Vittori (2008).

The relative evolution over the sample period is captured in Figure 3.3, which illustrates for each country, the change in inequality as measured by the Gini, Theil, Atkinson and D9/D1 index. Based on Gini, the highest increase in inequality was recorded by Netherlands (around 15\%), followed by Greece, Finland, Portugal, Luxembourg, Italy and Germany. The highest decrease was recorded in Ireland (around 20\%), followed by Austria, Denmark, Belgium, Spain, France and UK. Based on the Theil index, Portugal records a higher increase than Finland, Italy a higher increase than Luxembourg and Spain a higher decrease than Belgium. Based on Atkinson index, Portugal records a higher increase than Finland, and UK a higher decrease than France.

For Netherlands, Finland and Greece the increase in the distance between the top and bottom of the distribution and in the overall level of inequality can be explained by the improved earnings position of the better off individuals. Hence in these countries, the economic growth benefitted the high income people and led to an increase in earnings inequality. 


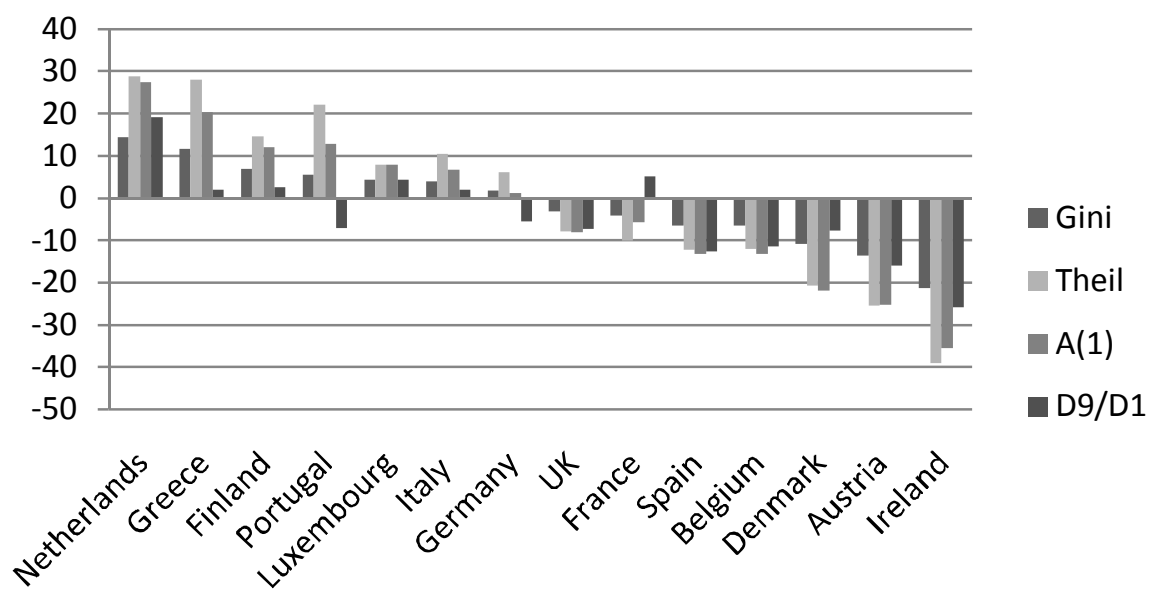

Figure 3.3.Relative Change in Inequality over Time - Gini, Theil, Atkinson(1), D9/D128

Luxembourg and Italy recorded an increase in inequality based on all indices, but the situation at the bottom improved to a larger extent than for the top. Thus the increase in inequality might be the result of other forces affecting the distribution, such as mobility in the bottom and top deciles.

For France, the relative distance between the top and the bottom 10\% appears to increase over time, in spite of a higher relative increase in mean earnings at the bottom of the distribution compared with the top. This discrepancy could be explained by the presence of earnings mobility in the bottom and top $10 \%$ of the earnings distribution. The improved conditions for people in the bottom of the distributions could explain the decrease in earnings inequality as displayed by the other three indices.

Germany records opposite trends from France: the situation of the better off individuals improved to a larger extent than for low paid ones, which explains the increase in the overall inequality as captured by the Gini, Theil and Atkinson indices. The evolution of the ratio between mean earnings at the top and the bottom deciles is opposite to what was expected: the decrease might suggest that there are other forces at work, such as mobility in the top part of the distribution, which determined mean earnings to decrease for this group.

Portugal records similar trends with Germany, except for the negative correlation between the rank in the earnings distribution and the growth in earnings. Thus, the fact that low paid individuals improved their earnings position to a higher extent

${ }^{28}$ Countries are ranked based on Gini index. 
relative to high paid individuals, lowering the distance between the bottom and the top deciles of the earnings distribution did not have the expected effect of lowering overall earnings inequality as measured by the Gini, Theil and Atkinson indices. Mobility is expected to be the factor counteracting all these movements.

For the rest of the countries, the increase in the overall mean, coupled with the higher relative increase in the earnings position of the low paid individuals compared with high earnings individuals can be an explanation for their decrease in inequality.

Besides the direction of evolution, also the magnitude of the change records differences among inequality indices. In general, the magnitude of the change is the highest for the index that is most sensitive to the income differences at the top of the distribution, followed by bottom and middle sensitive one, sign that most of the major changes happened at the top and the bottom of the distribution. There are a few exceptions. In UK, Spain, Belgium and Denmark the magnitude of the evolution is the highest for the bottom sensitive one, followed by the top and middle ones.

\subsubsection{Changes in the earnings distribution over the lifecycle: short versus long-term income inequality}

Finally we complete the earnings distribution picture with the evolution of earnings inequality when we extend the horizon over which inequality is measured. We consider both the balanced and the unbalanced approach. We report only the results for the Theil index. The results on the other inequality indices can be provided upon request from the authors.

Table 3.3 and Table 3.4 illustrate the evolution of inequality at different time horizons for all EU14 countries using a balanced and an unbalanced sample. Inequality measures based on the unbalanced approach are higher than those based on the balanced approach. This is not surprising given that people working over the entire sample are expected to have more stable jobs, and thus lower earnings differentials as opposed to the case when we include also those with instable jobs.

As expected, as time horizon increases, inequality reduces in all countries, except Portugal under the balanced approach. ${ }^{29}$ The rate of change in inequality as the time horizon increases differs across countries. As proof, Figure 3.4 (Panel A balanced approach and Panel B - unbalanced approach) shows the short and long-

${ }^{29}$ This trend is confirmed by all four inequality indices, for all countries. 
term earnings inequality (left) and their relative difference (right). Short-term refers to inequality in average earnings measured over two years, meaning in the first and the second wave, and long-term refers to inequality in average earnings measured over the sample period.
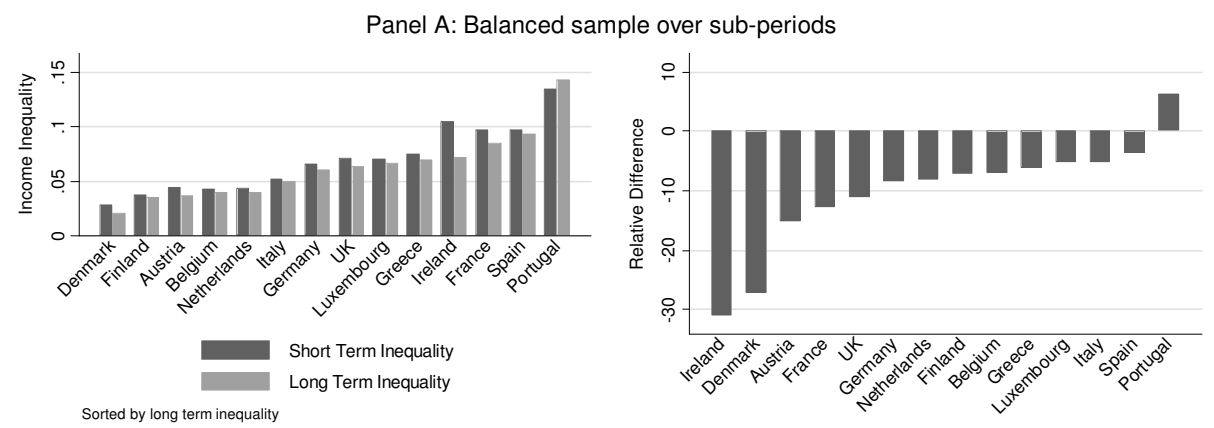

Panel B: Unbalanced sample over sub-periods
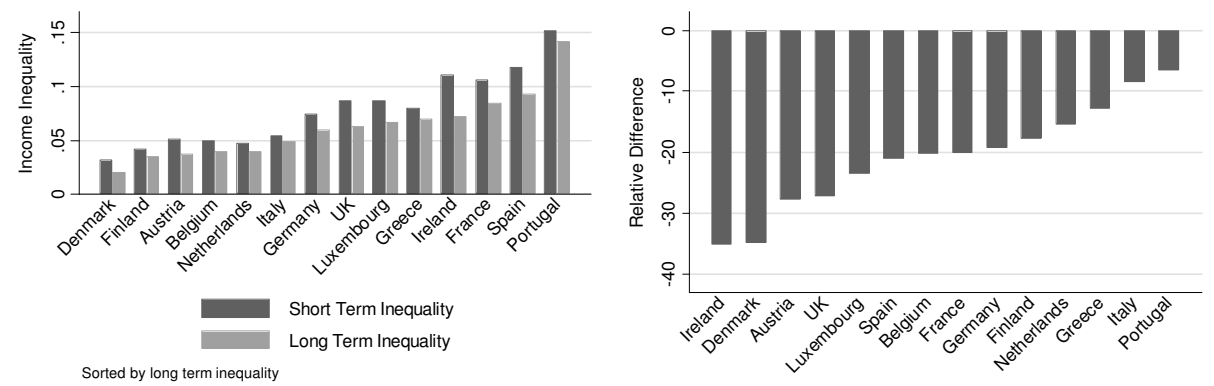

Figure 3.4. Short and Long Term Income Inequality and their Relative Difference

Note: 1 .Short-term refers to inequality in average earnings measured over two years, meaning in the first and the second wave, and long-term refers to inequality in average earnings measured over the sample period.

2. The right graph in each panel illustrates the relative difference between short and long-term inequality displayed in the left graphs. 


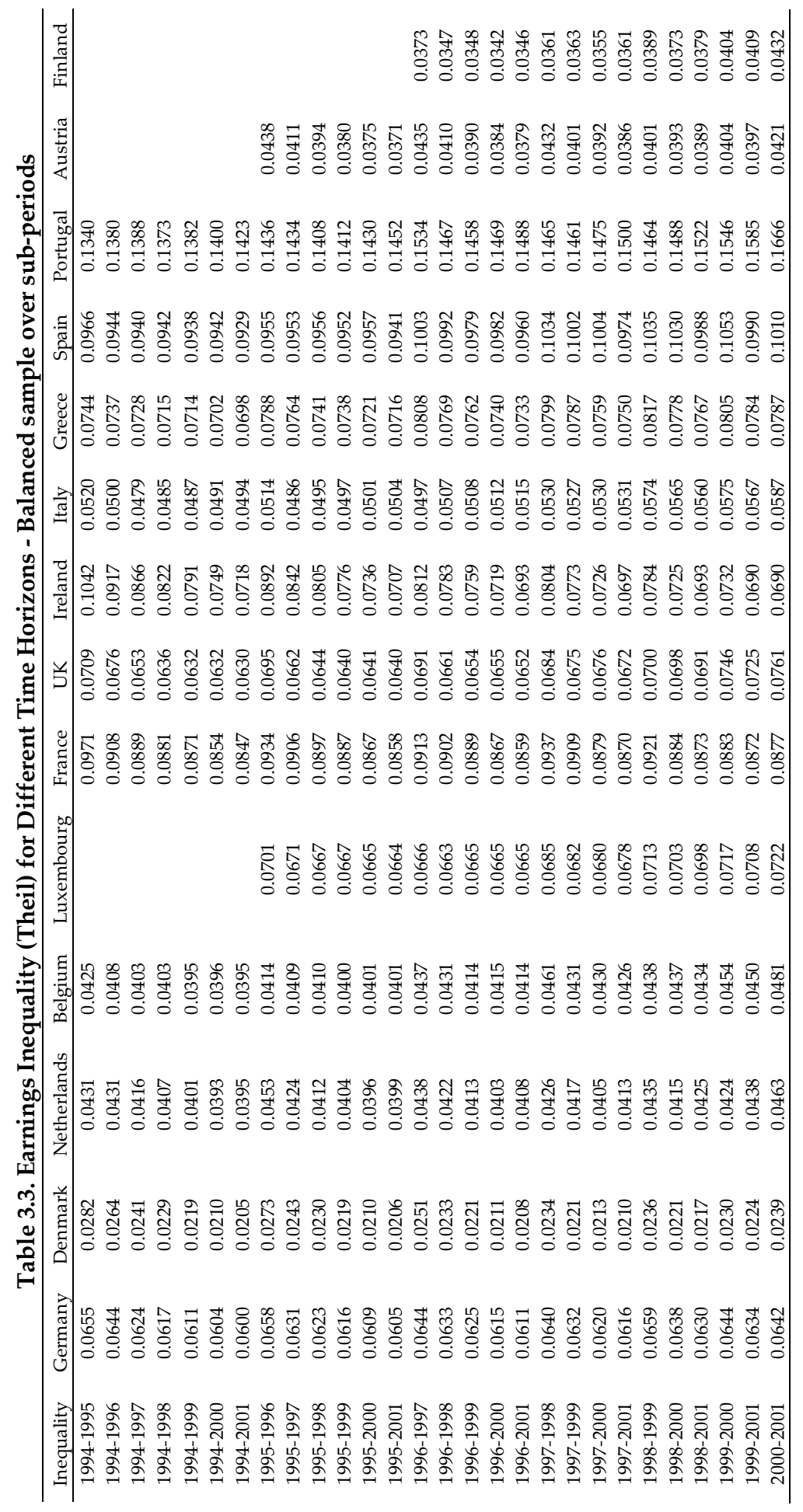

ำ 


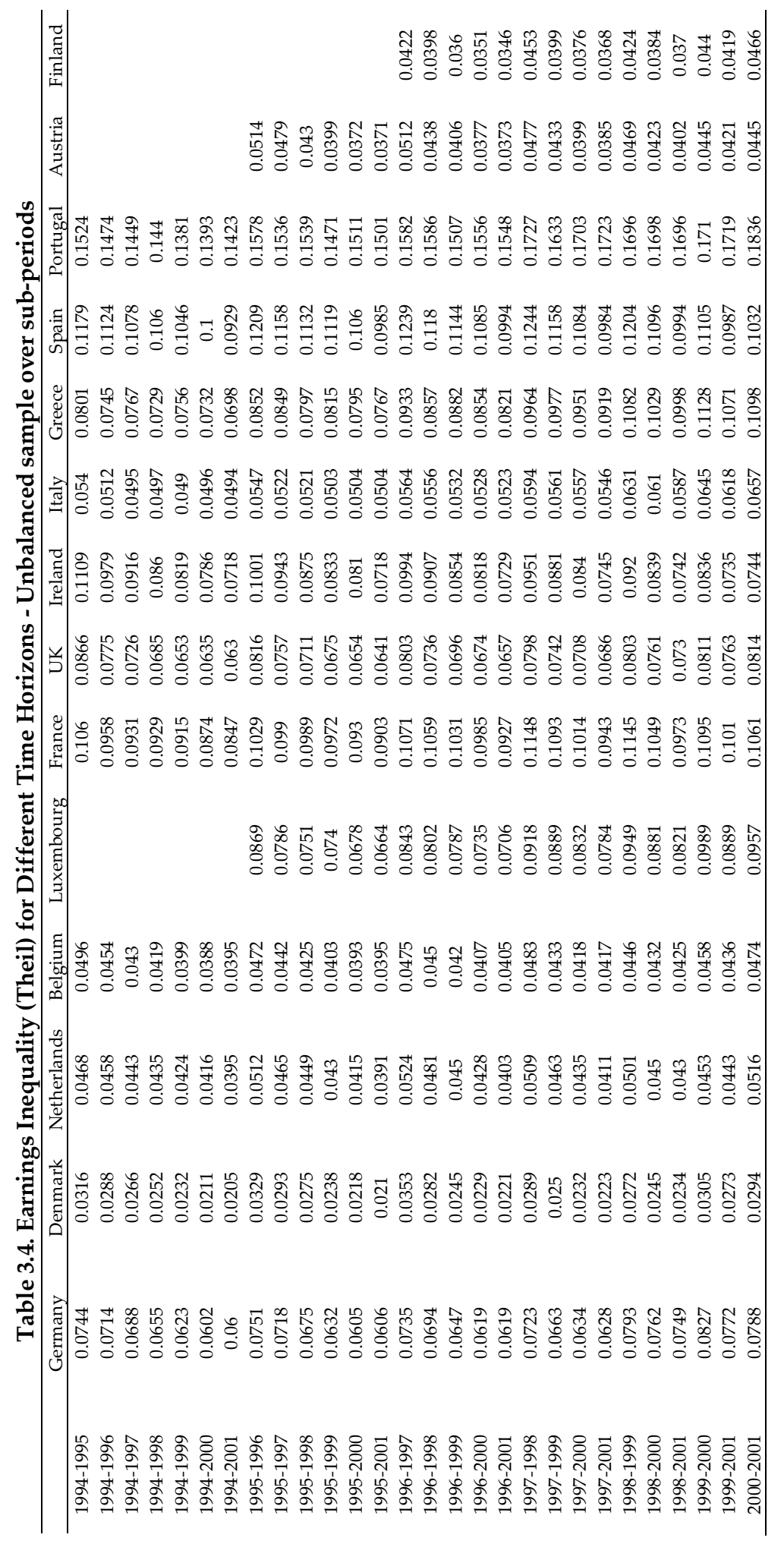

ஃ 
The ranking in inequality when the horizon is extended from one to two years is roughly maintained and this is consistent across both approaches. Short-term Denmark is the least unequal and Portugal the most unequal. A difference in shortterm ranking between the two approaches is observed for Greece, which is more unequal than Denmark, Finland, Austria, Belgium, Netherland, Italy, Germany, UK, and Luxembourg in the balanced approach and more unequal than the former 7 countries in the unbalanced approach. Similarly, Spain is less unequal than Ireland and Portugal under the balanced approach, and less unequal than Portugal under the unbalanced approach. Thus short-term differential attrition affects Greece and Spain the most. More shuffling occurs as the horizon is extended to the sample period.

The relative difference between short and long-term inequality displayed in Figure 3.4 (right) provide a first clue regarding the degree to which each country manages to reduce long-term earnings differentials compared with short-term ones. If inequality measured over the whole sample period can be considered as a proxy for lifetime earnings inequality or inequality in the permanent component of earnings, the rate of decrease with the time horizon can be interpreted as a reduction in the transitory earnings inequality over the lifetime or the fading off of the transitory component of earnings. Some countries manage to reduce inequality over the lifetime at a higher extent than others.

Based on the balanced approach (Figure 3.4 - Panel A) Ireland and Denmark display the highest reduction in long-term earnings inequality as the time horizon increases (over 30\%), followed by Austria (over 15\%), France and UK (over 10\%), and the rest below $9 \%$. Portugal is the only one recoding an increase in long-term inequality relative to short-term (over 6\%). Based on these trends, we expect Ireland and Denmark to have the highest equalizing mobility over the lifecycle, Italy and Spain the lowest, and Portugal to have a disequalizing mobility.

The relative difference between long-term and short-run inequality is lower in the balanced (Figure 3.4 - Panel A) compared with the unbalanced approach (Figure 3.4 - Panel B), showing that differential attrition affects all countries. The explanation is that looking only at people that work over the entire sample period might overestimate the degree of earnings persistency and underestimate the degree of earnings instability.

Comparing between the two approaches, the most drastic difference is observed for Portugal, where also the direction of change differs, indicating an increase in long-term differentials relative to short-term ones. Also the ranking in the relative changes differs under the two approaches. Under the unbalanced approach, Portugal still records the lowest rank, and Ireland, Denmark and Austria the 
highest. For the rest the ranks are shuffled. UK, Luxembourg and Spain jump towards higher positions, after Ireland, Denmark and Austria. The rest lower their rank. Thus except for the extremes, differential attrition plays a significant role in country ranking with respect to the degree to which earnings differentials are reduced with the time horizon.

The countries with the highest reduction in long-term inequality relative to shortterm inequality (over 20\%) in the unbalanced approach (Figure 3.4 - Panel B) are observed to be also the ones which record a decrease in inequality ${ }^{30}$ over time, except Luxembourg. Hence, on the one hand one might expect that the reduction in the transitory earnings inequality is one of the factors determining the decrease in the overall inequality over time. This might indicate the presence of a shock in the beginning of the sample period that influenced the temporary component of earnings and whose impact faded off over time. One the other hand, it might indicate that people became more mobile, improved their income position in the long run and reduced permanent income differentials. The outcome depends mainly on the evolution of mobility over time.

Under the balanced approach, the situation is confirmed for the countries with decreasing cross-sectional inequality, except for Spain and Belgium, which record among the smallest decreases in long-term inequality relative to short-term inequality. Thus among the countries with decreasing cross-sectional inequality, based on the differences between the balanced and the unbalanced approach, Spain and Belgium appear to be the most affected by differential attrition.

Based on the balanced approach, for countries that recorded an increase in the overall inequality over the sample period, the small decrease in inequality with the time horizon, signals the presence of strong permanent earnings differences between individuals or the existence of some shocks with permanent effects, whose inequality is accentuated by the inequality in the transitory component of earnings. Moreover, the magnitude of the transitory component of earnings is expected to be lower for these countries. Except for Luxembourg which records a high decrease in inequality with the time horizon, the unbalanced approach reveals a similar picture.

Under the unbalanced approach, in Luxembourg, the increase in the overall inequality over the sample period coupled with the high decrease in inequality with the time horizon signals the presence of some transitory shocks, which fade away in the long run. The difference in the two approached indicate that the

\footnotetext{
${ }^{30}$ as measured by the Gini, Theil and Atkinson index
} 
attrition incidence is higher in Luxembourg compared with the other countries where cross-sectional inequality increased.

To conclude, even based on average earnings over the whole sample period, a substantial inequality in the permanent component of earnings is still present in all countries under analysis. The lowest long-term inequality, meaning the lowest inequality in permanent earnings, is recorded in Denmark, followed by Finland, Austria, Belgium and Netherlands with similar values, then Italy, Germany, UK, Luxembourg, Greece, Ireland, France and Spain. Portugal differentiates itself with a particularly high long-term inequality compared with the other countries. (Figure 3.4)

\subsection{Mobility profile}

What are the possible implications in a lifetime perspective? To answer this question we need to couple the information on the evolution of inequality with earnings mobility. Is there any earnings mobility in a lifetime perspective, meaning are the relative income positions observed on an annual basis shuffled long-term? If yes, is mobility equalizing or disequalizing lifetime earnings differentials compared with annual earnings differentials? We report the mobility indices based on the Theil index. The ones based on the other inequality indices can be provided upon request from the authors.

\subsubsection{Stability profile - Shorrocks}

To answer the first question we look at the stability profile, both under the balanced and the unbalanced approach, illustrated in Figure 3.5 and Figure 3.6. Both figures contain the same information, organized differently for the ease of the interpretation. 

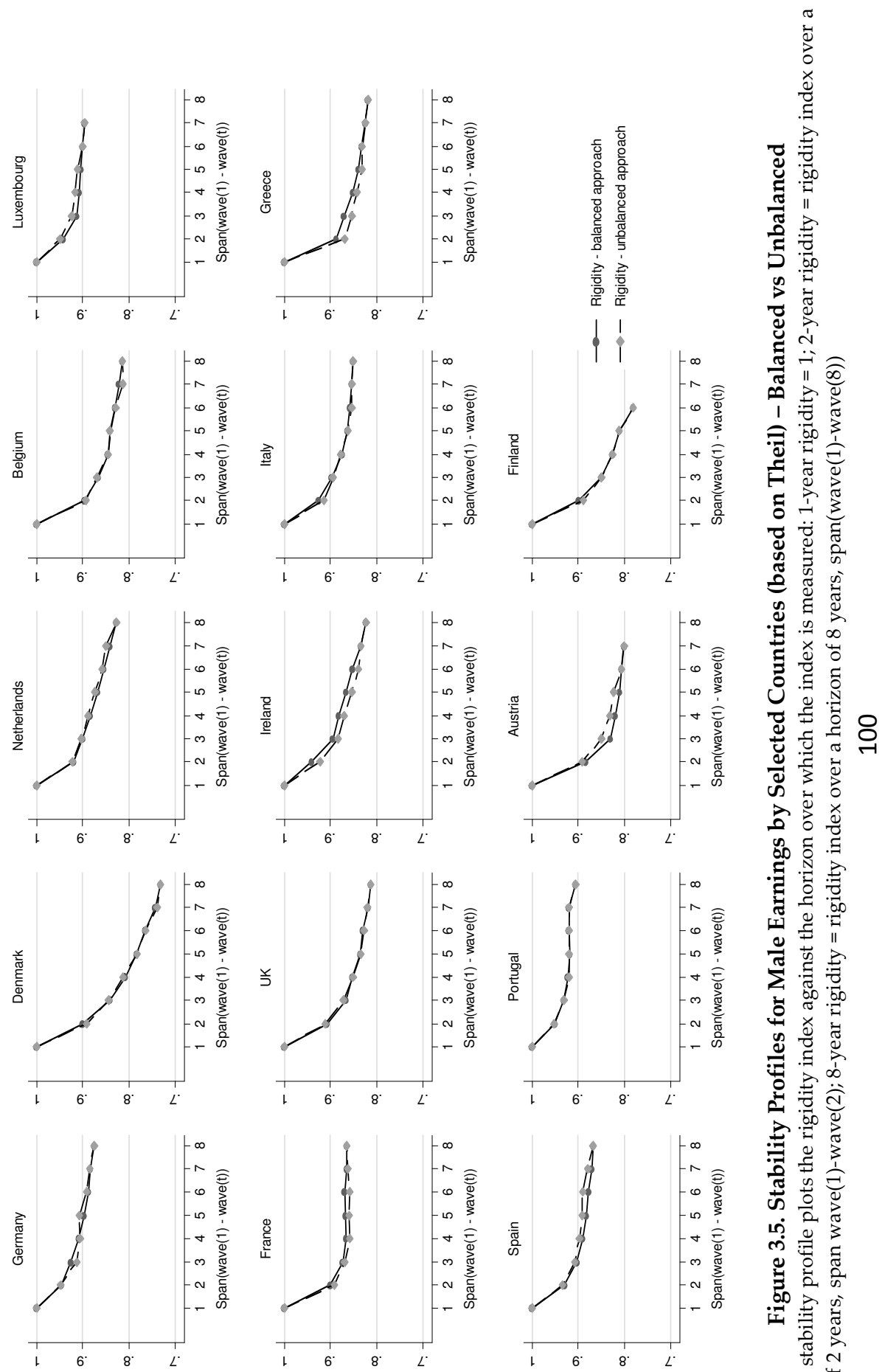

青

도 모

党营恵

5

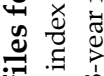

要要

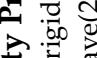

䍂

कँ

เा $2 \frac{0}{2}$

ले

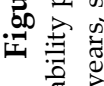
के तै 
Panel A: Balanced sample over sub-periods
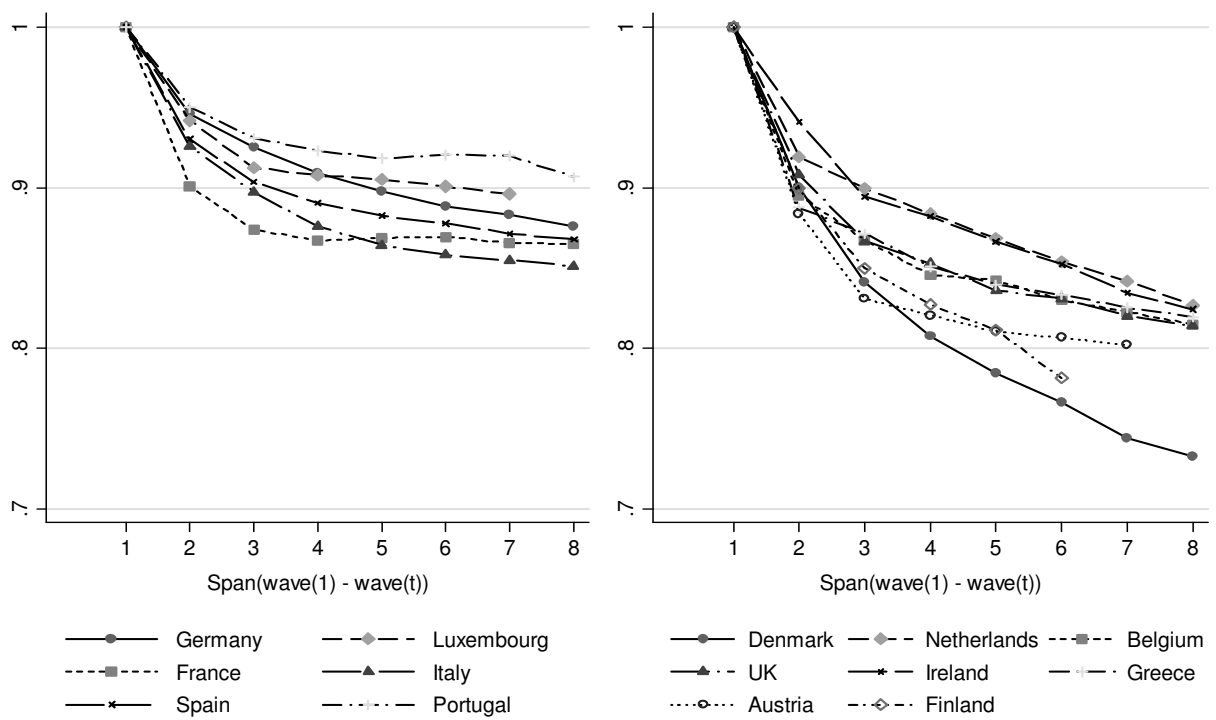

Panel B: Unbalanced sample over sub-periods
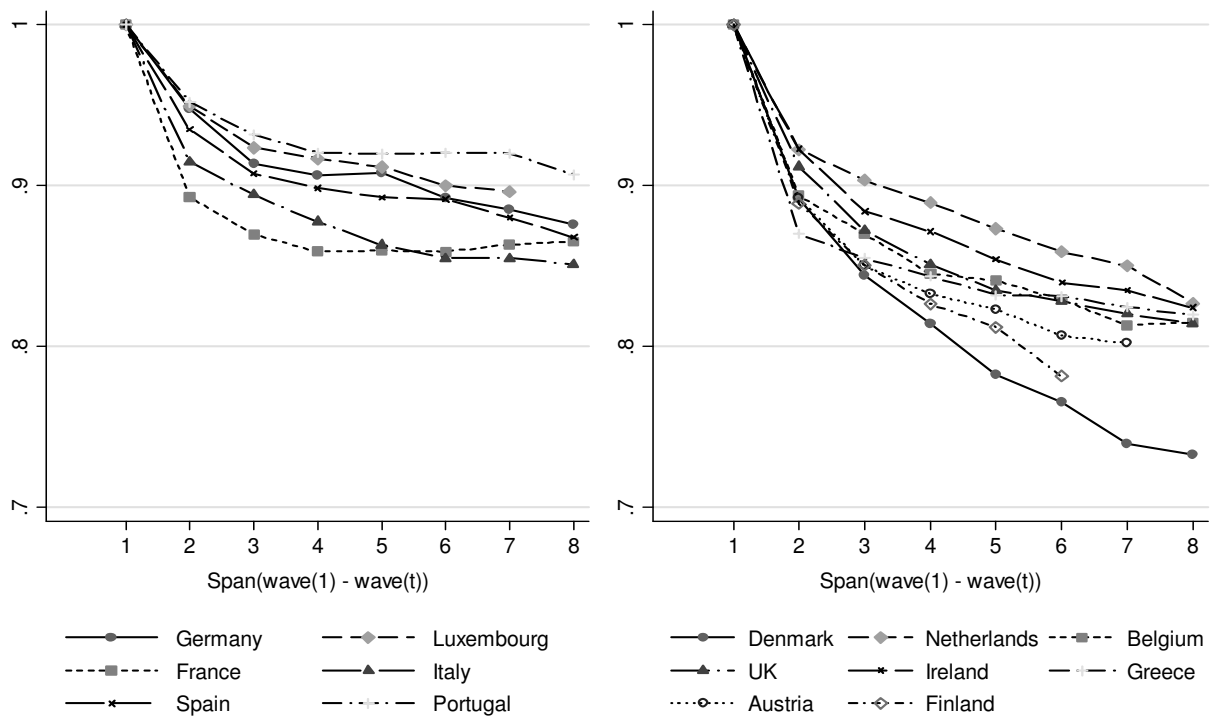

Figure 3.6. Stability Profiles for Male Earnings for Selected Countries (based on Theil) Balanced vs Unbalanced

Note: The stability profile plots the rigidity index against the horizon over which the index is measured: 1 -year rigidity $=1 ; 2$-year rigidity $=$ rigidity index over a horizon of 2 years, span wave(1)-wave(2); 8year rigidity $=$ rigidity index over a horizon of 8 years, $\operatorname{span}($ wave(1)-wave(8)) 
To recall, the stability profile plots the Shorrocks rigidity index ${ }^{31}$ across different time horizons. In Figure 3.5 and Figure 3.6 the time horizons are expressed in reference to the $1^{\text {st }}$ wave for each country. The stability profile allows the visual identification of the presence of permanent and transitory earnings components.

All countries record similar trends: the rigidity declines monotonically as the time horizon is extended (Figure 3.5 and Figure 3.6). Moreover, the longer the timehorizon is, the more heterogeneous the stability profiles become. The story is confirmed by both approaches. As illustrated in Figure 3.5, the profiles under the two approaches evolve close to one another sign that the impact of attrition is limited. Some countries are affected to a larger extent by attrition than others. A larger impact is identified in Luxembourg, France, Ireland, Greece, Spain and Austria, which have a higher differentiation between the two profiles. For Luxembourg, Spain and Austria the rigidity index under the unbalanced approach is higher than in the balanced approach for horizons 1 to 4 , suggesting that including also those individuals that move in and out of employment results in a higher degree of earnings rigidity. The opposite is observed in Ireland, Greece and France, suggesting that more income rigidity is observed among those that worked for the whole sample than including also those that moved in and out of paid work over the sample period.

Based on the stability profiles in Figure 3.5 and Figure 3.6, we make inferences concerning the source of mobility in each country. Based on the overall pattern of the profiles, we identify two country clusters, confirmed under both approaches, illustrated in Figure 3.6. Overall, the stability profiles on the right side of Figure 3.6 are steeper than on the left side, suggesting that income changes in Denmark, Finland, Austria, UK, Belgium, Greece, Ireland and Netherlands are due to transitory effects to a larger extent than in the other countries. Hence we can expect a higher lifetime mobility in the former.

Among the countries with less steep profiles, we identify countries where the profile (both the balanced and the unbalanced one) drops sharply in the beginning and then tends to become horizontal after a few years, suggesting that the income changes are purely due to transitory effects which average out over time. (Figure 3.5) Thus relative incomes approach rapidly their permanent values and there is no further equalization. It is the case of France. A similar trend (consistent across the two approaches) is observed in Portugal, except the last drop in the 8-year period

\footnotetext{
${ }^{31} \mathrm{R}$ is based in the Theil index. $\mathrm{R}$ based on other inequality can be provided upon request from the authors.
} 
rigidity ${ }^{32}$ which signals the presence of mobility in the permanent earnings for horizons equal and longer than 8 years. (Figure 3.5)

In Germany and Spain, the "balanced" and the "unbalanced" profiles communicate a consistent story for the rigidity over a horizon shorter than 3-4 years and a slightly different picture for longer horizons. (Figure 3.5) For a horizon shorter than 4 years the two profiles both record a sharp decreasing slope, signalling income changes due to transitory effects. Spain has a sharper decrease, suggesting more transitory changes than Germany for horizons shorter or equal to 4 years. For a horizon longer than 4 years, the two profiles communicate a slightly different picture. In Germany the unbalanced profile becomes flat between the 4 and 5-year period mobility, suggesting that the income changes are due to transitory effects. Thereafter it decreases suggesting the presence of mobility in the permanent component at longer horizons. The same trend is observed in Spain, except that the flattening of the unbalanced profile occurs between a span of 4 to 5 years. The decrease observed in the unbalanced profiles at longer aggregation periods signals the presence of mobility in the permanent component.

Based on the balanced approach (Figure 3.5), in Germany and Spain, the profiles continue to decrease as the aggregation period is extended, suggesting more mobility in the permanent component than observed in the unbalanced approach. Thus considering also the people that move in and out of paid work over the sample period decreases the degree of mobility observed in the permanent component. This is expected, given that those that keep their jobs over the sample period are expected to be also the ones with higher opportunities of improving their relative position in the distribution of lifetime income.

As illustrated in Figure 3.5, the other two countries from the first cluster identified in Figure 3.6 (Luxembourg and Italy) record a sharp decrease over a horizon of two years, followed by curves which decrease at a decreasing rate, in a convergent trend towards a horizontal profile. Given that in Luxembourg and Italy the rigidity curve continues to decline as the aggregation period is extended, suggest that income changes in these countries are due to more mobility in permanent incomes. These trends are confirmed by both approaches.

The overall rank in the stability profiles between the countries with less steep profiles differs slightly based on the horizon and the approach. Under the balanced approach (Figure 3.6), Panel A), the stability profile is the highest in Portugal, followed by Germany, Luxembourg, Spain, Italy and France, except for a horizon

\footnotetext{
32 8-year period rigidity $=$ rigidity computed over a horizon of 8 years corresponding to the span wave(1)-wave(8)
} 
longer than 4 years when the rigidity is higher in France than in Italy, and in Luxembourg than in Germany. Under the unbalanced approach (Figure 3.6), Panel B), the ranking in the stability profile is similar. Two exceptions are present: the rigidity is higher in Luxembourg than in Germany for all horizons, and in France than in Italy for a horizon longer than 5 year.

As illustrated in Figure 3.5, the countries with the steepest profiles - the right country cluster in Figure 3.6 - record a sharp decrease over a horizon of two years, followed by curves which continue to decline as the aggregation period is extended, suggesting that income changes in these countries are due to more mobility in permanent incomes. The curves under the balanced and unbalanced approach communicate a similar story in most countries. Some differences are observed for Belgium and Greece for longer horizons. In Belgium, a differentiation between the two profiles occurs between a 7 and 8-year horizon, when the unbalanced profile becomes horizontal, whereas the balanced one keeps declining. In Greece, the unbalanced profile becomes horizontal between the 5 and 6-year horizon and decreases thereafter, whereas the balanced profile continues to decline with the horizon.

The overall rank in the rigidity profiles between the countries with the steepest profiles - right country cluster in Figure 3.6 - differs based on the horizon and the used approach to a larger extent compared with the countries with less steep profiles - left country cluster in Figure 3.6.

Under the balanced approach (Figure 3.6, Panel A), the steepest profile over a 2year horizon is recorded in Austria and Greece, followed by a cluster with similar vales, then UK, Netherlands, and finally Ireland. Over a 3-year horizon the ranks are slightly shuffled: Austria, Denmark and Finland have the lowest rigidity, followed by a cluster formed of UK, Belgium, and Greece, then Ireland and Netherlands with similar values. After the 3-year horizon, the profile for Austria becomes less steep, crossing the profiles of Denmark and Finland, which record the lowest rigidity thereafter. At higher levels of rigidity we observe the profiles for Greece, UK and Belgium, which evolve together, followed by the profiles of Netherlands and Ireland.

The unbalanced approach (Figure 3.6, Panel B) reveals a higher differentiation between the profiles at shorter horizons and a higher degree of convergence at longer horizons. Over a 2-year horizon, the lowest rigidity is recorded in Greece, followed by a cluster formed of Finland, Denmark, Austria and Belgium, then UK, and finally Ireland and Netherlands with similar values. The profiles become more heterogenous at longer profiles. The lowest profile is observed in Denmark, followed by Finland, Austria, then a cluster formed by Greece, UK and Belgium, 
then Ireland and finally Netherlands. Over an 8-year horizon, Denmark stands out with the lowest rigidity, whereas a convergence is observed for the rest ${ }^{33}$.

We conclude this section with an overview of the long-period Shorrocks mobility country ranking.

All these trends lead to a change in long-period mobility ranking as the horizon is extended. In the beginning of the sample period, under the balanced approach, over a horizon of 2 years, the lowest mobility is recorded in Portugal, followed by Germany, Luxembourg, Ireland, Spain, Italy, Netherlands, UK, France, Denmark, Finland, Belgium, Greece and Austria. Under the unbalanced approach, the ranking changes slightly: Portugal, Luxembourg, Germany, Spain, Ireland, Netherlands, Italy, UK, Belgium, France, Austria, Denmark, Finland and Greece. The largest jumps in ranking are observed in Austria and Belgium. More shuffling occurs as the period over which mobility is measured is extended. (Table 3.5 and Table 3.6)

${ }^{33}$ Except Austria and Finland. 


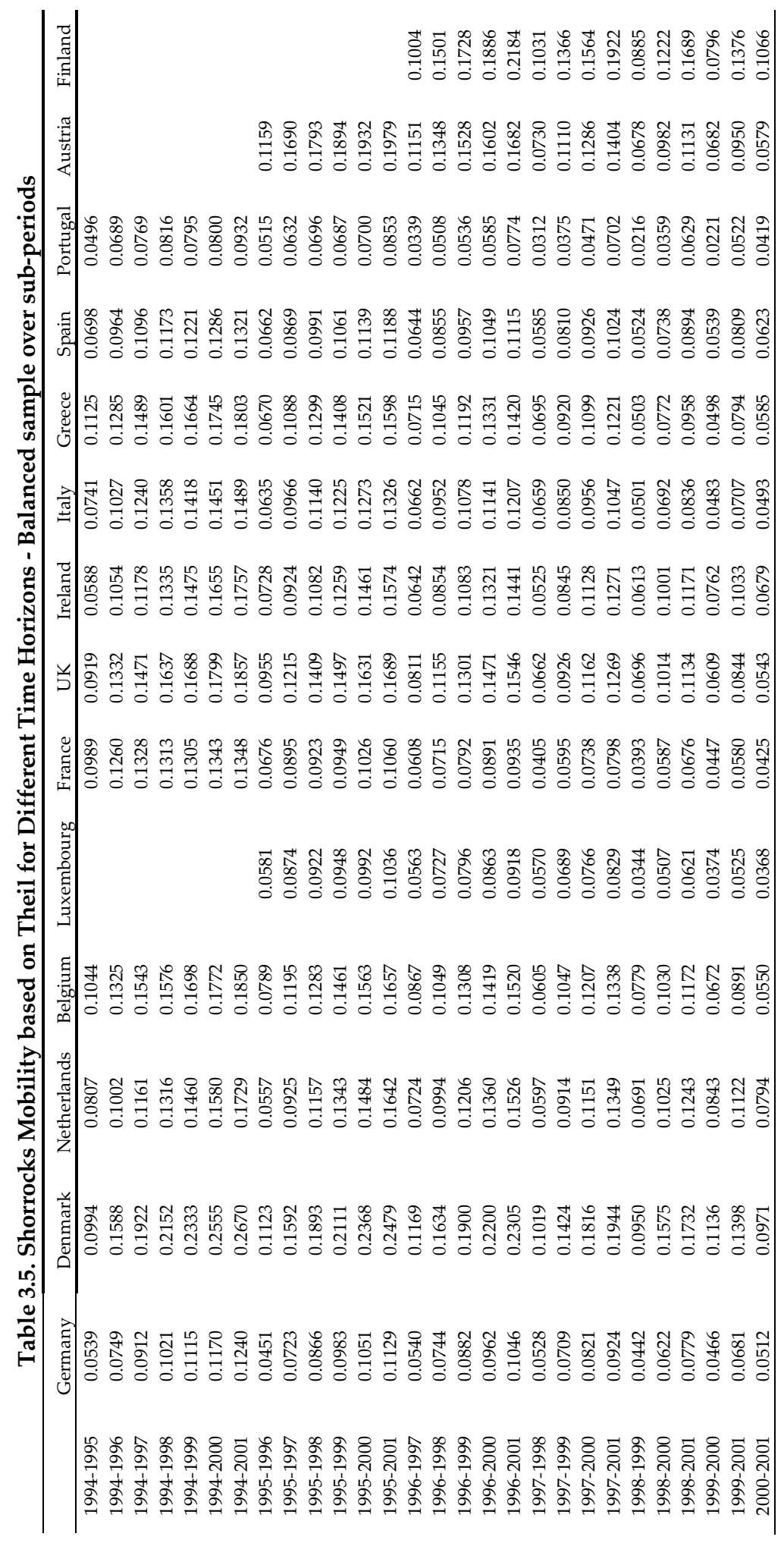

$\stackrel{\circ}{\circ}$ 


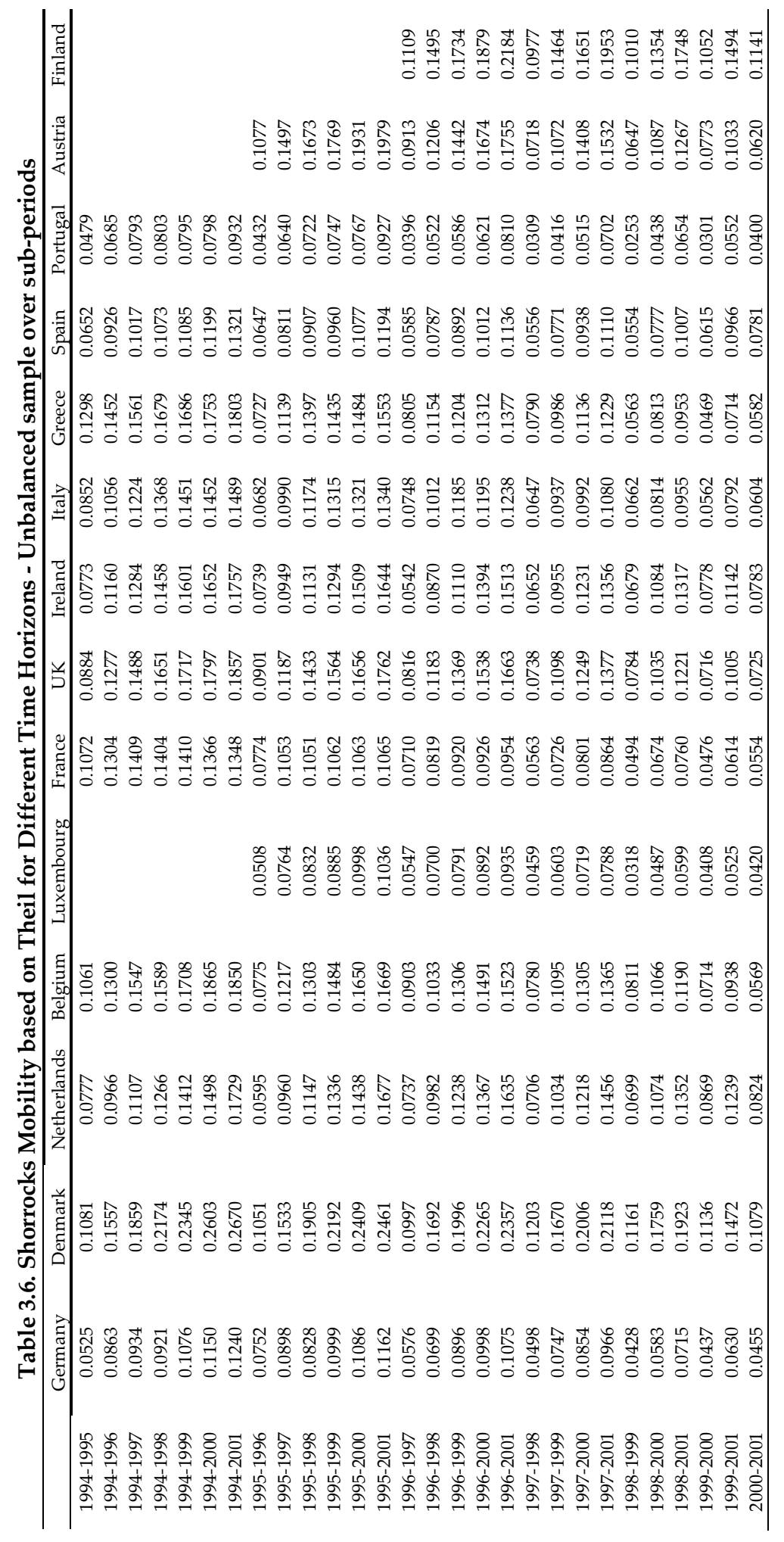


Following these changes, the ranking in long-term earnings Shorrocks mobility is revealed in Figure 3.7.
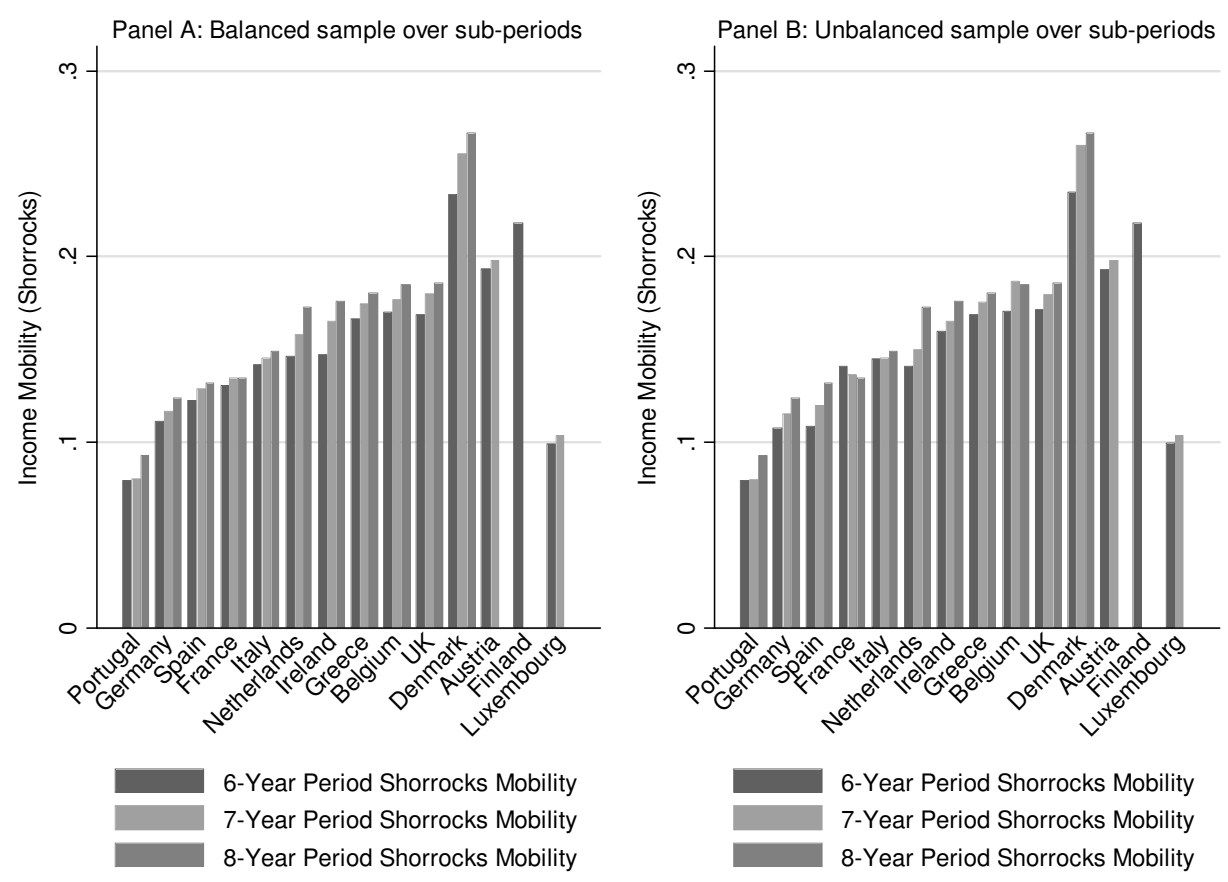

Figure 3.7. Long-Term Earnings Mobility based on the Shorrocks Index

Note: Ranked in an ascendant order based on the 8-year period mobility. Austria Finland and Luxembourg are displayed the last because the 8-year period mobility is missing.

Based on the balanced approach, the highest mobility over a horizon of 6 years is recorded in Denmark and Finland, followed by Austria, Belgium, UK, Greece, Ireland, Netherlands, Italy, France, Spain, Germany, Luxembourg and Portugal. Denmark and Finland record the lowest annual inequality, and Portugal the highest annual inequality. Thus we can expect, among the selected countries, Denmark and Finland to trigger the lowest lifetime inequality and Portugal the highest. The country ranking is confirmed by the unbalanced approach, except Netherlands which, under the unbalanced approach, has a lower mobility than Italy.

Based on the balanced approach, over a horizon of 7 years the ranking is in general preserved: Denmark and Austria record the highest mobility, and Portugal and Luxembourg the lowest. One exception is UK which scores a higher rank than 
Belgium. Austria has the $5^{\text {th }}$ lowest annual inequality and Luxembourg the $9^{\text {th }}$. Thus we expect Austria to reduce lifetime earnings differential compared with annual differentials to a higher extent than Portugal and Luxembourg, and to a lesser extent than Denmark. This result is consistent with Hofer and Weber (2002). Similarly, we expect Luxembourg to reduce lifetime differentials to a higher extent than Portugal and to a lesser extent than Denmark. The ranking is confirmed by the unbalanced approach, except for the UK which ranks lower than Belgium.

Finally, over an eight-year horizon ${ }^{34}$, the ranking is in general preserved. The highest mobility is recorded in Denmark, followed by UK, Belgium, Greece, Ireland, Netherlands, Italy, France, Spain, Germany, and the lowest, Portugal. Therefore Denmark provides the highest opportunity of reducing lifetime earnings differentials and Portugal the lowest. The ranking between Denmark, UK, Spain and Germany is consistent with the one found by Gregg and Vittori (2008) using the Shorrocks index based on all indices considered, including Theil and Gini.

To sum up, all countries record an increase in earnings mobility when the horizon over which mobility is measured is extended. This shows that men do have an increasing mobility in the distribution of lifetime earnings as they advance in their career. This result is confirmed both by the balanced and the unbalanced approach. The differential attrition appears to have a limited impact on the stability profiles, but a higher impact on the country ranking which decreases with the horizon over which mobility is measured.

But is this mobility equalizing or disequalizing lifetime earnings differentials?

\subsubsection{Mobility Profile - as equalizer on long-term earnings inequality}

Next we introduce the mobility profile based on the Fields index, which unlike Shorrocks captures whether mobility is equalizing or disequalizing long-term differentials. (Table 3.7, Table 3.8, Figure 3.8 and Figure 3.9)

\footnotetext{
${ }^{34}$ The balanced and unbalanced approach are the same for the 8-year horizon because they use the same sample.
} 


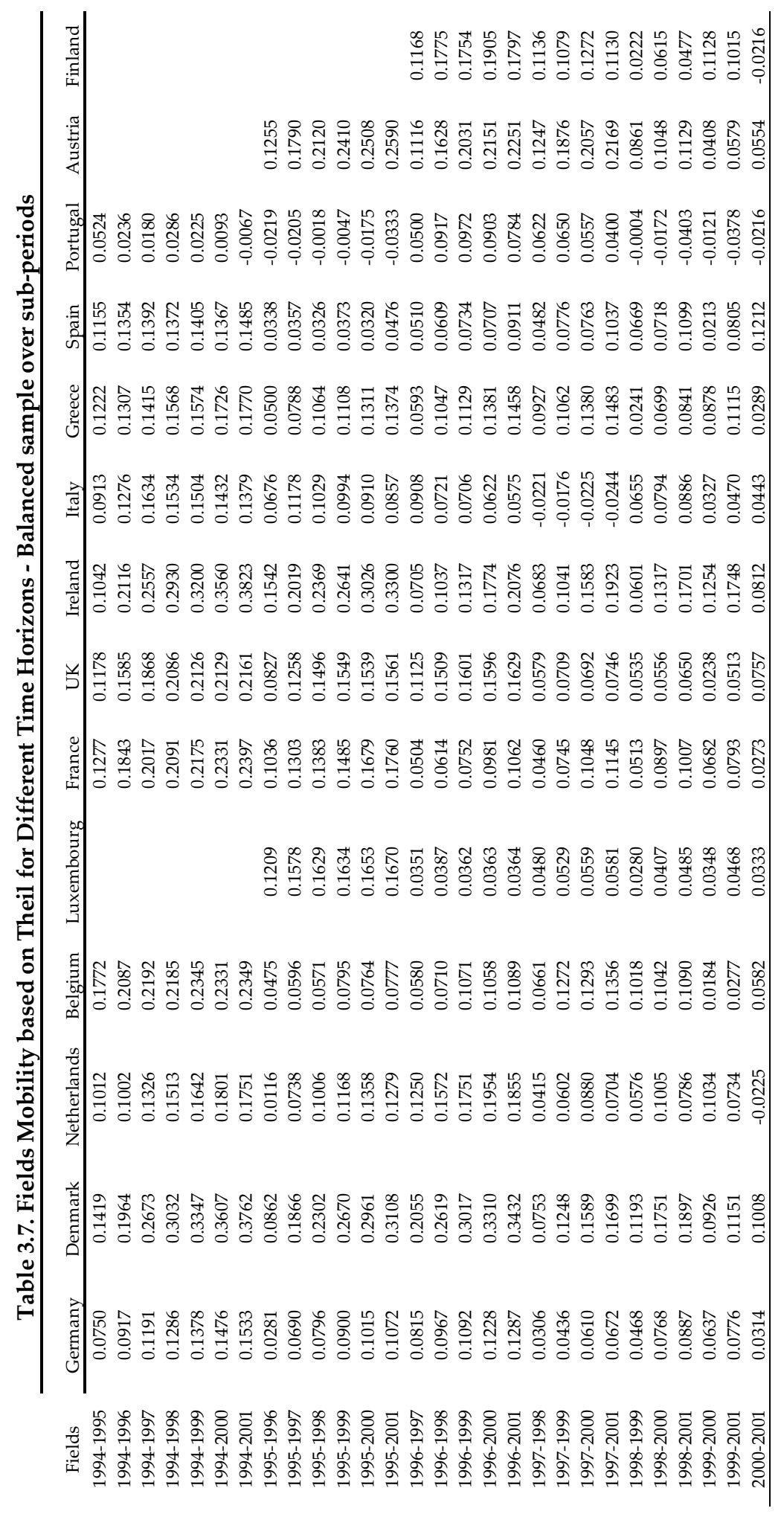

옥 


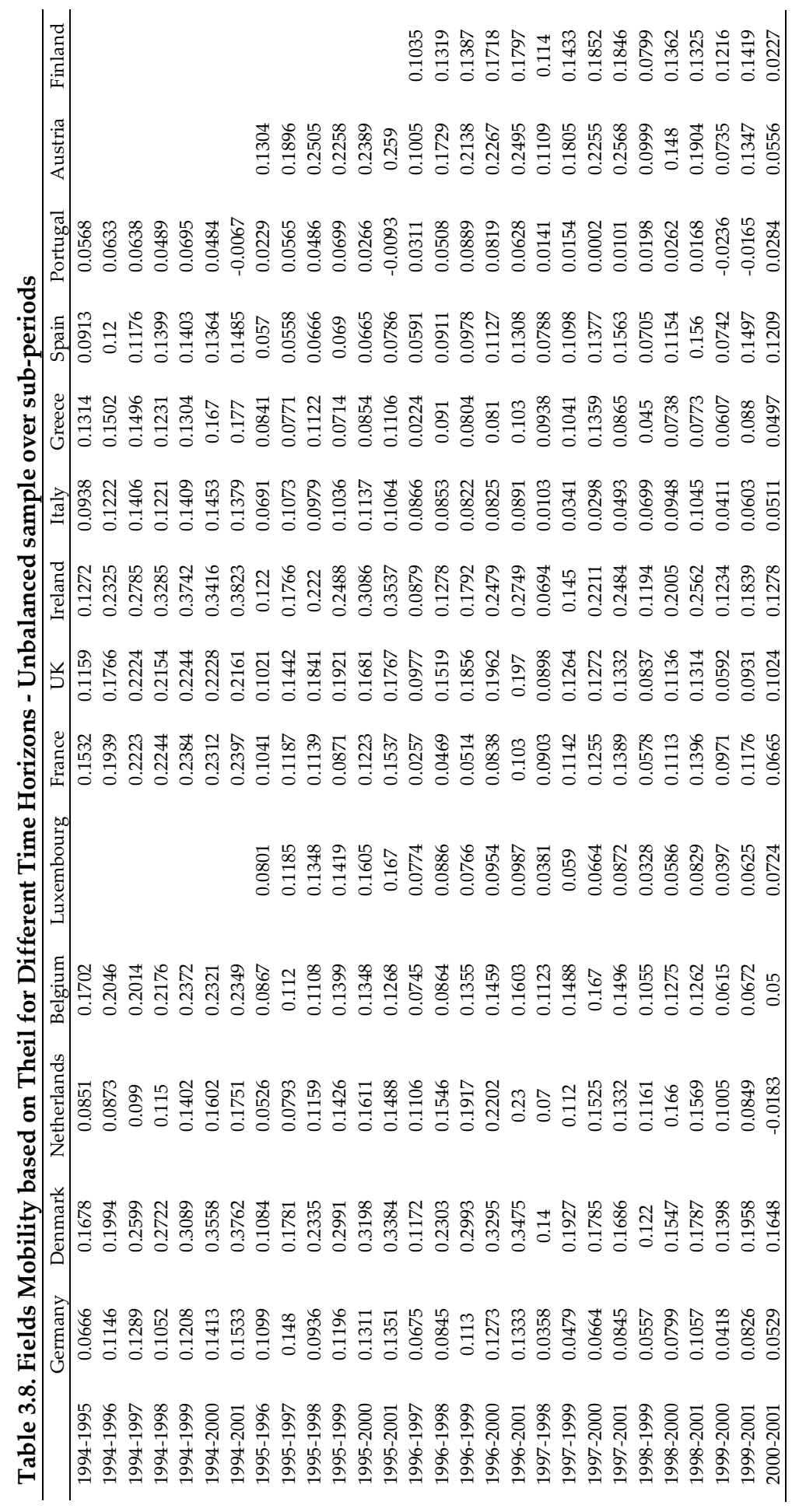




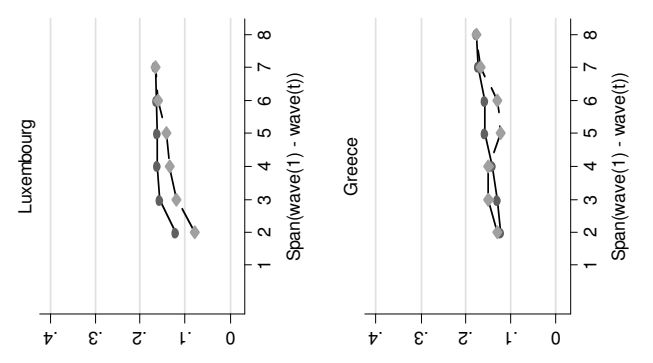

ठั
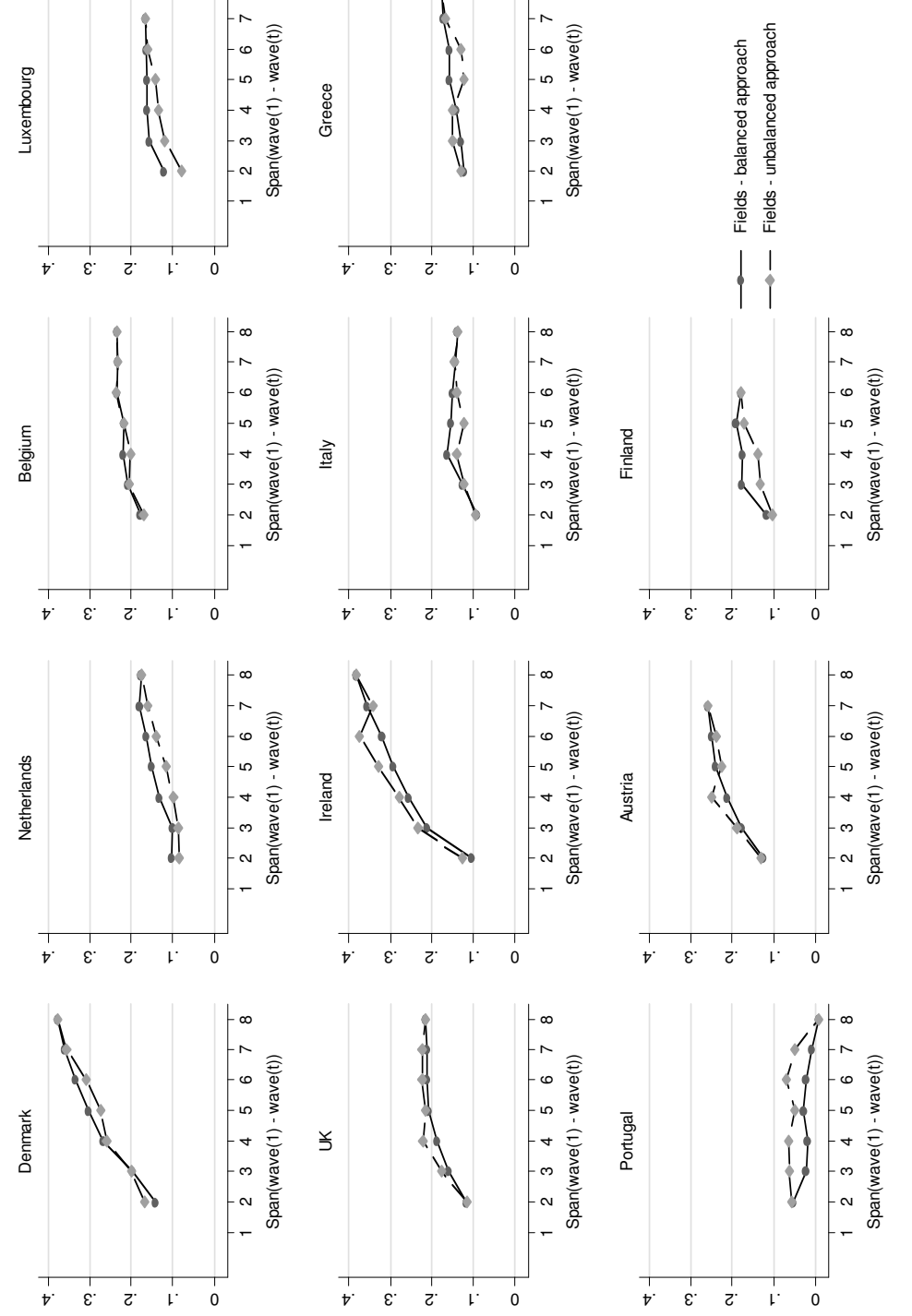

咅䁗

i

峞

ฮี

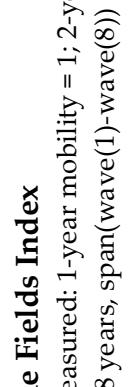

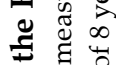

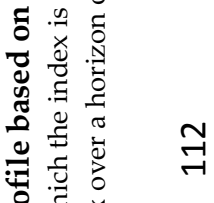
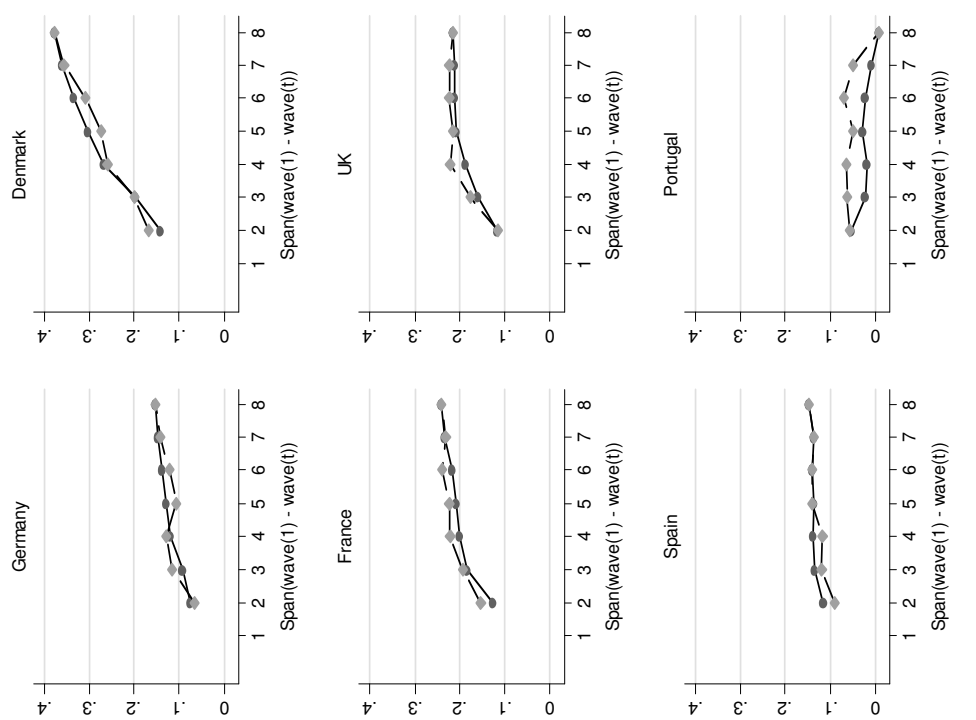

닐

要 
Panel A: Balanced sample over sub-periods
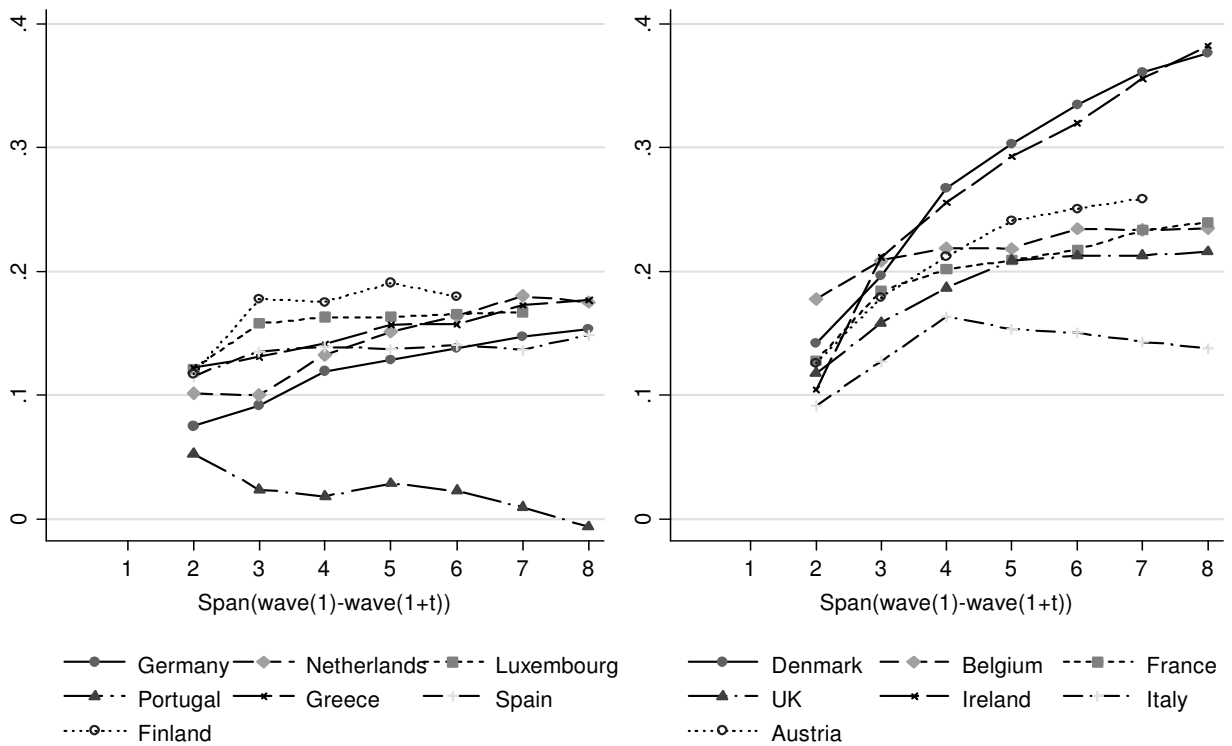

Panel B: Unbalanced sample over sub-periods
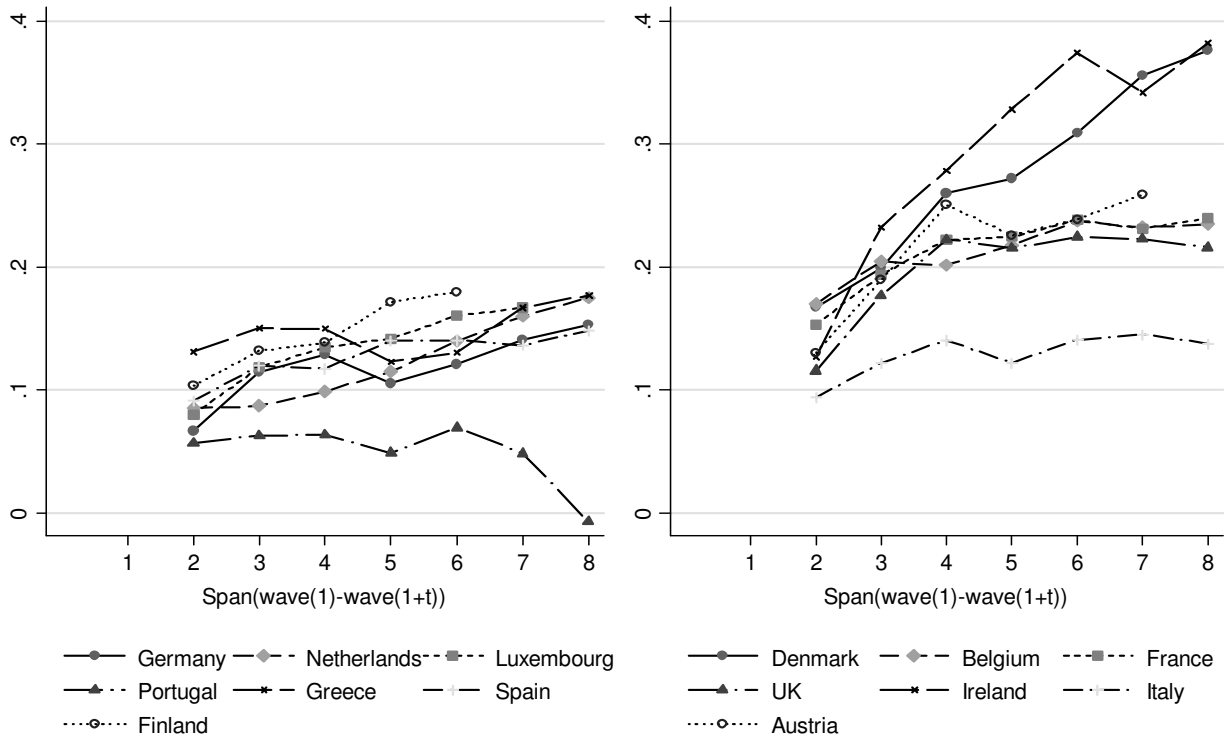

Figure 3.9. Mobility Profile based on the Fields Index

Note: The mobility profile plots the Fields index against the horizon over which the index is measured: 1 -year mobility $=1$; 2-year mobility = mobility index over a horizon of 2 years, span wave(1)-wave(2); 8year mobility = mobility index over a horizon of 8 years, $\operatorname{span}($ wave(1)-wave(8)) 
Overall, mobility increases with the horizon for all countries, except Portugal. The evolution, however, is not monotonic for all countries. Except Portugal, all countries record positive values of mobility, showing that mobility is equalizing earnings differentials long-term. The story is confirmed by both approaches. For Portugal, mobility turns negative when measured over an 8-year horizon, showing that mobility is exacerbating long-term earning differentials. We conclude that all countries, except Portugal, manage to reduce earnings differentials in a lifetime perspective.

Comparing between Figure 3.8 and Figure 3.5 reveals that the Fields index is affected to a larger extent by differential attrition than the Shorrocks index: the differentiation between the mobility profile under the balanced approach and the one under the unbalanced approach is evident in all countries, in some more than in others. The largest differences between the two curves are observed in Netherlands, Luxembourg, Ireland, Greece, Portugal and Finland.

The mobility ratio for the balanced approach is higher than for the unbalanced approach in Netherlands, Luxembourg and Finland, suggesting that including also the people that moved into and out of employment and those that entered and exited the sample leads to higher levels of mobility as equalizer of long-term differentials. The reverse is observed in France, UK, Portugal and Ireland (except for the 7-year horizon). We tried to relate back to Table 3-A-1 (Annex) to identify the possible driving factors in these results, but the patterns in the inflows and outflows in the data do not reveal any distinctive pattern.

For the rest the results are mixed. In Germany, Denmark, Greece and Austria, the mobility under the unbalanced approach is higher than under the balanced approach for shorter horizons and lower for longer horizons. In Spain the "unbalanced" mobility is lower until the 4-year horizon and similar with the "balanced" mobility thereafter. Possible explanations for the trends in the mobility profile in the two approaches can be found in Table 3-A-1 (Annex). In Germany, Denmark, Greece and Austria, the "unbalanced" mobility becomes lower than the balanced one in 1998, 1998, 1998 and 1999 (Figure 3.8), which is the year when the attrition rates increase, and the share and the number of individuals with positive earnings in 1998 from those that were present in the sample in 1997 decrease compared with the previous years. For example, in Germany, 9.06\% of the people who were in the sample in 1997 disappeared in 1998, which is almost twice the rate observed one year before (5.18\%). From those that were present in the sample in 1997 , only $63.01 \%$ record positive earnings in 1998 , as compared to $66.2 \%$ in the previous year (Table 3-A-1, Annex) 
Four clusters are identified in the evolution of long-term mobility profiles, confirmed both by the balanced and the unbalanced approach. (Figure 3.9) Independent of the horizon, Portugal and Italy have the lowest profiles, indicating that they have the lowest mobility as equalizer of long term differentials. The ranking for the other countries changes to a large extent for horizons up to 4 years. Looking after the $4^{\text {th }}$ horizon, three clusters are observed. The first cluster, with values higher than Portugal and Italy, is formed by Germany, Spain, Netherlands, Greece, Luxembourg and Finland. This is followed by a cluster formed by UK, Belgium, France and Austria. Finally, Denmark and Ireland stand out with respect to the steepness of their profiles and to the high level of their long-term mobility.

Some convergence trends emerge as the horizon over which mobility is measured increases. For a horizon of 7-8 years, mobility converges to similar values in Denmark and Ireland, in Belgium and France, in Spain and Germany, and in Luxembourg, Greece and Netherlands. (Figure 3.9)

We conclude this section with an overview of the country ranking in Fields mobility. Similar with the trend observed for the Shorrocks index, the country ranking changes with the horizon over which mobility is measured.

Based on the balanced approach, the 2-year mobility is the highest in Belgium, followed by Denmark, France, Greece, Austria, Luxembourg, UK, Finland, Spain, Ireland, Netherlands, Italy, Germany and Portugal. The unbalanced approach reveals a slightly different picture than the balanced one, sign that the Fields index is more sensitive to differential attrition compared with the Shorrocks index where the rankings are similar between the two approaches. Belgium, Denmark, France, Greece, Austria still have the highest mobility, and Germany and Portugal the lowest. In between, in a descendent order we find Ireland, UK, Finland, Italy, Spain, Netherlands and Luxembourg.

Figure 3.10 displays the ranking in long-term Fields mobility. Based on the balanced approach (Panel A), over a horizon of 6 years, Denmark, Ireland and Austria record the highest mobility, followed by Belgium, France, UK, Finland, Luxembourg, Netherlands, Greece, Italy, Spain Germany and Portugal. Thus except for Portugal, the mobility picture over the 6-year horizon looks different from the one over the 2-year horizon. Based on the unbalanced approach (Panel B), Ireland has the highest mobility, followed by Denmark, Austria, France, Belgium, UK, Finland, Luxembourg, Italy, Spain, Netherlands, Greece, Germany and Portugal.

Over a 7-year horizon, the balanced approach reveals the same ranking as over a 6year horizon for the first 6 countries and Portugal. In between, in a descending 
order, we find Netherlands, Greece, Luxembourg, Germany, Italy and Spain. Based on the unbalanced approach, the first 3 countries maintain the ranks from the balanced approach, followed by Belgium, France, UK, Netherlands, Greece and Luxembourg with similar values, then Germany, Italy, Spain and Portugal.
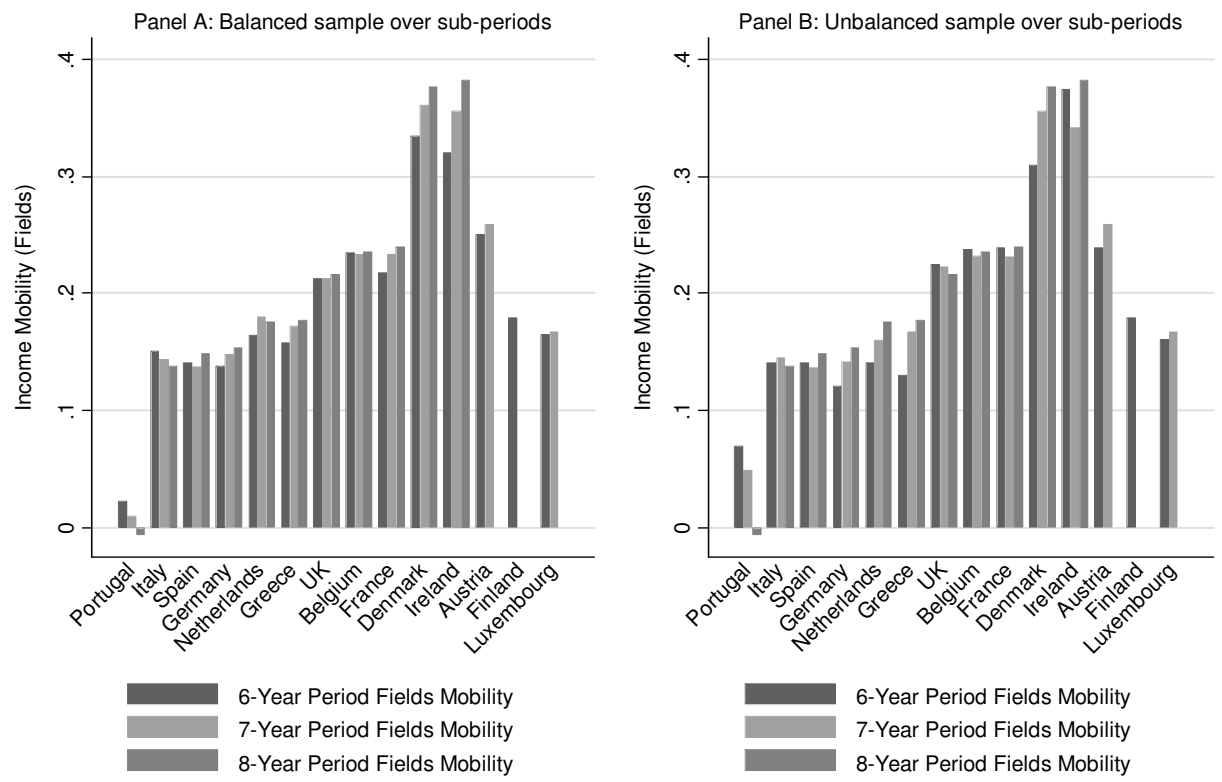

Figure 3.10. Long-Term Earnings Mobility (Fields)

Note: Ranked in an ascendant order based on the 8-year period mobility. Austria Finland and Luxembourg are displayed the last because the 8 -year period mobility is missing

Finally, over a horizon of 8 years, the highest mobility is recorded in Ireland and Denmark, followed by France and Belgium with similar values, then UK, Greece, Netherlands, Germany, Spain, Italy, and Portugal with a negative value. Thus, assuming that the 8-year mobility is a good approximation of lifetime mobility, Ireland and Denmark have the highest equalizing mobility in a lifetime perspective, and Italy, Spain and Germany the lowest. Portugal is the only country where mobility acts as a disequalizer of lifetime differentials.

The overall information revealed by the two indices is summarized in Figure 3.11, Figure 3.12 and Table 3.9. Comparing the rankings in 6, 8, 7-year mobility between the Shorrocks and the Fields index the mobility pictures differ to a certain extent. 
Based on the 8-year mobility (Figure 3.12 and Table 3.9), Portugal records the lowest values based on both indices. Lifetime mobility is present in Portugal, but is disequalizing, thus it does not benefit low earnings individuals.

Among the countries with the highest 5 values in lifetime Shorrocks mobility Denmark, UK, Belgium, Greece, Ireland - only Denmark, Ireland, Belgium and UK score among the 5 highest in the Fields lifetime equalizing mobility, suggesting that these countries have the highest lifetime mobility with the highest equalizing impact on lifetime earnings differentials. Denmark scores the highest in lifetime mobility, but the second highest after Ireland in equalizing mobility, suggesting that mobility in Ireland is slightly more equalizing in a lifetime perspective than in Denmark. Compared with the other countries, Denmark has a higher lifetime mobility with a higher lifetime equalizing impact.

UK has a lower lifetime mobility and a lower equalizing impact than Denmark. Compared with Ireland, Belgium and France, UK has a higher lifetime mobility, but with a lower equalizing impact. A possible explanation is that UK has a higher share of lifetime mobility which is disequalizing than Ireland, Belgium and France. Compared with the remaining countries, UK has a higher lifetime mobility with a higher lifetime equalizing impact.

Belgium scores the third highest after Denmark and UK based on Shorrocks and the 4th highest after Ireland, Denmark, and France based on Fields. Thus Belgium has a lower lifetime mobility with a lower equalizing impact than Denmark, a higher lifetime mobility and a lower equalizing mobility than Ireland and France, and a lower lifetime mobility but with a higher equalizing impact than in UK. Compared with the remaining countries Belgium has a higher lifetime mobility with a higher lifetime equalizing impact. 

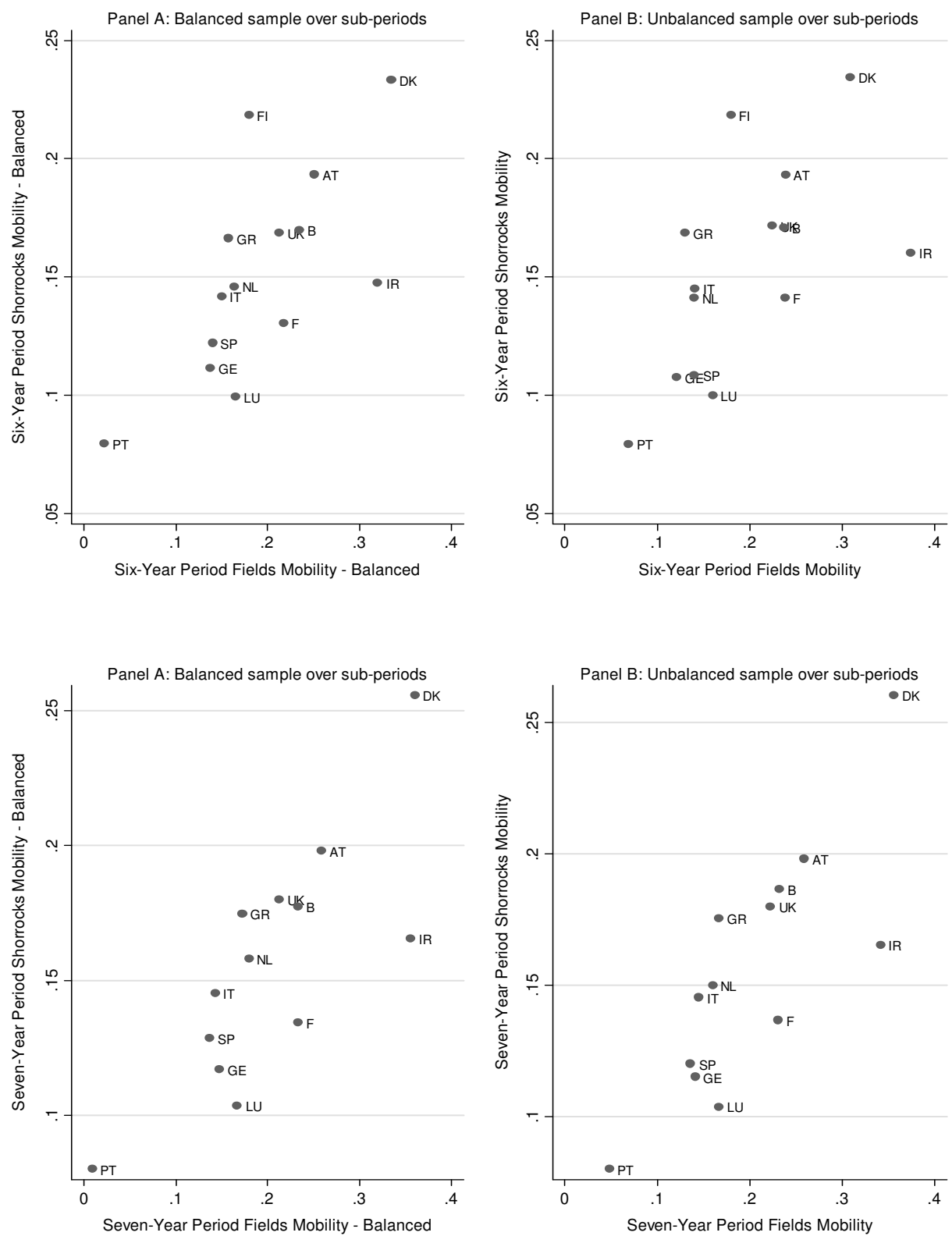

Figure 3.11. Scatter plot of 6-year and 7-year period mobility: Shorrocks vs. Fields 


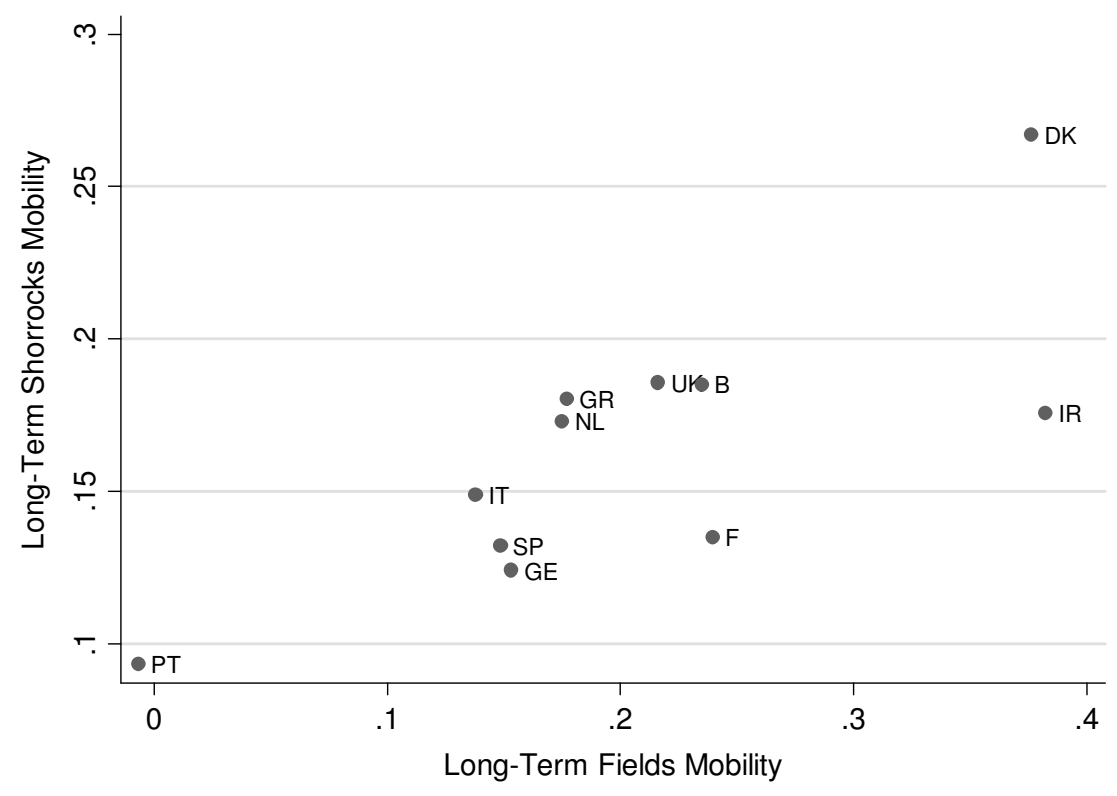

Figure 3.12. Scatter plot of 8-year period mobility: Shorrocks vs. Fields

Greece has a higher lifetime mobility with a higher equalizing impact than Netherlands, Italy, Germany, Spain and Portugal. Compared with Denmark, Belgium and UK, Greece has a lower lifetime mobility and a lower equalizing mobility. Compared with Ireland and France, Greece has a higher lifetime mobility and a lower equalizing impact, signalling that a lower part of the mobility in Greece is equalizing lifetime earnings differentials compared with Ireland and France.

Ireland has a higher lifetime mobility than Netherlands, Italy, France, Spain, Germany and Portugal, and a lower lifetime mobility than the other countries. In terms of equalizing impact, however, Ireland is the strongest.

Netherlands has a middle rank both in lifetime mobility and in lifetime equalizing mobility. It has a higher lifetime mobility and a higher equalizing impact than Germany, Spain, Italy and Portugal. Compared to France it has a higher lifetime mobility, but a lower equalizing mobility, sign that a higher share of mobility is disequalizing in the Netherlands.

Italy has a lower lifetime mobility with a lower equalizing impact compared with most countries, except Portugal, for which the opposite holds, and Germany, 
Spain, and France, which have a lower lifetime mobility and a higher equalizing mobility.

France has a higher lifetime mobility and a higher equalizing mobility than Spain, Germany and Portugal, and a lower lifetime inequality coupled with a lower equalizing mobility than Denmark and Ireland. Compared with the rest, France has a lower lifetime inequality but with a higher equalizing impact.

Spain has a higher lifetime mobility with a higher equalizing impact than Portugal, a higher lifetime mobility and a lower equalizing mobility than Germany and the reverse compared with Italy. Compared with the remaining countries, Spain has a lower lifetime mobility with a lower equalizing impact.

Germany has a higher lifetime mobility with a higher equalizing impact than Portugal, a lower lifetime mobility and a higher equalizing mobility than Spain and Italy. Compared with the remaining countries, Germany has a lower lifetime mobility with a lower equalizing impact.

Based on the 7-year mobility (Figure 3.11 and Table 3.9), Austria has a higher lifetime mobility with a higher equalizing impact than most countries, except Denmark where the reverse holds, and Ireland which has a higher equalizing mobility. This is confirmed under both approaches. Using the same horizon as Austria, Luxembourg has a lower lifetime mobility with a lower equalizing impact than most countries, except Portugal, where the reverse holds, and Germany, Spain and Italy, which have a higher lifetime mobility but with a lower equalizing impact.

Based on the 6-year mobility (Figure 3.11 and Table 3.9), Finland has a higher lifetime mobility with a higher equalizing impact than Germany, Netherlands, Luxembourg, Italy, Greece, Spain, and Portugal, a lower lifetime mobility with a lower equalizing impact than Denmark, and a higher lifetime mobility but with a lower equalizing mobility than Belgium, France, UK, Ireland and Austria. 


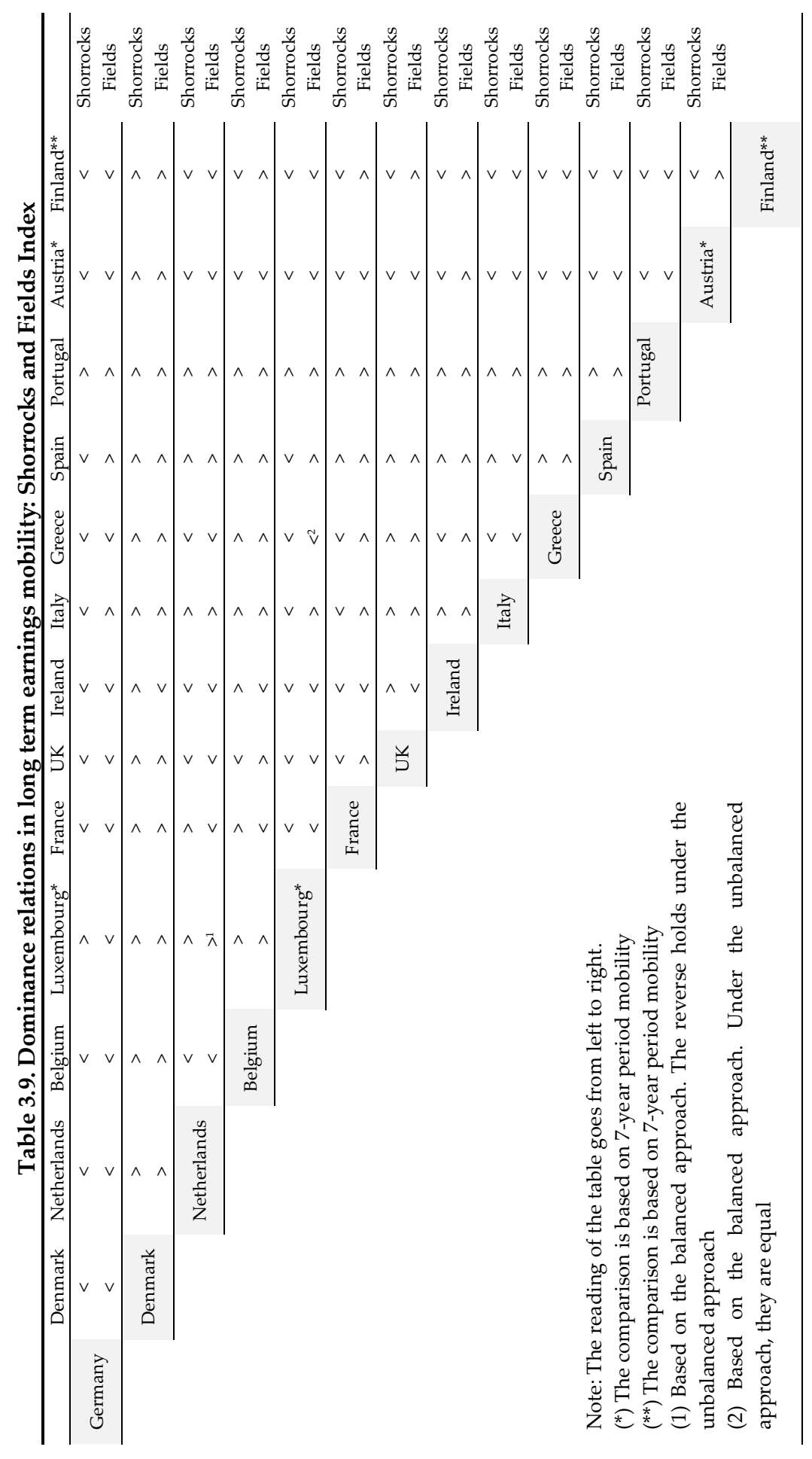

ت 


\subsubsection{The evolution of mobility over time}

As a last step, we investigate how long-term mobility evolved over time. We look at a horizon of 2 years and 4 year, both under a balanced and unbalanced approach. The results for the 2-year period mobility, illustrated in Figure 3.13, reveal that the information provided by the two indices differs to some extent.

We start with the Shorrocks index, displayed in the upper panel in Figure 3.13. The largest differences between the curves for the balanced and unbalanced approach are observed in Denmark, France, UK, Ireland, Italy and Finland. The mobility based on the unbalanced sample is higher than the one based on the balanced one in Germany until 1996, in Denmark after 1997, in Netherlands after 1995, in Belgium after 1996, in Luxembourg after 1999, in France, in UK after 1997, in Ireland except in 1996, in Italy except 1997, in Greece until 1998, in Spain after 1998, in Portugal except 1994, 1995 and 2000, in Austria after 1999, and in Finland except 1997.

Despite these differences, the conclusions regarding the overall trend over the sample period do not differ to a large extent. Based on the balanced approach, the 2-year period mobility decreased over the sample period in all countries, except Ireland and Finland, showing that in 2000 men had a decreased opportunity of reducing earnings differentials over a 2-year period compared with the $1^{\text {st }}$ wave. The opposite holds in Ireland and Finland. The unbalanced approach is consistent with the balanced one, except for Netherlands and Spain which record increases in the 2-year period mobility.

As revealed by Figure 3.13, the evolution of the Shorrocks index was not monotonic and the yearly trends differ between the balanced and unbalanced approach.

We turn to the Fields index, displayed in the lower panel in Figure 3.13. Similar with the previous sections, the Fields index appears to have a higher sensitivity to attrition or to including also the people which become unemployed or inactive or find a job during the sample period than the Shorrocks index. The highest differences are observed for Denmark, Netherlands, Belgium, France, UK, Ireland, and Portugal. The conclusions on the overall trend however do not differ much. 


\section{2-Year Shorrocks Mobility Over Time}
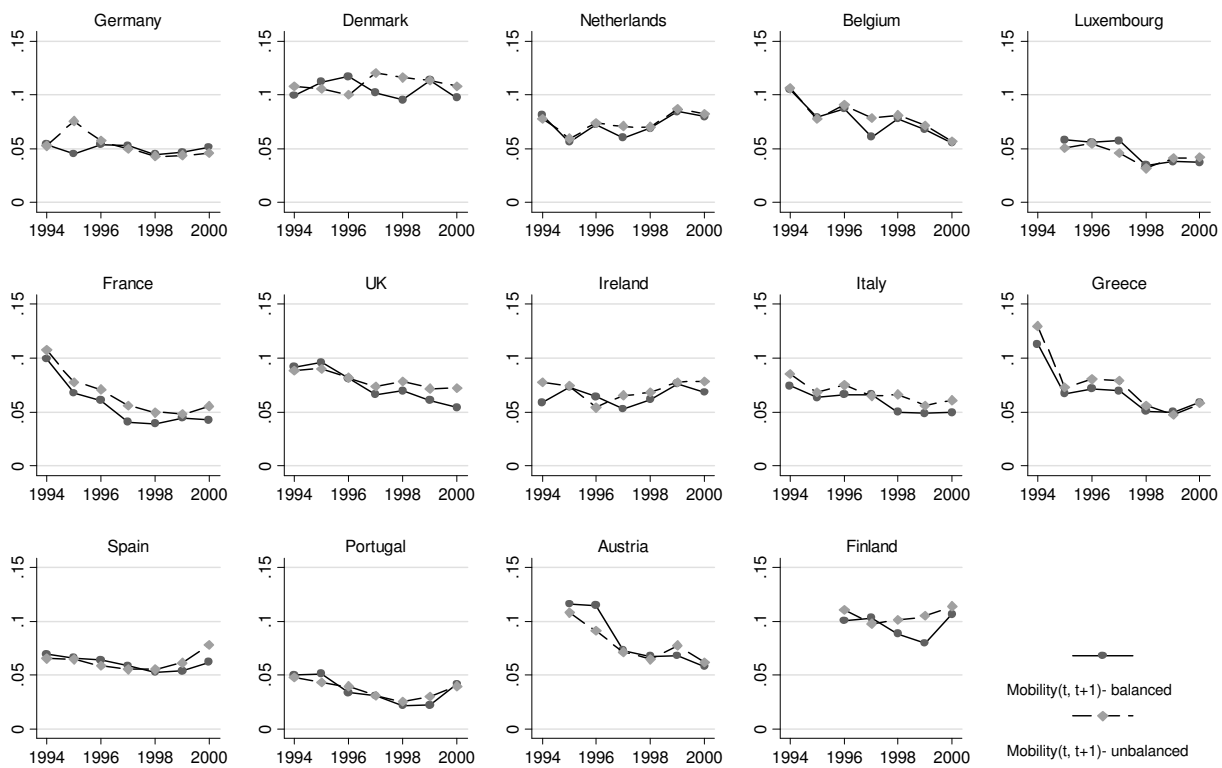

Mobility(t, $t+1)$ - unbalanced

\section{2-Year Fields Mobility Over Time}
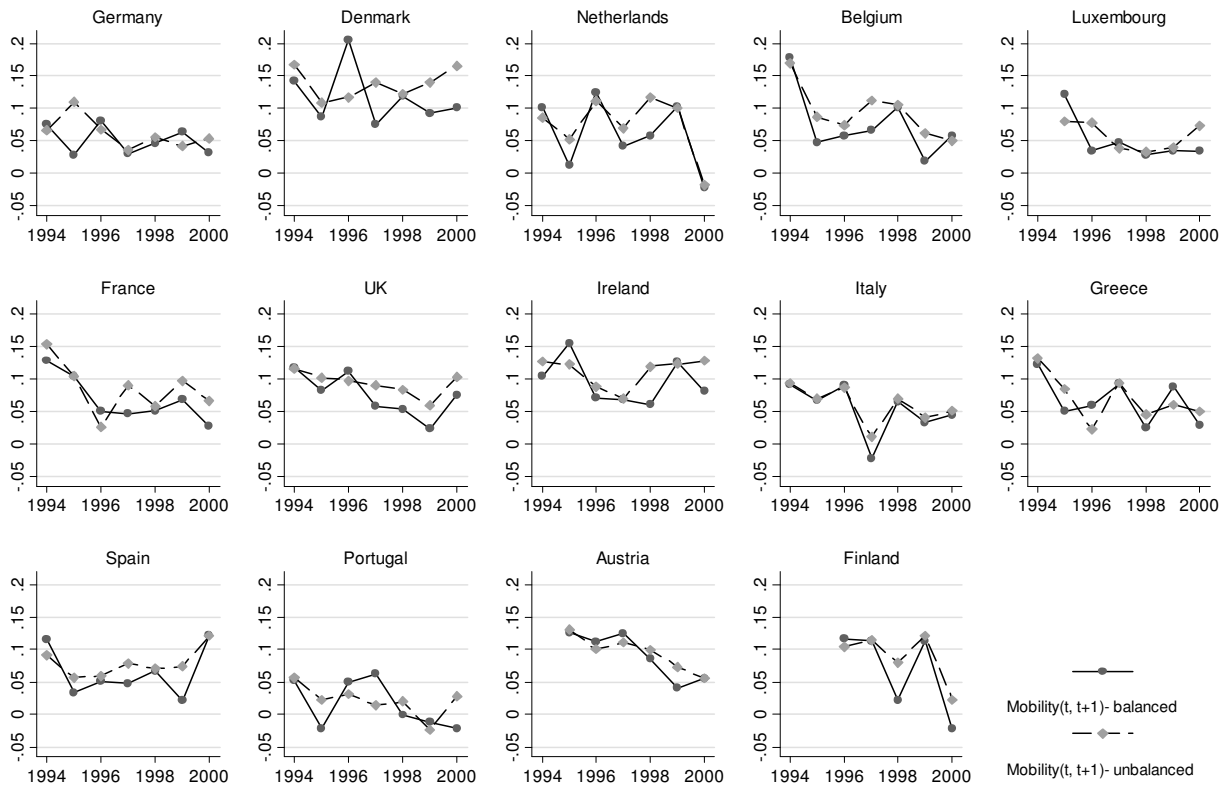

Mobility(t, $t+1)$ - balanced $-\diamond-$

Mobility(t, $t+1)$ - unbalanced

Figure 3.13. The Evolution of 2-Year Period Mobility 
Based on the balanced approach, the evolution of the 2-year Fields index reveals that mobility became less equalizing in 2000-2001 compared with the first two waves in most countries, except Spain where it became more equalizing, and Netherlands, Portugal and Finland, where 2-year period mobility turned disequalizing. Based on the unbalanced approach, 2-year period mobility became more equalizing in Spain and Ireland, disequalizing in Netherlands and less equalizing in the other countries.

Similar with the Shorrocks index, the evolution of the Fields index was not monotonic and the yearly trends differ between the balanced and unbalanced approach.

Figure 3.14 shows the evolution of the 4-year mobility using both the Fields and the Shorrocks index. Based on the balanced approach (Panel A) using the Shorrocks index, long-term mobility decreased over time in all countries. The same is observed in the unbalanced approach (Panel B), except for Netherlands and Denmark where long-period mobility increased.

The balanced approach (Panel A) using the Fields index reveals that the 4-year period mobility became less equalizing over time in all countries, except Portugal, where it became more equalizing, and Italy it became disequalizing. The unbalanced approach (Panel B) reveals a slightly different picture for some countries, highlighting again that the Fields index is more sensitive to differential attrition. The 4-year period mobility became less equalizing in all countries, except Spain and Netherlands. No country records a disequalizing mobility under the unbalanced approach.

To sum up, under the balanced approach all countries record a decrease in longterm mobility which also becomes less equalizing in most countries. Exceptions are Italy where it becomes disequalizing, and Portugal, where it becomes more equalizing. The divergent trend between the Shorrocks and the Fields index might signal that Portugal records a decrease in the disequalizing part of mobility, which in turn increases the Fields index.

Turning to the unbalanced approach, all countries except Netherlands and Denmark, record a decrease in long-term mobility, which also becomes less equalizing in all countries except Spain and Netherlands. The divergent trend between the two indices in Spain and Denmark might signal that Spain records a decrease in the disequalizing part of mobility, which in turn increases the Fields index, whereas Denmark records an increase in the disequalizing part of mobility, which in turn decreases the Fields index. In Netherlands long-term mobility increases, becoming more equalizing. 

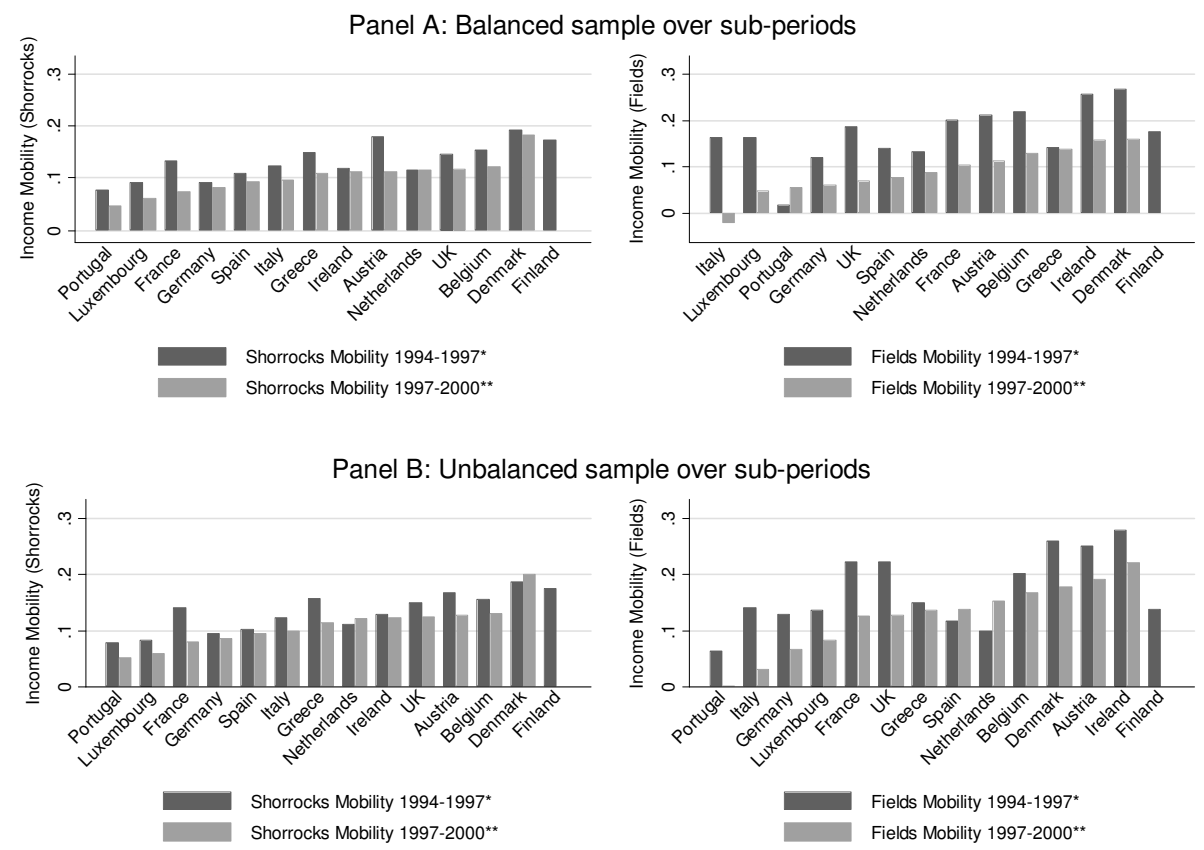

Figure 3.14. The Evolution of Long-Term Mobility Over Time

Note: $\quad\left({ }^{*}\right)$ For Luxembourg and Austria the figure displays the value for 1995-1998, and for Finland for 1996-1999

$\left.{ }^{(* *}\right)$ For Luxembourg and Austria the figure displays the value for 1998-2001

\subsection{Concluding remarks}

This paper explores the degree of lifetime earnings mobility for men in $14 \mathrm{EU}$ countries using ECHP between 1994 and 2001. We address two questions. First, do EU citizens have an increased opportunity to improve their position in the distribution of lifetime earnings? Second, to what extent does earnings mobility work to equalize/disequalize longer-term earnings relative to cross-sectional inequality and how does it differ across the EU? Moreover, we explored how the findings differ, first if we consider only individuals which record positive earnings in each year between 1994 and 2001 - "the balanced approach", and second if we consider also individuals which do not record positive earnings in each year between 1994 and 2001, but only during the horizon over which mobility is measured - "the unbalanced approach". The basic assumption is that mobility measured over a horizon of 8 years is a good proxy for lifetime mobility. 
The first question is answered by applying the Shorrocks (1978) index. We find that all countries record an increase in earnings mobility when the horizon over which mobility is measured is extended. This shows that men do have an increasing mobility in the distribution of lifetime earnings as they advance in their career, result confirmed both by the "balanced" and the "unbalanced" approach. Differential attrition appears to have a limited impact on the stability profiles, but a higher impact on the country ranking in Shorrock mobility.

Using the mobility index computed over a horizon of 8 years, we conclude that the highest lifetime mobility is recorded in Denmark, followed by the UK, Belgium, Greece, Ireland, Netherlands, Italy, France, Spain, Germany, and the lowest, Portugal. Therefore Denmark provides the highest opportunity of reducing lifetime earnings differentials and Portugal the lowest. Based on the 6-year mobility, Finland records the second highest lifetime mobility after Denmark. Based on the 7-year mobility, Austria records the second highest lifetime mobility after Denmark, and Luxembourg the second lowest after Portugal. Both approaches confirm these rankings.

The main limitation of this approach is that it fails to answer our second question, whether this mobility is equalizing or disequalizing lifetime earnings differentials. To overcome this limitation we applied the newly developed Fields index. (Fields 2008) In general, mobility increases with the horizon in all countries, except Portugal where mobility decreases with the horizon, turning negative when measured over an 8-year horizon. This finding is confirmed both by the balanced and the unbalanced approach. Thus only in Portugal mobility is exacerbating longterm earning differentials, whereas the other countries manage to reduce earnings differentials in a lifetime perspective.

The Fields index however is affected to a larger extent by differential attrition than the Shorrocks index: the differentiation between the mobility profile under the balanced approach and the one under the unbalanced approach is evident in all countries, in some more than in others. The largest differences between the two curves are observed in Netherlands, Luxembourg, Ireland, Greece, Portugal and Finland.

Using the mobility index computed over a horizon of 8 years as proxy for lifetime mobility, we conclude that in all countries, except Portugal, mobility acts as an equalizer of lifetime differentials. The highest mobility as equalizer of longer term inequality is recorded in Ireland and Denmark, followed by France and Belgium with similar values, then UK, Greece, Netherlands, Germany, Spain and Italy. Based on the 6-year mobility, Finland records the 7th highest equalizing mobility. Based on the 7-year mobility, Austria records the third highest equalizing mobility 
after Ireland and Denmark, and Luxembourg the fifth lowest according to the balanced approach and the sixth lowest according to the unbalanced approach.

Regarding the evolution of long-term mobility over time, the two indices bring complementary pieces of information. The longest time horizon to be followed over time in our data is of 4 years. Due to the short horizon, the implications of the trends in the 4-year period mobility for the evolution of lifetime mobility should be regarded with caution. Some differences are present between the balanced and the unbalanced approach.

Under the balanced approach all countries record a decrease in long-term mobility which also becomes less equalizing in most countries. Exceptions are Italy where it becomes disequalizing, and Portugal, where it becomes more equalizing. The divergent trend between the Shorrocks and the Fields index might signal that Portugal records a decrease in the disequalizing part of mobility, which in turn increases the Fields index.

Turning to the unbalanced approach, all countries except Netherlands and Denmark, record a decrease in long-term mobility, which also becomes less equalizing in all countries except Spain and Netherlands. The divergent trend between the two indices in Spain and Denmark might signal that Spain records a decrease in the disequalizing part of mobility, which in turn increases the Fields index, whereas Denmark records an increase in the disequalizing part of mobility, which in turn decreases the Fields index. Netherlands records an increase in longterm mobility, which also becomes more equalizing.

What are the possible implications for lifetime earnings inequality, assuming that the 8-year period mobility is a good proxy for lifetime mobility? Among the countries which recorded an increase in cross-sectional earnings inequality over the sample period - Netherlands, Greece, Finland, Portugal, Luxembourg, Italy, and Germany - only in Portugal lifetime mobility is expected to exacerbate annual differentials in a lifetime perspective. For the rest, mobility acts as an equalizer of lifetime differentials, thus counteracting the increase in annual inequality. For the countries recording a decrease in annual inequality - Ireland, Austria, Denmark, Belgium, Spain, France, and UK - lifetime mobility is expected to enhance the reduction in lifetime earnings differentials.

Given these trends we expect Portugal to record the highest and Denmark the lowest lifetime earnings inequality among the $14 \mathrm{EU}$ countries. The outstanding performance of the labour market in Denmark, which records the lowest crosssectional earnings inequality, coupled with the highest lifetime mobility and the second highest equalizing lifetime mobility - might be due to the so called 
"flexicurity approach" (OECD, 2004), which represents an interesting combination of high labour market dynamism and a relatively high social protection. It is a mix of flexibility (a high degree of job mobility thanks to low employment protection legislation), social security (a generous system of unemployment benefits) and active labour market programmes. The coupled effect of these factors assures a small annual inequality and an earnings mobility which acts as an equalizer of lifetime differentials, offering at the same time a high opportunity to low wage individuals to improve their relative position in the distribution of lifetime earnings.

Our paper has a threefold contribution to the existing literature. First, by exploring a different facet of mobility - as an equalizer or disequalizer of lifetime earnings differentials -, we fill part of the gap in the study of earnings mobility at the EU level. Second, we apply a new class of measures of mobility as equalizer of longterm differentials - developed by Fields (2008) -, which complement the information provided by the well-known Shorrocks measure. Therefore we highlight once again the limitations of the Shorrocks measure put forward by Benabou and Ok (2001) and Fields (2008), and the need to provide additional measures for capturing the real nature of lifetime earnings mobility. Third, by comparing the findings between the "unbalanced" and the "balanced approach", meaning between including/and not the individuals that exited and (re)entered the panel, we explored the impact of differentials attrition on the study of earnings mobility as an equalizer of long-term differentials. 


\subsection{Annex}

Table 3-A-1. Inflows and Outflows of Individuals in the Sample - Germany

\begin{tabular}{|c|c|c|c|c|c|c|c|c|}
\hline & 1994 & 1995 & 1996 & 1997 & 1998 & 1999 & 2000 & 2001 \\
\hline $\begin{array}{l}\text { Number of individuals with } \\
\text { positive earnings }\end{array}$ & 25018 & 26059 & 25806 & 24889 & 23290 & 22955 & 21909 & 20703 \\
\hline $\begin{array}{l}\text { Number of individuals with } \\
\text { positive earnings over the entire } \\
\text { sample }\end{array}$ & \multicolumn{8}{|c|}{11057} \\
\hline \multicolumn{9}{|c|}{$\begin{array}{c}\text { Absolute number and proportion of individuals who report positive earnings in current year conditional on being in } \\
\text { the sample in previous year }\end{array}$} \\
\hline & Frequencies & 23956 & 25224 & 24197 & 22814 & 22321 & 21290 & 20107 \\
\hline & $\%$ & 66.99 & 67.37 & 66.2 & 63.01 & 64.84 & 64.86 & 64.39 \\
\hline \multicolumn{9}{|c|}{$\begin{array}{l}\text { Absolute number and proportion of individuals who report no earnings in current year conditional on being in the } \\
\text { sample in the previous year }\end{array}$} \\
\hline Unemployed & Frequencies & 3448 & 3461 & 4119 & 3932 & 3055 & 2787 & 2766 \\
\hline Inactive & $\%$ & 9.64 & 9.24 & 11.27 & 10.86 & 8.87 & 8.49 & 8.86 \\
\hline \multirow{2}{*}{ Attrition } & Frequencies & 1885 & 2182 & 1892 & 3280 & 2951 & 2924 & 2830 \\
\hline & $\%$ & 5.27 & 5.83 & 5.18 & 9.06 & 8.57 & 8.91 & 9.06 \\
\hline \multirow{2}{*}{ Missing Wage } & Frequencies & 6470 & 6576 & 6345 & 6180 & 6100 & 5826 & 5524 \\
\hline & $\%$ & 18.09 & 17.56 & 17.36 & 17.07 & 17.72 & 17.75 & 17.69 \\
\hline \multirow[t]{2}{*}{ Total } & Frequencies & 35759 & 37443 & 36553 & 36206 & 34427 & 32827 & 31227 \\
\hline & $\%$ & 100 & 100 & 100 & 100 & 100 & 100 & 100 \\
\hline
\end{tabular}

Table 3-A-1. Inflows and Outflows of Individuals in the Sample - Denmark

\begin{tabular}{|c|c|c|c|c|c|c|c|c|}
\hline & 1994 & 1995 & 1996 & 1997 & 1998 & 1999 & 2000 & 2001 \\
\hline $\begin{array}{l}\text { Number of individuals with } \\
\text { positive earnings }\end{array}$ & 20899 & 20399 & 19190 & 19062 & 17321 & 16235 & 15678 & 15380 \\
\hline $\begin{array}{l}\text { Number of individuals with } \\
\text { positive earnings over the entire } \\
\text { sample }\end{array}$ & \multicolumn{8}{|c|}{8247} \\
\hline \multicolumn{9}{|c|}{$\begin{array}{l}\text { Absolute number and proportion of individuals who report positive earnings in current year conditional on being in the } \\
\text { sample in previous year }\end{array}$} \\
\hline & Frequencies & 19854 & 18527 & 18110 & 16442 & 15334 & 14865 & 14642 \\
\hline & $\%$ & 68.74 & 66.59 & 69.43 & 66.23 & 67.41 & 69.6 & 71.6 \\
\hline \multicolumn{9}{|c|}{$\begin{array}{c}\text { Absolute number and proportion of individuals who report no earnings in current year conditional on being in the } \\
\text { sample in the previous year }\end{array}$} \\
\hline Unemployed & Frequencies & 1535 & 1744 & 951 & 899 & 732 & 658 & 958 \\
\hline Inactive & $\%$ & 5.31 & 6.27 & 3.65 & 3.62 & 3.22 & 3.08 & 4.68 \\
\hline \multirow{2}{*}{ Attrition } & Frequencies & 2440 & 3096 & 2914 & 3603 & 2922 & 2133 & 1775 \\
\hline & $\%$ & 8.45 & 11.13 & 11.17 & 14.51 & 12.85 & 9.99 & 8.68 \\
\hline \multirow{2}{*}{ Missing Wage } & Frequencies & 5054 & 4454 & 4110 & 3881 & 3759 & 3703 & 3074 \\
\hline & $\%$ & 17.5 & 16.01 & 15.76 & 15.63 & 16.53 & 17.34 & 15.03 \\
\hline \multirow[t]{2}{*}{ Total } & Frequencies & 28883 & 27821 & 26085 & 24825 & 22747 & 21359 & 20449 \\
\hline & $\%$ & 100 & 100 & 100 & 100 & 100 & 100 & 100 \\
\hline
\end{tabular}


Table 3-A-1.Inflows and Outflows of Individuals in the Sample - Netherlands

\begin{tabular}{|c|c|c|c|c|c|c|c|c|}
\hline & 1994 & 1995 & 1996 & 1997 & 1998 & 1999 & 2000 & 2001 \\
\hline $\begin{array}{l}\text { Number of individuals with } \\
\text { positive earnings }\end{array}$ & 20221 & 22100 & 22892 & 22753 & 22863 & 23233 & 24065 & 24130 \\
\hline $\begin{array}{l}\text { Number of individuals with } \\
\text { positive earnings over the entire } \\
\text { sample }\end{array}$ & \multicolumn{8}{|c|}{8173} \\
\hline \multicolumn{9}{|c|}{$\begin{array}{c}\text { Absolute number and proportion of individuals who report positive earnings in current year conditional on being in the } \\
\text { sample in previous year }\end{array}$} \\
\hline & Frequencies & 20578 & 21328 & 21221 & 21055 & 20545 & 21026 & 21341 \\
\hline & $\%$ & 69.07 & 71.37 & 68.68 & 67.52 & 67.24 & 68.56 & 69.59 \\
\hline \multicolumn{9}{|c|}{$\begin{array}{c}\text { Absolute number and proportion of individuals who report no earnings in current year conditional on being in the } \\
\text { sample in the previous year }\end{array}$} \\
\hline Unemployed & Frequencies & 2418 & 2356 & 2536 & 2120 & 1984 & 1840 & 1689 \\
\hline Inactive & $\%$ & 8.12 & 7.88 & 8.21 & 6.8 & 6.49 & 6 & 5.51 \\
\hline \multirow{2}{*}{ Attrition } & Frequencies & 2941 & 1889 & 2591 & 3562 & 3984 & 4301 & 4891 \\
\hline & $\%$ & 9.87 & 6.32 & 8.39 & 11.42 & 13.04 & 14.02 & 15.95 \\
\hline \multirow{2}{*}{ Missing Wage } & Frequencies & 3857 & 4310 & 4550 & 4448 & 4042 & 3502 & 2745 \\
\hline & $\%$ & 12.95 & 14.42 & 14.73 & 14.26 & 13.23 & 11.42 & 8.95 \\
\hline \multirow[t]{2}{*}{ Total } & Frequencies & 29794 & 29883 & 30898 & 31185 & 30555 & 30669 & 30666 \\
\hline & $\%$ & 100 & 100 & 100 & 100 & 100 & 100 & 100 \\
\hline
\end{tabular}

Table 3-A-1.Inflows and Outflows of Individuals in the Sample - Belgium

\begin{tabular}{|c|c|c|c|c|c|c|c|c|}
\hline & 1994 & 1995 & 1996 & 1997 & 1998 & 1999 & 2000 & 2001 \\
\hline $\begin{array}{l}\text { Number of individuals with } \\
\text { positive earnings }\end{array}$ & 35342 & 34367 & 33280 & 32378 & 31129 & 29414 & 28087 & 26538 \\
\hline $\begin{array}{l}\text { Number of individuals with } \\
\text { positive earnings over the entire } \\
\text { sample }\end{array}$ & \multicolumn{8}{|c|}{16910} \\
\hline \multicolumn{9}{|c|}{$\begin{array}{l}\text { Absolute number and proportion of individuals who report positive earnings in current year conditional on being in the } \\
\text { sample in previous year }\end{array}$} \\
\hline & Frequencies & 33277 & 32384 & 31564 & 30575 & 28731 & 27460 & 25790 \\
\hline & $\%$ & 63.43 & 63.65 & 64.38 & 63.88 & 64.28 & 65.15 & 64.38 \\
\hline \multicolumn{9}{|c|}{$\begin{array}{l}\text { Absolute number and proportion of individuals who report no earnings in current year conditional on being in the } \\
\text { sample in the previous year }\end{array}$} \\
\hline Unemployed & Frequencies & 3810 & 5127 & 4378 & 3601 & 3040 & 3090 & 2540 \\
\hline Inactive & $\%$ & 7.26 & 10.08 & 8.93 & 7.52 & 6.8 & 7.33 & 6.34 \\
\hline \multirow{2}{*}{ Attrition } & Frequencies & 4145 & 3798 & 3473 & 4803 & 4421 & 3851 & 4930 \\
\hline & $\%$ & 7.9 & 7.46 & 7.08 & 10.04 & 9.89 & 9.14 & 12.31 \\
\hline \multirow{2}{*}{ Missing Wage } & Frequencies & 11228 & 9573 & 9614 & 8882 & 8504 & 7748 & 6798 \\
\hline & $\%$ & 21.4 & 18.81 & 19.61 & 18.56 & 19.03 & 18.38 & 16.97 \\
\hline \multirow[t]{2}{*}{ Total } & Frequencies & 52460 & 50882 & 49029 & 47861 & 44696 & 42149 & 40058 \\
\hline & $\%$ & 100 & 100 & 100 & 100 & 100 & 100 & 100 \\
\hline
\end{tabular}


Table 3-A-1.Inflows and Outflows of Individuals in the Sample - Luxembourg

\begin{tabular}{|c|c|c|c|c|c|c|c|c|}
\hline & 1994 & 1995 & 1996 & 1997 & 1998 & 1999 & 2000 & 2001 \\
\hline $\begin{array}{l}\text { Number of individuals with } \\
\text { positive earnings }\end{array}$ & & 15829 & 13695 & 14489 & 13403 & 14075 & 12667 & 12992 \\
\hline $\begin{array}{l}\text { Number of individuals with } \\
\text { positive earnings over the entire } \\
\text { sample }\end{array}$ & & & & & 7283 & & & \\
\hline \multicolumn{9}{|c|}{$\begin{array}{c}\text { Absolute number and proportion of individuals who report positive earnings in current year conditional on being in the } \\
\text { sample in previous year }\end{array}$} \\
\hline & Frequencies & & 13417 & 12498 & 13190 & 12257 & 12402 & 11457 \\
\hline & $\%$ & & 64.75 & 69.48 & 69.33 & 69.81 & 68.71 & 70.39 \\
\hline \multicolumn{9}{|c|}{$\begin{array}{c}\text { Absolute number and proportion of individuals who report no earnings in current year conditional on being in the } \\
\text { sample in the previous year }\end{array}$} \\
\hline Unemployed & Frequencies & & 1765 & 1559 & 1505 & 1408 & 1246 & 954 \\
\hline Inactive & $\%$ & & 8.52 & 8.67 & 7.91 & 8.02 & 6.9 & 5.86 \\
\hline \multirow{2}{*}{ Attrition } & Frequencies & & 3423 & 1663 & 2109 & 1913 & 2346 & 1940 \\
\hline & $\%$ & & 16.52 & 9.25 & 11.09 & 10.9 & 13 & 11.92 \\
\hline \multirow{2}{*}{ Missing Wage } & Frequencies & & 2116 & 2267 & 2220 & 1980 & 2057 & 1926 \\
\hline & $\%$ & & 10.21 & 12.6 & 11.67 & 11.28 & 11.4 & 11.83 \\
\hline \multirow[t]{2}{*}{ Total } & Frequencies & & 20721 & 17987 & 19024 & 17558 & 18051 & 16277 \\
\hline & $\%$ & 100 & 100 & 100 & 100 & 100 & 100 & 100 \\
\hline
\end{tabular}

Table 3-A-1.Inflows and Outflows of Individuals in the Sample - France

\begin{tabular}{|c|c|c|c|c|c|c|c|c|}
\hline & 1994 & 1995 & 1996 & 1997 & 1998 & 1999 & 2000 & 2001 \\
\hline $\begin{array}{l}\text { Number of individuals with } \\
\text { positive earnings }\end{array}$ & 20137 & 19270 & 19042 & 17906 & 14467 & 14012 & 13760 & 14212 \\
\hline $\begin{array}{c}\text { Number of individuals with } \\
\text { positive earnings over the entire } \\
\text { sample }\end{array}$ & \multicolumn{8}{|c|}{5895} \\
\hline \multicolumn{9}{|c|}{$\begin{array}{l}\text { Absolute number and proportion of individuals who report positive earnings in current year conditional on being in the } \\
\text { sample in previous year }\end{array}$} \\
\hline & Frequencies & 19143 & 18197 & 17243 & 14014 & 12209 & 12080 & 12468 \\
\hline & $\%$ & 62.47 & 64.76 & 62 & 52.08 & 54.24 & 55.54 & 60.8 \\
\hline \multicolumn{9}{|c|}{$\begin{array}{l}\text { Absolute number and proportion of individuals who report no earnings in current year conditional on being in the } \\
\text { sample in the previous year }\end{array}$} \\
\hline Unemployed & Frequencies & 3259 & 3042 & 3426 & 3006 & 2607 & 2072 & 1995 \\
\hline Inactive & $\%$ & 10.64 & 10.83 & 12.32 & 11.17 & 11.58 & 9.53 & 9.73 \\
\hline \multirow{2}{*}{ Attrition } & Frequencies & 3371 & 2213 & 2785 & 5584 & 3531 & 3786 & 2658 \\
\hline & $\%$ & 11 & 7.88 & 10.01 & 20.75 & 15.69 & 17.41 & 12.96 \\
\hline \multirow{2}{*}{ Missing Wage } & Frequencies & 4871 & 4646 & 4358 & 4304 & 4162 & 3811 & 3385 \\
\hline & $\%$ & 15.9 & 16.53 & 15.67 & 16 & 18.49 & 17.52 & 16.51 \\
\hline \multirow[t]{2}{*}{ Total } & Frequencies & 30644 & 28098 & 27812 & 26908 & 22509 & 21749 & 20506 \\
\hline & $\%$ & 100 & 100 & 100 & 100 & 100 & 100 & 100 \\
\hline
\end{tabular}


Table 3-A-1. Inflows and Outflows of Individuals in the Sample - UK

\begin{tabular}{|c|c|c|c|c|c|c|c|c|}
\hline & 1994 & 1995 & 1996 & 1997 & 1998 & 1999 & 2000 & 2001 \\
\hline $\begin{array}{l}\text { Number of individuals with } \\
\text { positive earnings }\end{array}$ & 24949 & 25329 & 25495 & 26010 & 26145 & 25750 & 25674 & 25264 \\
\hline $\begin{array}{l}\text { Number of individuals with } \\
\text { positive earnings over the entire } \\
\text { sample }\end{array}$ & \multicolumn{8}{|c|}{13977} \\
\hline \multicolumn{9}{|c|}{$\begin{array}{l}\text { Absolute number and proportion of individuals who report positive earnings in current year conditional on being in the } \\
\text { sample in previous year }\end{array}$} \\
\hline & Frequencies & 24511 & 24848 & 25303 & 25278 & 25006 & 24881 & 24467 \\
\hline & $\%$ & 64.59 & 66.31 & 67.06 & 67.04 & 67.36 & 68.33 & 68.58 \\
\hline \multicolumn{9}{|c|}{$\begin{array}{l}\text { Absolute number and proportion of individuals who report no earnings in current year conditional on being in the } \\
\text { sample in the previous year }\end{array}$} \\
\hline Unemployed & Frequencies & 4712 & 5053 & 4663 & 4140 & 3941 & 3607 & 3595 \\
\hline Inactive & $\%$ & 12.42 & 13.48 & 12.36 & 10.98 & 10.62 & 9.91 & 10.08 \\
\hline \multirow{2}{*}{ Attrition } & Frequencies & 1836 & 966 & 1169 & 2073 & 1919 & 2153 & 2105 \\
\hline & $\%$ & 4.84 & 2.58 & 3.1 & 5.5 & 5.17 & 5.91 & 5.9 \\
\hline \multirow{2}{*}{ Missing Wage } & Frequencies & 6888 & 6605 & 6597 & 6213 & 6257 & 5774 & 5510 \\
\hline & $\%$ & 18.15 & 17.63 & 17.48 & 16.48 & 16.85 & 15.86 & 15.44 \\
\hline \multirow[t]{2}{*}{ Total } & Frequencies & 37947 & 37472 & 37732 & 37704 & 37123 & 36415 & 35677 \\
\hline & $\%$ & 100 & 100 & 100 & 100 & 100 & 100 & 100 \\
\hline
\end{tabular}

Table 3-A-1. Inflows and Outflows of Individuals in the Sample - Ireland

\begin{tabular}{|c|c|c|c|c|c|c|c|c|}
\hline & 1994 & 1995 & 1996 & 1997 & 1998 & 1999 & 2000 & 2001 \\
\hline $\begin{array}{l}\text { Number of individuals with } \\
\text { positive earnings }\end{array}$ & 13937 & 13221 & 12590 & 12515 & 12435 & 12091 & 10745 & 9727 \\
\hline $\begin{array}{l}\text { Number of individuals with } \\
\text { positive earnings over the entire } \\
\text { sample }\end{array}$ & \multicolumn{8}{|c|}{4453} \\
\hline \multicolumn{9}{|c|}{$\begin{array}{l}\text { Absolute number and proportion of individuals who report positive earnings in current year conditional on being in the } \\
\text { sample in previous year }\end{array}$} \\
\hline & Frequencies & 12750 & 12217 & 12212 & 12020 & 11668 & 10236 & 9507 \\
\hline & $\%$ & 49.99 & 50.04 & 52.41 & 53.13 & 54.1 & 51.63 & 54.65 \\
\hline \multicolumn{9}{|c|}{$\begin{array}{l}\text { Absolute number and proportion of individuals who report no earnings in current year conditional on being in the } \\
\text { sample in the previous year }\end{array}$} \\
\hline Unemployed & Frequencies & 4930 & 4723 & 4254 & 3374 & 2905 & 2185 & 2307 \\
\hline Inactive & $\%$ & 19.33 & 19.35 & 18.26 & 14.91 & 13.47 & 11.02 & 13.26 \\
\hline \multirow{2}{*}{ Attrition } & Frequencies & 2167 & 2115 & 1600 & 1936 & 2516 & 3288 & 2362 \\
\hline & $\%$ & 8.5 & 8.66 & 6.87 & 8.56 & 11.66 & 16.59 & 13.58 \\
\hline \multirow{2}{*}{ Missing Wage } & Frequencies & 5656 & 5359 & 5235 & 5292 & 4480 & 4116 & 3220 \\
\hline & $\%$ & 22.18 & 21.95 & 22.47 & 23.39 & 20.77 & 20.76 & 18.51 \\
\hline \multirow[t]{2}{*}{ Total } & Frequencies & 25503 & 24414 & 23301 & 22622 & 21569 & 19825 & 17396 \\
\hline & $\%$ & 100 & 100 & 100 & 100 & 100 & 100 & 100 \\
\hline
\end{tabular}


Table 3-A-1.Inflows and Outflows of Individuals in the Sample - Italy

\begin{tabular}{|c|c|c|c|c|c|c|c|c|}
\hline & 1994 & 1995 & 1996 & 1997 & 1998 & 1999 & 2000 & 2001 \\
\hline $\begin{array}{l}\text { Number of individuals with } \\
\text { positive earnings }\end{array}$ & 32633 & 32236 & 32111 & 29661 & 28865 & 26993 & 26912 & 25170 \\
\hline $\begin{array}{l}\text { Number of individuals with } \\
\text { positive earnings over the entire } \\
\text { sample }\end{array}$ & \multicolumn{8}{|c|}{12070} \\
\hline \multicolumn{9}{|c|}{$\begin{array}{l}\text { Absolute number and proportion of individuals who report positive earnings in current year conditional on being in the } \\
\text { sample in previous year }\end{array}$} \\
\hline & Frequencies & 30946 & 31028 & 28717 & 27188 & 25717 & 25348 & 24139 \\
\hline & $\%$ & 51.58 & 51.19 & 47.18 & 47.34 & 46.87 & 48.73 & 48.86 \\
\hline \multicolumn{9}{|c|}{$\begin{array}{c}\text { Absolute number and proportion of individuals who report no earnings in current year conditional on being in the } \\
\text { sample in the previous year }\end{array}$} \\
\hline Unemployed & Frequencies & 7900 & 7799 & 7670 & 6627 & 6890 & 5662 & 5027 \\
\hline Inactive & $\%$ & 13.17 & 12.87 & 12.6 & 11.54 & 12.56 & 10.88 & 10.18 \\
\hline \multirow{2}{*}{ Attrition } & Frequencies & 3175 & 2947 & 5922 & 6030 & 5941 & 5399 & 5920 \\
\hline & $\%$ & 5.29 & 4.86 & 9.73 & 10.5 & 10.83 & 10.38 & 11.98 \\
\hline \multirow{2}{*}{ Missing Wage } & Frequencies & 17978 & 18836 & 18559 & 17585 & 16325 & 15610 & 14315 \\
\hline & $\%$ & 29.96 & 31.08 & 30.49 & 30.62 & 29.75 & 30.01 & 28.98 \\
\hline \multirow[t]{2}{*}{ Total } & Frequencies & 59999 & 60610 & 60868 & 57430 & 54873 & 52019 & 49401 \\
\hline & $\%$ & 100 & 100 & 100 & 100 & 100 & 100 & 100 \\
\hline
\end{tabular}

Table 3-A-1. Inflows and Outflows of Individuals in the Sample - Greece

\begin{tabular}{|c|c|c|c|c|c|c|c|c|}
\hline & 1994 & 1995 & 1996 & 1997 & 1998 & 1999 & 2000 & 2001 \\
\hline $\begin{array}{l}\text { Number of individuals with } \\
\text { positive earnings }\end{array}$ & 27974 & 27654 & 26150 & 24865 & 22675 & 22001 & 21335 & 21929 \\
\hline $\begin{array}{l}\text { Number of individuals with } \\
\text { positive earnings over the entire } \\
\text { sample }\end{array}$ & \multicolumn{8}{|c|}{9404} \\
\hline \multicolumn{9}{|c|}{$\begin{array}{c}\text { Absolute number and proportion of individuals who report positive earnings in current year conditional on being in the } \\
\text { sample in previous year }\end{array}$} \\
\hline & Frequencies & 26868 & 25946 & 24385 & 21815 & 20357 & 20443 & 21342 \\
\hline & $\%$ & 45.83 & 45.69 & 44.98 & 42.09 & 43.52 & 46.06 & 49.72 \\
\hline \multicolumn{9}{|c|}{$\begin{array}{l}\text { Absolute number and proportion of individuals who report no earnings in current year conditional on being in the } \\
\text { sample in the previous year }\end{array}$} \\
\hline Unemployed & Frequencies & 7537 & 6813 & 6419 & 4523 & 4489 & 4427 & 3858 \\
\hline Inactive & $\%$ & 12.86 & 12 & 11.84 & 8.73 & 9.6 & 9.97 & 8.99 \\
\hline \multirow{2}{*}{ Attrition } & Frequencies & 4417 & 4392 & 4347 & 7892 & 6222 & 4159 & 2363 \\
\hline & $\%$ & 7.53 & 7.73 & 8.02 & 15.23 & 13.3 & 9.37 & 5.5 \\
\hline \multirow{2}{*}{ Missing Wage } & Frequencies & 19802 & 19640 & 19068 & 17599 & 15707 & 15352 & 15365 \\
\hline & $\%$ & 33.78 & 34.58 & 35.17 & 33.96 & 33.58 & 34.59 & 35.79 \\
\hline \multirow[t]{2}{*}{ Total } & Frequencies & 58624 & 56791 & 54219 & 51829 & 46775 & 44381 & 42928 \\
\hline & $\%$ & 100 & 100 & 100 & 100 & 100 & 100 & 100 \\
\hline
\end{tabular}


Table 3-A-1. Inflows and Outflows of Individuals in the Sample - Spain

\begin{tabular}{|c|c|c|c|c|c|c|c|c|}
\hline & 1994 & 1995 & 1996 & 1997 & 1998 & 1999 & 2000 & 2001 \\
\hline $\begin{array}{l}\text { Number of individuals with } \\
\text { positive earnings }\end{array}$ & 22559 & 21863 & 21296 & 20975 & 20371 & 20580 & 19898 & 20185 \\
\hline $\begin{array}{c}\text { Number of individuals with } \\
\text { positive earnings over the entire } \\
\text { sample }\end{array}$ & \multicolumn{8}{|c|}{7234} \\
\hline \multicolumn{9}{|c|}{$\begin{array}{c}\text { Absolute number and proportion of individuals who report positive earnings in current year conditional on being in the } \\
\text { sample in previous year }\end{array}$} \\
\hline & Frequencies & 21460 & 20521 & 20329 & 19456 & 19679 & 19167 & 19352 \\
\hline & $\%$ & 47.6 & 48.29 & 48.49 & 48.63 & 52.13 & 52.12 & 56.06 \\
\hline \multicolumn{9}{|c|}{$\begin{array}{l}\text { Absolute number and proportion of individuals who report no earnings in current year conditional on being in the } \\
\text { sample in the previous year }\end{array}$} \\
\hline Unemployed & Frequencies & 8419 & 8230 & 7353 & 5970 & 5083 & 4512 & 4761 \\
\hline Inactive & $\%$ & 18.67 & 19.37 & 17.54 & 14.92 & 13.46 & 12.27 & 13.79 \\
\hline \multirow{2}{*}{ Attrition } & Frequencies & 4467 & 3000 & 4120 & 4327 & 3188 & 3922 & 3052 \\
\hline & $\%$ & 9.91 & 7.06 & 9.83 & 10.81 & 8.44 & 10.66 & 8.84 \\
\hline \multirow{2}{*}{ Missing Wage } & Frequencies & 10741 & 10742 & 10121 & 10259 & 9802 & 9176 & 7357 \\
\hline & $\%$ & 23.82 & 25.28 & 24.14 & 25.64 & 25.96 & 24.95 & 21.31 \\
\hline \multirow[t]{2}{*}{ Total } & Frequencies & 45087 & 42493 & 41923 & 40012 & 37752 & 36777 & 34522 \\
\hline & $\%$ & 100 & 100 & 100 & 100 & 100 & 100 & 100 \\
\hline
\end{tabular}

Table 3-A-1. Inflows and Outflows of Individuals in the Sample - Portugal

\begin{tabular}{|c|c|c|c|c|c|c|c|c|}
\hline & 1994 & 1995 & 1996 & 1997 & 1998 & 1999 & 2000 & 2001 \\
\hline $\begin{array}{l}\text { Number of individuals with } \\
\text { positive earnings }\end{array}$ & 14653 & 15450 & 15379 & 15087 & 14837 & 14569 & 14604 & 14550 \\
\hline $\begin{array}{c}\text { Number of individuals with } \\
\text { positive earnings over the entire } \\
\text { sample }\end{array}$ & \multicolumn{8}{|c|}{6214} \\
\hline \multicolumn{9}{|c|}{$\begin{array}{l}\text { Absolute number and proportion of individuals who report positive earnings in current year conditional on being in the } \\
\text { sample in previous year }\end{array}$} \\
\hline & Frequencies & 13892 & 14538 & 14321 & 13977 & 13921 & 13952 & 13942 \\
\hline & $\%$ & 57.84 & 57.5 & 57.32 & 56.98 & 59.12 & 60.83 & 62.16 \\
\hline \multicolumn{9}{|c|}{$\begin{array}{l}\text { Absolute number and proportion of individuals who report no earnings in current year conditional on being in the } \\
\text { sample in the previous year }\end{array}$} \\
\hline Unemployed & Frequencies & 2187 & 2264 & 2396 & 2019 & 2067 & 1843 & 1702 \\
\hline Inactive & $\%$ & 9.11 & 8.95 & 9.59 & 8.23 & 8.78 & 8.04 & 7.59 \\
\hline \multirow{2}{*}{ Attrition } & Frequencies & 1701 & 1908 & 1918 & 2346 & 1956 & 1617 & 1575 \\
\hline & $\%$ & 7.08 & 7.55 & 7.68 & 9.56 & 8.31 & 7.05 & 7.02 \\
\hline \multirow{2}{*}{ Missing Wage } & Frequencies & 6236 & 6573 & 6350 & 6189 & 5602 & 5525 & 5211 \\
\hline & $\%$ & 25.97 & 26 & 25.42 & 25.23 & 23.79 & 24.09 & 23.23 \\
\hline \multirow[t]{2}{*}{ Total } & Frequencies & 24016 & 25283 & 24985 & 24531 & 23546 & 22937 & 22430 \\
\hline & $\%$ & 100 & 100 & 100 & 100 & 100 & 100 & 100 \\
\hline
\end{tabular}


Table 3-A-1. Inflows and Outflows of Individuals in the Sample - Austria

\begin{tabular}{|c|c|c|c|c|c|c|c|c|}
\hline & 1994 & 1995 & 1996 & 1997 & 1998 & 1999 & 2000 & 2001 \\
\hline $\begin{array}{l}\text { Number of individuals with } \\
\text { positive earnings }\end{array}$ & & 17944 & 17789 & 17199 & 16209 & 15162 & 13816 & 13056 \\
\hline $\begin{array}{l}\text { Number of individuals with } \\
\text { positive earnings over the entire } \\
\text { sample }\end{array}$ & & & & & 8127 & & & \\
\hline \multicolumn{9}{|c|}{$\begin{array}{c}\text { Absolute number and proportion of individuals who report positive earnings in current year conditional on being in the } \\
\text { sample in previous year }\end{array}$} \\
\hline & Frequencies & & 16472 & 16384 & 15634 & 14551 & 13403 & 12601 \\
\hline & $\%$ & & 67.96 & 68.2 & 67.49 & 67.2 & 66.51 & 68.21 \\
\hline \multicolumn{9}{|c|}{$\begin{array}{c}\text { Absolute number and proportion of individuals who report no earnings in current year conditional on being in the } \\
\text { sample in the previous year }\end{array}$} \\
\hline Unemployed & Frequencies & & 1209 & 1231 & 906 & 790 & 803 & 843 \\
\hline Inactive & $\%$ & & 4.99 & 5.12 & 3.91 & 3.65 & 3.98 & 4.56 \\
\hline \multirow{2}{*}{ Attrition } & Frequencies & & 2195 & 2080 & 2435 & 2470 & 2409 & 1794 \\
\hline & $\%$ & & 9.06 & 8.66 & 10.51 & 11.41 & 11.95 & 9.71 \\
\hline \multirow{2}{*}{ Missing Wage } & Frequencies & & 4361 & 4330 & 4189 & 3842 & 3538 & 3235 \\
\hline & $\%$ & & 17.99 & 18.02 & 18.08 & 17.74 & 17.56 & 17.51 \\
\hline \multirow[t]{2}{*}{ Total } & Frequencies & & 24237 & 24025 & 23164 & 21653 & 20153 & 18473 \\
\hline & $\%$ & & 100 & 100 & 100 & 100 & 100 & 100 \\
\hline
\end{tabular}

Table 3-A-1. Inflows and Outflows of Individuals in the Sample - Finland

\begin{tabular}{|c|c|c|c|c|c|c|c|}
\hline & & 1996 & 1997 & 1998 & 1999 & 2000 & 2001 \\
\hline $\begin{array}{l}\text { Number of individuals with } \\
\text { positive earnings }\end{array}$ & & 15811 & 15845 & 15895 & 15546 & 13329 & 13057 \\
\hline $\begin{array}{l}\text { Number of individuals with } \\
\text { positive earnings over the entire } \\
\text { sample }\end{array}$ & & \multicolumn{6}{|c|}{6913} \\
\hline \multicolumn{8}{|c|}{$\begin{array}{l}\text { Absolute number and proportion of individuals who report positive earnings in current year conditional on being in the } \\
\text { sample in previous year }\end{array}$} \\
\hline & Frequencies & & 15246 & 15345 & 14753 & 12756 & 12588 \\
\hline & $\%$ & & 55.95 & 57.2 & 59.29 & 53.83 & 64.16 \\
\hline \multicolumn{8}{|c|}{$\begin{array}{l}\text { Absolute number and proportion of individuals who report no earnings in current year conditional on being in the } \\
\text { sample in the previous year }\end{array}$} \\
\hline Unemployed & Frequencies & & 3446 & 2327 & 1657 & 1326 & 1267 \\
\hline Inactive & $\%$ & & 12.65 & 8.67 & 6.66 & 5.6 & 6.46 \\
\hline \multirow{2}{*}{ Attrition } & Frequencies & & 1933 & 3219 & 2658 & 5219 & 1708 \\
\hline & $\%$ & & 7.09 & 12 & 10.68 & 22.02 & 8.71 \\
\hline \multirow{2}{*}{ Missing Wage } & Frequencies & & 6623 & 5937 & 5814 & 4398 & 4057 \\
\hline & $\%$ & & 24.31 & 22.13 & 23.37 & 18.56 & 20.68 \\
\hline \multirow[t]{2}{*}{ Total } & Frequencies & & 27248 & 26828 & 24882 & 23699 & 19620 \\
\hline & $\%$ & & 100 & 100 & 100 & 100 & 100 \\
\hline
\end{tabular}



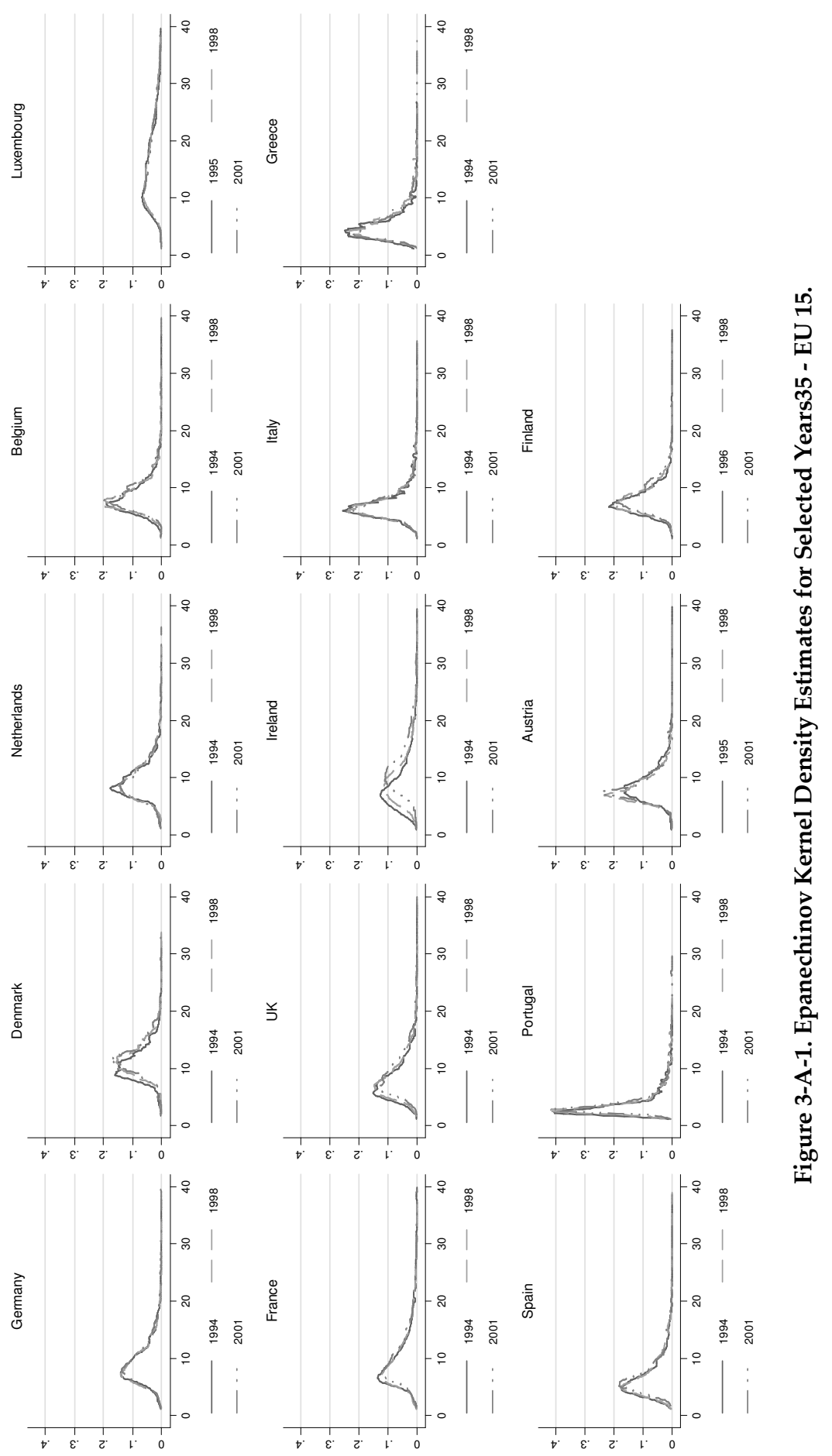

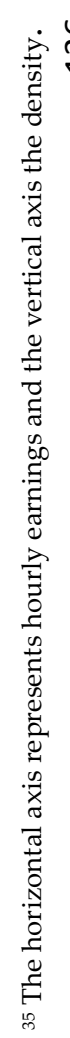




\section{EARNINGS DYNAMICS AND INEQUALITY IN EU, 1994-2001}




\subsection{Introduction}

Interest in the extent of individual earnings dynamics has increased greatly in recent years and was fuelled mainly by the rise in earnings inequality experienced by many developed countries during the 1980s and 1990s, which triggered a strong debate with respect to the driving factors and the implications of this increase.

This paper analyses the dynamic structure of individual earnings in order to explain what is happening behind the changes in the distribution of labour market income across 14 EU countries over the period 1994-2001 using ECHP. More precisely, the aim is to examine the extent to which changes in cross-sectional earnings inequality reflect transitory or permanent components of individual lifecycle earnings variation. So far, at the EU level, no study attempted to analyse and to understand these issues in a comparative manner.

Understanding wage dynamics is vitally important from a welfare perspective, particularly given the large variation in the evolution of cross-sectional wage inequality across Europe over the period 1994-2001. It is highly relevant to understand what the source of this variation is. Did the increase in cross-sectional wage inequality observed in some countries result from greater transitory fluctuations in earnings and individuals facing a higher degree of earnings mobility? Or is this rise reflecting increasing permanent differences between individuals with mobility remaining constant or even falling? What about countries that recorded a decrease in cross-sectional earnings inequalities, what lessons can we learn from them? Is this decrease the effect of an increase in mobility which helped individuals improve their income position in the distribution of permanent income? Are there common trends in earnings inequality and mobility across different countries? Understanding the contributions of the changes in permanent and transitory components of earnings variation to increased cross-sectional earnings inequality is very useful in the evaluation of alternative hypotheses for wage structure changes and for determining the potential welfare consequences of rising inequality. (Katz and Autor, 1999)

These questions are highly relevant in the context of the changes that took place in the EU labour market policy framework after 1995 under the incidence of the 1994 OECD Jobs Strategy, which recommended policies to increase wage flexibility, lower non-wage labour costs and allow relative wages to better reflect individual differences in productivity and local labour market conditions (OECD 2004; DewBecker and Gordon 2008). This appears to have worsened the apparent trade-off 
between a strong employment performance and a more equal distribution of earnings, consistent with relative labour demand having shifted towards highskilled workers OECD (2004).

As pointed out by OECD (2004) and Dew-Becker and Gordon (2008), the most notable change after 1995 in Europe has been increased country heterogeneity. We will investigate how this heterogeneity translates itself in the level and components of the cross-sectional earnings inequality and earnings mobility. Equally weighted minimum distance methods are used to estimate the covariance structure of earnings, decompose earnings into a permanent and a transitory component and conclude about their evolution.

The structure of this paper is as follows. Section two presents an overview of the literature review. Section three introduces the theoretical background for wage differentials. Section four provides a description of the data. Section five introduces the econometric specification and estimation method. Section six describes the dynamic structure of individual log earnings for $14 \mathrm{EU}$ countries. Section seven fits the error components models to the covariance structure for each country, decomposing the change in inequality into that accounted for by the change in the permanent and transitory components. Lastly, section eight offers some conclusions.

\subsection{Literature review}

The existing literature on earnings dynamics is predominantly based on US data. Atkinson, Bourguignon et al. (1992) provide a comprehensive survey of the literature on earnings dynamics until 1992. Earlier work focused on fitting statistical models to the earnings process. E.g. Lillard and Willis (1978), Lillard and Weiss (1979), MaCurdy (1982), Abowd and Card (1989) fitted models to the autocovariance structure of earnings and hours, but they did not account for the changes in the autocovariance structure of earnings over time.

Later work, Moffitt and Gottschalk (1995, 1998, 2002) used PSID to estimate the permanent and transitory components of male earnings and how it evolved over time. In Moffitt and Gottschalk (1998), the earnings process was fit by a permanent component, modelled as a random walk in age and a highly persistent serially correlated transitory component, with weights on these components for each year. They found that the increase in the cross-sectional inequality of individual earnings and wage rates in the U.S. between 1969 and 1991 has been roughly equally composed of increases in the variances of the permanent and transitory components of earnings, with little change in earnings mobility rates. Since most of 
the theoretical explanations for the increase in inequality have been aimed at explaining increases in the variance of the permanent component of earnings (e.g. increases in the price of skills), they found their result surprising and unexpected. Therefore, in their most recent study, Moffitt and Gottschalk (2008) estimated the trend in the transitory variance of male earnings using PSID from 1970 to 2004. They found that the transitory variance increased substantially in the 1980's and remained at the same level until 2004, for both less and more educated workers. Moreover, the transitory variance appears to have a strong cyclical component: its increase accounts for between $30 \%$ and $65 \%$ of the rise in the overall inequality, depending on the period.

Using the PSID, Baker (1997) compared two competing specifications for the permanent component of earnings: the "profile heterogeneity or the random growth model" and the "random walk model". In spite of the increased popularity of the latter, Baker (1997) proved that the profile heterogeneity model provides a better representation of the data.

Baker and Solon (2003) decomposed the growth in earnings inequality into its persistent and transitory components using longitudinal income tax records from Canada. The earnings process was fit by a permanent component, modelled as a mixed process composed of a random growth and a random walk in age and a highly persistent serially correlated transitory component, with weights on these components for each year. They found that growth in earnings inequality reflects both an increase in the long-run inequality and an increase in earnings instability.

Up until recently, little work has been carried out in Europe on the dynamic nature of individual earnings. Dickens (2000b) analysed the pattern of individual male wages over time in UK using the New Earnings Survey (NES) panel data set for the period 1975-1995. This study divided the data into year birth cohorts and analysed the auto-covariance structure of hourly and weekly earnings for each cohort. In the tradition of Moffitt and Gottschalk (1998), the earnings process was fit by a permanent component, modelled as a random walk in age and a highly persistent serially correlated transitory component, with weights on these components for each year. The results showed that about half of the rise of the overall crosssectional inequality can be explained by the rise in the permanent variance and the rest by the rise in the persistent transitory component.

Ramos (2003) analysed the dynamic structure of earnings in UK using the British Household Panel Study for the period 1991-1999. The earnings specification followed a similar specification with Baker and Solon (2003). Using information on monthly earnings of male full-time employees, this study decomposed the covariance structure of earnings into its permanent and transitory components and 
concluded that the increase in inequality over the 1990's was due to increased in earnings volatility. Moreover, the relative earnings persistent was found to decline over the lifecycle, which implies a lower mobility for younger cohorts. These findings are at odds with previous literature on earnings dynamics both for UK and the OECD. Unlike previous literature, this study considered also the effects of observed characteristics and found that human capital and job related characteristics account for nearly all persistent earnings differences and that the transitory component is highly persistent.

Kalwij and Alessie (2003) examined the variance-covariance structure of log-wages over time and over the lifecycle of British men from 1975 to 2001, controlling for cohort effects. Their model follows closely the specification used by Abowd and Card (1989), Dickens (2000b) and Baker and Solon (2003) accounting also for cohort effects. They showed that the increase in the cross-sectional inequality was caused mainly by the increase in the transitory component of earnings and to a lesser extent by an increase in the permanent wage inequality. Thus the increase in crosssectional inequality was accompanied by an increase in earnings mobility.

Cappellari (2003) used the Italian National Social Security Institute for the period 1979-1995 and decomposed the male earnings autocovariance structure into its long-term and transitory components using a model specification similar with Moffitt and Gottschalk (1995) and Backer (1997). The model included a permanent component, modelled as a random growth in age and a highly persistent serially correlated transitory component, with weights on these components for each year and cohort. The findings showed that growth was determined by the long-term earnings component. Other evidence on the contribution of permanent and transitory earnings components to cross-sectional inequality has become available in recent year in Sweden (Gustavson, 2004).

\subsection{Theoretical model of the determinants of wage differentials}

\subsubsection{Determinants of earnings inequality}

As pointed out by Katz and Autor (1999), the existing literature contains many explanations for the rise in earnings inequality experienced by many developed countries during the 1980s and 1990s. One approach for explaining the changes in wage differential is to decompose overall wage inequality into permanent inequality and transitory inequality. 
Following the terminology introduced by Friedman and Kuznets (1954), individual earnings are composed of a permanent and a transitory component, assumed to be independent of each other. The permanent component of earnings reflects personal characteristics, education, training and other persistent elements. The transitory component captures the chance and other factors influencing earnings in a particular period and is expected to average out over time. Following the structure of individual earnings, overall inequality at any point in time is composed from inequality in the transitory component and inequality in the permanent component of earnings. The evolution of the overall earnings inequality is determined by the cumulative changes in the two inequality components.

A rise in permanent inequality is consistent with increasing returns to education, on-the-job training and other persistent abilities that are among the main determinants of the permanent component of earnings, meaning enhanced relative earnings position of the highly skilled individuals (Mincer, 1957, 1958, 1962, 1974; Hause, 1980).

An increase in transitory inequality can be attributed to the weakening of the labour market institutions (e.g. unions, government wage regulation, and internal labour markets), increased labour market instability, increased competitiveness, a rise in the temporary workforce which increase earnings exposure to shocks. A period of skill-biased technological change with the spread of new technologies can, both, increase the demand for skills, and increase earnings instability (Katz and Autor, 1999). Rodrik (1997) argued that also globalization and international capital mobility can increase wage instability. Overall, the increase in the return to persistent skills is expected to have a much larger impact on long-run earnings inequality than an increase in the transitory component of earnings (Katz and Autor, 1999; Moffitt and Gottschalk, 2002).

\subsubsection{Alternative model specifications for the permanent and transitory components}

Next we introduce several models of earnings dynamics that have been dominating the literature on permanent and transitory earnings inequality over the past 30 years. To begin with, we introduce the simplest specification, which in spite of its simplicity provides a very intuitive insight into the decomposition of earnings into their permanent and transitory components. Based on this specification earnings are being decomposed as follows:

$$
Y_{i t}=\mu_{i}+v_{i t}, \quad \mu_{i} \sim \operatorname{iid}\left(0, \sigma_{\mu}^{2}\right), \quad v_{i t} \sim \operatorname{iid}\left(0, \sigma_{v}^{2}\right), \quad t=1, \ldots, T_{i}, \quad i=1, \ldots, N
$$


where $\mu_{i}$ represents the permanent time-invariant individual specific component and $v_{i t}$ represents the transitory component, which is independent distributed both over individuals and time. This model imposes very rigid restrictions on the covariance structure of earnings:

$$
\operatorname{Cov}\left(Y_{i t}, Y_{i s}\right)= \begin{cases}\sigma_{\mu}^{2}+\sigma_{v}^{2}, & t=s \\ \sigma_{\mu}^{2}, & t \neq s\end{cases}
$$

Since $\mu_{i}$ is assumed to incorporate the effect of lifetime persistent individual specific characteristics such as ability, the variance of the permanent component $\sigma_{\mu}^{2}$ represents the persistent dispersion of earnings or permanent earnings inequality. The transitory shocks are captured by the transitory variance $\sigma_{v}^{2}$ and are assumed to persist only one year.

This model facilitates the understanding of the inequality decomposition into its permanent and transitory components. The variance of earnings at a certain point in time $\left(\sigma_{y}^{2}\right)$, as a measure of earnings dispersion, is composed both from a permanent and transitory dispersion $\left(\sigma_{\mu}^{2}+\sigma_{v}^{2}\right)$. The covariances are determined solely by the permanent component $\left(\sigma_{\mu}^{2}\right)$. Therefore, the assessment of the relative importance of the two components in the overall earnings dispersion is straightforward: the ratio $\sigma_{\mu}^{2} / \sigma_{y}^{2}$ captures the relative importance of the permanent component, whereas the ratio $\sigma_{v}^{2} / \sigma_{y}^{2}$ captures the relative importance of the transitory component.

Notwithstanding its attractive features, the empirical evidence rejected the rigid restrictions imposed by model (4.1). One of the main drawbacks of model (4.1) is that it does not allow for changes in earnings inequality over time (Lillard and Willis, 1978; Lillard and Weiss, 1979; MaCurdy, 1982; Abowd and Card, 1989). Other studies (Katz, 1994; Moffitt and Gottschalk, 1995) took the model complexity further by allowing the covariance structure of earnings to vary over time. To account for these time effects, these models considered also time specific loading factors or shifters on both components, which allow the parameters of the process to change with calendar time.

$$
Y_{i t}=\lambda_{1} \mu_{i t}+\lambda_{2 t} v_{i t}
$$


$\lambda_{k t}, k=1,2$ are time-varying factor loadings on the permanent and transitory components of earnings. The variance of $Y_{i t}$ implied by this model takes the form:

$$
\operatorname{Var}\left(Y_{i t}\right)=\lambda_{1 t}^{2} \sigma_{\mu}^{2}+\lambda_{2 t}^{2} \sigma_{v}^{2}
$$

An increase in either time loading factors generates an increase in the crosssectional earnings inequality. The nature of the change in inequality depends on which of the loading factors changes. On the one hand, a persistent rise in $\lambda_{1 t}$ increases the permanent or long-run inequality (inequality in earnings measured over a long period of time, such as lifetime earnings). As $\lambda_{1 t}$ is interpreted as timevarying return to skills or skill price, its increase suggests that the relative labour market advantage of high-skilled workers is enhanced. In this situation, the autocovariances grow in greater proportion than the variance, causing the autocorrelation to increase. As a consequence, the increase in overall crosssectional inequality is accompanied by a decrease in mobility.

On the other hand, an increase in $\lambda_{2 t}$ without a change in $\lambda_{1 t}$ increases crosssectional earnings inequality by increasing the transitory inequality, but without any impact on long-run or permanent inequality. In this situation the rise in the variances is not accompanied by a rise in the autocovariances, hence the autocorrelations decrease and the increase in the overall inequality is accompanied by an increase in mobility (Baker and Solon, 2003). As pointed out by Katz and Autor (1999), $\lambda_{1 t}$ maintains the rank of the individuals in the earnings distribution, but causes a persistent increase in the spread of the distribution and an increase in $\lambda_{2 t}$ changes the rank of the individual in the short-run. In other words an increase in the time parameters associated with the permanent component of earnings indicates a growing earnings inequality with no impact on the relative position of individuals in the distribution of permanent earnings, whereas an increase in the transitory time parameters indicates an increase in earnings instability.

Although model (4.2) incorporates changes over time in the permanent and temporary components of earnings inequality, it disregards other important features of earnings dynamics. Firstly, it disregards the cohort effects. As argued by Katz and Autor (1999), the increased wage inequality may arise from greater dispersion of unobserved labour quality within younger cohorts, resulting from unequal school quality. Some studies rejected the hypothesis that the return to education is the same across cohorts. These differences could be attributed either to the cohort effects or to the larger impact of the labour market shocks on younger than on older cohorts of workers. In the same line of thought, Freeman (1975) put 
forward the "active labour market" hypothesis, which postulates that changes in the labour market conditions, such as changes in the supply and demand for skills, affect mainly new entrants in the labour market.

To account for these cohort effects, these models considered also cohort specific loading factors or shifters on both components, which allow the parameters of the process to change with cohort.

$Y_{i t}=\gamma_{1 c} \lambda_{1 t} \mu_{i t}+\gamma_{2 c} \lambda_{2 t} \nu_{i t}$

where $\gamma_{j c}, j=1,2$ are cohort specific loading factors.

Secondly, regarding the permanent component, some studies brought evidence in favour of the "random growth rate model" or the "profile heterogeneity model": (Hause, 1977; Lillard and Weiss, 1979; MaCurdy, 1982; Baker, 1997; Cappellari, 2003)

$\mu_{i t}=\mu_{i}+\varphi_{i} a g e_{i t}, \quad \mu_{i} \sim \operatorname{iid}\left(0, \sigma_{\mu}^{2}\right), \quad \varphi_{i} \sim \operatorname{iid}\left(0, \sigma_{\varphi}^{2}\right), \quad E\left(\mu_{i}, \varphi_{i}\right)=\sigma_{\mu \varphi}$

According to this model, which is consistent with labour market theories such as human capital, and matching models, each individual has a unique age-earning profile with an individual specific intercept (initial earnings $\mu_{i}$ ) and slope (earnings growth $\varphi_{i}$ ) that may be systematically related. The variances $\sigma_{\mu}^{2}$ and $\sigma_{\varphi}^{2}$ capture individual heterogeneity with respect to time-invariant characteristics and age-earnings profiles. The covariance between $\mu_{i}$ and $\varphi_{i}, \sigma_{\mu \varphi}$, represents a key element in the development of earnings differentials over the active life. A positive covariance between $\mu_{i}$ and $\varphi_{i}$ implies a rising inequality in the permanent component of earnings over the life cycle. This is consistent with the school-matching models where the more tenure one individual accumulates, the more is revealed about his ability. Thus highly educated people are expected to experience a faster growth in their earnings as the quality of the match is revealed to their employers. A negative covariance implies that the two sources of heterogeneity offset each other, which is consistent with the on-the-job training hypothesis (Mincer, 1974; Hause, 1980). A negative covariance is expected to generate mobility within the distribution of the permanent component of earnings (Cappellari, 2003).

This structure is equivalent to a random coefficient model where the intercept and the coefficient on age in model (4.5) are randomly distributed across individuals. Therefore, because earnings evolve along an individual specific age profile, a good 
prediction of future earnings requires additional information besides the current earnings.

An alternative/additional specification for the permanent component of earnings is the "random walk model" or the "unit root model", which is used in the literature to accommodate earnings shocks that might have permanent effects: (MaCurdy, 1982; Abowd and Card, 1989; Moffitt and Gottschalk, 1995; Dickens, 2000b)

$$
u_{i a}=u_{i, a-1}+\pi_{i a}, \quad \pi_{i a} \sim \operatorname{iid}\left(0, \sigma_{\pi}^{2}\right), \quad E\left(u_{i, a-1}, \pi_{i a}\right)=0
$$

Equation (4.6) specifies a random walk process in age, where the current value depends on the one from the previous age and an innovation term $\pi_{i a}$, which represent white-noise non-mean-reverting shocks to permanent earnings. In other words, $\pi_{i a}$ accommodates any permanent re-ranking of individuals in the earnings distribution. As argued by Baker (1997), the intuition for this model is not obvious, but the high persistency of the unit root model might result from low rates of depreciation of human capital investments or labour market conditions through implicit contracts. In this model, current earnings are a sufficient statistic for future earnings.

Thirdly, previous research found that the transitory component of earnings is serially correlated. Therefore, a more general autocorrelation structure is called for, that relaxes the restriction on $v_{i t}{ }^{\prime} s$ from the canonical model. For the construction of such a structure, longitudinal studies on earnings dynamics turned to error processes from the literature on time series analysis. Based on MaCurdy (1982), the structure of the transitory component, $v_{i t}$, is assumed to follow an $\operatorname{ARMA}(\mathrm{p}, \mathrm{q})$ process:

$\sum_{j=0}^{p} \rho_{j} v_{i t-j}=\sum_{j=0}^{q} \theta_{j} \varepsilon_{i t-j}, \quad \varepsilon_{i t} \sim \operatorname{iid}\left(0, \sigma_{\varepsilon}^{2}\right), \quad v_{i 0} \sim\left(0, \sigma_{0, c}^{2}\right)$,

$\varepsilon_{i t}$ is assumed to be white noise with mean 0 and variance $\sigma_{\varepsilon}^{2}$. The variance $\sigma_{0, c}^{2}$ measures the volatility of shocks at the start of the sample period and $\sigma_{\varepsilon}^{2}$ the volatility of shocks in subsequent years. $\rho_{j}$ is the autoregressive parameter with $\rho_{0}=1$, which measures the persistence of shocks. $\theta_{j}$ is the moving average parameter with $\theta_{0}=1$, which accommodates sharp drops of the lag-j autocovariance compared with the other autocovariances. In this model, the autoregressive and moving average parameters are assumed to be constant over time. 


\subsubsection{Earnings mobility}

Another aspect relevant for the evolution of earnings differentials is earnings mobility, defined by Katz and Autor (1999) as the rate at which individuals shift positions in the earnings distribution. Earnings mobility is closely related to the importance of the permanent and transitory components in earnings variation. A large contribution of the permanent component implies that individual earnings are highly correlated over time and individuals do not change their income position to a large extent experiencing low rates of earnings mobility. Therefore, the changes in earnings mobility are determined by the extent to which changes in cross-sectional inequality are driven by changes in the permanent or transitory variance.

Earnings mobility is a very complex phenomenon, and the ways of measuring it are diverse. We look at the degree of immobility, measured by the ratio between permanent and transitory inequality, following Kalwij and Alessie (2003). This measure offers also a summary of the evolution in the structure of inequality: a(n) decrease (increase) in the immobility ratio indicates an increase (decrease) in earnings mobility, equivalent with a(n) decrease (increase) in the relative share of permanent differentials in the overall inequality. This mobility index captures nondirectional earnings movements and can be interpreted as the opportunity to improve one's position in the distribution of lifetime earnings.

An increase in cross-sectional inequality accompanied by a decrease in earnings mobility is expected to have negative implications for long-run or lifetime earnings differentials, as it shows that over time low wage men get worse off both in terms of their relative earnings position and in terms of their opportunity to escape low wage trap. Thus it is reasonable to expect that cross-sectional earnings differentials will be enhanced in a lifetime perspective.

An increase in cross-sectional inequality accompanied by an increase in earnings mobility has uncertain implications for long-run or lifetime earnings differentials. Over time low wage men get worse off in terms of their relative earnings position, but better off in terms of the opportunity to escape low wage trap in a lifetime perspective. Thus earnings mobility could either enhance or decrease lifetime earnings differentials compared with the cross-sectional ones.

A decrease in cross-sectional inequality accompanied by an increase in earnings mobility is expected to have positive implications for lifetime earnings differentials, as over time low wage men better their relative earnings position and their opportunity to escape low wage trap in a lifetime perspective. Thus, lifetime 
earnings differentials are expected to be reduced compared with annual differentials.

A decrease in cross-sectional inequality accompanied by a decrease in earnings mobility has uncertain implications for lifetime earnings differentials, as over time low wage men get better off in terms of their relative earnings position, but worse off in terms of their opportunity to escape low wage trap in a lifetime perspective. Thus, lifetime earnings differentials could be either reduced or enhanced compared with annual differentials.

It becomes obvious that the question regarding the link between earnings mobility and earnings inequality does not have a straight forward answer and mobility is not always beneficial. It depends on the underlying factors: "changes in earnings mobility could either work to offset or to increase changes in cross-sectional dispersion", with very different implications for permanent earnings inequality (Dickens, 2000a). Nonetheless, no controversy surrounds the fact that mobility is beneficial when it helps low paid individuals to improve their income position in the long-term or lifetime income distribution.

\subsection{Data ${ }^{36}$}

The study is conducted using the European Community Household Panel $\left(\right.$ ECHP) ${ }^{37}$ over the period 1994-2001 for 14 EU countries. Not all countries are present for all waves. Luxembourg and Austria are observed between 1995 and 2001 and Finland between 1996 and 2001. Following the tradition of previous studies, the analysis focuses only on men to avoid the selection bias associated with women's earnings.

A special problem with panel data is that of attrition over time, as individuals are lost at successive dates causing the panel to decline in size and raising the problem of representativeness. Several papers analysed the extent and the determinants of panel attrition in ECHP. Behr, Bellgardt and Rendtel (2005) found that the extent and the determinants of panel attrition vary between countries and across waves within one country, but these differences do not bias the analysis of income or the ranking of the national results. Ayala, Navrro and Sastre (2006) assessed the effects of panel attrition on income mobility comparisons for some EU countries. The results show that ECHP attrition is characterized by a certain degree of selectivity,

\footnotetext{
${ }^{36}$ Part of the information in section 4.4 has been discussed in section 2.4 and 3.4.

37 The European Community Household Panel provided by Eurostat via the Department of Applied Economics at the Université Libre de Bruxelles.
} 
but only affecting some variables and some countries. Moreover, income mobility indicators show certain sensitivity to the weighting system.

We apply the weighting system recommended by Eurostat, namely the "base weights" of the last wave observed for each individual, bounded between 0.25 and 10. The dataset is scaled up to a multiplicative constant ${ }^{38}$ of the base weights of the last year observed for each individual.

For the empirical analysis, individuals are categorized into four birth cohorts, which are followed through time. Ideally, one should use birth cohorts formed from people born in a particular year. The limited number of observations forces us to group more birth years in one cohort. The first birth cohort contains people born between 1940-1950, the second one people born between 1951-1960, the third cohort people born between 1961-1970 and lastly people born between 1971-1981. This grouping allows the analysis of the earnings covariance structure for individuals of the same age, followed at different points in time.

Earnings are expressed in real log net hourly wage adjusted for CPI of male workers aged 20 to 57, born between 1940 and 1981. Only observations with hourly wage lower than 50 Euros and higher than 1 Euro were considered in the analysis. The resulting sample for each country is an unbalanced panel. The choice of using unbalanced panels for estimating the covariance structure of earnings is motivated by the need to mitigate the potential overestimation of earnings persistence that would arise from balanced panels where the estimation is based only on people that have positive earnings for the entire sample period.

\footnotetext{
${ }^{38}$ The multiplicative constant equals e.g. $p^{*}$ (Population above 16/Sample Population). The ratio $p$ varies across countries so that sensible samples are obtained. It ranges between 0.001-0.01.
} 
Table 4.1. Mean hourly earnings ( Euro) and number of individuals with positive earnings

\begin{tabular}{|c|c|c|c|c|c|c|c|c|c|}
\hline & & 1994 & 1995 & 1996 & 1997 & 1998 & 1999 & 2000 & 2001 \\
\hline \multirow[t]{2}{*}{ Germany } & Mean & 9.43 & 9.49 & 9.61 & 9.52 & 9.57 & 9.48 & 9.60 & 9.72 \\
\hline & $\mathrm{N}$ & 25018 & 26059 & 25806 & 24889 & 23290 & 22955 & 21909 & 20703 \\
\hline \multirow[t]{2}{*}{ Denmark } & Mean & 10.89 & 11.40 & 11.58 & 11.61 & 11.86 & 11.85 & 12.02 & 12.08 \\
\hline & $\mathrm{N}$ & 20899 & 20399 & 19190 & 19062 & 17321 & 16235 & 15678 & 15380 \\
\hline \multirow[t]{2}{*}{ Netherlands } & Mean & 9.69 & 9.56 & 9.59 & 9.70 & 10.02 & 9.88 & 10.04 & 9.91 \\
\hline & $\mathrm{N}$ & 33277 & 32384 & 31564 & 30575 & 28731 & 27460 & 25790 & 33277 \\
\hline \multirow[t]{2}{*}{ Belgium } & Mean & 8.48 & 8.82 & 8.71 & 8.75 & 8.81 & 8.83 & 8.92 & 9.10 \\
\hline & $\mathrm{N}$ & 20221 & 22100 & 22892 & 22753 & 22863 & 23233 & 24065 & 24130 \\
\hline \multirow[t]{2}{*}{ Luxembourg } & Mean & & 16.18 & 15.81 & 16.73 & 17.39 & 17.15 & 17.22 & 17.10 \\
\hline & $\mathrm{N}$ & & 15829 & 13695 & 14489 & 13403 & 14075 & 12667 & 12992 \\
\hline \multirow[t]{2}{*}{ France $^{39}$} & Mean & 10.23 & 9.92 & 9.87 & 10.05 & 10.33 & 10.60 & 10.55 & 10.87 \\
\hline & $\mathrm{N}$ & 20137 & 19270 & 19042 & 17906 & 14467 & 14012 & 13760 & 14212 \\
\hline \multirow[t]{2}{*}{ UK } & Mean & 8.16 & 8.11 & 8.22 & 8.34 & 8.68 & 9.01 & 9.21 & 9.68 \\
\hline & $\mathrm{N}$ & 24949 & 25329 & 25495 & 26010 & 26145 & 25750 & 25674 & 25264 \\
\hline \multirow[t]{2}{*}{ Ireland } & Mean & 9.30 & 9.54 & 9.76 & 10.02 & 10.43 & 10.84 & 11.69 & 12.44 \\
\hline & $\mathrm{N}$ & 13937 & 13221 & 12590 & 12515 & 12435 & 12091 & 10745 & 9727 \\
\hline \multirow[t]{2}{*}{ Italy } & Mean & 7.16 & 6.91 & 6.96 & 7.05 & 7.29 & 7.37 & 7.28 & 7.32 \\
\hline & $\mathrm{N}$ & 32633 & 32236 & 32111 & 29661 & 28865 & 26993 & 26912 & 25170 \\
\hline \multirow[t]{2}{*}{ Greece } & Mean & 4.95 & 5.03 & 5.23 & 5.59 & 5.63 & 5.85 & 5.70 & 5.77 \\
\hline & $\mathrm{N}$ & 27974 & 27654 & 26150 & 24865 & 22675 & 22001 & 21335 & 21929 \\
\hline \multirow[t]{2}{*}{ Spain } & Mean & 6.83 & 6.95 & 7.09 & 6.89 & 7.18 & 7.37 & 7.45 & 7.42 \\
\hline & $\mathrm{N}$ & 22559 & 21863 & 21296 & 20975 & 20371 & 20580 & 19898 & 20185 \\
\hline \multirow[t]{2}{*}{ Portugal } & Mean & 3.70 & 3.74 & 3.84 & 3.92 & 3.99 & 4.08 & 4.31 & 4.46 \\
\hline & $\mathrm{N}$ & 14653 & 15450 & 15379 & 15087 & 14837 & 14569 & 14604 & 14550 \\
\hline \multirow[t]{2}{*}{ Austria } & Mean & & 9.08 & 8.33 & 8.37 & 8.49 & 8.55 & 8.55 & 8.54 \\
\hline & $\mathrm{N}$ & & 17944 & 17789 & 17199 & 16209 & 15162 & 13816 & 13056 \\
\hline \multirow[t]{2}{*}{ Finland } & Mean & & & 7.89 & 8.01 & 8.41 & 8.45 & 8.66 & 8.86 \\
\hline & $\mathrm{N}$ & & & 15811 & 15845 & 15895 & 15546 & 13329 & 13057 \\
\hline
\end{tabular}

Details on the number of observations, inflows and outflows of the sample by cohort over time for each country, mean yearly hourly earnings are provided in Table 4-A-1 (Annex) and Table 4.1. For more descriptive statistics refer to Sologon and O'Donoghue (2009a, 2009b).

Mean hourly earnings increase in all countries, except Austria where it records a slight decrease. In general, as illustrated by Table 4-A-1 (Annex) the highest attrition rates from one year to the next are recorded in Ireland, Italy, Greece, Spain and Portugal, where, on average, less than $60 \%$ of those who were in the sample in the previous year reported positive earnings in the current year.

\footnotetext{
${ }^{39}$ Gross Amounts
} 


\subsection{Econometric specification and estimation method of covariance structures}

In this section, we fit a parsimonious model to the autocovariance structure of earnings for all cohorts and for all countries. This model can be used to analyse the changes in the permanent and transitory components of earnings over the sample period and their impact on the overall level of earnings inequality.

\subsubsection{Econometric earnings specification}

In order to differentiate lifecycle dynamics from secular changes in earnings inequality, earnings differentials are explored by cohort. Earnings are de-trended for each cohort. The empirical specification of earnings follows the structure:

$$
Y_{i c t}=\bar{Y}_{c t}+r_{i c t}, \quad t=1, \ldots, T_{i}, i=1, \ldots, N_{c}
$$

where $Y_{i c t}$ is the natural logarithm of real hourly earnings of the $i$-th individual, from the $c$-th cohort in the $t$-th year, $\overline{Y_{c t}}$ is the year-cohort specific mean and $r_{i c t}$ is an error term which represents the individual-specific deviation from the yearcohort specific mean. . The demeaned earnings $r_{i c t}$ adjust for year, age and cohort effects in a less restrictive way than the preliminary regressions typically used, which assume that age and cohort effects within any year can be approximated by a polynomial in age (Baker and Solon, 2003). The demeaned earnings $r_{i c t}$ are assumed to be independently distributed across individuals, but autocorrelated over time. Earnings differentials within each cohort can be characterised by modelling the covariance structure of individual earnings:

$\operatorname{VarCov}\left(Y_{i c t}\right)=E\left(r_{i c t}, r_{i c t-s}\right), s=0, \ldots, T_{c}-t_{0 c} .40$

This study approaches the problem of choosing a longitudinal process for the demeaned earnings, $r_{i c t}$, in a similar manner with time series, following MaCurdy(1981) and MaCurdy (1982). The graphical inspection of the autocovariance structure of earnings, presented in the section 4.7, suggests the following features of the data:

(i) the elements of the autocovariance structure decrease with the lag at a decreasing rate and

${ }_{40} T_{c}$ and $t_{0 c}$ represent the total number of years and the first year observed for each cohort. 
they converge gradually at a positive level;

(ii) the lag-1 autocovariance drops to a larger extent compared with higher order autocovariances, which decline more gradually;

(iii) the autocovariances and mean earnings vary over the sample period, so they cannot be assumed to be stationary over sample period;

(iv) the autocovariances vary with age controlling for the period effect, hence they cannot be assumed to be stationary over the life cycle;

(v) the variance covariance structure appears to be cohort specific.

Our model incorporates these features. Feature (i) suggests the presence of an AR(1) process, but the presence of feature (iii) calls for a more complex ARMA (1, 1). Feature (ii) is captured by the presence of the permanent component. Feature (iv) is captured by incorporating period specific parameters, meaning that the permanent individual component and the transitory component of earnings are allowed to vary with time. The life cycle non-stationarity of the autocovariance structure of earnings in feature $(\mathrm{v})$ is captured by modelling the permanent individual component as random walk and/or random growth in age. Cohort heterogeneity (vi) is incorporated by parameters that allow the permanent and transitory components to vary between cohorts.

To avoid choosing a model specification that is inconsistent with the data, we start with a broad class of models for $r_{i c t}$ and employ preliminary data analysis procedures to choose among competing specifications. The following general specification encompasses the relevant aspects of earnings dynamics considered above.

$$
\begin{aligned}
& Y_{i c t}-\overline{Y_{c t}}=r_{i c t}=\gamma_{1 c} \lambda_{1 t}\left[\mu_{i}+\varphi_{i} a g e_{i t}+u_{i a t}\right]+\gamma_{2 c} \lambda_{2 t} v_{i t} \\
& \mu_{i} \sim \operatorname{iid}\left(0, \sigma_{\mu}^{2}\right), \quad \varphi_{i} \sim \operatorname{iid}\left(0, \sigma_{\varphi}^{2}\right), \quad E\left(\mu_{i}, \varphi_{i}\right)=\sigma_{\mu \varphi} \\
& u_{i a t}=u_{i, a-1, t-1}+\pi_{i a}, \quad \pi_{i a} \sim \operatorname{iid}\left(0, \sigma_{\pi}^{2}\right), \quad E\left(u_{i, a-1, t-1}, \pi_{i a t}\right)=0 \\
& v_{i t}=\rho v_{i t-1}+\varepsilon_{i t}+\theta \varepsilon_{i t-1}, \quad \varepsilon_{i t} \sim\left(0, \sigma_{\varepsilon}^{2}\right), \quad v_{i 0} \sim\left(0, \sigma_{0, c}^{2}\right)
\end{aligned}
$$

Based on equation (4.9), earnings can be decomposed into a permanent component $\gamma_{1 c} \lambda_{1 t}\left[\mu_{i}+\varphi_{i} a g e_{i t}+u_{i a t}\right]$ and a transitory component $\gamma_{2 c} \lambda_{2 t} v_{i t}$. The component $\mu_{i}+\varphi_{i} a_{g} e_{i t}$ models the individual age-profile heterogeneity, called also a random growth (Moffitt and Gottschalk, 1995; Baker, 1997), where $\mu_{i}$ and $\varphi_{i}$ are time invariant individual-specific intercept and slopes with variance $\sigma_{\mu}^{2}$ and $\sigma_{\varphi}^{2}$. The parameterization of the permanent component includes also a random walk 
process in age (Equation (4.10)) (Moffit and Gottschalk 1995, Baker and Solon 2003). The variance of the first period shock (assumed to be at age 20, which is also the lowest age observed in our dataset) is estimated together with the $\sigma_{\mu}^{2}$ and is considered part of the unobserved heterogeneity.

The transitory component follows an $\operatorname{ARMA}(1,1)$ process (equation (4.11)), where the serial correlation $\rho$ parameter captures the decreasing rate of decay of the covariances with the lag, the moving-average parameter $\theta$ captures the sharp drop of the lag- 1 autocovariance compared with the other autocovariances, and $\varepsilon_{i t}$ the white-noise mean-reverting transitory shocks. The variances $\sigma_{0, c}^{2}$ measure the volatility of shocks at the start of the sample period, $\sigma_{\varepsilon}^{2}$ the volatility of shocks in subsequent years and $\rho$ the persistence of shocks. Measurement error in this model is captured by this transitory component.

The non-stationary pattern of earnings is captured by time specific loading factors, both on the permanent and transitory component of earnings, $\lambda_{k t, k=1,2 ; t=0,7}$, normalized to 1 in the first wave for identification ${ }^{41}$. Cohort heterogeneity is accommodated by allowing both the permanent and the transitory component to vary by cohort. $\gamma_{j c}, j=1,2$ are cohort loading factor, normalized to 1 for the oldest cohort for identification.

\subsubsection{Specification of the covariance structure of earnings}

When working with ARMA $(\mathrm{p}, \mathrm{q})$ processes in the context of panel data, MaCurdy $(1981,1982)$ and Anderson and Hsiao (1982) underlined the need for a treatment of initial conditions ${ }^{42}$. As illustrated in equations (4.13) and (4.14), the autoregressive process induces a recursive structure in the moments: the variance-covariance in year $t$ depends on the transitory variance-covariance in year $t-1$. If one tracks the recursion back to the first sample year for each cohort, this raises the question of what is the transitory variance for each cohort in that year. In the earlier stage of the literature on earnings dynamics, it was common to restrict the initial transitory variance to be the same for all cohorts. In line with the most recent literature on earnings dynamics, our model acknowledges that earnings volatility varies across cohorts because they illustrate different stages of the lifecycle and they have experienced different period effects. Therefore such a strong assumption is untenable.

\footnotetext{
41994 refers to $\mathrm{t}=0$

42 See MaCurdy(1982, page 92/93)
} 
Following MaCurdy (1981, 1982), the cohort initial transitory variances are treated as 4 additional parameters to be estimated. The covariance structure for the first sample period takes the form:

$$
\begin{aligned}
& \operatorname{Var}\left(Y_{i c 0}\right)= \\
& =E\left(r_{i c 0} r_{i c 0}\right)= \\
& =\sigma_{\mu}^{2}+\sigma_{\varphi}^{2} E\left(\operatorname{age}_{i 0}^{2}\right)+2 \operatorname{cov}\left(\mu_{i} \varphi_{i}\right) E\left(\operatorname{age}_{i 0}\right)+\left(a_{0}-20\right)^{2} \sigma_{\pi}^{2}+\operatorname{Var}\left(v_{i 0}\right) \text { if } t=0
\end{aligned}
$$

where $a_{0}$ is the central age of the cohort c in the first wave.

The covariance structure for subsequent years is expressed as follows:

$$
\begin{aligned}
& \operatorname{Var}\left(Y_{i c t}\right)=E\left(r_{i c t} r_{i c t}\right)= \\
& =\gamma_{1 c}^{2} \lambda_{1 t}^{2}\left[\sigma_{\mu}^{2}+\sigma_{\varphi}^{2} E\left(\text { age }_{i t}^{2}\right)+2 \operatorname{cov}\left(\mu_{i} \varphi_{i}\right) E\left(\text { age }_{i t}\right)+\sigma_{\pi}^{2}\left(a_{t}-20\right)^{2}\right]+ \\
& +\gamma_{2 c}^{2} \lambda_{2 t}^{2}\left[\rho^{2} \operatorname{Var}\left(v_{i t-1}\right)+\sigma_{\varepsilon}^{2}\left(1+2 \rho \theta+\theta^{2}\right)\right] \text { if } t>0 \\
& \operatorname{Cov}\left(Y_{i c t} Y_{i c t-s}\right)=E\left(r_{i c t} r_{i c t-s}\right)= \\
& =\gamma_{1 c}^{2} \lambda_{1 t}^{2}\left\{\sigma_{\mu}^{2}+\sigma_{\varphi}^{2} E\left(\text { age }_{i t}\right) E\left(\operatorname{age}_{i t-s}\right)+\operatorname{cov}\left(\mu_{i} \varphi_{i}\right)\left[E\left(\text { age }_{i t}\right)+E\left(\text { age }_{i t-s}\right)\right]+\right. \\
& \left.+\sigma_{\pi}^{2}\left(a_{t}-20\right)\left(a_{t}-s-20\right)\right\}+\gamma_{2 c}^{2} \lambda_{2 t} \lambda_{2 t-s}\left[\rho \operatorname{Cov}\left(v_{i t-1}, v_{i t-s}\right)\right] \text { if } t>0 \& s>1 \\
& \operatorname{Cov}\left(Y_{i c t} Y_{i c t-1}\right)=E\left(r_{i c t} r_{i c t-1}\right)= \\
& =\gamma_{1 c}^{2} \lambda_{1 t}^{2}\left\{\sigma_{\mu}^{2}+\sigma_{\varphi}^{2} E\left(\text { age }_{i t}\right) E\left(\text { age }_{i t-1}\right)+\operatorname{cov}\left(\mu_{i} \varphi_{i}\right)\left[E\left(\operatorname{age}_{i t}\right)+E\left(\operatorname{age}_{i t-1}\right)\right]+\right. \\
& \left.\left.+\sigma_{\pi}^{2}\left(a_{t}-20\right)\left(a_{t}-1-20\right)\right\}+\gamma_{2 c}^{2} \lambda_{2 t} \lambda_{2 t-1}\left\{\rho \operatorname{Var}\left(v_{i t-1}\right)+\theta \sigma_{\varepsilon}^{2}\right)\right\} \text { if } t>0 \& s=1 \\
& , \text { where } a_{t} \text { is the central age of the cohort c in period t. }
\end{aligned}
$$

The degree of immobility is measured by the ratio between the permanent and transitory variance.

\subsubsection{Estimation of covariance structures}

The parameters of the models are fit to the covariance structure for each cohort using equally weighted minimum distance methods of estimation. The methodology is similar with Cappellari (2003), Baker and Solon (2003), Ramos (2003), Kalwij and Alessie (2003), Dickens (2000b), Baker (1997), Abowd and Card (1989), Cervini and Ramos (2006) adapted to unbalanced panels.

For each cohort $\boldsymbol{c}$ and individual $\boldsymbol{i}$, define a vector which identifies the presence for each individual in the respective cohort and year: 


$$
\mathbf{d}_{\mathrm{ic}}=\left(\begin{array}{c}
d_{i c_{1}} \\
\vdots \\
d_{i t_{c}}
\end{array}\right)
$$

where $d_{i c t}$ is an indicator variable that is equal to 1 if the individual from cohort $c$ is present in year $t$ of the panel and $t_{c}$ is the total length of the panel for each cohort. Similarly, the vector containing the cohort earnings residuals can be represented as follows:

$$
\mathbf{R}_{\mathbf{i c}}=\left(\begin{array}{l}
r_{i c_{1}} \\
\vdots \\
r_{i c_{c}}
\end{array}\right)
$$

where $r_{i c t}$ are the earnings residuals for individual $i$ belonging to cohort $c$, in year $t$ in mean deviation form for each cohort and year. The elements of the $\mathbf{R}_{\mathrm{ic}}$ corresponding to missing years are set to 0 . The variance-covariance matrix of the earnings is computed separately for each cohort, $\mathbf{C}_{\mathbf{c}}$. The elements of the variancecovariance matrix for cohort $\mathrm{c}, \mathbf{C}_{\mathrm{c}}$, which is of dimension $\left(t_{c} \times t_{c}\right)$ are computed as follows:

$$
m_{c}[k, l]=\frac{\sum_{i=1}^{n_{c}} r_{i c k} r_{i c l}}{\sum_{i=1}^{n_{c}} d_{i c k} d_{i c l}}
$$

where $n_{c}$ is the total number of individuals in cohort $c, k, l=\left\{1, \ldots, t_{c}\right\}$. Conformably with $m_{c}, m_{c i}$ represent the distinct elements of the individual crossproduct matrix $\mathbf{R}_{\mathbf{i c}} \mathbf{R}_{\mathbf{i c}}^{\prime}$. Then $m_{c}[k, l]=\frac{\sum_{i=1}^{n_{c}} m_{c i}[k, l]}{\sum_{i=1}^{n_{c}} d_{i c k} d_{i c l}}$.

The matrix $C_{c}$ is symmetric with $\left(\frac{t_{c}\left(t_{c}+1\right)}{2} \times 1\right)$ distinct elements. Let $\operatorname{Vech}\left(\mathbf{C}_{\mathbf{c}}\right)$ be a column vector of dimension $\left(\frac{t_{c}\left(t_{c}+1\right)}{2} \times 1\right)$ which stacks all the 
elements of the variance covariance matrix $\mathbf{C}_{\mathbf{c}}$ for cohort c. The aggregate vector of moments for all cohorts is denoted by: $\mathbf{m}=\left(\operatorname{Vech}\left(\mathbf{C}_{1}\right)^{\mathrm{T}}, \ldots, \operatorname{Vech}\left(\mathbf{C}_{4}\right)^{\mathrm{T}}\right)^{\mathrm{T}}$, which is a column vector of dimension $\left(\sum_{c=1}^{4} \frac{t_{c}\left(t_{c}+1\right)}{2} \times 1\right)$. In this paper, each cohort is observed between 1994 and 2001, therefore $t_{c}=8$. Since the individuals were grouped in four cohorts, $\mathbf{m}$ is a column vector of dimension $(144 \times 1)$.

To estimate the error components of the structural model illustrated by equations (4.9), (4.10) and (4.11), the elements of $\mathbf{m}$ are fit to a parameter vector $\boldsymbol{\theta}$, so that $\mathbf{m}=f(\boldsymbol{\theta}), f(\boldsymbol{\theta})$ takes the form of equations (4.12), (4.13), (4.14), and (4.15). Minimum distance estimation requires minimising the weighted sum of the squared distance between the actual covariances $(\mathbf{m})$ and a function of the parameter vector $(f(\boldsymbol{\theta}))$ which encapsulates the covariance structure implied by the error component model. Therefore, minimum distance estimation involves the following quadratic form: $D(\boldsymbol{\theta})=[\mathbf{m}-f(\boldsymbol{\theta})] \mathbf{W}[\mathbf{m}-f(\boldsymbol{\theta})]^{\prime}$, where $\mathbf{W}$ is a positive definite weighting matrix. Minimum distance estimator chooses $\hat{\boldsymbol{\theta}}$ to minimise the distance function $D(\hat{\boldsymbol{\theta}})$.

Based on Chamberlain (1984), the asymptotic optimal choice of $\mathbf{W}$ is the inverse of a matrix that consistently estimates the covariance matrix of $\mathbf{m}$, which leads to the optimum minimum distance estimator (OMD). However, Clark (1996) and Altonji and Segal (1994) provided Monte Carlo evidence that OMD is biased in small samples because of the correlation between the measurement error in the second moments and forth moments. Instead, they proposed using the identity matrix as a weighting matrix. This approach, often called "equally weighted minimum distance estimation" (EWMD), involves using the standard nonlinear least squares to fit $f(\boldsymbol{\theta})$ to $\mathbf{m}$. The same procedure is followed in this paper.

For estimating the asymptotic standard errors of the parameter estimates, we apply the delta method. Following Chamberlain (1984), the asymptotic variancecovariance matrix of the estimated parameters is obtained from the following formula:

\section{$\operatorname{Asy} \operatorname{Var}(\theta)=\left(G^{\prime} W G\right)^{-1} G^{\prime} W V W G\left(G^{\prime} W G\right)^{-1}$}

where $\mathbf{G}$ is the Jacobian of the transformation $f(\boldsymbol{\theta})$ evaluated at $\boldsymbol{\theta}=\hat{\boldsymbol{\theta}}$. $\mathbf{G}$ has dimension $\left(t_{m} \times p\right)$ and rank $\mathrm{p}$, where $t_{m}$ is the sum across cohorts of 
$\left(\frac{t_{c}\left(t_{c}+1\right)}{2} \times 1\right)$ and $\mathrm{p}$ is the number of parameters. $\mathbf{W}$ is the identity matrix and $\mathbf{V}$ the matrix of fourth sample moments.

Chamberlain (1984) showed that under some fairly general regularity assumptions, the independence of $\mathbf{R}_{\text {ic }}$ implies that the sample mean of $m_{c i}$ has an asymptotic normal distribution $m_{c} \sim N\left(m_{c}^{*}, \mathbf{V}_{c}^{*}\right)$, where $m_{c}^{*}$ is the expectation of $m_{c i}$, meaning the true covariance matrix of earnings, and $\mathbf{V}_{c}^{*}$ is the variance-covariance matrix, which can be estimated consistently by computing the sample moment matrix of the $\operatorname{Vech}\left(\mathbf{C}_{\mathbf{c}}\right)$ vector, $\mathbf{V}_{\mathbf{c}}$. The elements of the variance covariance $\mathbf{V}_{\mathbf{c}}$ can be written as follows:

$\operatorname{Cov}\left(m_{c}[k, l], m_{c}[p, q]\right)=\frac{\sum_{i=1}^{n_{c}} d_{i c k} d_{i c l} d_{i c p} d_{i c q}}{\sum_{i=1}^{n_{c}} d_{i c k} d_{i c l} \sum_{i=1}^{n_{c}} d_{i c p} d_{i c q}}\left(m_{c}[k, l, p, q]-m_{c}[k, l] m_{c}[p, q]\right)$

where $m_{c}[k, l, p, q]=\frac{\sum_{i=1}^{n_{c}} r_{i c k} r_{i c l} r_{i c p} r_{i c q}}{\sum_{i=1}^{n_{c}} d_{i c k} d_{i c l} d_{i c p} d_{i c q}}$

The variance-covariance matrix of $\mathbf{m}$ was denoted by $\mathbf{V}$, where $\mathbf{V}$ is the block diagonal matrix which is constructed from all the $\mathbf{V}_{\mathbf{c}}$ matrices.

\subsection{Strategy for model specification}

The chi-squared goodness of fit statistic is computed following Newey(1985):

$$
\chi=[\mathbf{m}-f(\hat{\boldsymbol{\theta}})] \mathbf{R}^{-1}[\mathbf{m}-f(\hat{\boldsymbol{\theta}})]^{\prime}
$$

where $\chi$ follows a chi-squared distribution with degrees of freedom equal to $\sum_{c=1}^{4} \frac{t_{c}\left(t_{c}+1\right)}{2}-p=144-p, \quad \mathbf{R}^{-1}=\left(\mathbf{W V W} \mathbf{W}^{-1}\right.$ and $\mathbf{W}=\mathbf{I}-\mathbf{G}\left(\mathbf{G}^{\prime} \mathbf{A G}\right)^{-\mathbf{1}} \mathbf{G}^{\prime} \mathbf{A}$.

The majority of the existing studies estimating the covariance structure of earnings used this general form of specification test to assess the goodness of fit of the model. However, in most cases, all models have been rejected. Baker and Solon (2003), Baker (1997), Leamer (1983) criticized these type of tests for several reasons. 
First, Baker and Solon (2003) and Leamer (1983) underlined that "diagnostic tests such as goodness-of-fit tests, without explicit alternative hypothesis, are useless, since if the sample size is large enough, any maintained hypothesis will be rejected. Such tests therefore degenerate into elaborate rituals for measuring the effective sample size." Second, as pointed by Baker and Solon (2003), an additional problem is that these specification tests have inflated size in small samples and the inflation is positively related with the number of overidentifying restrictions. For example, Baker (1997) revealed through a Monte Carlo study, that for a test with fewer than 150 overidentifying restrictions, the critical values are $40 \%-50 \%$ greater than the critical values based on the asymptotic theory. Therefore, we decided to report this statistic as a reference, but not to use it to assess the goodness of fit of our model. Instead we employed the SSR as a measure of fit.

To test between nested models, we could use Preposition 3' in Chamberlain (1984) or the LR test. Based on Preposition 3' in Chamberlain (1984), assuming that the general model has p parameters, to test between two nested models, one in which $k_{1}$ parameters are restricted to $0\left(\chi_{p-k_{1}}\right)$ and one in which $k_{2}{ }^{43}$ parameters are restricted to $0\left(\chi_{p-k_{2}}\right)$, Chamberlain (1984) showed that the incremental chi square statistic $\chi=\chi_{p-k_{1}}-\chi_{p-k_{2}}$ follows a chi-squared distribution with $k_{1}-k_{2}$ degrees of freedom. The LR test takes the following form: $L R=N \log \frac{S S E_{R}}{S S E_{U}}$. Under the null hypothesis, LR follows a chi-square distribution with d.o.f equal to the number of restrictions $k_{1}-k_{2}$. To test between non-nested model, we use the BIC criterion: the smaller the value of BIC, the better the fit.

$$
B I C=\left(S S E \cdot 144^{k / 144}\right) /(144-k)
$$

\subsection{The dynamic autocovariance structure of hourly earnings}

To begin with, it is informative to have a description of the dynamic structure of individual $\log$ hourly earnings for all 14 countries under analysis. The autocovariance structure of earnings is computed for each cohort separately, as well as overall, using formula (4.16) introduced in the previous section. The overall autocovariance structure of earnings is displayed in Figure 4.1, whereas the structure by cohort is included in Figure 4-A-1. The model used to fit the

${ }^{43} \mathrm{k}_{1}>\mathrm{k}_{2}$ 
autocovariance structure of earnings for all cohorts must be consistent with the trends observed in the dynamic autocovariance structure.

In the beginning of the sample period, the overall inequality, measured by the variance of log hourly earnings, is the highest in Portugal, followed by Ireland, Spain, France, Luxembourg, UK, Greece, Germany, Austria, Italy, Belgium, Netherlands, Finland and Denmark. Overall inequality decreases over the sample period in Germany, Denmark, Belgium, France, UK, Ireland, Spain and Austria, and increases in Netherlands, Luxembourg, Greece, Portugal and Finland. Following these changes, in 2001, Portugal still records the highest inequality, followed by Luxembourg, France, Greece, Spain, UK, Italy, Germany, Ireland, Netherlands, Finland, Belgium, Austria and Denmark.

The scope of this study is to decompose earnings inequality for each country into the permanent and transitory inequality, and conclude which of these components is the main factor triggering the evolution of overall inequality over time.

The overall autocovariance structure of earnings (Figure 4.1) displays both similar and diverging patterns across countries. The common pattern across all countries is that all lags autocovariances show in general a similar pattern as the variance. They are positive and quite large in magnitude relative to the variances. The distance between autocovariances at consecutive lags falls at a decreasing rate. The biggest fall is registered by the lag- 1 autocovariance, after which the covariances appear to converge gradually at a positive level. Variances reflect both the permanent and the transitory components of earnings, whereas higher order covariances reflect the permanent component of earnings. Therefore, the evolution of the covariances, at all orders, suggests the presence of a permanent individual component of wages and a transitory component which is serially correlated. Moreover, the sharp decline of the first lag autocovariance is consistent with the presence of a moving average process of first order.

Both mean earnings (Table 4.1) and all lags autocovariances (Figure 4.1) vary over time, which signals the presence of nonstationarity in the dynamic structure of earnings. 

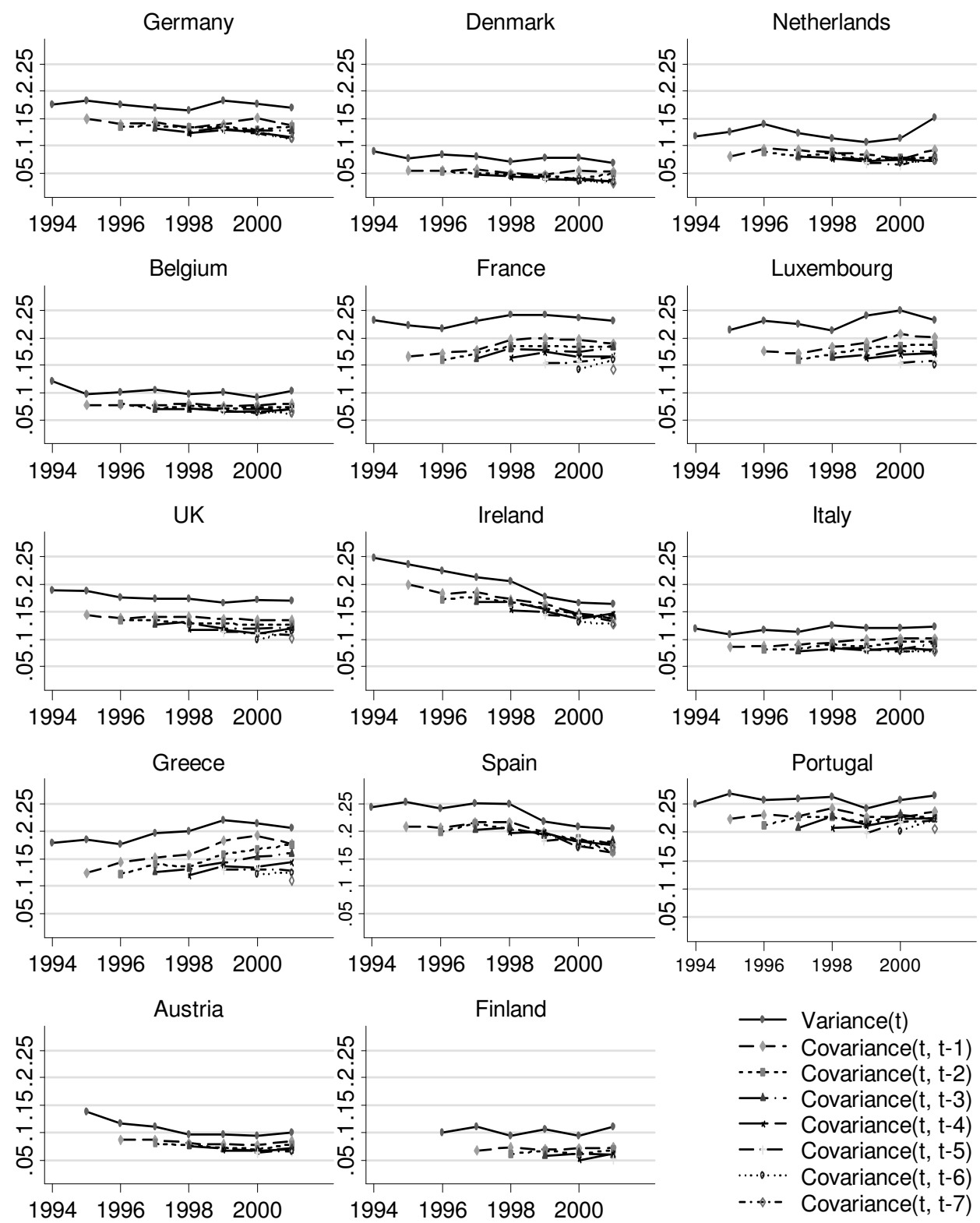

Figure 4.1. Overall Autocovariance Structure of Hourly Earnings: Years 1994-2001 
In all countries, the autocovariances display different patterns across cohorts (Figure 4-A-1, Annex), supporting the hypothesis of cohort heterogeneity with respect to individual earnings dynamics. In most countries, the variance of earnings for all cohorts follows the evolution of the overall variance. Mixed trends across cohorts are observed in Germany - where the variance increased for the cohorts born in 1941-1950 and 1961-1970 -, in Belgium - where the variance increased for the youngest cohort -, in France - where the variance increased for the cohort born in 1961-1970 -, in UK - where the variance increased for the youngest two cohorts -, in Spain - where the variance increased for the youngest and the oldest cohorts, and in Finland - where the variance decreased for the youngest cohort.

The evolution of the variance is not monotonic and the rate of change differs among cohorts. In general, in countries that record a decrease in the variance, the older the cohort, the steeper the decrease. For those that record an increase in the variance over time, the older the cohort, the steeper the increase is. Moreover, the younger the cohort is, the lower are the autocovariances. Hence, given that higher order autocovariances capture the permanent component of earnings, it is reasonable to expect that in all countries, for younger cohorts, the transitory variance plays a larger role in the earnings formation than the permanent component compared with older cohorts.

As illustrated in Figure 4-A-1 (Annex), for all cohorts, all lags autocovariances show in general similar pattern as the variance, in line with the overall pattern. The evolution of the covariances, at all orders, suggests the presence of a permanent individual component of wages and a transitory component which is serially correlated. Moreover, the sharp decline of the first lag autocovariance is consistent with the presence of a moving average process of first order. Similar with the overall trend, there is evidence of nonstationarity in the dynamic structure of earnings by cohort.

To look at these lifecycle effects more clearly, it is necessary to remove the time effect that is present in these within cohort autocovariances. Lifecycle autocovariances are illustrated in Figure 4-A-2 (Annex). They are positive and evolve at different rates over the life cycle. The smoothed lifecycle profiles illustrate that, on average, all lags autocovariances increase with age at a decreasing rate, which is consistent with the presence of a permanent component of earnings that rises with age at a diminishing rate. (Dickens, 2000b)

To sum up, the description of the dynamic structure of individual earnings for men suggests five main features of the data, which were incorporated in our model, as mentioned previously: 
- First, the covariance elements are not the same at all lags. They decrease with the lag at a decreasing rate and converge gradually at a positive level, suggesting the presence of a transitory element, which is serially correlated, and of a permanent individual component of earnings. The most popular specification for the serially correlated term is the AR(1) process. However, the fact that the lag-1 autocovariance drops to a larger extent compared with the other autocovariances and that the autocovariances at high orders decline very slowly suggest that earnings cannot be modelled simply as a first-order autoregressive process. Therefore a more complex ARMA (p, q) process might be a better choice, where $p$ represents the order of the autoregressive process and $\mathrm{q}$ the order of the moving average process.

- Second, as the autocovariances and mean earnings vary over the sample period, they cannot be assumed to be stationary over sample period. The stationarity assumption was tested and rejected using the methodology introduced by MaCurdy (1982). One way to capture this feature is to incorporate period specific parameters, meaning that the permanent individual component and the transitory component of earnings are allowed to vary with time.

- Third, as autocovariances vary with age controlling for the period effect, they cannot be assumed to be stationary over the life cycle. This non-stationarity can be captured by modelling the permanent individual component as random walk and/or random growth in age.

- Lastly, the variance covariance structure appears to be cohort specific, which can be incorporated by parameters that allow the permanent and transitory components to vary between cohorts. 


\subsection{Results of covariance structure estimation}

\subsubsection{Error component model estimation results}

The general specification of the error component model outlined in section 4.5.2, which encompasses all relevant aspects of earnings dynamics considered above, is fit to the elements of the covariance matrix of each country, for all cohorts pooled together ${ }^{44}$. For choosing the best model for each country we followed a general to specific strategy, by imposing additional restrictions on the general model. The estimation of the general model which incorporates both the random growth and the random walk specifications in the permanent component had some identification problems in all countries. The ARMA process was found only in three countries and homogenous initial conditions only in four. In all countries, the models incorporating both time and cohort shifters performed the best.

We present the parameter estimates only for the models that fit data the best for each country. The estimation results are illustrated in Table 4.2. Similar to Dickens (2000b), all variances are restricted to be positive by estimating the variance equal to the exponent of the parameter. The reported estimates of the variances represent the exponent of the parameter and the reported standard errors correspond to the parameter estimates. ${ }^{45}$

\footnotetext{
44 i.e. 144 auto-covariances for countries observed over 8 waves, 122 for those with 7 waves and 84 for those with 6 waves.

45 The SE column reports the standard error for the parameter estimate. Where I report the $\exp ($ estimate $)$, the SE corresponds to the $\log (\exp (\operatorname{estimate}))=$ estimate
} 


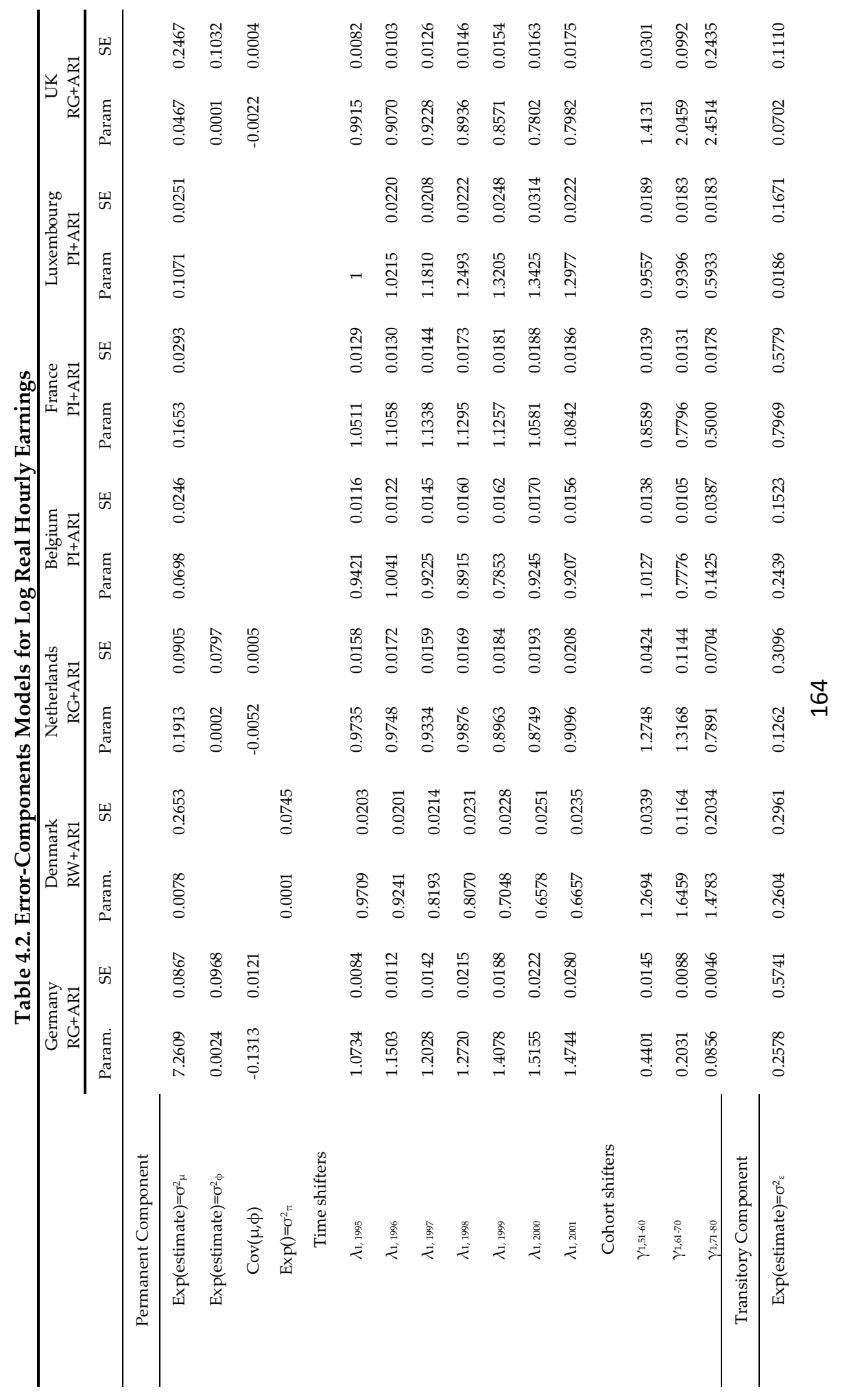




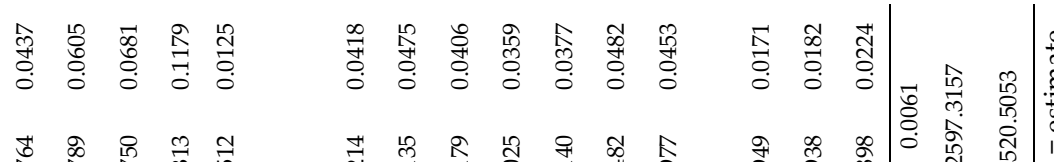

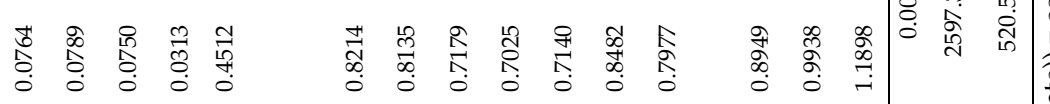

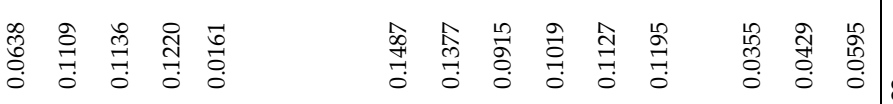

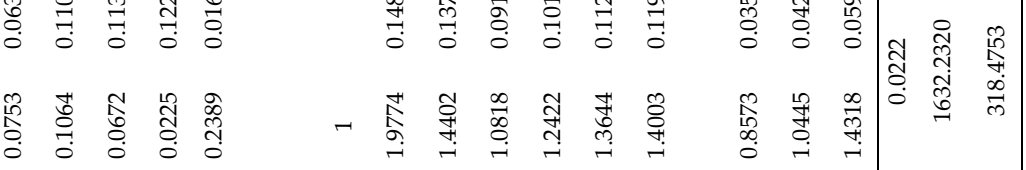

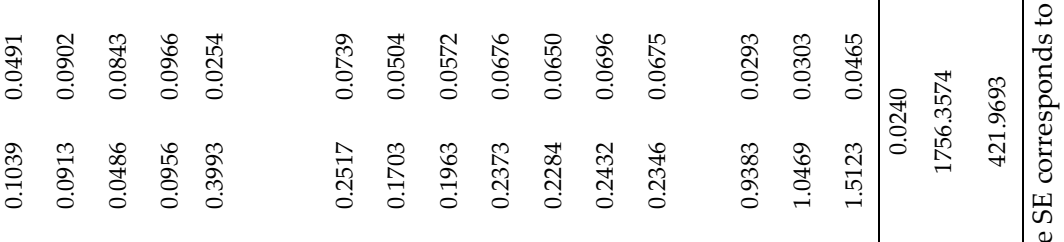

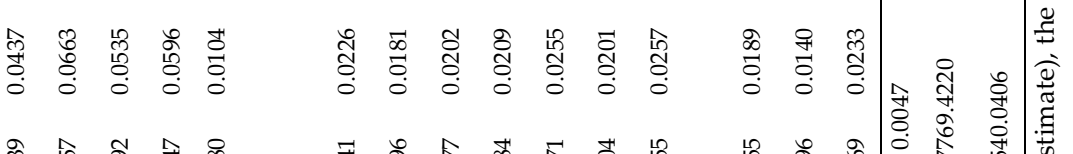

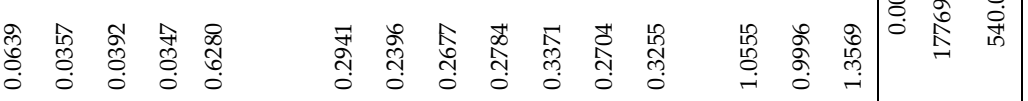

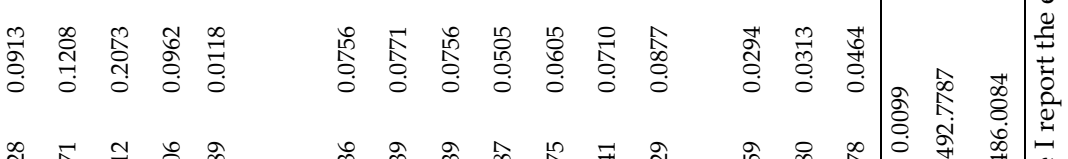

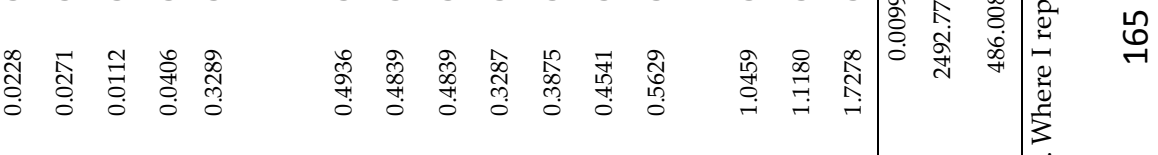

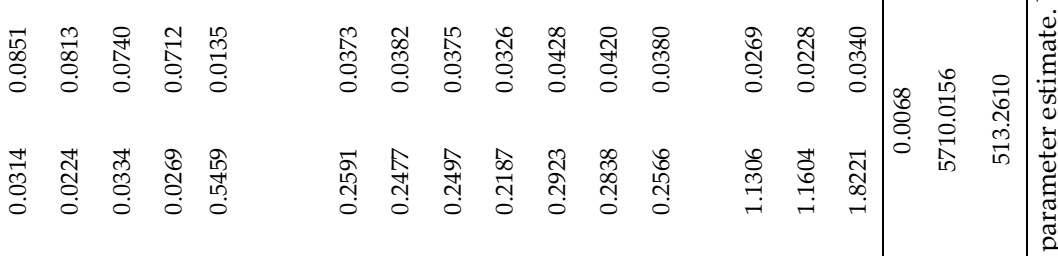

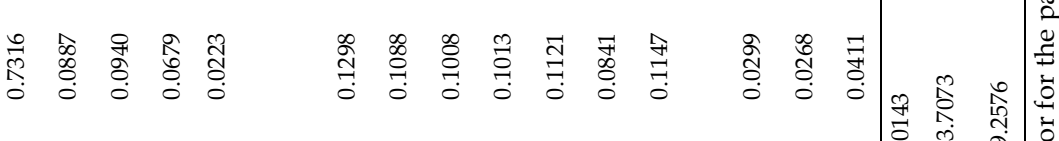

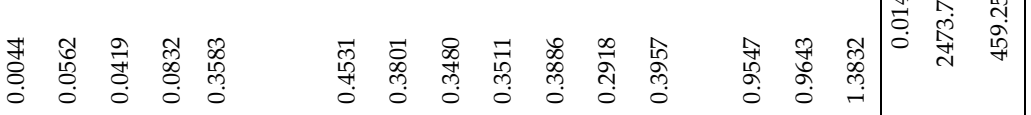

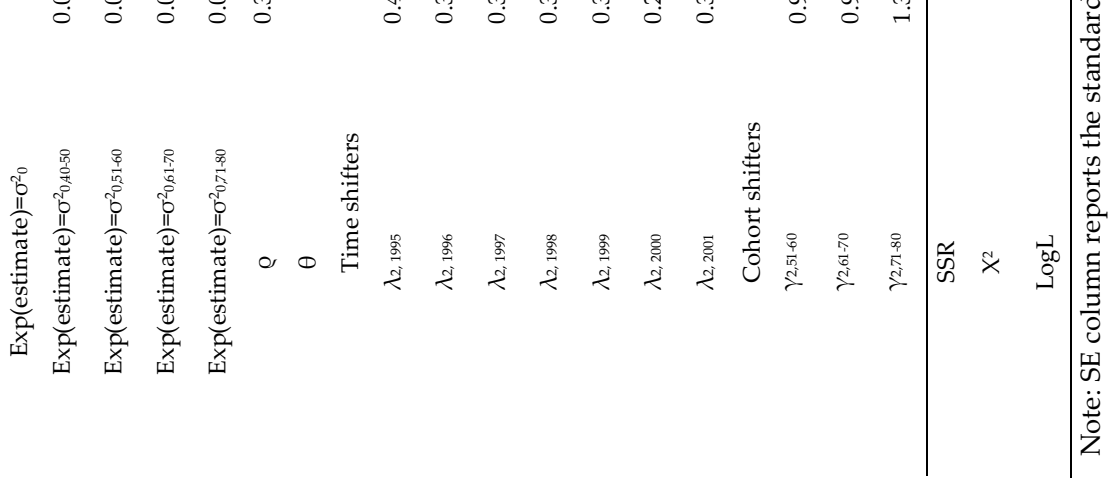




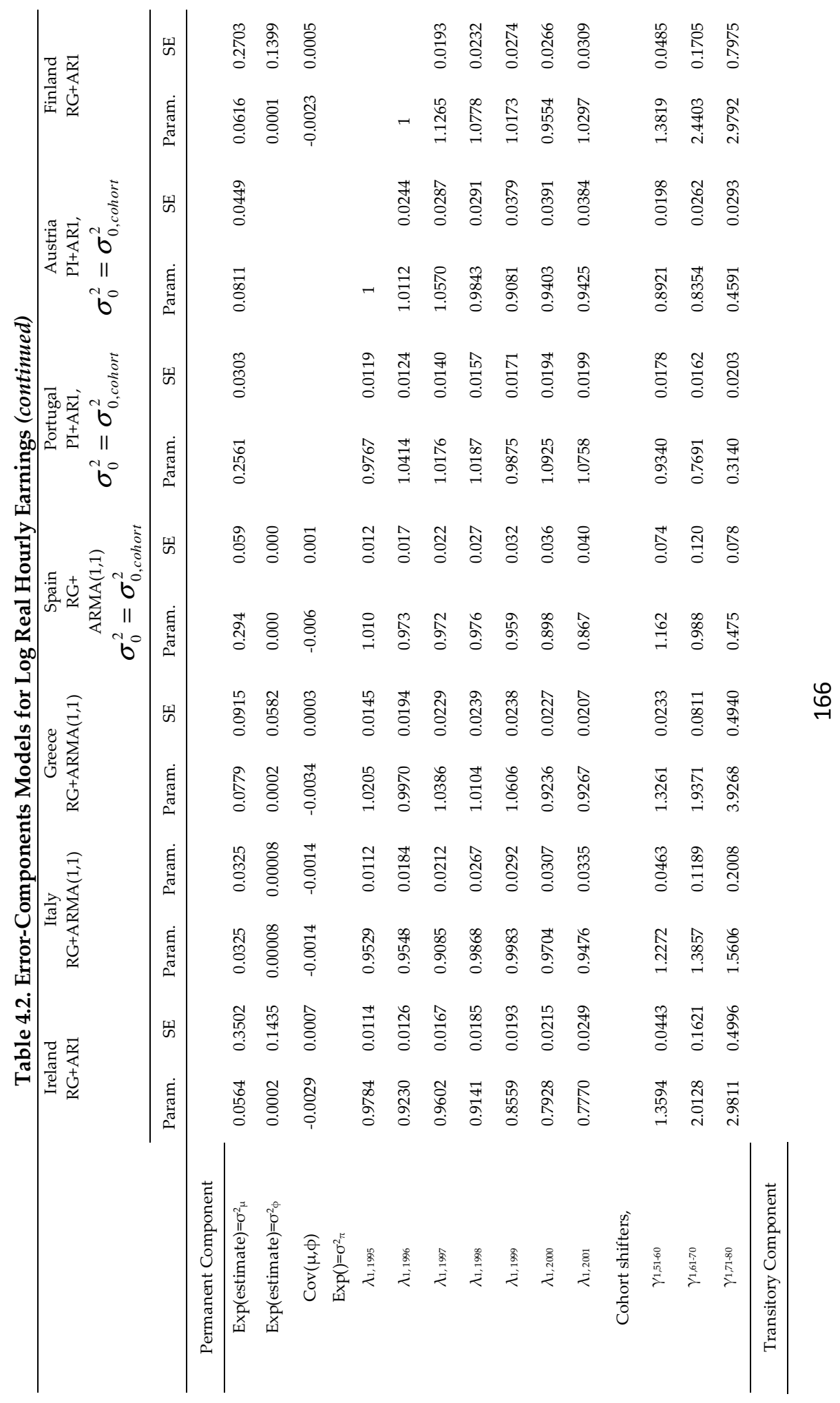




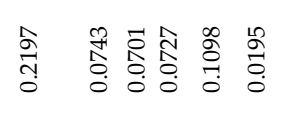

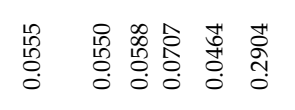

产褰

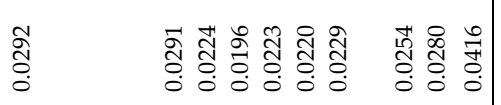

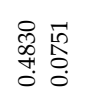

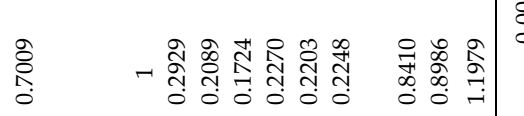

寒喜

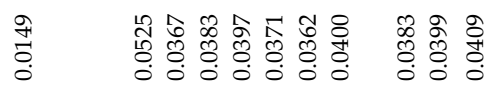

憘爱

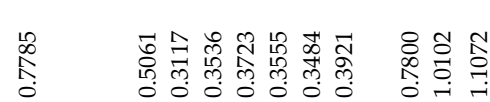

용홍

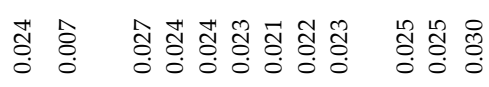

옿영

善若

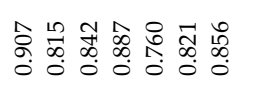

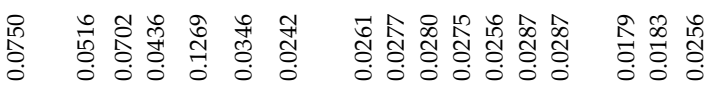

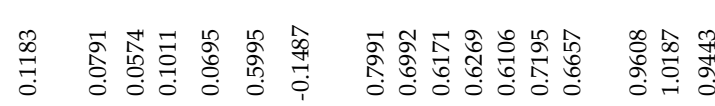

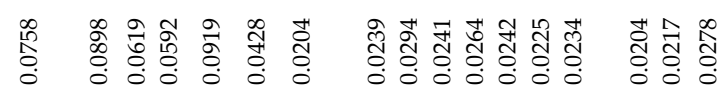

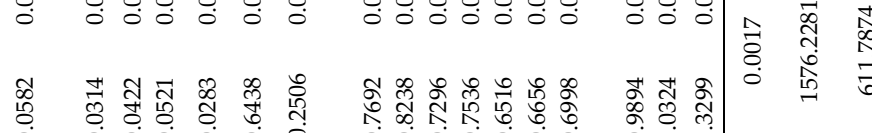

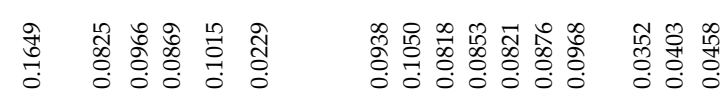

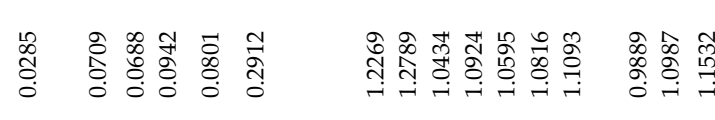

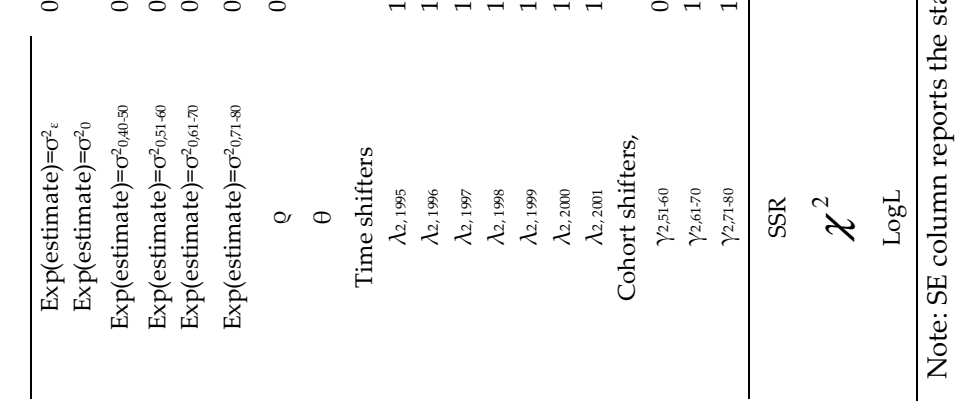


The formulation of the permanent and transitory components of earnings differs between countries.

\section{Permanent component}

In Germany, Netherlands, UK, Ireland, Italy, Greece, Spain and Finland, the permanent component follows a random growth model with time and cohort specific loading factors. The estimated coefficients for the permanent component of earnings show that time-invariant heterogeneity and age-earning profile heterogeneity play a significant role in the formation of long-term earnings differentials in all these countries. Individual specific heterogeneity plays the highest role in Germany, followed by Spain, Netherlands, Greece, UK, Ireland and Italy, which suggests that in Germany there is a higher dispersion in the timeinvariant individual specific attributes that determine wage differentials.

The estimated random slope variance implies that hourly earnings growth for an individual located one standard deviation above the mean in the distribution of $\phi$ is the largest in Germany, where it is with $4.89 \%{ }^{46}$ faster than the cohort mean, followed by Greece, Ireland, Spain, Netherlands, UK and Finland with rates between $1 \%$ and $1.41 \%$ and Italy with $0.89 \%$. All these countries have a negative covariance between the time invariant individual specific effect and the individual specific slope of the age-earning profile, which implies that the initial and lifecycle heterogeneity are negatively associated. This negative association corresponds to the trade-off between earnings early in the career and subsequent earnings growth and is consistent with the on-the-job training hypothesis (Mincer, 1974). Therefore, this suggests the presence of mobility within the distribution of permanent earnings over the sample period. These findings reinforce the results from previous studies.

Therefore, for these countries the evolution of the permanent component without the time loading factors could be either increasing or decreasing. The time-specific loading factors for the permanent component are highly significant with values close to 1 in all countries. The trends of the returns to the permanent component vary to a large extent across countries. One common feature is that they reflect the trends in the high-order autocovariances in the data. These estimates show that overall, controlling for age and cohort effects, the returns to skills decreased over the sample period in Netherlands, UK, Ireland, Italy, Greece, Spain and increased

${ }_{46} 4.89=100 \cdot \sqrt{\sigma_{\varphi}^{2}}$ 
in Germany and Finland. The trends over time differ between countries, some record a smooth evolution, others noisier. For example, Netherlands experienced decreases in returns almost every second year. In UK the returns increased in 1997 and 2001, and decreased in the rest. Ireland recorded a decrease until 1996, a boost in 1997 and a clear decline thereafter. In Italy, 1998 and 1999 appear to be years with increases in the return to skills, in Greece every second year, in Spain 1995 and 1998. Germany experienced increasing returns to human capital until 2000, and Finland in 1997 and 2001. Therefore, in these years, the relative position of the highly skilled individuals was enhanced.

In Denmark the permanent component follows a random walk in age. The variance of the innovation in the random walk is significantly larger than zero. As the variance of a variable that follows a random walk is the sum of the variances of the innovation term, this finding implies that permanent inequality increases over lifetime. In Denmark, the variance at the age of 20 is lower than the variance at subsequent ages, suggesting the presence of larger permanent shocks at older ages, which is consistent with matching models, in which the information revealed about a worker's ability increases with time. The final trend in the permanent variance depends on the period specific loading factors, which reveal that overall, the relative position of the highly skilled individuals decreased over the sample period in Denmark. The yearly evolution revealed a smooth decrease until 2000, followed by a small increase in 2001.

In Belgium, France, Luxembourg, Portugal and Austria the persistent dispersion of earnings follows the canonical model, where the permanent component is timeinvariant. The highest variance in the time invariant characteristics is recorded in Portugal, followed by France, Luxembourg, Austria and Belgium. In this case, the time-specific loading factors determine the final trend of the permanent differentials: they decreased in Belgium and Austria, and increased in France, Luxembourg and Portugal. Year by year, France records an increase in the returns to skills until 1997 and again in 2001, Luxembourg until 2000, Belgium in 1996 and 2000, Austria during most of the period, except 1998-1999, and Portugal in 1996, 1998 and 2000.

The estimates of the cohort-specific shifters for the permanent earnings are highly significant in all countries. The trends, however, differ between countries. A monotonic increase over the lifecycle is observed in Germany, France, Luxembourg, Portugal and Austria. In Denmark, Netherlands, Belgium and Spain the permanent component of earnings has an inverted- $U$ shape evolution over the lifecycle. These trends confirm the expectation that permanent earnings differentials play a much larger role in the formation of overall earnings 
differentials of older cohorts compared with younger ones, which experience higher earnings volatility due to temporary contracts. We expect the opposite to hold in the case of cohort-specific shifters for transitory earnings.

The permanent component of earnings decreases over the life cycle in UK, Ireland, Italy, Greece and Finland. This may be due to younger cohorts having more heterogeneous skills or experiencing larger permanent shocks even without a larger dispersion of skills. This could be the case if the labour market has become tougher over time, as in the case of Italy, which is characterised by high rates of youth unemployment.

\section{Transitory component}

The formulation of the temporary component of earnings differs between countries. It follows an AR(1) process with time and cohorts loading factors in all countries, except Italy, Greece and Spain, where it follows an ARMA(1,1). Except for Spain, Portugal and Austria, the other countries are characterized by heteroskedastic initial conditions. The estimated coefficients for the transitory component of earnings are all significant, suggesting that the initial variance(s), the $\mathrm{AR}(1)$ process, the ARMA $(1,1)$ process, and the time and cohort loading factors contribute significantly to earnings volatility in all countries.

The variance of initial conditions, which represents the accumulation of shocks up to the starting year of the panel, is smaller than the variance of subsequent shocks in all countries, except Luxembourg, Ireland, the oldest three cohorts in UK, and the middle two cohorts in Finland. Overall, the variance of initial conditions increases over the lifecycle in Denmark, Belgium, France, Luxembourg, UK, Italy, Greece and Finland, suggesting that the initial variance plays a larger role in the formation of earnings differentials for the oldest cohort compared with the youngest. The opposite is observed in Germany, Netherlands and Ireland.

The pattern of the heteroskedstic initial conditions, however, is not monotonic across cohorts. In Luxembourg, UK, Italy, and Finland it follows an inverted-U shape: the variance of initial conditions increases over the lifecycle and decreases at the end. The opposite holds for France, where the oldest and the youngest cohorts have the highest initial variances.

In Germany and Netherlands the pattern of the heteroskedastic initial conditions records a sharp drop for the second youngest cohort, an increase for the second oldest and a small drop for the oldest cohort. In Denmark, Belgium, Ireland and 
Greece, the variance of initial conditions records an increase for the second youngest cohort, a drop for the second oldest and an increase for the oldest cohort.

The magnitude of the autoregressive parameter varies between countries. A large autoregressive parameter, which suggests that shocks are persistent, is recorded in Spain with $26.9 \%$ of a shock still present after 8 years, in Portugal with $13.5 \%$ and in Austria with $5.8 \%$. A moderate autoregressive parameter suggesting that shocks die out rather quickly is recorded in Italy with $2.8 \%$ of a shock still present after 8 years, in Belgium with $2.4 \%$, and in Greece with $1.4 \%$. A small autoregressive parameter is present in Luxembourg, Ireland, Finland, Netherlands, Germany, France, UK and Denmark, where between $0.0008 \%$ and $0.8 \%$ of a shock is still present after 8 years. The negative sign of the MA component implies that the autocovariances decline sharply over the first period, confirming the trends observed in the previous section for Italy, Greece and Spain. ${ }^{47}$

The time-specific loading factors for the transitory component are highly significant and display a higher variation than for the permanent component in all countries. The trends of the transitory inequality vary to a large extent across countries. These estimates show that overall the transitory variance decreased over the sample period in all countries, except Luxembourg and Ireland.

The estimates of the cohort-specific shifters for the transitory earnings are highly significant in all countries. They indicate that earnings volatility is higher for younger cohorts, thus confirming the pattern observed in the dynamic description of the autocovariance structure of earnings, where autocovariances were found to be lower for younger cohorts. This is expected, given that younger people experience in general more frequent job changes, and consequently less stable earnings.

\section{Alternative model specifications}

Table 4.3 introduces the alternative model specifications for each country to justify the choice for the preferred models. Through these models, we tested whether the restrictions imposed by previous studies hold for each country.

First compared with the simple canonical model, our country-models revealed a significant improvement, both with respect to SSR and the Newey chi-squared goodness of fit. Moreover, the overall Wald test showed that, for each country, the

\footnotetext{
${ }^{47}$ For the other countries, the MA component was either rejected by the data or could not be identified due to the low number of waves.
} 
restrictions imposed by the canonical model do not hold in the data. In Germany, assuming away the restrictions imposed by the canonical model decreased the $\chi^{2}$ with 46764.97 at a cost of 26 degrees of freedom. Similarly, in Denmark the decrease in $\chi^{2}$ was of 23668.02, in Netherlands of 21880.65, in Belgium of 28937.06, in France of 6602.395, in Luxembourg of 33598.94, in UK of 9651.35, in Ireland of 22338.56, in Italy of 10858.77, in Greece of 23150.67, in Spain of 9833.018, in Portugal of 35182.5, in Austria of 12829.92 and in Finland of 5733.26. We then tested these restrictions in turn.

If we assume away the random growth in the permanent component $\left(\sigma_{\varphi}^{2}=0\right.$ and $\operatorname{cov}(\mu, \varphi)=0)$, the Wald test on this restrictions clearly rejects the null in Germany $\left(\chi^{2}=859.6255, \mathrm{df}=2\right)$, Netherlands $\left(\chi^{2}=178.7331, \mathrm{df}=3\right), \mathrm{UK}\left(\chi^{2}=185.2973\right.$, $\mathrm{df}=2)$, Ireland $\left(\chi^{2}=8.8093, \mathrm{df}=2\right)$, Italy $\left(\chi^{2}=65.2755, \mathrm{df}=2\right)$, Spain $\left(\chi^{2}=28.2711\right.$ , $\mathrm{df}=2)$, Finland $\left(\chi^{2}=99.2208, \mathrm{df}=2\right)$. In Greece, this assumption leads to an unidentified model. Identification problems from incorporating a random growth are found in Belgium, France, Luxembourg, Portugal and Austria.

Assuming away the random walk in the permanent component was rejected by the Wald test in Denmark $\left(\chi^{2}=115.65, \mathrm{df}=1\right)$. Incorporating a random walk in the permanent component was rejected in Portugal, and led to identification problems in Belgium, France, Luxembourg and Austria. Among the countries that favoured the random growth, the random walk either triggered some identification problems or a higher BIC than the model incorporating a random growth.

Based on Wald test, the restriction of homogenous initial conditions ( $\left.\sigma_{0}^{2}=\sigma_{0,40-50}^{2}=\sigma_{0,51-60}^{2}=\sigma_{0,61-70}^{2}=\sigma_{0,71-80}^{2}\right)$ was rejected in Germany $\left.\chi^{2}=125.1595, \mathrm{df}=5\right), \quad$ Denmark $\quad\left(\chi^{2}=436.3263, \mathrm{df}=3\right)$, Netherlands $\quad($ $\left.\chi^{2}=207.3169, \mathrm{df}=3\right)$, Belgium $\left(\chi^{2}=1063.161, \mathrm{df}=3\right)$, France $\left(\chi^{2}=61.0812\right.$, $\mathrm{df}=3)$, Luxembourg $\left(\chi^{2}=268.491, \mathrm{df}=3\right)$, Ireland $\left(\chi^{2}=8.8093, \mathrm{df}=2\right)$, Italy ( $\left.\chi^{2}=70.1507, \mathrm{df}=3\right)$ and Greece $\left(\chi^{2}=172.1103, \mathrm{df}=3\right)$. Assuming heterogeneous initial conditions worsened the fit of the model in Portugal and Austria, as illustrated by the increase of 11613.2 and 152.77 in $\chi^{2}$. A similar result was obtained in Finland, however given that in our preferred model the SSR is smaller and the parameter estimates are significant, we decided to keep the specification. Assuming heterogenous initial conditions led to convergence or identification problems in UK and Spain. 
Introducing an $\mathrm{MA}(1)$ component besides the $\mathrm{AR}(1)$ improved significantly the fit of the model in Italy $\left(\chi^{2}=323.1314, \mathrm{df}=1\right)$, Greece $\left(\chi^{2}=121.2267, \mathrm{df}=1\right)$ and Spain $\left(\chi^{2}=47.9717, \mathrm{df}=1\right)$. MA(1) component was rejected in Luxembourg and Portugal, as suggested by the increase of 1.073 , respectively 4015.76 in $\chi^{2}$. In rest, this specification failed to converge or suffered from identification problems. 
Table 4.3. Alternative Model Specifications

\begin{tabular}{|c|c|c|c|c|c|}
\hline & Alternative Model & SSR & Chi2 & $\log L$ & Parameters \\
\hline \multirow{3}{*}{ Germany } & PI+AR1 & .0171 & 3333.3328 & 446.4264 & 27 \\
\hline & PI+AR1, $\sigma_{0}^{2}=\sigma_{0, \text { cohort }}^{2}$ & 0.0168 & 2598.8668 & 447.7299 & 26 \\
\hline & Canonical Model & 0.3314 & 43238.681 & 233.051 & 2 \\
\hline \multirow{3}{*}{ Denmark } & $\mathrm{PI}+\mathrm{AR} 1$ & 0.0069 & 5825.6657 & 511.8177 & 27 \\
\hline & $\mathrm{RW}+\mathrm{AR} 1, \sigma_{0}^{2}=\sigma_{0, \text { cohort }}^{2}$ & 0.0069 & 6308.8755 & 511.6101 & 25 \\
\hline & Canonical model & 0.0273 & 29378.035 & 412.7862 & 2 \\
\hline \multirow{3}{*}{ Netherlands } & PI+AR1 & .0104 & 2671.5118 & 482.3131 & 27 \\
\hline & $\mathrm{RG}+\mathrm{AR}, \sigma_{0}^{2}=\sigma_{0, \text { cohort }}^{2}$ & .0107 & 2700.0947 & 480.0743 & 26 \\
\hline & Canonical model & 0.0769 & 24373.43 & 338.163 & 2 \\
\hline \multirow[t]{2}{*}{ Belgium } & $\mathrm{PI}+\mathrm{AR} 1, \sigma_{0}^{2}=\sigma_{0, \text { cohort }}^{2}$ & 0.005 & 18832.583 & 533.4292 & 24 \\
\hline & Canonical model & 0.0751 & 46706.478 & 339.8958 & 2 \\
\hline \multirow[t]{2}{*}{ France } & $\mathrm{PI}+\mathrm{AR} 1, \sigma_{0}^{2}=\sigma_{0, c o h o r t}^{2}$ & 0.0255 & 1817.4386 & 417.7385 & 24 \\
\hline & Canonical model & 0.3668 & 8599.1199 & 225.739 & 2 \\
\hline \multirow{3}{*}{ Luxembourg } & $\mathrm{PI}+\mathrm{AR} 1, \sigma_{0}^{2}=\sigma_{0, \text { cohort }}^{2}$ & 0.026 & 1900.723 & 309.4077 & 22 \\
\hline & PI+ARMA(1,1) & 0.0222 & 1633.305 & 318.5007 & 26 \\
\hline & Canonical model & 0.2064 & 35231.176 & 193.6939 & 2 \\
\hline \multirow{2}{*}{ UK } & PI+AR1 & 0.0072 & 2782.613 & 508.905 & 27 \\
\hline & Canonical model & 0.1062 & 12248.666 & 314.9804 & 2 \\
\hline \multirow{3}{*}{ Ireland } & PI+AR1 & 0.0323 & 2125.021 & 400.506 & 27 \\
\hline & $\mathrm{RG}+\mathrm{AR} 1, \sigma_{0}^{2}=\sigma_{0, \text { cohort }}^{2}$ & 0.0276 & 2324.4346 & 412.13 & 26 \\
\hline & Canonical model & 0.2028 & 24662.992 & 268.4008 & 2 \\
\hline \multirow{4}{*}{ Italy } & PI+ARMA $(1,1)$ & 0.002 & 1641.5036 & 598.0915 & 28 \\
\hline & $\operatorname{RG}+\operatorname{ARMA}(1,1), \sigma_{0}^{2}=\sigma_{0, \text { cohort }}^{2}$ & 0.002 & 1646.3788 & 598.1981 & 27 \\
\hline & RG+AR1 & 0.002 & 1899.3595 & 600.8606 & 29 \\
\hline & Canonical model & 0.097 & 12434.997 & 12434.997 & 2 \\
\hline \multirow{3}{*}{ Greece } & $\mathrm{RG}+\operatorname{ARMA}(1,1), \sigma_{0}^{2}=\sigma_{0, \text { cohort }}^{2}$ & 0.0153 & 3996.5599 & 454.4974 & 27 \\
\hline & $\mathrm{RG}+\mathrm{AR} 1$ & 0.0147 & 3945.6763 & 457.1551 & 29 \\
\hline & Canonical model & 0.2507 & 26975.122 & 253.1378 & 2 \\
\hline \multirow{3}{*}{ Spain } & $\mathrm{PI}+\mathrm{ARMA}(1,1), \sigma_{0}^{2}=\sigma_{0, \text { cohort }}^{2}$ & 0.0098 & 2013.2298 & 486.3516 & 25 \\
\hline & $\mathrm{RG}+\mathrm{AR} 1, \sigma_{0}^{2}=\sigma_{0, \text { cohort }}^{2}$ & 0.0109 & 2032.9304 & 478.5467 & 26 \\
\hline & Canonical model & 0.551 & 11817.977 & 196.4497 & 2 \\
\hline \multirow{4}{*}{ Portugal } & $\mathrm{RW}+\mathrm{AR} 1, \sigma_{0}^{2}=\sigma_{0, \text { cohort }}^{2}$ & 0.0287 & 3737.4586 & 408.9498 & 25 \\
\hline & $\mathrm{PI}+\mathrm{AR} 1$ & 0.0274 & 15350.702 & 412.4226 & 27 \\
\hline & $\mathrm{PI}+\mathrm{ARMA}(1,1), \sigma_{0}^{2}=\sigma_{0, \text { cohort }}^{2}$ & 0.0261 & 7753.2688 & 415.9961 & 25 \\
\hline & Canonical model & 1.208 & 38920.003 & 139.9288 & 2 \\
\hline \multirow{3}{*}{ Austria } & PI+AR1 & 0.0049 & 2382.0622 & 402.5245 & 25 \\
\hline & Simple model & 0.0539 & 15059.202 & 268.8687 & 2 \\
\hline & $\mathrm{PI}+\mathrm{AR} 1$ & 0.0049 & 1044.3253 & 290.5622 & 23 \\
\hline \multirow[t]{2}{*}{ Finland } & $\mathrm{RG}+\mathrm{AR} 1, \sigma_{0}^{2}=\sigma_{0, \text { cohort }}^{2}$ & 0.0039 & 947.6261 & 298.9057 & 22 \\
\hline & Canonical model & 0.0197 & 6678.3651 & 231.7795 & 2 \\
\hline
\end{tabular}




\subsection{Inequality decomposition into permanent and transitory inequality}

Having estimated a suitable error component model for earnings in each country, next we use these parameters estimates to decompose earnings inequality into its permanent and transitory components, assess their absolute and relative contribution to the evolution of overall inequality, and estimate earnings mobility over the sample period, by cohort.

There is a fundamental conceptual underidentification of time, life-cycle, and cohort effects due to the exact multicollinearity of time, age, and birth year. Our decompositions control for cohort effects, but the age and period effects are confounded. Since our scope is to decompose within-cohort inequality into the two components, the lifecycle effect is considered part of the permanent component, and thus its specific identification was disregarded.

\subsubsection{Absolute decomposition}

Figure 4.3 illustrates the absolute decomposition of the variance, together with the actual and predicted variance of earnings by cohort. The decomposition by cohort identifies how inequality and its components are affected by labour market changes at different lifecycle stages. For all countries, the evolution of the predicted variance follows closely the evolution of the actual variance, confirming the fit of the country models, indicated by the low sum of square residuals.

Earnings inequality measured by the actual variance decreased overall in Germany - except for the cohorts born in 1941-1950 and 1961-1970 where it increased -, in Denmark, in Belgium - except for the youngest cohort where it increased -, in France - except for the cohort born in 1961-1970 -, in UK - except for the youngest two cohorts where it increased -, in Ireland, in Spain - except the youngest and the oldest cohort -, and in Austria. Earnings inequality measured by the actual variance increased overall for all cohorts in Netherlands, Luxembourg, Italy, Greece, Portugal, and Finland - except for the youngest cohort. These are countries where wages appear to be more responsive to market forces.

The pattern of the absolute decomposition of the overall variance varies between countries and cohorts. Nevertheless, some common traits emerge. Permanent variance is higher and transitory variance is lower, the older is the cohort, which is consistent with the evidence of lifecycle earnings divergence showing that older 
cohorts experience a lower earnings volatility compared with younger cohorts. Similar results are found by Dickens $(2000 b)$ and Ramos $(1999,2003)$ for UK, Cervini and Ramos (2006) for Spain, and Capellari (2003) for Italy.

The decrease in the overall cross-sectional inequality is the result of decreasing permanent and transitory differentials in Denmark and Austria, of decreasing permanent differentials with offsetting effect over the increasing transitory differentials in Belgium and Spain, and of decreasing transitory differentials with offsetting effects over the increasing permanent differentials in Germany, France, UK and Ireland. In most countries, these trends are consistent across cohorts. Mixed trends across cohorts are observed in: Denmark - where the transitory variance increased for the second oldest cohort -, Belgium - where both component decreased for the oldest cohort and the increase in the transitory variance dominated for the youngest cohort -, Spain - where the increase in the transitory variance dominated for the oldest and the youngest cohort -, Germany - where both components increased for the 1941-1950 and 1961-1970 cohorts, and decreased for the cohort 1951-1960 -; France - where both components increased for the second youngest cohort -, Ireland - where both components decreased for the oldest cohort -, and UK - where both components decreased for the oldest cohort, and the increase in inequality for the youngest two cohorts was determined by an increase in the permanent variance for the cohort 1961-1970 and by an increase in the transitory variance for the cohort 1971-1980.

In Luxembourg, Italy, Greece and Finland, the exacerbation of permanent differentials, meaning the increase in returns to skills was the dominant factor behind the increase in overall inequality, offsetting the decrease in transitory differentials, whereas in Portugal and Netherlands both components increased. These trends are consistent across cohorts, except for the youngest cohort in Luxembourg and Italy, and the second oldest cohort in Greece - where both components increased -, the youngest two cohorts in Netherlands - where permanent differentials decreased -, and Finland - where both components decreased.

To summarize these trends we averaged permanent and transitory variance across cohorts: the decrease in overall inequality was driven by a decrease in both components in Denmark and Austria, by a decrease in permanent differentials in Belgium and Spain, and by a decrease in transitory differentials in Germany, France, UK and Ireland. The exacerbation of overall inequality was the result of increasing permanent differentials in Luxembourg, Italy, Greece and Finland, and of an increase in both components in Portugal and Netherlands. 
Comparing with national results, Cervini and Ramos (2006) obtained similar results with respect to overall within-cohort inequality in Spain, however differed in respect of the component trends.

Daly and Valletta's (2005) findings for Germany and the UK are reasonably consistent with those reported here. For the UK, for the period 1994-1999, our results are only partially in line with Ramos (2003). First, the sharp increase he found in 1999 is not present in our data or in other recent studies ${ }^{48}$. Second, between 1994 and 1998, he got a similar trend in actual inequality for the oldest two cohorts, but the trends in the two components differ, which might result from the mismatch between the trends in actual and predicted variances.

For Ireland, Doris et al.'s (2008) results for overall and transitory inequality are in line ours. For permanent inequality, only the oldest cohort matches their trend. The findings for Italy are consistent with Capellari (2003).

Following these changes, the ranking in permanent and transitory dispersion for all countries by cohort in 2001 are illustrated in Figure 4.2. The figures are in ascending order for the transitory variance. For the oldest three cohorts, the highest permanent inequality is observed in Portugal, and for the youngest cohort in Luxembourg. Denmark, Belgium and Austria have the lowest permanent dispersion across all cohorts. Portugal, Greece and Spain have the highest transitory variance for all cohorts, except the youngest one, where Netherlands is the highest. The lowest transitory variance is observed in Denmark for the oldest cohort, in Finland for the middle cohorts, and in Ireland for the youngest cohort.

We summarize the changes in country ranking in permanent and transitory inequality over the sample period by reporting the averages across cohorts. In 1994, the highest average permanent inequality ${ }^{49}$ was recorded in Portugal and Spain, followed by France, Ireland, Germany, UK, Greece, Italy, Netherlands, Belgium and Denmark. The highest transitory variance was recorded in France, Ireland, Greece, UK, Germany, Spain, Belgium, Denmark, Netherlands, Italy and Portugal. In 1995, Austria and Luxembourg had a middle ranking in permanent inequality and a top ranking 50 in transitory inequality. In 1996, Finland had the second lowest permanent inequality and a middle ranking in transitory inequality.

In 2001 the rankings looks slightly different. Portugal records the highest average permanent differentials, followed by Luxembourg, France, Spain, Ireland,

\footnotetext{
48 Our trend in overall inequality is consistent also with Cholezas and Tsakloglou (2008), which compared hourly earnings inequality across EU using ECHP.

${ }^{49}$ Average permanent variance and transitory variance represent average across cohorts.

${ }^{50}$ Among the highest four.
} 
Germany, Greece, UK, Italy, Finland, Netherlands, Austria, Belgium and Denmark. In terms of transitory inequality, Portugal appears to be the most dispersed, followed by Spain, Netherlands, France, Greece, UK, Germany, Belgium, Luxembourg, Austria, Ireland, Denmark, Finland and Italy.

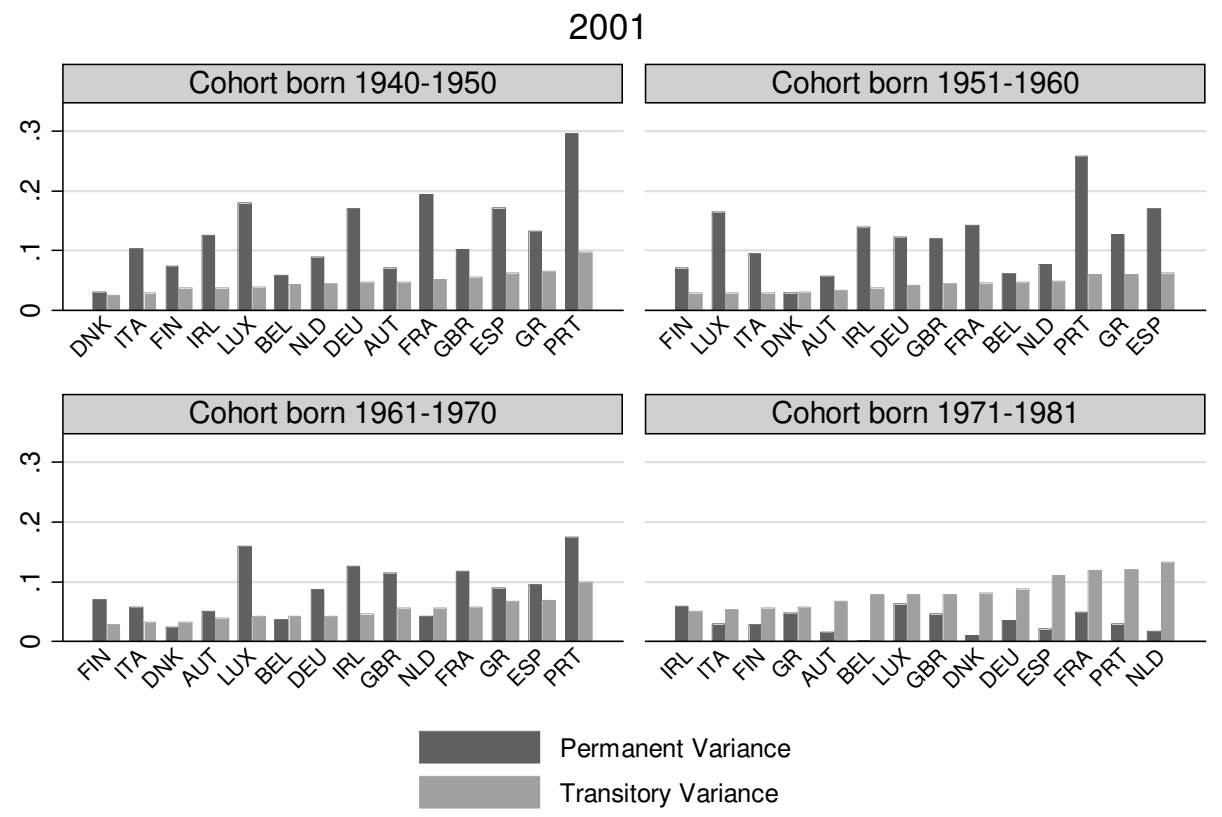

Graphs by Cohort

Figure 4.2. Permanent and Transitory Variance for Selected Cohorts in 2001

Note: The figures are in ascending order for the transitory variance 

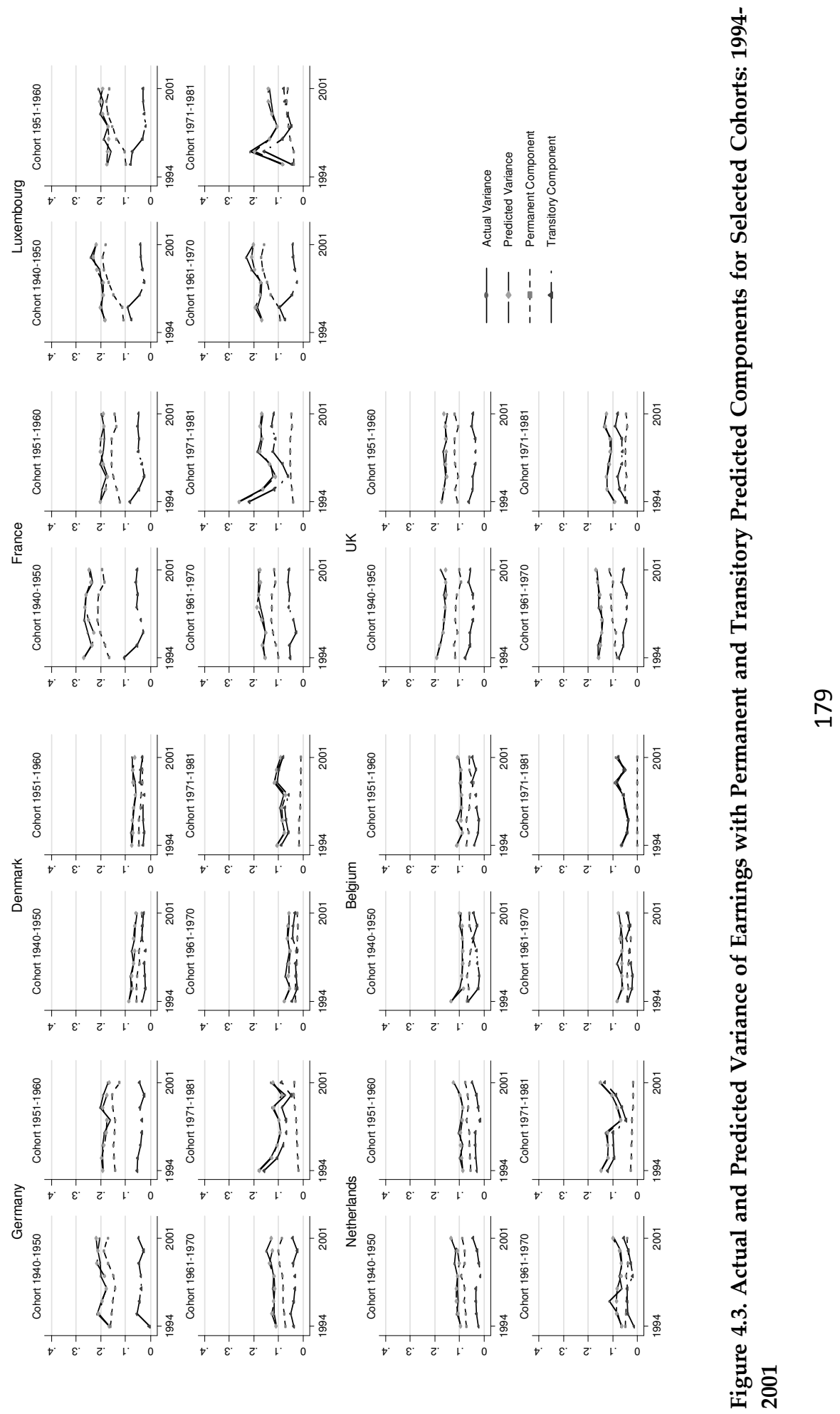

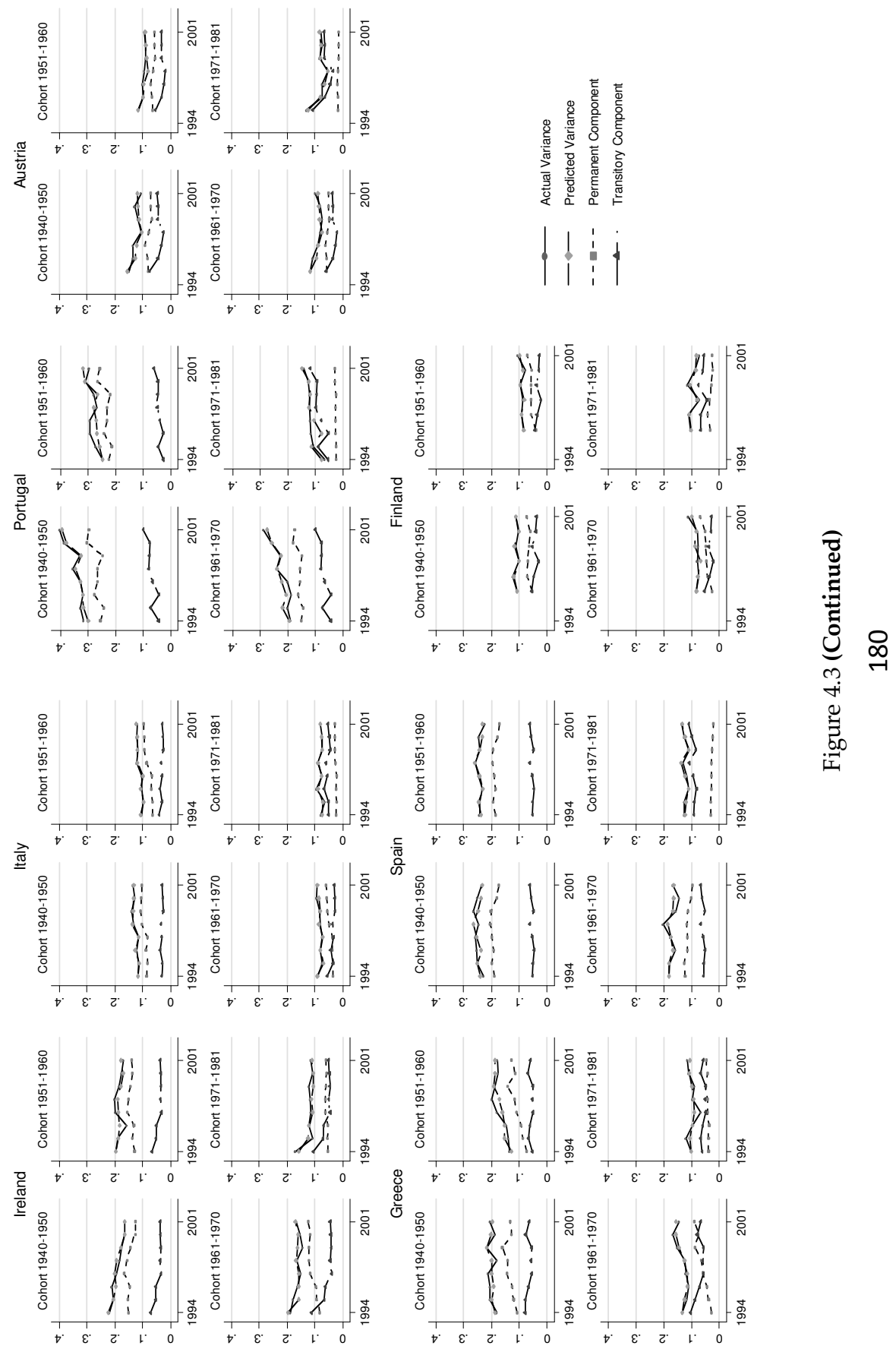


\subsubsection{Relative decomposition - structure of inequality}

Figure 4.4 illustrates the evolution of the structure of inequality, expressed by the relative decomposition of the overall predicted variance of earnings into its permanent and transitory components.

Figure 4.5 translates these trends into earnings immobility, measured as the ratio between permanent variance and transitory variance following Kalwij and Alessie (2003). An increase in the immobility ratio indicates a decrease in earnings mobility, equivalent to an increase in the share of the permanent differentials in overall inequality. This mobility index captures non-directional earnings movements and can be interpreted as the opportunity to improve one's position in the distribution of lifetime earnings.

The pattern of the relative decomposition of the overall variance and the trends in earnings immobility vary between countries and cohorts. Nevertheless, some common traits emerge. Inequality in the permanent component of earnings accounts for a higher share of the overall variance the older the cohort is, which is consistent with the evidence of lifecycle earnings divergence showing that older cohorts experience a lower earnings volatility compared with younger cohorts. Moreover, for the youngest cohort, temporary inequality has a dominant share in overall inequality, which reinforces that earnings volatility is higher at younger ages. (Figure 4.4) The same pattern was found by Capelari (2003), Ramos (2003) and Cervini and Ramos (2006).

Similarly, in all countries, the degree of immobility is higher for older cohorts compared with younger cohorts, which suggests that the opportunity to improve one's position in the earnings distribution is lower the older is the cohort. (Figure 4.5)

Figure 4.6 summarizes the country ranking with respect to earnings persistency and earnings immobility over the sample period, by cohort. The higher the share of permanent inequality, the higher the immobility. In the first wave, for the oldest cohort, the highest share of the permanent component (the lowest mobility) is in Germany $(97 \%)$, followed by Portugal, Spain, Netherlands, Italy, Ireland, Denmark, France and UK with shares between $85 \%$ and $60 \%$, and the rest with shares between $60 \%$ and $49 \%$. For the cohort 1951-1960, the highest permanent share (the lowest mobility) is in Portugal ( $89 \%$ ), followed by Spain, Germany, Ireland, 

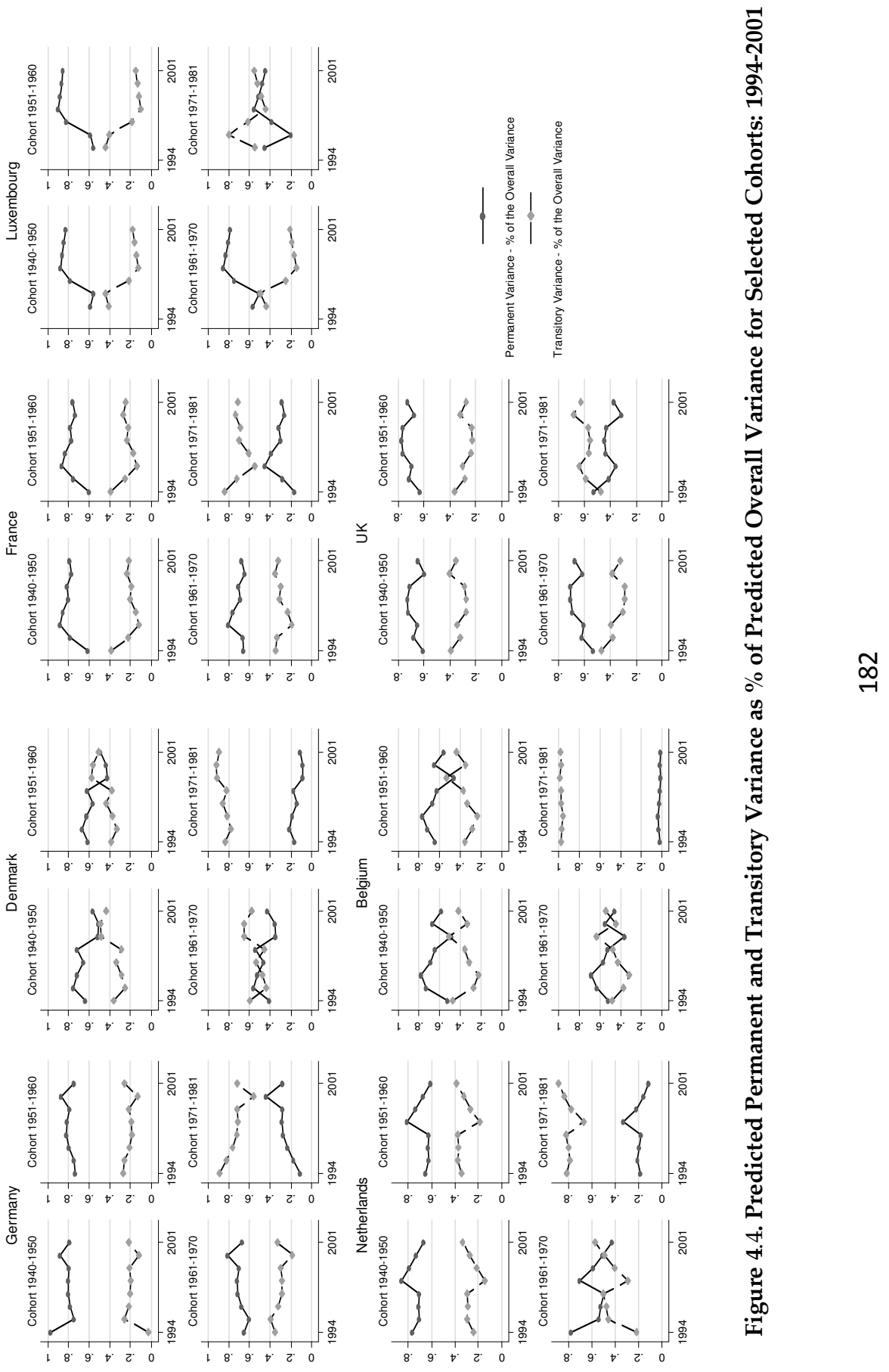

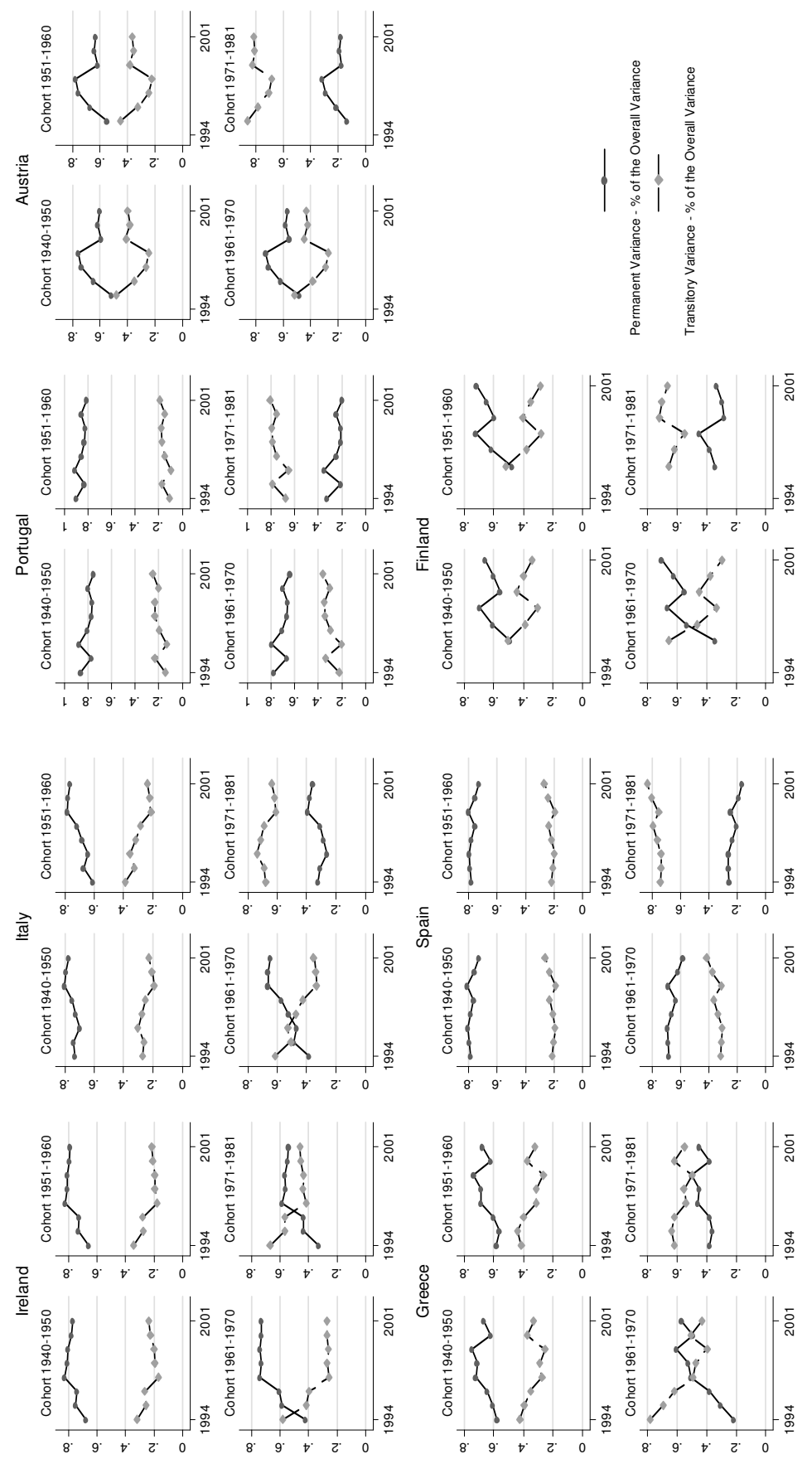

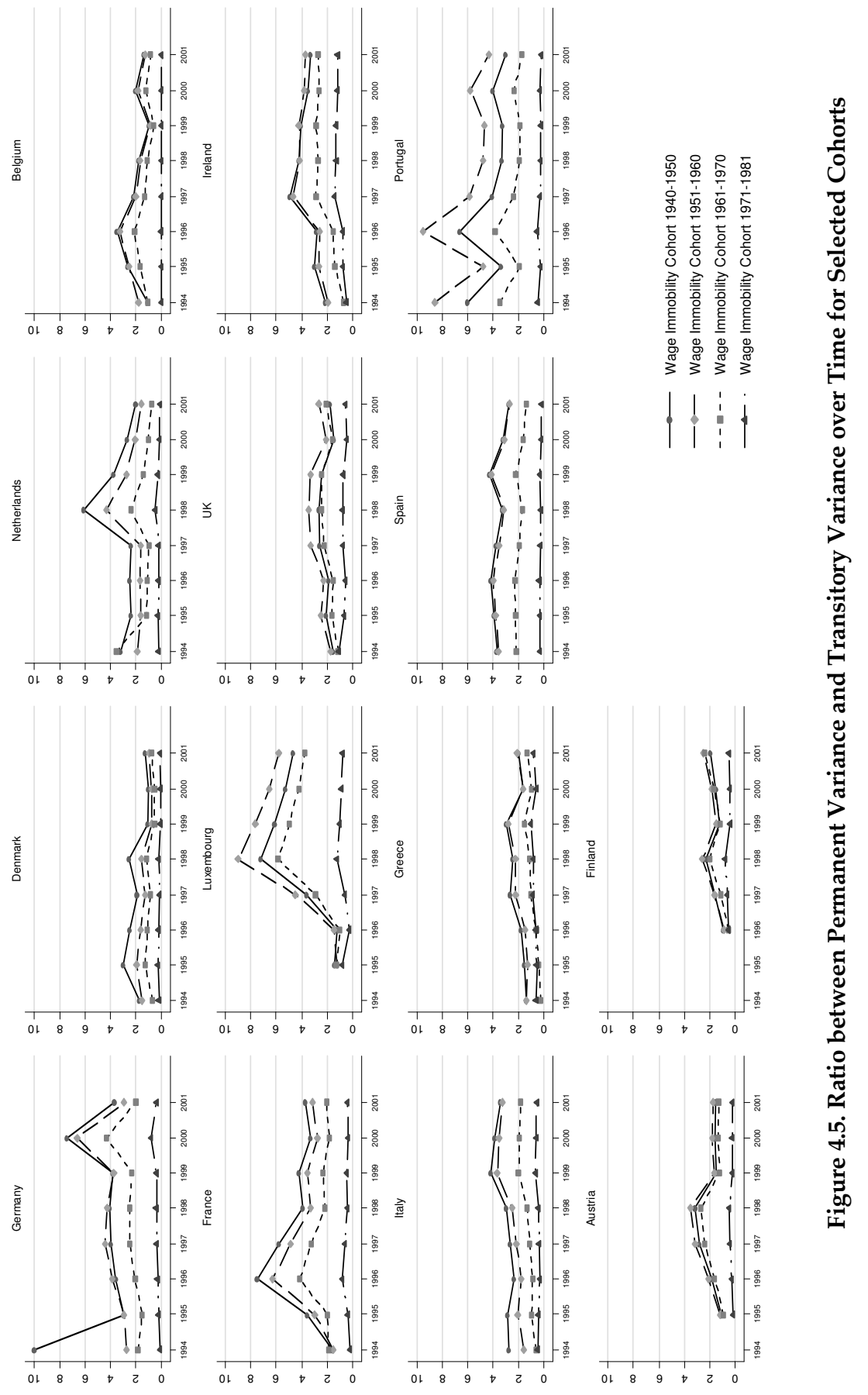

$\stackrel{\infty}{+}$ 
Netherlands, Belgium, UK, Italy, Denmark and France with shares between 78\% and $60 \%$, and the rest with shares between 58\% (Greece) and 47\% (Finland).

For the 1961-1970 cohort, the highest permanent shares (the lowest mobility) are in Netherlands and Portugal (77\%), followed by Spain, France and Germany - with shares between 68\% and 64\% -, Luxembourg, UK, Belgium, Austria and Ireland with shares between $56 \%$ and $42 \%$-, and the rest with shares between $40 \%$ (Denmark) and 21\% (Greece). For the cohort 1971-1981, the highest permanent share is recorded in UK (52\%), followed by Luxembourg (45\%), Greece, Finland, Ireland, Portugal, Italy and Spain - with shares between $38 \%$ and $25 \%-$, and the rest with shares between 18\% (Netherlands) and 2\% (Belgium).
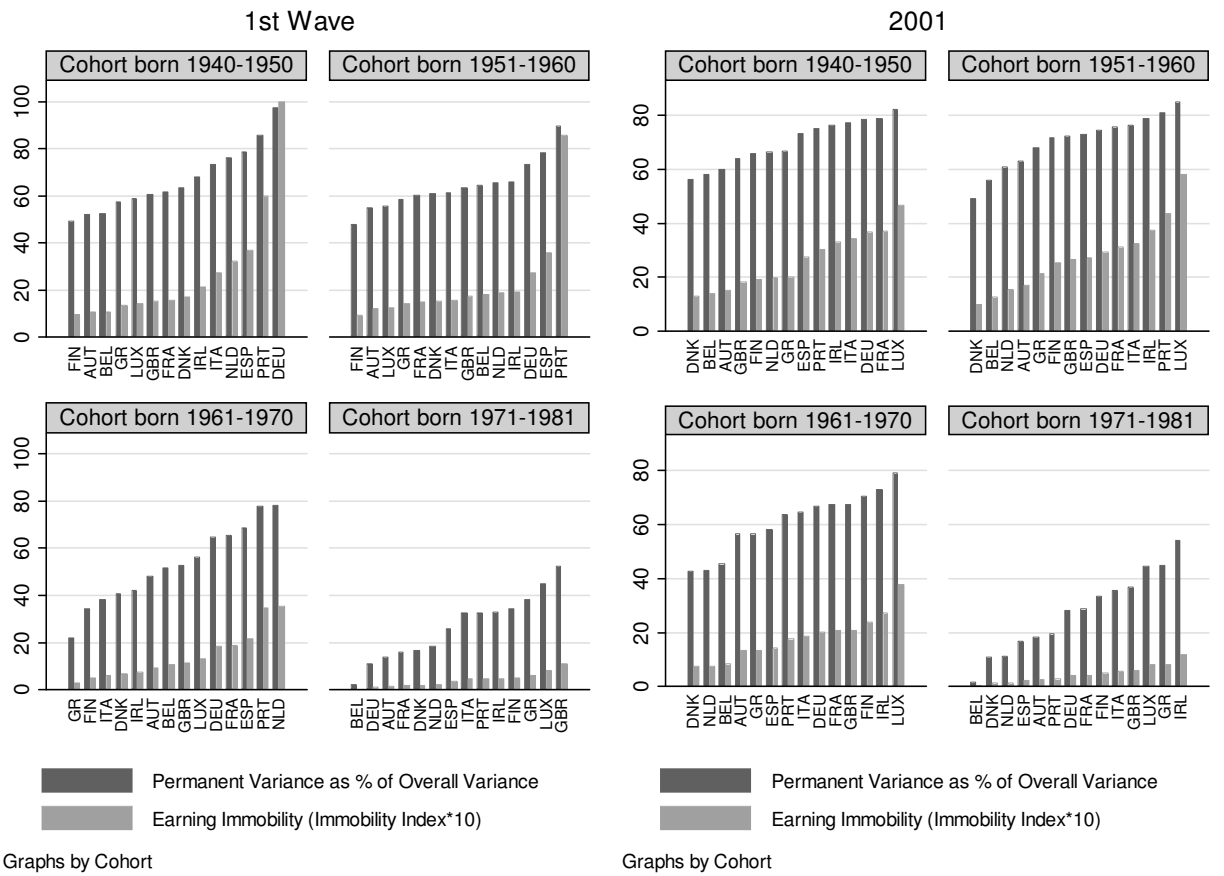

Figure 4.6. Permanent Inequality - \% of the Overall Inequality and Earnings Immobility for Selected Cohorts over Time

Turning to Figure 4.4 and Figure 4.5 we observe that among the countries with decreasing inequality, in Denmark, Belgium and Spain the structure of inequality and earnings mobility by cohort did not change much in 2001 compared with 1994. 
The share of the permanent component decreased - the immobility ratio decreased, thus mobility increased - for all cohorts in Spain, for all cohorts except the second youngest in Denmark, and for the youngest three cohorts in Belgium. For the other countries with decreasing inequality, the structure of inequality changed to a large extent and led to an increase in the share of the permanent inequality - an increase in the immobility ratio, thus a decrease in mobility- for all cohorts, except the oldest in Germany and the youngest in UK.

Most countries with increasing inequality recorded an increasing share of permanent inequality - an increasing immobility ratio, thus decreasing mobility for all cohorts. Netherlands, Portugal, and the youngest cohort in Luxembourg and Finland, however, are exceptions.

The results for Germany over 1994-1999 and for UK over 1994-1998 are in line with Daly and Valletta (2005), which found increasing shares of permanent differentials. For UK, Ramos(2003) found decreasing shares between 1994-1999 for all cohorts. For Spain, our results are at odds with Cervini and Ramos (2006), which found increasing shares of permanent inequality for all cohorts. For Ireland, our results are in line with Doris et al. (2008). For Italy, the results are in line with Capelari (2003).

Following these changes, the structure of inequality and earnings immobility in 2001 is summarized in Figure 4.6. For the oldest cohort, the highest share of permanent inequality implying the highest earning persistency (lowest mobility) is found in Luxembourg, France, Germany, Italy, Ireland, Portugal and Spain, with rates between $82 \%$ and $73 \%$. Greece, Netherlands, Finland, UK and Austria are less persistent with values between $70 \%$ and $60 \%$. The least persistent - most mobile are Denmark and Belgium, where permanent variance accounts for $56-58 \%$ of the overall variance.

For the 1951-1960 cohort, the highest persistency - lowest mobility - is recorded by the same countries, including UK and Finland, with shares between $85 \%$ and $71 \%$, followed by Greece, Austria and Netherlands with shares between $68 \%$ and $61 \%$, and lastly Belgium (56\%) and Denmark (49\%). For the 1961-1970 cohort in Luxembourg, Ireland and Finland permanent variance accounts for $79 \%$ to $70 \%$ of the overall variance, followed by UK, France, Germany, Italy and Portugal with shares between $66 \%$ and $63 \%$, by Spain, Greece and Austria with shares between $58 \%$ and $56 \%$, and by Belgium, Netherlands and Denmark with shares between $45 \%$ and $42 \%$.

For the youngest cohort, the variance is dominantly transitory in all countries, except Ireland where the transitory variance accounts for $46 \%$ of the overall 
variance, suggesting that Irish youngsters have the lowest degree of earnings mobility in Europe. The most volatile earnings are found in Belgium, where 98.5\% of the variance is transitory. Next follow Denmark and Netherlands where transitory variance accounts for $89 \%$ of the overall variance; Spain, Austria and Portugal, with transitory shares between $84 \%$ and $81 \%$; Germany, France, Finland, Italy and UK with transitory shares between $72 \%$ and $63 \%$; Greece and Luxembourg where transitory inequality accounts for $56 \%$ of the variance.

Based on Daly and Valetta (2007) the contribution of permanent variance to the overall inequality is of $54 \%$ for the US, $58 \%$ for Germany and $52 \%$ for Great Britain over the 1990's. For UK, over 1994-1999, Ramos (2003) found a lower persistency than us: the permanent component varied from about $60 \%$ to $30-40 \%$ for people born after 1960, and from 50\% to 30-40\% for people born between 1941 and 1960 . For Spain, over 1994-2000, Cervini and Ramos (2006) found an increasing contribution from $60 \%$ and $70 \%$ to $90 \%$ and $80 \%$ for people born in 1944-1953 and 1954-1963, and from 30\% to 40\% for people born after 1964. For Ireland, Doris et al. (2008) reported an average permanent share of $71 \%$.

The evolution of the two components, both in absolute and relative terms, and of earnings immobility was not monotonic. Most countries experienced a turnaround after 1996-1999. The labour market explanations for these changes are explored in Sologon and O'Donoghue (2009e).

To sum up, the decrease in inequality was accompanied by an increase in mobility (decrease in immobility ratio) only in Denmark, Belgium and Spain. In a few countries some cohorts diverged from the general trend. The youngest cohort recorded an increase in inequality accompanied by an increase in mobility (decrease in immobility ratio) in Belgium, Spain, and UK. The second youngest cohort recorded a decrease in inequality accompanied by a decrease in mobility (increase in immobility ratio) in Denmark, and an increase in inequality accompanied by a decrease in mobility (increase in immobility ratio) in Germany, France and UK. The oldest cohort recorded an increase in inequality accompanied by an increase in mobility (decrease in immobility ratio) in Germany and Spain, and a decrease in inequality accompanied by a decrease in mobility (increase in immobility ratio) in Belgium.

Except for Netherlands and Portugal, all countries recording an increase in inequality experienced also a decrease in mobility (increase in immobility ratio). This trend is valid across cohorts, which suggests that the changes in the labour market affected all workers in a similar way. The youngest cohort in Luxembourg and Finland are exceptions: the increase in inequality in Luxembourg and the 
decrease in inequality in Finland was accompanied by an increase in mobility (decrease in immobility ratio).

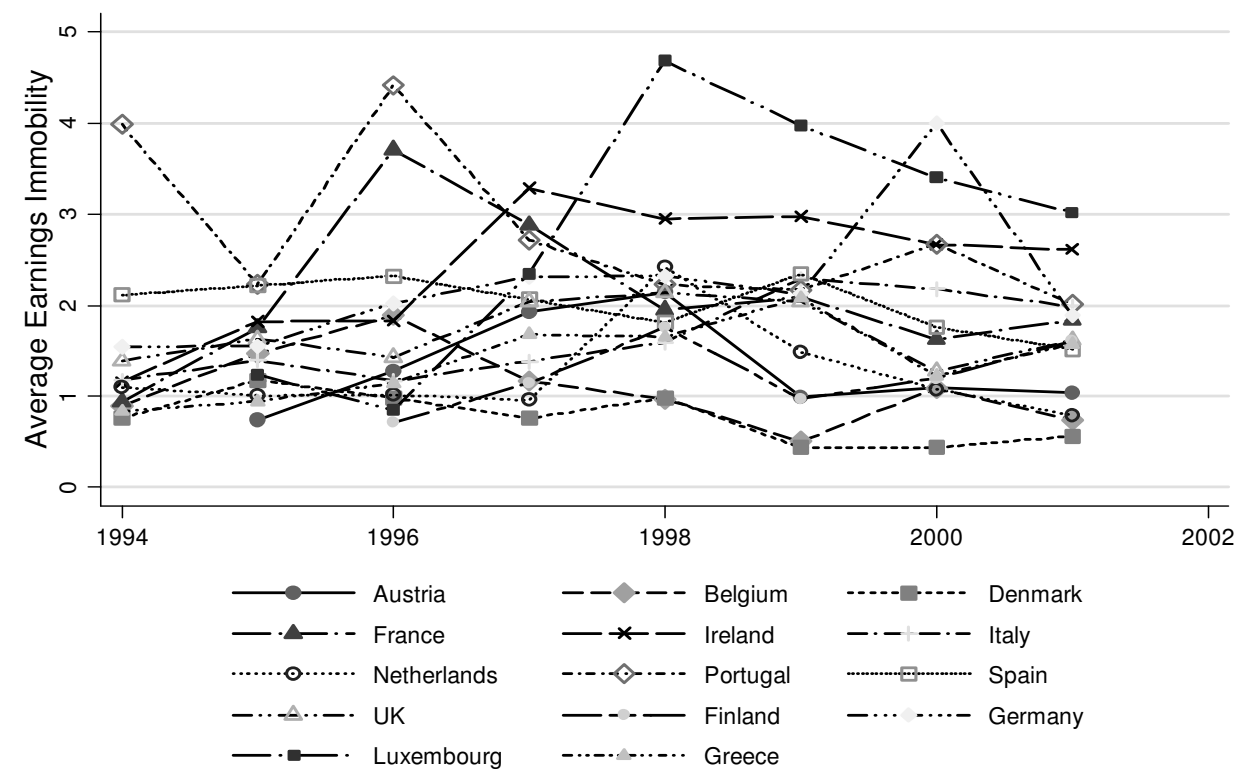

Figure 4.7. Average Earnings Immobility - Ratio between Average Permanent Variance and Average Transitory Variance over Time

Averaged across cohorts, earnings mobility ${ }^{51}$ decreased over time in most countries, except Denmark, Belgium, Spain, Netherlands and Portugal. In 2001, Denmark has the highest average earnings mobility, followed by Belgium, Netherlands, Austria, Spain, Greece, Finland, UK, France, Germany, Italy, Portugal, Ireland and Luxembourg. (Figure 4.7)

${ }^{51}$ Average Immobility=Average Permanent Variance/Average Transitory Variance 


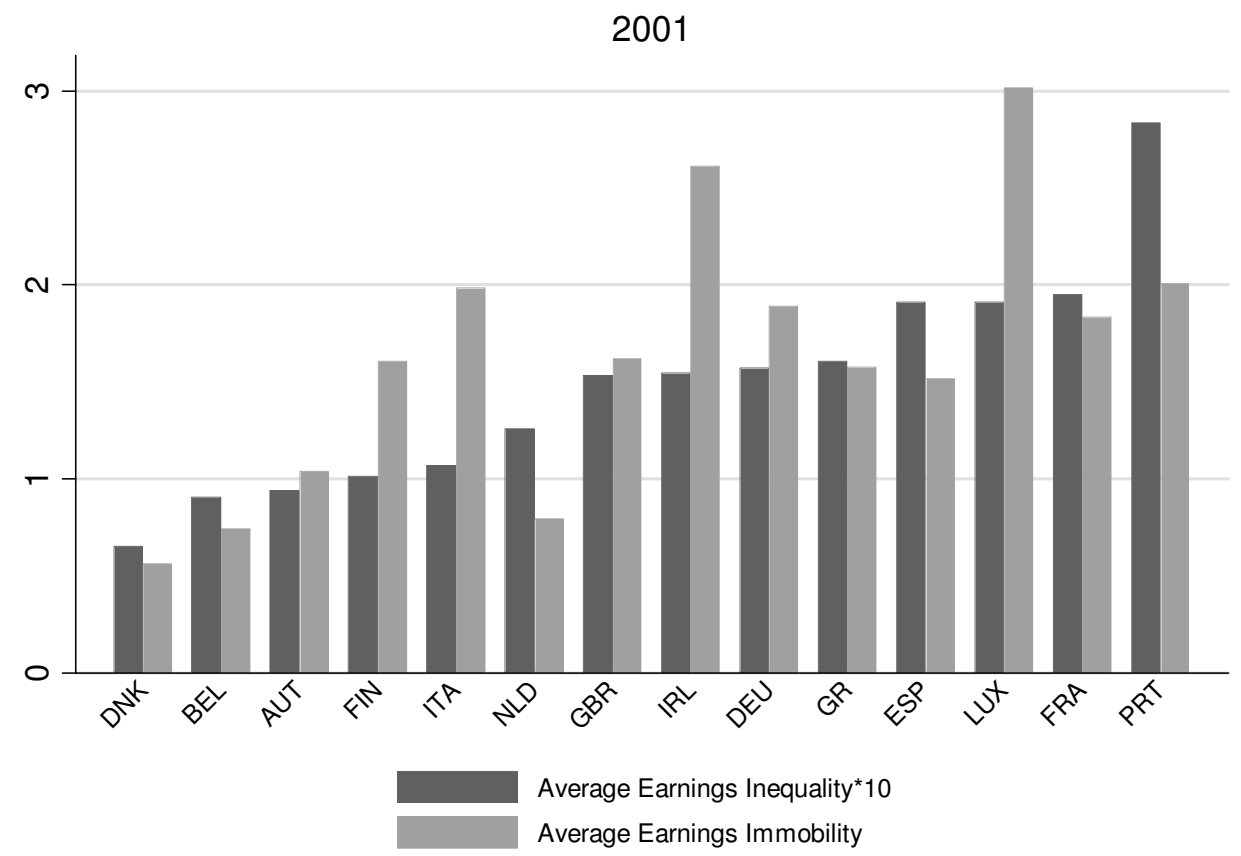

Figure 4.8. Average Earnings Inequality and Average Earnings Immobility Ratio in 2001 Note: The figures are in ascending order for the Average Earnings Inequality, rescaled by multiplying with 10 .

Based on Figure 4.8, which illustrates the average inequality and average immobility in 2001, ranked in ascendant order of the average inequality, the level of cross-sectional inequality appears to be positively ${ }^{52}$ associated with the level of earnings immobility. Denmark, Belgium and Austria have the lowest inequality and the lowest immobility in 2001. Thus, assuming that lifetime earnings mobility acts towards reducing lifetime earnings differentials, we expect these countries to trigger the lowest degree of lifetime inequality. The lifetime inequality ranking between Austria and Netherlands, however, is undetermined. Finland is expected to trigger a lower lifetime inequality than Italy, UK, Ireland, Germany, Luxembourg and Portugal; Netherlands a lower lifetime inequality than UK,

\footnotetext{
${ }^{52}$ The correlation coefficient indicates a strong positive association (0.5864), sig at 5\% level of confidence.
} 
Ireland, Denmark, Greece, Spain, Luxembourg, France and Portugal; UK a lower lifetime inequality than Ireland Germany, Luxembourg, France and Portugal; Ireland a lower lifetime inequality than Luxembourg; Germany a lower lifetime inequality than Luxembourg and Portugal; Greece and Spain a lower lifetime inequality than Luxembourg, France and Portugal; and France a lower lifetime inequality than Portugal.

These expectations, however, are based on the strong assumption that lifetime mobility acts towards reducing lifetime differentials.

\subsection{Concluding remarks}

We explored the extent to which the changes in cross-sectional earnings inequality in 14 EU countries over the period 1994 and 2001 reflect changes in transitory and/or permanent earnings inequality and the potential link with earnings mobility. The analysis was broken down by cohorts to identify the potential consequences of the labour market changes occurred after 1995 on earnings persistency and mobility at different lifecycle stages.

Overall earnings inequality, measured by the variance in log hourly earnings, decreased in Germany, Denmark, Belgium, France, UK, Ireland, Spain, Austria and increased in Netherlands, Luxembourg, Italy, Greece, Portugal and Finland. For all countries, both in relative and absolute terms, individual earnings inequality contains a highly permanent component for the oldest three cohorts and a highly transitory component for the youngest cohort. This is consistent with the evidence of lifecycle earnings divergence showing that earnings volatility is higher at younger ages. The degree of immobility is higher for older cohorts compared with younger cohorts, which suggests that the older the cohort, the lower the opportunity to improve one's position in the distribution of lifetime earnings.

Overall, the decrease in inequality resulted from a decrease in transitory differentials in Germany, France, UK and Ireland, in permanent differentials in Belgium and Spain, and in both components in Denmark and Austria. The increase in inequality reflects an increase in permanent differentials in Luxembourg, Italy, Greece and Finland, and an increase in both components in Portugal and Netherlands. The decrease in inequality was accompanied by an increase in mobility only in Denmark, Belgium and Spain. Except for Netherlands and Portugal, all countries recording an increase in inequality experienced also a decrease in mobility. 
More important are the welfare implications of these trends. We start with the countries recording a decrease in overall inequality. In Denmark, Belgium and Spain, mobility appears to be beneficial: in 2001, low wage individuals are better off both in terms of their relative wage and in terms of the opportunities to escape the low-wage trap in a lifetime perspective. Thus in a lifetime perspective, Denmark, Belgium and Spain are expected to reduce lifetime earnings differentials compared with annual differentials.

In Austria, Germany, France, UK and Ireland, in 2001, low-wage individuals are worse off in terms of the opportunity to escape the low-wage trap, but their relative position in the earnings distribution is improved compared with the 1st wave. For these countries mobility is expected to play a decreasing role in reducing lifetime inequality, therefore annual differentials have a high chance of being preserved in a lifetime perspective.

The inequality and mobility behaviour across cohorts differ from the general trend in a few countries. The youngest cohort recorded an increase in inequality accompanied by an increase in mobility in Belgium, Spain, and UK, suggesting that in 2001 young low wage workers are worst of in terms of their relative wage, but better off in terms of their opportunity to improve their earnings position in a lifetime perspective. Hence, the reforms might have increased employment and wage flexibility among young workers. The second youngest cohort recorded a decrease in inequality accompanied by a decrease in mobility in Denmark, and an increase in inequality accompanied by a decrease in mobility in Germany, France and UK. The oldest cohort recorded an increase in inequality accompanied by an increase in mobility in Germany and Spain, suggesting that in 2001 older low wage workers are worst off in terms of their relative wage, but better off in terms of their opportunity to escape low-wage trap. This might result from increased employment and wage flexibility among older workers. In Belgium, the oldest cohort recorded a decrease in inequality accompanied by a decrease in mobility, suggesting that in 2001, among older workers, low wage workers are better off in terms of their relative wage, but worst off in terms of the opportunity to escape low-wage trap in a lifetime perspective.

Among countries recording an increase in earnings inequality, in Luxembourg, Italy, Greece, and Finland, besides the widening wages differentials, low wage individuals find it harder to better their position in the wage distribution in 2001 compared with the first wave. Thus we can expect these countries to increase lifetime earnings differentials compared with annual differentials. Netherlands and Portugal record widening wages differentials accompanied by increased opportunity of low wage individuals to improve their position in the distribution 
of lifetime earnings. Thus, for Netherlands and Portugal, earnings mobility could either decrease or exacerbate lifetime earnings differentials compared with annual ones.

These trends are valid across cohorts, suggesting that the changes in the labour market affected all workers in a similar way. Two exceptions are Finland, where for the youngest cohort inequality decreased and was accompanied by an increase in mobility, and Luxembourg, where for the youngest cohort inequality increased and was accompanied by an increase in mobility.

The evolution of the inequality structure and earnings mobility was not monotonic. Most countries experienced a sharp turnaround around 1996-1999, which could be linked with the EU labour market changes after 1995. Hence, future research could explore the role of labour market factors in explaining cross-national differences in permanent and transitory inequality, and earnings mobility, a topic neglected by the existing literature. 


\subsection{Annex}

Table 4-A-1. Inflows Inflows and Outflows of Individuals in the Sample - Germany

\begin{tabular}{|c|c|c|c|c|c|c|c|c|}
\hline & 1994 & 1995 & 1996 & 1997 & 1998 & 1999 & 2000 & 2001 \\
\hline $\begin{array}{l}\text { Number of individuals with } \\
\text { positive earnings }\end{array}$ & 25018 & 26059 & 25806 & 24889 & 23290 & 22955 & 21909 & 20703 \\
\hline \multicolumn{9}{|c|}{$\begin{array}{l}\text { Absolute number and proportion of individuals who report positive earnings in current year conditional on being in } \\
\text { the sample in previous year }\end{array}$} \\
\hline & Frequencies & 23956 & 25224 & 24197 & 22814 & 22321 & 21290 & 20107 \\
\hline & $\%$ & 66.99 & 67.37 & 66.2 & 63.01 & 64.84 & 64.86 & 64.39 \\
\hline \multicolumn{9}{|c|}{$\begin{array}{l}\text { Absolute number and proportion of individuals who report no earnings in current year conditional on being in the } \\
\text { sample in the previous year }\end{array}$} \\
\hline Unemployed & Frequencies & 3448 & 3461 & 4119 & 3932 & 3055 & 2787 & 2766 \\
\hline Inactive & $\%$ & 9.64 & 9.24 & 11.27 & 10.86 & 8.87 & 8.49 & 8.86 \\
\hline \multirow{2}{*}{ Attrition } & Frequencies & 1885 & 2182 & 1892 & 3280 & 2951 & 2924 & 2830 \\
\hline & $\%$ & 5.27 & 5.83 & 5.18 & 9.06 & 8.57 & 8.91 & 9.06 \\
\hline \multirow{2}{*}{ Missing Wage } & Frequencies & 6470 & 6576 & 6345 & 6180 & 6100 & 5826 & 5524 \\
\hline & $\%$ & 18.09 & 17.56 & 17.36 & 17.07 & 17.72 & 17.75 & 17.69 \\
\hline \multirow[t]{2}{*}{ Total } & Frequencies & 35759 & 37443 & 36553 & 36206 & 34427 & 32827 & 31227 \\
\hline & $\%$ & 100 & 100 & 100 & 100 & 100 & 100 & 100 \\
\hline
\end{tabular}

Table 4-A-1. Inflows and Outflows of Individuals in the Sample - Denmark

\begin{tabular}{|c|c|c|c|c|c|c|c|c|}
\hline & 1994 & 1995 & 1996 & 1997 & 1998 & 1999 & 2000 & 2001 \\
\hline $\begin{array}{l}\text { Number of individuals with } \\
\text { positive earnings }\end{array}$ & 20899 & 20399 & 19190 & 19062 & 17321 & 16235 & 15678 & 15380 \\
\hline \multicolumn{9}{|c|}{$\begin{array}{c}\text { Absolute number and proportion of individuals who report positive earnings in current year conditional on being in the } \\
\text { sample in previous year }\end{array}$} \\
\hline & Frequencies & 19854 & 18527 & 18110 & 16442 & 15334 & 14865 & 14642 \\
\hline & $\%$ & 68.74 & 66.59 & 69.43 & 66.23 & 67.41 & 69.6 & 71.6 \\
\hline \multicolumn{9}{|c|}{$\begin{array}{c}\text { Absolute number and proportion of individuals who report no earnings in current year conditional on being in the } \\
\text { sample in the previous year }\end{array}$} \\
\hline Unemployed & Frequencies & 1535 & 1744 & 951 & 899 & 732 & 658 & 958 \\
\hline Inactive & $\%$ & 5.31 & 6.27 & 3.65 & 3.62 & 3.22 & 3.08 & 4.68 \\
\hline \multirow{2}{*}{ Attrition } & Frequencies & 2440 & 3096 & 2914 & 3603 & 2922 & 2133 & 1775 \\
\hline & $\%$ & 8.45 & 11.13 & 11.17 & 14.51 & 12.85 & 9.99 & 8.68 \\
\hline \multirow{2}{*}{ Missing Wage } & Frequencies & 5054 & 4454 & 4110 & 3881 & 3759 & 3703 & 3074 \\
\hline & $\%$ & 17.5 & 16.01 & 15.76 & 15.63 & 16.53 & 17.34 & 15.03 \\
\hline \multirow[t]{2}{*}{ Total } & Frequencies & 28883 & 27821 & 26085 & 24825 & 22747 & 21359 & 20449 \\
\hline & $\%$ & 100 & 100 & 100 & 100 & 100 & 100 & 100 \\
\hline
\end{tabular}


Table 4-A-1. Inflows and Outflows of Individuals in the Sample - Netherlands

\begin{tabular}{|c|c|c|c|c|c|c|c|c|}
\hline & 1994 & 1995 & 1996 & 1997 & 1998 & 1999 & 2000 & 2001 \\
\hline $\begin{array}{l}\text { Number of individuals with } \\
\text { positive earnings }\end{array}$ & 20221 & 22100 & 22892 & 22753 & 22863 & 23233 & 24065 & 24130 \\
\hline \multicolumn{9}{|c|}{$\begin{array}{l}\text { Absolute number and proportion of individuals who report positive earnings in current year conditional on being in the } \\
\text { sample in previous year }\end{array}$} \\
\hline & Frequencies & 20578 & 21328 & 21221 & 21055 & 20545 & 21026 & 21341 \\
\hline & $\%$ & 69.07 & 71.37 & 68.68 & 67.52 & 67.24 & 68.56 & 69.59 \\
\hline \multicolumn{9}{|c|}{$\begin{array}{c}\text { Absolute number and proportion of individuals who report no earnings in current year conditional on being in the } \\
\text { sample in the previous year }\end{array}$} \\
\hline Unemployed & Frequencies & 2418 & 2356 & 2536 & 2120 & 1984 & 1840 & 1689 \\
\hline Inactive & $\%$ & 8.12 & 7.88 & 8.21 & 6.8 & 6.49 & 6 & 5.51 \\
\hline \multirow{2}{*}{ Attrition } & Frequencies & 2941 & 1889 & 2591 & 3562 & 3984 & 4301 & 4891 \\
\hline & $\%$ & 9.87 & 6.32 & 8.39 & 11.42 & 13.04 & 14.02 & 15.95 \\
\hline \multirow{2}{*}{ Missing Wage } & Frequencies & 3857 & 4310 & 4550 & 4448 & 4042 & 3502 & 2745 \\
\hline & $\%$ & 12.95 & 14.42 & 14.73 & 14.26 & 13.23 & 11.42 & 8.95 \\
\hline \multirow[t]{2}{*}{ Total } & Frequencies & 29794 & 29883 & 30898 & 31185 & 30555 & 30669 & 30666 \\
\hline & $\%$ & 100 & 100 & 100 & 100 & 100 & 100 & 100 \\
\hline
\end{tabular}

Table 4-A-1. Inflows and Outflows of Individuals in the Sample - Belgium

\begin{tabular}{|c|c|c|c|c|c|c|c|c|}
\hline & 1994 & 1995 & 1996 & 1997 & 1998 & 1999 & 2000 & 2001 \\
\hline $\begin{array}{l}\text { Number of individuals with } \\
\text { positive earnings }\end{array}$ & 35342 & 34367 & 33280 & 32378 & 31129 & 29414 & 28087 & 26538 \\
\hline \multicolumn{9}{|c|}{$\begin{array}{l}\text { Absolute number and proportion of individuals who report positive earnings in current year conditional on being in the } \\
\text { sample in previous year }\end{array}$} \\
\hline & Frequencies & 33277 & 32384 & 31564 & 30575 & 28731 & 27460 & 25790 \\
\hline & $\%$ & 63.43 & 63.65 & 64.38 & 63.88 & 64.28 & 65.15 & 64.38 \\
\hline \multicolumn{9}{|c|}{$\begin{array}{l}\text { Absolute number and proportion of individuals who report no earnings in current year conditional on being in the } \\
\text { sample in the previous year }\end{array}$} \\
\hline Unemployed & Frequencies & 3810 & 5127 & 4378 & 3601 & 3040 & 3090 & 2540 \\
\hline Inactive & $\%$ & 7.26 & 10.08 & 8.93 & 7.52 & 6.8 & 7.33 & 6.34 \\
\hline \multirow{2}{*}{ Attrition } & Frequencies & 4145 & 3798 & 3473 & 4803 & 4421 & 3851 & 4930 \\
\hline & $\%$ & 7.9 & 7.46 & 7.08 & 10.04 & 9.89 & 9.14 & 12.31 \\
\hline \multirow{2}{*}{ Missing Wage } & Frequencies & 11228 & 9573 & 9614 & 8882 & 8504 & 7748 & 6798 \\
\hline & $\%$ & 21.4 & 18.81 & 19.61 & 18.56 & 19.03 & 18.38 & 16.97 \\
\hline \multirow[t]{2}{*}{ Total } & Frequencies & 52460 & 50882 & 49029 & 47861 & 44696 & 42149 & 40058 \\
\hline & $\%$ & 100 & 100 & 100 & 100 & 100 & 100 & 100 \\
\hline
\end{tabular}


Table 4-A-1.. Inflows and Outflows of Individuals in the Sample - Luxembourg

\begin{tabular}{|c|c|c|c|c|c|c|c|c|}
\hline & & 1995 & 1996 & 1997 & 1998 & 1999 & 2000 & 2001 \\
\hline $\begin{array}{l}\text { Number of individuals with } \\
\text { positive earnings }\end{array}$ & & 15829 & 13695 & 14489 & 13403 & 14075 & 12667 & 12992 \\
\hline \multicolumn{9}{|c|}{$\begin{array}{l}\text { Absolute number and proportion of individuals who report positive earnings in current year conditional on being in } \\
\text { the sample in previous year }\end{array}$} \\
\hline & Frequencies & & 13417 & 12498 & 13190 & 12257 & 12402 & 11457 \\
\hline & $\%$ & & 64.75 & 69.48 & 69.33 & 69.81 & 68.71 & 70.39 \\
\hline \multicolumn{9}{|c|}{$\begin{array}{l}\text { Absolute number and proportion of individuals who report no earnings in current year conditional on being in the } \\
\text { sample in the previous year }\end{array}$} \\
\hline Unemployed & Frequencies & & 1765 & 1559 & 1505 & 1408 & 1246 & 954 \\
\hline Inactive & $\%$ & & 8.52 & 8.67 & 7.91 & 8.02 & 6.9 & 5.86 \\
\hline \multirow{2}{*}{ Attrition } & Frequencies & & 3423 & 1663 & 2109 & 1913 & 2346 & 1940 \\
\hline & $\%$ & & 16.52 & 9.25 & 11.09 & 10.9 & 13 & 11.92 \\
\hline \multirow{2}{*}{ Missing Wage } & Frequencies & & 2116 & 2267 & 2220 & 1980 & 2057 & 1926 \\
\hline & $\%$ & & 10.21 & 12.6 & 11.67 & 11.28 & 11.4 & 11.83 \\
\hline \multirow[t]{2}{*}{ Total } & Frequencies & & 20721 & 17987 & 19024 & 17558 & 18051 & 16277 \\
\hline & $\%$ & & 100 & 100 & 100 & 100 & 100 & 100 \\
\hline
\end{tabular}

Table 4-A-1. Inflows and Outflows of Individuals in the Sample - France

\begin{tabular}{|c|c|c|c|c|c|c|c|c|}
\hline & 1994 & 1995 & 1996 & 1997 & 1998 & 1999 & 2000 & 2001 \\
\hline $\begin{array}{l}\text { Number of individuals with } \\
\text { positive earnings }\end{array}$ & 20137 & 19270 & 19042 & 17906 & 14467 & 14012 & 13760 & 14212 \\
\hline \multicolumn{9}{|c|}{$\begin{array}{l}\text { Absolute number and proportion of individuals who report positive earnings in current year conditional on being in the } \\
\text { sample in previous year }\end{array}$} \\
\hline & Frequencies & 19143 & 18197 & 17243 & 14014 & 12209 & 12080 & 12468 \\
\hline & $\%$ & 62.47 & 64.76 & 62 & 52.08 & 54.24 & 55.54 & 60.8 \\
\hline \multicolumn{9}{|c|}{$\begin{array}{c}\text { Absolute number and proportion of individuals who report no earnings in current year conditional on being in the } \\
\text { sample in the previous year }\end{array}$} \\
\hline Unemployed & Frequencies & 3259 & 3042 & 3426 & 3006 & 2607 & 2072 & 1995 \\
\hline Inactive & $\%$ & 10.64 & 10.83 & 12.32 & 11.17 & 11.58 & 9.53 & 9.73 \\
\hline \multirow{2}{*}{ Attrition } & Frequencies & 3371 & 2213 & 2785 & 5584 & 3531 & 3786 & 2658 \\
\hline & $\%$ & 11 & 7.88 & 10.01 & 20.75 & 15.69 & 17.41 & 12.96 \\
\hline \multirow{2}{*}{ Missing Wage } & Frequencies & 4871 & 4646 & 4358 & 4304 & 4162 & 3811 & 3385 \\
\hline & $\%$ & 15.9 & 16.53 & 15.67 & 16 & 18.49 & 17.52 & 16.51 \\
\hline \multirow[t]{2}{*}{ Total } & Frequencies & 30644 & 28098 & 27812 & 26908 & 22509 & 21749 & 20506 \\
\hline & $\%$ & 100 & 100 & 100 & 100 & 100 & 100 & 100 \\
\hline
\end{tabular}


Table 4-A-1.1. Inflows and Outflows of Individuals in the Sample - UK

\begin{tabular}{|c|c|c|c|c|c|c|c|c|}
\hline & 1994 & 1995 & 1996 & 1997 & 1998 & 1999 & 2000 & 2001 \\
\hline $\begin{array}{l}\text { Number of individuals with } \\
\text { positive earnings }\end{array}$ & 24949 & 25329 & 25495 & 26010 & 26145 & 25750 & 25674 & 25264 \\
\hline \multicolumn{9}{|c|}{$\begin{array}{c}\text { Absolute number and proportion of individuals who report positive earnings in current year conditional on being in the } \\
\text { sample in previous year }\end{array}$} \\
\hline & Frequencies & 24511 & 24848 & 25303 & 25278 & 25006 & 24881 & 24467 \\
\hline & $\%$ & 64.59 & 66.31 & 67.06 & 67.04 & 67.36 & 68.33 & 68.58 \\
\hline \multicolumn{9}{|c|}{$\begin{array}{c}\text { Absolute number and proportion of individuals who report no earnings in current year conditional on being in the } \\
\text { sample in the previous year }\end{array}$} \\
\hline Unemployed & Frequencies & 4712 & 5053 & 4663 & 4140 & 3941 & 3607 & 3595 \\
\hline Inactive & $\%$ & 12.42 & 13.48 & 12.36 & 10.98 & 10.62 & 9.91 & 10.08 \\
\hline \multirow{2}{*}{ Attrition } & Frequencies & 1836 & 966 & 1169 & 2073 & 1919 & 2153 & 2105 \\
\hline & $\%$ & 4.84 & 2.58 & 3.1 & 5.5 & 5.17 & 5.91 & 5.9 \\
\hline \multirow{2}{*}{ Missing Wage } & Frequencies & 6888 & 6605 & 6597 & 6213 & 6257 & 5774 & 5510 \\
\hline & $\%$ & 18.15 & 17.63 & 17.48 & 16.48 & 16.85 & 15.86 & 15.44 \\
\hline \multirow[t]{2}{*}{ Total } & Frequencies & 37947 & 37472 & 37732 & 37704 & 37123 & 36415 & 35677 \\
\hline & $\%$ & 100 & 100 & 100 & 100 & 100 & 100 & 100 \\
\hline
\end{tabular}

Table 4-A-1.. Inflows and Outflows of Individuals in the Sample - Ireland

\begin{tabular}{|c|c|c|c|c|c|c|c|c|}
\hline & 1994 & 1995 & 1996 & 1997 & 1998 & 1999 & 2000 & 2001 \\
\hline $\begin{array}{l}\text { Number of individuals with } \\
\text { positive earnings }\end{array}$ & 13937 & 13221 & 12590 & 12515 & 12435 & 12091 & 10745 & 9727 \\
\hline \multicolumn{9}{|c|}{$\begin{array}{l}\text { Absolute number and proportion of individuals who report positive earnings in current year conditional on being in the } \\
\text { sample in previous year }\end{array}$} \\
\hline & Frequencies & 12750 & 12217 & 12212 & 12020 & 11668 & 10236 & 9507 \\
\hline & $\%$ & 49.99 & 50.04 & 52.41 & 53.13 & 54.1 & 51.63 & 54.65 \\
\hline \multicolumn{9}{|c|}{$\begin{array}{l}\text { Absolute number and proportion of individuals who report no earnings in current year conditional on being in the } \\
\text { sample in the previous year }\end{array}$} \\
\hline Unemployed & Frequencies & 4930 & 4723 & 4254 & 3374 & 2905 & 2185 & 2307 \\
\hline Inactive & $\%$ & 19.33 & 19.35 & 18.26 & 14.91 & 13.47 & 11.02 & 13.26 \\
\hline \multirow{2}{*}{ Attrition } & Frequencies & 2167 & 2115 & 1600 & 1936 & 2516 & 3288 & 2362 \\
\hline & $\%$ & 8.5 & 8.66 & 6.87 & 8.56 & 11.66 & 16.59 & 13.58 \\
\hline \multirow{2}{*}{ Missing Wage } & Frequencies & 5656 & 5359 & 5235 & 5292 & 4480 & 4116 & 3220 \\
\hline & $\%$ & 22.18 & 21.95 & 22.47 & 23.39 & 20.77 & 20.76 & 18.51 \\
\hline \multirow[t]{2}{*}{ Total } & Frequencies & 25503 & 24414 & 23301 & 22622 & 21569 & 19825 & 17396 \\
\hline & $\%$ & 100 & 100 & 100 & 100 & 100 & 100 & 100 \\
\hline
\end{tabular}


Table 4-A-1. Inflows and Outflows of Individuals in the Sample - Italy

\begin{tabular}{|c|c|c|c|c|c|c|c|c|}
\hline & 1994 & 1995 & 1996 & 1997 & 1998 & 1999 & 2000 & 2001 \\
\hline $\begin{array}{l}\text { Number of individuals with } \\
\text { positive earnings }\end{array}$ & 32633 & 32236 & 32111 & 29661 & 28865 & 26993 & 26912 & 25170 \\
\hline \multicolumn{9}{|c|}{$\begin{array}{l}\text { Absolute number and proportion of individuals who report positive earnings in current year conditional on being in the } \\
\text { sample in previous year }\end{array}$} \\
\hline & Frequencies & 30946 & 31028 & 28717 & 27188 & 25717 & 25348 & 24139 \\
\hline & $\%$ & 51.58 & 51.19 & 47.18 & 47.34 & 46.87 & 48.73 & 48.86 \\
\hline \multicolumn{9}{|c|}{$\begin{array}{c}\text { Absolute number and proportion of individuals who report no earnings in current year conditional on being in the } \\
\text { sample in the previous year }\end{array}$} \\
\hline Unemployed & Frequencies & 7900 & 7799 & 7670 & 6627 & 6890 & 5662 & 5027 \\
\hline Inactive & $\%$ & 13.17 & 12.87 & 12.6 & 11.54 & 12.56 & 10.88 & 10.18 \\
\hline \multirow{2}{*}{ Attrition } & Frequencies & 3175 & 2947 & 5922 & 6030 & 5941 & 5399 & 5920 \\
\hline & $\%$ & 5.29 & 4.86 & 9.73 & 10.5 & 10.83 & 10.38 & 11.98 \\
\hline \multirow{2}{*}{ Missing Wage } & Frequencies & 17978 & 18836 & 18559 & 17585 & 16325 & 15610 & 14315 \\
\hline & $\%$ & 29.96 & 31.08 & 30.49 & 30.62 & 29.75 & 30.01 & 28.98 \\
\hline \multirow[t]{2}{*}{ Total } & Frequencies & 59999 & 60610 & 60868 & 57430 & 54873 & 52019 & 49401 \\
\hline & $\%$ & 100 & 100 & 100 & 100 & 100 & 100 & 100 \\
\hline
\end{tabular}

Table 4-A-1. Inflows and Outflows of Individuals in the Sample - Greece

\begin{tabular}{|c|c|c|c|c|c|c|c|c|}
\hline & 1994 & 1995 & 1996 & 1997 & 1998 & 1999 & 2000 & 2001 \\
\hline $\begin{array}{l}\text { Number of individuals with } \\
\text { positive earnings }\end{array}$ & 27974 & 27654 & 26150 & 24865 & 22675 & 22001 & 21335 & 21929 \\
\hline \multicolumn{9}{|c|}{$\begin{array}{c}\text { Absolute number and proportion of individuals who report positive earnings in current year conditional on being in } \\
\text { the sample in previous year }\end{array}$} \\
\hline & Frequencies & 26868 & 25946 & 24385 & 21815 & 20357 & 20443 & 21342 \\
\hline & $\%$ & 45.83 & 45.69 & 44.98 & 42.09 & 43.52 & 46.06 & 49.72 \\
\hline \multicolumn{9}{|c|}{$\begin{array}{l}\text { Absolute number and proportion of individuals who report no earnings in current year conditional on being in the } \\
\text { sample in the previous year }\end{array}$} \\
\hline Unemployed & Frequencies & 7537 & 6813 & 6419 & 4523 & 4489 & 4427 & 3858 \\
\hline Inactive & $\%$ & 12.86 & 12 & 11.84 & 8.73 & 9.6 & 9.97 & 8.99 \\
\hline \multirow{2}{*}{ Attrition } & Frequencies & 4417 & 4392 & 4347 & 7892 & 6222 & 4159 & 2363 \\
\hline & $\%$ & 7.53 & 7.73 & 8.02 & 15.23 & 13.3 & 9.37 & 5.5 \\
\hline \multirow{2}{*}{ Missing Wage } & Frequencies & 19802 & 19640 & 19068 & 17599 & 15707 & 15352 & 15365 \\
\hline & $\%$ & 33.78 & 34.58 & 35.17 & 33.96 & 33.58 & 34.59 & 35.79 \\
\hline \multirow[t]{2}{*}{ Total } & Frequencies & 58624 & 56791 & 54219 & 51829 & 46775 & 44381 & 42928 \\
\hline & $\%$ & 100 & 100 & 100 & 100 & 100 & 100 & 100 \\
\hline
\end{tabular}


Table 4-A-1. Inflows and Outflows of Individuals in the Sample - Spain

\begin{tabular}{|c|c|c|c|c|c|c|c|c|}
\hline & 1994 & 1995 & 1996 & 1997 & 1998 & 1999 & 2000 & 2001 \\
\hline $\begin{array}{l}\text { Number of individuals with } \\
\text { positive earnings }\end{array}$ & 22559 & 21863 & 21296 & 20975 & 20371 & 20580 & 19898 & 20185 \\
\hline \multicolumn{9}{|c|}{$\begin{array}{l}\text { Absolute number and proportion of individuals who report positive earnings in current year conditional on being in the } \\
\text { sample in previous year }\end{array}$} \\
\hline & Frequencies & 21460 & 20521 & 20329 & 19456 & 19679 & 19167 & 19352 \\
\hline & $\%$ & 47.6 & 48.29 & 48.49 & 48.63 & 52.13 & 52.12 & 56.06 \\
\hline \multicolumn{9}{|c|}{$\begin{array}{l}\text { Absolute number and proportion of individuals who report no earnings in current year conditional on being in the } \\
\text { sample in the previous year }\end{array}$} \\
\hline Unemployed & Frequencies & 8419 & 8230 & 7353 & 5970 & 5083 & 4512 & 4761 \\
\hline Inactive & $\%$ & 18.67 & 19.37 & 17.54 & 14.92 & 13.46 & 12.27 & 13.79 \\
\hline \multirow{2}{*}{ Attrition } & Frequencies & 4467 & 3000 & 4120 & 4327 & 3188 & 3922 & 3052 \\
\hline & $\%$ & 9.91 & 7.06 & 9.83 & 10.81 & 8.44 & 10.66 & 8.84 \\
\hline \multirow{2}{*}{ Missing Wage } & Frequencies & 10741 & 10742 & 10121 & 10259 & 9802 & 9176 & 7357 \\
\hline & $\%$ & 23.82 & 25.28 & 24.14 & 25.64 & 25.96 & 24.95 & 21.31 \\
\hline \multirow[t]{2}{*}{ Total } & Frequencies & 45087 & 42493 & 41923 & 40012 & 37752 & 36777 & 34522 \\
\hline & $\%$ & 100 & 100 & 100 & 100 & 100 & 100 & 100 \\
\hline
\end{tabular}

Table 4-A-1. Inflows and Outflows of Individuals in the Sample - Portugal

\begin{tabular}{|c|c|c|c|c|c|c|c|c|}
\hline & 1994 & 1995 & 1996 & 1997 & 1998 & 1999 & 2000 & 2001 \\
\hline $\begin{array}{l}\text { Number of individuals with } \\
\text { positive earnings }\end{array}$ & 14653 & 15450 & 15379 & 15087 & 14837 & 14569 & 14604 & 14550 \\
\hline \multicolumn{9}{|c|}{$\begin{array}{l}\text { Absolute number and proportion of individuals who report positive earnings in current year conditional on being in the } \\
\text { sample in previous year }\end{array}$} \\
\hline & Frequencies & 13892 & 14538 & 14321 & 13977 & 13921 & 13952 & 13942 \\
\hline & $\%$ & 57.84 & 57.5 & 57.32 & 56.98 & 59.12 & 60.83 & 62.16 \\
\hline \multicolumn{9}{|c|}{$\begin{array}{c}\text { Absolute number and proportion of individuals who report no earnings in current year conditional on being in the } \\
\text { sample in the previous year }\end{array}$} \\
\hline Unemployed & Frequencies & 2187 & 2264 & 2396 & 2019 & 2067 & 1843 & 1702 \\
\hline Inactive & $\%$ & 9.11 & 8.95 & 9.59 & 8.23 & 8.78 & 8.04 & 7.59 \\
\hline \multirow{2}{*}{ Attrition } & Frequencies & 1701 & 1908 & 1918 & 2346 & 1956 & 1617 & 1575 \\
\hline & $\%$ & 7.08 & 7.55 & 7.68 & 9.56 & 8.31 & 7.05 & 7.02 \\
\hline \multirow{2}{*}{ Missing Wage } & Frequencies & 6236 & 6573 & 6350 & 6189 & 5602 & 5525 & 5211 \\
\hline & $\%$ & 25.97 & 26 & 25.42 & 25.23 & 23.79 & 24.09 & 23.23 \\
\hline \multirow[t]{2}{*}{ Total } & Frequencies & 24016 & 25283 & 24985 & 24531 & 23546 & 22937 & 22430 \\
\hline & $\%$ & 100 & 100 & 100 & 100 & 100 & 100 & 100 \\
\hline
\end{tabular}


Table 4-A-1. Inflows and Outflows of Individuals in the Sample - Austria

\begin{tabular}{|c|c|c|c|c|c|c|c|c|}
\hline & 1994 & 1995 & 1996 & 1997 & 1998 & 1999 & 2000 & 2001 \\
\hline $\begin{array}{l}\text { Number of individuals with } \\
\text { positive earnings }\end{array}$ & & 17944 & 17789 & 17199 & 16209 & 15162 & 13816 & 13056 \\
\hline \multicolumn{9}{|c|}{$\begin{array}{l}\text { Absolute number and proportion of individuals who report positive earnings in current year conditional on being in the } \\
\text { sample in previous year }\end{array}$} \\
\hline & Frequencies & & 16472 & 16384 & 15634 & 14551 & 13403 & 12601 \\
\hline & $\%$ & & 67.96 & 68.2 & 67.49 & 67.2 & 66.51 & 68.21 \\
\hline \multicolumn{9}{|c|}{$\begin{array}{l}\text { Absolute number and proportion of individuals who report no earnings in current year conditional on being in the } \\
\text { sample in the previous year }\end{array}$} \\
\hline Unemployed & Frequencies & & 1209 & 1231 & 906 & 790 & 803 & 843 \\
\hline Inactive & $\%$ & & 4.99 & 5.12 & 3.91 & 3.65 & 3.98 & 4.56 \\
\hline \multirow{2}{*}{ Attrition } & Frequencies & & 2195 & 2080 & 2435 & 2470 & 2409 & 1794 \\
\hline & $\%$ & & 9.06 & 8.66 & 10.51 & 11.41 & 11.95 & 9.71 \\
\hline \multirow{2}{*}{ Missing Wage } & Frequencies & & 4361 & 4330 & 4189 & 3842 & 3538 & 3235 \\
\hline & $\%$ & & 17.99 & 18.02 & 18.08 & 17.74 & 17.56 & 17.51 \\
\hline \multirow[t]{2}{*}{ Total } & Frequencies & & 24237 & 24025 & 23164 & 21653 & 20153 & 18473 \\
\hline & $\%$ & & 100 & 100 & 100 & 100 & 100 & 100 \\
\hline
\end{tabular}

Table 4-A-1.. Inflows and Outflows of Individuals in the Sample - Finland

\begin{tabular}{|c|c|c|c|c|c|c|c|}
\hline & & 1996 & 1997 & 1998 & 1999 & 2000 & 2001 \\
\hline $\begin{array}{l}\text { Number of individuals with } \\
\text { positive earnings }\end{array}$ & & 15811 & 15845 & 15895 & 15546 & 13329 & 13057 \\
\hline \multicolumn{8}{|c|}{$\begin{array}{l}\text { Absolute number and proportion of individuals who report positive earnings in current year conditional on being in the } \\
\text { sample in previous year }\end{array}$} \\
\hline & Frequencies & & 15246 & 15345 & 14753 & 12756 & 12588 \\
\hline & $\%$ & & 55.95 & 57.2 & 59.29 & 53.83 & 64.16 \\
\hline \multicolumn{8}{|c|}{$\begin{array}{l}\text { Absolute number and proportion of individuals who report no earnings in current year conditional on being in the } \\
\text { sample in the previous year }\end{array}$} \\
\hline Unemployed & Frequencies & & 3446 & 2327 & 1657 & 1326 & 1267 \\
\hline Inactive & $\%$ & & 12.65 & 8.67 & 6.66 & 5.6 & 6.46 \\
\hline \multirow{2}{*}{ Attrition } & Frequencies & & 1933 & 3219 & 2658 & 5219 & 1708 \\
\hline & $\%$ & & 7.09 & 12 & 10.68 & 22.02 & 8.71 \\
\hline \multirow{2}{*}{ Missing Wage } & Frequencies & & 6623 & 5937 & 5814 & 4398 & 4057 \\
\hline & $\%$ & & 24.31 & 22.13 & 23.37 & 18.56 & 20.68 \\
\hline \multirow[t]{2}{*}{ Total } & Frequencies & & 27248 & 26828 & 24882 & 23699 & 19620 \\
\hline & $\%$ & & 100 & 100 & 100 & 100 & 100 \\
\hline
\end{tabular}


Germany

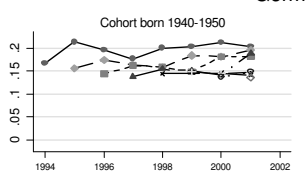

Cohort born 1961-1970
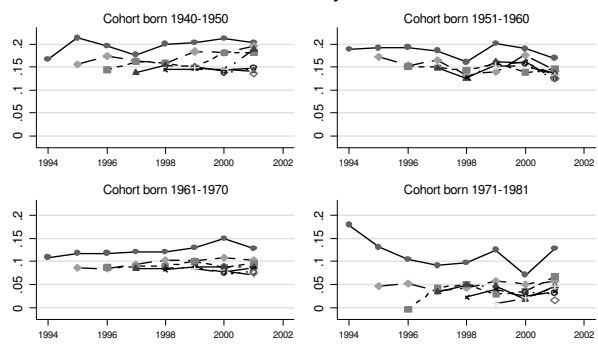

Cohort born 1971-1981

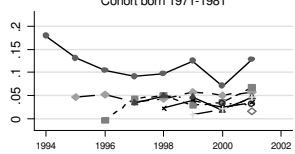

Netherlands

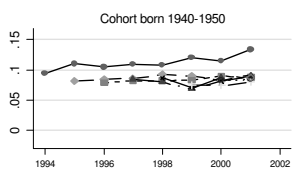

Cohort born 1961-1970
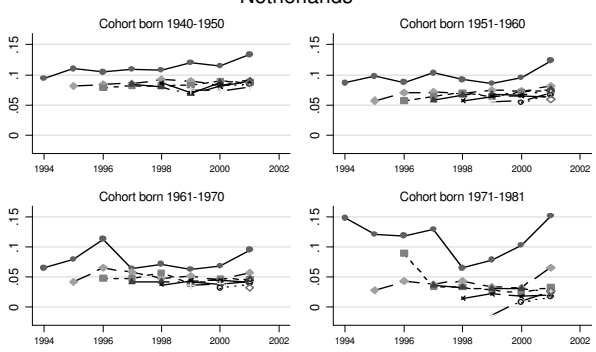

France
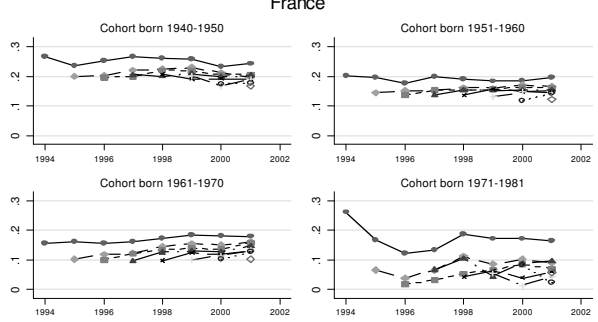

UK
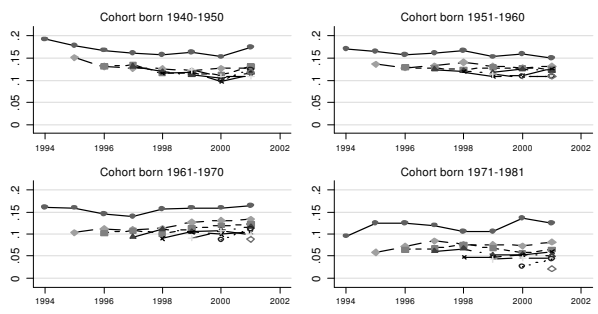

Denmark
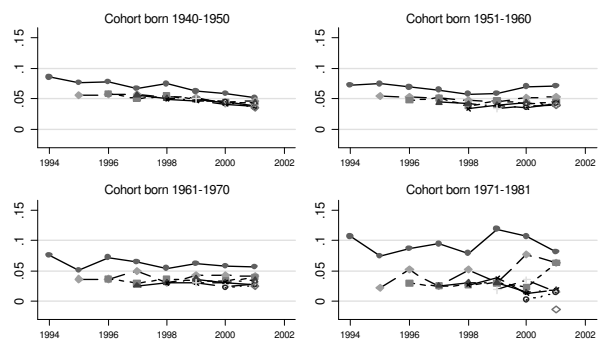

Belgium
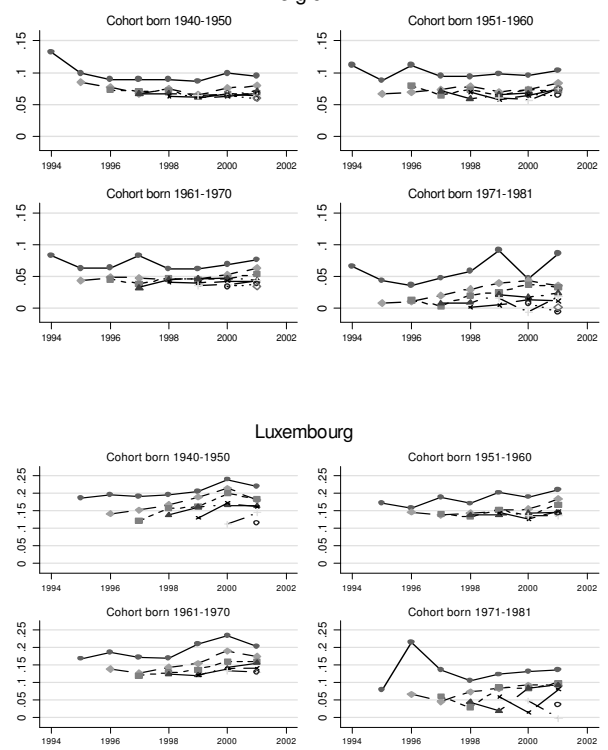

Ireland
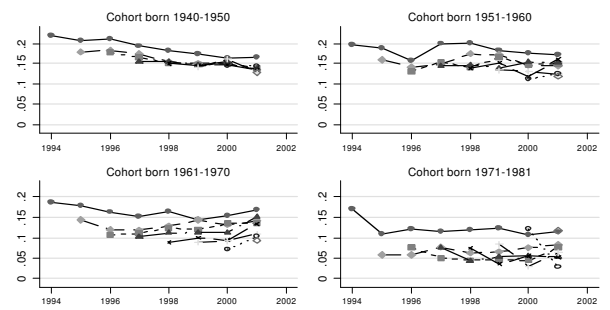

Figure 4-A-1. Autocovariance Structure of Hourly Earnings for Selected Cohorts: years 1994-2001 
Italy
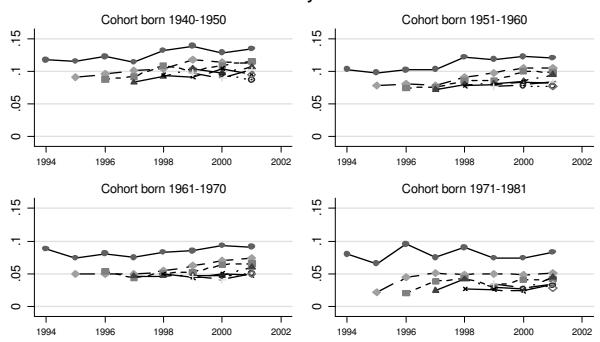

Spain
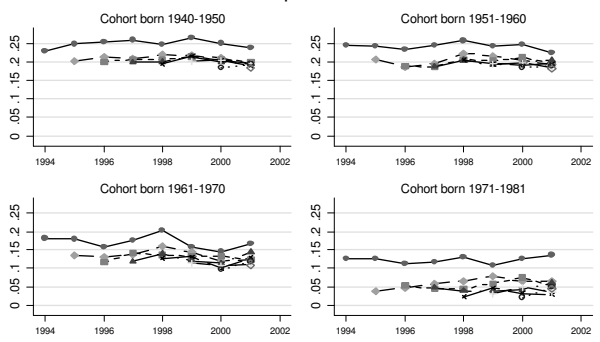

Austria

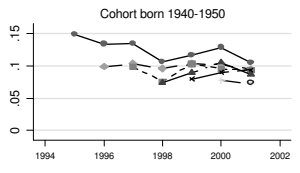

Cohort born 1961-1970
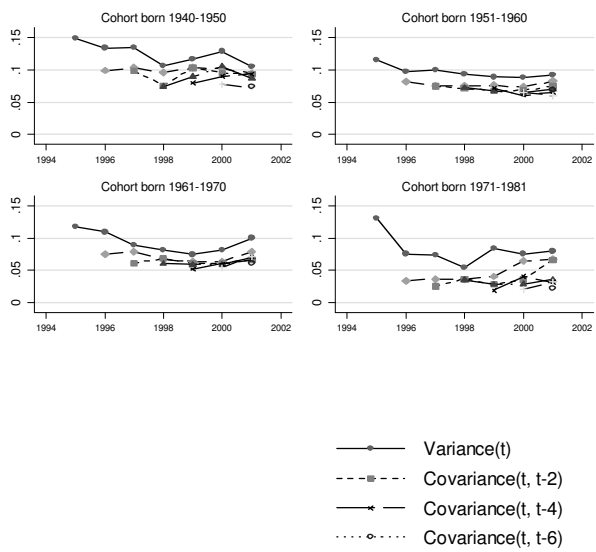
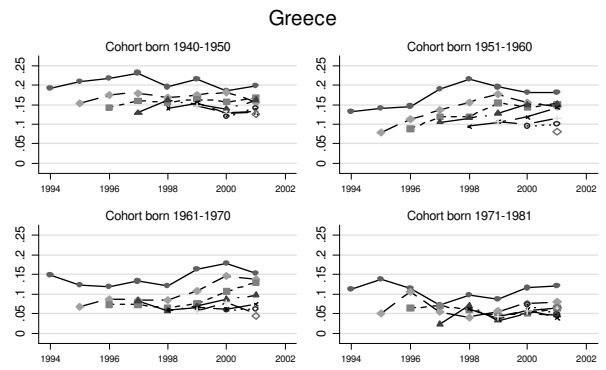

Portugal
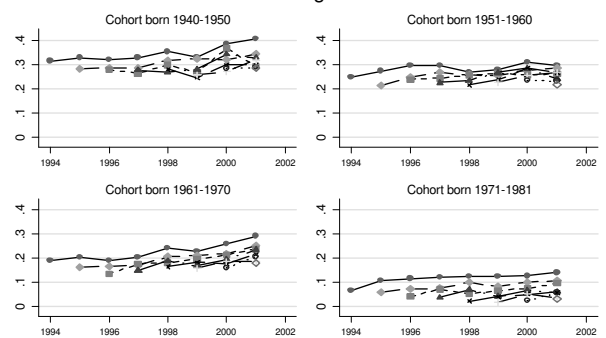

Finland
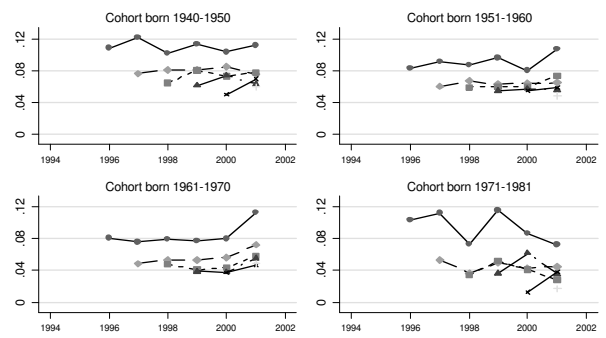

Figure 4-A-1. (Continued) 


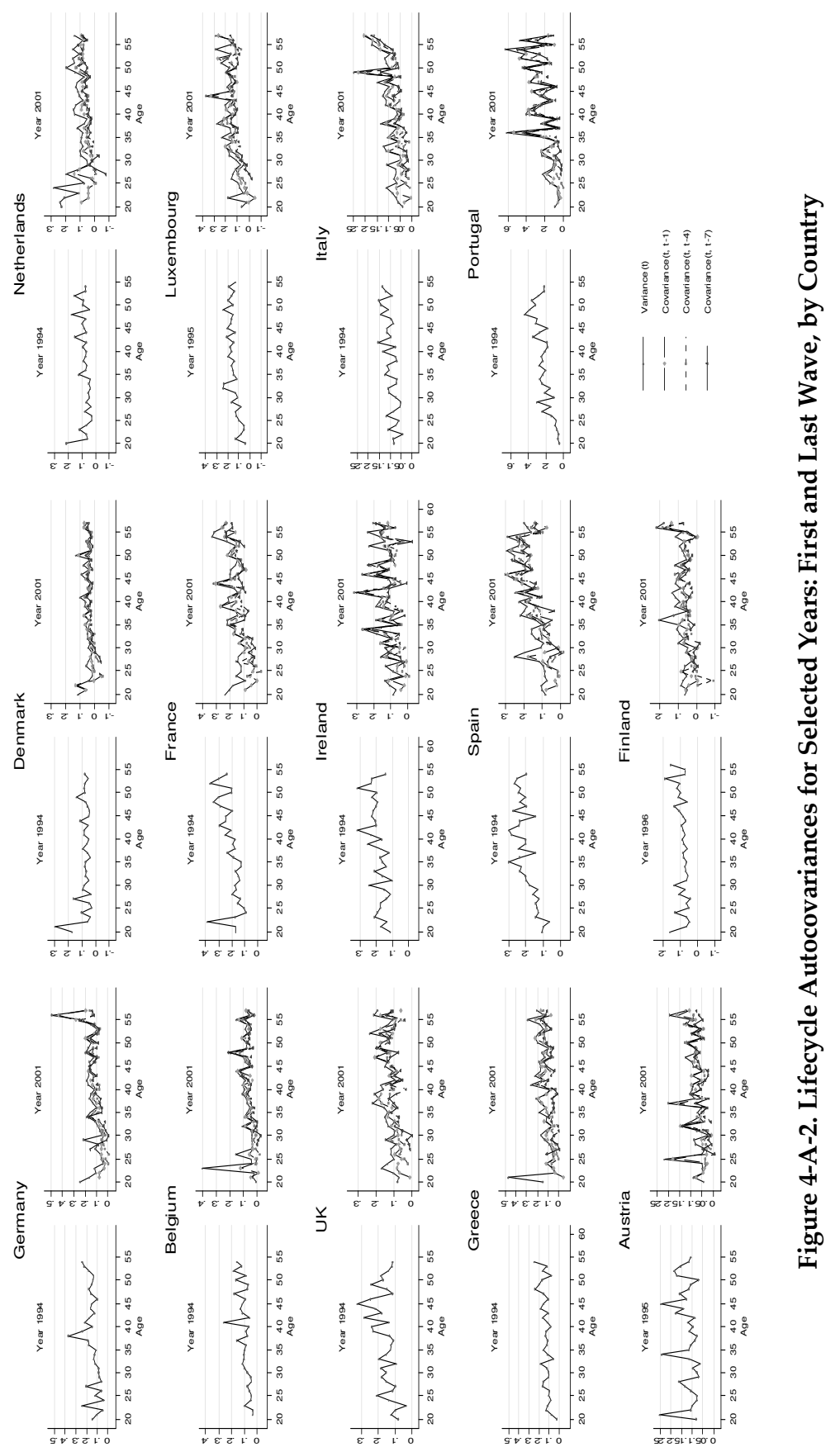

ปี 
5. POLICY, INSTITUTIONAL FACTORS AND EARNINGS MOBILITY 


\subsection{Introduction ${ }^{53}$}

The rise in earnings inequality experienced by many developed countries during the 1980s and 1990s triggered a strong debate with respect to the driving factors behind individual earnings dynamics and the implications of this increase. The empirical literature has covered extensively the driving factors behind the increase in cross-sectional earnings inequality. Factors like economic growth ("Kuznetz hypothesis"); "the shift in demand away from unskilled labour in favour of skilled workers" (Atkinson 1996) under the impact of trade liberalization, skill-biased technological change and organizational change; the role of changes in the labour market institutions, such as unionization and centralized bargaining, macroeconomic volatility, are among the main possible drivers of income inequality as identified by the empirical literature (Freeman and Katz, 1994; 1995; Fortin and Lemieux, 1997; Gottschalk and Smeeding, 1997; Katz and Autor, 1999; Aghion and Williamson, 2001).

Notwithstanding this, the empirical literature has neglected so far the driving factors behind the two components of earnings inequality: permanent and transitory inequality. Even less attention was given to the driving factors behind earnings mobility, which, as stated by Milton Friedman (1962), represents a very important aspect for understanding inequality. All these labour market outcomes are highly important given that the interplay between them determines the final earnings inequality outcome, both in an annual and lifetime perspective.

In this line of thought, this paper explores the role of labour market policy and institutional factors in explaining cross-national differences in the evolution of permanent inequality, transitory inequality and earnings mobility across $14 \mathrm{EU}$ countries. So far, at the EU level, no study attempted to analyse and to understand the driving factors behind the three labour market outcomes in a comparative manner.

\footnotetext{
53 This Chapter builds on the results discussed in Chapter 4: using the predicted components from the error component models estimated in Chapter 4 and the OECD data, we estimate the relationship between the three labour market outcomes - permanent inequality, transitory inequality and earnings immobility - and the labour market policy and institutional factors. Since this Chapter is written as a standalone paper, the information in sections 5.2.3.1, 5.2.3.2, 5.4.1, 5.5.1, 5.6 summarises the core aspects of Chapter 4: the econometric specification and estimation method of the covariance earnings structure, the dynamic autocovariance structure of hourly earnings, and the results of the covariance structure estimation for each country.
} 
Understanding the driving forces behind these labour market outcomes is vitally important from a welfare perspective, particularly given the large variation in the evolution of cross-sectional wage inequality across Europe over the period 19942001. Did the increase in cross-sectional wage inequality observed in some countries result from greater transitory fluctuations in earnings and individuals facing a higher degree of earnings mobility? Or is this rise reflecting increasing permanent differences between individuals with mobility remaining constant or even falling? What about countries that recorded a decrease in cross-sectional earnings inequalities, what lessons can we learn from them? What are the possible labour market policy and institutional factors that can explain these trends in permanent and transitory differentials, and earnings mobility?

These questions have a twofold importance. On the one hand, understanding the contributions of the changes in permanent and transitory components of earnings variation to the changes in cross-sectional earnings inequality is very useful in the evaluation of alternative hypotheses for wage structure changes and for determining the potential welfare consequences of rising inequality (Katz and Autor 1999).

On the other hand, understanding the driving factors behind the changes in permanent and transitory inequality and earnings mobility is very useful for the design of policies and labour market institutions. Earnings mobility is perceived in the literature as a way out of poverty. In the absence of mobility the same individuals remain stuck at the bottom of the distribution, hence annual earnings differentials are transformed into lifetime earnings differentials. Understanding the factors that enhance earnings mobility, represents a step forward towards designing policies and institutions that enable low-wage workers to escape lowwage jobs and improve their position in the distribution of lifetime earnings.

These questions are highly relevant in the context of the changes that took place in the EU labour market policy framework under the incidence of the 1994 OECD Jobs Strategy and the 2000 Lisbon Agenda, which recommended policies to increase wage flexibility, lower non-wage labour costs and allow relative wages to better reflect individual differences in productivity and local labour market conditions. The turnaround in the institutional and policy framework occurred more or less after 1995 (OECD, 2004; Dew-Becker and Gordon, 2008). Before 1995, Europe could have been described as making labour more expensive, accompanied by a decline in employment and an increase in productivity. Starting at different dates for different policies, Europe began the process of shifting toward making labour less expensive, accompanied by higher employment per capita but lower average productivity per hour (Dew-Becker and Gordon 2008). Moreover, all 
OECD countries moved towards greater decentralization, which could result in greater inter-firm wage differentials. These trends appear to have worsened the apparent trade-off between a strong employment performance and a more equal distribution of earnings, consistent with relative labour demand having shifted towards high-skilled workers OECD (2004).

As pointed out by Dew-Becker and Gordon (2008) and OECD (2004), the most notable change after 1995 in Europe has been increased country heterogeneity. We will investigate how the heterogeneity in main labour market policy and institutional factors translates itself in the level and components of cross-sectional earnings inequality and earnings mobility.

Using ECHP we apply equally weighted minimum distance methods to estimate the covariance structure of earnings by four birth cohorts for each country, decompose earnings into a permanent and a transitory component and compute earnings mobility. The predicted components - permanent variance, transitory variance and earnings mobility -, together with OECD data on institutional factors, are used to estimate the relationship between these components and labour market policy and institutional factors. The relationship between the labour market policy and institutional factors and the three labour market outcomes is estimated using non-linear least squares.

The structure of this paper is as follows. Section two introduces the literature review, the theoretical background for wage differentials and the theoretical link between labour market factors and the three labour market outcomes. Section three provides a description of the ECHP and OECD data. Section four introduces the econometric specifications and estimation methods for the covariance structure of earnings and for the link between institutional and policy factors and labour market outcomes. Section five describes the dynamic structure of individual log earnings for $14 \mathrm{EU}$ countries and the evolution of the labour market institutions and policies. Section six fits the error components models to the covariance structure for each country, decomposing the change in inequality into that accounted for by the change in the permanent and transitory components. Section seven presents the results on the link between policies and outcomes. Lastly, section eight offers some conclusions. 


\subsection{Theoretical model of the determinants of wage differentials}

\subsubsection{Literature review}

The existing literature on earnings dynamics is predominantly based on US data. Atkinson, Bourguignon et al. (1992) provide a comprehensive survey of the literature on earnings dynamics until 1992. The most representative contributions using US or Canadian data were brought by Lillard and Willis (1978), Lillard and Weiss (1979), MaCurdy (1982), Abowd and Card (1989)), Moffitt and Gottschalk (1995, 1998, 2002, 2008), Baker (1997), Baker and Solon (2003). For Europe, the most representative papers are Dickens (2000b), Ramos (2003), Kalwij and Alessie (2003), Cappellari (2003), Gustavson (2004).

Finally, Sologon and O'Donoghue (2009a, 2009b) used ECHP for 14 EU countries to explore the dynamic structure of individual earnings and the extent to which changes in cross-sectional earnings inequality reflect transitory or permanent components of individual lifecycle earnings variation. Their main findings are used further in this paper.

The main limitation of the existing studies on earnings dynamics is that they do not explain the main labour market policy and institutional driving factors behind the evolution of the two inequality component and earnings mobility. Our paper attempts to fill part of this gap.

\subsubsection{Determinants of earnings inequality}

As pointed out by Katz and Autor (1999), the existing literature contains many explanations for the rise in earnings inequality experienced by many developed countries during the 1980s and 1990s. The theory regarding the determinants of wage differentials goes back to Adam Smith, who provided a comprehensive discussion in his capital work, The Wealth of Nations. It was emphasized that wage differentials are determined by competitive factors relating to the workplace (e.g. cost of training), by innate abilities and by labour market institutional factors, which regulated wages, restricted wages and labour mobility. The tension between the demand and supply factors and the institutional factors affecting wage structures that emerged from Adam Smith's analysis has remained until today one of the key themes of research on the wage structure. Following Freeman and Katz (1994), this supply-demand-institutions (SDI) explanation for the changes in the wage structure has three parts. 
The first part assumes that different demographic and skill groups are imperfect substitutes in production, which implies that shifts in the demand and supply for labour skills can alter wage and employment outcomes. Potential important sources of shifts in the relative demand among skill groups include skill-biased technological change and a complementary increase in the prices of other inputs, and forces of globalization (trade and outsourcing). Sources of relative supply include cohort size variation, changes in access to education, immigration. Supply and demand factors are expected to have their largest effect on young workers as opposed to experienced workers with substantial work tenure (Freeman, 1976).

However, since most advanced countries operate in the same world markets, with similar technology, industry and occupation mixes, demand and supply factors cannot by themselves explain all the differing changes in inequality among these countries. To fully understand the differences in labour market outcomes across advanced countries something else is needed: the institutional framework (Freeman and Katz 1994).

The second part states that the shock in the demand and supply may have different effects on wages and employment, depending on different wage-setting mechanisms and other labour market institutional factors. The stronger the wagesetting mechanism is, meaning the higher trade union density, the higher the union coverage and the higher the centralisation/co-ordination of wage bargaining, the less impact these shocks have on wages. As argued by OECD (2004), there is a strong evidence that unions reduce wage inequality and that this compression effect is stronger in countries where union membership and bargaining coverage are high, and bargaining is centralised and/or co-ordinated (Aidt and Tzannatos, 2002; Blau and Kahn, 1999, 2002; OECD, 1997a). National labour markets characterized by decentralized wage bargaining experience also a higher skill premia and a higher responsiveness of wages to local conditions, therefore a higher wage inequality.

The third part states that institutional changes, such as changes in the degree of unionization, the degree of centralization/co-ordination of collective bargaining, or product market regulation have an impact on the wage structures.

Katz and Autor (1999) used the SDI model to look at cross-country differences in wage structure changes. The shift in the demand for more skilled workers did not result in a sharp increase in wage dispersion for all OECD countries. The differences in the growth of skills supply appear to be an important factor in explaining cross-country differences. The same holds for labour market institutions. Countries, where unions, wage bargaining structure play a larger role 
in the determination of wages recorded smaller increases in inequality. The key issue in the interplay between demand, supply and institutions, however, is the erroneous assumption that institutional change is exogenous. The reality is that institutions are influenced by labour market forces. As argued by Freeman and Gibbons (1995), shifts in supply and demand that raise relative wage differentials are expected to reduce the strength of the centralized collective bargaining and lower union influence on the wage setting mechanism.

\subsubsection{Permanent and transitory components of earnings inequality}

Following the terminology introduced by Friedman and Kuznets (1954), individual earnings are composed from a permanent and a transitory component. The permanent component of earnings reflects personal characteristics, education, training and other persistent elements. The transitory component captures both individual random factors (e.g. illness and accident) and random changes in the market conditions in a particular period and is expected to average out over time, with no influence on permanent earnings. In general terms, these are factors which are random to the individual perception. Hence, it is logical to require independence between the permanent component and the transitory component (Weizsäcker, 1993). Following the structure of individual earnings and the independence assumption between the two components, overall inequality at any point in time is composed from inequality in the permanent component of earnings and inequality in the transitory component.

One approach for explaining changes in wage differential is to decompose overall wage inequality into the two components. The evolution of the overall earnings inequality is determined by the cumulative changes in the two inequality components. As the factors from the SDI model influence overall inequality, implicitly they influence its two components. The intriguing question that arises is which factors influence which component and to what extent. Our focus in this paper is mainly on labour market policy and institutional factors.

This section tries to establish a theoretical link between the changes in the two inequality components and earnings mobility, and labour market policy and institutional factors. First we introduce alternative specifications for decomposing inequality. Second we introduce the concept of earnings mobility and its link with permanent and transitory inequality. Finally we present the theoretical link between institutions and the three labour marker outcomes - permanent inequality, transitory inequality and earnings mobility. 


\subsubsection{Alternative model specifications for the permanent and transitory components ${ }^{54}$}

Based on Sologon and O'Donoghue (2009a, 2009b), we summarize several models of earnings dynamics that have been dominating the literature on permanent and transitory earnings inequality over the past 30 years. For a full review, please refer to Sologon and O'Donoghue (2009a, 2009b). We begin with the simplest specification, which provides a very intuitive insight into the decomposition of earnings into their permanent and transitory components. Based on this specification earnings are being decomposed as follows:

$$
Y_{i t}=\mu_{i}+v_{i t}, \quad \mu_{i} \sim \operatorname{iid}\left(0, \sigma_{\mu}^{2}\right), \quad v_{i t} \sim \operatorname{iid}\left(0, \sigma_{v}^{2}\right), \quad t=1, \ldots, T_{i}, i=1, \ldots, N
$$

where $\mu_{i}$ represents the permanent time-invariant individual specific component and $v_{i t}$ represents the transitory component, which is independently distributed both over individuals and time. This model imposes very rigid restrictions on the covariance structure of earnings:

$$
\operatorname{Cov}\left(Y_{i t}, Y_{i s}\right)= \begin{cases}\sigma_{\mu}^{2}+\sigma_{v}^{2}, & t=s \\ \sigma_{\mu}^{2}, & t \neq s\end{cases}
$$

Because $\mu_{i}$ is assumed to incorporate the effect of lifetime persistent individual specific characteristics such as ability, the variance of the permanent component $\sigma_{\mu}^{2}$ represents the persistent dispersion of earnings or the inequality in the permanent component of earnings. The transitory shocks are captured by the transitory variance $\sigma_{v}^{2}$ and are assumed to persist only one year.

This model facilitates the understanding of the inequality decomposition into its permanent and transitory components. The variance of earnings at a certain point in time, as a measure of earnings dispersion, is composed both from a permanent and a transitory dispersion $\left(\sigma_{\mu}^{2}+\sigma_{v}^{2}\right)$. The covariances, on the other hand, are determined solely by the permanent component $\left(\sigma_{\mu}^{2}\right)$. Therefore, the assessment of the relative importance of the two components in the overall earnings dispersion is straightforward: the ratio $\sigma_{\mu}^{2} / \sigma_{y}^{2}$ captures the relative importance of the

\footnotetext{
54 The information in this section has already been discussed in section 4.3.2.
} 
permanent component, whereas the ratio $\sigma_{v}^{2} / \sigma_{y}^{2}$ captures the relative importance of the transitory component.

Notwithstanding its attractive features, the empirical evidence rejected the rigid restrictions imposed by model (5.1). One of the main drawbacks of model (5.1) is that it does not allow for changes in earnings inequality over time. Other studies (Katz, 1994; Moffitt and Gottschalk, 1995) took the model complexity further by allowing the covariance structure of earnings to vary over time. To account for these time effects, these models considered also time specific loading factors or shifters on both components, which allow the parameters of the process to change with calendar time.

$Y_{i t}=\lambda_{1 t} \mu_{i t}+\lambda_{2 t} \nu_{i t}$

$\lambda_{k t}, k=1,2$ are time-varying factor loadings on the permanent and transitory components of earnings. The variance of $Y_{i t}$ implied by this model takes the form:

$\operatorname{Var}\left(Y_{i t}\right)=\lambda_{1 t}^{2} \sigma_{\mu}^{2}+\lambda_{2 t}^{2} \sigma_{v}^{2}$

An increase in either time loading factors generates an increase in the crosssectional earnings inequality. The nature of the change in inequality depends on which of the loading factors changes. On the one hand, a persistent rise in $\lambda_{1 t}$ increases the permanent or long-run inequality (inequality in earnings measured over a long period of time, such as lifetime earnings). As $\lambda_{1 t}$ can be interpreted as time-varying return to skills or skill price, its increase suggests that the relative labour market advantage of high skill workers is enhanced. In this situation, the autocovariances grow in greater proportion than the variance, causing the autocorrelation to increase. As a consequence, the increase in overall crosssectional inequality is accompanied by a decrease in mobility. On the other hand, an increase in $\lambda_{2 t}$ without a change in $\lambda_{1 t}$ increases cross-sectional earnings inequality by increasing the transitory inequality, but without any impact on longrun or permanent inequality. In this situation the rise in the variances is not accompanied by a rise in the autocovariances, hence autocorrelations decrease and the increase in the overall inequality is accompanied by an increase in mobility. (Baker and Solon, 2003) As pointed out by Katz and Autor (1999), $\lambda_{1 t}$ maintains the rank of the individuals in the earnings distribution, but causes a persistent increase in the spread of the distribution and an increase in $\lambda_{2 t}$ changes the rank of the individual in the short-run. In other words an increase in the time parameters associated with the permanent component of earnings indicates a 
growing earnings inequality with no impact on the relative position of individuals in the distribution of permanent earnings, whereas an increase in the transitory time parameters indicates an increase in earnings mobility.

Although model (5.2) incorporates changes over time in the permanent and temporary components of earnings inequality, it disregards other important features of earnings dynamics. Firstly, it disregards the cohort effects. As argued by Katz and Autor (1999), the increased wage inequality may arise from increased dispersion of unobserved labour quality within recent entry cohorts, resulting from unequal school quality. Some studies brought evidence against the hypothesis that the return to education is the same for different cohorts. These changes could be attributed either to the cohort effects or to the larger impact of the labour market shocks on younger than on older cohorts of workers. In the same line of thought, Freeman (1975) put forward the "active labour market" hypothesis, which postulates that changes in the labour market conditions, such as changes in the supply and demand for skills, affect mainly new entrants in the labour market. To account for these cohort effects, these models considered also cohort specific loading factors or shifters on both components, which allow the parameters of the process to change with cohort.

$Y_{i t}=\gamma_{1 c} \lambda_{1 t} \mu_{i t}+\gamma_{2 c} \lambda_{2 t} v_{i t}$

where $\gamma_{j c}, j=1,2$ are cohort specific loading factors.

Secondly, regarding the permanent component, some studies brought evidence in favour of the "random growth rate model" 55 or the "profile heterogeneity model": (Hause, 1977; Lillard and Weiss, 1979; MaCurdy, 1982; Baker, 1997; Cappellari, 2003; Sologon and O'Donoghue, 2009a, 2009b). According to this model, which is consistent with labour market theories such as human capital, and matching models (Mincer, 1974; Hause, 1980), each individual has a unique age-earning profile with an individual specific intercept (initial earnings) and slope (earnings growth) that may be systematically related.

${ }_{55} \mu_{i t}=\mu_{i}+\varphi_{i}$ age $_{i t}, \quad \mu_{i} \sim \operatorname{iid}\left(0, \sigma_{\mu}^{2}\right), \quad \varphi_{i} \sim \operatorname{iid}\left(0, \sigma_{\varphi}^{2}\right), \quad E\left(\mu_{i}, \varphi_{i}\right)=\sigma_{\mu \varphi}$. The variances $\sigma_{\mu}^{2}$ and $\sigma_{\varphi}^{2}$ capture individual heterogeneity with respect to time-invariant characteristics and ageearnings profiles. A positive covariance between $\mu_{i}$ and $\varphi_{i}$ implies a rising inequality in the permanent component of earnings over the life cycle, which is consistent with the school-matching models. A negative covariance implies that the two sources of heterogeneity offset each other, which is consistent with the on-the-job training. A negative covariance is expected to generate mobility within the distribution of the permanent component of earnings. Cappellari, L. (2003). 
An alternative/additional specification for the permanent component of earnings is the "random walk model"56 or the "unit root model", which is used in the literature to accommodate earnings shocks that might have permanent effects (MaCurdy 1982; Abowd and Card 1989; Moffitt and Gottschalk 1995; Baker 1997; Dickens 2000b; Sologon and O'Donoghue 2009a, 2009b).

Thirdly, regarding the transitory component of earnings, previous research has brought evidence that transitory earnings are serially correlated. Therefore, a more general autocorrelation structure is called for that relaxes the restriction on $v_{i t}{ }^{\prime} s$ from the canonical model. For the construction of such a structure, longitudinal studies on earnings dynamics turned to error processes from the literature on time series analysis. Based on MaCurdy (1982), the structure of the transitory component, $v_{i t}$, is assumed to follow an $\operatorname{ARMA}(\mathrm{p}, \mathrm{q})$ process $^{57}$.

\subsubsection{Earnings Mobility ${ }^{58}$}

Another aspect relevant for the evolution of earnings differentials is earnings mobility, defined by Katz and Autor (1999) as the rate at which individuals shift positions in the earnings distribution. Earnings mobility is closely related to the importance of the permanent and transitory components in earnings variation. A large contribution of the permanent component implies that individual earnings are highly correlated over time and individuals do not change their income position to a large extent experiencing low rates of earnings mobility. Therefore, the changes in earnings mobility are determined by the extent to which changes in cross-sectional inequality are driven by changes in the permanent or transitory variance.

Earnings mobility is a very complex phenomenon, and the ways of measuring it are diverse. We look at the degree of immobility, measured by the ratio between permanent and transitory inequality, following Kalwij and Alessie (2003). This

${ }^{56} u_{i a}=u_{i, a-1}+\pi_{i a}, \quad \pi_{i a} \sim \operatorname{iid}\left(0, \sigma_{\pi}^{2}\right), \quad E\left(u_{i, a-1}, \pi_{i a}\right)=0$ The current value depends on the one from the previous age and an innovation term $\pi_{i a}$, which accommodates any permanent re-ranking of individuals in the earnings distribution. The high persistency of the unit root model might result from low rates of depreciation on human capital investments or labour market conditions through implicit contacts. (Baker 1997)

$57 \sum_{j=0}^{p} \rho_{j} v_{i t-j}=\sum_{j=0}^{q} \theta_{j} \varepsilon_{i t-j}, \quad \varepsilon_{i t} \sim \operatorname{iid}\left(0, \sigma_{\varepsilon}^{2}\right), \quad v_{i 0} \sim\left(0, \sigma_{0, c}^{2}\right)$

${ }^{58}$ The information in this section has already been discussed in section 4.3.3. 
measure offers also a summary of the evolution in the structure of inequality: a(n) decrease (increase) in the immobility ratio indicates an increase (decrease) in earnings mobility, equivalent with a(n) decrease (increase) in the relative share of permanent differentials in the overall inequality. This mobility index captures nondirectional earnings movements and can be interpreted as the opportunity to improve one's position in the distribution of lifetime earnings.

An increase in cross-sectional inequality accompanied by a decrease in earnings mobility is expected to have negative implications for long-run or lifetime earnings differentials, as it shows that over time low wage men get worse off both in terms of their relative earnings position and in terms of their opportunity to escape low wage trap. Thus it is reasonable to expect that cross-sectional earnings differentials will be enhanced in a lifetime perspective.

An increase in cross-sectional inequality accompanied by an increase in earnings mobility has uncertain implications for long-run or lifetime earnings differentials. Over time low wage men get worse off in terms of their relative earnings position, but better off in terms of the opportunity to escape low wage trap in a lifetime perspective. Thus earnings mobility could either enhance or decrease lifetime earnings differentials compared with the cross-sectional ones.

A decrease in cross-sectional inequality accompanied by an increase in earnings mobility is expected to have positive implications for lifetime earnings differentials, as over time low wage men better their relative earnings position and their opportunity to escape low wage trap in a lifetime perspective. Thus, lifetime earnings differentials are expected to be reduced compared with annual differentials.

A decrease in cross-sectional inequality accompanied by a decrease in earnings mobility has uncertain implications for lifetime earnings differentials, as over time low wage men get better off in terms of their relative earnings position, but worse off in terms of their opportunity to escape low wage trap in a lifetime perspective. Thus, lifetime earnings differentials could be either reduced or enhanced compared with annual differentials.

It becomes obvious that the question regarding the link between earnings mobility and earnings inequality does not have a straight forward answer and mobility is not always beneficial. It depends on the underlying factors: "changes in earnings mobility could either work to offset or to increase changes in cross-sectional dispersion", with very different implications for permanent earnings inequality (Dickens, 2000a). Nonetheless, no controversy surrounds the fact that mobility is 
beneficial when it helps low paid individuals to improve their income position in the long-term or lifetime income distribution.

\subsubsection{Linking labour market policies and institutions with outcomes}

To understand the differences in labour market outcomes - permanent inequality, transitory inequality and earnings mobility - across the 14 EU countries we relate to factors from the "SDI explanation of change" - the institutional setting. To our knowledge no study before tried to determine the possible links between these outcomes and the main labour market policy and institutional factors. Moreover, there is no specific theory that can explain this link. Therefore, we build our expectations based on existing labour market theories and empirical findings regarding the impact of the SDI factors on overall earnings inequality.

The rise of inequality in the permanent component of earnings may be consistent with increasing returns to education, on-the-job training and other persistent abilities that are among the main determinants of the permanent component of earnings, meaning enhanced relative earnings position of the highly skilled individuals (Mincer, 1957, 1958, 1962, 1974; Hause, 1980). Thus the increase in permanent differentials may be driven by an increase in the relative demand for high-skilled labour which has outstripped the rise in supply.

Among the factors that determine shifts in relative demand are skill-biased technological changes, which enhances the relative earnings position of the highlyskilled workers, the increase in prices of the other products, which imply changes in product demands, and forces of globalization, such as reduction in trade barriers and outsourcing (Fortin and Lemieux, 1997; Topel, 1997). A possible solution to the economic and social problem of rising permanent earnings differentials is to enhance the supply of high skill labour through investment in human capital to match the rise in the demand (Topel 1997). Shifts in the supply demand are determined by cohort variation, changes in access to education and immigration.

Another factor is the change in the interest rate. Von Weizsäcker (1993) analysed its influence on permanent inequality and concluded that an increase in the interest rate leads to a decrease in permanent inequality within the younger cohort and to a rise in permanent inequality in the older cohorts.

As underlined by Katz and Autor (1999), the rise of earnings instability appears to be "a bit of a puzzle for hypotheses only emphasizing rising skills prices associated with increased growth in the demand for skills relative to the supply of skills". 
However, some explanations could be formulated. The increase in the inequality of the transitory component of earnings may be attributed to increased earnings exposure to macroeconomic shocks and/or a rise in the temporary workforce which increases earnings exposure to shocks, increased labour market instability, increased competitiveness, globalization, increasing international capital mobility, and to the weakening of the labour market institutions (e.g. unions, government wage regulation, and internal labour markets) in filtering the impact of these shocks on earnings (Rodrik, 1997; Katz and Autor, 1999).

Some of the factors influencing directly permanent inequality might impact also transitory inequality. E.g. a period of skill-biased technological change with the spread of new technologies can, on the one hand, increase the demand for skills, and on the other hand increase earnings instability, as firms might face uncertainty with respect to the abilities of the individual workers (Katz and Autor 1999).

Overall, the increase in the return to persistent skills is expected to have a much larger impact on long-run earnings inequality than an increase in the transitory component of earnings.. (Katz and Autor 1999; Moffitt and Gottschalk 2002). Across age groups, as postulated by Freeman's (1975) “active labour market hypothesis", similarly with overall income, supply and demand factors together with the other macroeconomic shocks are expected to have the largest effect on the youngest generations of workers. Moreover the limiting impact of these factors on both inequality components is expected to be lower for younger workers, which have a weaker attachment to the labour market compared with senior workers.

The discussion is summarized in Figure 5.1. Permanent earnings inequality within birth cohorts is the result of the interactions between ability distributions, lifecycle decisions, economic structures and labour market policy and institutions. Transitory inequality within birth cohorts is expected to be driven mainly by random macroeconomic and individual-specific shocks, but its final evolution depends on the ability of the labour market policy and institutions to minimize its increase. 


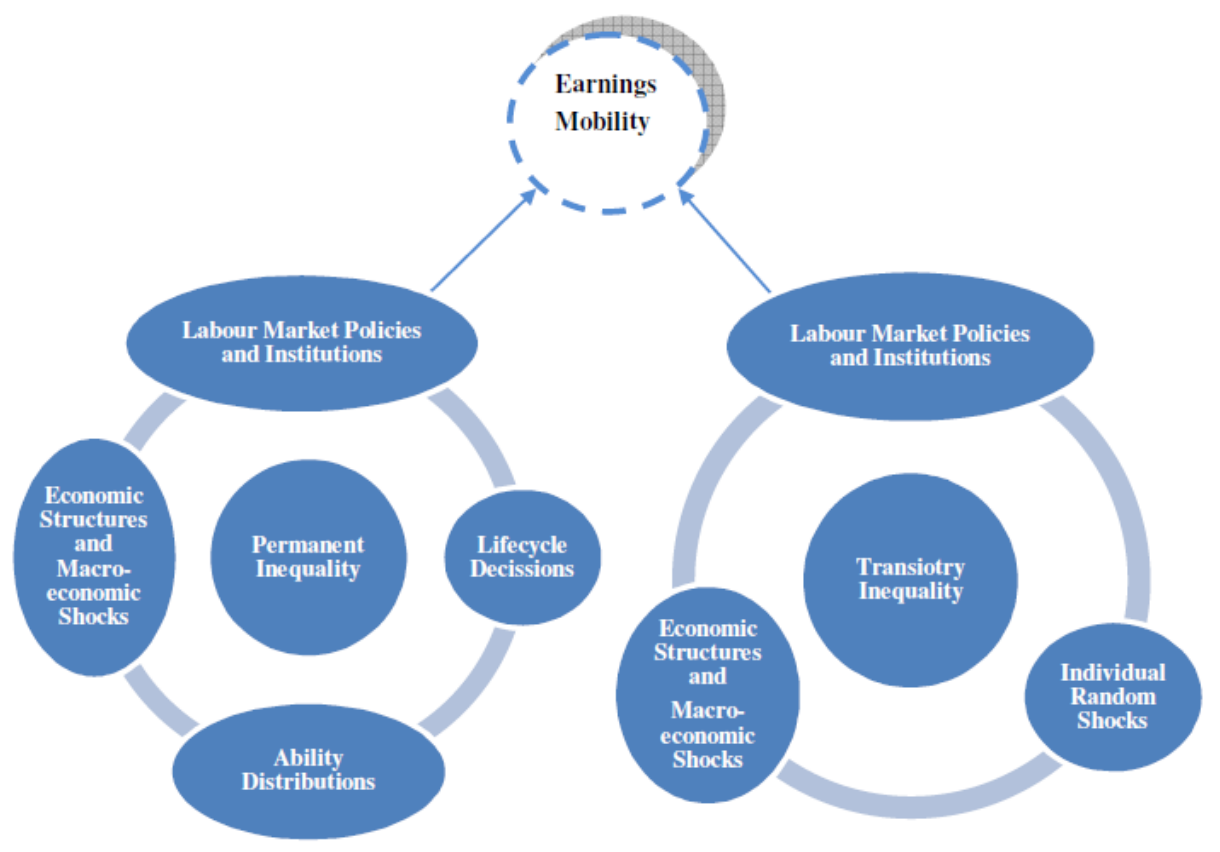

Figure 5.1. Determinants of Permanent and Transitory Inequality and Earnings Mobility

Once we account for all these factors influencing each component, the complexity of the mechanism determining earnings mobility is revealed. The evolution of mobility, which reflects the evolution in the structure of inequality, depends on which component is influenced the most: an increase in mobility is triggered when transitory inequality becomes relatively more important than permanent differentials in the composition of overall inequality and people manage to change their position in the income distribution. An equal relative increase in both components suggests an increase in earnings instability with no change in mobility, which might point to an increase in persistent differentials which are exacerbated by transitory differentials.

\section{Policies and Institutions - permanent effects}

Economic theory and previous empirical studies have identified a number of possible policy and institutional determinants of inequality. These include inter alia trade union bargaining power and the structure of collective bargaining, employment protection legislation (EPL), anti-competitive product market 
regulation (PMR), taxes, active labour market policies (ALMPs) and unemployment benefits. We investigate to what extent the changes in permanent earnings inequality, transitory earnings variability and earnings mobility are related to changes in these policy and institutional variables.

$$
\text { Trade unions and the structure of collective bargaining }
$$

Unionization and collective bargaining represent important institutional factors in the determination of wages and implicitly earnings inequality. It is well recognized that the stated purpose of unions is to reduce earnings disparities, and covered workers earn significantly higher wages and have less volatile profiles than the uncovered ones. Hence, unionization could be expected to lower transitory differentials.

Unions affect wage dispersion indirectly, mainly through their impact on training and minimum wage. By forcing employers to provide training to their employees, they increase the employees' human capital and adaptability to new technologies (Aghion and Williamson 2001). Thus unionization stimulates earnings mobility and increases employees' opportunity to improve their position in the permanent earnings distribution. Hence permanent earnings inequality can be reduced at any given rate of technical change (Aghion and Williamson 2001). In conclusion, unionization could be expected to lower both components and enhance earnings mobility.

However, even if unions decrease within-group earnings disparities, they may still increase both overall transitory and permanent inequality by increasing betweengroup wage differentials, meaning between those unionized and non-unionized. Thus, the impact of unionization depends also on the wage gap between unionized and non-unionised workers.

Furthermore, strong trade unions have the ability to increase wages above marketclearing levels at the cost of lower employment, which affects mainly workers with more elastic labour supply, such as younger workers, women and older workers (Bertola, Blau, and Kahn, 2002). Hence, by pushing these workers out of the labour market, both components might be expected to decrease for those still in the labour market. Similarly with overall inequality, because of these potentially offsetting effects, the impact of unionization on permanent differentials, transitory differentials and earnings mobility can only be resolved empirically (Fortin and Lemieux 1997). 
Existing studies brought evidence that a high union density is usually associated with a low overall earnings inequality, which results from claims for high wages and earnings stability for covered workers OECD (2004).

Nonetheless, it has long been argued that, in practice, union influence on wage formation depends on the structure of collective bargaining. On the one hand, a low degree of corporatism, meaning a decentralized wage bargaining at the firm level is expected to prevent excessive wage claims since this would lead to a loss of market shares to competitors with detrimental effects on employment. This implies that wages are less uniformly distributed, meaning that there is a higher dispersion in the returns to skills and in earnings variability (Bassanini and Duval 2006). Therefore we can expect countries with low degrees of corporatism to display high levels of permanent earnings inequality, a high variability and a high degree of earnings mobility.

The impact of coupling a high union density with low corporatism can be argued either way. On the one hand, a high or increasing union density could decrease the level of the high permanent and transitory inequality associated with low corporatism and might stimulate earnings mobility. On the other hand, even if union density increases, in the absence of coordination, this might lead to even higher permanent and transitory differentials. Moreover, as mentioned above, the wage gap between those unionized and those non-unionized is expected to play a significant role as well in determining the final outcome.

On the other hand, a very high degree of corporatism, meaning a very centralized and coordinated bargaining system is associated with a compressed wage structure across qualification levels because it is expected to exclude low skilled workers from the labour market (Calmfors, 1993). Therefore we can expect permanent and transitory earnings inequality and mobility to be lower the higher is the degree of centralization/coordination and the effect to be stronger the stronger the unionization. Again, the union-non-union wage gap might play a role.

Nonetheless, a very high degree of corporatism is more likely to lead to wage modernization, because they induce unions to internalize the detrimental macroeconomic effects of excessive wage pressure by restraining the wage demands. In this situation the degree of permanent inequality under high corporatism might be similar as under low corporatism. Thus the relationship between the degree of corporatism and wages may not be monotonic, but follow a "U-shaped" pattern, similar with employment.

For employment, an intermediate level of corporatism is expected to trigger the worst labour market outcomes, as they do not benefit from either of the advantages 
of low and high corporatism: when bargaining takes place at the firm level (without coordination), the high elasticity of demand in the product market implies that any price increase resulting from higher wages would result in severe drops both in output and employment. By contrast, when the bargaining takes place at the industry level, unions are able to secure higher wages because product demand elasticity is generally lower, given the lower substitution possibilities compared with the firm level (Bassanini and Duval, 2006b, 2006a; Calmfors and Driffill, 1988). Thus it is reasonable to expect both higher transitory and permanent differentials for intermediate levels of corporatism compared with low and high levels. Given the high earnings volatility, we might expect also higher levels of earnings mobility for intermediate corporatism compared with the other two.

(ii) Employment protection legislation (EPL)

EPL is one of the factors which affect the elasticity of labour demand to the bargained wage. It is considered to be a key factor in generating labour market rigidity by incurring costs to employers when dismissing workers. Two consequences emerge. On the one hand, employers might offer lower wages in order to compensate for the firing costs. On the other hand, employees might feel better protected and push for higher wages, which in turn puts a pressure on employers. Employers will reduce hiring rates, thus increase unemployment spells. Consequently, the cost of unemployment becomes too high, which might create an incentive for employees to accept lower wages to maintain their wage. Hence the equilibrium is restored (Blanchard, 1999). Therefore, theory predicts that EPL increases the cost of hiring and of layoffs, and consequently lowers labour turnover, which might reduce transitory inequality and earnings mobility, and wages, which might reduce permanent inequality. This is consistent with OECD (2004) findings, which state that a strict EPL is usually associated with a low overall inequality. Moreover, the low turnover is expected to affect mainly workers with temporary contracts, because they have a weaker protection in the labour market.

In conclusion, an increase in the strictness of the EPL can be expected to decrease both permanent and transitory earnings inequality and earnings mobility. However, the overall impact of the EPL depends on the difference in regulating regular (EPLR) and temporary contracts (EPLT), which affects the labour market structure with respect to the type of contract. A higher share of transitory contracts is expected to bring along a higher transitory inequality, given the higher exposure of these workers to the economic shocks. 
If a strict EPLR coexists with a low EPLT, this represents a strong disincentive for employers to train temporary workers, as the cost of their layoff is low. Consequently, temporary workers are trapped in this type of contracts, without a chance towards permanent contracts, meaning without a chance towards increasing their human capital and, at the same time, facing more earnings instability under the impact of macroeconomic shocks. However, this type of earnings instability is not expected to increase mobility rates that could help these individuals improve their relative position in the distribution of lifetime earnings. At the same time, workers with a permanent contract might benefit from higher bargaining power and might push towards higher wages. Thereby, permanent differentials and earnings instability are expected to be enhanced, and earnings mobility to be reduced by an increase in the relative difference between EPLR and EPLT.

(iii) Tax wedge

An increase in the tax wedge, defined as the sum of the personal income tax and all social security contributions as a percentage of total labour cost, results in employers paying more and employees receiving less. The resulting impact on permanent inequality is twofold. On the one hand, tax wedge influences permanent inequality through its influence on human capital price. An increase in the tax wedge lowers human capital price. Von Weizsäcker (1993) proved within the context of an explicit comparative dynamic inequality analysis that a decrease in human capital price results in a decrease in permanent inequality within age groups.

On the other hand, an increase in the tax wedge suggests that the cost to employers increases to a larger extent than the increase of the wage offered. This has detrimental effects especially for employment, pushing minimum wage workers, for which the rise in payroll taxes cannot be shifted onto, into unemployment (Bassanini and Duval, 2006b, 2006a). Thus an increase in the tax wedge is expected to push low wage workers into unemployment and to decrease permanent earnings inequality for the working population. These effects might be exacerbated by strong unions. Similarly with the findings for employment, its effects are expected to depend also on the degree of corporatism. No direct effect is expected on transitory income.

(iv) Product market regulation (PMR)

A good example of the impact of product market regulation on wage inequality is the comparison between public and private sector: the public sector, which is 
highly regulated, displays a more compressed earnings structure. Hence, we expect highly regulated sectors to display reduced permanent and transitory differentials.

Lower product market regulations (PMR) are expected to determine an increase in competition in the previously regulated sectors, and consequently lower market rents, which in turn determine lower wage claims, aimed to close the gap between productivity and real wages that generates unemployment. Therefore a decrease in product market regulation is expected to shift labour demand, increase its elasticity to wages, increase the returns to skills, and consequently increase permanent differentials in the previously regulated sectors. At the same time, increased competition is expected to increase transitory inequality. In the same line of thought, more competitive environments are expected to determine higher levels of earnings mobility.

These effects might hold in the previously regulated sectors, but the impact on the overall level of inequality, including also those which were not regulated, might be different. The final effect depends on a large extent on the ex-ante wage gap between regulated and non-regulated sectors. Moreover, interaction effects with other institutions cannot be neglected. For example, previous findings showed that the effect of deregulation on wage differentials depend on union density and the degree of corporatism. For example, Fortin and Lemieux (1997) found that deregulation increases overall inequality, but the effect is larger among unionized male workers.

(v) Active labour market policies (ALMPs)

Active Labour Market Programs (ALMP), which typically consist of job placement services and labour market programmes such as job-search, vocational training or hiring subsidies can reduce permanent earnings differentials by improving the efficiency of the job matching process and by enhancing the work experience and skills of the unemployed. Thus by increasing human capital of low wage individuals and decreasing permanent wage differentials, ALMP is expected to increase their wage mobility, helping them improve their position in the distribution of permanent earnings.

However, these reintegrated workers are the ones with least protection in the labour market and they are expected to be the most affected by macroeconomic shocks. Hence, in the face of macroeconomic shocks, their presence in the labour market might exacerbate permanent and transitory differentials. 
Another aspect to be considered are interactions with other factors: the effects of the ALMP depend on the other labour market policies and institutions. For example, a strict EPL is expected to dampen the effect of active labour market policies aimed to reintegrate the unemployed into the labour market (Bassanini and Duval, 2006b, 2006a). On the one hand, the increase in the ALMP increases employability and on the other hand the low EPL facilitates their labour market reintegration. Hence, an increase in ALMP coupled with a low or decreasing EPL could be expected to reduce permanent differentials and increase earnings mobility.

(vi) Unemployment benefits

The expected impacts of the unemployment benefits on labour market outcomes are not so straightforward. On the one hand, generous unemployment benefits are expected to weaken the job-search intensity and decrease the employability and human capital for the unemployed, thus increase permanent differentials. Moreover, generous unemployment benefits are expected to increase the economic cost of employment, which in turn may put an upward pressure on worker's wage claims and exacerbate the increase in permanent earnings dispersion.

On the other hand, longer and more generous unemployment benefits represent incentives not to accept low-paid jobs and improve the job-matching, thus increasing the likelihood of a more stable employment and earnings patterns (Bassanini and Duval, 2006b, 2006a). In this situation, both transitory and permanent differentials are expected to be reduced. Moreover, if they are coupled with active labour market programs they are expected to increase human capital even further, thereby reducing permanent differentials.

Regarding the interactions between all these policy and institutional factors that are expected to impact permanent inequality, transitory inequality and earnings mobility, based on the standard wage-setting/price-setting (WS/PS) model (Layard, Nickell, and Jackman, 1991), any factor that affects the slope of the wage-setting curve - the elasticity of wage claims to employment (e.g. unemployment benefits, unionization, degree of corporatism, PMR) and/or the slope of the price-setting curve - elasticity of labour demand to bargaining wage (e.g EPL, PMR, tax wedge) may be expected to interact with policies and institutions that affect the level of the wage-setting - level of wage claims (e.g. unemployment benefits) and the level of price-setting curve - level of labour demand (e.g. PMR) (Bassanini and Duval, 2006b, 2006a). 
Similar with the conclusions reached by Bassanini and Duval (2006a, 2006b) regarding the impact of the labour market institutional and policy factors, the overall lessons that emerge are that, in theory, all possible interactions across policies and institutions can affect permanent inequality, transitory inequality and earnings mobility. And which policies complement each other should be established empirically.

Interactions between policies, institutions and macroeconomic shocks - transitory effects

From what has been presented so far, policies and institutions appear to play a major role in shaping primarily permanent differentials and earnings mobility. However, for transitory differentials and earnings mobility a big part of the story is missing. Besides their permanent effects, policies and institutions may also have a temporary impact via their interactions with a series of macroeconomic shocks which have affected the OECD countries. We are going to consider the impact of globalization, technological changes, interest rate, labour demand shocks, aggregate supply and demand shocks. These macroeconomic shocks are expected to explain to a larger extent the evolution of the transitory variance and earnings mobility compared with permanent variance, which appears to be shaped at a larger extent by institutional and policy factors.

The effects of these shocks on all three elements are expected to be "filtered" by the labour market policies and institutions, which are put in place to protect earnings against the exposure to the possible adverse effects of these shocks.

We expect that strong unionization, a high degree of corporatism, strict EPL, strict PMR and high unemployment benefits will have a dampening effect on the sensitivity of wages to general economic conditions, thus limiting the increase or even reducing transitory variance, and thus reducing earnings mobility. The effectiveness of these policies and institutions is expected to be lower for the youngest cohort compared with more experienced workers, as younger workers are expected to be affected the most by demand and supply shocks. 


\subsection{Data ${ }^{59}$}

The estimation of the permanent variance, transitory variance and earnings mobility is done using the European Community Household Panel (ECHP) ${ }^{60}$ over the period 1994-2001 for 14 EU countries. Not all countries are present for all waves. Luxembourg and Austria are observed between 1995 and 2001 and Finland between 1996 and 2001. Following the tradition of previous studies, the analysis focuses only on men.

A special problem with panel data is that of attrition over time, as individuals are lost at successive dates causing the panel to decline in size and raising the problem of representativeness. Several papers analysed the extent and the determinants of panel attrition in ECHP. Behr, Bellgardt and Rendtel (2005) found that the extent and the determinants of panel attrition vary between countries and across waves within one country, but these differences do not bias the analysis of income or the ranking of the national results. Ayala, Navrro and Sastre (2006) assessed the effects of panel attrition on income mobility comparisons for some EU countries from ECHP. The results show that ECHP attrition is characterized by a certain degree of selectivity, but only affecting some variables and some countries. Moreover, the income mobility indicators show certain sensitivity to the weighting system.

In this paper, the weighting system applied to correct for the attrition bias is the one recommended by Eurostat, namely using the "base weights" of the last wave observed for each individual, bounded between 0.25 and 10. The dataset is scaled up to a multiplicative constant ${ }^{61}$ of the base weights of the last year observed for each individual.

For the empirical analysis, individuals are categorized into four birth cohorts, which are followed through time. Ideally, one should use birth cohorts formed from people born in a particular year. The limited number of observations forces us to group more birth years in one birth cohort. The first birth cohort are people born between 1940-1950, the second one people born between 1951-1960, the third cohort people born between 1961-1970 and lastly people born between 1971-1981.

\footnotetext{
59 The description of the ECHP has been covered in section 4.4. The readers, who already covered it, should proceed with the description of the OECD data set.

${ }^{60}$ The European Community Household Panel provided by Eurostat via the Department of Applied Economics at the Université Libre de Bruxelles.

${ }^{61}$ The multiplicative constant equals e.g. $\mathrm{p}^{*}$ (Population above 16/Sample Population). The ratio $\mathrm{p}$ varies across countries so that sensible samples are obtained. It ranges between 0.001-0.01.
} 
This grouping allows the analysis of the earnings covariance structure for individuals of the same age, followed at different points in time.

For this study we use real log hourly wage adjusted for CPI of male workers aged 20 to 57, born between 1940 and 1981. Only observations with hourly wage lower than 50 Euros and higher than 1 Euro were considered in the analysis. The resulting sample for each country is an unbalanced panel. The choice of using unbalanced panels for estimating the covariance structure of earnings is motivated by the need to mitigate the potential overestimation of earnings persistence that would arise from balanced panels where the estimation is based only on people that have positive earnings for the entire sample period.

Table 5.1. Mean hourly earnings and number of individuals with positive earnings

\begin{tabular}{|c|c|c|c|c|c|c|c|c|c|}
\hline & & 1994 & 1995 & 1996 & 1997 & 1998 & 1999 & 2000 & 2001 \\
\hline \multirow[t]{2}{*}{ Germany } & Mean & 9.43 & 9.49 & 9.61 & 9.52 & 9.57 & 9.48 & 9.60 & 9.72 \\
\hline & $\mathrm{N}$ & 25018 & 26059 & 25806 & 24889 & 23290 & 22955 & 21909 & 20703 \\
\hline \multirow[t]{2}{*}{ Denmark } & Mean & 10.89 & 11.40 & 11.58 & 11.61 & 11.86 & 11.85 & 12.02 & 12.08 \\
\hline & $\mathrm{N}$ & 20899 & 20399 & 19190 & 19062 & 17321 & 16235 & 15678 & 15380 \\
\hline \multirow[t]{2}{*}{ Netherlands } & Mean & 9.69 & 9.56 & 9.59 & 9.70 & 10.02 & 9.88 & 10.04 & 9.91 \\
\hline & $\mathrm{N}$ & 33277 & 32384 & 31564 & 30575 & 28731 & 27460 & 25790 & 33277 \\
\hline \multirow[t]{2}{*}{ Belgium } & Mean & 8.48 & 8.82 & 8.71 & 8.75 & 8.81 & 8.83 & 8.92 & 9.10 \\
\hline & $\mathrm{N}$ & 20221 & 22100 & 22892 & 22753 & 22863 & 23233 & 24065 & 24130 \\
\hline \multirow[t]{2}{*}{ Luxembourg } & Mean & & 16.18 & 15.81 & 16.73 & 17.39 & 17.15 & 17.22 & 17.10 \\
\hline & $\mathrm{N}$ & & 15829 & 13695 & 14489 & 13403 & 14075 & 12667 & 12992 \\
\hline \multirow[t]{2}{*}{ France $^{62}$} & Mean & 10.23 & 9.92 & 9.87 & 10.05 & 10.33 & 10.60 & 10.55 & 10.87 \\
\hline & $\mathrm{N}$ & 20137 & 19270 & 19042 & 17906 & 14467 & 14012 & 13760 & 14212 \\
\hline \multirow[t]{2}{*}{ UK } & Mean & 8.16 & 8.11 & 8.22 & 8.34 & 8.68 & 9.01 & 9.21 & 9.68 \\
\hline & $\mathrm{N}$ & 24949 & 25329 & 25495 & 26010 & 26145 & 25750 & 25674 & 25264 \\
\hline \multirow[t]{2}{*}{ Ireland } & Mean & 9.30 & 9.54 & 9.76 & 10.02 & 10.43 & 10.84 & 11.69 & 12.44 \\
\hline & $\mathrm{N}$ & 13937 & 13221 & 12590 & 12515 & 12435 & 12091 & 10745 & 9727 \\
\hline \multirow[t]{2}{*}{ Italy } & Mean & 7.16 & 6.91 & 6.96 & 7.05 & 7.29 & 7.37 & 7.28 & 7.32 \\
\hline & $\mathrm{N}$ & 32633 & 32236 & 32111 & 29661 & 28865 & 26993 & 26912 & 25170 \\
\hline \multirow[t]{2}{*}{ Greece } & Mean & 4.95 & 5.03 & 5.23 & 5.59 & 5.63 & 5.85 & 5.70 & 5.77 \\
\hline & $\mathrm{N}$ & 27974 & 27654 & 26150 & 24865 & 22675 & 22001 & 21335 & 21929 \\
\hline \multirow[t]{2}{*}{ Spain } & Mean & 6.83 & 6.95 & 7.09 & 6.89 & 7.18 & 7.37 & 7.45 & 7.42 \\
\hline & $\mathrm{N}$ & 22559 & 21863 & 21296 & 20975 & 20371 & 20580 & 19898 & 20185 \\
\hline \multirow[t]{2}{*}{ Portugal } & Mean & 9.08 & 8.33 & 8.37 & 8.49 & 8.55 & 8.55 & 8.54 & 9.08 \\
\hline & $\mathrm{N}$ & 14653 & 15450 & 15379 & 15087 & 14837 & 14569 & 14604 & 14550 \\
\hline \multirow[t]{2}{*}{ Austria } & Mean & & 9.08 & 8.33 & 8.37 & 8.49 & 8.55 & 8.55 & 8.54 \\
\hline & $\mathrm{N}$ & & 17944 & 17789 & 17199 & 16209 & 15162 & 13816 & 13056 \\
\hline \multirow[t]{2}{*}{ Finland } & Mean & & & 7.89 & 8.01 & 8.41 & 8.45 & 8.66 & 8.86 \\
\hline & $\mathrm{N}$ & & & 15811 & 15845 & 15895 & 15546 & 13329 & 13057 \\
\hline
\end{tabular}

Note: Mean hourly earnings are expressed in Euro.

\footnotetext{
62 Gross Amounts
} 
Details on the number of observations and mean yearly hourly earnings are provided in Table 5.1. Mean hourly earnings appear to increase in all countries except for Austria where it records a slight decrease. Based on Sologon and O'Donoghue (2009a, 2009b), the highest attrition rates from one year to the next are recorded in Ireland, Italy, Greece, Spain and Portugal, where, on average, less than $60 \%$ of those who were in the sample in the previous year reported positive earnings in the current year. For more descriptive statistics please refer to Sologon and O'Donoghue (2009a, 2009b).

The link between the evolution of the two inequality components and the labour market policies and institutions is investigated using the estimated components from the first part of the analysis and the OECD data on the labour market indicators, which is a combination of two data sets. The first dataset is the one used by Bassanini and Duval (2006a, 2006b) ${ }^{63}$ and the second one is the Lindert-Allard OECD data set 1950-200164.

The following institutional variables are included in the analysis: employment protection legislation overall (EPL), for temporary (EPLT) and for regular contracts (EPLR), the relative difference between EPLR and EPLT, trade union density, product market regulation (PMR), tax wedge, degree of corporatism, degree of bargaining coverage, average unemployment benefit replacement rate and spending on active labour market programmes (ALMP). The macroeconomic shock variables included are: labour demand shock, terms of trade shock, total factor production shock, real interest shock, aggregate demand shock and aggregate supply shock. These variables are observed at the country level, over the period 1994-2001.

A description of the variables is included in Table 5-A-1 (Annex). For a more detailed description, please refer to Bassanini and Duval (2006a, 2006b) and the Lindert-Allard OECD data sets 1950-2001. The summary statistics of the institutional variables and shock variables are illustrated in Table 5-A-2 (Annex). Luxembourg and Greece have some missing institutional and shock variables and they are dropped from the final estimations. Portugal, Denmark and Ireland record some missing values for labour demand shock.

Additional control variables by cohort are included in the final estimations estimation: the share of university degrees, the share of upper-secondary degrees, share of permanent contracts, share of private employees and share of employees

\footnotetext{
${ }^{63}$ The data was provided by email from the authors.

${ }^{64} \mathrm{http}$ ///www.econ.ucdavis.edu/faculty/fzlinder/OECD\%20data.htm
} 
by occupation. The summary statistics for the control variables are presented in Table 5-A-4 (Annex).

\subsection{Econometric specifications and estimation methods}

The aim of this section is twofold: first, to fit a parsimonious model to the autocovariance structure of earnings for all countries, decompose overall earnings inequality into its permanent and transitory components and compute earnings immobility; second to estimate the relationship between these estimated components and the main labour market policy and institutional factors.

\subsubsection{Econometric specifications and estimation methods of covariance structures ${ }^{65}$}

\subsubsection{Econometric Earnings Specification}

The methodology used to estimate earnings inequality, its permanent and transitory component, and earnings mobility by cohorts and for each country follows Sologon and O'Donoghue (2009a, 2009b). This paper represents a followup of their analysis. We use the same data and the models identified by Sologon and O'Donoghue (2009a, 2009b) as the best fit for each country to estimate the two inequality components and earnings mobility. A summary of this methodology is provided below.

The inspection of the covariance structure of earnings, included in section 5.5.1, suggests the following features of the data, which must be incorporated in the model:

(i) the elements of the autocovariance structure decrease with the lag at a decreasing rate and

(ii) they converge gradually at a positive level;

(iii) the lag-1 autocovariance drops to a larger extent compared with higher order autocovariances, which decline more gradually;

(iv) the autocovariances and mean earnings vary over the sample period, so they cannot be assumed to be stationary over sample period;

(v) the autocovariances vary with age controlling for the period effect, hence they cannot be assumed to be stationary over the life cycle;

65 The information in this section has been discussed in section 4.5 and 4.6. 
(vi) the variance covariance structure appears to be cohort specific.

Each of the above features are incorporated in the general model. Feature (i) suggests the presence of an $\mathrm{AR}(1)$ process, but the presence of feature (iii) calls for an ARMA $(1,1)$ process. Feature (ii) can be captured by the presence of the permanent component. Feature (iv) is captured by incorporating period specific parameters, meaning that the permanent individual component and the transitory component of earnings are allowed to vary with time. The life cycle nonstationarity of the autocovariance structure of earnings in feature $(\mathrm{v})$ is captured by modelling the permanent individual component as a random walk and/or random growth in age. Cohort heterogeneity is incorporate by parameters that allow the permanent and transitory components to vary between cohorts.

The following general specification encompasses all the relevant aspects of earnings dynamics considered above.

$$
\begin{aligned}
& Y_{i c t}-\overline{Y_{c t}}=r_{i c t}=\gamma_{1 c} \lambda_{1 t}\left[\mu_{i}+\varphi_{i} a g e_{i t}+u_{i a t}\right]+\gamma_{2 c} \lambda_{2 t} v_{i t}, \quad t=1, \ldots, T_{i}, \quad i=1, \ldots, N_{c} \\
& \mu_{i} \sim \operatorname{iid}\left(0, \sigma_{\mu}^{2}\right), \quad \varphi_{i} \sim \operatorname{iid}\left(0, \sigma_{\varphi}^{2}\right), \quad E\left(\mu_{i}, \varphi_{i}\right)=\sigma_{\mu \varphi} \\
& u_{i a t}=u_{i, a-1, t-1}+\pi_{i a}, \quad \pi_{i a} \sim \operatorname{iid}\left(0, \sigma_{\pi}^{2}\right), \quad E\left(u_{i, a-1, t-1}, \pi_{i a t}\right)=0 \\
& v_{i t}=\rho v_{i t-1}+\varepsilon_{i t}+\theta \varepsilon_{i t-1}, \quad \varepsilon_{i t} \sim\left(0, \sigma_{\varepsilon}^{2}\right), \quad v_{i 0} \sim\left(0, \sigma_{0, c}^{2}\right)
\end{aligned}
$$

$Y_{i c t}$ is the natural logarithm of real hourly earnings of the $i$-th individual, from the $c$-th cohort in the $t$-th year, $\overline{Y_{c t}}$ is the year-cohort specific mean and $r_{i c t}$ is an error term which represents the individual-specific deviation from the year-cohort specific mean. The demeaned earnings $r_{i c t}$ are assumed to be independently distributed across individuals, but autocorrelated over time. Earnings differentials within each cohort can be characterised by modelling the covariance structure of individual earnings $\operatorname{Var} \operatorname{Cov}\left(Y_{i c t}\right)=E\left(r_{i c t}, r_{i c t-s}\right), s=0, \ldots, T_{c}-t_{0 c} \cdot{ }^{66}$

Based on equation (5.5), earnings are decomposed into a permanent component $\gamma_{1 c} \lambda_{1 t}\left[\mu_{i}+\varphi_{i} a g e_{i t}+u_{i a t}\right]$ and a transitory component $\gamma_{2 c} \lambda_{2 t} v_{i t}$. The component $\mu_{i}+\varphi_{i} a g e_{i t}$ models an individual profile heterogeneity as a function of age - the random growth model (Baker 1997, Moffitt and Gottschalk 1995), where $\mu_{i}$ and $\varphi_{i}$ are time invariant individual intercept and slopes with variance $\sigma_{\mu}^{2}$ and $\sigma_{\varphi}^{2}$.

${ }_{66} T_{c}$ and $t_{0 c}$ represent the total number of years and the first year observed for each cohort. 
Besides the random vector of intercepts and slopes $\left(\mu_{i}, \varphi_{i}\right)$ the parameterization of individual earnings dynamics includes also a random walk process (Equation (5.6)). (Moffit and Gottschalk 1995, Baker and Solon 2003) The variance of the first period shock (assumed to be at age 20, which is also the lowest age observed in our dataset) is estimated together with the $\sigma_{\mu}^{2}$ and is considered part of the unobserved heterogeneity.

Equation (5.7) specifies the transitory component of earnings which evolves as an $\operatorname{ARMA}(1,1)$ process, where the serial correlation $\rho$ parameter captures the decreasing rate of decay of the covariances with the lag, the moving-average parameter $\theta$ captures the sharp drop of the lag- 1 autocovariance compared with the other autocovariances, and $\varepsilon_{i t}$ are white-noise mean-reverting transitory shocks. The variance $\sigma_{0, c}^{2}$ measures the volatility of shocks at the start of the sample period for each cohort, $\sigma_{\varepsilon}^{2}$ the volatility of shocks in subsequent years and $\rho$ the persistence of shocks. Measurement error in this model is captured by the transitory component.

When working with $\operatorname{ARMA}(\mathrm{p}, \mathrm{q})$ processes in the context of panel data, MaCurdy $(1981,1982)$ and Anderson and Hsiao (1982) underlined the need for a treatment of initial conditions ${ }^{67}$. Following MaCurdy $(1981,1982)$ and Sologon and O'Donoghue (2009a, 2009b), we treat the initial transitory variances of the 4 cohorts as 4 additional parameters to be estimated.

The non-stationary pattern of earnings is accommodated using time specific loading factors, both on the permanent and transitory component of earnings, $\lambda_{k t, k=1,2 ; t=0,7}$, normalized to 1 in the first wave for identification ${ }^{68}$. Cohort heterogeneity is accommodated by allowing both the permanent and the transitory component to vary by cohort. $\gamma_{j c}, j=1,2$ are cohort loading factor, normalized to 1 for the oldest cohort born for identification.

\subsubsection{Specification and estimation of the covariance structure of earnings}

Following Sologon \& O'Donoghue (2009a, 2009b), the covariance structure for the first sample period takes the form:

\footnotetext{
67 See Macurdy(1982, page 92/93)

681994 refers to $\mathrm{t}=0$
} 
$\operatorname{Var}\left(Y_{i c 0}\right)=E\left(r_{i c 0} r_{i c 0}\right)=\sigma_{\mu}^{2}+\sigma_{\varphi}^{2} E\left(\operatorname{age}_{i 0}^{2}\right)+2 \operatorname{cov}\left(\mu_{i} \varphi_{i}\right) E\left(\right.$ age $\left.\left._{i 0}\right)+(a-20) \sigma_{\pi}^{2}+\sigma_{0, c}^{2}\right)$ if $t=0$

The covariance structure for subsequent years can be expressed as follows:

$$
\begin{aligned}
& \operatorname{Var}\left(Y_{i c t}\right)=E\left(r_{i c t} r_{i c t}\right)=\gamma_{1 c}^{2} \lambda_{1 t}^{2}\left[\sigma_{\mu}^{2}+\sigma_{\varphi}^{2} E\left(a g e_{i t}^{2}\right)+2 \operatorname{cov}\left(\mu_{i} \varphi_{i}\right) E\left(a g e_{i t}\right)+\sigma_{\pi}^{2}\left(a_{t}-20\right)^{2}\right]+ \\
& +\gamma_{2 c}^{2} \lambda_{2 t}^{2}\left[\rho^{2} \operatorname{Var}\left(v_{i t-1}\right)+\sigma_{\varepsilon}^{2}\left(1+2 \rho \theta+\theta^{2}\right)\right] \text { if } t>0
\end{aligned}
$$

$\operatorname{Cov}\left(Y_{i c t} Y_{i c t-s}\right)=E\left(r_{i c t} r_{i c t-s}\right)=$

$=\gamma_{1 c}^{2} \lambda_{1 t}^{2}\left\{\sigma_{\mu}^{2}+\sigma_{\varphi}^{2} E\left(\right.\right.$ age $\left._{i t}\right) E\left(\right.$ age $\left._{i t-s}\right)+\operatorname{cov}\left(\mu_{i} \varphi_{i}\right)\left[E\left(\right.\right.$ age $\left._{i t}\right)+E\left(\right.$ age $\left.\left.\left._{i t-s}\right)\right]+\sigma_{\pi}^{2}\left(a_{t}-20\right)\left(a_{t}-s-20\right)\right\}+$

$+\gamma_{2 c}^{2} \lambda_{2 t} \lambda_{2 t-s}\left[\rho \operatorname{Cov}\left(v_{i t-1}, v_{i t-s}\right)\right]$ if $t>0 \quad \& \quad s>1$

$\operatorname{Cov}\left(Y_{i c t} Y_{\text {ict-1 }}\right)=E\left(r_{\text {ict }} r_{\text {ict }-1}\right)=$

$=\gamma_{1 c}^{2} \lambda_{1 t}^{2}\left\{\sigma_{\mu}^{2}+\sigma_{\varphi}^{2} E\left(\right.\right.$ age $\left._{i t}\right) E\left(\right.$ age $\left._{i t-1}\right)+\operatorname{cov}\left(\mu_{i} \varphi_{i}\right)\left[E\left(\right.\right.$ age $\left._{i t}\right)+E\left(\right.$ age $\left.\left.\left._{i t-1}\right)\right]+\sigma_{\pi}^{2}\left(a_{t}-20\right)\left(a_{t}-1-20\right)\right\}+$

$\left.+\gamma_{2 c}^{2} \lambda_{2 t} \lambda_{2 t-1}\left\{\rho \operatorname{Var}\left(v_{i t-1}\right)+\theta \sigma_{\varepsilon}^{2}\right)\right\}$ if $t>0 \quad \& \quad s=1$

Basically the parameters that are estimated are:

$\gamma_{1 c}, \lambda_{1 t}, \sigma_{\mu}^{2}, \sigma_{\varphi}^{2}, \operatorname{cov}\left(\mu_{i} \varphi_{i}\right), \sigma_{\pi}^{2}, \gamma_{2 c}, \lambda_{2 t}, \rho, \theta, \sigma_{\varepsilon}^{2}, \sigma_{0, c}^{2}, c=1, \ldots 4$

The parameters of the models are fit to the covariance structure for each cohort by country using equally weighted minimum distance methods of estimation. The methodology used is the same as that utilized by Cappellari (2003), Baker and Solon (2003), Ramos (2003), Kalwij and Alessie (2003), Dickens (2000b), Baker (1997), Abowd and Card (1989), Cervini, Ramos (2006) and Sologon and O'Donoghue (2009a, 2009b) adapted to unbalanced panels.

This paper uses the specification that fits the data the best for each country, as found by Sologon and O'Donoghue (2009a, 2009b). For the complete description of the methodology and the strategy on model selection, please refer to Sologon and O'Donoghue (2009a, 2009b). 


\subsubsection{Estimation of the links between policy, institutions and outcomes}

This section describes the methodology used to estimate the relationships between labour market policy and institutional factors as independent variables and permanent inequality, transitory inequality and earnings mobility, as dependent variables. Each model is estimated independently, for all cohorts and countries pooled together. The unit of analysis is the cohort. Hence we have four cohorts for each country, observed between 1994-200169.

The analysis follows a general to specific strategy. First, we test whether policies interact with the overall institutional framework, controlling for the cohorts effects and for all the unobserved shocks. Second, we test whether there are any specific interactions between different institutional factors, and between the institutional factors and the observed aggregate shocks in shaping the pattern of the two inequality components and earnings mobility.

\subsubsection{Systemic interactions}

In macroeconomic equations interactions between institutions are usually specified in a multiplicative form between deviations of institutions from their sample mean, which enables the interpretation of the marginal effects of each institution when the others are kept constant at the sample mean. Before analysing the specific cross-interactions between all institutions, we want to get a grasp of the systemic interactions, meaning the interactions between each institution and the overall institutional setting.

Systemic reform complementarity patterns are explored by estimating a separate non-linear equation for each labour market outcome, pooling all cohorts, where each institution is interacted with the overall institutional framework, defined as the sum of the direct effects of institutions.

$y_{i t}=\delta_{c} \tau_{t}\left(\sum_{k=1}^{K} v_{k} X_{k i t}+\sum_{k=1}^{K} \varphi_{k}\left(X_{k i t}-\overline{X_{k}}\right)\left(\sum_{k=1}^{K} v_{k}\left(X_{k i t}-\overline{X_{k}}\right)\right)+\mu_{i}+v_{i t}\right.$

$y_{i t}$ represents the labour market outcomes -permanent variance, temporary variance and wage immobility of the cohort $i$ in year $t$. The parameters $v_{k}, \varphi_{j}, \delta_{c}$

\footnotetext{
${ }^{69}$ Exception are countries which are not observed for all eight waves, and consequently will have less observations.
} 
and $\tau_{t}$ are estimated simultaneously. $v_{k}$ denotes the direct effect of institution $X_{k}$ on $y_{i t}$, for a country with an average mix of policies and institutions, while $\varphi_{k}$ indicates the strength of the interaction between $X_{k}$ and the overall institutional framework, expressed as the sum of direct effect of policies and institutions, expressed in deviation form in the interaction. $X_{k}$ is measured at the country level. A negative and significant effect suggests that there is a systemic reform complementarity between $X_{k}$ and the overall framework in reducing permanent variance, temporary variance and earnings immobility, at the cohort level. $\delta_{c}$ and $\tau_{t}$ represent cohort and respectively period shifters, which capture cohorts heterogeneity and all the unobserved shocks that might affect permanent variance, transitory variance and earnings immobility by altering the slopes of the direct and indirect effects.

The estimation results are included in Table 5.5.

\subsubsection{Specific $2-$ by-2 interactions between institutions, and between institutions and shocks}

This section attempts to open the black box of the systemic interactions investigated in the previous section and explore the specific interactions between institutions, and between institutions and shocks, which are expected to shape the pattern of permanent inequality, transitory inequality and earnings mobility. We start with a relatively simple model in which we explore the direct effect of institutions, shocks and the interactions between shocks and institutions. Moreover, we allow the effects to differ by cohorts to account for cohort heterogeneity. The model is expressed as follows:

$y_{i t}=\delta_{c}\left[\sum_{k=1}^{K} v_{k} X_{k i t}+\sum_{s=1}^{S} \psi_{s}\left(Z_{s i t}-\overline{Z_{s}}\right)\left(1+\left(\sum_{k=1}^{K} \gamma_{k}\left(X_{k i t}-\overline{X_{k}}\right)\right)\right]+\mu_{i}+v_{i t}\right.$

where $\sum_{s=1}^{S} \psi_{s}\left(Z_{s i t}-\overline{Z_{s}}\right)$ is a set of observed macroeconomic shocks expressed in deviation from their mean, which are interacted with policy and institutional factors. $\delta_{c}, v_{k}, \psi_{s}$ and $\gamma_{k}$ are estimated simultaneously. As before $\delta_{c}$ represent the cohort shifters, normalized to 1 for the oldest cohort for identification, $v_{k}$ represents the direct effect of institution $X_{k}$ when the other intuitions and shocks 
are at their sample means, $\psi_{s}$ captures the direct effects of shocks and $\gamma_{k}$ capture the interaction effects between institution $X_{k}$ and the aggregate effects of macroeconomic shocks. The estimation results are presented in Model 2, Table 5.6. The final model augments model (5.13) by adding also the 2-by-2 interaction effects between institutions and policies. Moreover, additional controls are added, which are aimed to control for educational structure (proportions of university and upper-secondary graduates), for sector structure (proportion of private employees), for the structure of the type of contract (proportion of employees with a permanent contract), for the structure of employment status (proportion of unemployed) and for occupational structure, by cohort. The estimation results are presented in Model 3, Table 5.6.

One note needs to be made. $\mu_{i}$ captures the unobserved unit-specific heterogeneity, in our case cohort-specific heterogeneity. One might argue that our model suffers from unobserved heterogeneity bias. We tested for unobserved heterogeneity for each model, by cohort, using the Breusch and Pagan Lagrangian multiplier test for random effects. The test rejected the presence of unit-specific effects at $5 \%$ level of confidence.

Another problem is the endogeneity between institutions and overall inequality that is expected to be transferred to the estimation of the two inequality components. The lack of good instruments prevented us from correcting for this problem. Hence, our estimates reflect the complex associations that exist within the institutional framework, and between the institutional framework and the macroeconomic shocks, and not causal relationships.

\subsection{Results - descriptive}

\subsubsection{The dynamic autocovariance structure of hourly earnings ${ }^{70}$}

We begin with the description of the dynamic structure of individual log hourly earnings for all 14 countries under analysis. This description is used to confirm that the model used to fit the autocovariance structure of earnings for all cohorts is consistent with the trends observed in the dynamic autocovariance structure. For a

\footnotetext{
70 The information in this section summarizes the discussion in section 4.7.
} 
full description of the overall and cohort autocovariance structure of earnings please refer to Sologon and O'Donoghue (2009a, 2009b). The overall autocovariance structure of earnings is presented in Figure 5-A-1 (Annex). We summarize the main findings as follows.

In the beginning of the sample period, the overall inequality, measured by the variance of log hourly earnings, is the highest in Portugal, followed by Ireland, Spain, France, Luxembourg, UK, Greece, Germany, Austria, Italy, Belgium, Netherlands, Finland and Denmark. Overall inequality decreases over the sample period in Germany, Denmark, Belgium, France, UK, Ireland, Spain and Austria, and increases in Netherlands, Luxembourg, Greece, Portugal and Finland. Following these changes, in 2001, Portugal still records the highest inequality, followed by Luxembourg, France, Greece, Spain, UK, Italy, Germany, Ireland, Netherlands, Finland, Belgium, Austria and Denmark.

In summary, the description of the dynamic structure of individual earnings for men for each country suggests five main common features of the data, which are incorporated in our model, as mentioned previously:

- First, the covariance elements are not the same at all lags. They decrease with the lag at a decreasing rate and converge gradually at a positive level, suggesting the presence of a transitory element which is serially correlated and of a permanent individual component of earnings.

- Second, as the autocovariances and mean earnings vary over the sample period, they cannot be assumed to be stationary over sample period. The stationarity assumption was tested and rejected using the methodology introduced by MaCurdy (1982).

- Third, as the autocovariances vary with age controlling for the period effect, they cannot be assumed to be stationary over the life cycle.

- Lastly, the variance-covariance structure appears to be cohort specific. In most countries, the variance of earnings for all cohorts follows the evolution of the overall variance. Mixed trends across cohorts are observed in Germany where the variance increased for the cohorts born in 1941-1950 and 1961-1970 -, in Belgium - where the variance increased for the youngest cohort -, in France where the variance increased for the cohort born in 1961-1970 -, in UK - where the variance increased for the youngest two cohorts -, in Spain - where the variance increased for the youngest and the oldest cohorts, and in Finland where the variance decreased for the youngest cohort. 


\subsubsection{The evolution of the main labour market and institutional factors}

This section presents the evolution of the main labour market policy and institutional variables that will be used to explain the differences in labour market outcomes - permanent inequality, transitory inequality and earnings mobility across the 14 EU countries. A summary is provided in Table 5-A-3 (Annex) and Figure 5.2.

Over the period 1994-2001, the OECD index of employment protection legislation decreased in most countries under analysis, except for Austria, France, Ireland and Greece, where it was constant and UK, where it increased slightly. Employment protection legislation (EPL) exhibited a sharp turnaround around 1995 in Denmark, 1996 in Portugal, 1997 in Belgium, Germany and Spain, 1999 in Netherlands, 2000 in Finland, which marked the year when EPL started decreasing. For Italy the decrease continued through the rest of the period, whereas for the others the evolution was roughly stable. An increase in EPL was recorded in Spain in 2001 and in Ireland in 2000.

Employment protection legislation for regular contracts (EPLR) did not change much, except for Spain and Finland, where it decreased in 1997, respectively in 2001, and France and UK, where it increased in 2000, respectively in 1999.

The greatest changes were recorded for employment protection legislation for temporary contracts (EPLT). A decrease was recorded in Denmark, Portugal, Germany, Belgium, Italy and Netherland, and an increase in Spain. The rest remained constant. Denmark recorded a sharp drop in 1995, Belgium and Germany in 1997, Italy in 1997-1998, Portugal in 1996, Netherlands in 1998.

As a result, over the sample period, an increasing or stagnant positive relative difference between EPL for permanent contracts and for temporary contracts was recorded in Austria, Ireland, Netherlands, Portugal, UK and Finland. Denmark, Germany and Netherlands recorded a sharp increase in the relative difference between EPL for permanent contracts and for temporary contracts, which turned from a negative value in 1994 to a positive one in 2001. Belgium, France, Italy, Spain and Greece exhibited a negative relative difference between EPL for permanent contracts (EPLP) and for temporary contracts (EPLT), which, over the sample period, decreased or remained constant in absolute value, except for Spain. 

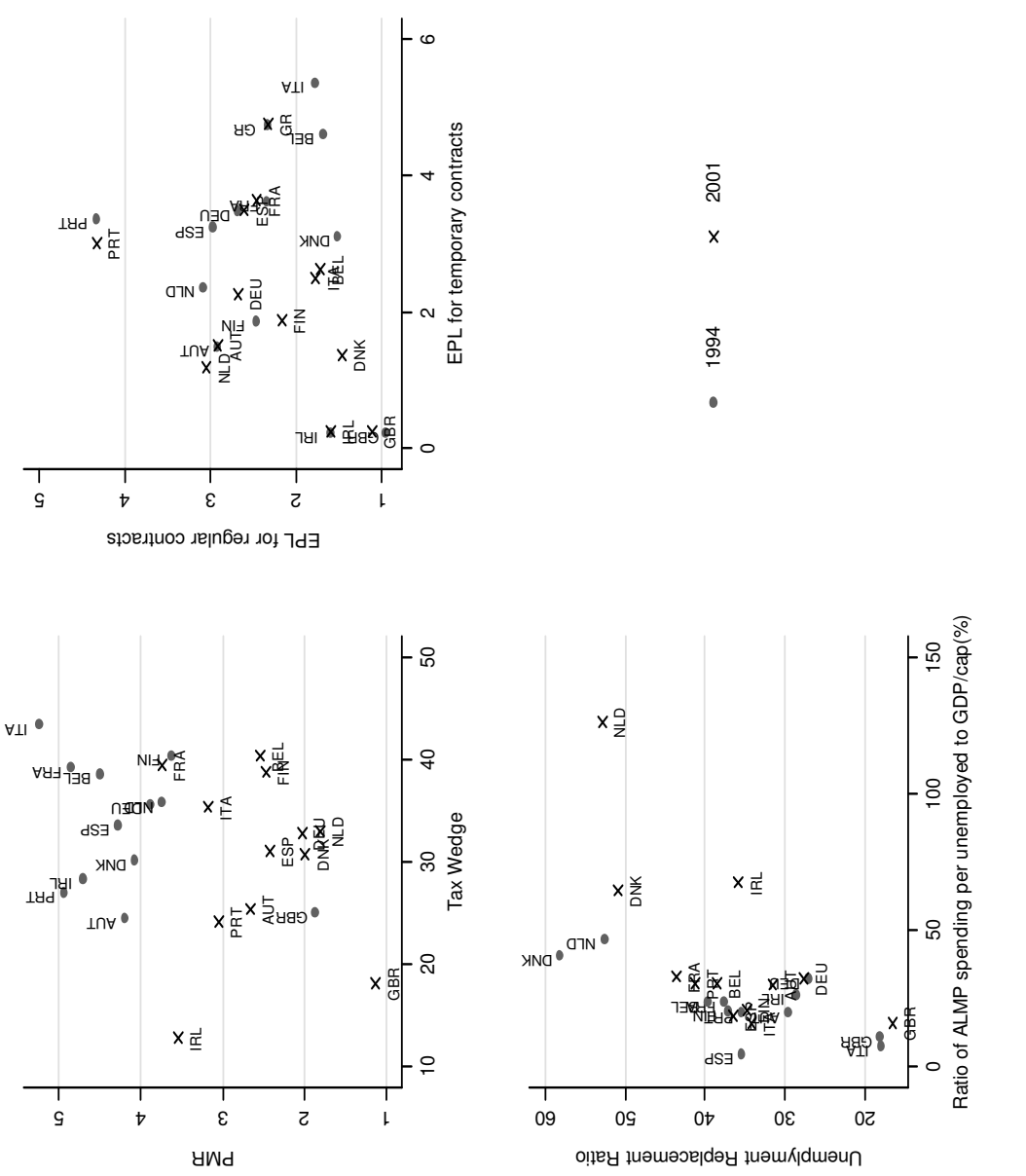

ñ
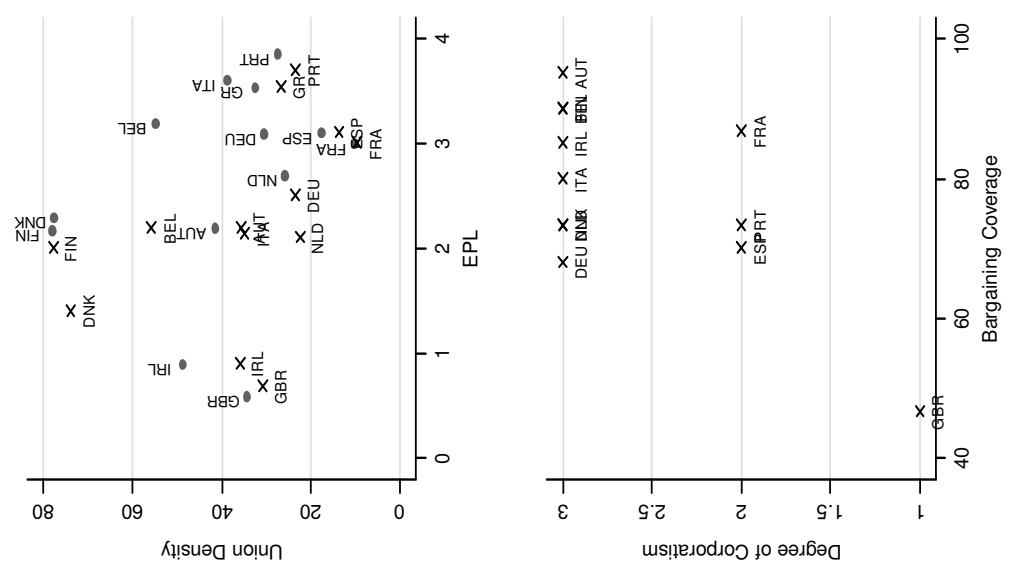

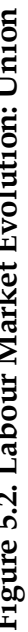


A decrease in union density is reported in all countries, except Belgium. The degree of corporatism was characterized by stable rates in all countries. The tax wedge exhibited a high turnaround in 1995 for all countries, except the continental ones. The largest decline was in the Anglo-Saxon countries, followed by Nordic and Mediterranean countries. Exceptions are Austria, Belgium, Denmark and France, where the tax wedge increased. The index of product market regulation (PMR) declined through the entire period, but the rate of decrease intensified after 1998 for most countries. Unemployment benefits replacement rates rose in all countries, except Denmark, Finland and UK. Sharp increases were recorded around 1998-1999 in Italy and Portugal, and around 2000-2001 in France and Ireland. Active labour market policies (ALMP) developed in all countries, except Germany, where they decreased. The largest increases were recorded in Netherlands, Denmark and Ireland.

The possible static effects of these policies are raising employment and reducing productivity, whereas the possible dynamic effects are raising investment following the raise in employment and raising incentives for adoption of new technologies, which implies a shift in the demand for skills. (Dew-Becker and Gordon 2008) Hence all these are expected to influence permanent earnings inequality and volatility and earnings mobility.

Nevertheless, institutional factors do not exist in a vacuum. They are expected to interact with external factors, such as macroeconomic shocks. The evolution of the macroeconomic shocks is illustrated in Figure 5-A- 2 (Annex). Changes in demand and supply factors, in technology, in terms of trade, in real interest do not differ significantly among countries; hence they cannot by themselves explain all the changes in the inequality components. These trends are not surprising, given that all these countries operate in the same world markets, with similar technology, industry and occupation mixes.

For example, all countries experience the same turning points in both demand and supply shocks. The supply shocks had three turning points: a decrease until 1996, followed by a decrease until 1998, an increase until 2000, and a drop thereafter. The supply shocks converged in a decreasing trend for all countries towards 1999, followed by an increase in 2000, and a slight decrease in 2001. The convergence in the trends was maintained until 2001. Overall, the highest demand and supply shocks are experienced by Ireland, followed by Belgium, Austria and Netherlands. One country stands out with respect to its evolution in total production factors shock: Ireland. It records a sharp increase until 1997, followed by stabilization 
towards 2001. Similarly, the real interest shock drops towards 1998 and stabilizes afterwards. These trends are most likely related to the Celtic Tiger.

The OECD data on education attainment by country reveals that the average level of education has an increasing trend and evolves parallel for all countries. Three clusters can be identified. A high average level is achieved in Germany, followed by Finland, Denmark, then very closely Ireland, UK and Belgium. A medium level is recorded in Greece, Austria, France, Spain and Italy. The lowest level is in Portugal.

To sum up, labour market policy and institutional factors are expected to interact significantly with each other and with the macroeconomic shocks in shaping the patterns of permanent inequality, transitory inequality and earnings mobility.

\subsection{Results of covariance structure estimation ${ }^{71}$}

\subsubsection{Estimation results}

The general specification of the error component model outlined in section 4.5.2, which encompasses all relevant aspects of earnings dynamics considered above, is fit to the elements of the covariance matrix of each country, for all cohorts pooled together ${ }^{72}$. We present only the models that fit the data the best for each country, as identified by Sologon and O'Donoghue (2009a, 2009b). The estimation results are illustrated in Table 5-A-5 (Annex). Similar to Dickens (2000b), all variances are restricted to be positive by estimating the variance equal to the exponent of the parameter. The reported estimates of the variance in Table 5-A-5 (Annex) represent the exponent of the parameter and the reported standard errors correspond to the parameter estimates. ${ }^{73}$

We summarize the interpretation from Sologon and O'Donoghue (2009a, 2009b). The formulation of the permanent and transitory components of earnings differs between countries.

\footnotetext{
71 This section summarizes the estimation results in Chapter 4.

72 i.e. 144 auto-covariances for countries observed over 8 waves, 122 for those with 7 waves and 84 for those with 6 waves.

73 The SE column reports the standard error for the parameter estimate. Where I report the $\exp ($ estimate $)$, the SE corresponds to the $\log (\exp (\operatorname{estimate}))=$ estimate
} 


\section{Permanent component}

In Germany, Netherlands, UK, Ireland, Italy, Greece, Spain and Finland, the permanent component follows a random growth model with time and cohort specific loading factors. The estimated coefficients for the permanent component of earnings show that time-invariant heterogeneity and age-earning profile heterogeneity play a significant role in the formation of long-term earnings differentials in all these countries. Individual specific heterogeneity plays the highest role in Germany, followed by Spain, Netherlands, Greece, UK, Ireland and Italy, which suggests that in Germany there is a higher dispersion in the timeinvariant individual specific attributes that determine wage differentials.

The estimated random slope variance implies that hourly earnings growth for an individual located one standard deviation above the mean in the distribution of $\phi$ is the largest in Germany, where it is with $4.89 \%^{74}$ faster than the cohort mean, followed by Greece, Ireland, Spain, Netherlands, UK and Finland with rates between $1 \%$ and $1.41 \%$ and Italy with $0.89 \%$. All these countries have a negative covariance between the time invariant individual specific effect and the individual specific slope of the age-earning profile, which implies that the initial and lifecycle heterogeneity are negatively associated. This negative association corresponds to the trade-off between earnings early in the career and subsequent earnings growth and is consistent with the on-the-job training hypothesis (Mincer, 1974). Therefore, this suggests the presence of mobility within the distribution of permanent earnings over the sample period. These findings reinforce the results from previous studies.

Therefore, for these countries the evolution of the permanent component without the time loading factors could be either increasing or decreasing. The time-specific loading factors for the permanent component are highly significant with values close to 1 in all countries. The trends of the returns to the permanent component vary to a large extent across countries. One common feature is that they reflect the trends in the high-order autocovariances in the data. These estimates show that overall, controlling for age and cohort effects, the returns to skills decreased over the sample period in Netherlands, UK, Ireland, Italy, Greece, Spain and increased in Germany and Finland. The trends over time differ between countries, some record a smooth evolution, others noisier. For example, Netherlands experienced decreases in returns almost every second year. In UK the returns increased in 1997

$744.89=100 \cdot \sqrt{\sigma_{\varphi}^{2}}$ 
and 2001, and decreased in the rest. Ireland recorded a decrease until 1996, a boost in 1997 and a clear decline thereafter. In Italy, 1998 and 1999 appear to be years with increases in the return to skills, in Greece every second year, in Spain 1995 and 1998. Germany experienced increasing returns to human capital until 2000, and Finland in 1997 and 2001. Therefore, in these years, the relative position of the highly skilled individuals was enhanced.

In Denmark the permanent component follows a random walk in age. The variance of the innovation in the random walk is significantly larger than zero. As the variance of a variable that follows a random walk is the sum of the variances of the innovation term, this finding implies that permanent inequality increases over lifetime. In Denmark, the variance at the age of 20 is lower than the variance at subsequent ages, suggesting the presence of larger permanent shocks at older ages, which is consistent with matching models, in which the information revealed about a worker's ability increases with time. The final trend in the permanent variance depends on the period specific loading factors, which reveal that overall, the relative position of the highly skilled individuals decreased over the sample period in Denmark. The yearly evolution revealed a smooth decrease until 2000, followed by a small increase in 2001.

In Belgium, France, Luxembourg, Portugal and Austria the persistent dispersion of earnings follows the canonical model, where the permanent component is timeinvariant. The highest variance in the time invariant characteristics is recorded in Portugal, followed by France, Luxembourg, Austria and Belgium. In this case, the time-specific loading factors determine the final trend of the permanent differentials: they decreased in Belgium and Austria, and increased in France, Luxembourg and Portugal. Year by year, France records an increase in the returns to skills until 1997 and again in 2001, Luxembourg until 2000, Belgium in 1996 and 2000, Austria during most of the period, except 1998-1999, and Portugal in 1996, 1998 and 2000.

The estimates of the cohort-specific shifters for the permanent earnings are highly significant in all countries. The trends, however, differ between countries. A monotonic increase over the lifecycle is observed in Germany, France, Luxembourg, Portugal and Austria. In Denmark, Netherlands, Belgium and Spain the permanent component of earnings has an inverted-U shape evolution over the lifecycle. These trends confirm the expectation that permanent earnings differentials play a much larger role in the formation of overall earnings differentials of older cohorts compared with younger ones, which experience higher earnings volatility due to temporary contracts. We expect the opposite to hold in the case of cohort-specific shifters for transitory earnings. 
The permanent component of earnings decreases over the life cycle in UK, Ireland, Italy, Greece and Finland. This may be due to younger cohorts having more heterogeneous skills or experiencing larger permanent shocks even without a larger dispersion of skills. This could be the case if the labour market has become tougher over time, as in the case of Italy, which is characterised by high rates of youth unemployment.

\section{Transitory component}

The formulation of the temporary component of earnings differs between countries. It follows an AR(1) process with time and cohorts loading factors in all countries, except Italy, Greece and Spain, where it follows an ARMA(1,1). Except for Spain, Portugal and Austria, the other countries are characterized by heteroskedastic initial conditions. The estimated coefficients for the transitory component of earnings are all significant, suggesting that the initial variance(s), the $\operatorname{AR}(1)$ process, the ARMA $(1,1)$ process, and the time and cohort loading factors contribute significantly to earnings volatility in all countries.

The variance of initial conditions, which represents the accumulation of shocks up to the starting year of the panel, is smaller than the variance of subsequent shocks in all countries, except Luxembourg, Ireland, the oldest three cohorts in UK, and the middle two cohorts in Finland. Overall, the variance of initial conditions increases over the lifecycle in Denmark, Belgium, France, Luxembourg, UK, Italy, Greece and Finland, suggesting that the initial variance plays a larger role in the formation of earnings differentials for the oldest cohort compared with the youngest. The opposite is observed in Germany, Netherlands and Ireland.

The pattern of the heteroskedstic initial conditions, however, is not monotonic across cohorts. In Luxembourg, UK, Italy, and Finland it follows an inverted-U shape: the variance of initial conditions increases over the lifecycle and decreases at the end. The opposite holds for France, where the oldest and the youngest cohorts have the highest initial variances.

In Germany and Netherlands the pattern of the heteroskedstic initial conditions records a sharp drop for the second youngest cohort, an increase for the second oldest and a small drop for the oldest cohort. In Denmark, Belgium, Ireland and Greece, the variance of initial conditions records an increase for the second youngest cohort, a drop for the second oldest and an increase for the oldest cohort.

The magnitude of the autoregressive parameter varies between countries. A large autoregressive parameter, which suggests that shocks are persistent, is recorded in 
Spain with $26.9 \%$ of a shock still present after 8 years, in Portugal with $8.5 \%$ and in Austria with $5.7 \%$. A moderate autoregressive parameter suggesting that shocks die out rather quickly is recorded in Italy with $2.8 \%$ of a shock still present after 8 years, in Belgium with $2.4 \%$, and in Greece with $1.4 \%$. A small autoregressive parameter is present in Luxembourg, Ireland, Finland, Netherlands, Germany, France, UK and Denmark, where between $0.0008 \%$ and $0.8 \%$ of a shock is still present after 8 years. The negative sign of the MA component implies that the autocovariances decline sharply over the first period, confirming the trends observed in the previous section for Italy, Greece and Spain. ${ }^{75}$

The time-specific loading factors for the transitory component are highly significant and display a higher variation than for the permanent component in all countries. The trends of the transitory inequality vary to a large extent across countries. These estimates show that overall the transitory variance decreased over the sample period in all countries, except Luxembourg and Ireland.

The estimates of the cohort-specific shifters for the transitory earnings are highly significant in all countries. They indicate that earnings volatility is higher for younger cohorts, thus confirming the pattern observed in the dynamic description of the autocovariance structure of earnings, where autocovariances were found to be lower for younger cohorts. This is expected, given that younger people experience in general more frequent job changes, and consequently less stable earnings.

\subsubsection{Inequality decomposition into permanent and transitory inequality}

Having estimated a suitable error component model for earnings in each country, next we use these parameters estimates to decompose the variance-covariance structure of earnings into its permanent and transitory components, assess their relative importance, and estimate earnings immobility over the sample period, by cohort.

Following Sologon and O'Donoghue (2009a, 2009b), Figure 5.3 illustrates the absolute decomposition of the variance, together with the actual and predicted variance of earnings by cohort. The decomposition by cohort identifies how inequality and its components are affected by labour market changes at different lifecycle stages. For all countries, the evolution of the predicted variance follows

\footnotetext{
${ }^{75}$ For the other countries, the MA component was either rejected by the data or could not be identified due to the low number of waves.
} 
closely the evolution of the actual variance, confirming the fit of the country models, indicated by the low sum of square residuals. Figure 5.4 illustrates the evolution of the structure of inequality, expressed by the relative decomposition of the overall predicted variance of earnings into its permanent and transitory components. Figure 5.5 translates these trends into earnings immobility, measured by the ratio between permanent and transitory differentials. An increase in the immobility ratio indicates a decrease in mobility, equivalent to an increase in the share of the permanent differentials in the overall inequality. This mobility index captures non-directional earnings movements and can be interpreted as the opportunity to improve one's position in the distribution of lifetime earnings.

The trends by cohort illustrated in Figure 5.3, Figure 5.4 and Figure 5.5 for the actual earnings inequality, permanent inequality, transitory inequality, the share of the permanent inequality in the overall inequality, and the immobility ratio are described in Table 5.2. The trends in average actual inequality, average components and average immobility ratio ${ }^{76}$ across cohorts are described in Table 5.3. We underline only the key points. For a complete description, please refer to Table 5.2, Table 5.3 and Sologon and O'Donoghue (2009a, 2009b).

For all countries, both in relative and absolute terms (Figure 5.3 and Figure 5.4), individual earnings inequality contains a highly permanent component for the oldest three cohorts and a highly transitory component for the youngest cohort. This is consistent with the evidence of lifecycle earnings divergence showing that earnings volatility is higher at younger ages. The degree of immobility (Figure 5.5) is higher for older cohorts compared with younger cohorts, which suggests that the older the cohort, the lower the opportunity to improve one's position in the distribution of lifetime earnings.

The overall trends are established by looking at averages across cohorts (Table 5.3). Overall, the decrease in inequality resulted from a decrease in transitory differentials in Germany, France, UK and Ireland, in permanent differentials in Belgium and Spain, and in both components in Denmark and Austria. The increase in inequality reflects an increase in permanent differentials in Luxembourg, Italy, Greece and Finland, and an increase in both components in Portugal and Netherlands.

The decrease in inequality was accompanied by an increase in mobility only in Denmark, Belgium and Spain. Except for Netherlands and Portugal, all countries recording an increase in inequality experienced also a decrease in mobility.

${ }^{76}$ Average Immobility Ratio $=$ Average Permanent Variance/Average Transitory Variance 

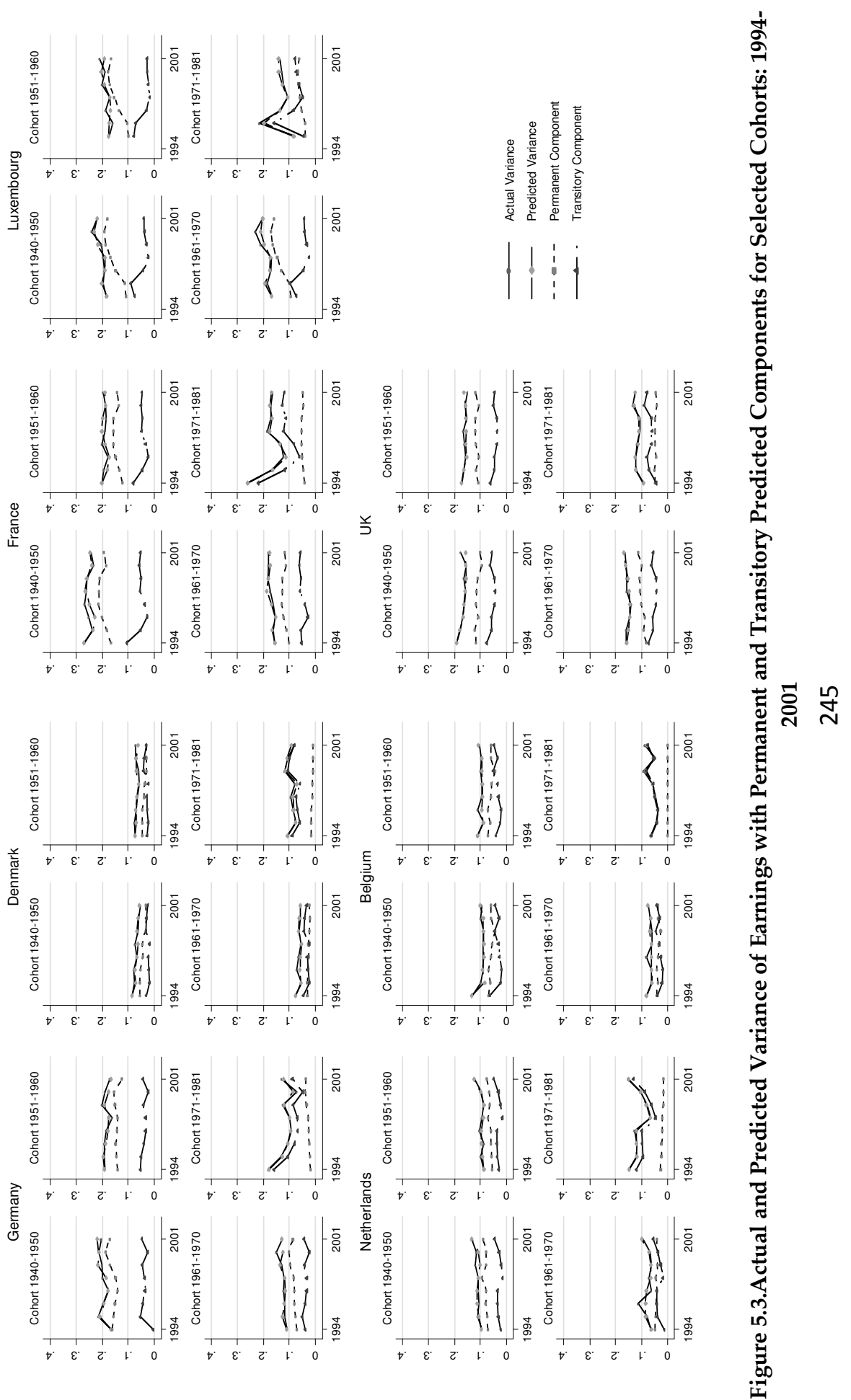

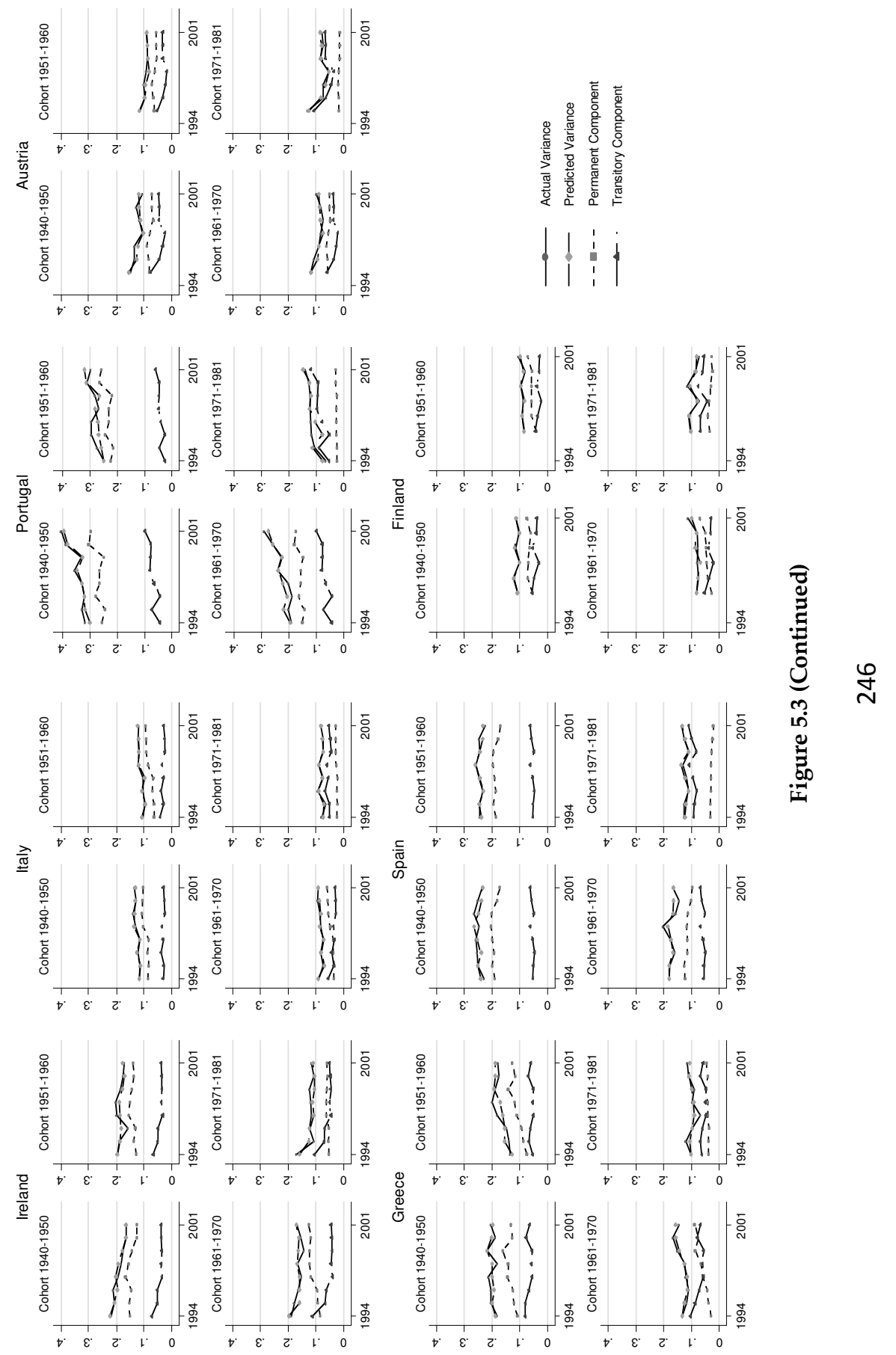

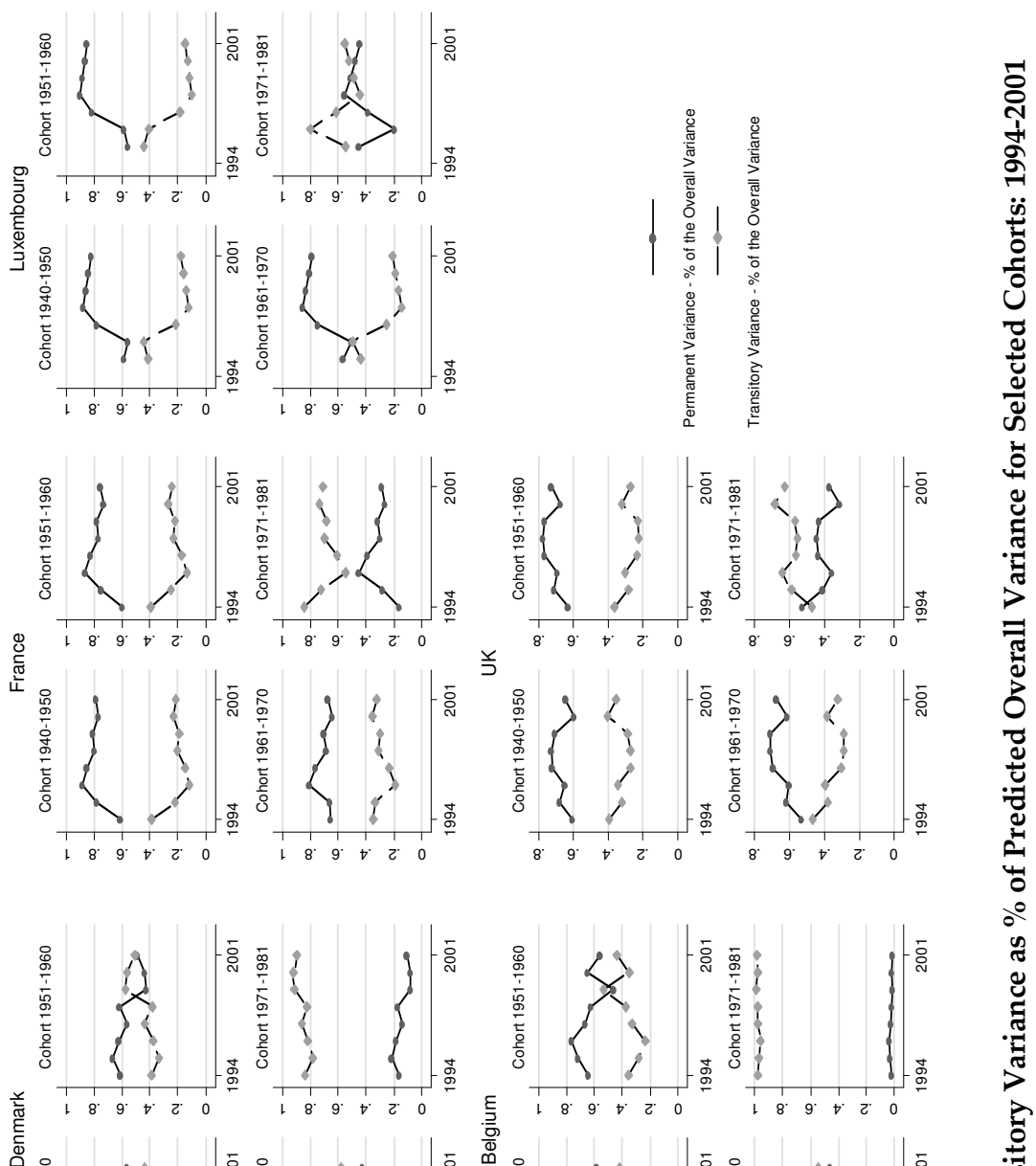

ป
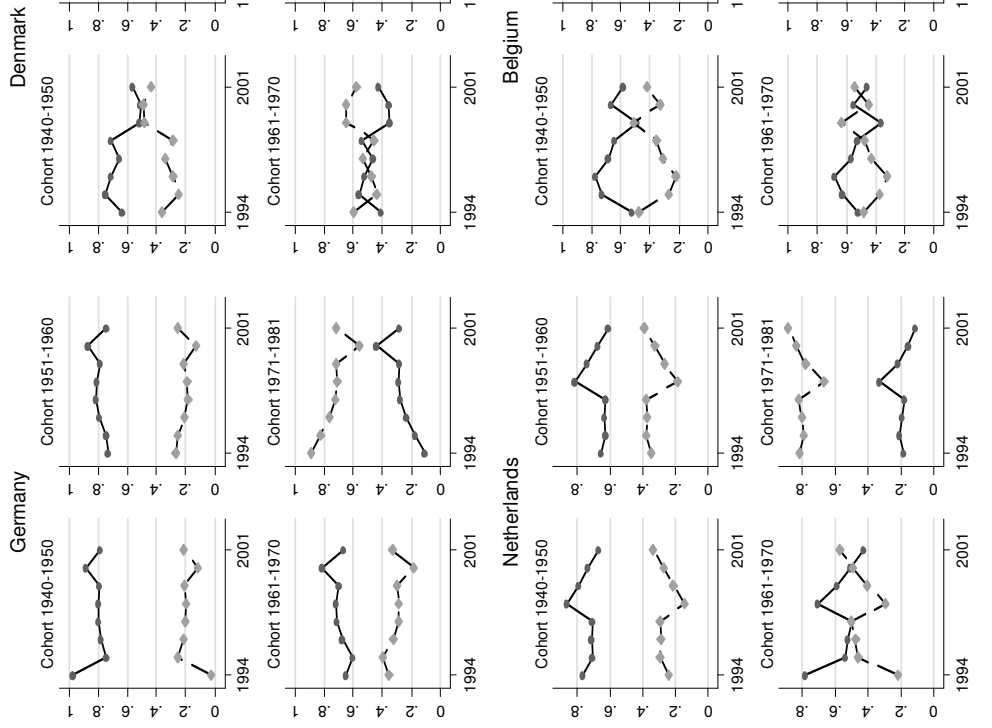

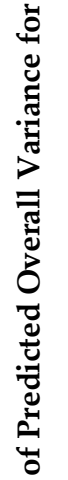

ป

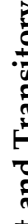



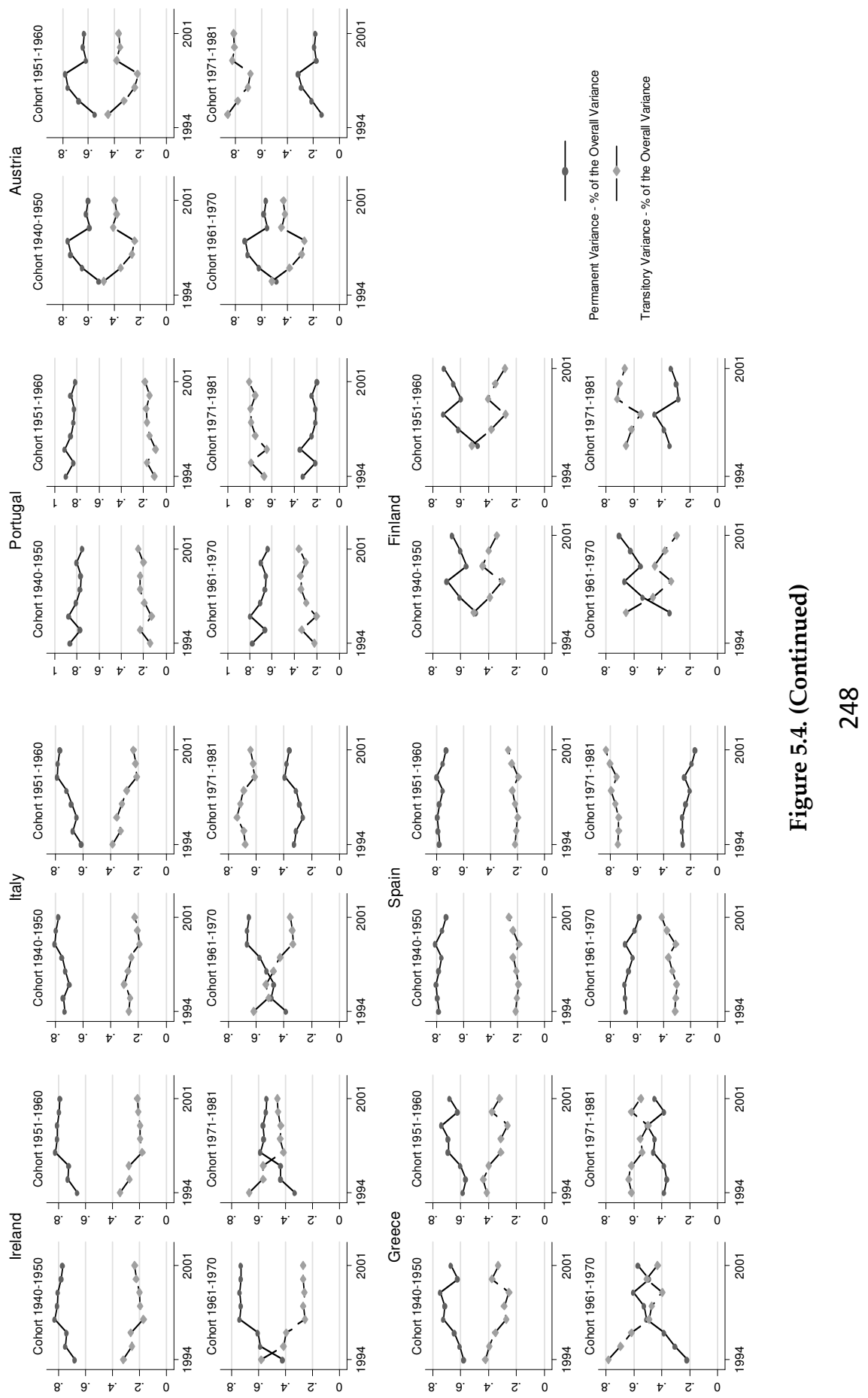


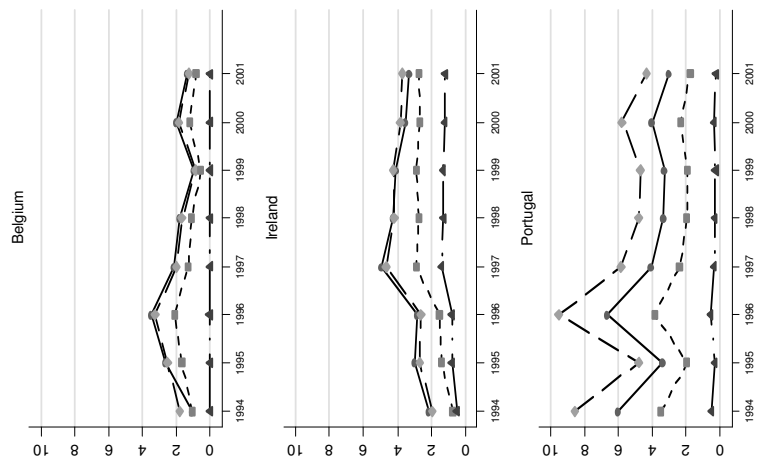

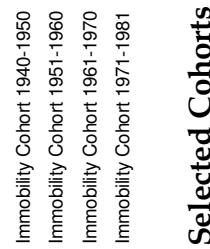
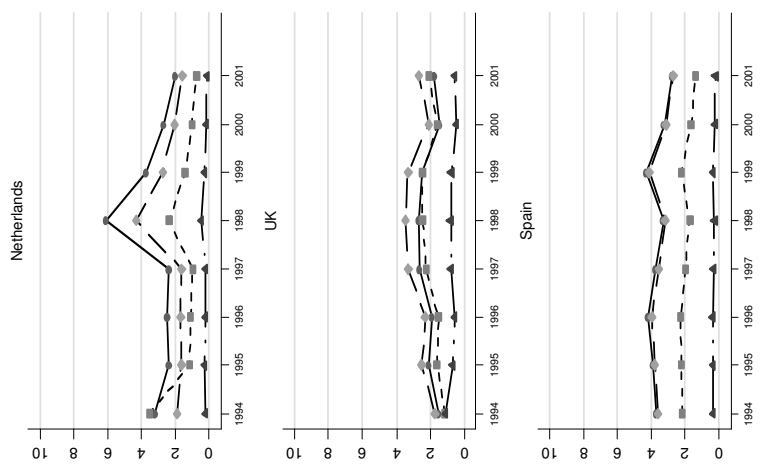

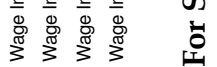
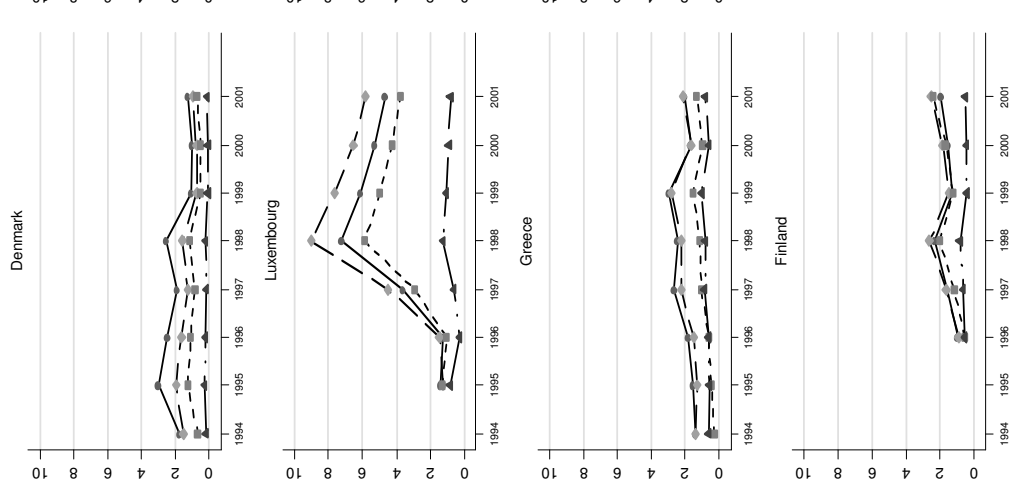

ণ
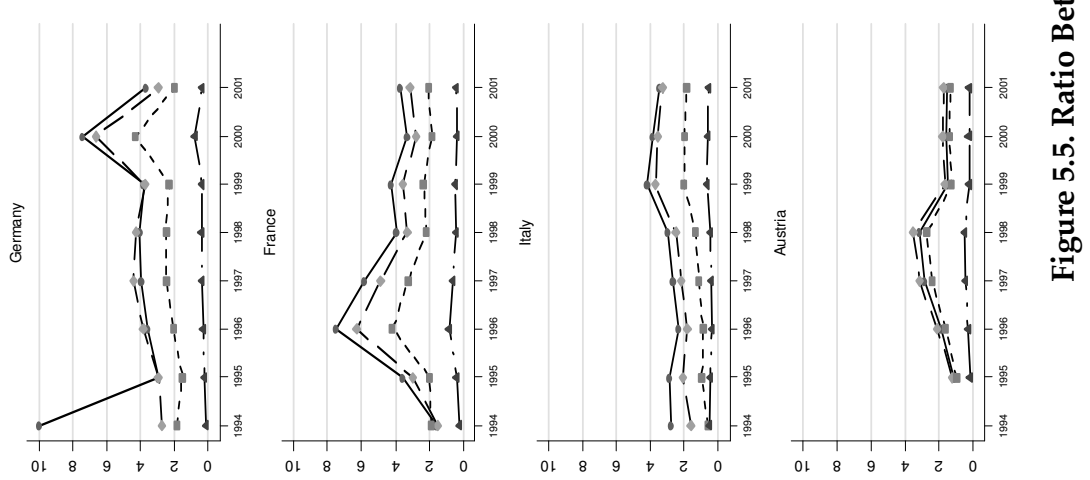


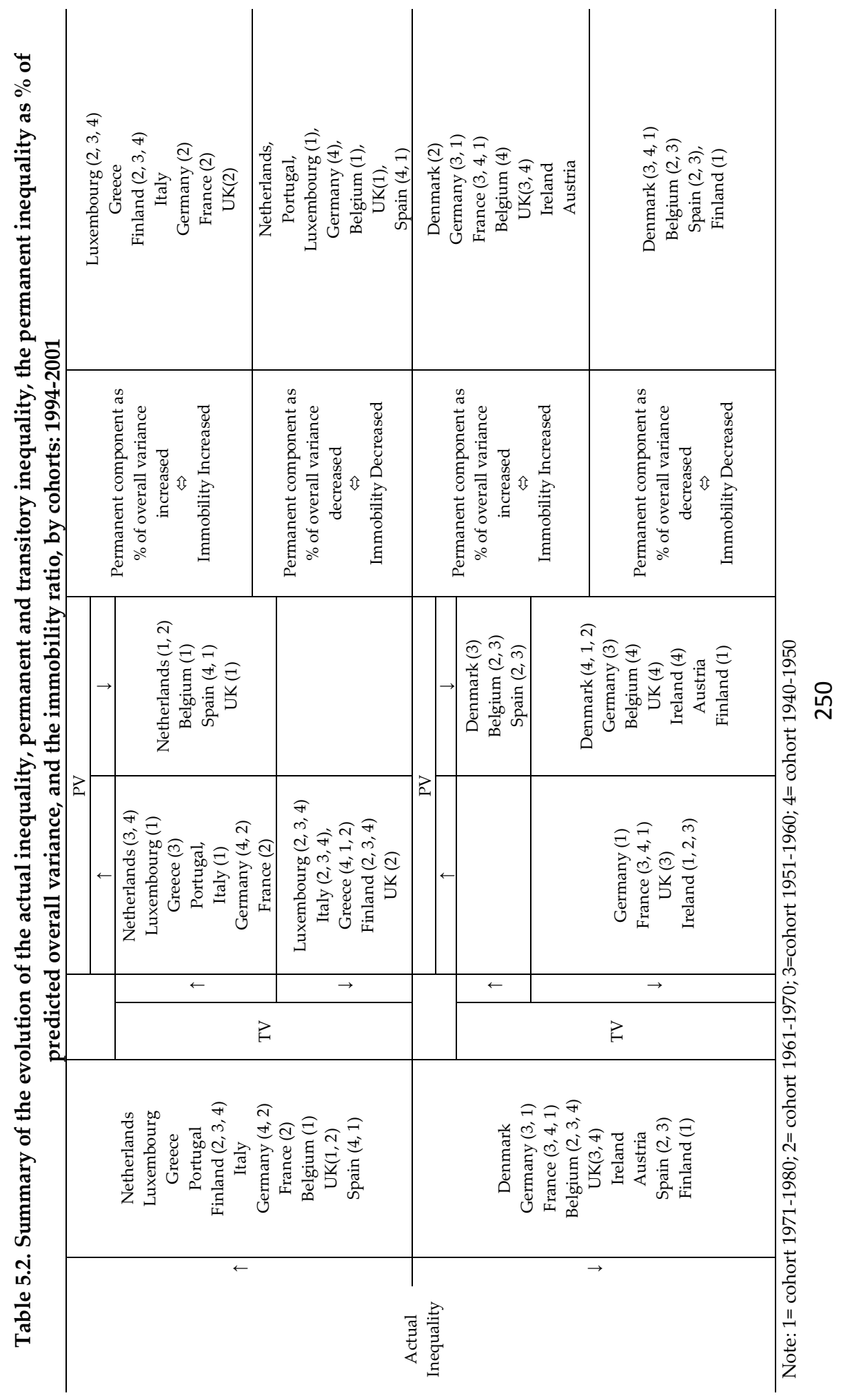




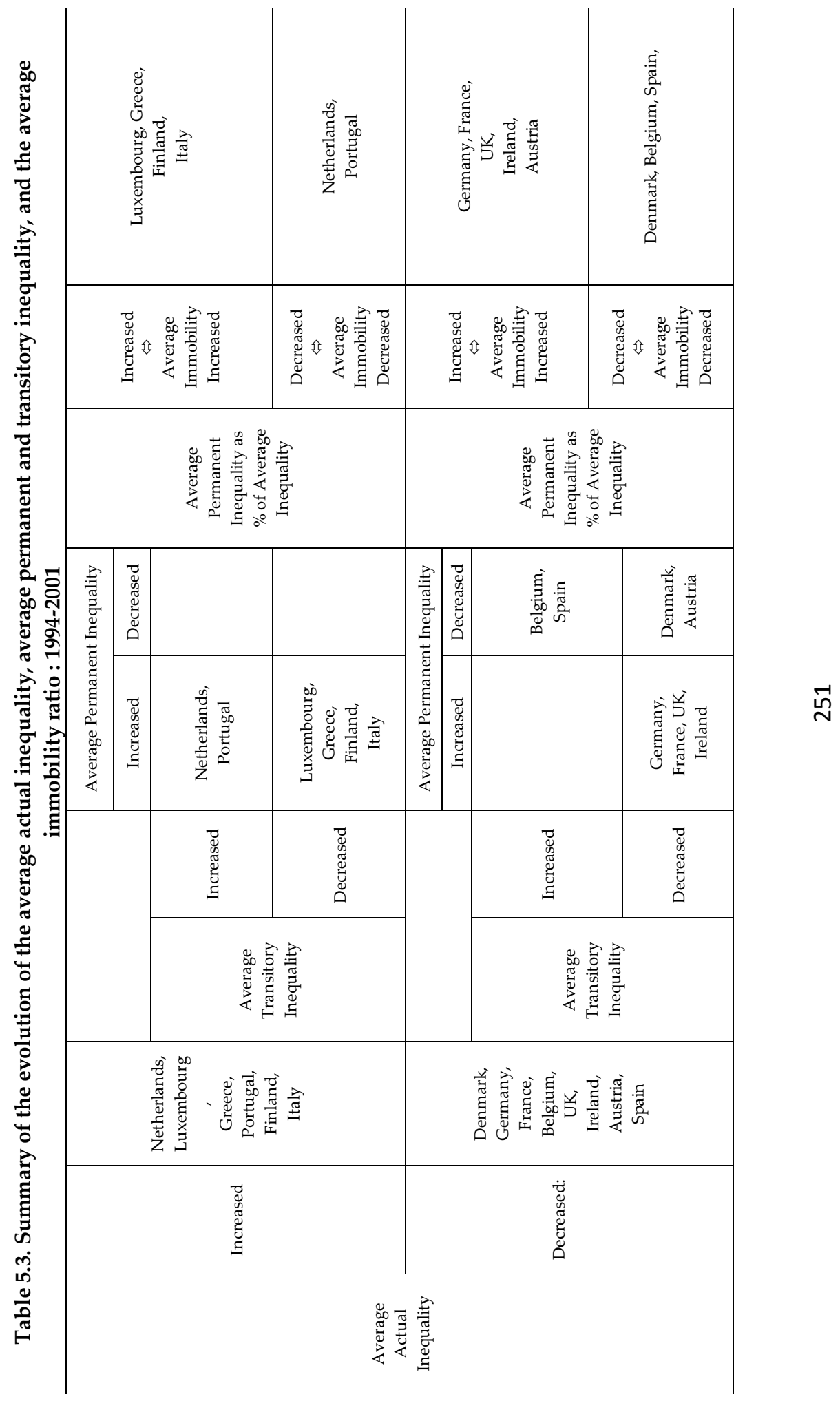


More important are the welfare implications of these trends. In Denmark, Belgium and Spain, in 2001, low wage individuals are better off both in terms of their relative wage and in terms of the opportunities to escape the low-wage trap in a lifetime perspective. Thus in a lifetime perspective, Denmark, Belgium and Spain are expected to reduce lifetime earnings differentials compared with annual differentials. In Austria, Germany, France, UK and Ireland, in 2001, low-wage individuals are worse off in terms of the opportunity to escape the low-wage trap, but their relative position in the earnings distribution is improved compared with the 1st wave. For these countries mobility is expected to play a decreasing role in reducing lifetime inequality, therefore annual differentials have a high chance of being preserved in a lifetime perspective.

In Luxembourg, Italy, Greece, and Finland, besides the widening wages differentials, low wage individuals find it harder to better their position in the wage distribution in 2001 compared with the first wave. Thus we can expect these countries to increase lifetime earnings differentials compared with annual differentials. Netherlands and Portugal record widening wages differentials accompanied by increased opportunity of low wage individuals to improve their position in the distribution of lifetime earnings. Thus, for Netherlands and Portugal, earnings mobility could either decrease or exacerbate lifetime earnings differentials compared with annual ones.

The evolution of the actual inequality, permanent inequality transitory inequality, and the immobility ratio differ from the general trend across cohorts in a few countries, suggesting that the reforms influenced differently older from younger workers. (see Table 5.2, Figure 5.3, Figure 5.4, Figure 5.5)

These trends in the structure of inequality and immobility, however, were not monotonic, as can be observed in Figure 5.4 and Figure 5.5. For Denmark and Spain, a turnaround is observed around 1998-1999, when the share of the permanent component and earnings immobility started decreasing, following the increase over the period 1994-1998. For Denmark, 1998 was a year which marked the end of a period of continuous economic growth which began in 1993. (EIROnline) In Spain, 1999 marked the year of the approval of the National Action Plan and of the reform of the Spanish legislation on temporary employment agencies, which improved the pay for temporary workers. (EIROnline) In Belgium, the adoption of the NAP took place around 1999-2000. (EIROnline).

In France, a significant change occurred after 1996, when the share of the permanent component and earnings immobility started to decrease. This might be explained by the rapid increase in employment which occurred in France between 
1997 and 2002 as a result of the policies aimed to lower the cost of unskilled jobs and stimulate job creation.

In Ireland, the significant turnaround in 1997 might be due to the slowing down of the Celtic Tiger: the remarkable economic growth which started in 1994 was accompanied by a rise in the share of permanent inequality and earnings immobility, which contracted slightly after 1997 . Hence, the economic growth was a shock that accentuated the share of permanent differentials in the overall inequality and increased earnings immobility between 1994 and 1997. After 1997, the trends reversed.

A dramatic change occurred in Austria after 1998. Until 1998, wage immobility and the share of permanent inequality increased sharply. In 1999, Austria experienced a considerable rise in employment and a further decline in unemployment, which was the effect of the labour market initiatives pursued by the Austrian Government. This explains the increase in inequality after 1999: higher employment is usually accompanied by higher inequality. These measures appear to have decreased earnings immobility and the share of permanent inequality in 1999, which stabilized thereafter.

In Netherlands, a significant change occurred after 1998, when immobility and the share of permanent inequality started decreasing, offsetting the increasing trend which dominated the period before 1998. Among the important issues addressed by the labour market legislation in 1998 were part-time employment, labour market flexibility and active labour market policies. In 2001, the share of the permanent components was the lowest among all countries which recorded an increase in overall inequality.

For Luxembourg, Italy, Portugal, Greece and Finland, a turning point occurred around 1998-1999. This period coincides with the approval of the National Action plan for employment aimed, among others, to lower labour cost, promote active labour market policies, training and increase labour market flexibility. This appears to have affected the structure of wage differentials to a large extent. Immediately after 1998-1999, the share of permanent inequality and wage immobility started to decrease. 

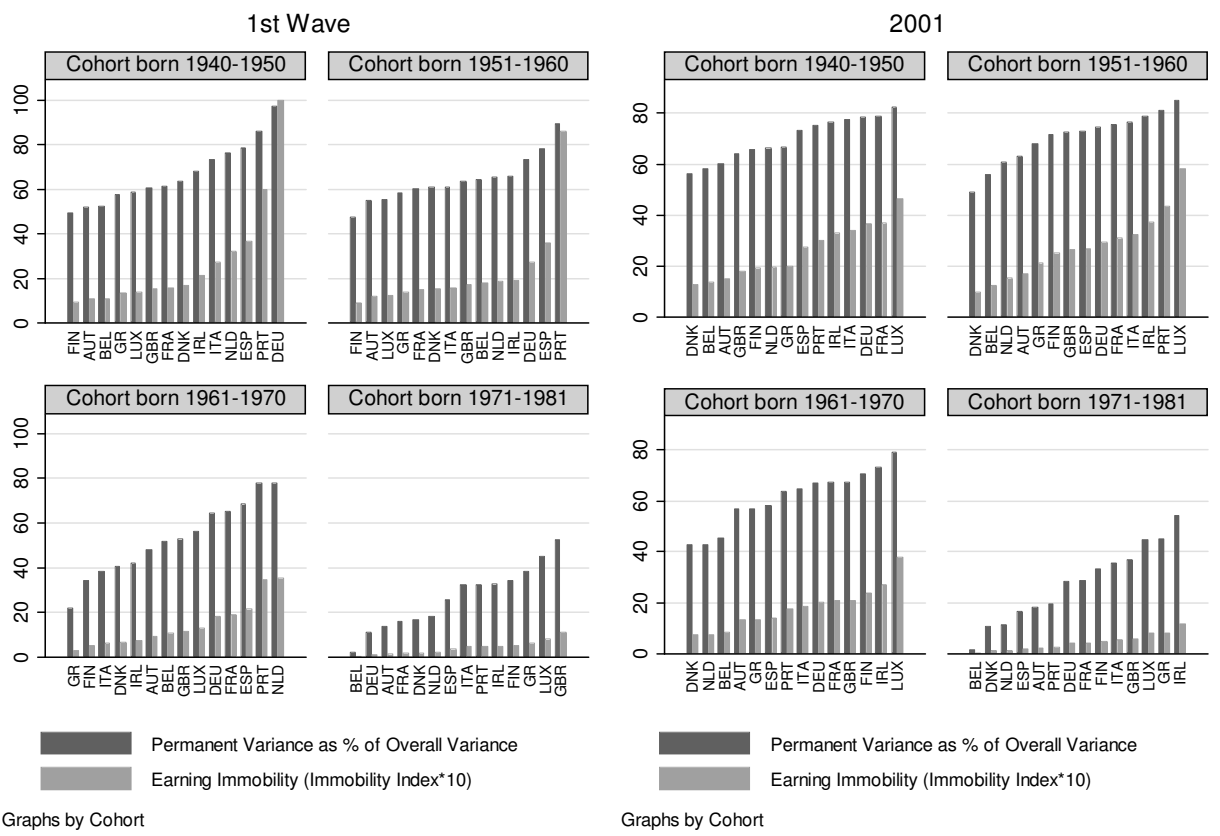

Figure 5.6. Permanent Inequality - \% of the Overall Inequality and Earnings Immobility for Selected Cohorts over Time

Following Sologon and O'Donoghue (2009a, 2009b), Figure 5.6 summarizes the country ranking with respect to earnings persistency and earnings immobility over the sample period, by cohort. The higher the share of permanent inequality, the higher the immobility. In the first wave, for the oldest cohort, the highest share of the permanent component (the lowest mobility) is in Germany $(97 \%)$, followed by Portugal, Spain, Netherlands, Italy, Ireland, Denmark, France and UK with shares between $85 \%$ and $60 \%$, and the rest with shares between $60 \%$ and $49 \%$. For the cohort 1951-1960, the highest permanent share (the lowest mobility) is in Portugal $(89 \%)$, followed by Spain, Germany, Ireland, Netherlands, Belgium, UK, Italy, Denmark and France with shares between $78 \%$ and $60 \%$, and the rest with shares between 58\% (Greece) and 47\% (Finland).

For the 1961-1970 cohort, the highest permanent shares (the lowest mobility) are in Netherlands and Portugal (77\%), followed by Spain, France and Germany - with shares between $68 \%$ and $64 \%$-, Luxembourg, UK, Belgium, Austria and Ireland with shares between $56 \%$ and $42 \%$-, and the rest with shares between $40 \%$ (Denmark) and 21\% (Greece). For the cohort 1971-1981, the highest permanent 
share is recorded in UK (52\%), followed by Luxembourg (45\%), Greece, Finland, Ireland, Portugal, Italy and Spain - with shares between $38 \%$ and $25 \%$-, and the rest with shares between 18\% (Netherlands) and 2\% (Belgium).

Following these changes, the structure of inequality and earnings immobility in 2001, for the oldest cohort, the highest share of permanent inequality implying the highest earning persistency (lowest mobility) is found in Luxembourg, France, Germany, Italy, Ireland, Portugal and Spain, with rates between $82 \%$ and $73 \%$. Greece, Netherlands, Finland, UK and Austria are less persistent with values between $70 \%$ and $60 \%$. The least persistent - most mobile - are Denmark and Belgium, where permanent variance accounts for $56-58 \%$ of the overall variance.

For the 1951-1960 cohort, the highest persistency - lowest mobility - is recorded by the same countries, including UK and Finland, with shares between $85 \%$ and $71 \%$, followed by Greece, Austria and Netherlands with shares between $68 \%$ and $61 \%$, and lastly Belgium (56\%) and Denmark (49\%). For the 1961-1970 cohort in Luxembourg, Ireland and Finland permanent variance accounts for $79 \%$ to $70 \%$ of the overall variance, followed by UK, France, Germany, Italy and Portugal with shares between $66 \%$ and $63 \%$, by Spain, Greece and Austria with shares between $58 \%$ and $56 \%$, and by Belgium, Netherlands and Denmark with shares between $45 \%$ and $42 \%$.

For the youngest cohort, the variance is dominantly transitory in all countries, except Ireland where the transitory variance accounts for $46 \%$ of the overall variance, suggesting that Irish youngsters have the lowest degree of earnings mobility in Europe. The most volatile earnings are found in Belgium, where 98.5\% of the variance is transitory. Next follow Denmark and Netherlands where transitory variance accounts for $89 \%$ of the overall variance; Spain, Austria and Portugal, with transitory shares between $84 \%$ and $81 \%$; Germany, France, Finland, Italy and UK with transitory shares between $72 \%$ and $63 \%$; Greece and Luxembourg where transitory inequality accounts for $56 \%$ of the variance.

Based on Sologon and O'Donoghue (2009a, 2009b), we summarize the changes in country ranking in permanent inequality, transitory inequality, and earnings immobility over the sample period by reporting the averages across cohorts. In 1994, the highest average permanent inequality ${ }^{77}$ was recorded in Portugal and Spain, followed by France, Ireland, Germany, UK, Greece, Italy, Netherlands, Belgium and Denmark. The highest transitory variance was recorded in France, Ireland, Greece, UK, Germany, Spain, Belgium, Denmark, Netherlands, Italy and

77 Average permanent variance and transitory variance represent average across cohorts. 
Portugal. Portugal has the lowest mobility, followed by Spain, Germany, UK, Italy, Ireland, Netherlands, France, Belgium, Greece and Denmark. In 1995, Austria and Luxembourg had a middle ranking in permanent inequality and a top ranking ${ }^{78}$ in transitory inequality and mobility. In 1996, Finland had the second lowest permanent inequality, a middle ranking in transitory inequality, and the highest mobility.

In 2001 the rankings looks slightly different. Portugal records the highest average permanent differentials, followed by Luxembourg, France, Spain, Ireland, Germany, Greece, UK, Italy, Finland, Netherlands, Austria, Belgium and Denmark. In terms of transitory inequality, Portugal appears to be the most dispersed, followed by Spain, Netherlands, France, Greece, UK, Germany, Belgium, Luxembourg, Austria, Ireland, Denmark, Finland and Italy. Denmark has the highest average earnings mobility, followed by Belgium, Netherlands, Austria, Spain, Greece, Finland, UK, France, Germany, Italy, Portugal, Ireland and Luxembourg.

\subsection{Linking policy with outcomes}

What are the factors explaining country heterogeneity in the level and the evolution of permanent differentials, transitory differentials and earnings mobility? We try to explain the cross-country differences in these labour market outcomes by relating to the differences in the wage setting mechanism and the other labour marker institutions and policies - such as active labour market policies and income maintenance institutions (e.g. unemployment benefits) -, and the institutional and policy changes - such as employment protection legislation, product market regulation, tax wedge, unionization.

First we describe with the naked eye the possible associations that can be formed between the trends in the labour market outcomes identified in the previous section and the changes in the labour market policy and institutional factors identified in Section 5.5.2 and summarized in Figure 5.2. Second, by cohorts, we estimate uncontrolled pairwise correlations to put some numbers on the observed trends and see whether the relationships differ by cohorts- Finally, using nonlinear least squares, we estimate the complex relationship between the institutional factors and permanent inequality, transitory inequality and earnings immobility.

${ }^{78}$ Among the highest four. 


\subsubsection{Explaining the changes and differences}

We start with the rankings in average permanent and transitory differentials and average mobility observed in 1994 and 2001 (see Section 5.6.2). At a first glance, the diverging characteristics of the labour markets (see Figure 5.2) recording the highest and the lowest average permanent differentials - Portugal and Denmark -, suggest that permanent variance appears to be positively associated with employment protection legislation (EPL), employment protection legislation for regular contracts (EPLR), employment protection legislation for temporary contracts (EPLT), the relative difference between the EPLR and EPLT, and product market regulation (PMR), and negatively associated with union density, the degree of corporatism, the tax wedge, the generosity of the unemployment benefit and the level of spending for active labour market policies (ALMPs).

Similarly, temporary variance appears to be positively associated with EPLT, the unemployment benefit generosity, and negatively with union density, PMR and the degree of corporatism.

Looking at the labour markets with the highest and lowest average immobility in 1994 and 2001 (Section 5.6.2), a positive association was found with the union density, the tax wedge and the unemployment benefit replacement rate, and a negative association with EPLR, the relative difference between EPLR and EPLT, and PMR. For the other factors the trend is less clear-cut.

Next, we try to link the evolution of the three labour market outcomes with the evolution of the institutional factors summarized in Figure 5.2.

The common factors that might explain the common trends in permanent differentials and mobility in Denmark, Belgium and Spain are the decrease in EPL, the increase in ALMP and the decrease in PMR. ALMP can reduce permanent and transitory differentials by improving the efficiency of the job matching process and by enhancing the skills of the unemployed. Moreover its effects are expected to be enhanced when they are coupled with a low or decreasing EPL. Denmark represents a proof of the efficiency of this mix in reducing both components.

The ALMP-EPL mix might also be one of the factors explaining the divergence in the transitory variance trends between these countries: Denmark exhibits a high ALMP coupled with a low EPL, whereas the other two exhibit a relatively low ALMP coupled with a medium high EPL. This suggests that the impact of ALMP on transitory inequality might decrease with the EPL. A second factor could be the interaction between the decrease in PMR and the other factors. Lower PMRs are expected to determine an increase in both components. However, these effects 
appear to be completely offset in Denmark, whereas in Belgium and Spain they are offset only for permanent differentials.

Third, the decrease in transitory variance in Denmark might signal the presence of strong wage bargaining structures, finding supported by the high union density, corporatism and bargaining coverage indicators. This is consistent with the OECD (2004) results, which placed Denmark as having one of the highest collective bargaining and trade union density among all $14 \mathrm{EU}$ countries under analysis. In Belgium and Spain, another potential factor explaining the increase in transitory inequality might be immigration, which increased considerably with the expansion of the European Union.

To sum up, the outstanding performance of the labour market in Denmark which assured a decreasing cross-sectional inequality by reducing both components, might be due to the so called "flexicurity approach" $(\operatorname{OECD}(2004))$, which represents an interesting combination of high labour market dynamism and relatively high social protection. It is a mix of flexibility (a high degree of job mobility thanks to low EPL), social security (a generous system of unemployment benefits) and active labour market programmes, which allows individuals to improve their position in the permanent income distribution by reducing permanent income differentials, maintain at the same time a low degree of earnings volatility.

The common factors that might explain the decrease in transitory differentials and the decrease in mobility in Germany, France, UK, Ireland and Austria are the decrease in union density and PMR, the increase in ALMP and the low EPL which was roughly constant, except for Germany where the latter two factors decreased. The decrease in union density and PMR are potential factors explaining the increase in permanent differentials in Germany, France, UK and Ireland, which appear to have offset the effect of the increase in ALMP present in the latter three countries. UK, Ireland and Austria exhibit another factor with a potential increasing effect on permanent differentials: the decrease in the tax wedge.

The decrease in transitory variance, which is common to all these countries, reinforces the finding that developed increasing ALMP coupled with a relatively low EPL can be expected to dampen earnings volatility. Hence, for transitory differentials, the impact of the ALMP-EPL mix appears to have offset the potential effects of the decrease in union density and PMR. Moreover, the dampening effect of the ALMP-EPL mix on the transitory inequality appears to be accentuated when it is coupled with an increase in the unemployment benefit generosity. It is the case in France, Ireland and Austria. 
In France, other factors which might contribute to the absolute increase in the permanent component are the increase in EPLR, because of the potential reducing effect on the incidence of permanent contracts. The decrease in transitory inequality might also signal a labour market mechanism put in place to reduce transitory inequality. This is consistent with OECD (2004): France ranks the lowest on union density, but managed to increase coverage levels after the introduction of the legislation promoting collective bargaining and is now among the countries with the highest coverage rates of $90 \%$ and above, together with Austria, Belgium and Finland. Moreover, based on OECD (2004), France was found to have a low level of labour market dynamics, which might explain the reduction in transitory inequality and mobility.

In UK, the positive increasing relative difference between EPLR and EPLT, coupled with the low degree of corporatism could have accentuated the disincentive for employers to train temporary workers, and thus could have contributed to increase permanent differentials.

In Luxembourg, Italy, Greece, Finland, and Portugal the common institutional trends that might explain the increase in permanent differentials are the decrease or constant evolution of the EPL, the decrease in union density, PMR and the tax wedge. Italy and Portugal exhibit also a decrease in EPLT relative to EPLR, which might accentuate permanent differentials. The decrease in transitory differentials and the increase in immobility in Luxembourg, Italy, Greece, and Finland might be explained by the increase in the ALMPs, coupled with the increase in the generosity of the unemployment benefit, except for Finland. The increase in transitory differentials recorded by Portugal might be due to the level of corporatism: an intermediate level appears to accentuate transitory differentials, whereas a high level might help to reduce them.

\subsubsection{Correlations}

Given the clear distinction in the trends of the two components and earnings immobility between the oldest three cohort and the youngest cohorts, we expect also the underlying factors to differ to a certain extent. Thus, it is necessary to account for cohort heterogeneity when analysing the link between the three labour market outcomes and the institutional and policy factors. As a first step, we estimate the simple uncontrolled correlations (Table 5.4) comparatively between the oldest there cohorts, polled together, and the youngest one. Permanent variance for the older cohorts is significantly ${ }^{79}$ positively associated with all the

\footnotetext{
${ }^{79}$ At $1 \%$ and $5 \%$ level of confidence
} 
EPL factors and PMR, and significantly negatively associated with union density, the degree of corporatism, the tax wedge, the ALMPs, and the unemployment replacement rate. Discrepancies between cohorts with respect to permanent variance are recorded for the EPL factors, which are negatively associated, and PMR which is insignificant. For the other factors the associations are consistent across cohorts ${ }^{80}$.

\section{Table 5.4. Pair wise Correlations Between the Labour Market Outcomes, Labour Market} Institutional Factors and Macroeconomic Shocks

\begin{tabular}{|c|c|c|c|c|c|c|}
\hline \multirow[b]{2}{*}{ Pair wise Correlations } & \multicolumn{2}{|c|}{ Permanent Variance } & \multicolumn{2}{|c|}{ Temporary Variance } & \multicolumn{2}{|c|}{ Immobility (PV/TV) } \\
\hline & $\begin{array}{c}\text { Cohort } \\
1940-1969\end{array}$ & $\begin{array}{c}\text { Cohort } \\
1970-1981 \\
\end{array}$ & $\begin{array}{c}\text { Cohort } \\
1940-1969\end{array}$ & $\begin{array}{c}\text { Cohort } \\
1970-1981 \\
\end{array}$ & $\begin{array}{c}\text { Cohort } \\
1940-1969\end{array}$ & $\begin{array}{c}\text { Cohort } \\
1970-1981\end{array}$ \\
\hline \multirow{2}{*}{ EPL } & 0.313 & -0.245 & 0.207 & 0.166 & 0.140 & -0.317 \\
\hline & 0.000 & 0.014 & 0.000 & 0.096 & 0.015 & 0.001 \\
\hline \multirow{2}{*}{ EPL regular contracts (EPLR) } & 0.488 & -0.171 & 0.190 & 0.259 & 0.225 & -0.263 \\
\hline & 0.000 & 0.087 & 0.001 & 0.009 & 0.000 & 0.008 \\
\hline \multirow{2}{*}{ EPL temporary contracts (EPLT) } & 0.122 & -0.213 & 0.158 & 0.070 & 0.051 & -0.254 \\
\hline & 0.034 & 0.032 & 0.006 & 0.488 & 0.380 & 0.010 \\
\hline \multirow{2}{*}{ 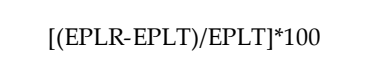 } & 0.116 & 0.555 & 0.086 & -0.147 & 0.024 & 0.593 \\
\hline & 0.041 & 0.000 & 0.135 & 0.142 & 0.674 & 0.000 \\
\hline \multirow{2}{*}{ Union Density } & -0.588 & -0.333 & -0.323 & -0.340 & -0.245 & -0.110 \\
\hline & 0.000 & 0.000 & 0.000 & 0.000 & 0.000 & 0.256 \\
\hline \multirow{2}{*}{ Degree of Corporatism } & -0.498 & -0.441 & -0.477 & -0.228 & -0.086 & -0.201 \\
\hline & 0.000 & 0.000 & 0.000 & 0.028 & 0.151 & 0.054 \\
\hline \multirow{2}{*}{ Tax Wedge } & -0.3 & -0.385 & -0.245 & 0.096 & -0.066 & -0.449 \\
\hline & 0.000 & 0.000 & 0.000 & 0.361 & 0.271 & 0.000 \\
\hline \multirow{2}{*}{ PMR } & 0.247 & 0.041 & 0.053 & 0.046 & 0.160 & 0.018 \\
\hline & 0.000 & 0.695 & 0.381 & 0.664 & 0.007 & 0.863 \\
\hline \multirow{2}{*}{ Active Labour Market Policies } & -0.267 & -0.219 & -0.240 & 0.150 & -0.063 & -0.184 \\
\hline & 0.000 & 0.035 & 0.000 & 0.151 & 0.294 & 0.077 \\
\hline Average Unemployment & -0.223 & -0.450 & -0.225 & 0.214 & -0.114 & -0.465 \\
\hline Benefit Replacement Rate & 0.000 & 0.000 & 0.000 & 0.039 & 0.057 & 0.000 \\
\hline \multirow{2}{*}{ Labour Demand Shock } & 0.177 & 0.605 & 0.021 & 0.005 & 0.066 & 0.574 \\
\hline & 0.005 & 0.000 & 0.742 & 0.966 & 0.291 & 0.000 \\
\hline \multirow{2}{*}{ Terms of Trade Shock } & -0.03 & 0.151 & -0.061 & -0.068 & 0.105 & 0.102 \\
\hline & 0.623 & 0.149 & 0.314 & 0.520 & 0.080 & 0.330 \\
\hline \multirow{2}{*}{ Total Factor Production Shock } & -0.241 & -0.082 & -0.371 & -0.259 & -0.041 & 0.163 \\
\hline & 0.000 & 0.454 & 0.000 & 0.017 & 0.517 & 0.137 \\
\hline \multirow{2}{*}{ Real Interest Shock } & -0.148 & -0.134 & -0.010 & -0.011 & -0.056 & -0.218 \\
\hline & 0.013 & 0.200 & 0.875 & 0.918 & 0.352 & 0.036 \\
\hline \multirow{2}{*}{ Aggregate Supply Shock } & -0.104 & -0.075 & -0.007 & -0.008 & -0.014 & -0.103 \\
\hline & 0.071 & 0.456 & 0.903 & 0.934 & 0.805 & 0.308 \\
\hline \multirow{2}{*}{ Aggregate Demand Shock } & -0.208 & -0.156 & -0.237 & -0.236 & -0.092 & -0.003 \\
\hline & 0.000 & 0.121 & 0.000 & 0.017 & 0.111 & 0.977 \\
\hline
\end{tabular}

Note: P-values are reported below the correlations.

${ }^{80}$ The associations for the youngest cohorts are significant at $1 \%, 5 \%$ and $10 \%$ level of confidence. 
Transitory variance for the older cohorts is significantly ${ }^{81}$ positively associated with the EPL, EPLR and EPLT, and significantly negatively associated with the rest, except the relative difference between EPLR and EPLT and PMR which are insignificant. The youngest cohort records fewer significant associations: a positive association $^{82}$ is recorded with EPL, EPLR and the unemployment replacement rate, and a negative association ${ }^{83}$ with union density and the degree of corporatism.

The immobility ratio for the oldest three cohorts exhibits a positive significant association with EPL, EPLR and PMR, and a significant negative association with union density ${ }^{84}$ and the unemployment benefit replacement rate ${ }^{85}$. For the youngest cohort, the immobility ratio is significantly positively associated with the relative difference between EPLR and EPLT, and significantly negatively ${ }^{86}$ associated with the other factors except the union density and PMR, which are insignificant.

The trend differences in permanent inequality, transitory inequality and immobility observed between cohorts (Figure 5.3, Figure 5.5, and Table 5.2) might be related also with the different levels of responsiveness to the macroeconomic shocks and their interactions with the other labour market policy and institutional factors. Younger workers are expected to be affected to a larger extent by these shocks, compared with experienced workers, which have a high attachment to the labour market and a better protection from the institutional framework. This might explain the much higher share of transitory inequality observed for younger cohorts.

The correlations with the macroeconomic shocks (Table 5.4) reveal differences between cohorts. For permanent variance, the youngest cohort records a much stronger positive correlation with labour demand shocks compared with the oldest cohorts, and insignificant correlations for the other shocks. For the oldest cohorts, the other shocks exhibit significant negative correlations, except the terms of trade shock. For transitory variance, only the total factor production and the aggregate demand shocks exhibit a significant negative association. Across cohorts, the negative association with the total factor production shock is stronger for the oldest cohorts. More differences between cohorts emerge for earnings immobility.

\footnotetext{
${ }^{81}$ At $1 \%$ evel of confidence

${ }^{82}$ Significant at $5 \%$ and $10 \%$ level of confidence

${ }^{83}$ Significant at $1 \%$ and $5 \%$ level of confidence

${ }^{84}$ At $1 \%$ level of confidence

${ }^{85}$ At $10 \%$ level of confidence

${ }^{86}$ At $1 \%, 5 \%$ and $10 \%$ levels of confidence
} 
For the oldest cohorts, a significant ${ }^{87}$ positive association is observed for the terms of trade shock. For the youngest cohort, a significant ${ }^{88}$ positive association is observed for the labour demand shock, and a significant negative association ${ }^{89}$ with the real interest rate shock

Nevertheless, these correlations are far from telling the true story given the complexity of the interactions that take place between institutions on the one hand, and between institutions and macroeconomic shocks on the other hand.

To conclude, the institutional factors are expected to shape the pattern and the level of permanent inequality, transitory inequality and earnings immobility not only directly, but also in interaction with macroeconomic shocks. The overall institutional factors is expected to be a "filtering mechanism" for the adverse effect that these shocks might have on the three labour market outcomes, provided that their aim is to keep permanent and transitory inequality low, assuring at the same time that low wage individuals are not trapped in low pay, but have the opportunity to improve their position in the distribution of lifetime income through earnings mobility.

Moreover, we expect institutional factors to play a much larger role in shaping permanent differentials compared with transitory differentials and earnings immobility, given that the latter two are exposed to a much larger extent to random shocks, against which the institutional factors might have a delayed response or any at all.

\subsubsection{Estimation}

This section aims to provide some empirical evidence with respect to the impact of the main labour market policy and institutional factors and their complex interactions in shaping permanent inequality, transitory inequality and earnings immobility.

\subsubsection{Systemic interactions: do policies and institutions interact with the overall institutional framework?}

The results regarding systemic interactions are included in Model 1 in Table 5.5. A summary of the results is displayed in Model 1 in Table 5.7-Table 5.9. The models with systemic interactions are estimated to explain $97.8 \%$ of the cross-country

\footnotetext{
${ }^{87}$ At $10 \%$ level of confidence

${ }^{88}$ At $1 \%$ level of confidence

${ }^{89}$ At $5 \%$ level of confidence
} 
variation in permanent inequality, $93.2 \%$ of the cross-country variation in transitory inequality, and $71.6 \%$ of the cross-country variation in earnings immobility, between 1994 and 2001.

The cohorts shifters are highly significant in all models, confirming the cohortheterogeneous trends identified previously by the error component model (Figure 5.3): the older the cohort, the higher the permanent variance and wage immobility, and the lower the transitory inequality.

Similarly, the time effects are highly significant in all models. They indicate that, overall, at the EU level, controlling for the effects of institutional and policy factors, the unobserved shocks had a decreasing impact on permanent variance in 1995, an increasing impact until 1997 and decreasing impact thereafter. The impact of the unobserved shocks on transitory inequality decreased until 2000 and increased in 2001. For wage immobility more variation is observed: it decreased in 1995, increased until 1997, decreased until 1999, increased again in 2000, followed by a drop in 2001. Overall, it appears that the unobserved shocks had a decreasing effect on both permanent and transitory dispersion, and an increasing effect on wage mobility.

The direct effects, controlling for the systemic interactions, cohort and the period effects, indicate that, except for product market regulation (PMR) and active labour market policies (ALMPs), all other factors have a significant impact on permanent dispersion. Factors that appear to reduce permanent inequality are the union density and the average unemployment benefit replacement rate. The hump shape profile of the impact of the degree of corporatism is confirmed: the intermediate level of corporatism appears to trigger the highest permanent dispersion, followed by a high and then a low corporatism. 
Table 5.5. Model 1 - Systemic Effects across Institutions

\begin{tabular}{|c|c|c|c|c|c|c|}
\hline & \multicolumn{2}{|c|}{ Permanent Variance } & \multicolumn{2}{|c|}{ Temporary Variance } & \multicolumn{2}{|c|}{ Wage Immobility } \\
\hline & $\begin{array}{c}\text { Parameter } \\
\text { Estimate }\end{array}$ & SE & $\begin{array}{c}\text { Parameter } \\
\text { Estimate }\end{array}$ & SE & $\begin{array}{c}\text { Parameter } \\
\text { Estimate }\end{array}$ & SE \\
\hline \multicolumn{7}{|c|}{ Systemic Interactions } \\
\hline EPL & $0.198^{* * *}$ & 0.061 & 0.026 & 0.019 & 0.112 & 0.073 \\
\hline Relative EPL & $0.098^{* * *}$ & 0.025 & 0.008 & 0.008 & -0.005 & 0.037 \\
\hline Union Density & $-1.201^{* * *}$ & 0.349 & -0.024 & 0.039 & $-1.566^{* *}$ & 0.530 \\
\hline Int. Corp. & $-0.892^{* * *}$ & 0.054 & $-0.538^{* * *}$ & 0.109 & $-1.166^{* * *}$ & 0.114 \\
\hline High Corp. & $-0.559^{* * *}$ & 0.112 & $-0.898^{* * *}$ & 0.066 & $-0.823^{* * *}$ & 0.070 \\
\hline Tax Wedge & $-1.462^{* *}$ & 0.588 & 0.070 & 0.072 & -0.718 & 0.744 \\
\hline PMR & $-0.069^{* *}$ & 0.024 & 0.004 & 0.009 & $0.181^{* *}$ & 0.069 \\
\hline ALMPs & 0.058 & 0.091 & 0.016 & 0.033 & $1.863^{* *}$ & 0.598 \\
\hline Unemployment Benefit & $1.074^{* * *}$ & 0.329 & $0.192^{*}$ & 0.111 & 0.712 & 0.434 \\
\hline \multicolumn{7}{|l|}{ Direct Effects } \\
\hline EPL & $0.080^{* * *}$ & 0.021 & 0.056 & 0.065 & $14.787^{* *}$ & 5.416 \\
\hline Relative EPL & $0.054^{* * *}$ & 0.008 & 0.022 & 0.018 & $3.173^{*}$ & 1.801 \\
\hline Union Density & $-0.335^{* * *}$ & 0.102 & -0.388 & 0.242 & $-17.637^{* *}$ & 8.613 \\
\hline Intermediate Corporatism & $0.307^{* * *}$ & 0.081 & -0.175 & 0.379 & $-6.448^{*}$ & 3.369 \\
\hline High Corporatism & $0.092^{* * *}$ & 0.026 & -0.986 & 0.845 & $13.095^{* *}$ & 4.463 \\
\hline Tax Wedge & $0.708^{* * *}$ & 0.117 & 0.248 & 0.152 & 28.619 & 18.631 \\
\hline PMR & 0.008 & 0.013 & $-0.084^{* * *}$ & 0.025 & 1.852 & 1.495 \\
\hline ALMPs & 0.014 & 0.037 & $0.321^{*}$ & 0.171 & $12.592^{* *}$ & 5.534 \\
\hline Unemployment Benefit & $-0.842^{* * *}$ & 0.252 & $0.756^{* *}$ & 0.367 & $-130.927^{* *}$ & 43.999 \\
\hline Cohort 1940-1950 & 1 & & 1 & & 1 & \\
\hline Cohort 1951-1960 & $0.886^{* * *}$ & 0.015 & $0.884^{* * *}$ & 0.046 & $0.651^{* * *}$ & 0.048 \\
\hline Cohort 1961-1970 & $0.621^{* * *}$ & 0.014 & $1.041^{* * *}$ & 0.050 & $0.386^{* * *}$ & 0.043 \\
\hline Cohort 1971-1980 & $0.205^{* * *}$ & 0.012 & $1.806^{* * *}$ & 0.071 & $0.082^{* *}$ & 0.041 \\
\hline 1994 & 1 & & 1 & & 1 & \\
\hline 1995 & $0.960^{* * *}$ & 0.032 & $0.729^{* * *}$ & 0.040 & $0.348^{* * *}$ & 0.055 \\
\hline 1996 & $0.976^{* * *}$ & 0.032 & $0.563^{* * *}$ & 0.036 & $0.546^{* * *}$ & 0.064 \\
\hline 1997 & $1.020^{* * *}$ & 0.034 & $0.505^{* * *}$ & 0.036 & $0.697^{* * *}$ & 0.085 \\
\hline 1998 & $0.980^{* * *}$ & 0.036 & $0.465^{* * *}$ & 0.035 & $0.677^{* * *}$ & 0.087 \\
\hline 1999 & $0.916^{* * *}$ & 0.040 & $0.436^{* * *}$ & 0.038 & $0.677^{* * *}$ & 0.104 \\
\hline 2000 & $0.893^{* * *}$ & 0.044 & $0.405^{* * *}$ & 0.037 & $0.786^{* * *}$ & 0.129 \\
\hline 2001 & $0.872^{* * *}$ & 0.046 & $0.424^{* * *}$ & 0.040 & $0.526^{* * *}$ & 0.102 \\
\hline Adj. R-squared & 0.97 & & 0.9 & & 0.7 & \\
\hline $\mathrm{N}$ & 37 & & 37 & & 37 & \\
\hline
\end{tabular}

Note: Estimated with non-linear least squares

The systemic interaction effects for union density, the degree of corporatism, the tax wedge and the PMR provide evidence of reform complementarity in reducing permanent inequality. Hence the more equality-friendly the overall labour market policy and institutional framework is, the greater is the reducing impact of a high union density, an intermediate and high degree of corporatism, a high tax wedge and a high PMR. 
The model for transitory variance, despite having a similar level of explained variation as the model for permanent inequality, exhibits fewer significant effects for the institutional factors. The period effects and the cohort effects explain a large share of the variation in transitory inequality: random exogenous shocks increase earnings variability and the magnitude of their impact depends on the specific lifecycle stage a respective cohort is in.

Only the PMR, the ALMPs and the unemployment benefit replacement rate have a significant direct impact on transitory inequality. Ceteris paribus, an increase in the spending for ALMPs and in the unemployment benefit replacement rate increases transitory differentials, whereas an increase in the PMR reduces transitory differentials. Moreover, albeit insignificant, the higher the union density and the higher the degree of corporatism are, the larger is the reduction in transitory variance.

The systemic interactions suggest that there is a complementarity with the overall framework in reducing transitory inequality for the union density and the degree of corporatism. Hence, the more inclined the overall framework is towards reducing transitory differentials, the effect is larger the higher is the union density and the larger is the degree of corporatism. The effect of union density, however, is not significant at conventional levels. The other factors appear to counteract with the overall system, but the effect is significant only for the unemployment benefit replacement rate.

For earnings immobility, ceteris paribus, a significant positive direct effect is found for employment protection legislation (EPL), the relative difference between employment protection legislation for regular contracts (EPLR) and temporary contracts (EPLT), a high degree of corporatism and ALMPs. Similarly for PMR, but the effect is insignificant. A U-shaped profile is found for the degree of corporatism: a high degree of corporatism is found to increase wage immobility compared with low corporatism, whereas an intermediate corporatism appears to decrease it. Besides an intermediate corporatism, other factors that contribute directly to decrease earnings immobility are the union density and the unemployment benefit replacement rate.

The systemic interactions suggest that there is a complementarity with the overall framework in reducing wage immobility for the union density, and the degree of corporatism - with an stronger negative effect for the intermediate level than for a high level. The tax wedge also has a negative effect, but insignificant. PMR and ALMPs counteract with the overall framework, in a tendency to increase wage immobility. 


\subsubsection{Specific Interactions}

This section explores the specific interactions between institutions, and between institutions and observed macroeconomic shocks, expected to shape the pattern of permanent inequality, transitory inequality and earnings immobility. First we look at the direct effect of shocks and institutions, and the interactions between institutions and the systemic shock (Model 2 in Table 5.6). Second, we enhance the model by adding cross-interactions between institutions, and other controls (Model 3 in Table 5.6).

Model 2 in Table 5.6 illustrates the estimates for the direct effects of institutions, observed macroeconomic shocks, and the interactions between institutions and the systemic shock. A summary of the results is displayed in Model 2 in Table 5.7Table 5.9.

The models for the three labour market outcomes explain $97.9 \%$ of the variation in permanent inequality, $92.9 \%$ of the variation in the transitory inequality and $68.9 \%$ of the variation in wage immobility.

Compared with Model 1, including the effects of the observed macroeconomic shocks and the interactions between institutions and the systemic shock (Model 2), affects the direct effects of the institutions on all three labour market outcomes. For transitory inequality and earnings immobility, however, the direct effects of the institutions change to a larger extent than for permanent inequality.

For permanent inequality, most coefficient estimates maintain the direction of influence and the significance level, except the union density which becomes insignificant, a high corporatism and the PMR which become negative, the ALMPs which become significant, and the unemployment benefit replacement rate which becomes positive and insignificant. Among those that maintained the direction of influence, the magnitude of the direct effects reduced in absolute value in Model 2 compared with Model 1, except for the ALMPs where it increased.

For transitory inequality, the EPL factors become significant, the degree of corporatism becomes positive and significant, and ALMPs become negative and insignificant. Among those that maintained the direction of influence and the significance, the magnitude of the effects decreased in absolute value in Model 2 compared with Model 1.

For earnings immobility, the EPL, the union density, and the high degree of corporatism become insignificant, the tax wedge becomes negative, the intermediate degree of corporatism becomes positive and insignificant, the ALMPs 
become negative and insignificant, and the unemployment benefit replacement rate becomes positive. Among those that maintained the direction of influence and the significance, the magnitude of the effects decreased in absolute value in Model 2 compared with Model 1. These results reinforce our expectation that the institutional factors are a "filtering mechanism" for the effects of the macro shocks on the three labour market outcomes.

We turn to the direct effects of the macroeconomic shocks. As expected, permanent inequality appears to be affected directly by these shocks to a much lesser extent compared with transitory inequality and wage immobility: only the aggregate demand and the terms of trade shock are significant. For transitory inequality all shocks show a highly significant effect, and for wage immobility all except the aggregate labour supply shock.

For permanent inequality, a negative influence is observed for the terms of trade shock and a positive one for the aggregate demand shock. Transitory inequality is positively affected by the aggregate supply, the terms of trade and the total factor production shocks, and negatively by the rest. Wage immobility is affected negatively by the aggregate demand, the labour demand and the interest rate shock, and positively by the rest.

The explanation for the lack of significance of the direct effects of shock in explaining permanent inequality is found in the interaction effects between the institutional factors and the aggregate shock. All interaction effects are significant, except for ALMPs, suggesting that these policies and institution filter out the effects of the macro shocks. EPL, the relative difference between EPLR and EPLT and the tax wedge have a positive significant direct effect on permanent variance, which is amplified under the aggregate impact of these shocks. The positive significant effect of ALMPs is diminished under the impact of aggregate shocks, but the interaction term is not significant at conventional levels.

If for the directs effects the hump-shaped pattern of the relationship between the degree of corporatism and permanent inequality is confirmed, with the high level triggering the lowest permanent inequality, followed by low and intermediate corporatism, in interaction with aggregate shocks the degree of corporatism clearly becomes a tool for reducing permanent differentials: the higher is the degree of corporatism, the larger is the magnitude of the negative impact in reducing permanent inequality. The union density, the PMR and the unemployment benefit replacement rate have an insignificant direct effect, but in interaction with the aggregate shock they appear to work significantly towards increasing permanent differentials. 
Compared with permanent inequality and wage immobility, fewer factors are significant in filtering out the effects of the systemic shock on transitory inequality. The direct effect for intermediate corporatism appears to trigger the highest transitory inequality, followed by high and low corporatism. In interaction with the aggregate shocks, however, the impact of an intermediate corporatism impact becomes insignificant, whereas for high corporatism it becomes negative and highly significant. Thus, similarly with permanent inequality, a high corporatism is an efficient tool in reducing or limiting the increase of transitory inequality under in the impact of macroeconomic shocks. A more generous unemployment benefit appears to have a significant positive impact on transitory inequality that is reduced in interaction with macroeconomic shocks.

The tax wedge does not have a significant direct effect on transitory inequality, but in interaction with macroeconomic shocks, it appears to be an efficient tool in reducing or limiting the increase of transitory inequality under the impact of macroeconomic shocks. The opposite holds for PMR and ALMPs ${ }^{90}$ : they have a negative direct effect, but in interaction with the systemic shock, they appear to have a positive impact on transitory inequality.

Wage immobility is explained to a lesser extent by the direct effects of institutions than permanent and transitory inequality. Most of the direct and interaction effects of shocks, however, are highly significant, suggesting that wage immobility is influenced mainly by the macroeconomic shocks and their interaction with the institutional setting. The relative difference between EPLR and EPLT and unemployment benefit generosity have a positive effect on wage immobility, which is diminished in interaction with the systemic shock. The effect of the systemic macroeconomic shock on wage immobility appears to increase significantly with the EPL, the union density, the PMR and the ALMPs, and to decrease with the degree of corporatism, the tax wedge, and the unemployment benefit replacement rate. An intermediate level of corporatism appears to be the most effective in reducing the impact of shocks, followed by a high and a low level of corporatism.

In order to grasp more in depth the nature of the relationship between institutions and shocks, these models are augmented by including also 2-by-2 interactions between the institutional factors, and other controls. The results are illustrated in Model 3 in Table 5.6. A summary of the results is displayed in Model 3 in Table 5.7-Table 5.9.

${ }^{90}$ Albeit insignificant 
The new model specifications explain $98.9 \%$ of the variance in permanent inequality, $94.2 \%$ for transitory inequality and $80.6 \%$ for wage immobility.

Including the institutional interaction effects and the other controls at the cohort level (the shares of university and upper- secondary graduates, the sector structure, the occupational structure, the share of unemployed, the share of permanent contracts), several changes are observed.

First, for permanent inequality, the direct effects of institutions and most of their cross interactions are highly significant, whereas all six macroeconomic shocks and their interactions with the institutional factors become insignificant, except for high corporatism. This suggests that the overall institutional structure manages to filter out all direct and indirect effect of these shocks. Hence, in shaping permanent inequality patterns, not the interactions between the systemic shock and the institutions count, but how institutions interact with each other in dealing with the effects of these shocks. One factor which interacts significantly with the aggregate shock is high corporatism, which decreases the impact of the aggregate macroeconomic shock on permanent inequality to a larger extent compared with low and intermediate corporatism.

All direct effects that were insignificant in the previous specification of the permanent inequality become significant once we control for cross-institutional interactions. Among those that were significant in Model 2, a change in sign is observed for the EPL, the relative difference between EPLR and EPLT, the tax wedge, and a high degree of corporatism.

EPL has a negative direct effect on permanent inequality, enhanced by the relative difference between EPLR and EPLT, and counteracted by the tax wedge. Union density has a positive direct effect, which increases in interaction with the tax wedge and decreases in interaction with PMR and ALPMs. The interaction with the degree of corporatism confirms the hump-shaped pattern hypothesis: the positive effect of the union density is enhanced in interaction with an intermediate level of corporatism, and counteracted in interaction with a high level of corporatism. The tax wedge has a negative direct effect on permanent inequality, which is accentuated in interaction with the PMR and the generosity of the unemployment benefit, and counteracted in interaction with the EPL, the union density and the ALMPs.

PMR has a positive direct effect, counteracted in interaction with the union density, the tax wedge and the ALMPs. ALMPs increases permanent inequality, effect which is accentuated in interaction with the tax wedge, and reduced in interaction with the PMR. Also union density and unemployment benefit lower the effect of 
ALMP, but the effect is not significant. Unemployment benefit has a negative direct effect on permanent inequality, which is reinforced by the tax wedge and the AMPLs ${ }^{91}$, and counteracted by PMR.

Second, for transitory inequality, similarly with permanent inequality, controlling for the interactions between institutions renders the direct and indirect effects of shocks insignificant. This reconfirms that the key role in shaping transitory and permanent inequality patterns is played by the interplay between labour market policies and institutions in dealing with macroeconomic shocks.

The direct effects on transitory inequality modify to large extent when these interactions are being introduced. Among those that remained significant, an intensification of the effects is recorded by the EPL, and a change in sign is recorded by the degree of corporatism, which exhibits a U-shaped relationship with transitory inequality: the lowest transitory inequality is triggered by an intermediate level, followed by a high level and a low level. The relative difference between EPLR and EPLT becomes insignificant, the unemployment benefit becomes negative and insignificant, the tax wedge negative and significant, and the union density becomes positive but remains insignificant.

EPL increases transitory inequality, but the effect is counteracted by an intermediate and a high corporatism, the tax wedge and the ALMPs. Union density has an insignificant positive direct effect, which decreases in interaction with an intermediate degree of corporatism, and increases in interaction with the tax wedge and the PMR. The tax wedge reduces transitory inequality, effect amplified by the EPL and the unemployment benefit replacement rate, and counteracted by union density. PMR has a negative direct effect, counteracted by the interaction effect with the union density. The ALMPs have a negative but insignificant direct effect, which is amplified in interaction with EPL. Similarly, the unemployment benefit replacement rate has an insignificant negative effect, which is amplified in interaction with the tax wedge.

Third, for earnings immobility, the inclusion of the cross-institution interactions renders all institutional factors highly significant, except the tax wedge and the ALMPs. Among those that remain significant, a change in sign is observed for the relative difference between the EPLR and EPLT, which turn negative. Among those that turn significant in the last specification, a change in sign is recorded for the union density, the degree of corporatism, and the PMR.

${ }^{91}$ Albeit not significant 
For the macro shocks and their interactions with the institutional setting, the inclusion of the cross-institutional interactions had the opposite effect compared with the permanent and transitory inequality. The direct effects of macroeconomic shocks increased in absolute value, kept the same direction of influence and remained highly significant, except for aggregate supply shock, which remained insignificant. Similarly, the interactions effects between institutions and the systemic shock maintained their direction of influence and the significance. One exception is the interaction with the relative EPLR-EPLT difference, which is insignificant in both specifications.

EPL has a strong positive effect on wage immobility, which increases in interaction with the union density and the aggregate macroeconomic shock, and decreases in interaction with the degree of corporatism and with the PMR.

Union density has a negative impact on wage immobility, which is counteracted by the interaction with the EPL, the tax wedge and aggregate macro shock.

Intermediate corporatism is associated with the lowest wage immobility, followed by high corporatism and low corporatism. The negative impact of high corporatism, however, is exacerbated in interaction with the EPL and the aggregate shock to a larger extent than for intermediate corporatism. The tax wedge has a positive, yet insignificant effect, which appears to increase significantly with the union density, and to decrease significantly with the ALMPs and the aggregate shock.

PMR lowers wage immobility, effect enhanced in interaction with the EPL, the unemployment replacement rate, and the union density ${ }^{92}$, and counteracted by the interaction with an intermediate and high corporatism, the ALMPs and the aggregate macro shock. In interaction with an intermediate corporatism, the positive impact on wage immobility is stronger than in the interaction with a high corporatism.

ALMPs have a negative, yet insignificant effect. Its interaction effects, however are significant: it decreases wage immobility when coupled with the tax wedge, and increases wage immobility in interaction with the PMR, the unemployment benefit replacement rate, and the aggregate shock.

Unemployment benefit increases wage immobility, effect which is accentuated when coupled with a high spending on ALMPs, and diminished when coupled

${ }^{92}$ Insignificant at conventional levels 
with a high PMR. Moreover, in interaction with the systemic shock, the positive impact on wage immobility is being reduced. 
Table 5.6. Models with cross-interactions between institutions and macroeconomic shocks, and between institutions

\begin{tabular}{|c|c|c|c|c|c|c|c|c|c|c|c|c|}
\hline \multirow{3}{*}{$\begin{array}{c}\text { Labour market } \\
\text { factors and } \\
\text { institutions }\end{array}$} & \multicolumn{6}{|c|}{$\begin{array}{c}\text { Model } 2 . \\
\text { Cross-interactions between institutions, and between } \\
\text { institutions and macroeconomic shocks }\end{array}$} & \multicolumn{6}{|c|}{$\begin{array}{c}\text { Model } 3 . \\
\text { Specific interactions between institutions and shocks }\end{array}$} \\
\hline & \multicolumn{2}{|c|}{$\begin{array}{l}\text { Permanent } \\
\text { Variance }\end{array}$} & \multicolumn{2}{|c|}{$\begin{array}{l}\text { Temporary } \\
\text { Variance }\end{array}$} & \multicolumn{2}{|c|}{ Wage Immobility } & \multicolumn{2}{|c|}{$\begin{array}{l}\text { Permanent } \\
\text { Variance }\end{array}$} & \multicolumn{2}{|c|}{$\begin{array}{l}\text { Temporary } \\
\text { Variance }\end{array}$} & \multicolumn{2}{|c|}{ Wage Immobility } \\
\hline & Est. & SE & Est. & SE & Est. & SE & Est. & SE & Est. & SE & Est. & SE \\
\hline \multicolumn{13}{|c|}{ Direct effects of institutions } \\
\hline EPL & $0.028 * * *$ & 0.006 & $0.011 * *$ & 0.004 & 0.437 & 0.874 & $-0.111 * * *$ & 0.013 & $0.186 * *$ & 0.081 & $92.057 * * *$ & 22.646 \\
\hline Relative EPL & $0.027 * * *$ & 0.002 & $0.012 * * *$ & 0.001 & $0.898^{* * *}$ & 0.223 & $-0.076^{* * *}$ & 0.011 & 0.007 & 0.005 & $-5.885 * * *$ & 1.406 \\
\hline Union Density & -0.010 & 0.014 & -0.001 & 0.009 & -3.881 & 2.656 & $0.666^{* * *}$ & 0.133 & 0.237 & 0.269 & $-14.649 * *$ & 4.904 \\
\hline Int. Corp. & $0.077 * * *$ & 0.011 & $0.037 * * *$ & 0.007 & 0.069 & 2.079 & $0.764 * * *$ & 0.108 & $-0.410^{* *}$ & 0.170 & $-179.828 * * *$ & 40.646 \\
\hline High Corp. & $-0.045^{* * *}$ & 0.011 & $0.016^{* *}$ & 0.007 & 1.091 & 1.964 & $0.158 * *$ & 0.051 & $-0.298^{*}$ & 0.158 & $-168.413^{* * *}$ & *39.556 \\
\hline Tax Wedge & $0.111^{* *}$ & 0.040 & 0.019 & 0.026 & -0.746 & 7.023 & $-0.289 * * *$ & 0.088 & $-0.267 * * *$ & 0.059 & 47.965 & 51.584 \\
\hline PMR & -0.001 & 0.004 & $-0.011^{* * *}$ & 0.003 & 0.127 & 0.433 & $0.022^{* * *}$ & 0.004 & $-0.011^{* * *}$ & 0.003 & $-19.667 * *$ & 7.188 \\
\hline ALMPs & $0.061^{*}$ & 0.032 & -0.023 & 0.017 & -2.783 & 2.293 & $0.121^{* * *}$ & 0.035 & -0.007 & 0.016 & -6.193 & 7.571 \\
\hline Unempl. Ben. & 0.003 & 0.037 & $0.067^{* *}$ & 0.022 & $9.423 * *$ & 4.258 & $-0.208^{* * *}$ & 0.041 & -0.259 & 0.374 & $21.463^{* *}$ & 9.373 \\
\hline \multicolumn{13}{|c|}{ Interactions between Institutions } \\
\hline \multirow{2}{*}{\multicolumn{7}{|c|}{$\begin{array}{l}\text { EPL*Relative EPL } \\
\text { EPL*Union Density }\end{array}$}} & $-0.040^{* * *}$ & 0.007 & -0.003 & 0.004 & & \\
\hline & & & & & & & & & -0.059 & 0.041 & $81.033^{* * *}$ & 12.866 \\
\hline \multicolumn{7}{|c|}{ EPL*Intermediate Corporatism } & & & $-0.243^{* *}$ & 0.082 & $-69.142^{* * *}$ & 21.388 \\
\hline \multicolumn{7}{|c|}{ EPL*High Corporatism } & & & $-0.155^{*}$ & 0.082 & $-105.246^{* * * *}$ & *23.671 \\
\hline \multicolumn{7}{|l|}{ EPL*Tax Wedge } & $0.367 * * *$ & 0.094 & $-0.290^{* * *}$ & 0.086 & 24.219 & 21.655 \\
\hline \multicolumn{7}{|l|}{ EPL*PMR } & & & 0.001 & 0.008 & $-8.419 * * *$ & 1.725 \\
\hline \multicolumn{7}{|l|}{ EPL*ALMPs } & & & $-0.055 * *$ & 0.026 & -7.589 & 10.205 \\
\hline \multicolumn{7}{|c|}{ EPL* Unemployment Benefit } & & & 0.014 & 0.048 & 3.152 & 14.398 \\
\hline \multicolumn{7}{|c|}{ Union Density* Intermediate Corporatism } & $1.348 * * *$ & 0.371 & $-0.934 * *$ & 0.361 & & \\
\hline \multicolumn{7}{|c|}{ Union Density *High Corporatism } & $-0.941^{* * *}$ & 0.145 & -0.221 & 0.272 & & \\
\hline \multicolumn{7}{|c|}{ Union Density *Tax Wedge } & $2.276 * * *$ & 0.501 & $0.654 *$ & 0.340 & $260.189 * *$ & 90.354 \\
\hline \multicolumn{7}{|c|}{ Union Density *PMR } & $-0.053^{* *}$ & 0.023 & $0.058 * *$ & 0.019 & -4.670 & 4.770 \\
\hline Union Density * & *ALMPs & & & & & & -0.159 & 0.144 & & & & \\
\hline Union Density * & * Unemploy & yment 1 & Benefit RI & & & & & & & & & \\
\hline Tax Wedge * In & termediate & Corpo & ratism & & & & & & & & 45.070 & 58.520 \\
\hline Tax Wedge *Hi & igh Corpora & tism & & & & & & & & & -88.375 & 58.709 \\
\hline Tax Wedge *PN & & & & & & & $-0.185 * *$ & 0.061 & & & & \\
\hline Tax Wedge $* A$ & LMPs & & & & & & $1.610^{* *}$ & 0.785 & & & $-379.209 * *$ & 129.38 \\
\hline Tax Wedge * U & nemployme & ent Ber & nefit & & & & $-4.379 * * *$ & 0.988 & $-1.029 * *$ & 0.479 & & \\
\hline PMR * Interme & diate Corpo & ratism & & & & & & & & & $23.478^{* *}$ & 7.449 \\
\hline PMR *High Cor & rporatism & & & & & & & & & & $16.438 * *$ & 6.961 \\
\hline PMR *ALMPs & & & & & & & $-0.087^{* * *}$ & 0.022 & & & $15.667 * *$ & 5.126 \\
\hline PMR * Unempl & oyment Ber & nefit & & & & & $0.329 * * *$ & 0.047 & & & $-34.293 * * *$ & 8.2 \\
\hline ALMPs * Intern & mediate Cor & rporatis & & & & & & & & & & \\
\hline ALMPs *High & Corporatisn & & & & & & & & & & & \\
\hline ALMPs * Unem & aployment 1 & Benefit & & & & & -0.445 & 0.310 & & & $293.951 * * *$ & 62.901 \\
\hline Unemploymen & Benefit *In & atermec & diate C & tism & & & & & 0.462 & 0.397 & & \\
\hline Unemployment & Benefit $* \mathrm{H}$ & Iigh Co & rporatism & & & & & & 0.274 & 0.379 & & \\
\hline
\end{tabular}


Direct effects of shocks

\begin{tabular}{|c|c|c|c|c|c|c|c|c|c|c|c|c|}
\hline $\begin{array}{l}\text { Aggregate } \\
\text { Supply Shock }\end{array}$ & -0.0003 & 0.002 & $0.006 * *$ & 0.002 & -0.19 & 0.416 & & & 0.0003 & 0.005 & 1.106 & 0.906 \\
\hline $\begin{array}{l}\text { Aggregate } \\
\text { Demand Shock }\end{array}$ & $0.007 * *$ & 0.003 & $-0.009 * *$ & 0.003 & $-1.53 * *$ & 0.622 & & & -0.0002 & 0.004 & $-8.963 * * *$ & 1.484 \\
\hline $\begin{array}{l}\text { Labour } \\
\text { Demand Shock }\end{array}$ & 0.017 & 0.079 & $-0.142^{* * *}$ & 0.063 & $\begin{array}{c}-139.51 \\
\text { \$क* } \%\end{array}$ & 40.93 & 0.253 & 0.232 & 0.005 & 0.078 & $-386.792 * * *$ & $* 60.692$ \\
\hline $\begin{array}{l}\text { Terms of Trade } \\
\text { Shock }\end{array}$ & $-1.054^{* * *}$ & 0.292 & $0.398 * *$ & 0.155 & $\begin{array}{c}202.302 \\
* * *\end{array}$ & 53.47 & -0.166 & 0.155 & -0.0005 & 0.007 & $726.740^{* * * *}$ & * 118.68 \\
\hline $\begin{array}{l}\text { TF Production } \\
\text { Shock }\end{array}$ & 0.205 & 0.249 & $0.217^{* * * *}$ & 0.091 & $\begin{array}{c}175.117 \\
* *\end{array}$ & 73.99 & -0.033 & 0.049 & 0.007 & 0.106 & $144.281 *$ & 80.708 \\
\hline $\begin{array}{l}\text { Interest Rate } \\
\text { Shock }\end{array}$ & -0.095 & 0.243 & $-0.471^{\text {*** }}$ & 0.180 & $\begin{array}{c}-346.24 \\
* * *\end{array}$ & 100.56 & -0.026 & 0.044 & -0.005 & 0.081 & $\begin{array}{c}-1042.999 \\
* * *\end{array}$ & 147.86 \\
\hline \multicolumn{13}{|c|}{ Interactions between institutions and shocks } \\
\hline$\overline{\mathrm{EPL}}$ & $0.483 * * * *$ & 0.119 & -0.131 & 0.288 & $0.587 * * *$ & 0.114 & -0.311 & 0.480 & 14.189 & 220.044 & t $0.475 * * *$ & 0.079 \\
\hline Relative EPL & $0.345 * * *$ & 0.093 & -0.128 & 0,128 & $-0,003$ & 0.062 & & & 1.266 & 19.637 & -0.032 & 0.036 \\
\hline Union Density & $2.005^{\text {s:*:* }}$ & 0.535 & -0.446 & 0.595 & 1.060 *के & 0.281 & 5.731 & 5.643 & -79.468 & 1236.53 & $1.153 * \approx *$ & 0.159 \\
\hline $\begin{array}{l}\text { Intermediate } \\
\text { Corporatism }\end{array}$ & $-0.420 * *$ & 0.187 & 0.008 & 0.368 & $\begin{array}{c}-1.061 \\
* * *\end{array}$ & 0.159 & 7.685 & 8.505 & 77.631 & 1221.39 & $-0.730 * * *$ & 0.066 \\
\hline $\begin{array}{l}\text { High } \\
\text { Corporatism }\end{array}$ & $-1.646^{* * *}$ & 0.187 & $\begin{array}{c}-0.668 \\
* * *\end{array}$ & 0.133 & $\begin{array}{c}-0.622 \\
* * *\end{array}$ & 0.118 & $-1.948^{*}$ & 1.008 & 26.103 & 421.66 & 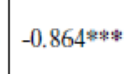 & 0.030 \\
\hline Tax Wedge & $3.597 * *$ & 1.627 & $-3.093 *$ & 1.782 & $-4.682 * *$ & $=1.853$ & 2.822 & 4.206 & -205.500 & 3197.89 & $-3.664 * * *$ & 0.680 \\
\hline PMR & $0.206 * *$ & 0.080 & $0.595^{* * *}$ & 0.205 & $0.162 * *$ & 0.065 & -0.056 & 0.256 & -1.025 & 16.072 & $0.097 * * *$ & 0.029 \\
\hline ALMPs & -0.139 & 0.344 & $1.362 * *$ & 0.647 & $1.029 * *$ & 0.444 & -3.350 & 4.755 & -4.938 & 82.823 & $2.136^{* * * *}$ & 0.293 \\
\hline $\begin{array}{l}\text { Unemployment } \\
\text { Benefit }\end{array}$ & $1.783 * *$ & 0.697 & $-2.015^{*}$ & 1.214 & $-1.423^{*}$ & 0.796 & 7.987 & 7.320 & -37.678 & 593.17 & $-2.036^{* * * *}$ & 0.328 \\
\hline \multicolumn{13}{|c|}{ Controls - cohort level } \\
\hline \multirow{2}{*}{\multicolumn{7}{|c|}{$\begin{array}{l}\text { Proportion of university degree } \\
\text { Proportion of upper-secondary degree }\end{array}$}} & & & & & 0.165 & 0.787 \\
\hline & & & & & & & & & & & 0.236 & 0.564 \\
\hline \multicolumn{7}{|c|}{ Proportion of private employees } & $-0.019 * *$ & 0.007 & 0.013 & 0.012 & $-1.695 * *$ & 0.691 \\
\hline \multicolumn{7}{|c|}{ Proportion of permanent contracts } & $0.034 * * *$ & 0.007 & 0.004 & 0.009 & 0.953 & 0.702 \\
\hline \multicolumn{13}{|c|}{ Proportion of unemployed } \\
\hline \multicolumn{7}{|c|}{ Share of managers, legislators, etc. } & $0.132 * * *$ & 0.038 & & & $7.986^{* * * *}$ & 2.456 \\
\hline \multicolumn{7}{|c|}{ Share of professionals } & $0.050 *$ & 0.028 & & & & \\
\hline \multicolumn{7}{|c|}{ Share of technicians \& assoc. professionals } & $-0.052 *$ & 0.029 & & & & \\
\hline \multicolumn{13}{|c|}{ Share of clerks } \\
\hline \multicolumn{7}{|c|}{ Share of service \& sales w orkers } & $0.132 * * *$ & 0.034 & & & & \\
\hline \multicolumn{7}{|c|}{ Share of skilled agricultural\& fishery workers } & & & & & 8.249 & 5.765 \\
\hline \multicolumn{7}{|c|}{ Share of craft \& related trade workers } & $-0.059 * * *$ & 0.016 & 0.024 & 0.025 & & \\
\hline \multicolumn{7}{|c|}{ Share of plant \& machine operators } & & & -0.044 & 0.039 & $9.059 * *$ & 4.145 \\
\hline \multicolumn{7}{|c|}{ Share of elementary occupations } & & & 0.060 & 0.044 & 4.681 & 3.452 \\
\hline \multicolumn{13}{|l|}{ Cohort Shifters } \\
\hline $1940-1950$ & 1 & & 1 & & 1 & & 1 & & 1 & & 1 & \\
\hline $1951-1960$ & $0.882^{* \% 8}$ & 0.016 & $0.935 * \approx *$ & 0.054 & $0.589 * * *$ & 0.052 & $0.869 \% * \%$ & 0.016 & $0.862^{* * *}$ & 0.078 & $0.159 * * *$ & 0.043 \\
\hline $1961-1970$ & $0.619^{* * *}$ & 0.014 & $1.040^{* * *}$ & 0.057 & $0.376^{* * *}$ & $* 0.048$ & $0.599 * * *$ & $=0.017$ & $0.954 * * *$ & 0.099 & $0.086^{* *}$ & 0.044 \\
\hline $1971-1980$ & $0.242^{* * * *}$ & 0.012 & $1.917 * * *$ & 0.086 & $0.081^{*}$ & 0.045 & $0.218^{* * *}$ & $=0.022$ & $2.267^{* * *}$ & 0.248 & 0.016 & 0.045 \\
\hline $\begin{array}{l}\text { Adjuster } \mathrm{R}^{2} \\
\mathrm{~N}\end{array}$ & \multicolumn{2}{|c|}{0.979} & \multicolumn{2}{|c|}{$\begin{array}{c}0.929 \\
320\end{array}$} & \multicolumn{2}{|c|}{$\begin{array}{c}0.689 \\
320\end{array}$} & \multicolumn{2}{|c|}{$\begin{array}{c}0.989 \\
320\end{array}$} & \multicolumn{2}{|c|}{$\begin{array}{c}0.942 \\
320\end{array}$} & \multicolumn{2}{|l|}{$\begin{array}{c}0.806 \\
320\end{array}$} \\
\hline
\end{tabular}




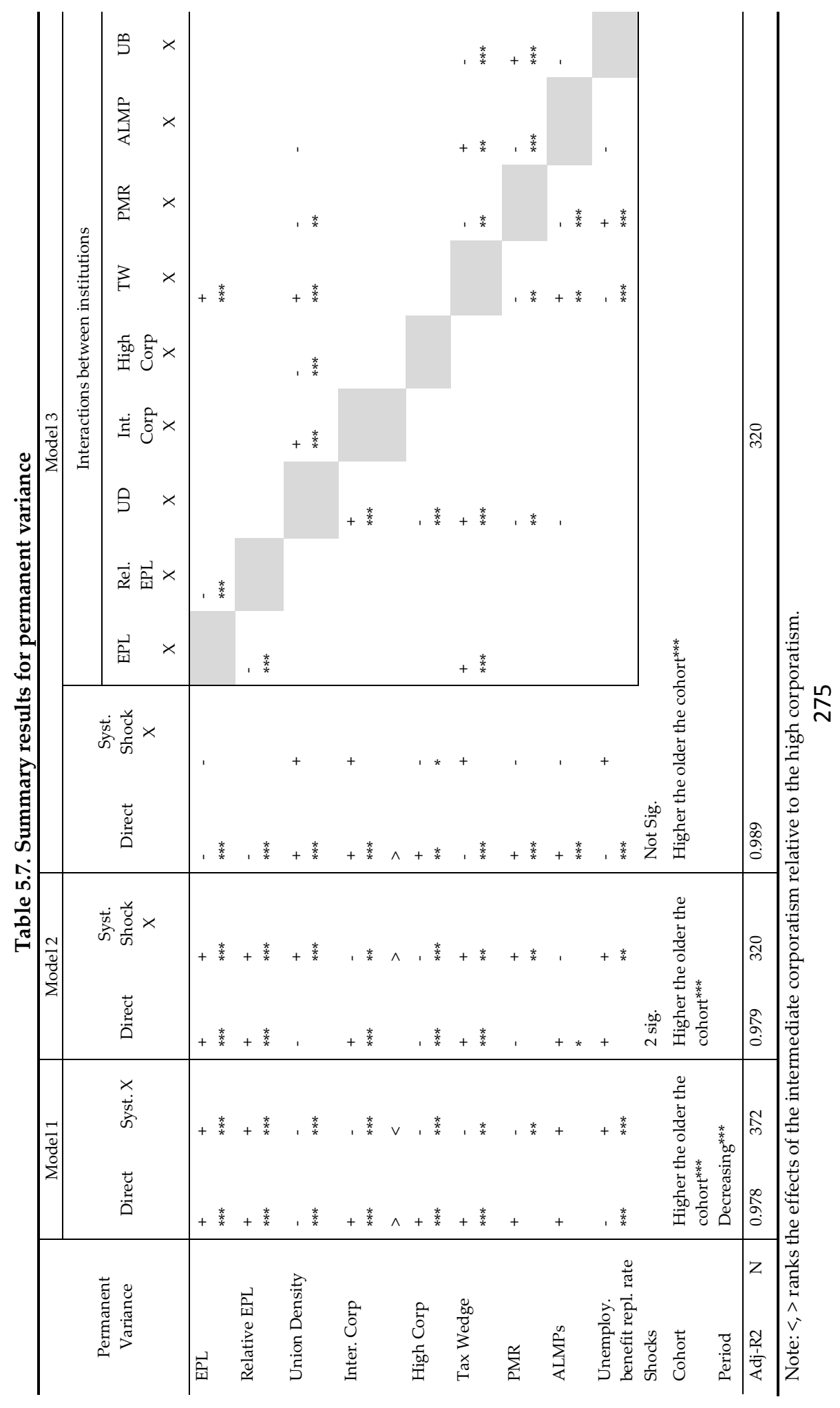




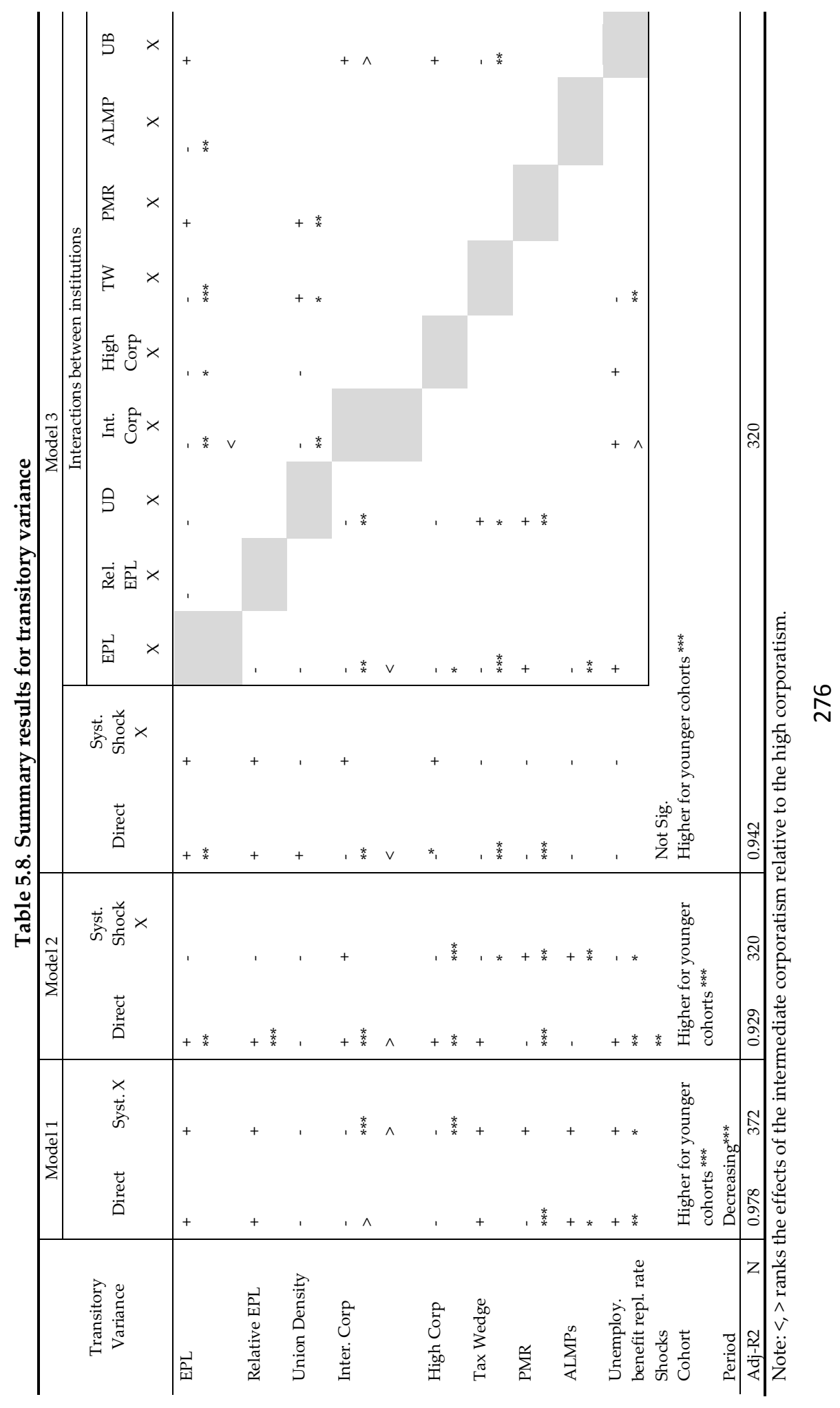




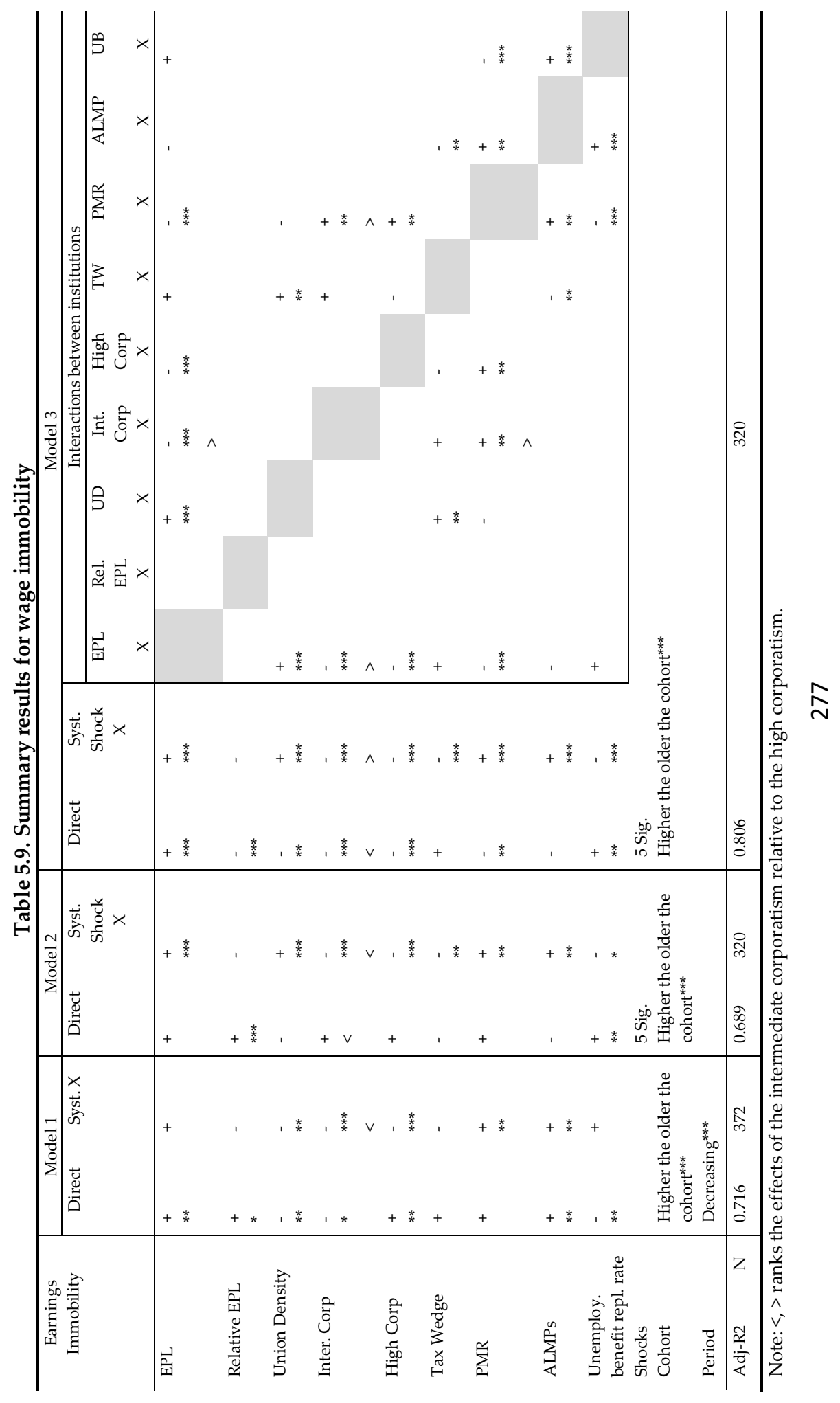




\subsection{Concluding remarks}

Using the ECHP and OECD data, this paper explores the role of labour market policy and institutional factors in explaining cross-national differences in the evolution of permanent inequality, transitory inequality and earnings mobility across 14 EU countries. So far, at the EU level, no study attempted to analyse and to understand the driving factors behind the three labour market outcomes in a comparative manner. In Europe, the most notable change after 1995, which is the approximate year of the turnaround in the labour market institutional and policy framework, represents the increased country heterogeneity, which translated itself in the level and the evolution of the cross-sectional earnings inequality components and earnings mobility.

Overall, the decrease in inequality resulted from a decrease in transitory differentials in Germany, France, UK and Ireland, in permanent differentials in Belgium and Spain, and in both components in Denmark and Austria. The increase in inequality reflects an increase in permanent differentials in Luxembourg, Italy, Greece and Finland, and an increase in both components in Portugal and Netherlands. The decrease in inequality was accompanied by an increase in mobility only in Denmark, Belgium and Spain. Except for Netherlands and Portugal, all countries recording an increase in inequality experienced also a decrease in mobility. Several common traits emerge across countries: the older the cohort, the higher the impact of permanent variance and wage immobility, and the lower the impact transitory inequality. Thus earnings volatility is higher at younger ages.

To what extent do labour market policies and institutional factors shape the pattern in permanent inequality, transitory inequality and earnings immobility? The estimation results reveal a highly complex framework, where institutions interact significantly not only with each other and with the overall institutional setting, but also with the macroeconomic shocks in shaping the pattern of the three labour market outcomes. A summary of the estimation results is provided in Table 5.7, Table 5.8 and Table 5.9.

Permanent inequality and transitory inequality are determined mainly by the institutional setting, which wipe out both the direct and interaction effects of the macro shocks. This suggests that the overall institutional structure manages to filter out all direct and indirect effect of the macro shocks. Hence, in shaping permanent and transitory inequality patterns, not the individual interactions 
between shocks and each institution count, but how institutions interact with each other in dealing with the effects of these shocks. We identified more significant institutional direct and indirect effects for permanent inequality, sign that the institutional factors play a larger role in shaping permanent than transitory inequality. The only stand-alone factor which is effective in reducing or limiting the increase of permanent inequality under in the impact of macroeconomic shocks is the high degree of corporatism.

Earnings immobility is determined by the direct effects of institutions, macro shocks and their interactions with the institutional setting. The institutional and policy factors that amplify the positive impact of the systemic shock on wage immobility are the EPL, the union density, the PMR, the ALMPs. The factors that decrease the impact of the systemic shock on wage immobility are the degree of corporatism, and the generosity of the unemployment benefit.

The direct effects of the institutions are mixed, depending on the interactions included in the model. Controlling for cross-institutional interactions, macro shocks and their interactions with the institutional setting, a positive direct effect on permanent inequality is identified for the union density - which intensifies in interaction with an intermediate corporatism, and the tax wedge, and decreases in interaction with a high corporatism and the PMR -, for an intermediate corporatism - which increases in interaction with the union density -, for a high corporatism - which decreases with union density -, for the PMR - which increases with the unemployment benefit replacement rate, and decreases in interaction with the union density, the tax wedge, and the ALMPs -, and for the ALMPs - which increases in interaction with the tax wedge, and decreases in interaction with the PMR. A negative effect is identified for the EPL - which intensifies in interaction with the relative EPL, and is counteracted in interaction with the tax wedge -, for the tax wedge - which is amplified in interaction with the PMR and the unemployment benefit replacement rate, and is counteracted in interaction with the EPL, the union density, and the ALMPs -, and for the unemployment benefit replacement rate - which intensifies with the tax wedge, and is counteracted in interaction with the PMR.

For transitory inequality, a positive direct effect is identified for the EPL - which decreases with an intermediate corporatism to a larger extent compared with a high corporatism, with the tax wedge, and with the ALMPs. A negative effect is identified for an intermediate corporatism - which intensifies with the EPL and the union density -, for a high corporatism - which intensifies with the EPL -, for the tax wedge - which intensifies with the EPL and the unemployment benefit 
replacement rate, and is counteracted in interaction with union density -, for the PMR - which is counteracted in interaction with union density.

For earnings immobility, a positive direct effect is recorded for the EPL - which intensifies with the union density, and decreases with the degree of corporatism and the PMR -, and for the unemployment benefit replacement rate - which increases with the ALMPs and decreases with the PMR. A negative effect is observed for the union density - which is counteracted in interaction with the EPL and the tax wedge -, for the degree of corporatism - which intensifies in interaction with EPL, and is counteracted in interaction with the PMR -, for the PMR - which intensifies in interaction with the EPL and the unemployment benefit replacement rate, and is counteracted in interaction with the degree of corporatism and the ALMPs.

The systemic interactions reveal that the more equality/mobility-friendly the overall labour market policy and institutional framework is, the greater is the reducing impact: (i) of the union density, the degree of corporatism - a stronger reducing effect for an intermediate level than for a high level -, the tax wedge and the product market regulation on permanent inequality; (ii) of the union density and the degree of corporatism on transitory inequality; and (iii) of the union density and the degree of corporatism - a stronger reducing effect for an intermediate level than for a high level - on earnings immobility.

To conclude, a highly complex institutional mechanism is at work in shaping the pattern of the three labour market outcomes. This complexity is enhanced by the endogeneity bias characterising this framework, which in the absence of reliable instruments, prevents the establishment of causality. 


\subsection{Annex}

Table 5-A-1. Description of OECD variables

\begin{tabular}{|c|c|}
\hline OECD Variables & Description \\
\hline \multicolumn{2}{|r|}{ Source: Bassanini and Duval (2006) } \\
\hline $\begin{array}{c}\text { EPL }=\text { Employment } \\
\text { Protection Legislation }\end{array}$ & $\begin{array}{c}\text { OECD summary indicator of the stringency of Employment Protection Legislation. EPL } \\
\text { ranges from } 0 \text { to } 6 .\end{array}$ \\
\hline $\begin{array}{l}\text { EPLR }=\text { Employment } \\
\text { Protection Legislation for } \\
\text { regular contracts }\end{array}$ & $\begin{array}{c}\text { OECD summary indicator of the stringency of Employment Protection Legislation for } \\
\text { regular contracts }\end{array}$ \\
\hline $\begin{array}{l}\text { EPLT }=\text { Employment } \\
\text { Protection Legislation for } \\
\text { temporary contracts }\end{array}$ & $\begin{array}{l}\text { OECD summary indicator of the stringency of Employment Protection Legislation for } \\
\text { temporary contracts }\end{array}$ \\
\hline Union Density & Trade union density rate, i.e. the share of workers affiliated to a trade union, in $\%$. \\
\hline Union Coverage & $\begin{array}{c}\text { Collective bargaining coverage rate, i.e. the share of workers covered by a collective } \\
\text { agreement, in } \% .\end{array}$ \\
\hline Degree of & $\begin{array}{l}\text { Indicator of the degree of centralisation/co-ordination of the wage bargaining processes, } \\
\text { which takes values } 1 \text { for decentralised and uncoordinated processes, and } 2 \text { and } 3 \text { for } \\
\text { intermediate and high }\end{array}$ \\
\hline Tax & $\begin{array}{l}\text { The tax wedge expresses the sum of personal income tax and all social security } \\
\text { contributions as a percentage of total labour cost. }\end{array}$ \\
\hline $\begin{array}{c}\text { PMR } \\
=\text { Product Market } \\
\text { Regulation } \\
\end{array}$ & $\begin{array}{l}\text { OECD summary indicator of regulatory impediments to product market competition in } \\
\text { seven non-manufacturing industries. The data used in this paper cover regulations and } \\
\text { market conditions in seven energy and service industries. PMR ranges from } 0 \text { to } 6 \text {. }\end{array}$ \\
\hline $\begin{array}{l}\text { ALMPs = Public } \\
\text { expenditures on active } \\
\text { labour market } \\
\text { policies }\end{array}$ & $\begin{array}{l}\text { Public expenditures on active labour market programmes per unemployed worker as a } \\
\text { share of } \\
\text { GDP per capita, in } \% .\end{array}$ \\
\hline $\begin{array}{l}\text { Average unemployment } \\
\text { benefit replacement rate }\end{array}$ & $\begin{array}{l}\text { Average unemployment benefit replacement rate across two income situations ( } 100 \% \text { and } \\
67 \% \text { of APW earnings), three family situations (single, with dependent spouse, with } \\
\text { spouse in work) }\end{array}$ \\
\hline Labour Demand Shock & $\begin{array}{l}\begin{array}{l}\text { Logarithm of the labour share in business sector GDP purged from the short-run } \\
\text { influence of factor prices. }\end{array} \\
\end{array}$ \\
\hline Terms of Trade Shock & Logarithm of the relative price of imports weighted by the share of imports in GDP \\
\hline $\begin{array}{l}\text { Total Factor Productivity } \\
\text { Shock }\end{array}$ & $\begin{array}{l}\text { Deviation of the logarithm of Total Factor Productivity (TFP) from its trend calculated by } \\
\text { means of a Hodrick-Prescott (HP) filter (smoothing parameter } \lambda=100 \text { ) }\end{array}$ \\
\hline Real Interest Shock & $\begin{array}{c}\text { Difference between the 10-year nominal government bond yield (in \%) and the annual } \\
\text { change in the GDP deflator (in \%). }\end{array}$ \\
\hline \multicolumn{2}{|r|}{ Lindert-Allard OECD data sets 1950-2001 } \\
\hline Aggregate Supply Shock & $\begin{array}{l}\text { At the OECD level, amplified by openness = (INFLOECD-UNCHOECD)*OPEN/100, } \\
\text { INFLOECD = inflation for the OECD as a whole, averaged over the } 21 \text { countries, } \\
\text { UNCHOECD= Three-year change in the unemployment rate for the OECD as a whole) } \\
\text { OPEN= (exports + imports) as a percentage of GDP, from Penn World Tables }\end{array}$ \\
\hline $\begin{array}{l}\text { Aggregate Demand } \\
\text { Shock }\end{array}$ & amplified by openness $=(\text { INFLOECD+UNCHOECD })^{*}$ OPEN/100 \\
\hline
\end{tabular}


Table 5-A-2. Institutional Variables - Summary Statistics

\begin{tabular}{|c|c|c|c|c|c|c|}
\hline Variable & & Mean & Std. Dev. & Min & Max & Observations \\
\hline \multirow[t]{3}{*}{ EPL } & overall & 2.423 & 0.956 & 0.600 & 3.854 & $\mathrm{~N}=101$ \\
\hline & between & & 0.944 & 0.621 & 3.739 & $\mathrm{n}=$ \\
\hline & within & & 0.251 & 1.537 & 3.211 & 7.769 \\
\hline \multirow[t]{3}{*}{ EPLR } & overall & 2.322 & 0.847 & 0.948 & 4.333 & $N=101$ \\
\hline & between & & 0.865 & 0.990 & 4.333 & $\mathrm{n}=$ \\
\hline & within & & 0.057 & 2.187 & 2.546 & 7.769 \\
\hline \multirow[t]{3}{*}{ EPLT } & overall & 2.522 & 1.461 & 0.250 & 5.375 & $\mathrm{~N}=101$ \\
\hline & between & & 1.409 & 0.250 & 4.750 & $\mathrm{n}=13$ \\
\hline & within & & 0.496 & 0.769 & 4.053 & 7.769 \\
\hline \multirow[t]{3}{*}{ [(EPLR-EPLT)/EPLT] ${ }^{*} 100$} & overall & 0.676 & 1.683 & -0.670 & 5.413 & $N=101$ \\
\hline & between & & 1.704 & -0.553 & 5.413 & $\mathrm{n}=$ \\
\hline & within & & 0.216 & 0.166 & 1.471 & 7.769 \\
\hline \multirow[t]{3}{*}{ Union Density } & overall & 0.371 & 0.191 & 0.096 & 0.794 & $N=108$ \\
\hline & between & & 0.201 & 0.098 & 0.779 & $\mathrm{n}=14$ \\
\hline & within & & 0.017 & 0.302 & 0.429 & 7.714 \\
\hline \multirow[t]{3}{*}{ Degree of Corporatism } & overall & 2.570 & 0.649 & 1.000 & 3.000 & $\mathrm{~N}=$ \\
\hline & between & & 0.669 & 1.000 & 3.000 & $\mathrm{n}=12$ \\
\hline & within & & 0.000 & 2.570 & 2.570 & 7.75 \\
\hline \multirow[t]{3}{*}{ Tax Wedge } & overall & 0.326 & 0.068 & 0.128 & 0.449 & $\mathrm{~N}=$ \\
\hline & between & & 0.067 & 0.219 & 0.404 & $\mathrm{n}=12$ \\
\hline & within & & 0.022 & 0.234 & 0.390 & 7.75 \\
\hline \multirow[t]{3}{*}{ PMR } & overall & 3.394 & 1.015 & 1.133 & 5.236 & $\mathrm{~N}=$ \\
\hline & between & & 0.871 & 1.454 & 4.415 & $\mathrm{n}=12$ \\
\hline & within & & 0.563 & 2.155 & 4.459 & 7.75 \\
\hline \multirow[t]{3}{*}{ ALMPs } & overall & 0.301 & 0.209 & 0.048 & 1.261 & $\mathrm{~N}=$ \\
\hline & between & & 0.188 & 0.094 & 0.750 & $\mathrm{n}=12$ \\
\hline & within & & 0.101 & -0.035 & 0.812 & 7.75 \\
\hline \multirow[t]{3}{*}{ Unemployment Benefit RR } & overall & 0.360 & 0.117 & 0.166 & 0.649 & $\mathrm{~N}=$ \\
\hline & between & & 0.115 & 0.174 & 0.599 & $\mathrm{n}=12$ \\
\hline & within & & 0.030 & 0.271 & 0.451 & 7.75 \\
\hline \multirow[t]{3}{*}{ Labour demand shock } & overall & 0.062 & 0.062 & -0.075 & 0.167 & $N=$ \\
\hline & between & & 0.063 & -0.068 & 0.147 & $\mathrm{n}=11$ \\
\hline & within & & 0.013 & 0.028 & 0.099 & $\mathrm{~T}=7.727$ \\
\hline \multirow[t]{3}{*}{ Terms of Trade Shocks } & overall & -0.094 & 0.040 & -0.178 & -0.027 & $\mathrm{~N}=$ \\
\hline & between & & 0.035 & -0.146 & -0.042 & $\mathrm{n}=12$ \\
\hline & within & & 0.022 & -0.142 & -0.041 & $\mathrm{~T}=7.75$ \\
\hline \multirow[t]{3}{*}{ Total Factor Production Shock } & overall & 0.007 & 0.016 & -0.058 & 0.047 & $\mathrm{~N}=$ \\
\hline & between & & 0.007 & -0.001 & 0.019 & $\mathrm{n}=11$ \\
\hline & within & & 0.015 & -0.056 & 0.049 & $\mathrm{~T}=7.727$ \\
\hline \multirow[t]{3}{*}{ Real Interest Shock } & overall & 0.039 & 0.018 & -0.016 & 0.080 & $N=$ \\
\hline & between & & 0.007 & 0.023 & 0.045 & $\mathrm{n}=12$ \\
\hline & within & & 0.017 & -0.001 & 0.088 & $\mathrm{~T}=7.75$ \\
\hline \multirow[t]{3}{*}{ Aggregate Labour Supply } & overall & 1.855 & 2.084 & -0.635 & 8.145 & 101 \\
\hline & between & & 0.924 & 1.054 & 3.692 & $\mathrm{n}=13$ \\
\hline & within & & 1.881 & -2.472 & 6.308 & $\mathrm{~T}=7.769$ \\
\hline \multirow[t]{3}{*}{ Aggregate Labour Demand } & overall & 3.388 & 1.776 & 1.175 & 8.158 & 101 \\
\hline & between & & 1.581 & 2.051 & 6.578 & $\mathrm{n}=13$ \\
\hline & within & & 0.871 & 0.534 & 4.968 & $\mathrm{~T}=7.769$ \\
\hline
\end{tabular}




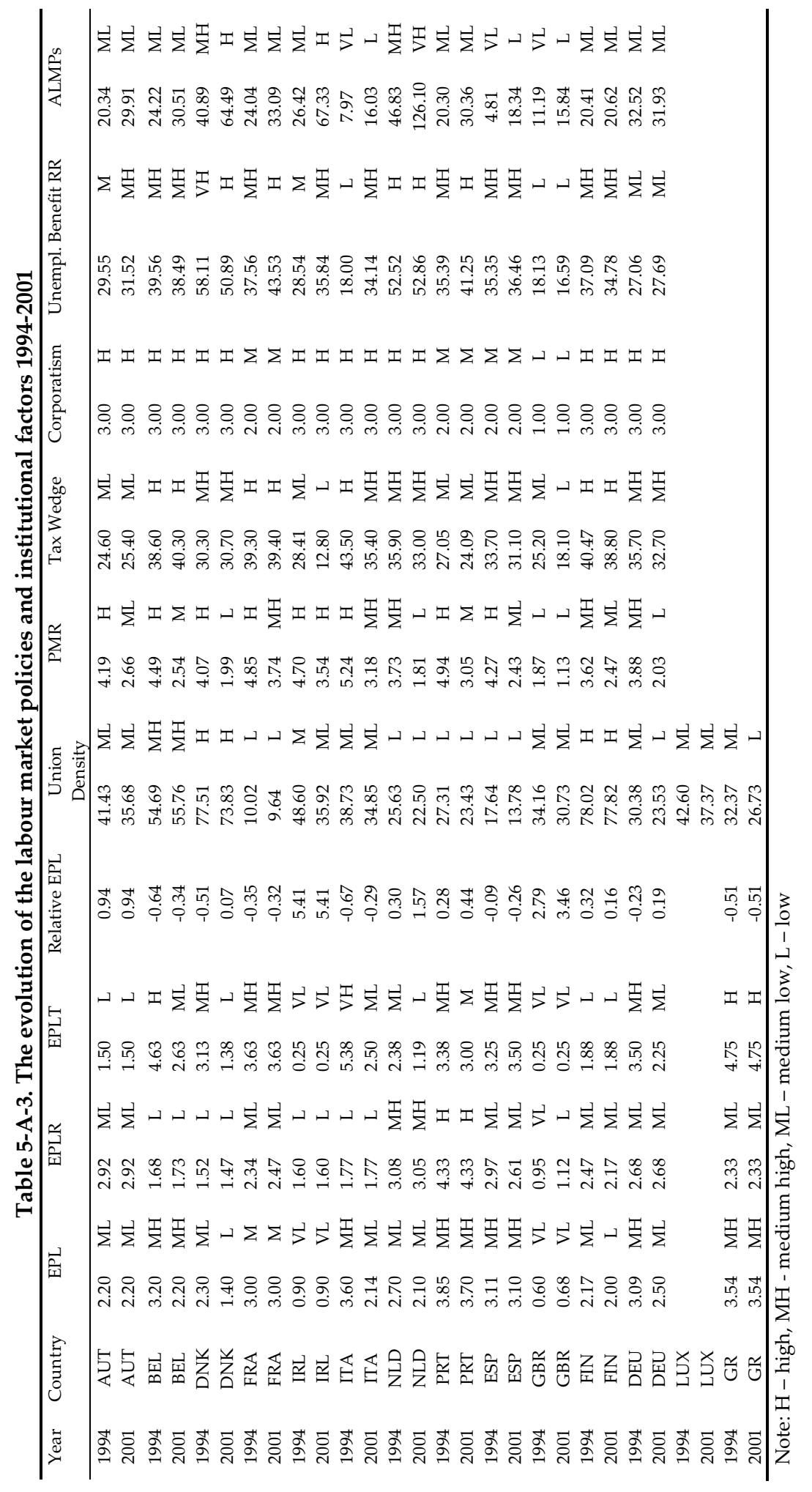

$\stackrel{\infty}{\sim}$ 
Table 5-A-4. Share of employees by educational level, by sector, by type of contract, by employment status, by occupational - for selected cohorts based on ECHP

\begin{tabular}{|c|c|c|c|c|c|c|c|c|c|}
\hline \multicolumn{2}{|l|}{ Variable } & \multicolumn{2}{|c|}{$\begin{array}{c}\text { Cohort } \\
1940-1950\end{array}$} & \multicolumn{2}{|c|}{$\begin{array}{c}\text { Cohort } \\
1951-1960\end{array}$} & \multicolumn{2}{|c|}{$\begin{array}{c}\text { Cohort } \\
1961-1970\end{array}$} & \multicolumn{2}{|c|}{$\begin{array}{c}\text { Cohort } \\
1971-1981\end{array}$} \\
\hline & Obs & $\begin{array}{c}\text { Mea } \\
\mathrm{n}\end{array}$ & $\begin{array}{l}\text { Std. } \\
\text { Dev. }\end{array}$ & Mean & Std. Dev. & Mean & Std. Dev. & Mean & Std. Dev. \\
\hline Share of University Degree & 108 & 0.228 & 0.115 & 0.248 & 0.128 & 0.250 & 0.130 & 0.134 & 0.144 \\
\hline Share of Upper-Sec Degree & 108 & 0.327 & 0.191 & 0.367 & 0.177 & 0.401 & 0.195 & 0.451 & 0.197 \\
\hline Share of permanent contracts & 108 & 0.896 & 0.074 & 0.875 & 0.060 & 0.849 & 0.087 & 0.755 & 0.170 \\
\hline Share of private employees & 108 & 0.657 & 0.096 & 0.678 & 0.082 & 0.789 & 0.052 & 0.860 & 0.055 \\
\hline Share of Unemployed & 108 & 0.068 & 0.033 & 0.057 & 0.037 & 0.078 & 0.043 & 0.129 & 0.096 \\
\hline Occupation Structure (ECHP) & & & & & & & & & \\
\hline Share of managers, legislators, etc. & 108 & 0.118 & 0.044 & 0.109 & 0.045 & 0.077 & 0.041 & 0.021 & 0.022 \\
\hline Share of professionals & 108 & 0.112 & 0.049 & 0.116 & 0.047 & 0.103 & 0.044 & 0.042 & 0.032 \\
\hline Share of technicians \& a & 108 & 0.099 & 0.039 & 0.118 & 0.044 & 0.111 & 0.045 & 0.069 & 0.035 \\
\hline Shar & 108 & 0.057 & 0.028 & 0.069 & 0.040 & 0.072 & 0.026 & 0.056 & 0.026 \\
\hline Share of service \& sales workers & 108 & 0.046 & 0.021 & 0.057 & 0.024 & 0.065 & 0.023 & 0.074 & 0.029 \\
\hline $\begin{array}{c}\text { Share of skilled agricultural \& fishery } \\
\text { workers }\end{array}$ & 108 & 0.052 & 0.042 & 0.042 & 0.025 & 0.037 & 0.025 & 0.024 & 0.017 \\
\hline Share of craft \& related trade workers & 108 & 0.160 & 0.046 & 0.185 & 0.054 & 0.197 & 0.062 & 0.165 & 0.071 \\
\hline Share of plant \& machine operators & 108 & 0.093 & 0.029 & 0.102 & 0.025 & 0.101 & 0.024 & 0.066 & 0.021 \\
\hline Share of elementary occupations & 108 & 0.052 & 0.022 & 0.062 & 0.023 & 0.063 & 0.026 & 0.066 & 0.032 \\
\hline
\end{tabular}




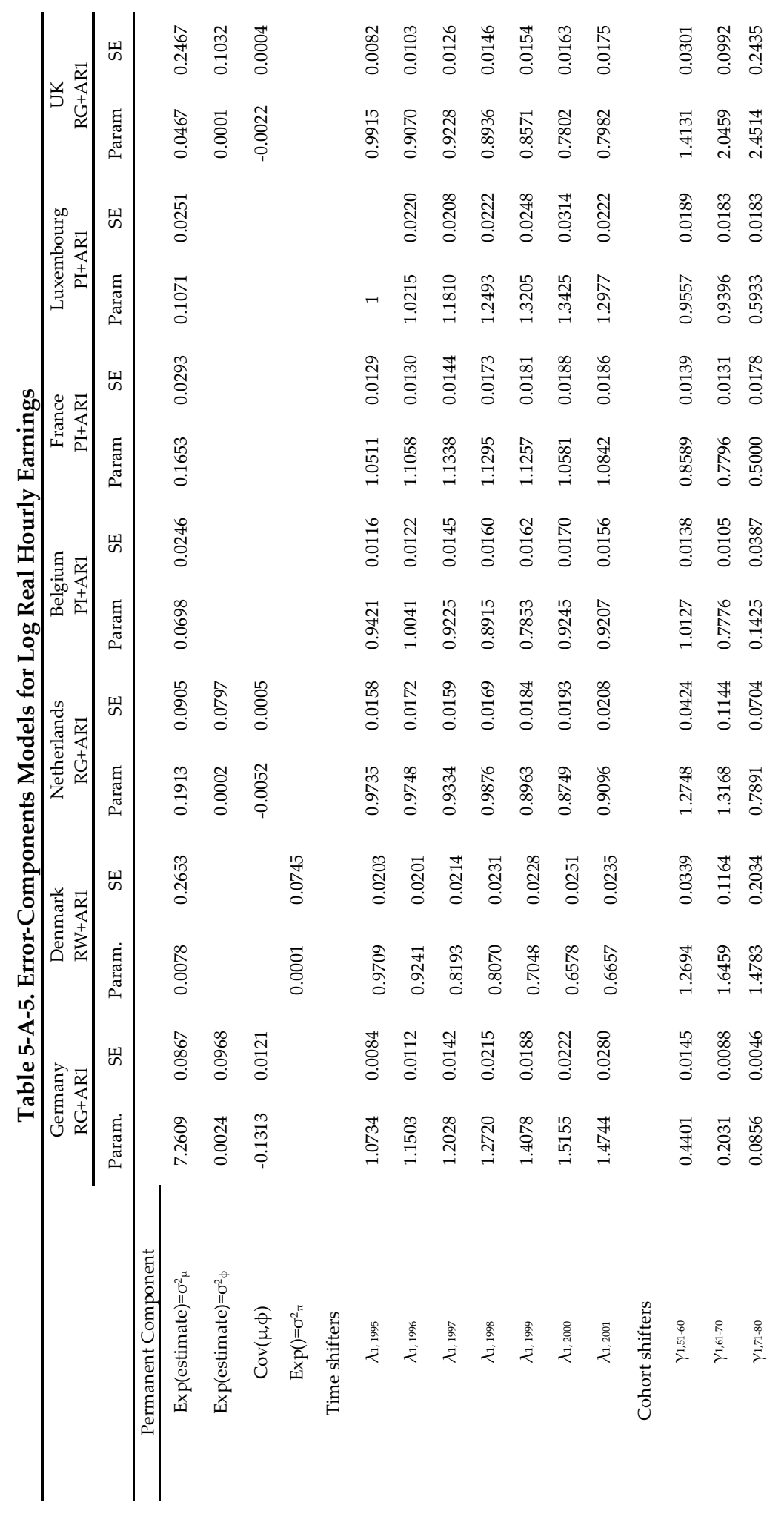

$\stackrel{\infty}{\sim}$ 


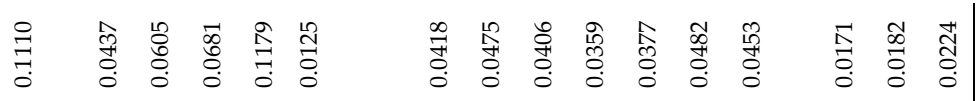

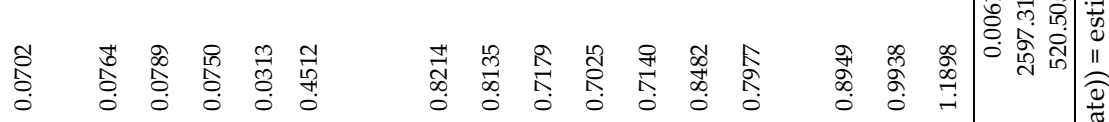

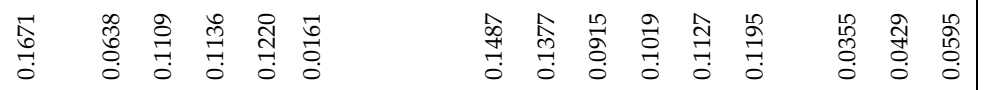

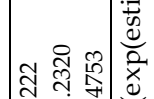

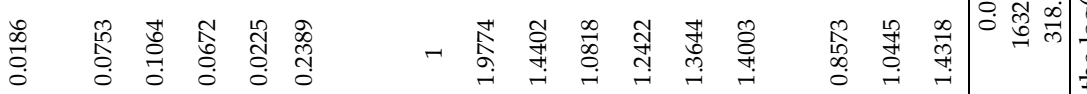

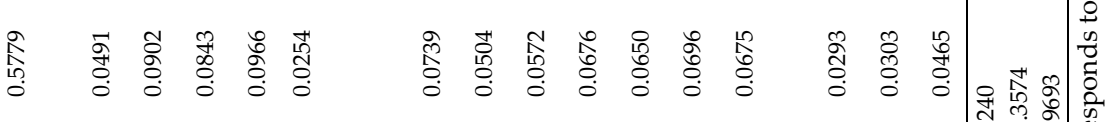

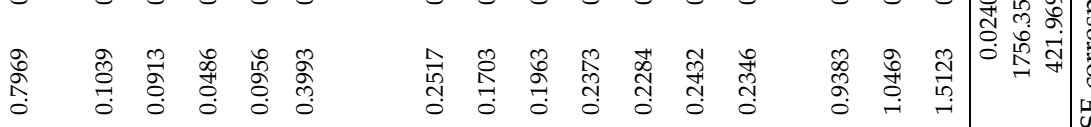

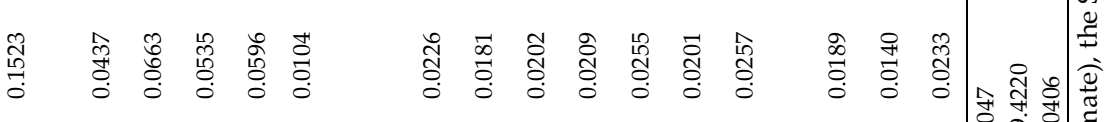

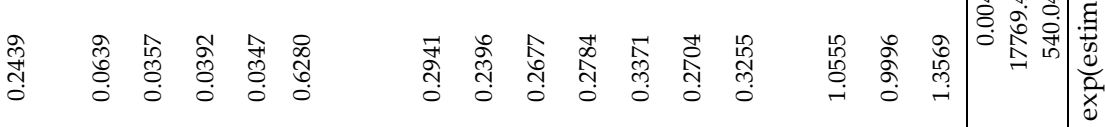

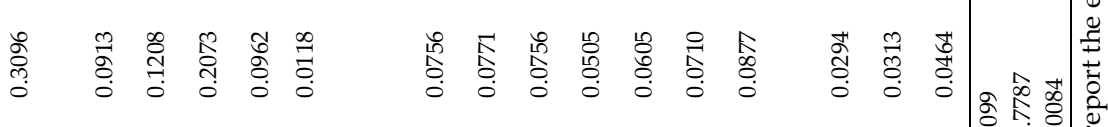

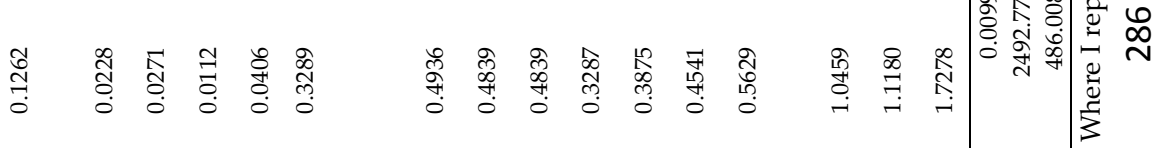

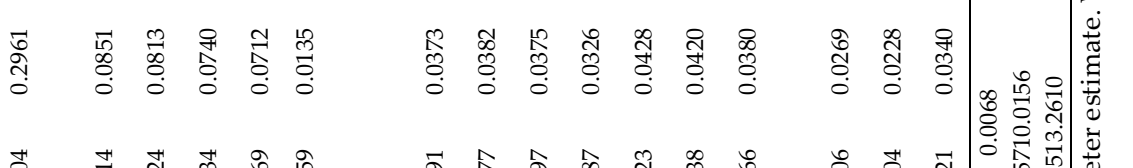

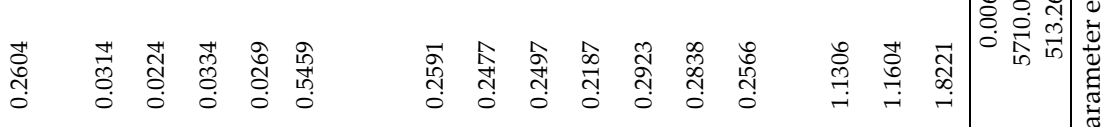

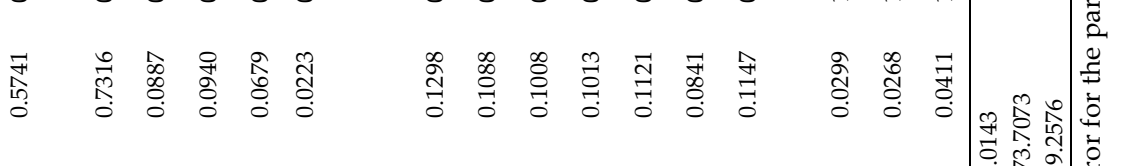

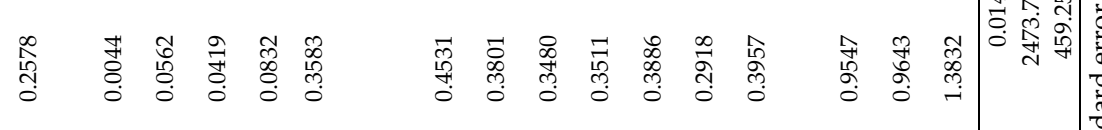

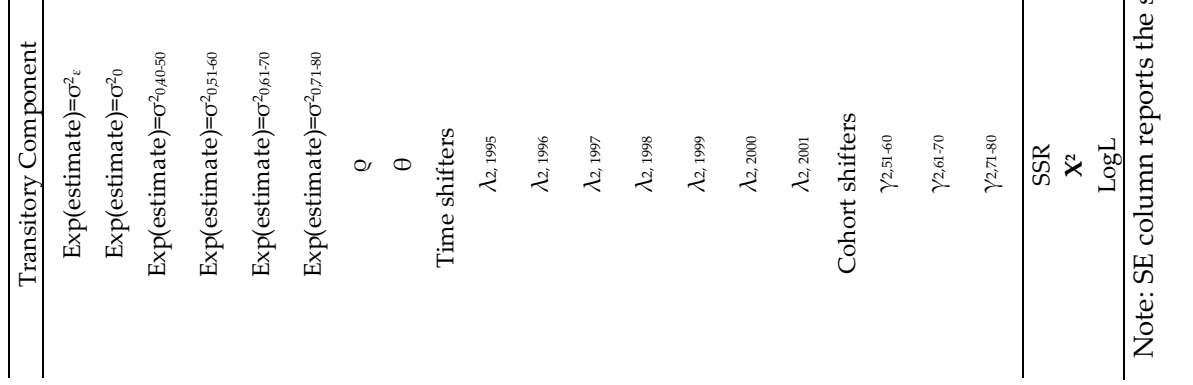




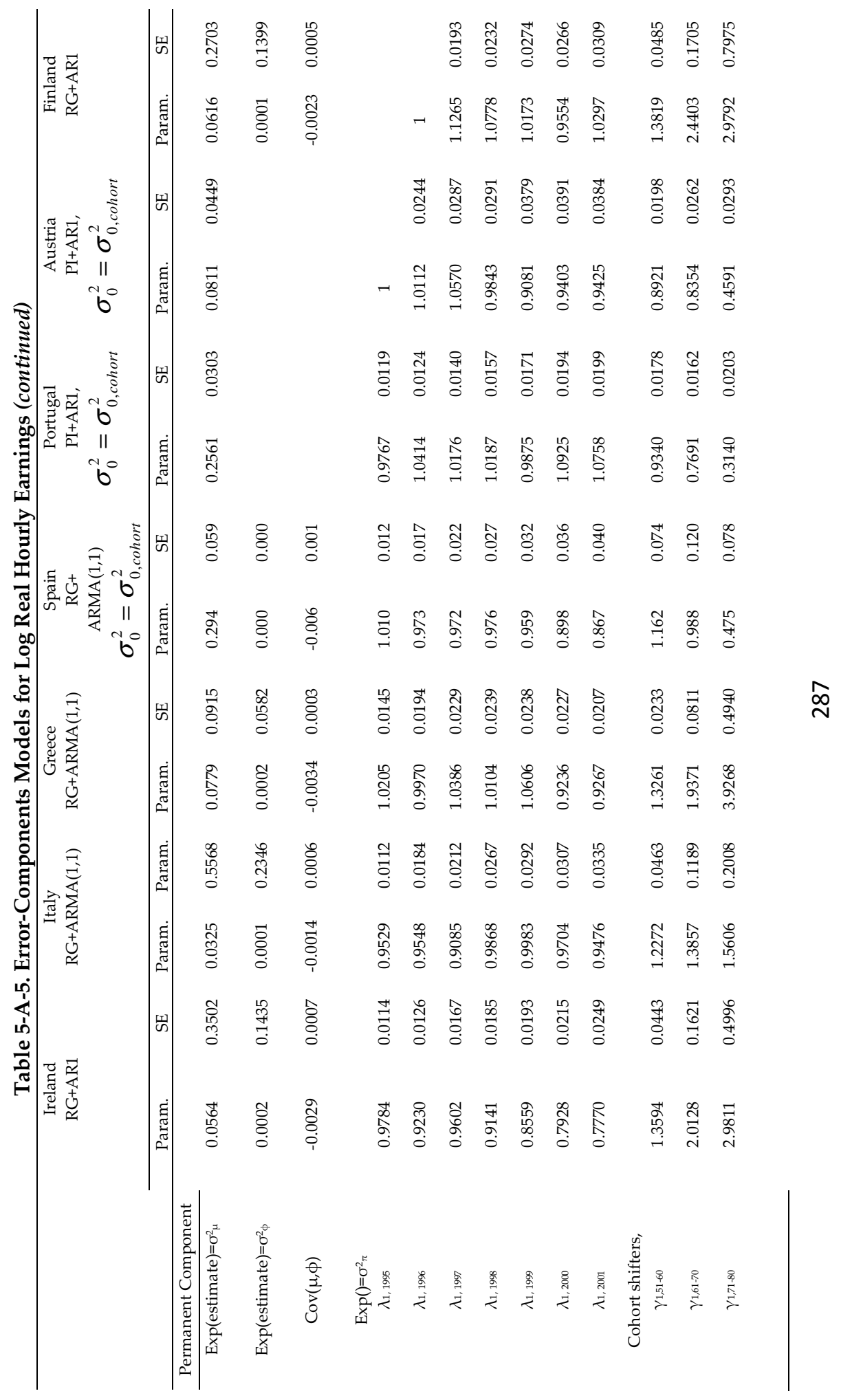




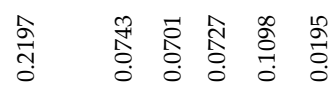

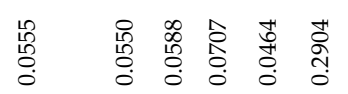

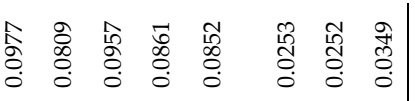

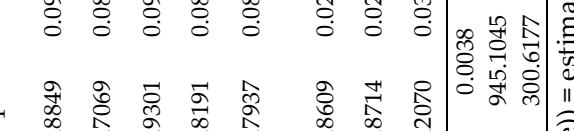

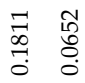

ริ

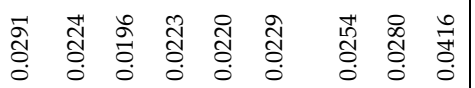

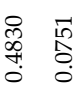

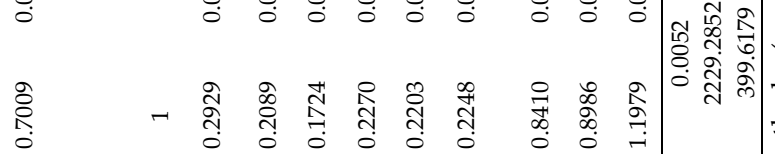

행홍

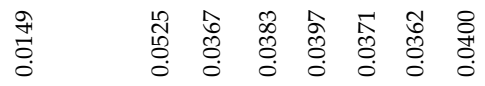

善器器

종 옇

罗

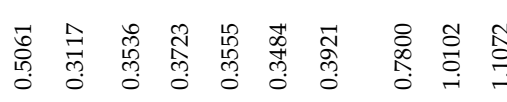

帘

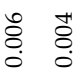

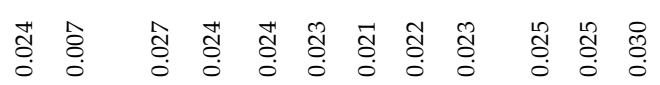

옹

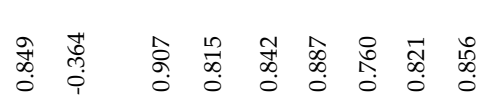

喜要目

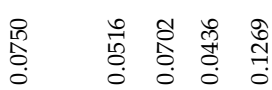

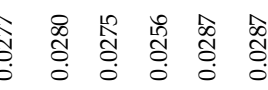

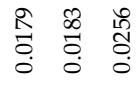

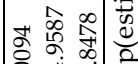

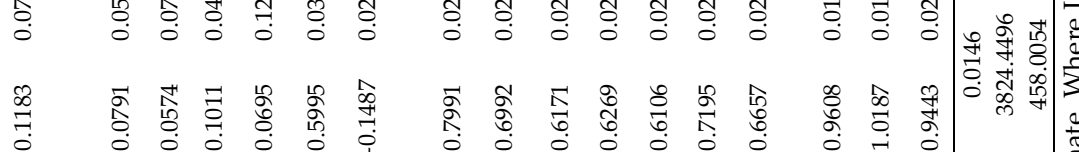

$\stackrel{\infty}{\sim}$

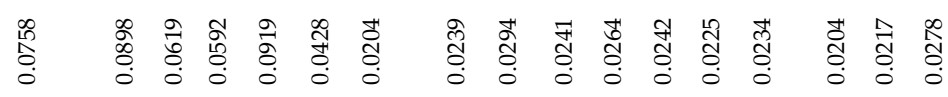

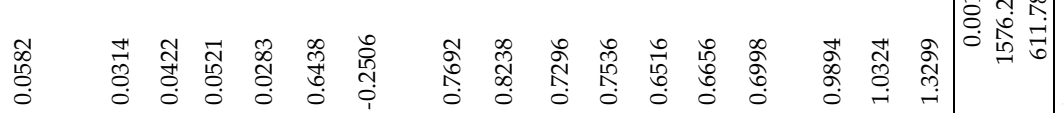

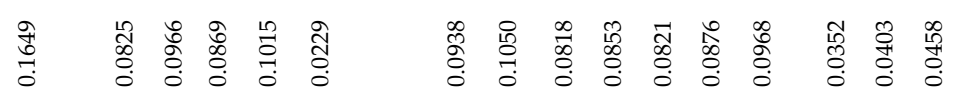

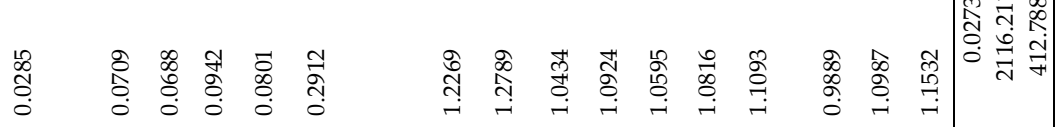



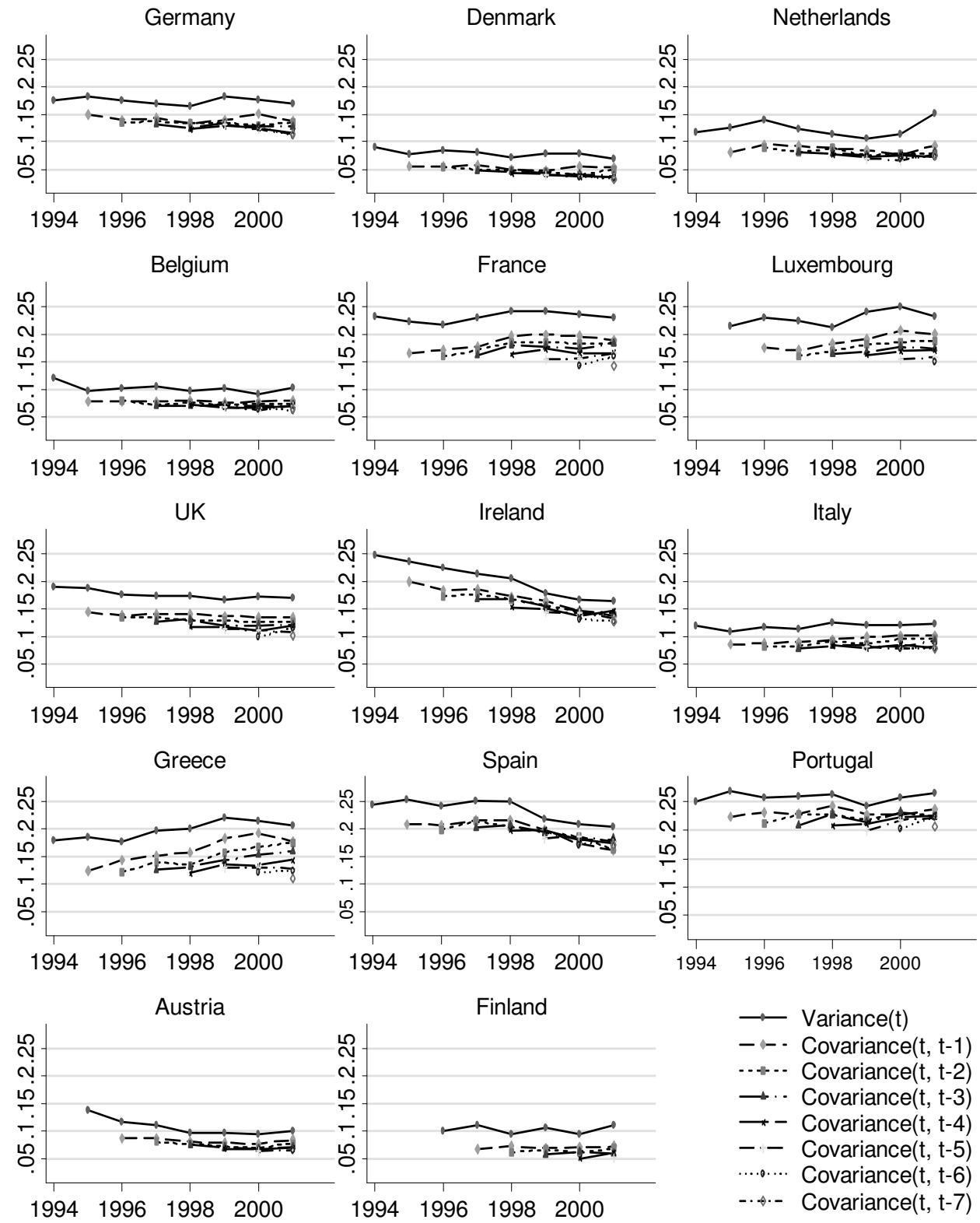

Figure 5-A-1. Overall Autocovariance Structure of Hourly Earnings: Years 1994-2001 

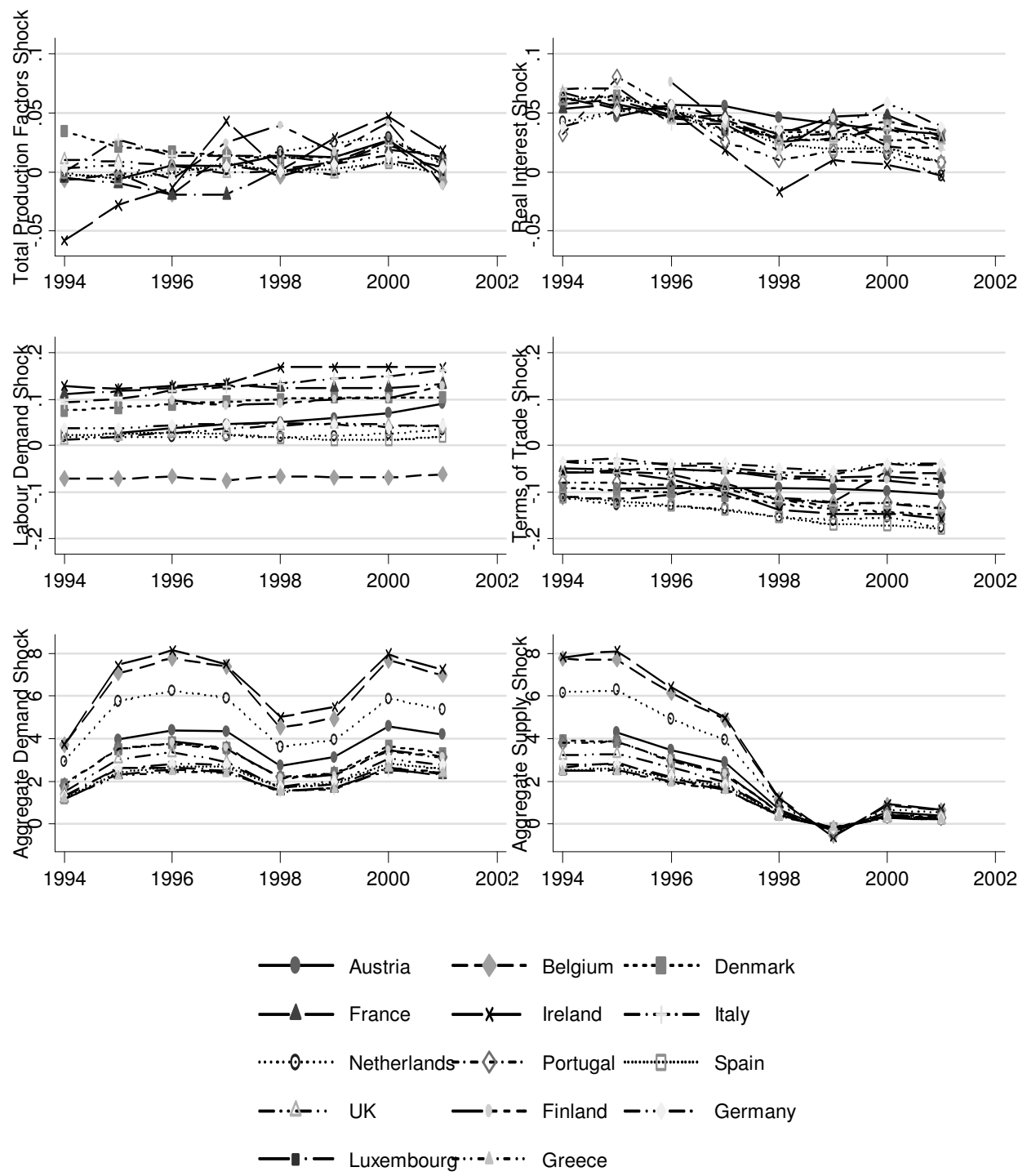

Figure 5-A- 2. Evolution of macroeconomic shocks 
6. EARNINGS DYNAMICS AND INEQUALITY AMONG MEN IN LUXEMBOURG, 1988-2004: EVIDENCE FROM ADMINISTRATIVE DATA 


\subsection{Introduction}

Understanding the source of the growth in earnings inequality has become a major topic in economics over the past two decades, fuelled mainly by the rise in earnings inequality experienced by many developed countries during the $1980 \mathrm{~s}$ and 1990s.

Starting with the US and Canada, followed by UK and Europe, recent studies on earnings dynamics have stressed the importance of decomposing the growth in earnings inequality into permanent and transitory components, due to their implications for long-run differentials. An increase in cross-sectional earnings inequality triggered by an increase in the permanent component signals an increase in lifetime earnings differentials, suggesting a worsening of the relative lifetime earnings position of the chronically poor. An increase in cross-sectional earnings differentials triggered by an increase in earnings instability signals an increase in earnings mobility, implying an increased opportunity for the poor to improve their relative income position in a lifetime perspective.

In Europe, the advancement and the full potential of this research in understanding the structural changes in inequality has been limited, due to insufficiently long panels. My study aims to fill part of this gap.

The contribution of this study to the literature on earnings dynamics and inequality is twofold. First, it aims to expand the research regarding the possible implications of the labour market structural changes on the structure of earnings inequality and earnings mobility. The specific context of the Luxembourgish labour market, which underwent significant structural changes during the last decades, makes Luxembourg a relevant case for studying the structural changes in earnings inequality and the implications for lifetime earnings differentials. This study is the first of its kind in Luxembourg. Following the tradition of previous studies I focus on men to avoid the problem of selection bias characterising female earnings.

Starting with the late 1970s and intensifying after early 1990s, Luxembourg evolved from an industrial economy to an economy dominated by the tertiary sector, which relies heavily on the cross-border workforce. Moreover, Luxembourg recorded a large increase in the number of active population, both residents and cross-borders, which more than doubled in 2004 compared with 1988. The change in the structure of the labour market by occupation status (Figure 6-A-1, Annex), reveals an increase in the share of white collars and civil servants, and a decrease in the share of blue collars. The change in the labour market structure by the sector 
of activity (Figure 6-A-2, Annex) reveals a significant increase in the share of the service sector and a decrease in the share of the industry sector. The evolution of the labour market age distribution (Figure 6-A-3, upper panel, Annex) reveals a clear shift in men's labour market behaviour due to the education system: from a high concentration of active men around ages 20-25 in 1988 to a high concentration around ages 25-45 in 2004. The change in the labour market behaviour is confirmed also by the cumulative age distribution (Figure 6-A-3, bottom panel, Annex), which shifted towards higher ages: e.g. the share of people present in the labour market until age 25 is almost double in 1988 than in 1996 or 2004. Following these changes cross-sectional earnings inequality increased.

What are the implications of these changes for the structure of earnings inequality and earnings mobility? Using 17 years of longitudinal earnings information drawn from the administrative data on the professional career, I decompose Luxembourg's growth in earnings inequality into persistent and transitory components. I explore the extent to which changes in cross-sectional earnings inequality in Luxembourg between 1988 and 2004 reflect changes in the transitory or permanent components of earnings.

On the one hand, did the increases in cross-sectional wage inequality result from greater transitory fluctuations and a higher degree of earnings mobility? Or does it reflect increasing permanent differences between individuals with mobility remaining constant or even falling? On the other hand, did mobility influence falls in cross-sectional inequality? Understanding the contributions of the changes in permanent and transitory inequality to increased cross-sectional inequality is useful therefore in evaluating alternative structural changes hypotheses and for determining the potential welfare consequences of rising inequality. (Katz and Autor, 1999)

Second, I exploit my extraordinary dataset to achieve some methodological advances at the EU level. The limited scale of most European panels has forced EU researchers to rely on simple country models, which impose economically implausible restrictions. For example, the 7 ECHP waves available for Luxembourg have forced Sologon and O'Donoghue (2009a, 2009b) to impose the assumption of invariant permanent component with no permanent shocks (age specific or not), no life-cycle variation in the variance of transitory earnings shocks and no MA process in the transitory variance. Due to my long panel, I am able to estimate much richer models that nest the various specifications used in the US, Canadian and European literature up to date. 
Unlike previous studies, I decompose my analysis by 36 birth cohorts composed of people born in a certain year. This small age window allows the precise identification of the two components at different lifecycle stages. Equally weighted minimum distance methods are used to estimate the covariance structure of earnings, decompose earnings inequality into a permanent and a transitory component, estimate earnings mobility and conclude about their evolution.

\subsection{Literature review ${ }^{93}$}

The existing literature on earnings dynamics is predominantly based on US data. Atkinson, Bourguignon et al. (1992) provide a comprehensive survey of the literature on earnings dynamics until 1992. Earlier work focused on fitting statistical models to the earnings process. E.g. Lillard and Willis (1978), Lillard and Weiss (1979), MaCurdy (1982), Abowd and Card (1989) fitted models to the autocovariance structure of earnings and hours, but they did not account for the changes in the autocovariance structure of earnings over time.

Later work, Moffitt and Gottschalk (1995, 1998, 2002) used PSID to estimate the permanent and transitory components of male earnings and how it evolved over time. In Moffitt and Gottschalk (1998), the earnings process was fit by a permanent component, modelled as a random walk in age and a highly persistent serially correlated transitory component, with weights on these components for each year. They found that the increase in the cross-sectional inequality of individual earnings and wage rates in the U.S. between 1969 and 1991 has been roughly equally composed of increases in the variances of the permanent and transitory components of earnings, with little change in earnings mobility rates. Since most of the theoretical explanations for the increase in inequality have been aimed at explaining increases in the variance of the permanent component of earnings (e.g. increases in the price of skills), they found their result surprising and unexpected. Therefore, in their most recent study, Moffitt and Gottschalk (2008) estimated the trend in the transitory variance of male earnings using PSID from 1970 to 2004. They found that the transitory variance increased substantially in the 1980's and remained at the same level until 2004, for both less and more educated workers. Moreover, the transitory variance appears to have a strong cyclical component: its increase accounts for between $30 \%$ and $65 \%$ of the rise in the overall inequality, depending on the period.

\footnotetext{
${ }^{93}$ Most of the information in this section has been covered in section 4.2.
} 
Using the PSID, Baker (1997) compared two competing specifications for the permanent component of earnings: the "profile heterogeneity or the random growth model" and the "random walk model". In spite of the increased popularity of the latter, Baker (1997) proved that the profile heterogeneity model provides a better representation of the data.

Baker and Solon (2003) decomposed the growth in earnings inequality into its persistent and transitory components using longitudinal income tax records from Canada. The earnings process was fit by a permanent component, modelled as a mixed process composed of a random growth and a random walk in age and a highly persistent serially correlated transitory component, with weights on these components for each year. They found that growth in earnings inequality reflects both an increase in the long-run inequality and an increase in earnings instability.

Up until recently, little work has been carried out in Europe on the dynamic nature of individual earnings. Dickens (2000b) analysed the pattern of individual male wages over time in UK using the New Earnings Survey (NES) panel data set for the period 1975-1995. This study divided the data into year birth cohorts and analysed the auto-covariance structure of hourly and weekly earnings for each cohort. In the tradition of Moffitt and Gottschalk (1998), the earnings process was fit by a permanent component, modelled as a random walk in age and a highly persistent serially correlated transitory component, with weights on these components for each year. The innovative element of their model was the extension of the random walk to a specification that allows for age-specific innovation variances until age 40 and a random effects model thereafter. The results showed that about half of the rise of the overall cross-sectional inequality can be explained by the rise in the permanent variance and the rest by the rise in the persistent transitory component.

Ramos (2003) analysed the dynamic structure of earnings in UK using the British Household Panel Study for the period 1991-1999. The earnings specification followed a similar specification with Baker and Solon (2003). Using information on monthly earnings of male full-time employees, this study decomposed the covariance structure of earnings into its permanent and transitory components and concluded that the increase in inequality over the 1990's was due to increased in earnings volatility. Moreover, the relative earnings persistency was found to decline over the lifecycle, which implies a lower mobility for younger cohorts. These findings are at odds with the previous literature on earnings dynamics both for UK and the OECD. Unlike previous literature, this study considered also for the effect of observed characteristics and found that human capital and job related characteristics account for nearly all persistent earnings differences and that the transitory component is highly persistent. 
Kalwij and Alessie (2003) examined the variance-covariance structure of log-wages over time and over the lifecycle of British men from 1975 to 2001, controlling for cohort effects. Their model follows closely the specification used by Abowd and Card (1989), Dickens (2000b) and Baker and Solon (2003) accounting also for cohort effects. They showed that the increase in the cross-sectional inequality was caused mainly by an increase in the transitory component of earnings and to a lesser extent by an increase in the permanent wage inequality. Thus the increase in crosssectional inequality was accompanied by an increase in earnings mobility.

Cappellari (2003) used the Italian National Social Security Institute for the period 1979-1995 and decomposed the male earnings autocovariance structure into its long-term and transitory components using a model specification similar with Moffitt and Gottschalk (1995) and Backer (1997). The model included a permanent component, modelled as a random growth in age and a highly persistent serially correlated transitory component, with weights on these components for each year and cohort. The findings showed that growth was determined by the long-term earnings component. Other evidence on the contribution of permanent and transitory earnings components to cross-sectional inequality has become available in recent year in Sweden. Gustavson (2004a, 2009b) used a hybrid model between Baker and Solon (2003) and Dickens (2000b) and concluded that the decrease in earnings inequality was due to a decrease in the permanent component.

Most recently, Sologon and O'Donoghue (2009a, 2009b) used the 8 waves of ECHP for $14 \mathrm{EU}$ countries to explore the dynamic structure of individual earnings and the extent to which changes in cross-sectional earnings inequality reflect transitory or permanent components of individual lifecycle earnings variation. Overall, the decrease in inequality resulted from a decrease in transitory differentials in Germany, France, UK and Ireland, in permanent differentials in Belgium and Spain and in both components in Denmark and Austria. The increase in inequality reflects an increase in permanent differentials in Luxembourg, Italy, Greece and Finland, and an increase in both components in Portugal and Netherlands. The decrease in inequality was accompanied by an increase in mobility only in Denmark, Belgium and Spain. Except for Netherlands and Portugal, all countries recording an increase in inequality experienced also a decrease in mobility. 


\subsection{Theoretical model of the determinants of wage differentials $^{94}$}

The theoretical and methodological specifications in this section follow closely Sologon and O'Donoghue (2009a, 2009b).

\subsubsection{Determinants of earnings inequality}

As pointed out by Katz and Autor (1999), the existing literature contains many explanations for the rise in earnings inequality experienced by many developed countries during the 1980s and 1990s. One approach for explaining changes in wage differential is to decompose overall wage inequality into permanent inequality and transitory inequality.

Following the terminology introduced by Friedman and Kuznets (1954), individual earnings are composed of a permanent and a transitory component, assumed to be independent of each other. The permanent component of earnings reflects personal characteristics, education, training and other systematic elements. The transitory component captures the chance and other factors influencing earnings in a particular period and is expected to average out over time. Following the structure of individual earnings, overall inequality at any point in time is composed from inequality in the transitory component and inequality in the permanent component of earnings. The evolution of the overall earnings inequality is determined by the cumulative changes in the two inequality components.

The rise in the inequality in the permanent component of earnings may be consistent with increasing returns to education, on-the-job training and other persistent abilities that are among the main determinants of the permanent component of earnings, meaning enhanced relative earnings position of the highly skilled individuals (Mincer, 1957, 1958, 1962, 1974; Hause, 1980).

The increase in the inequality of the transitory component of earnings may be attributed to the weakening of the labour market institutions (e.g. unions, government wage regulation, and internal labour markets), increased labour market instability, increased competitiveness, a rise in the temporary workforce which increase earnings exposure to shocks. A period of skill-biased technological change with the spread of new technologies can on the one hand increase the demand for skills, and on the other hand it can increase earnings instability (Katz and Autor, 1999). Rodrik (1997) argued that also globalization and international

\footnotetext{
94 The information in this section has been covered in section 4.3 .
} 
capital mobility can increase wage instability. Overall, the increase in the return to persistent skills is expected to have a much larger impact on long-run earnings inequality than an increase in the transitory component of earnings (Katz and Autor, 1999; Moffitt and Gottschalk, 2002).

\section{Alternative model specifications for the permanent and transitory components}

Next I introduce several models of earnings dynamics that have been dominating the literature on permanent and transitory earnings inequality over the past 30 years. To begin with, I introduce the simplest specification, which in spite of its simplicity provides a very intuitive insight into the decomposition of earnings into their permanent and transitory components. Based on this specification earnings are being decomposed as follows:

$$
Y_{i t}=\mu_{i}+v_{i t}, \quad \mu_{i} \sim \operatorname{iid}\left(0, \sigma_{\mu}^{2}\right), \quad v_{i t} \sim \operatorname{iid}\left(0, \sigma_{v}^{2}\right), \quad t=1, \ldots, T_{i}, i=1, \ldots, N
$$

where $\mu_{i}$ represents the permanent time-invariant individual specific component and $v_{i t}$ represents the transitory component, which is independent distributed both over individuals and time. This model imposes very rigid restrictions on the covariance structure of earnings:

$$
\operatorname{Cov}\left(Y_{i t}, Y_{i s}\right)= \begin{cases}\sigma_{\mu}^{2}+\sigma_{v}^{2}, & t=s \\ \sigma_{\mu}^{2}, & t \neq s\end{cases}
$$

Because $\mu_{i}$ is assumed to incorporate the effect of lifetime persistent individual specific characteristics such as ability, the variance of the permanent component $\sigma_{\mu}^{2}$ represents the persistent dispersion of earnings or the inequality in the permanent component of earnings. The transitory shocks are captured by the transitory variance $\sigma_{v}^{2}$ and are assumed to persist only one year.

This model facilitates the understanding of the inequality decomposition into its permanent and transitory components. The variance of earnings at a certain point in time, $\sigma_{y}^{2}$, as a measure of earnings dispersion, is composed both from a permanent and transitory dispersion $\left(\sigma_{\mu}^{2}+\sigma_{v}^{2}\right)$. The covariances, on the other hand, are determined solely by the permanent component $\left(\sigma_{\mu}^{2}\right)$. Therefore, the assessment of the relative importance of the two components in the overall 
earnings dispersion is straightforward: the ratio $\sigma_{\mu}^{2} / \sigma_{y}^{2}$ captures the relative importance of the permanent component, whereas the ratio $\sigma_{v}^{2} / \sigma_{y}^{2}$ captures the relative importance of the transitory component.

Notwithstanding its attractive features, the empirical evidence rejected the rigid restrictions imposed by model (6.1). One of the main drawbacks of model (6.1) is that it does not allow for changes in earnings inequality over time (Lillard and Willis, 1978; Lillard and Weiss, 1979; MaCurdy, 1982; Abowd and Card, 1989). Other studies (Katz, 1994; Moffitt and Gottschalk, 1995; Sologon and O'Donoghue, 2009a, 2009b) took the model complexity further by allowing the covariance structure of earnings to vary over time. To account for these time effects, these models considered also time specific loading factors or shifters on both components, which allow the parameters of the process to change with calendar time.

$Y_{i t}=\lambda_{1 t} \mu_{i t}+\lambda_{2 t} v_{i t}$

$\lambda_{k t}, k=1,2$ are time-varying factor loadings on the permanent and transitory components of earnings. The variance of $Y_{i t}$ implied by this model takes the form:

$\operatorname{Var}\left(Y_{i t}\right)=\lambda_{1 t}^{2} \sigma_{\mu}^{2}+\lambda_{2 t}^{2} \sigma_{v}^{2}$

An increase in either time loading factors generates an increase in the crosssectional earnings inequality. The nature of the change in inequality depends on which of the loading factors changes. On the one hand, a persistent rise in $\lambda_{1 t}$ increases the permanent or long-run inequality (inequality in earnings measured over a long period of time, such as lifetime earnings). As $\lambda_{1 t}$ can be interpreted as time-varying return to skills or skill price, its increase suggests that the relative labour market advantage of high skill workers is enhanced. In this situation, the autocovariances grow in greater proportion that than the variance, causing the autocorrelation to increase. As a consequence, the increase in overall crosssectional inequality is accompanied by a decrease in mobility. On the other hand, an increase in $\lambda_{2 t}$ without a change in $\lambda_{1 t}$ increases cross-sectional earnings inequality by increasing the transitory inequality, but without any impact on longrun or permanent inequality. In this situation the rise in the variances is not accompanied by a rise in the autocovariances, hence autocorrelations decrease and the increase in the overall inequality is accompanied by an increase in mobility (Baker and Solon, 2003). As pointed out by Katz and Autor (1999), $\lambda_{1 t}$ maintains 
the rank of the individuals in the earnings distribution, but causes a persistent increase in the spread of the distribution and an increase in $\lambda_{2 t}$ changes the rank of the individual in the short-run. In other words an increase in the time parameters associated with the permanent component of earnings indicates a growing earnings inequality with no impact on the relative position of individuals in the distribution of permanent earnings, whereas an increase in the transitory time parameters indicates an increase in earnings mobility.

Although model (6.2) incorporates changes over time in the permanent and transitory components of earnings inequality, it disregards other important features of earnings dynamics. Firstly, it disregards the cohort effects. As argued by Katz and Autor (1999), the increased wage inequality may arise from increased dispersion of unobserved labour quality within recent entry cohorts, resulting from unequal school quality. Some studies brought evidence against the hypothesis that the return to education is the same for different cohorts. These changes could be attributed either to the cohort effects or to the larger impact of the labour market shocks on younger than on older cohorts of workers. In the same line of thought, Freeman (1975) put forward the "active labour market" hypothesis, which postulates that changes in the labour market conditions, such as changes in the supply and demand for skills, affect mainly new entrants in the labour market. To account for these cohort effects, these models considered also cohort specific loading factors or shifters on both components, which allow the parameters of the process to change with cohort (Cappellari, 2003; Kalwij and Alessie, 2003; Sologon and O'Donoghue, 2009a, 2009b).

$$
Y_{i t}=\gamma_{1 c} \lambda_{1 t} \mu_{i t}+\gamma_{2 c} \lambda_{2 t} v_{i t}
$$

where $\gamma_{j c}, j=1,2$ are cohort specific loading factors. ${ }^{95}$

Secondly, regarding the permanent component, some studies brought evidence in favour of the "random growth rate model" or the "profile heterogeneity model": (Hause, 1977; Lillard and Weiss, 1979; MaCurdy, 1982; Baker, 1997; Cappellari, 2003; Sologon and O'Donoghue, 2009b, 2009a, 2009c)

$$
\mu_{i t}=\mu_{i}+\varphi_{i} a_{g e}, \quad \mu_{i} \sim \operatorname{iid}\left(0, \sigma_{\mu}^{2}\right), \quad \varphi_{i} \sim \operatorname{iid}\left(0, \sigma_{\varphi}^{2}\right), \quad E\left(\mu_{i}, \varphi_{i}\right)=\sigma_{\mu \varphi}
$$

According to this model, which is consistent with labour market theories such as human capital, and matching models, each individual has a unique age-earning

\footnotetext{
${ }^{95}$ This model represents the starting point of my model, which is developed in Section 6.5.
} 
profile with an individual specific intercept (initial earnings $\mu_{i}$ ) and slope (earnings growth $\varphi_{i}$ ) that may be systematically related. The variances $\sigma_{\mu}^{2}$ and $\sigma_{\varphi}^{2}$ capture individual heterogeneity with respect to time-invariant characteristics and age-earnings profiles. The covariance between $\mu_{i}$ and $\varphi_{i}, \sigma_{\mu \varphi}$, represents a key element in the development of earnings differentials over the active life. A positive covariance between $\mu_{i}$ and $\varphi_{i}$ implies a rising inequality in the permanent component of earnings over the life cycle. This is consistent with the school-matching models where the more tenure one individual accumulates, the more is revealed about his ability. Thus highly educated people are expected to experience a faster growth in their earnings as the quality of the match is revealed to their employers. A negative covariance implies that the two sources of heterogeneity offset each other, which is consistent with the on-the-job training hypothesis (Mincer, 1974; Hause, 1980). A negative covariance is expected to generate mobility within the distribution of the permanent component of earnings (Cappellari, 2003).

This structure is equivalent to a random coefficient model where the intercept and the coefficient on age in model (6.5) are randomly distributed across individuals. Therefore, because earnings evolve along an individual specific age profile, a good prediction of future earnings requires additional information besides the current earnings.

An alternative/additional specification for the permanent component of earnings is the "random walk model" or the "unit root model", which is used in the literature to accommodate earnings shocks that might have permanent effects: (MaCurdy, 1982; Abowd and Card, 1989; Moffitt and Gottschalk, 1995; Dickens, 2000b; Sologon and O'Donoghue, 2009a, 2009b)

$$
u_{i a}=u_{i, a-1}+\pi_{i a}, \quad \pi_{i a} \sim \operatorname{iid}\left(0, \sigma_{\pi}^{2}\right), \quad E\left(u_{i, a-1}, \pi_{i a}\right)=0
$$

Equation (6.6) specifies the random walk process, where the current value depends on the one from the previous age and an innovation term $\pi_{i a}$, which represent white-noise non-mean-reverting shocks to permanent earnings. In other words, $\pi_{i a}$ accommodates any permanent re-ranking of individuals in the earnings distribution. As argued by Baker (1997), the intuition for this model is not obvious, but the high persistency of the unit root model might result from low rates of depreciation of human capital investments or labour market conditions through implicit contacts. In this model, current earnings are a sufficient statistic for future 
earnings. Most studies forced the innovation variance to be lifecycle invariant, except for Gustavsson (2004b) and Dickens (2000b).

Thirdly, regarding the transitory component of earnings, previous research has brought evidence that transitory earnings might be serially correlated. Therefore, a more general autocorrelation structure is called for, that relaxes the restriction on $v_{i t}{ }^{\prime} s$ from the canonical model. For the construction of such a structure, longitudinal studies on earnings dynamics turned to error processes from the literature on time series analysis. Based on MaCurdy (1982), the structure of the transitory component, $v_{i t}$, is assumed to follow an $\operatorname{ARMA}(\mathrm{p}, \mathrm{q})$ process:

$\sum_{j=0}^{p} \rho_{j} v_{i t-j}=\sum_{j=0}^{q} \theta_{j} \varepsilon_{i t-j}, \quad \varepsilon_{i t} \sim \operatorname{iid}\left(0, \sigma_{\varepsilon}^{2}\right), \quad v_{i 0} \sim\left(0, \sigma_{0, c}^{2}\right)$,

$\varepsilon_{i t}$ is assumed to be white noise with mean 0 and variance $\sigma_{\varepsilon}^{2}$. The variance $\sigma_{0, c}^{2}$ measures the volatility of shocks at the start of the sample period and $\sigma_{\varepsilon}^{2}$ the volatility of shocks in subsequent years. $\rho_{j}$ is the autoregressive parameter with $\rho_{0}=1$, which measures the persistence of shocks. $\theta_{j}$ is the moving average parameter with $\theta_{0}=1$, which accommodates sharp drops of the lag-j autocovariance compared with the other autocovariances. In this model, the autoregressive and moving average parameters are assumed to be constant over time. Additionally, some studies have found that the variance of the transitory shocks, $\sigma_{\varepsilon}^{2}$, varies over the lifecycle and incorporated a polynomial in age in the transitory component (Backer and Solon, 2003; Gustavson, 2004b).

\subsubsection{Earnings mobility}

Another aspect relevant for the evolution of earnings differentials is earnings mobility, defined by Katz and Autor (1999) as the rate at which individuals shift positions in the earnings distribution. Earnings mobility is closely related to the importance of the permanent and transitory components in earnings variation. A large contribution of the permanent component implies that individual earnings are highly correlated over time and individuals do not change their income position to a large extent experiencing low rates of earnings mobility. Therefore, the changes in earnings mobility are determined by the extent to which changes in cross-sectional inequality are driven by changes in the permanent or transitory variance. 
Earnings mobility is a very complex phenomenon, and the ways of measuring it are diverse. We look at the degree of immobility, measured by the ratio between permanent and transitory inequality, following Kalwij and Alessie (2003). This measure offers also a summary of the evolution in the structure of inequality: a(n) decrease (increase) in the immobility ratio indicates an increase (decrease) in earnings mobility, equivalent with a(n) decrease (increase) in the relative share of permanent differentials in the overall inequality. This mobility index captures nondirectional earnings movements and can be interpreted as the opportunity to improve one's position in the distribution of lifetime earnings.

An increase in cross-sectional inequality accompanied by a decrease in earnings mobility is expected to have negative implications for long-run or lifetime earnings differentials, as it shows that over time low wage men get worse off both in terms of their relative earnings position and in terms of their opportunity to escape low wage trap. Thus it is reasonable to expect that cross-sectional earnings differentials will be enhanced in a lifetime perspective.

An increase in cross-sectional inequality accompanied by an increase in earnings mobility has uncertain implications for long-run or lifetime earnings differentials. Over time low wage men get worse off in terms of their relative earnings position, but better off in terms of the opportunity to escape low wage trap in a lifetime perspective. Thus earnings mobility could either enhance or decrease lifetime earnings differentials compared with the cross-sectional ones.

A decrease in cross-sectional inequality accompanied by an increase in earnings mobility is expected to have positive implications for lifetime earnings differentials, as over time low wage men better their relative earnings position and their opportunity to escape low wage trap in a lifetime perspective. Thus, lifetime earnings differentials are expected to be reduced compared with annual differentials.

A decrease in cross-sectional inequality accompanied by a decrease in earnings mobility has uncertain implications for lifetime earnings differentials, as over time low wage men get better off in terms of their relative earnings position, but worse off in terms of their opportunity to escape low wage trap in a lifetime perspective. Thus, lifetime earnings differentials could be either reduced or enhanced compared with annual differentials.

It becomes obvious that the question regarding the link between earnings mobility and earnings inequality does not have a straight forward answer and mobility is not always beneficial. It depends on the underlying factors: "changes in earnings mobility could either work to offset or to increase changes in cross-sectional 
dispersion", with very different implications for permanent earnings inequality. (Dickens, 2000a) Nonetheless, no controversy surrounds the fact that mobility is beneficial when it helps low paid individuals to improve their income position in the long-term or lifetime income distribution.

\subsection{Data}

The study is conducted using the administrative input data file on the professional career coming from the Social Security Institutions in Luxembourg. In Luxembourg each person with a gainful occupation must be affiliated to the social security system in the beginning of his professional career. The file contains detailed information on the professional career characteristics such as gross annual labour income, months, days or hours worked per year, occupational status, over the period 1950 and 2004. Important limitations of this file are that income from property is not recorded, wage income is known up to 4 times the minimum wage until 1991, and 5 times the minimum thereafter, and white collars' hours or days worked per year before 1988 are missing.

The chosen measure of earnings is real log gross hourly wage. Hourly wage is computed by dividing the capped gross annual income ${ }^{96}$ by the total number of hours worked. Given the missing information for white collars' hours of work prior to 1988, the study is restricted to 17 years of panel: 1988-2004. The monetary values recorded in the data set are at the "nombre indice 100" (price index) and at the wage level of 1984. In order to get these values at the price and wage level of 2004 they are multiplied by $6.2463 * 1.33797$. Overtime hours and multiple jobs are disregarded from the analysis, therefore the total number of hours worked is capped at 12 multiplied by 173 for white collars and 176 for the rest. The values of hourly wage below the minimum wage are set to the minimum wage ${ }^{98}$. Individuals with gross hourly wage above 100 Euro at 2004 level or who worked less than 1 hour per year are excluded from the analysis.

To avoid biases several filters are applied. Following the tradition of previous studies, the analysis focuses only on men to avoid the problem of selection bias characterising women's earnings. I choose individuals born between 1940 and 1975, with ages between 20 and 57, recorded working at least once during 1988 and 2004. Individuals that experienced at least five years of inactivity gaps because of

\footnotetext{
${ }_{96}$ Capped annual income was computed based on the capped monthly wage.

${ }^{97}$ n.i. 2004: 624.63 , wage level $+33,7 \%$

${ }_{98}$ The number of hours is recalculated accordingly.
} 
disability or who retired before the age of 57 with a disability benefit are dropped from the analysis.

Table 6.1. Cohorts Included in the Working Sample

\begin{tabular}{|c|c|c|c|}
\hline Cohort born in & Sample Size & Years Observed & Ages Observed \\
\hline 1940 & 1862 & $1988-1997$ & $48-57$ \\
\hline 1941 & 1878 & 1988-1998 & $47-57$ \\
\hline 1942 & 2288 & 1988-1999 & $46-57$ \\
\hline 1943 & 2495 & $1988-2000$ & $45-57$ \\
\hline 1944 & 2722 & 1988-2001 & $44-57$ \\
\hline 1945 & 2864 & 1988-2002 & $43-57$ \\
\hline 1946 & 3622 & $1988-2003$ & $42-57$ \\
\hline 1947 & 4161 & 1988-2004 & $41-57$ \\
\hline 1948 & 4463 & 1988-2004 & $40-56$ \\
\hline 1949 & 4725 & 1988-2004 & $39-55$ \\
\hline 1950 & 4865 & $1988-2004$ & $38-54$ \\
\hline 1951 & 5120 & $1988-2004$ & $37-53$ \\
\hline 1952 & 5712 & 1988-2004 & $36-52$ \\
\hline 1953 & 5901 & 1988-2004 & $35-51$ \\
\hline 1954 & 6475 & 1988-2004 & $34-50$ \\
\hline 1955 & 6564 & $1988-2004$ & $33-49$ \\
\hline 1956 & 6974 & $1988-2004$ & $32-48$ \\
\hline 1957 & 7481 & $1988-2004$ & $31-47$ \\
\hline 1958 & 7828 & $1988-2004$ & $30-46$ \\
\hline 1959 & 8562 & $1988-2004$ & $29-45$ \\
\hline 1960 & 8840 & $1988-2004$ & $28-44$ \\
\hline 1961 & 9621 & $1988-2004$ & $27-43$ \\
\hline 1962 & 10004 & 1988-2004 & $26-42$ \\
\hline 1963 & 10771 & 1988-2004 & $25-41$ \\
\hline 1964 & 11523 & $1988-2004$ & $24-40$ \\
\hline 1965 & 11671 & $1988-2004$ & $23-39$ \\
\hline 1966 & 11754 & $1988-2004$ & $22-38$ \\
\hline 1967 & 11928 & $1988-2004$ & $21-37$ \\
\hline 1968 & 11929 & $1988-2004$ & $20-36$ \\
\hline 1969 & 11739 & $1989-2004$ & $20-35$ \\
\hline 1970 & 11617 & $1990-2004$ & $20-34$ \\
\hline 1971 & 11657 & $1991-2004$ & $20-33$ \\
\hline 1972 & 11192 & $1992-2004$ & $20-32$ \\
\hline 1973 & 10443 & $1993-2004$ & $20-31$ \\
\hline 1974 & 9843 & 1994-2004 & $20-30$ \\
\hline 1975 & 9186 & 1995-2004 & $20-29$ \\
\hline Total & 270280 & & \\
\hline
\end{tabular}

The resulting sample is an unbalanced panel, consisting of 270240 men. The individuals are allowed to exit and (re)enter the panel. The choice of using unbalanced panels for estimating the covariance structure of earnings is motivated by the need to mitigate the potential overestimation of earnings persistence that would arise from balanced panels where the estimation is based only on people that have positive earnings for the entire sample period. 
For the empirical analysis, individuals are categorized into 36 birth cohorts formed from men born in a particular year, with ages between 20 and 57. I selected only cohorts observed for at least 10 years over the period 1988-2004, which allows exploring the earnings covariance structure for individuals of the same age, followed through time. Table 6.1 offers an overview of the sample size, the years observed and age range for each cohort. The evolution of the variance and mean of log hourly earnings is captured in Figure 6.1, which reports an increase earnings inequality and economic growth over the sample period. The evolution of the variance and mean earnings records a jump between 1991 and 1992. This jump is partially artificial because of a change in legislation: before 1992 the threshold for reporting wage was 4 times the minimum wage and 5 times thereafter. The highest jump in the evolution of mean wage is observed between 1998 and 199999, which is most probably due to the increase of $8 \%$ in the gross wage of civil servants as a measure to finance social contributions. Around the same time a small increase is observed also in the variance of earnings.

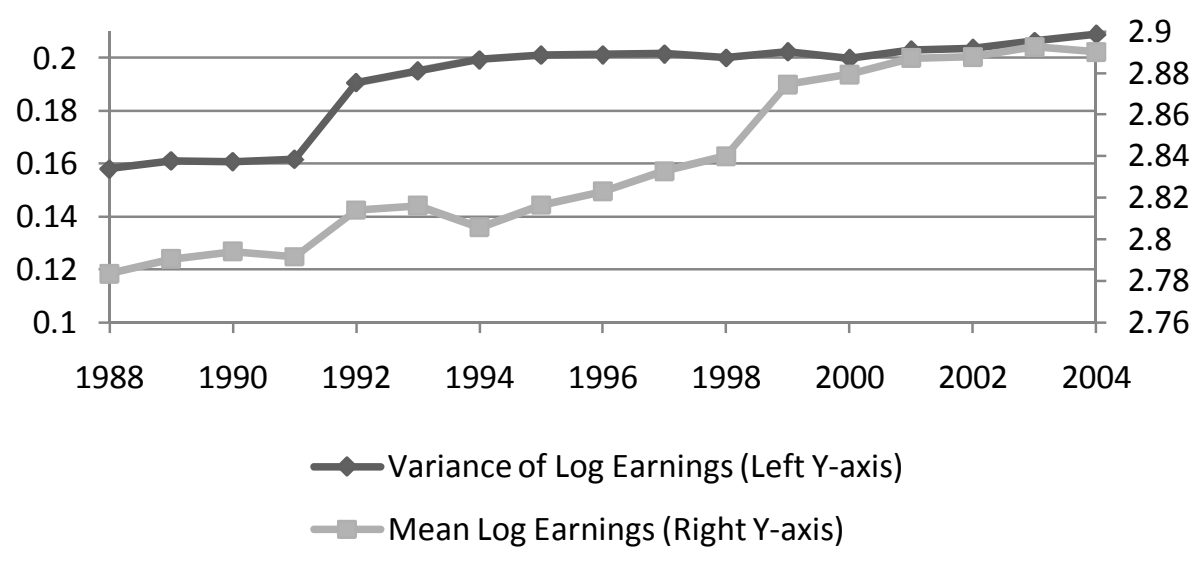

Figure 6.1. The variance and mean of log hourly earnings, 1988-2004

The Luxembourgish labour market went through structural changes which started at the end of the 1980's and intensified after 1995, resulting in a large increase in the active population after 1988. I present an overview of my sample following these structural changes.

\footnotetext{
991999 marks also the year when there was a change in the pension law for civil servants, and as a consequence some civil servants were included in the sample only starting with 1999. This effect is seems to affect the most the oldest cohorts.
} 
First, the number of active men more than doubled in 2004 compared with 1988, reaching a value of 160,315 in 2004.

Second, the evolution of the composite of the sample by occupation status and sector illustrated in Figure 6.2 and Figure 6.3 resemble the one for the whole population illustrated in Figure 6-A- 1 and Figure 6-A-2: there is a clear shift in the structure, with white collars and civil servants, and the tertiary sector recording a significant increase in their share over time. Thirdly, as illustrated in Figure 6.4, the evolution of the composite of the sample by age is affected slightly by the filters applied, but maintains similar characteristics as the whole population (Figure 6-A$3)$. 


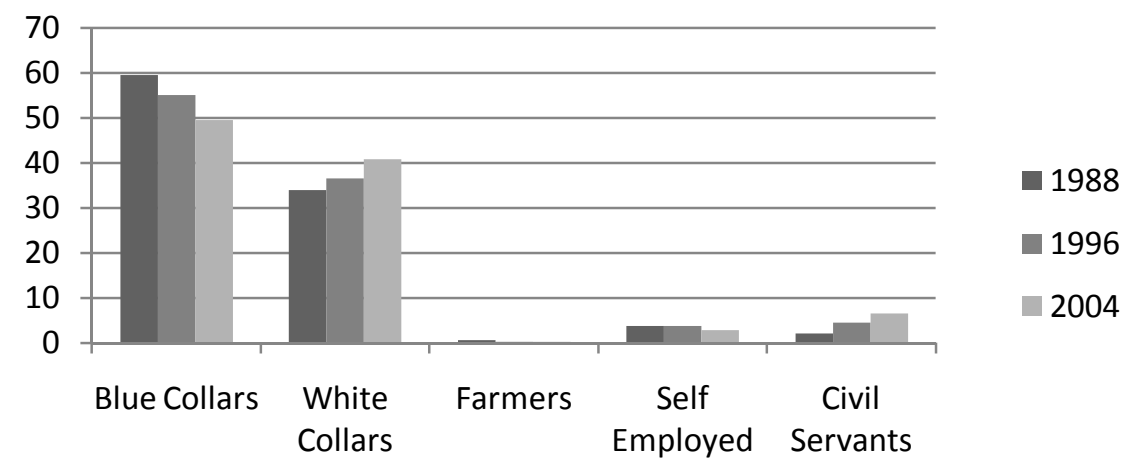

Figure 6.2. The evolution of the labour market structure by occupational status in the sample in 1988, 1996 and 2004.

Note: Vertical axis - share of workers by occupational status

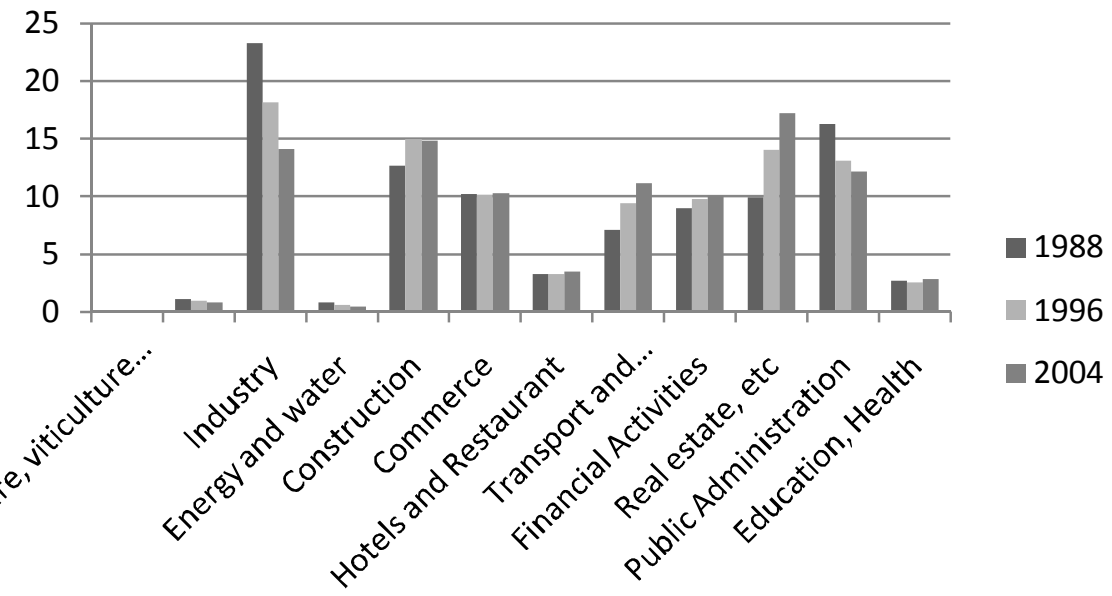

Figure 6.3. The evolution of the labour market structure by sector in the sample in 1988, 1996 and 2004.

Note: Vertical axis - share of workers by sector of activity 


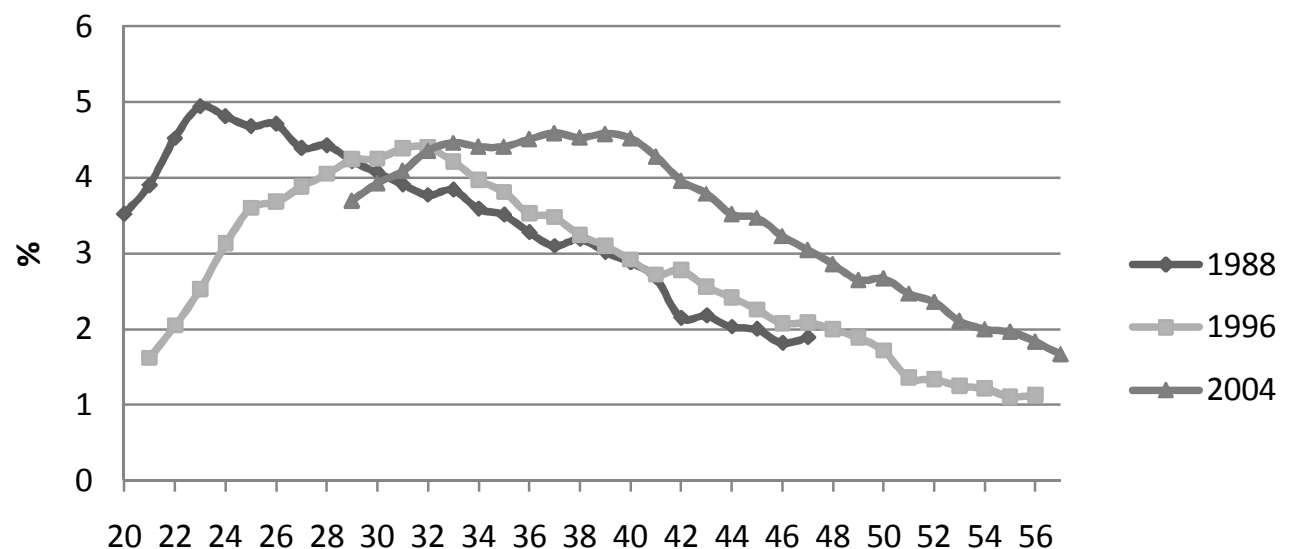

Age

Note: Vertical axis - share of workers by age groups

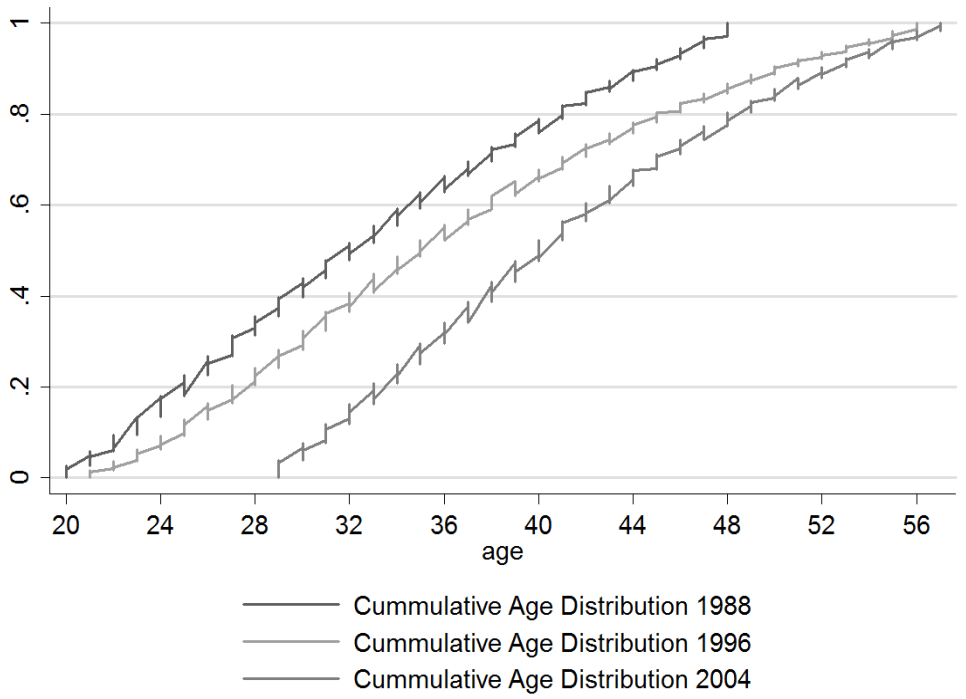

Figure 6.4. The evolution of the age structure of the active population in the sample Note: Vertical axis - cummulative share of workers by age groups 


\subsection{Econometric specification and estimation method of covariance structures}

The aim of this section is to fit a parsimonious model to the autocovariance structure of earnings for all cohorts. This model is use to explore the changes in the permanent and transitory components of earnings over the sample period and their impact on overall earnings inequality.

\subsubsection{Econometric earnings specification}

In order to differentiate lifecycle dynamics from secular changes in earnings inequality, the earnings differentials are analysed within the 36 cohorts defined in the previous section. The first step is to de-trend earnings for each cohort. The empirical specification of earnings follows the structure:

$$
Y_{i c t}=\bar{Y}_{c t}+r_{i c t}, \quad t=1, \ldots, T_{i}, i=1, \ldots, N_{c}
$$

where $Y_{i c t}$ is the natural logarithm of real hourly earnings of the $i$-th individual, from the $c$-th cohort in the $t$-th year, $\overline{Y_{c t}}$ is the year-cohort specific mean and $r_{i c t}$ is an error term which represents the individual-specific deviation from the yearcohort specific mean. The demeaned earnings $r_{i c t}$ are assumed to be independently distributed across individuals, but autocorrelated over time. Earnings differentials within each cohort can be characterised by modelling the covariance structure of individual earnings:

$\operatorname{Var} \operatorname{Cov}\left(Y_{i c t}\right)=E\left(r_{i c t}, r_{i c t-s}\right), s=0, \ldots, T_{c}-t_{0 c} \cdot{ }^{100}$

This study approaches the problem of choosing a longitudinal process for the demeaned earnings, $r_{i c t}$ following the methodology used by MaCurdy(1981) and MaCurdy (1982), meaning in a similar manner with time series. The inspection of the covariance structure of earnings, which is presented in section 6.6, suggests the following features of the data:

(i) the elements of the autocovariance structure decrease with the lag at a decreasing rate and

${ }_{100} T_{c}$ and $t_{0 c}$ represent the total number of years and the first year observed for each cohort. 
(ii) they converge gradually at a positive level101;

(iii) the lag-1 autocovariance drops to a larger extent compared with higher order autocovariances, which decline more gradually;

(iv) the autocovariances and mean earnings vary over the sample period, so they cannot be assumed to be stationary over sample period;

(v) the autocovariances vary with age controlling for the period effect, hence they cannot be assumed to be stationary over the life cycle;

(vi) the variance covariance structure appears to be cohort specific.

Feature (i) suggests the presence of an $\mathrm{AR}(1)$ process, but the presence of feature (iii) calls for a more complex $\operatorname{ARMA}(1,1)$ or $\operatorname{ARMA}(1,2)$ process. Feature (ii) can be captured by the presence of the permanent component. Feature (iv) is captured by incorporating period specific parameters, meaning that the permanent individual component and the transitory component of earnings are allowed to vary with time. The life cycle non-stationarity of the autocovariance structure of earnings mentioned in feature ( $\mathrm{v}$ ) is captured by modelling the permanent individual component as random walk and/or random growth in age. Cohort heterogeneity is incorporate by parameters that allow the permanent and transitory components to vary between cohorts. Additionally, unlike most studies, I allow for age-specific innovation variance and age-related heteroskedasticity in the transitory shocks.

I started with a general model specification that encompasses all the relevant aspects of earnings dynamics considered above. I employed preliminary data analysis procedures to choose among competing specifications in order to avoid choosing a model which is broadly inconsistent with the data. After much experimentation, the following general specification of equation (6.4) is found to best fit the data.

$$
\begin{aligned}
& Y_{i c t}-\overline{Y_{c t}}=r_{i c t}=\gamma_{1 c} \lambda_{1 t} u_{i a t}+\gamma_{2 c} \lambda_{2 t} v_{i t} \\
& u_{i a t}=u_{i, 20} \sim i i d\left(0, \sigma_{u_{20}}^{2}\right) \quad \text { if } \quad a=20 \\
& u_{i a t}=u_{i, a-1, t-1}+\pi_{i a} \quad \text { if } \quad 21 \leq a \leq 40, \quad \pi_{i a} \sim \operatorname{iid}\left(0, \sigma_{\pi_{a}}^{2}\right), \quad E\left(u_{i, a-1, t-1}, \pi_{i a t}\right)=0(6.10) \\
& u_{i a t}=u_{i, 40} \sim i i d\left(0, \sigma_{u_{40}}^{2}\right) \quad \text { if } \quad a>40 \\
& v_{i t}=\rho v_{i t-1}+\varepsilon_{i t}+\theta \varepsilon_{i t-1}, \quad \varepsilon_{i t} \sim\left(0, \sigma_{\varepsilon_{t}}^{2}\right), \quad v_{i 0} \sim\left(0, \sigma_{0, c}^{2}\right), \quad c=1945, \ldots, 1975 \\
& { }_{\text {convergence with increasing lags }}
\end{aligned}
$$




$$
\sigma_{\varepsilon_{t}}^{2}=\beta_{0}+\beta_{1}\left(\text { age }_{t}-20\right)+\beta_{2}\left(\text { age }_{t}-20\right)^{2}+\beta_{3}\left(\text { age }_{t}-20\right)^{3}+\beta_{3}\left(\text { age }_{t}-20\right)^{4}
$$

I refer to the model in equation (6.9)-(6.12) as my "base model". According to equation (6.9), earnings can be decomposed into a permanent component $\gamma_{1 c} \lambda_{1 t} u_{i a t}$ and a transitory component $\gamma_{2 c} \lambda_{2 t} v_{i t}$. The permanent component $u_{i a t}$ (Equation (6.10)) specifies a random walk in age in earnings growth after age 20 up to age 40, where $\pi_{i a} \sim \operatorname{iid}\left(0, \sigma_{\pi_{a}}^{2}\right)$ is the innovation at each age, and after that a random effects model with the distribution of the effects fixed at that implied by the random walk. Previous research forced the innovation variance $\sigma_{\pi_{a}}^{2}$ to be the same over the lifecycle. My rich data allowed us to estimate age specific innovation variances. The model with age-specific innovation variances until the age of 40 was found to fit the data the best. This decision is backed up also by Figure 6.6. I also estimate the variance of an initial permanent shock (assumed to be at age 20, which is also the lowest age observed in my dataset), denoted $\sigma_{u_{20}}^{2}$. Thus the permanent earnings variance within a cohort rises with age up until age 40, after which it remains at its current level. Consistent with many matching and human capital models, whereby human capital or ability is revealed for the first 20 years of labour market experience after which the permanent differentials start shrinking, I expect larger permanent shocks at younger age. (Jovanovic, 1979)

Equation (6.11) specifies the transitory component of earnings which evolves as an $\operatorname{ARMA}(1,1)$ process, where the serial correlation $\rho$ parameter captures the decreasing rate of decay of the covariances with the lag, the moving-average parameter $\theta$ captures the sharp drop of the lag-1 autocovariance compared with the other autocovariances, and $\varepsilon_{i t}$ are white-noise mean-reverting transitory shocks. The variance $\sigma_{0, c}^{2}$ measures the volatility of shocks at the start of the sample period, $\sigma_{\varepsilon_{t}}^{2}$ the volatility of shocks in subsequent years and $\rho$ the persistence of shocks. Measurement error in this model is captured by this transitory component. Additionally, equation (6.12) allows the variance of $\varepsilon_{i t}$ to change over the lifecycle, as a polynomial of order 4 in age.

The non-stationary pattern of earnings is accommodated using time specific loading factors, both on the permanent and transitory component of earnings, $\lambda_{k t, k=1,2 ; t=0,16}$, normalized to 1 in the first wave for identification ${ }^{102}$. Cohort 
heterogeneity is accommodated by allowing both the permanent and the transitory component to vary with the cohort. $\gamma_{j c}, j=1,2$ are cohort loading factor, normalized to 1 for the cohort born in 1945 for identification.

\subsubsection{Specification of the covariance structure of earnings}

When working with $\operatorname{ARMA}(\mathrm{p}, \mathrm{q})$ processes in the context of panel data, MaCurdy (1981), MaCurdy (1982) and Anderson and Hsiao (1982) underlined the need for a treatment of initial conditions ${ }^{103}$. As illustrated in equations (6.14) and (6.15), the autoregressive process induces a recursive structure in the moments: the variancecovariance in year $t$ depends on the transitory variance-covariance in year $t-1$. If one tracks the recursion back to the first sample year for each cohort, this raises the question of what is the transitory variance for each cohort in that year. In the earlier stage of the literature on earnings dynamics, it was common to restrict the initial transitory variance to be the same for all cohorts. In line with the most recent literature on earnings dynamics, my model acknowledges that earnings volatility varies across cohorts because they illustrate different stages of the lifecycle and they have experienced different period effects. Therefore such a strong assumption is untenable.

Following MaCurdy (1981), MaCurdy (1982), I treat the initial transitory variances of the 36 cohorts as 36 additional parameters to be estimated. The covariance structure for the first sample period takes the form:

$$
\begin{aligned}
& \operatorname{Var}\left(Y_{i c 0}\right)=E\left(r_{i c 0} r_{i c 0}\right)= \\
& =\sigma_{\mu_{20}}^{2}+\sum_{a=21}^{a_{0}} \sigma_{\pi_{a}}^{2}+\operatorname{Var}\left(v_{i 0}\right) \quad \text { if } t=0 \text { for } a_{0} \leq 40, \\
& =\sigma_{\mu_{20}}^{2}+\sigma_{u_{40}}^{2}+\operatorname{Var}\left(v_{i 0}\right) \quad \text { if } t=0 \text { for } a_{0}>40,
\end{aligned}
$$

where $a_{0}=$ age in period $0, \sigma_{u_{40}}^{2}=\sum_{a=21}^{40} \sigma_{\pi_{a}}^{2}$

The covariance structure for subsequent years can be expressed as follows:

103 See Macurdy(1982, page 92/93) 


$$
\begin{aligned}
& \operatorname{Var}\left(Y_{i c t}\right)=E\left(r_{i c t} r_{i c t}\right)= \\
& =\gamma_{1 c}^{2} \lambda_{1 t}^{2}\left[\sigma_{\mu_{20}}^{2}+\sum_{a=21}^{a_{t}} \sigma_{\pi_{a}}^{2}\right]+\gamma_{2 c}^{2} \lambda_{2 t}^{2}\left[\rho^{2} \operatorname{Var}\left(v_{i t-1}\right)+\sigma_{\varepsilon_{t}}^{2}\left(1+2 \rho \theta+\theta^{2}\right)\right] \quad \text { if } t>0 \text { for } a_{t} \leq 40 \\
& =\gamma_{1 c}^{2} \lambda_{1 t}^{2}\left[\sigma_{\mu_{20}}^{2}+\sigma_{u_{40}}^{2}\right]+\gamma_{2 c}^{2} \lambda_{2 t}^{2}\left[\rho^{2} \operatorname{Var}\left(v_{i t-1}\right)+\sigma_{\varepsilon_{t}}^{2}\left(1+2 \rho \theta+\theta^{2}\right)\right] \quad \text { if } t>0 \text { for } a_{t}>40, \\
& \text { where } \sigma_{u_{40}}^{2}=\sum_{a=21}^{40} \sigma_{\pi_{a}}^{2}
\end{aligned}
$$

$\operatorname{Cov}\left(Y_{i c t} Y_{i c t-s}\right)=E\left(r_{i c t} r_{i c t-s}\right)=$

$=\gamma_{1 c}^{2} \lambda_{1 t}^{2}\left[\sigma_{\mu_{20}}^{2}+\sum_{a=21}^{a_{t-s}} \sigma_{\pi_{a}}^{2}\right]+\gamma_{2 c}^{2} \lambda_{2 t} \lambda_{2 t-s}\left[\rho \operatorname{Cov}\left(v_{i t-1}, v_{i t-s}\right)\right] \quad$ if $t>0 \quad \& \quad s>1$ for $a_{t-s} \leq 40$

$=\gamma_{1 c}^{2} \lambda_{1 t}^{2}\left[\sigma_{\mu_{20}}^{2}+\sigma_{\mu_{40}}^{2}\right]+\gamma_{2 c}^{2} \lambda_{2 t} \lambda_{2 t-s}\left[\rho \operatorname{Cov}\left(v_{i t-1}, v_{i t-s}\right)\right] \quad$ if $t>0 \& s>1$ for $a_{t-s}>40$

where $\sigma_{\mu_{40}}^{2}=\sum_{a=21}^{a_{t-5}} \sigma_{\pi_{a}}^{2}$

$\operatorname{Cov}\left(Y_{i c t} Y_{i c t-1}\right)=E\left(r_{i c t} r_{i c t-1}\right)=$

$\left.=\gamma_{1 c}^{2} \lambda_{1 t}^{2}\left[\sigma_{\mu_{20}}^{2}+\sum_{a=21}^{a_{t-1}} \sigma_{\pi_{a}}^{2}\right]+\gamma_{2 c}^{2} \lambda_{2 t} \lambda_{2 t-1}\left\{\rho \operatorname{Var}\left(v_{i t-1}\right)+\theta \sigma_{\varepsilon_{t-1}}^{2}\right)\right\} \quad$ if $t>0 \& s=1$ for $a_{t-1} \leq 40$

$\left.=\gamma_{1 c}^{2} \lambda_{1 t}^{2}\left[\sigma_{\mu_{20}}^{2}+\sigma_{\mu_{t 0}}^{2}\right]+\gamma_{2 c}^{2} \lambda_{2 t} \lambda_{2 t-1}\left\{\rho \operatorname{Var}\left(v_{i t-1}\right)+\theta \sigma_{\varepsilon_{t-1}}^{2}\right)\right\} \quad$ if $t>0 \& s=1$ for $a_{t-1}>40$

where $\sigma_{\mu_{\mathrm{so}}}^{2}=\sum_{a=21}^{a_{t-1}} \sigma_{\pi_{a}}^{2}$

\subsubsection{Estimation of covariance structures ${ }^{104}$}

Covariance structures are models that specify a structure for the covariance matrix of the regression error. They can be used to model structures for error dynamics and measurement error. The goal is to estimate the parameters of the covariance structure of earnings for all cohorts. This can be used to analyse the changes in the permanent and transitory components of earnings over the sample period.

104 The information in this section has been covered in section 4.5.3. 
The parameters of the models are fit to the covariance structure for each cohort using equally weighted minimum distance methods of estimation. The methodology used is the same as that utilized by Cappellari (2003), Baker and Solon (2003), Ramos (2003), Kalwij and Alessie (2003), Dickens (2000b), Baker (1997), Abowd and Card (1989), Cervini and Ramos (2006), Sologon and O'Donoghue (2009a, 2009b).

Following Sologon and O'Donoghue (2009a, 2009b), for each cohort $c$ and individual $\boldsymbol{i}$, define a vector which identifies the presence for each individual in the respective cohort and year:

$$
\mathbf{d}_{\mathbf{i c}}=\left(\begin{array}{c}
d_{i c t_{1}} \\
\vdots \\
d_{i c t_{c}}
\end{array}\right)
$$

where $d_{i c t}$ is an indicator variable that is equal to 1 if the individual from cohort $c$ is present in year $t$ of the panel and $t_{c}$ is the total length of the panel for each cohort. Similarly, the vector containing the cohort earnings residuals can be represented as follows:

$$
\mathbf{R}_{\mathbf{i c}}=\left(\begin{array}{c}
r_{i c t_{1}} \\
\vdots \\
r_{i c t_{c}}
\end{array}\right)
$$

where $r_{i c t}$ are the earnings residuals for individual $i$ belonging to cohort $c$ in year $t$ in mean deviation form for each cohort and year. The elements of the $\mathbf{R}_{\text {ic }}$ corresponding to missing years are set to 0 . The variance-covariance matrix of the earnings is computed separately for each cohort, $\mathbf{C}_{\mathbf{c}}$. The elements of the variancecovariance matrix for cohort $\mathrm{c}, \mathbf{C}_{\mathbf{c}}$, which is of dimension $\left(t_{c} \times t_{c}\right)$ are computed follows:

$$
m_{c}[k, l]=\frac{\sum_{i=1}^{n_{c}} r_{i c k} r_{i c l}}{\sum_{i=1}^{n_{c}} d_{i c k} d_{i c l}}
$$


where $n_{c}$ is the total number of individuals in cohort $c, k, l=\left\{1, \ldots, t_{c}\right\}$. Conformably with $m_{c}, m_{c i}$ represent the distinct elements of the individual crossproduct matrix $\mathbf{R}_{\mathbf{i c}} \mathbf{R}_{\mathrm{ic}}^{\prime}$. Then $m_{c}[k, l]=\frac{\sum_{i=1}^{n_{c}} m_{c i}[k, l]}{\sum_{i=1}^{n_{c}} d_{i c k} d_{i c l}}$.

The matrix $C_{c}$ is symmetric with $\left(\frac{t_{c}\left(t_{c}+1\right)}{2} \times 1\right)$ distinct elements. Let $\operatorname{Vech}\left(\mathbf{C}_{\mathbf{c}}\right)$ be a column vector of dimension $\left(\frac{t_{c}\left(t_{c}+1\right)}{2} \times 1\right)$ which stacks all the elements of the variance covariance matrix $\mathbf{C}_{\mathbf{c}}$ for cohort $\mathrm{c}$. The aggregate vector of moments for all cohorts is denoted by: $\mathbf{m}=\left(\operatorname{Vech}\left(\mathbf{C}_{1}\right)^{\mathbf{T}}, \ldots, \operatorname{Vech}\left(\mathbf{C}_{4}\right)^{\mathrm{T}}\right)^{\mathrm{T}}$, which is a column vector of dimension $\left(\sum_{c=1}^{36} \frac{t_{c}\left(t_{c}+1\right)}{2} \times 1\right)=(N \times 1)$. In this paper, $\mathrm{N}=4668$.

To estimate the error components of the structural model illustrated by equations (6.9)-(6.12), the elements of $\mathbf{m}$ are fit to a parameter vector $\boldsymbol{\theta}$, so that $\mathbf{m}=f(\boldsymbol{\theta})$, $f(\boldsymbol{\theta})$ takes the form of equations (6.13) - (6.16). Minimum distance estimation requires minimising the weighted sum of the squared distance between the actual covariances $(\mathbf{m})$ and a function of the parameter vector $(f(\boldsymbol{\theta}))$ which encapsulates the covariance structure implied by the error component model. Therefore, minimum distance estimation involves the following quadratic form: $D(\boldsymbol{\theta})=[\mathbf{m}-f(\boldsymbol{\theta})] \mathbf{W}[\mathbf{m}-f(\boldsymbol{\theta})]^{\prime}$, where $\mathbf{W}$ is a positive definite weighting matrix. Minimum distance estimator chooses $\hat{\boldsymbol{\theta}}$ to minimise the distance function $D(\hat{\boldsymbol{\theta}})$.

Based on Chamberlain (1984), the asymptotic optimal choice of $\mathbf{W}$ is the inverse of a matrix that consistently estimates the covariance matrix of $\mathbf{m}$, which leads to the optimum minimum distance estimator (OMD). However, Clark (1996) and Altonji and Segal (1994) provided Monte Carlo evidence that OMD is biased in small samples because of the correlation between the measurement error in the second moments and forth moments. Instead, they proposed using the identity matrix as a weighting matrix. This approach, often called "equally weighted minimum distance estimation" (EWMD), involves using the standard nonlinear least squares to fit $f(\boldsymbol{\theta})$ to $\mathbf{m}$. The same procedure is followed in this paper. 
For estimating the asymptotic standard errors of the parameter estimates, I apply the delta method. Following Chamberlain (1984), the asymptotic variancecovariance matrix of the estimated parameters is obtained from the following formula:

\section{$\operatorname{Asy} \operatorname{Var}(\theta)=\left(G^{\prime} W G\right)^{-1} G^{\prime} W V W G\left(G^{\prime} W G\right)^{-1}$}

where $\mathbf{G}$ is the Jacobian of the transformation $f(\boldsymbol{\theta})$ evaluated at $\boldsymbol{\theta}=\hat{\boldsymbol{\theta}}$. $\mathbf{G}$ has dimension $\left(t_{m} \times p\right)$ and rank $\mathrm{p}$, where $t_{m}$ is the sum across cohorts of $\left(\frac{t_{c}\left(t_{c}+1\right)}{2} \times 1\right)$ and $\mathrm{p}$ is the number of parameters. $\mathbf{W}$ is the identity matrix and V the matrix of fourth sample moments.

Chamberlain (1984) showed that under some fairly general regularity assumptions, the independence of $\mathbf{R}_{\text {ic }}$ implies that the sample mean of $m_{c i}$ has an asymptotic normal distribution $m_{c} \sim N\left(m_{c}^{*}, \mathbf{V}_{c}^{*}\right)$, where $m_{c}^{*}$ is the expectation of $m_{c i}$, meaning the true covariance matrix of earnings, and $\mathbf{V}_{c}^{*}$ is the variancecovariance matrix, which can be estimated consistently by computing the sample moment matrix of the $\operatorname{Vech}\left(\mathbf{C}_{\mathbf{c}}\right)$ vector, $\mathbf{V}_{\mathbf{c}}$. The elements of the variance covariance $\mathbf{V}_{\mathbf{c}}$ can be written as follows:

$$
\begin{gathered}
\operatorname{Cov}\left(m_{c}[k, l], m_{c}[p, q]\right)=\frac{\sum_{i=1}^{n_{c}} d_{i c k} d_{i c l} d_{i c p} d_{i c q}}{\sum_{i=1}^{n_{c}} d_{i c k} d_{i c l} \sum_{i=1}^{n_{c}} d_{i c p} d_{i c q}}\left(m_{c}[k, l, p, q]-m_{c}[k, l] m_{c}[p, q]\right) \\
, \\
\text { where } m_{c}[k, l, p, q]=\frac{\sum_{i=1}^{n_{c}} r_{i c k} r_{i c l} r_{i c p} r_{i c q}}{\sum_{i=1}^{n_{c}} d_{i c k} d_{i c l} d_{i c p} d_{i c q}}
\end{gathered}
$$

The variance-covariance matrix of $\mathbf{m}$ was denoted by $\mathbf{V}$, where $\mathbf{V}$ is the block diagonal matrix which is constructed from all the $\mathbf{V}_{\mathbf{c}}$ matrices. 


\subsubsection{Strategy for model specification ${ }^{105}$}

The strategy for model specification follows Sologon and O'Donoghue (2009a, $2009 \mathrm{~b})$. The chi-squared goodness of fit statistic is computed following Newey(1985):

$$
\chi=[\mathbf{m}-f(\hat{\boldsymbol{\theta}})] \mathbf{R}^{-1}[\mathbf{m}-f(\hat{\boldsymbol{\theta}})]^{\prime}
$$

where $\chi$ follows a chi-squared distribution with degrees of freedom equal to $\sum_{c=1}^{36} \frac{t_{c}\left(t_{c}+1\right)}{2}-p=N-p, \mathbf{R}^{-1}=\left(\mathbf{W} \mathbf{V} \mathbf{W}^{\prime}\right)^{-\mathbf{1}}$ and $\mathbf{W}=\mathbf{I}-\mathbf{G}\left(\mathbf{G}^{\prime} \mathbf{A G}\right)^{-\mathbf{1}} \mathbf{G}^{\prime} \mathbf{A}$. The majority of the existing studies estimating the covariance structure of earnings used this general form of specification test to assess the goodness of fit of the model. However, in most cases, all models have been rejected. Baker and Solon (2003), Baker (1997), Leamer (1983) criticized these type of tests for several reasons.

First, Baker and Solon (2003) and Leamer (1983) underlined that "diagnostic tests such as goodness-of-fit tests, without explicit alternative hypothesis, are useless, since if the sample size is large enough, any maintained hypothesis will be rejected. Such tests therefore degenerate into elaborate rituals for measuring the effective sample size." Second, as pointed by Baker and Solon (2003), an additional problem is that these specification tests have inflated size in small samples and the inflation is positively related with the number of overidentifying restrictions. For example, Baker (1997) revealed through a Monte Carlo study, that for a test with fewer than 150 overidentifying restrictions, the critical values are $40 \%-50 \%$ greater than the critical values based on the asymptotic theory. Therefore, I decided to report this statistic as a reference, but not to use it to assess the goodness of fit of my model. Instead I employed the SSR as a measure of fit.

To test between nested models, I could use Preposition 3' in Chamberlain (1984) or the LR test. Based on Preposition 3' in Chamberlain (1984), assuming that the general model has p parameters, to test between two nested models, one in which $k_{1}$ parameters are restricted to $0\left(\chi_{p-k_{1}}\right)$ and one in which $k_{2}{ }^{106}$ parameters are restricted to $0\left(\chi_{p-k_{2}}\right)$, Chamberlain (1984) showed that the incremental chi square statistic $\chi=\chi_{p-k_{1}}-\chi_{p-k_{2}}$ follows a chi-squared distribution with $k_{1}-k_{2}$ degrees

\footnotetext{
105 The information of this section has been covered in section 4.6. $106 \mathrm{k}_{1}>\mathrm{k}_{2}$
} 
of freedom. The LR test takes the following form: $L R=N \log \frac{S S E_{R}}{S S E_{U}}$. Under the null hypothesis, LR is follows a chi-square distribution with d.o.f equal to the number of restrictions $k_{1}-k_{2}$. To test between non-nested model, I use BIC and AIC criterion.

$$
A I C=\frac{S S E \cdot e^{2 k / N}}{N-k} \quad \text { or } \quad B I C=\frac{S S E \cdot N^{k / N}}{N-k}
$$

The smaller the value of BIC and AIC are the better the fit is. The difference between the two is that BIC incorporates a higher penalty for additional parameters than AIC and is recommended as the first choice.

\subsection{The dynamic autocovariance structure of hourly earnings}

To begin with, it is informative to have a description of the dynamic structure of individual log hourly earnings. The autocovariance structure of earnings is computed for each cohort, adding up to 4668 sample moments. The autocovariance structure by cohorts is displayed in Figure 6.5. Based on these trends I establish the main characteristics of the model aimed to fit the autocovariance structure of earnings for all cohorts.

The autocovariances display different patterns across cohorts, supporting the hypothesis of cohort heterogeneity with respect to individual earnings dynamics. The general picture reveals that the variance of log hourly earnings increased for all cohorts between 1988 and 2004, but the rate of increase and the magnitude differs among cohorts. Similarly with Dickens' (2000b) results for UK, the younger the cohort the faster the rise in the autocovariances. The absolute magnitude of the autocovariance structure appears to have a hump-shaped pattern: the lowest values are recorded by the youngest cohorts, followed by the oldest cohorts and lastly by the middle-age cohorts.

For all cohorts, all lags autocovariances show a similar pattern as the variance. They are positive and evolve parallel with the variance. The distance between autocovariances at consecutive lags falls at a decreasing rate. The biggest fall is registered by the lag-1 autocovariance, after which the covariances appear to converge gradually at a positive level. Variances reflect both the permanent and the transitory components of earnings, whereas higher order covariances reflect 
the permanent component of earnings. Therefore, for all cohorts, the evolution of covariances, at all orders, suggests the presence of a permanent individual component of wages and a transitory component which is serially correlated. In addition, the magnitude of the longer lag covariances relative to the variances is higher the older the cohort.

One possible explanation for these trends is given by the theory on matching models, which sustains that the more experience an individual accumulates, the more information is revealed on the individual's ability. (Jovanovic, 1979) Therefore, permanent wage dispersion and implicitly overall inequality within a cohort is expected to rise as the cohort ages.

To look at the life cycle effects more clearly it is necessary to control for the period effect which is present in the within-cohort covariances. Thus I keep year constant and illustrate the life cycle autocovariances by age. Figure 6.6 presents the variance-covariance structure by age for the selected years.

All lags autocovariances of log real gross hourly earnings show a similar pattern as the variance. They are positive and evolve parallel with the variance, at different rates over the life cycle. They rise sharply over the life cycle until the late 30s and early 40s, after which they have a rather stable evolution up until late 50s. The diminishing rate of increase of all lags autocovariances observed from the age of 20 until the late $50 \mathrm{~s}$ is consistent with the presence of a permanent component of earnings that rises with age at a diminishing rate (Dickens, 2000b).

Comparing across years, the life cycle profile of the auto-covariances of log gross hourly earnings appears to become steeper over time. The slope of the life cycle profile can be interpreted as the returns to the permanent complement of earnings. Therefore, steeper slopes in later years imply increasing returns to the permanent component of earnings over time. 

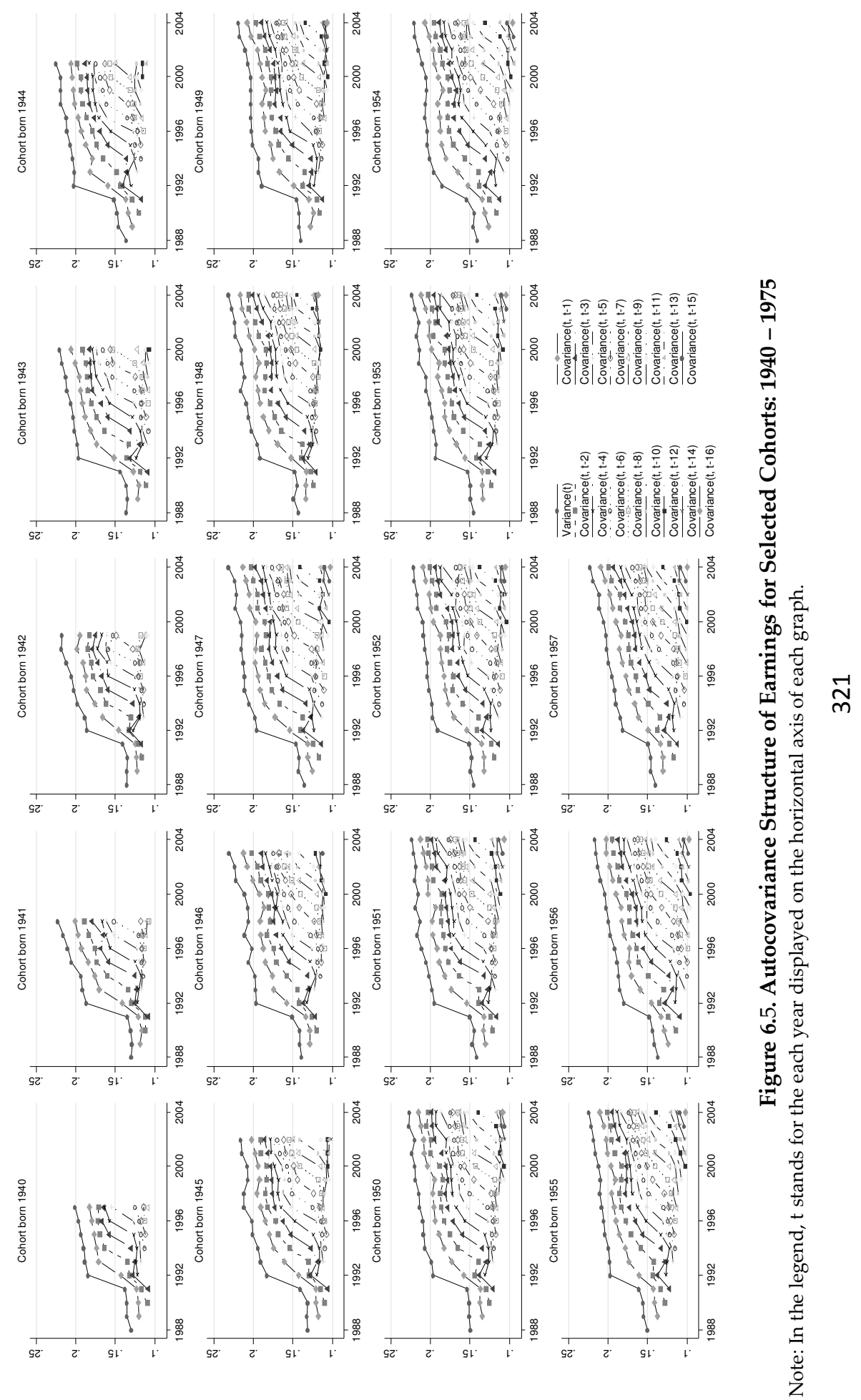

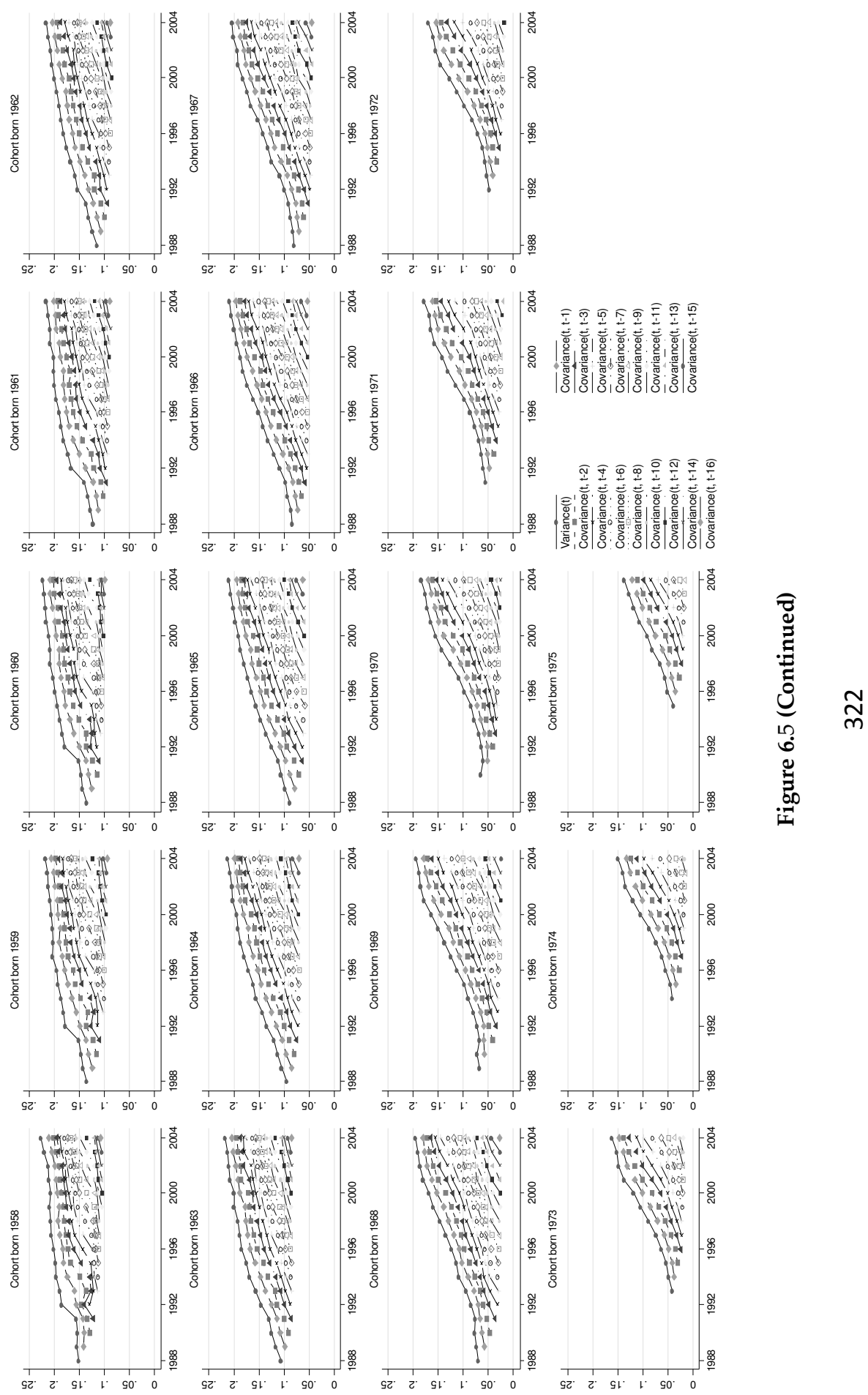
To sum up, the description of the dynamic structure of individual earnings for men suggests five main features of the data, which were incorporated in my model, as mentioned previously:

- First, the covariance elements are not the same at all lags. They decrease with the lag at a decreasing rate and converge gradually at a positive level, suggesting the presence of a transitory element, which is serially correlated, and of a permanent individual component of earnings.

- Second, as the autocovariances and mean earnings vary over the sample period, they cannot be assumed to be stationary over sample period. The stationarity assumption was tested and rejected using the methodology introduced by MaCurdy (1982).

- Third, as autocovariances vary with age controlling for the period effect, they cannot be assumed to be stationary over the life cycle.

- Lastly, the variance-covariance structure appears to be cohort specific.
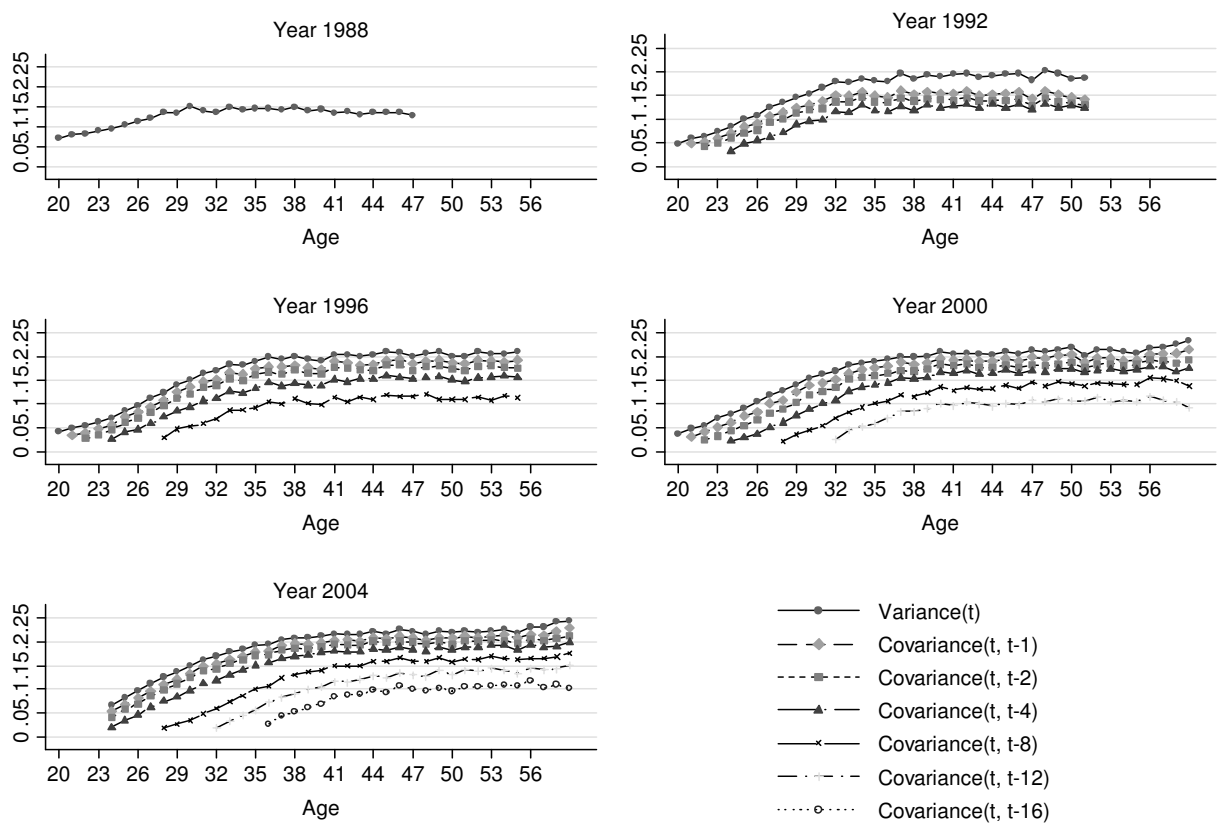

Figure 6.6. Lifecycle Autocovariances for Selected Years : 1988, 1992, 1996, 2000, 2004 Note: In the legend, $t$ stands for the each age displayed on the horizontal axis of each graph. 


\subsection{Results of Covariance Structure Estimation}

\subsubsection{Error component model estimation results}

To investigate these patterns more formally, I proceed to the GMM estimation of the earnings dynamics model described in Section 6.5. Table 6.3 shows the resulting estimates. The first three columns show the parameter estimates and the associated SE estimates for the base model outlined in equations (6.9)-(6.12). All the parameter estimates are highly significant. Recall that this model incorporates a persistent component, composed of terms capturing a random walk after age 20 until age 40, with age-specific innovation variances, and a random effects model after age 40 with the distribution of the effects fixed at that implied by the random walk, plus a transitory component following an ARMA $(1,1)$ process with agebased heteroskedastic innovations. Furthermore, the persistent and transitory components are allowed to shift over time and over cohort by separate yearspecific and cohort-specific factor loadings.

The significant estimates of $\sigma_{u_{20}}^{2}$ and $\sigma_{\pi_{a}}^{2}$, show that the variance of the initial permanent shock at age 20 and the random walk with age-specific innovation variances until age 40 play a significant role in the formation of the persistent component. As each cohort ages, the permanent component increases by the innovation variance, $\sigma_{\pi_{a}}^{2}$, which records the highest values at younger ages and declines with age. The pattern of the permanent variance, holding time and cohort shifters constant is captured in Figure 6.7. 


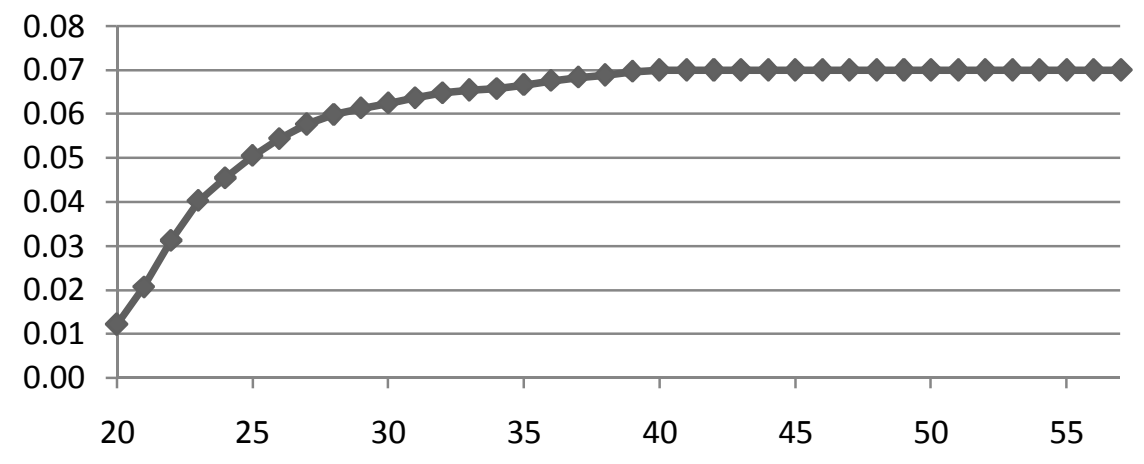

Figure 6.7. The pattern of the permanent component without time and cohort loading factors

Note: Based on the parameters estimates displayed in Table 6.3 - Base Model.

This pattern indicates that the persistent inequality increases over the lifecycle, but at a diminishing rate. Hence, within a cohort, the persistent variance increases with age until age 40 , remaining at the same level thereafter. The same result is also found by Dickens (2000b) for the UK between 1975 and 1995.

Table 6.3 (base model) reports next the estimates of the year-specific loading factors on the persistent component. For identification, the parameter for 1988 is normalized to 1 . The estimated factor loadings are significant and above one in all years, except 1990. Their pattern is captured in Figure 6.8.

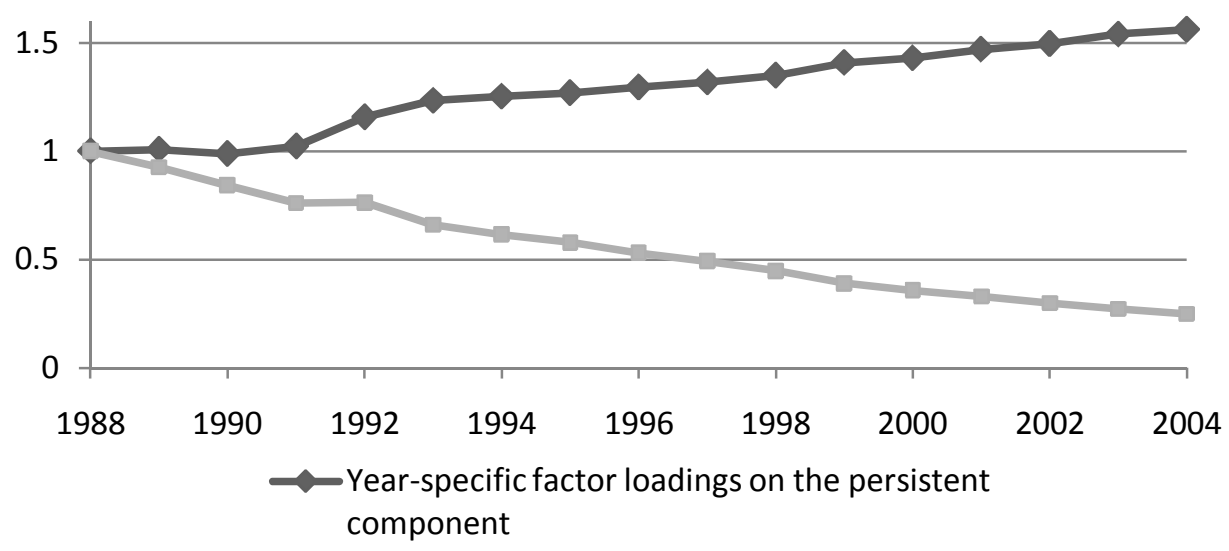

Figure 6.8. Year-specific factor loadings on the persistent and transitory components Note: Based on the parameters estimates displayed in Table 6.3 - Base Model. 
Except for the slight decrease in 1990, the factor loadings increase between 1988 and 2004, suggesting that the returns to the systematic earnings components, such as education, ability, increased over time in Luxembourg. Thus the permanent component is expected to play a relative large role in the increase in earnings inequality over this period. This is consistent with the trend estimated by Sologon and O'Donoghue (2009a, 2009b) for Luxebourg between 1995 and 2001.

Next, Table 6.3 (base model) reports the cohort-specific factor loadings. For identification, the parameter for the cohort born in 1940 is normalized to 1 . All parameters are significant and lower than 1. Their pattern is displayed in Figure 6.9: the permanent component plays a larger relative role in earnings differentials the older is the cohort. This is expected given that younger cohorts experience higher earnings volatility than older cohorts due to temporary contracts. The cohorts born between 1973 and 1975, appear to have a higher return to education than the cohorts born between 1967 and 1972. The overall trend is consistent with the trend estimated by Sologon and O'Donoghue (2009a, 2009b) for Luxembourg between 1995 and 2001. Opposite trends are obtained by Gustavsson (2004a, 2004b) for Sweden.

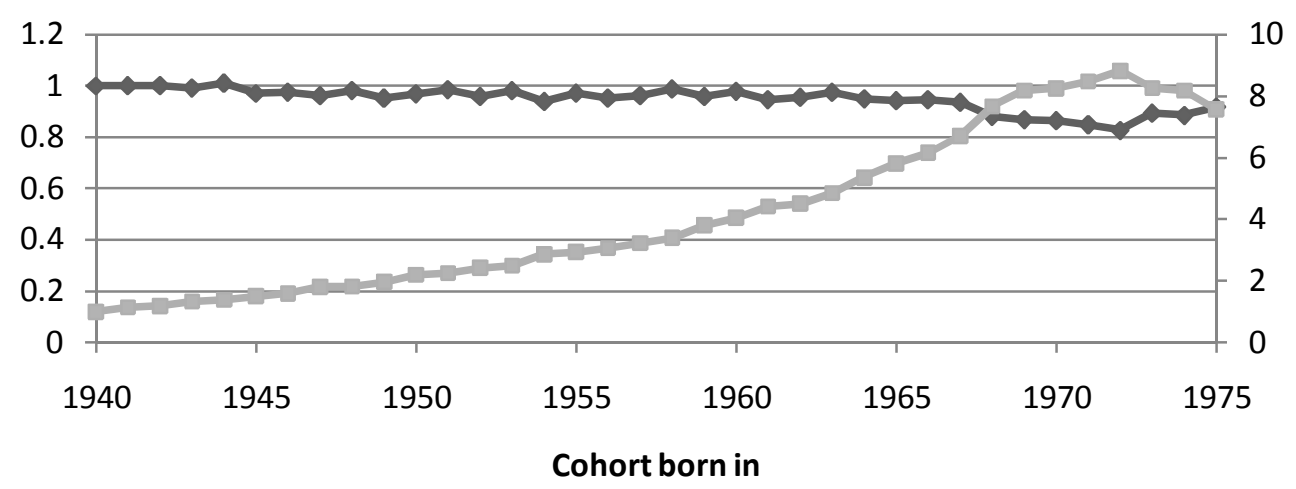

Cohort-specific factor loadings on the permanent component (left Y-axis) -Cohort-specific factor loadings on the transitory component (right Y-axis)

Figure 6.9. Cohort-specific loading factors on the permanent and transitory components Note: Based on the parameters estimates displayed in Table 6.3 - Base Model.

Further on, Table 6.3 (base model) reports the estimated parameters for the transitory component, which reveal that the initial cohort-specific variances, the 
ARMA $(1,1)$ process, the age-based heteroskedactic transitory shocks after age 20, the time and cohort-specific loading factors contribute significantly to earnings volatility in Luxembourg.

The pattern of the estimates of the cohort-specific initial variances, which capture the accumulation of the transitory process up to the start of the sample period for each cohort is illustrated in Figure 6.10: the older the cohort the higher the initial variance. The pattern evolves monotonically as a U-shape until the cohort born in 1948, and with spikes for the oldest cohort. The estimated initial variances for the cohorts born in 1968 through 1975 show how the accumulation of the transitory process changed for the 20-year-old over the period. The variance estimate more than doubled from 1988 (cohort 1968) to 1995 (cohort 1975), suggesting that dispersion has been increasing over time. A similar trend in the initial variances is obtained, for example, by Baker and Solon (2003) for Canada between 1976 and 1992.

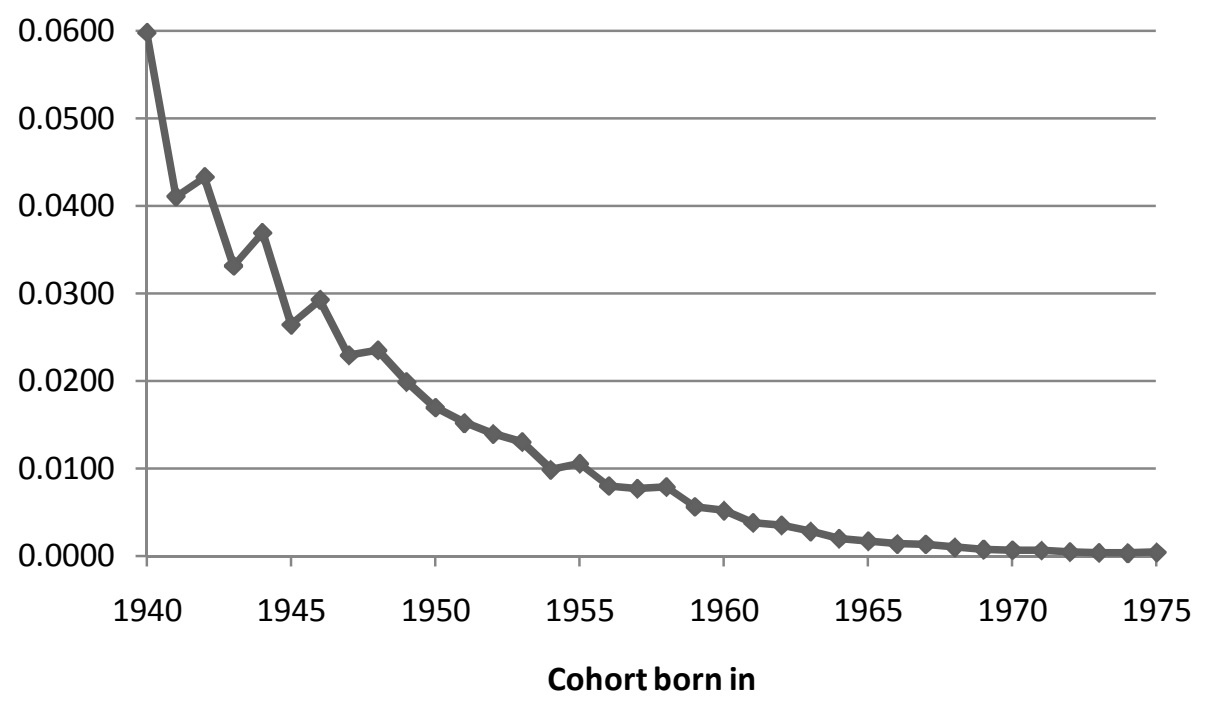

Figure 6.10. Cohort-specific initial transitory variances

Note: Based on the parameters estimates displayed in Table 6.3 - Base Model.

Next, Table 6.3 (base model) shows the estimates of the ARMA $(1,1)$ process. The large autoregressive parameter, $\hat{\rho}=0.964$, suggests that shocks are persistent, and the negative sign of $\hat{\theta}=-0.206$ implies that the autocovariances decline 327 
sharply over the first period, confirming the trends observed in the description of the autocovariance structure of earnings. The estimates suggest that $75.8 \%$ of a transitory shock is still present after 1 year, and $0.9 \%$ is still present after 17 years. My estimates for the ARMA(1,1) process are similar with Dickens's (2000b) and Gustavsson's (2004a, 2004b) most comparable estimates for the UK and Sweden.

Next ${ }^{107}$, I turn to the parameters that allow for age-related heteroskedasticity in the transitory shocks. The sign of the parameter estimates is consistent with those obtained by Baker and Solon (2004) for Canada and Gustvason (2004a, 2004b) for Sweden. The estimates of the age quadratic function determine the pattern illustrated in Figure 6.11. There is an initial decline in the variances of the innovations in early twenties, followed by a slow increase until early forties, and an accelerated increase thereafter. This pattern points to the importance of accounting for the systematic influence of age on the variance of the transitory earnings innovations.

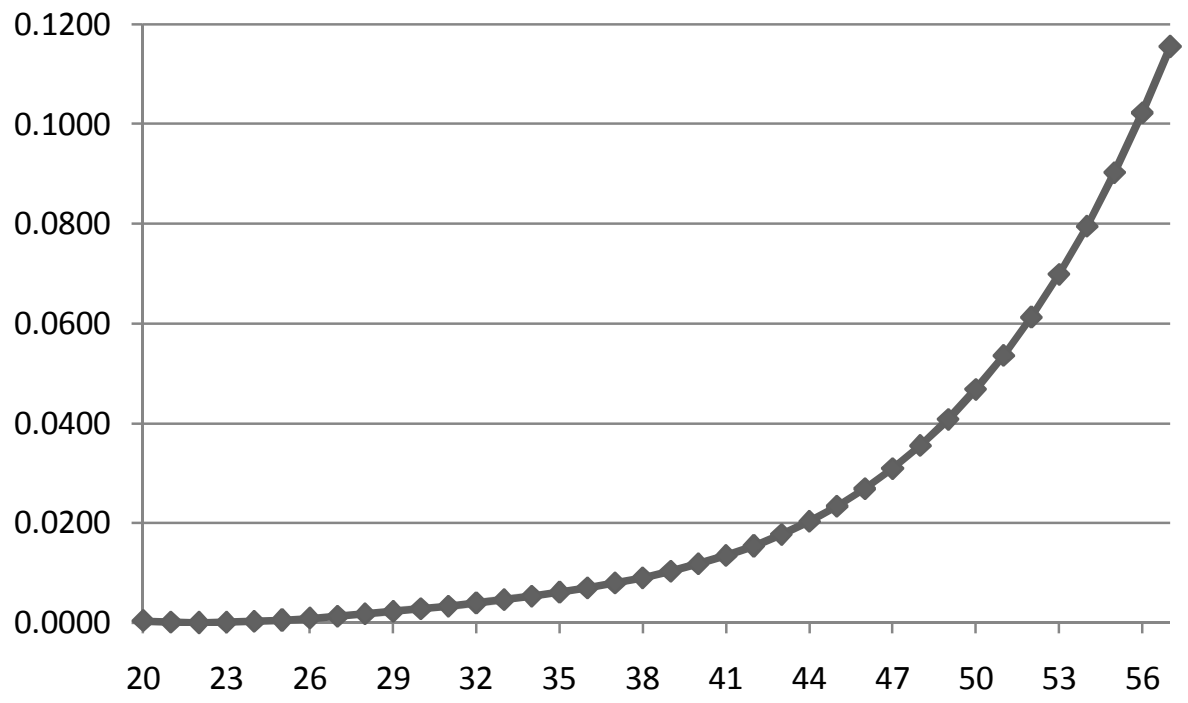

Figure 6.11. The age profile of the variance of the transitory innovation, base model Note: Based on the parameters estimates displayed in Table 6.3 - Base Model.

107 Table 6.3 (base model) 
Finally, I report the estimates of the period and cohort-specific loading factors for the transitory component. For identification, the factor loadings for 1988 and for the cohort born in 1940 were normalized to unity. The pattern of the year-specific loading factors is captured in Figure 6.8, which illustrate a monotonic decrease over the period. Thus the relative share of the transitory component appears to decrease over the sample period. The divergence observed in the trends of the time factor loading of the two components (Figure 6.8), suggest that the structural labour market changes favoured a rise in the returns to skills over time and a decrease in earnings instability.

Figure 6.9 captures the pattern of the cohort-specific loading factors for the transitory earnings, which reveals that earnings volatility is higher for younger cohorts, confirming the pattern observed in the dynamic description of the autocovariance structure of earnings, where autocovariances were found to be lower for younger cohorts. This is expected, given the more frequent job changes and less stable earnings of younger workers. A similar trend was obtained by Sologon and O'Donoghue (2009a, 2009b) for Luxembourg.

Our base model nests and extends most of the specification used in the US, Canadian, and European studies. The studies based on relatively small-scale panel surveys imposed often economically implausible restrictions. I tested whether some of these restrictions hold in my data. The Wald test and the p- values for testing these restrictions are reported in Table 6.2.

Table 6.2. Wald tests of model restrictions in the base model

\begin{tabular}{|c|c|c|c|}
\hline Restriction & $x^{2}$ & $\begin{array}{l}\text { Degrees of } \\
\text { freedom }\end{array}$ & P-value \\
\hline $\begin{array}{l}\text { (1) } \sigma_{\pi_{21}}^{2}=\sigma_{\pi_{22}}^{2}=\ldots=\sigma_{\pi_{40}}^{2}=0 \\
\text { (no random walk) }\end{array}$ & 10326.6302 & 31 & 0.0001 \\
\hline $\begin{array}{l}\text { (2) } \sigma_{\pi_{21}}^{2}=\sigma_{\pi_{22}}^{2}=\ldots=\sigma_{\pi_{40}}^{2}=\sigma_{\pi}^{2} \\
\text { (no age-specific innovation variance) }\end{array}$ & 2463.3344 & 21 & 0.0001 \\
\hline $\begin{array}{l}\text { (3) } \beta_{1}=0, \beta_{2}=0, \beta_{3}=0, \beta_{4}=0 \\
\text { (no age-related heteroskedastic transitory shocks) }\end{array}$ & 2963.499 & 4 & 0.0001 \\
\hline
\end{tabular}

Some studies assumed away the heterogeneity in earnings growth rates and/or the existence of earnings shocks with permanent effects. Backer and Solon (2003) and Ramos (2003) were able to incorporate both in the permanent component. My model, however incorporates only the random walk process, as a specification with 
both components leads to identification problems for two parameters of the random growth model.

I extended the specification of the permanent component to follow a random walk process with age-specific innovation variances until age 40, and a random effects model with the distribution of the effects fixed at that implied by the random walk thereafter. These features were incorporated only by Dickens (2000b) for the UK. Another study which did a similar attempt is Gustavsson (2004b), but he constrained the innovation variance to be the same for two adjacent ages between 28 and 53 .

If I assume away the random walk until age 40 in the permanent component, the Wald test on this restrictions clearly rejects the null $\left(\chi^{2}=10326.6302, \mathrm{df}=31\right)$. If I assume away the age-specific innovation variance until age 40, keeping all the other specifications of the base model, the Wald test on this restrictions rejects the null $\left(\chi^{2}=2463.3344, \mathrm{df}=21\right)$ with a $\mathrm{p}$-value equal to 0.0001 .

Except Baker and Solon (2003) and Gustavsson (2004b), previous studies imposed the restriction of invariant variance of the transitory shocks, which was rejected by the Canadian and Swedish data. My study proves once again that assuming away the presence of age-related heteroskedastic transitory shocks, meaning that $\beta_{1}=0, \beta_{2}=0, \beta_{3}=0, \beta_{4}=0$, is statistically indefensible: the $\mathrm{p}$-value for the Wald test is 0.0001 , clearly rejecting the null hypothesis in the Luxembourgish data.

In order to see the implications of imposing some of these restrictions on the inequality decomposition, I estimated a restricted model, where the permanent component follows a standard random walk in age with the variance of the first period shock at age 20 fixed at 0 , and the transitory component follows an $\operatorname{ARMA}(1,1)$ process with cohort-specific initial variances, with time and cohort loading factors on both components. The estimation results are displayed in Table 6.3, columns 4-6. 


\begin{tabular}{|c|c|c|c|c|c|c|}
\hline \multirow[b]{2}{*}{ Permanent Component } & \multicolumn{3}{|c|}{ Base model } & \multicolumn{3}{|c|}{$\begin{array}{c}\text { Restricted Model } \\
\text { Random Walk + ARMA }(1,1) \\
\end{array}$} \\
\hline & Exp(Estimate) & Estimate & SE & Exp(Estimate) & Estimate & SE \\
\hline $\exp ($ estimate $)=\sigma_{\mu_{20}}^{2}$ & 0.0122 & -4.4103 & 0.0681 & & & \\
\hline $\exp ($ estimate $)=\sigma_{\pi}^{2}$ & & & & 0.0001 & -8.9471 & 0.0831 \\
\hline $\exp ($ estimate $)=\sigma_{\pi_{21}}^{2}$ & 0.0085 & -4.7702 & 0.0668 & & & \\
\hline $\exp ($ estimate $)=\sigma_{\pi_{22}}^{2}$ & 0.0106 & -4.5495 & 0.0589 & & & \\
\hline $\exp ($ estimate $)=\sigma_{\pi_{23}}^{2}$ & 0.0090 & -4.7058 & 0.0599 & & & \\
\hline $\exp ($ estimate $)=\sigma_{\pi_{24}}^{2}$ & 0.0052 & -5.2677 & 0.0616 & & & \\
\hline $\exp ($ estimate $)=\sigma_{\pi_{25}}^{2}$ & 0.0051 & -5.2853 & 0.0639 & & & \\
\hline $\exp ($ estimate $)=\sigma_{\pi_{26}}^{2}$ & 0.0039 & -5.5439 & 0.0653 & & & \\
\hline $\exp ($ estimate $)=\sigma_{\pi_{27}}^{2}$ & 0.0033 & -5.7284 & 0.0675 & & & \\
\hline $\exp ($ estimate $)=\sigma_{\pi_{28}}^{2}$ & 0.0023 & -6.0951 & 0.0744 & & & \\
\hline $\exp ($ estimate $)=\sigma_{\pi_{29}}^{2}$ & 0.0014 & -6.5711 & 0.1053 & & & \\
\hline $\exp ($ estimate $)=\sigma_{\pi_{30}}^{2}$ & 0.0011 & -6.8030 & 0.1501 & & & \\
\hline $\exp ($ estimate $)=\sigma_{\pi_{31}}^{2}$ & 0.0013 & -6.6765 & 0.1434 & & & \\
\hline $\exp ($ estimate $)=\sigma_{\pi_{32}}^{2}$ & 0.0011 & -6.8453 & 0.1868 & & & \\
\hline $\exp ($ estimate $)=\sigma_{\pi_{33}}^{2}$ & 0.0007 & -7.3006 & 0.2934 & & & \\
\hline $\exp ($ estimate $)=\sigma_{\pi_{34}}^{2}$ & 0.0003 & -8.0633 & 0.6885 & & & \\
\hline $\exp ($ estimate $)=\sigma_{\pi_{35}}^{2}$ & 0.0008 & -7.0832 & 0.2881 & & & \\
\hline $\exp ($ estimate $)=\sigma_{\pi_{36}}^{2}$ & 0.0010 & -6.9368 & 0.2537 & & & \\
\hline $\exp ($ estimate $)=\sigma_{\pi_{37}}^{2}$ & 0.0008 & -7.1521 & 0.3257 & & & \\
\hline $\exp ($ estimate $)=\sigma_{\pi_{38}}^{2}$ & 0.0005 & -7.6076 & 0.5160 & & & \\
\hline $\exp ($ estimate $)=\sigma_{\pi_{39}}^{2}$ & 0.0008 & -7.1649 & 0.3545 & & & \\
\hline $\exp ($ estimate $)=\sigma_{\pi_{40}}^{2}$ & 0.0004 & -7.9056 & 0.8928 & & & \\
\hline Time shifters $\lambda_{1,1988}=1$ & & & & & & \\
\hline
\end{tabular}




\begin{tabular}{|c|c|c|c|c|}
\hline$\lambda_{1,1989}$ & 1.0079 & 0.0043 & 0.9131 & 0.0049 \\
\hline$\lambda_{1,1990}$ & 0.9881 & 0.0059 & 0.8059 & 0.0069 \\
\hline$\lambda_{1,1991}$ & 1.0219 & 0.0071 & 0.7756 & 0.0074 \\
\hline$\lambda_{1,1992}$ & 1.1567 & 0.0093 & 0.9140 & 0.0092 \\
\hline$\lambda_{1,1993}$ & 1.2329 & 0.0121 & 0.8867 & 0.0099 \\
\hline$\lambda_{1,1994}$ & 1.2521 & 0.0136 & 0.8245 & 0.0096 \\
\hline$\lambda_{1,1995}$ & 1.2682 & 0.0149 & 0.7899 & 0.0095 \\
\hline$\lambda_{1,1996}$ & 1.2939 & 0.0161 & 0.7566 & 0.0095 \\
\hline$\lambda_{1,1997}$ & 1.3167 & 0.0174 & 0.7327 & 0.0098 \\
\hline$\lambda_{1,1998}$ & 1.3488 & 0.0185 & 0.7139 & 0.0099 \\
\hline$\lambda_{1,1999}$ & 1.4073 & 0.0202 & 0.7046 & 0.0101 \\
\hline$\lambda_{1,2000}$ & 1.4291 & 0.0214 & 0.6938 & 0.0107 \\
\hline$\lambda_{1,2001}$ & 1.4689 & 0.0229 & 0.6914 & 0.0114 \\
\hline$\lambda_{1,2002}$ & 1.4952 & 0.0242 & 0.6892 & 0.0124 \\
\hline$\lambda_{1,2003}$ & 1.5388 & 0.0258 & 0.6881 & 0.0134 \\
\hline$\lambda_{1,2004}$ & 1.5601 & 0.0266 & 0.6805 & 0.0142 \\
\hline Cohort shifters $\gamma_{1}$, & & & & \\
\hline$\gamma_{1,1941}$ & 1.0011 & 0.0401 & 1.0361 & 0.0583 \\
\hline$\gamma_{1,1942}$ & 1.0016 & 0.0381 & 1.0559 & 0.0588 \\
\hline$\gamma_{1,1943}$ & 0.9924 & 0.0367 & 1.0867 & 0.0585 \\
\hline$\gamma_{1,1944}$ & 1.0100 & 0.0354 & 1.1290 & 0.0571 \\
\hline$\gamma_{1,1945}$ & 0.9708 & 0.0343 & 1.1188 & 0.0580 \\
\hline$\gamma_{1,1946}$ & 0.9763 & 0.0333 & 1.1563 & 0.0569 \\
\hline$\gamma_{1,1947}$ & 0.9616 & 0.0317 & 1.1600 & 0.0556 \\
\hline$\gamma_{1,1948}$ & 0.9831 & 0.0320 & 1.2381 & 0.0580 \\
\hline$\gamma_{1,1949}$ & 0.9519 & 0.0312 & 1.2255 & 0.0581 \\
\hline$\gamma_{1,1950}$ & 0.9695 & 0.0321 & 1.2742 & 0.0616 \\
\hline$\gamma_{1,1951}$ & 0.9857 & 0.0319 & 1.3615 & 0.0630 \\
\hline$\gamma_{1,1952}$ & 0.9583 & 0.0311 & 1.3482 & 0.0634 \\
\hline
\end{tabular}




\begin{tabular}{|c|c|c|c|c|c|c|}
\hline$\gamma_{1,1953}$ & & 0.9808 & 0.0314 & & 1.4439 & 0.0664 \\
\hline$\gamma_{1,1954}$ & & 0.9390 & 0.0305 & & 1.3903 & 0.0660 \\
\hline$\gamma_{1,1955}$ & & 0.9709 & 0.0311 & & 1.5023 & 0.0700 \\
\hline$\gamma_{1,1956}$ & & 0.9530 & 0.0306 & & 1.5502 & 0.0716 \\
\hline$\gamma_{1,1957}$ & & 0.9628 & 0.0308 & & 1.6323 & 0.0749 \\
\hline$\gamma_{1,1958}$ & & 0.9878 & 0.0313 & & 1.7380 & 0.0793 \\
\hline$\gamma_{1,1959}$ & & 0.9592 & 0.0306 & & 1.7389 & 0.0798 \\
\hline$\gamma_{1,1960}$ & & 0.9791 & 0.0286 & & 1.8759 & 0.0754 \\
\hline$\gamma_{1,1961}$ & & 0.9475 & 0.0279 & & 1.8959 & 0.0762 \\
\hline$\gamma_{1,1962}$ & & 0.9553 & 0.0282 & & 2.0361 & 0.0818 \\
\hline$\gamma_{1,1963}$ & & 0.9752 & 0.0290 & & 2.2006 & 0.0883 \\
\hline$\gamma_{1,1964}$ & & 0.9502 & 0.0284 & & 2.2670 & 0.0909 \\
\hline$\gamma_{1,1965}$ & & 0.9425 & 0.0284 & & 2.3467 & 0.0941 \\
\hline$\gamma_{1,1966}$ & & 0.9464 & 0.0287 & & 2.5782 & 0.1032 \\
\hline$\gamma_{1,1967}$ & & 0.9352 & 0.0285 & & 2.7112 & 0.1085 \\
\hline$\gamma_{1,1968}$ & & 0.8821 & 0.0271 & & 2.7789 & 0.1111 \\
\hline$\gamma_{1,1969}$ & & 0.8692 & 0.0267 & & 2.9177 & 0.1163 \\
\hline$\gamma_{1,1970}$ & & 0.8638 & 0.0265 & & 2.9631 & 0.1178 \\
\hline$\gamma_{1,1971}$ & & 0.8500 & 0.0261 & & 2.8585 & 0.1135 \\
\hline$\gamma_{1,1972}$ & & 0.8276 & 0.0255 & & 2.9451 & 0.1165 \\
\hline$\gamma_{1,1973}$ & & 0.8938 & 0.0273 & & 3.1080 & 0.1226 \\
\hline$\gamma_{1,1974}$ & & 0.8861 & 0.0270 & & 3.0035 & 0.1185 \\
\hline$\gamma_{1,1975}$ & & 0.9176 & 0.0278 & & 2.9632 & 0.1174 \\
\hline Transitory Component & Exp(Estimate) & Estimate & SE & Exp(Estimate) & Estimate & SE \\
\hline \multicolumn{7}{|l|}{$\exp ($ estimate $)=\sigma_{0}^{2}$} \\
\hline $\exp ($ estimate $)=\sigma_{0,1940}^{2}$ & 0.0597 & -2.8182 & 0.1292 & 0.0334 & -3.3990 & 0.3236 \\
\hline $\exp ($ estimate $)=\sigma_{0,1941}^{2}$ & 0.0411 & -3.1928 & 0.1599 & 0.0253 & -3.6788 & 0.3853 \\
\hline $\exp ($ estimate $)=\sigma_{0,1942}^{2}$ & 0.0433 & -3.1406 & 0.1355 & 0.0362 & -3.3196 & 0.2597 \\
\hline $\exp ($ estimate $)=\sigma_{0,1943}^{2}$ & 0.0331 & -3.4075 & 0.1364 & 0.0333 & -3.4026 & 0.2468 \\
\hline
\end{tabular}




\begin{tabular}{|c|c|c|c|c|c|c|}
\hline $\exp ($ estimate $)=\sigma_{0,1944}^{2}$ & 0.0369 & -3.3000 & 0.1244 & 0.0468 & -3.0623 & 0.1692 \\
\hline $\exp ($ estimate $)=\sigma_{0,1945}^{2}$ & 0.0264 & -3.6340 & 0.1292 & 0.0412 & -3.1905 & 0.1757 \\
\hline $\exp ($ estimate $)=\sigma_{0,1946}^{2}$ & 0.0292 & -3.5322 & 0.1141 & 0.0545 & -2.9091 & 0.1235 \\
\hline $\exp ($ estimate $)=\sigma_{0,1947}^{2}$ & 0.0229 & -3.7765 & 0.1123 & 0.0571 & -2.8627 & 0.1066 \\
\hline $\exp ($ estimate $)=\sigma_{0,1948}^{2}$ & 0.0235 & -3.7510 & 0.1106 & 0.0635 & -2.7560 & 0.0971 \\
\hline $\exp ($ estimate $)=\sigma_{0,1949}^{2}$ & 0.0199 & -3.9187 & 0.1116 & 0.0678 & -2.6906 & 0.0907 \\
\hline $\exp ($ estimate $)=\sigma_{0,1950}^{2}$ & 0.0170 & -4.0770 & 0.1158 & 0.0704 & -2.6536 & 0.0838 \\
\hline $\exp ($ estimate $)=\sigma_{0,1951}^{2}$ & 0.0152 & -4.1881 & 0.1207 & 0.0727 & -2.6212 & 0.0840 \\
\hline $\exp ($ estimate $)=\sigma_{0,1952}^{2}$ & 0.0139 & -4.2731 & 0.1216 & 0.0800 & -2.5259 & 0.0775 \\
\hline $\exp ($ estimate $)=\sigma_{0,1953}^{2}$ & 0.0130 & -4.3393 & 0.1273 & 0.0845 & -2.4712 & 0.0768 \\
\hline $\exp ($ estimate $)=\sigma_{0,1954}^{2}$ & 0.0099 & -4.6196 & 0.1296 & 0.0828 & -2.4915 & 0.0705 \\
\hline $\exp ($ estimate $)=\sigma_{0,1955}^{2}$ & 0.0105 & -4.5522 & 0.1349 & 0.0976 & -2.3269 & 0.0707 \\
\hline $\exp ($ estimate $)=\sigma_{0,1956}^{2}$ & 0.0080 & -4.8270 & 0.1429 & 0.0903 & -2.4042 & 0.0717 \\
\hline $\exp ($ estimate $)=\sigma_{0,1957}^{2}$ & 0.0077 & -4.8647 & 0.1450 & 0.1005 & -2.2976 & 0.0697 \\
\hline $\exp ($ estimate $)=\sigma_{0,1958}^{2}$ & 0.0079 & -4.8412 & 0.1482 & 0.1161 & -2.1532 & 0.0699 \\
\hline $\exp ($ estimate $)=\sigma_{0,1959}^{2}$ & 0.0056 & -5.1777 & 0.1517 & 0.1060 & -2.2448 & 0.0680 \\
\hline $\exp ($ estimate $)=\sigma_{0,1960}^{2}$ & 0.0052 & -5.2634 & 0.1429 & 0.1156 & -2.1575 & 0.0504 \\
\hline $\exp ($ estimate $)=\sigma_{0,1961}^{2}$ & 0.0038 & -5.5767 & 0.1492 & 0.1072 & -2.2329 & 0.0502 \\
\hline $\exp ($ estimate $)=\sigma_{0,1962}^{2}$ & 0.0035 & -5.6525 & 0.1550 & 0.1150 & -2.1631 & 0.0500 \\
\hline $\exp ($ estimate $)=\sigma_{0,1963}^{2}$ & 0.0028 & -5.8699 & 0.1617 & 0.1147 & -2.1651 & 0.0499 \\
\hline $\exp ($ estimate $)=\sigma_{0,1964}^{2}$ & 0.0020 & -6.2214 & 0.1690 & 0.1002 & -2.3004 & 0.0498 \\
\hline $\exp ($ estimate $)=\sigma_{0,1965}^{2}$ & 0.0017 & -6.3801 & 0.1740 & 0.0961 & -2.3429 & 0.0499 \\
\hline $\exp ($ estimate $)=\sigma_{0,1966}^{2}$ & 0.0014 & -6.5932 & 0.1771 & 0.0944 & -2.3607 & 0.0502 \\
\hline $\exp ($ estimate $)=\sigma_{0,1967}^{2}$ & 0.0014 & -6.6023 & 0.1795 & 0.0959 & -2.3446 & 0.0508 \\
\hline $\exp ($ estimate $)=\sigma_{0,1968}^{2}$ & 0.0010 & -6.9092 & 0.1859 & 0.0826 & -2.4939 & 0.0514 \\
\hline $\exp ($ estimate $)=\sigma_{0,1969}^{2}$ & 0.0008 & -7.1767 & 0.1849 & 0.0744 & -2.5986 & 0.0515 \\
\hline
\end{tabular}




\begin{tabular}{|c|c|c|c|c|c|c|}
\hline $\exp ($ estimate $)=\sigma_{0,1970}^{2}$ & 0.0007 & -7.2768 & 0.1844 & 0.0698 & -2.6622 & 0.0513 \\
\hline $\exp ($ estimate $)=\sigma_{0,1971}^{2}$ & 0.0006 & -7.3486 & 0.1836 & 0.0614 & -2.7902 & 0.0509 \\
\hline $\exp ($ estimate $)=\sigma_{0,1972}^{2}$ & 0.0005 & -7.6823 & 0.1819 & 0.0506 & -2.9829 & 0.0506 \\
\hline $\exp ($ estimate $)=\sigma_{0,1973}^{2}$ & 0.0004 & -7.8563 & 0.1824 & 0.0451 & -3.0991 & 0.0503 \\
\hline $\exp ($ estimate $)=\sigma_{0,1974}^{2}$ & 0.0004 & -7.9512 & 0.1816 & 0.0405 & -3.2065 & 0.0502 \\
\hline $\exp ($ estimate $)=\sigma_{0,1975}^{2}$ & 0.0004 & -7.7175 & 0.1824 & 0.0452 & -3.0968 & 0.0503 \\
\hline$\rho$ & & 0.9640 & 0.0052 & & 0.9508 & 0.0018 \\
\hline$\theta$ & & -0.2060 & 0.0037 & & -0.2700 & 0.0024 \\
\hline $\exp ($ estimate $)=\sigma_{\varepsilon}^{2}$ & & & & 0.0442 & -3.1180 & 0.0514 \\
\hline$\beta_{0}$ & & 0.0004 & 0.0001 & & & \\
\hline$\beta_{1}$ & & -0.0004 & 0.0000 & & & \\
\hline$\beta_{2}$ & & 0.0001 & 0.0000 & & & \\
\hline$\beta_{3}$ & & $-6.01 \mathrm{E}-06$ & 6.47E-07 & & & \\
\hline$\beta_{4}$ & & $1.54 \mathrm{E}-07$ & $1.37 \mathrm{E}-08$ & & & \\
\hline Time shifters $\lambda_{2,1988}=1$ & & & & & & \\
\hline$\lambda_{2,1989}$ & & 0.9258 & 0.0058 & & 0.9911 & 0.0038 \\
\hline$\lambda_{2,1990}$ & & 0.8420 & 0.0089 & & 0.9716 & 0.0056 \\
\hline$\lambda_{2,1991}$ & & 0.7603 & 0.0110 & & 0.9400 & 0.0067 \\
\hline$\lambda_{2,1992}$ & & 0.7626 & 0.0135 & & 0.9151 & \\
\hline$\lambda_{2,1993}$ & & 0.6603 & 0.0139 & & 0.9010 & 0.0086 \\
\hline$\lambda_{2,1994}$ & & 0.6153 & 0.0145 & & 0.9211 & 0.0090 \\
\hline$\lambda_{2,1995}$ & & 0.5781 & 0.0151 & & 0.9217 & 0.0091 \\
\hline$\lambda_{2,1996}$ & & 0.5310 & 0.0153 & & 0.9200 & 0.0092 \\
\hline$\lambda_{2,1997}$ & & 0.4925 & 0.0155 & & 0.9152 & 0.0094 \\
\hline$\lambda_{2,1998}$ & & 0.4466 & 0.0152 & & 0.9015 & 0.0096 \\
\hline$\lambda_{2,1999}$ & & 0.3898 & 0.0143 & & 0.8815 & 0.0099 \\
\hline$\lambda_{2,2000}$ & & 0.3579 & 0.0140 & & 0.8622 & 0.0107 \\
\hline$\lambda_{2,2001}$ & & 0.3293 & 0.0138 & & 0.8504 & 0.0116 \\
\hline$\lambda_{2,2002}$ & & 0.2990 & 0.0134 & & 0.8208 & 0.0127 \\
\hline$\lambda_{2,2003}$ & & 0.2710 & 0.0131 & & 0.8060 & \\
\hline
\end{tabular}




\begin{tabular}{|c|c|c|c|c|}
\hline$\lambda_{2,2004}$ & 0.2487 & 0.0129 & 0.7886 & 0.0155 \\
\hline Cohort shifters $\gamma_{2,}$ & & & & \\
\hline$\gamma_{2,1941}$ & 1.1373 & 0.0521 & 1.0572 & 0.0363 \\
\hline$\gamma_{2,1942}$ & 1.1860 & 0.0543 & 1.0323 & 0.0358 \\
\hline$\gamma_{2,1943}$ & 1.3352 & 0.0592 & 1.0617 & 0.0359 \\
\hline$\gamma_{2,1944}$ & 1.3868 & 0.0601 & 1.0368 & 0.0337 \\
\hline$\gamma_{2,1945}$ & 1.5069 & 0.0667 & 1.0411 & 0.0347 \\
\hline$\gamma_{2,1946}$ & 1.5928 & 0.0696 & 1.0246 & 0.0330 \\
\hline$\gamma_{2,1947}$ & 1.8069 & 0.0782 & 1.0661 & 0.0328 \\
\hline$\gamma_{2,1948}$ & 1.8197 & 0.0835 & 1.0163 & 0.0322 \\
\hline$\gamma_{2,1949}$ & 1.9607 & 0.0915 & 1.0130 & 0.0314 \\
\hline$\gamma_{2,1950}$ & 2.1941 & 0.1079 & 1.0598 & 0.0333 \\
\hline$\gamma_{2,1951}$ & 2.2548 & 0.1154 & 1.0201 & 0.0317 \\
\hline$\gamma_{2,1952}$ & 2.4227 & 0.1302 & 1.0230 & 0.0314 \\
\hline$\gamma_{2,1953}$ & 2.4951 & 0.1423 & 0.9973 & 0.0315 \\
\hline$\gamma_{2,1954}$ & 2.8690 & 0.1709 & 1.0538 & 0.0322 \\
\hline$\gamma_{2,1955}$ & 2.9363 & 0.1853 & 1.0216 & 0.0324 \\
\hline$\gamma_{2,1956}$ & 3.0621 & 0.2029 & 0.9973 & 0.0316 \\
\hline$\gamma_{2,1957}$ & 3.2217 & 0.2222 & 0.9817 & 0.0313 \\
\hline$\gamma_{2,1958}$ & 3.3996 & 0.2435 & 0.9753 & 0.0317 \\
\hline$\gamma_{2,1959}$ & 3.8064 & 0.2785 & 1.0066 & 0.0314 \\
\hline$\gamma_{2,1960}$ & 4.0505 & 0.2903 & 0.9904 & 0.0247 \\
\hline$\gamma_{2,1961}$ & 4.4171 & 0.3283 & 0.9923 & 0.0248 \\
\hline$\gamma_{2,1962}$ & 4.5102 & 0.3462 & 0.9466 & 0.0237 \\
\hline$\gamma_{2,1963}$ & 4.8457 & 0.3850 & 0.9424 & 0.0236 \\
\hline$\gamma_{2,1964}$ & 5.3518 & 0.4412 & 0.9490 & 0.0238 \\
\hline$\gamma_{2,1965}$ & 5.8114 & 0.4960 & 0.9544 & 0.0240 \\
\hline$\gamma_{2,1966}$ & 6.1591 & 0.5430 & 0.9070 & 0.0229 \\
\hline$\gamma_{2,1967}$ & 6.7065 & 0.6104 & 0.8898 & 0.0225 \\
\hline
\end{tabular}




\begin{tabular}{|c|c|c|c|c|}
\hline$\gamma_{2,1968}$ & 7.6686 & 0.7202 & 0.8706 & 0.0220 \\
\hline$\gamma_{2,1969}$ & 8.1754 & 0.7665 & 0.8558 & 0.0217 \\
\hline$\gamma_{2,1970}$ & 8.2511 & 0.7724 & 0.8524 & 0.0216 \\
\hline$\gamma_{2,1971}$ & 8.4753 & 0.7908 & 0.8900 & 0.0224 \\
\hline$\gamma_{2,1972}$ & 8.8249 & 0.8197 & 0.8773 & 0.0221 \\
\hline$\gamma_{2,1973}$ & 8.2619 & 0.7680 & 0.8924 & 0.0225 \\
\hline$\gamma_{2,1974}$ & 8.1837 & 0.7567 & 0.9057 & 0.0228 \\
\hline$\gamma_{2,1975}$ & 7.5667 & 0.6990 & 0.9082 & 0.0228 \\
\hline SSR & 0.0644 & & 0.0773 & \\
\hline$\chi^{2}$ & $5390.3708(\mathrm{df}=166)$ & & 7541.0155 & \\
\hline BIC & $1.9311 \mathrm{E}-05$ & & $2.2095 \mathrm{E}-05$ & \\
\hline
\end{tabular}




\subsubsection{Inequality Decomposition into Permanent and Transitory Inequality}

I now use the parameters estimates from the error component models to decompose earnings inequality into permanent and transitory inequality, assess their absolute and relative contribution to the evolution of overall inequality and estimate earnings mobility over the sample period. In interpreting the findings one has to keep in mind that there is a fundamental conceptual underidentification of time, life-cycle, and cohort effects due to the exact multicollinearity of time, age, and birth year. Thus two effects will always be confounded. In order to provide a more comprehensive picture, I perform first the inequality decomposition by cohort over time, second the decomposition of the cross-sectional age-inequality profile in four selected years, and third the inequality decomposition by selected age groups over time.

\subsubsection{Inequality decomposition by cohort over time}

I start with the decompositions by cohort over time, which reveals how the structure of inequality and earnings mobility evolved between 1988 and 2004 for people born in each birth cohort considered. This decomposition enables to see whether the labour market structural changes had a different impact depending on the birth year. This decomposition controls for the cohort effect, but confounds age and period effects.

\section{Absolute decomposition}

Figure 6.12 illustrates the absolute decomposition of the variance, together with the actual and predicted variance of earnings by cohort for the base model. The predicted variance follows closely the evolution of the actual variance, confirming the fit of the base model.

In a longitudinal view, over the sample period, earnings differentials increased for all cohorts. Overall, the increase in cross-sectional inequality is the result of increasing permanent differentials, trend consistent across cohorts. This finding is consistent with the results obtained by Sologon and O'Donoghue (2009a, 2009b) for Luxembourg between 1995 and 2001. More heterogeneity is observed in the evolution of the transitory variance, which increased for the oldest cohorts 19401945 and for the youngest cohorts 1964-1975, and decreased for the rest. Thus the cohorts 1940-1945 experienced an increase in their earnings instability between ages 43 (for the youngest) and 48 (for the oldest) until age 57. Similarly, earnings 
instability increased for cohorts 1964-1975 between early 20s until late 30s and 40s. For the middle cohorts, earnings instability decreased between age 25 and 57 .

The trends of the two components present some similarities across cohorts. For most cohorts permanent variance was lower than transitory variance in the beginning of the sample, and then surpassed it in 1993 for cohorts 1940-1963, in 1991 for cohorts 1964-1967, in 1992 for cohorts 1968-1970, in 1995 for cohort 19711973, in 1996 for cohort 1974, and in 1997 for cohort 1975. Thus the structural change appears to affect the cohorts born in 1940-1943 around their 50s, the cohorts born between 1944-1953 around their 40s, the cohorts 1954-1962 around their 30s, the cohorts 1963-1965 around their late 20s, and finally the cohorts 1966-1975 around their early 20 s.

Given that for most cohorts the changes occur around mid 1990's, suggest that the trends observed are not age effects, but the result of the changes in the structure of the labour market, which intensified beginning with early 1990's. This explanation is sustained by the evolution of the occupation structure for each cohort, which reveals a common trend: they all record an increase in the share of the white collars and civil servants, accompanied by a reduction in the share of blue collars. Similarly, the share of the tertiary sector increases for all cohorts over time. Moreover, these trends are more pronounced for younger compared with older cohorts. ${ }^{108}$

An explanation for the slightly delayed effect for the cohorts born 1971-1973, which record an intensification of their permanent differentials in 1995, meaning around age $22-23$ could be the evolution in the education and in the occupation structure. Younger cohorts tend to spend longer time in education and thus highly educated men enter the labour market after the age of 22, exacerbating permanent differentials. This effect coupled with the evolution towards a service economy results in an increasing share of men entering the labour market as highly educated white collars and civil servants. Similarly, for the youngest two cohorts, the structural change kicks in two years after their entrance into the labour market, meaning at 22, when also highly educated men join the labour market, probably as white collars or civil servants. For example, looking at the cohort born in 1975, the share of people working in the financial sector doubled in 1997, and quadrupled in

\footnotetext{
${ }^{108}$ The tables can be provided upon request from the author.
} 
2004 compared with 1995. Similarly, the share of white collars almost doubled in 1997 and more than tripled in 2004 compared with 1995. 109

Except for the youngest six cohorts, the persistent dispersion tends towards overall inequality during the last years of the panel and diverges from the trend of the transitory component, suggesting a general diffusion of earnings persistence for mid-career (older than 35) and older workers.

Following these trends, the contribution of the two components to the growth in overall inequality differs across periods and across cohorts. The inequality growth until 1992 was determined by an increase in both components for the cohorts 1940 through 1965, and by an increase in the permanent component counteracted by a decrease in the transitory component for the other cohorts. The increase between 1992 and 1997 was due to the increase in the permanent component counteracted by the decrease in the transitory component for most cohorts, except the cohorts born in 1963 through 1970. For the rest of the sample period, the growth in inequality was due to an increase in earnings persistency accompanied by a decrease in earnings instability for the cohorts born in 1940 through 1968, and by an increase in both components for the cohorts born in 1969 through 1975.

1997 appears to be an important period in the evolution of both components, marking the moment when the two components accentuated their fanning out pattern. First, permanent dispersion intensified its increase for all cohorts. This is what I expect given the increasing shares of white collars and civil servants, which for the youngest cohorts is equivalent also to an increasing share of highly educated people. Second, the intensification of the structural changes appears to have decreased transitory dispersion for older workers and increased it for the young. This might be linked with the increased ability of younger workers of adapting to the new economy as opposed to older workers, first due to their higher level of education and second due to their availability for flexible work contracts. The reduction in the transitory component for older workers might signal their reduced ability of adapting to the new economy.

\footnotetext{
${ }^{109}$ The tables can be provided upon request from the author.
} 

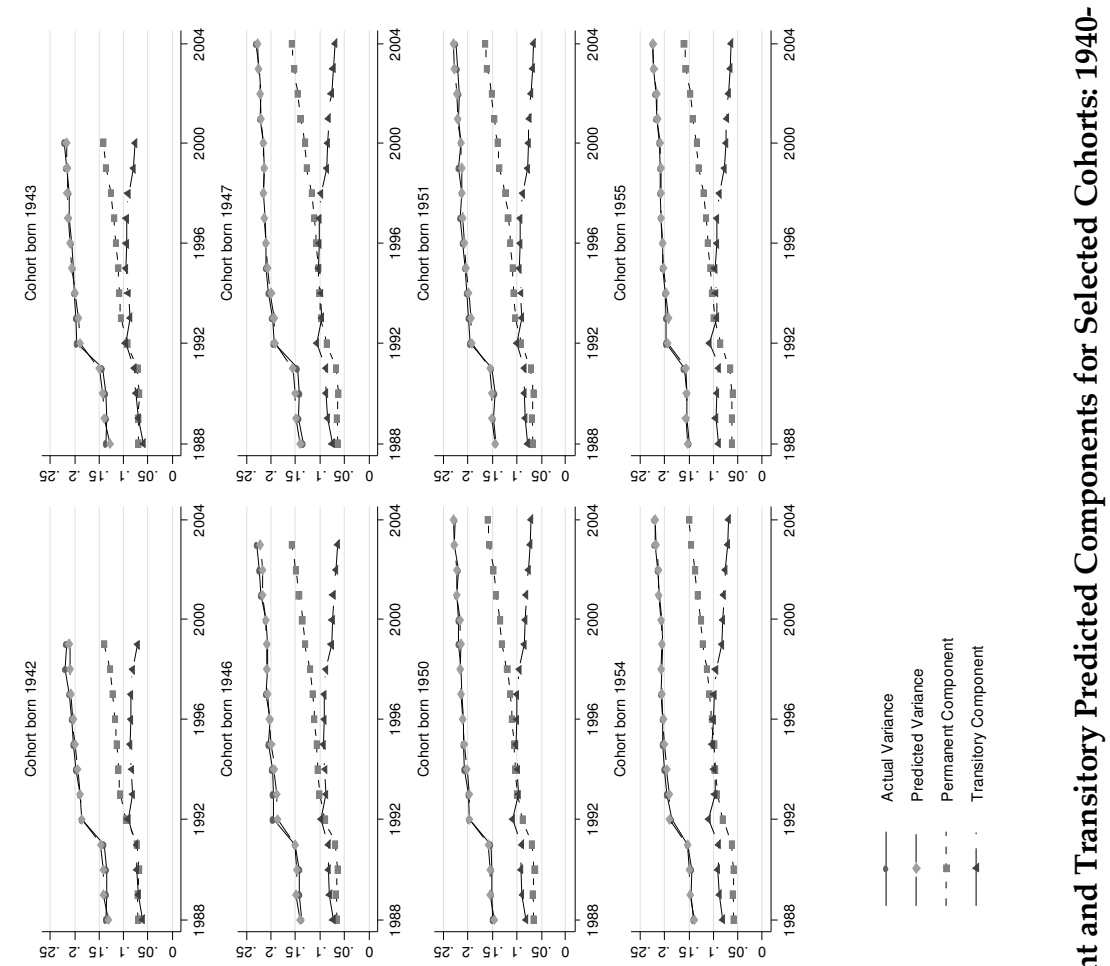

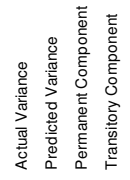
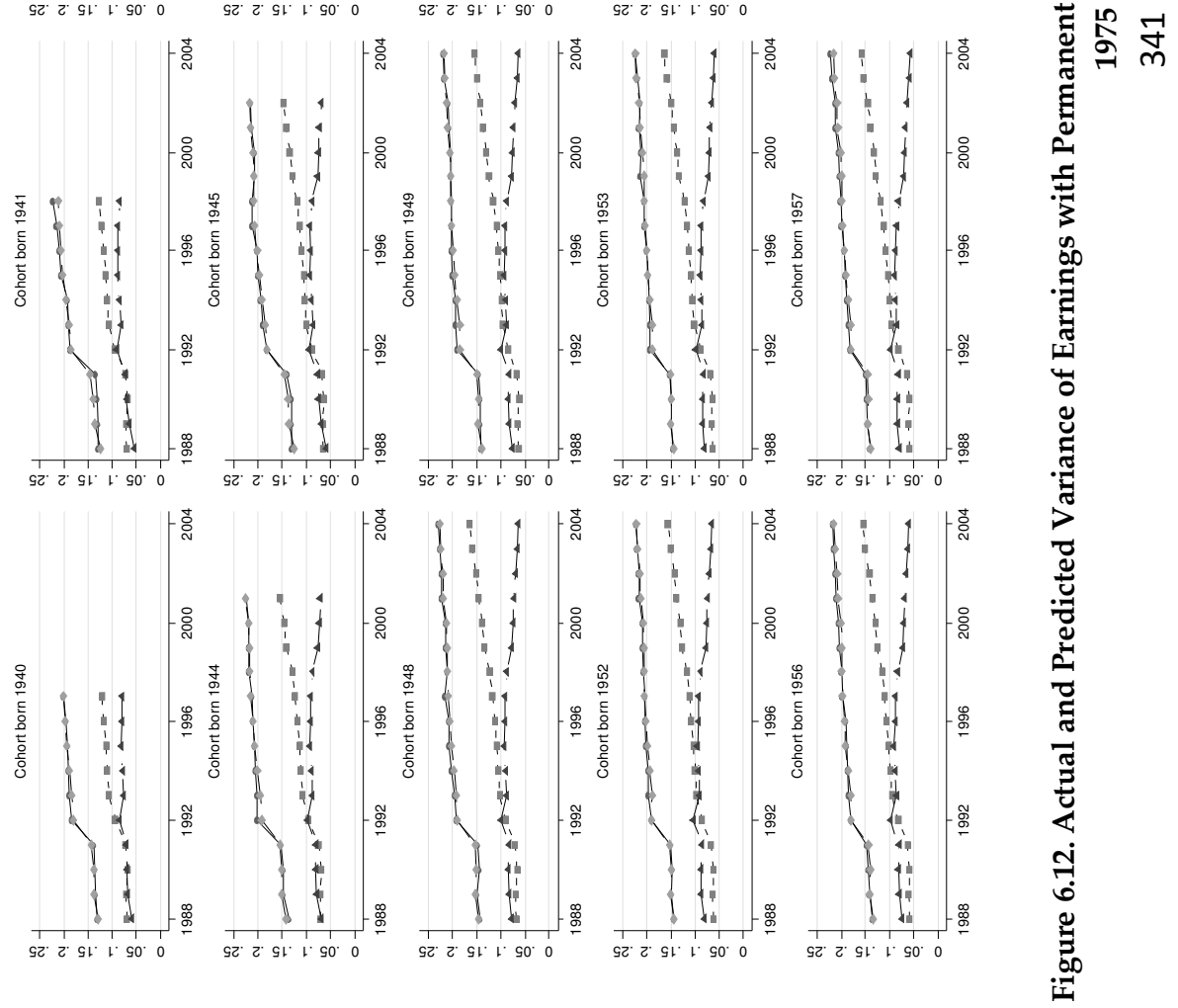

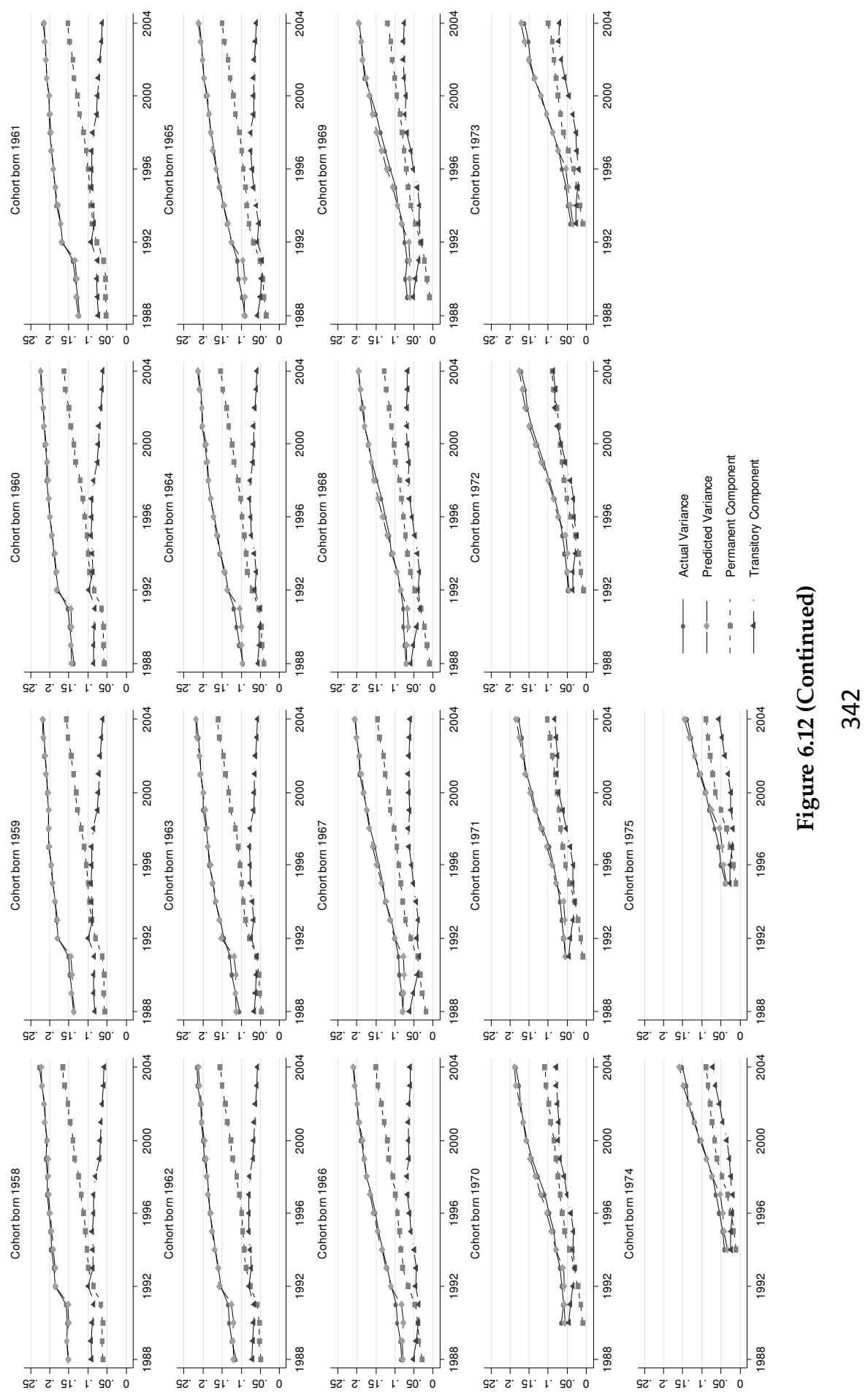


\section{Relative decomposition}

In order to assess how the structure of inequality evolved over time for each cohort, I computed the relative share of the two components in the overall predicted variance of earnings. Figure 6.13 illustrates the share of the two components over time by cohort.

The evolution of the structure of inequality reveals common and diverging patterns across cohorts. First, all cohorts recorded an overall increase in the share of the permanent component. The evolution however was not monotonic. The cohorts born 1940 through 1959 have a similar pattern in the evolution of the share of the permanent inequality, which decreased until 1990 at a decreasing rate the younger the cohort, then increased at an increasing rate until 1993 - when they turned between 52 and 34 years old -, slowed down until 1997, accelerated its increase towards 1999 and slowed down towards 2004. For these cohorts, the share of the permanent component was between roughly $40 \%-60 \%$ in the beginning of the sample - when they were between 42 and 29 years old -, and 65\%-75\% in $2004-$ when they were between 57 and 45 year old.

For the cohorts born in 1960 through 1968 the share of the permanent component increased at a higher rate the younger the cohort until 1993, when they turned between 33 and 25 years old. Until 1997, the share increased for the cohorts 19601963 at a decreasing rate the younger the cohort, remained constant for the cohort 1964 and decreased for the other cohorts at an increasing rate the younger the cohort. After 1997, the share increased at a decreasing rate the younger the cohort, ranging between $15 \%-42 \%$ in 1988 - when they were between 28 and 20 years old to $65 \%-74 \%$ in 2004 - when they were between 44 and 36 years old -, with the highest rates belonging to the oldest cohorts.

The youngest seven cohorts appear to have a different profile compared with the older cohorts, which might be due to the stronger age effects coupled with the change in the educational behaviour of younger cohorts and with the maturation of the labour market structural changes. Unlike the older cohorts where the changes in the structure of inequality occurred around a specific year, e.g. 1993, the changes in the inequality structure for the youngest cohorts occur around specific ages. They start from lower values of the share of the permanent component compared with the older cohorts and record a sharp increase over the first 6 years of their career until they reach the age of 25, which is 1994 for the cohort born in 1969, 1995 for the cohort born in 1970 and 2000 for cohort born in 1974, surpassing the values recorded by the older cohorts. Further, they decrease sharply until they 
reach the age of 30 and increase slightly thereafter, with lower shares of the permanent component compared with the older cohorts.

\section{Earnings mobility}

What are the implications for earnings mobility for each cohort over time? The answer is summarized in Figure 6.14, which plots the yearly evolution in earnings immobility 110 by cohort. The evolution of earnings immobility resembles the evolution of the share of the persistent component. An increase in the profile implies a decrease in earnings mobility, meaning a decrease in the opportunity for low income men in a specific cohort to improve their position in the distribution of lifetime earnings.

The overall picture is that for all cohorts mobility decreased over the sample period, meaning that low wage men in all cohorts find it more difficult at the end of the sample period to improve their income position in the distribution of lifetime earnings compared with the beginning of the sample period.

The evolution was not monotonic. Similar with the structure of inequality, the immobility profiles differ considerably between the cohorts 1940-1968 and 19691975. The cohorts 1940 - 1968 recorded a sharp increase in earnings immobility until 1993, followed by a positive trend for the cohorts 1940-1963 and a negative trend for the cohorts 1964-1968 until 1997, and by an increase thereafter. Given that the changes in mobility occur at the same time for all cohorts represents a strong clue that the changes in the economy are the main triggers.

The youngest seven cohorts recorded an increase in earning immobility until age 25, followed by a sharp decrease until age 30 and a slight increase thereafter. Unlike previous cohorts, the profiles of the youngest seven cohorts shift through time, with the main changes occurring around the same age, which indicate a strong age effect. Looking at the degree of immobility at age 25, the shift indicates an increasing immobility over time. At the end of the sample earnings mobility appears to be higher for younger cohorts compared with older cohorts.

${ }^{110} \mathrm{Immobility}=$ permanent variance/transitory variance 

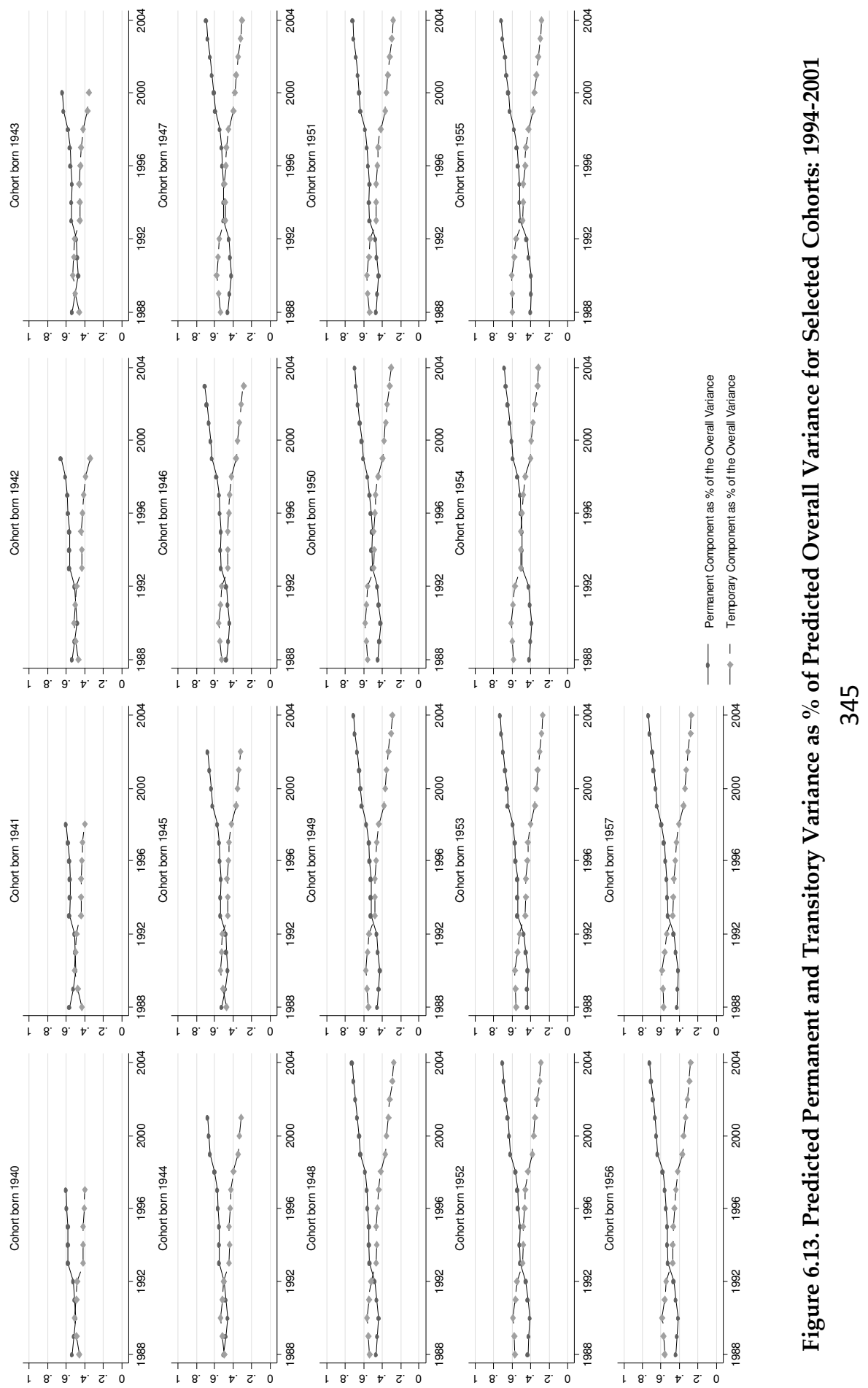

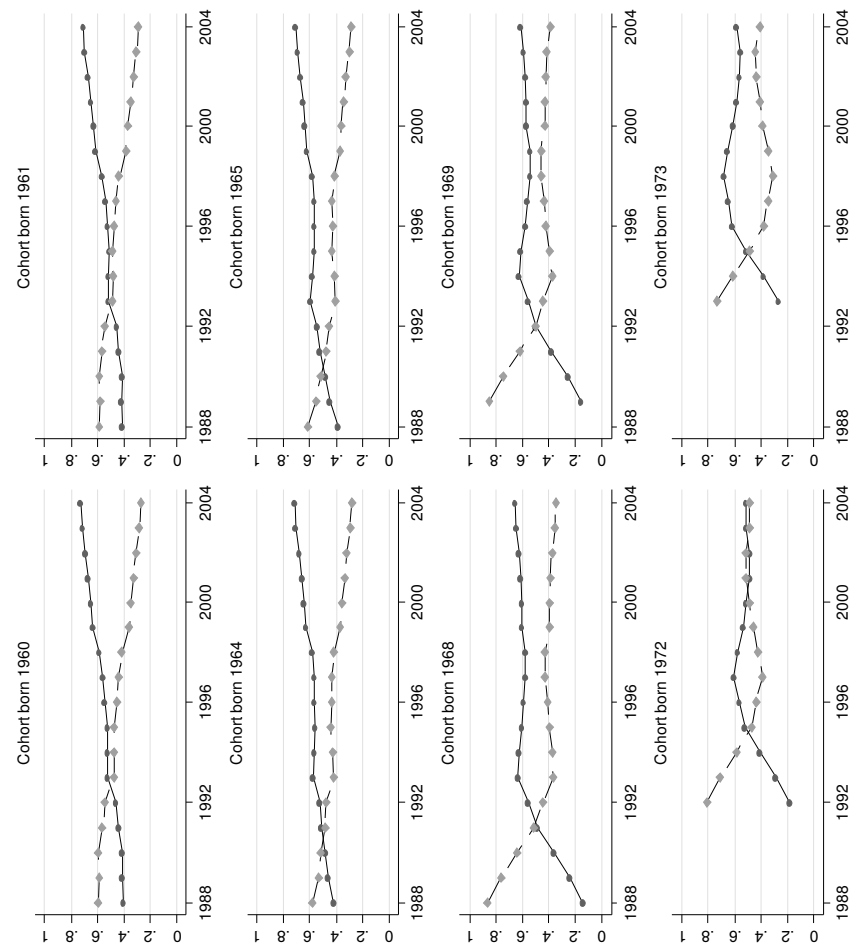

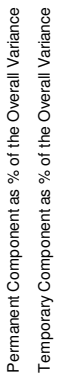
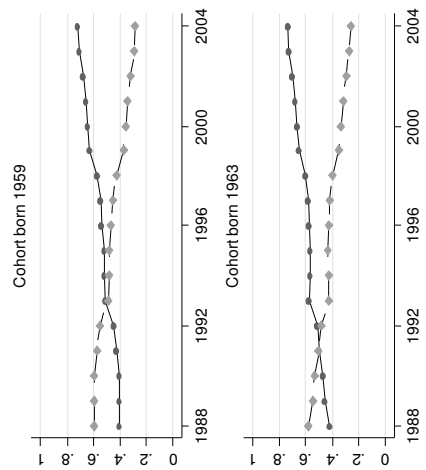

ัญ
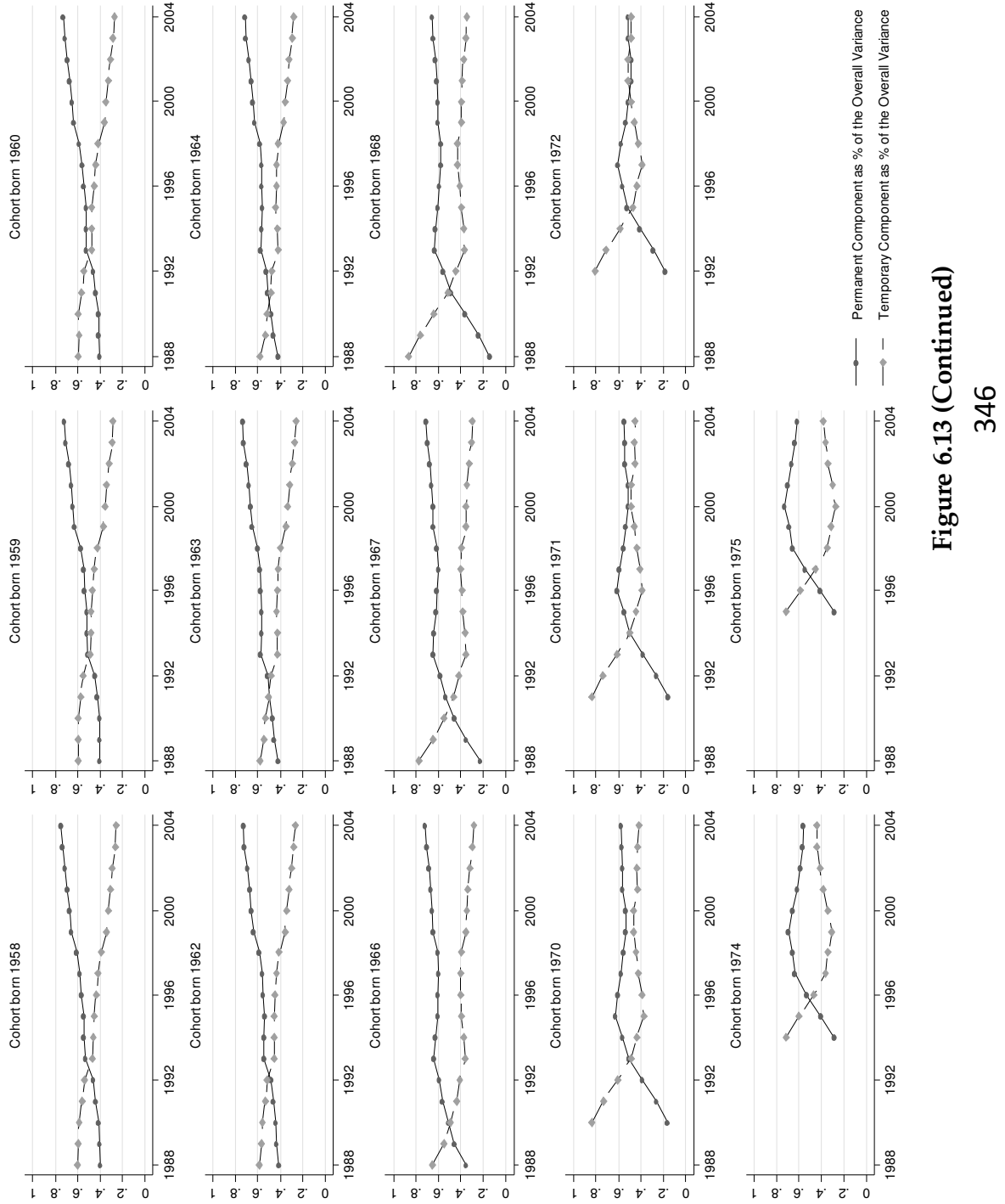

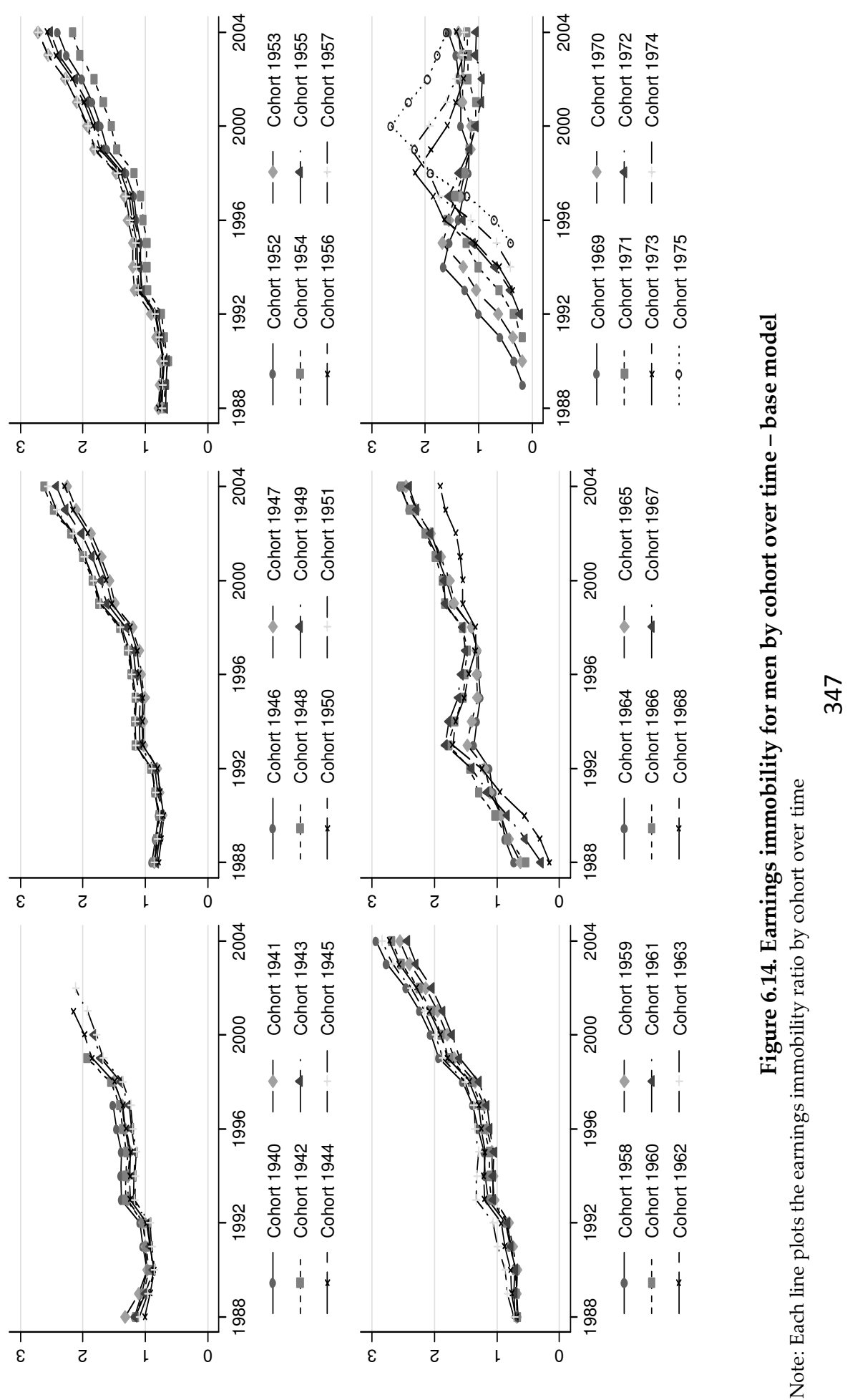


\subsubsection{Decomposition of the cross-sectional age-inequality profile}

In order to see the evolution of the structure of inequality and earnings mobility over the lifecycle, I reveal the profiles of the two components and earnings immobility by age in 1988, 1993, 1998 and 2004. Here, the cohort and age effects are confounded.

\section{Absolute decomposition}

Figure 6.15 illustrates the lifecycle profile of the permanent (left) and transitory (right) variance. In a cross-sectional view, in all years, permanent variance increases with age at a decreasing rate, which is consistent with the evidence of lifecycle earnings divergence provided earlier, showing that older cohorts experience a higher earnings persistency compared with younger cohorts. Similar results are found by Dickens $(2000 \mathrm{~b})$ and Ramos $(1999,2003)$ for UK, Cervini and Ramos (2006) for Spain, Capellari (2003) for Italy, and Sologon and O'Donoghue (2009a, 2009b) for 14 EU countries.

The profile of the permanent component, however, changed over time. For people older than mid 30s, the profile is higher the later the year, suggesting that the labour market structural changes and the increase in the educational attainment over time enhanced permanent differentials for these age groups. For men in their early 20s, permanent variance decreased slightly between 1988 and 1993. For men in their late 20s, permanent variance increased until 1993, and decreased until 1998 to a higher level than in 1988. For men in their early 30s, permanent variance increased until 1998 and decreased until 2004.

The transitory variance follows a similar inverted-U pattern over the lifecycle, but less steep than the permanent variance. The profile changed over time. In 1988, the transitory variance increased sharply until late 20 s, and slightly until late $40 \mathrm{~s}$. In 1993 the profile increased sharply until mid 30s, then slowed down until mid 40s, and decreased slightly thereafter. In 1998 the profile increased sharply until mid 30s, and slightly thereafter. In 2004, the profile differentiates itself with a steep increase until early 30s, followed by a decrease around mid 30s and a slight increase thereafter. 


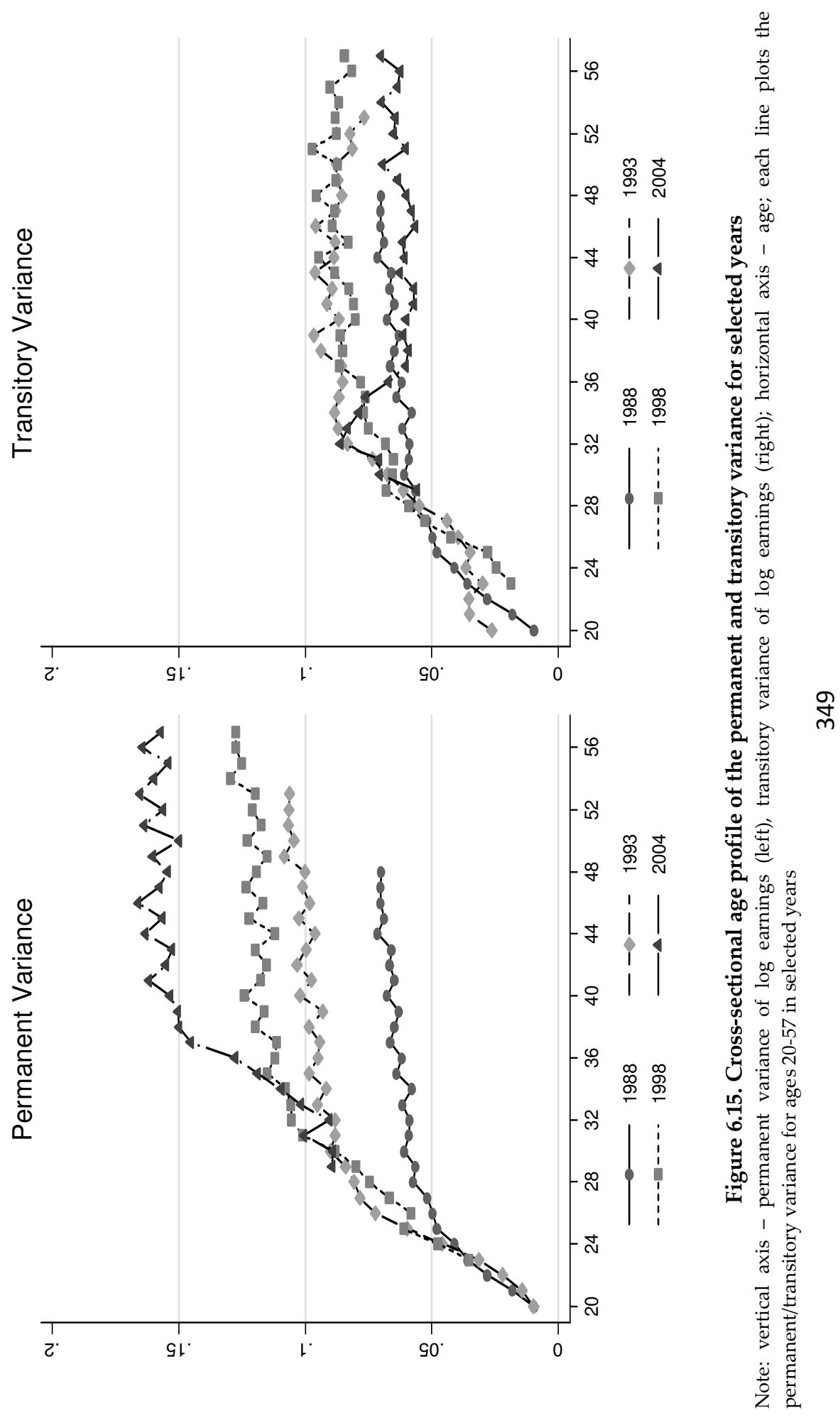


For men in their early 20s the transitory variance increased between 1988 and 1993. For men in their mid 20s the transitory variance decreased between 1988 and 1998. For people in their late 20s the profiles look similar. For men in their early $30 \mathrm{~s}$, the transitory variance increased between 1988 and 1993, decreased in 1998 and increased in 2004 to similar values as in 1993. For men older than mid 30s, the transitory variance increased until the 1990s, and decreased in 2004 to values lower than in 1988. Therefore in 2004 compared with 1988 I observe an increased transitory variance for men in their early 30 s and a decreased transitory variance for older ages. Thus the maturation of the labour market brought a decrease in earnings instability.

Overall, I conclude that, in Luxembourg, earnings variance increases over the lifecycle due to an increase in both components. The permanent component records a sharper increase than the transitory component, and its increase is enhanced over time. Thus the labour market structural changes and the evolution of the education system over time enhanced the increase in the persistent component over the lifecycle.

\section{Relative decomposition}

Further, Figure 6.16 illustrates the lifecycle evolution of the share of the permanent components in the overall variance in 1988, 1993, 1998 and 2004. The lifecycle profile of the structure of inequality reveals an increase in the share of the permanent component with age, in all years except 1998.

Over time, following the labour market structural changes, the lifecycle profile changed. In 1988 inequality became predominantly permanent (the share of the permanent component is higher than 50\%) after mid 40s, in 1993 after age 23, whereas in later years it was predominantly persistent for the entire age profile.

In 1988, the share of the persistent component increased sharply until mid 20s, stabilised until early 30s and intensified its increase thereafter, suggesting a higher persistency in earnings inequality the older the cohort. In 1993, the profile changed: it increased sharply until mid 20s, decreased slightly towards mid 30s, stabilised until mid 40s and increased thereafter to values lower than for mid 20s. Thus young cohorts appear to have a higher persistency than older cohorts and middle cohorts. The explanation might be the difference in the educational attainment between cohorts and the higher return to skills in the new economy. A similar trend is observed in 1998. Therefore, years 1993-1998 reflect the transition period between an industrial to a service economy. In 2004 the profile looks quite different: the share decreased for early 30s, increased sharply until early 40 s and 
decreased slightly thereafter. Thus in 2004, the middle and oldest cohort have the highest persistency.

Looking across age groups over time, for men in their early-mid 20s, the share of the permanent component increased over time. For those in their late 20s the share increased between 1988 and 1993, and decreased in 1998 to values above the ones in 1988. For men in their early 30s, the share increased until 1998 and decreased in 2004. For those older than 35, the share of the permanent component increased over time.

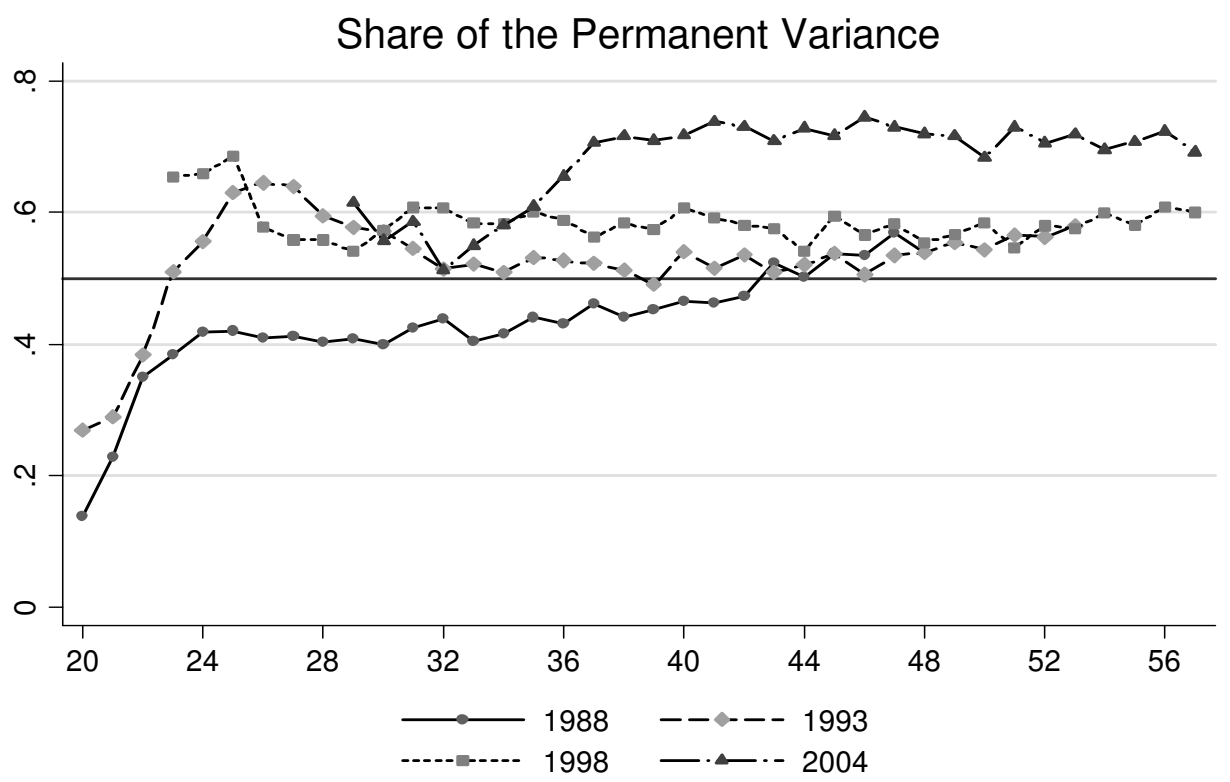

Figure 6.16. Cross-sectional age profile of the share of the permanent component from the overall variance for selected years: 1988, 1993, 1998, 2004

Note: vertical axis - share (\%) of the permanent component from the overall variance, horizontal axis age

\section{Earnings mobility}

What are the implications for earnings mobility? The lifecycle immobility profiles for years 1988, 1993, 1998 and 2004 are illustrated in Figure 6.17. Overall, earnings immobility increases over the lifecycle in all years, except 1998. The trend in immobility follows closely the trend in the share of the permanent component. Thus, in 1988, earnings immobility was higher the older the age. In 1993 and 1998 
immobility was the highest at younger ages, followed by mid career and older age. In 2004 immobility appears be the highest mid career, followed men in their 50s and their 30s.

For men in their early-mid 20s, immobility increased over time. For those in their late 20, earnings immobility increased between 1988 and 1993, and decreased in 1998 to values above the ones in 1988. For men in their early 30s, earnings immobility increased until 1998 and decreased in 2004. For those older than 35, immobility increased over time.

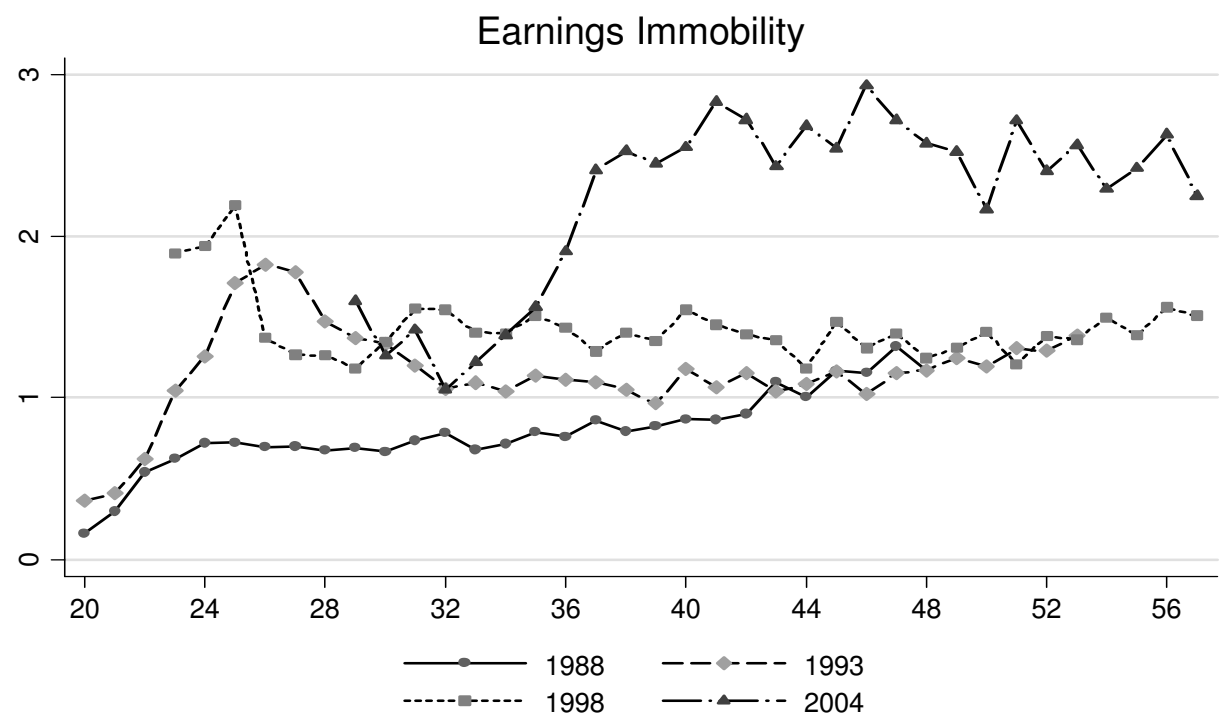

Figure 6.17. The cross-sectional age - immobility profile for selected years 1988, 1993, 1998, 2004

Note: vertical axis - immobility ratio; each line plots the immobility ratio for ages $20-56$, in the selected years

\subsubsection{Inequality decomposition by age-groups over time}

Finally, I perform the decomposition of inequality controlling for the age effect. This shows how the structure of inequality and earnings immobility evolved for people in a certain age group between 1988 and 2004 under the impact of the labour market structural changes. I follow Baker and Solon (2003) and perform the decomposition for 40 years old males, which is approximately the middle of the 
active career. The cohort and period effects are confounded, and the trend reveals the story for 40-year old men.

The absolute and relative inequality decomposition for men aged 40 is illustrated in Figure 6.18, which contains also the actual and predicted variances for the 40year old men, reconfirming the high fit of the base model. In moving from year to year, all parameters change according to the specific period and birth cohort.
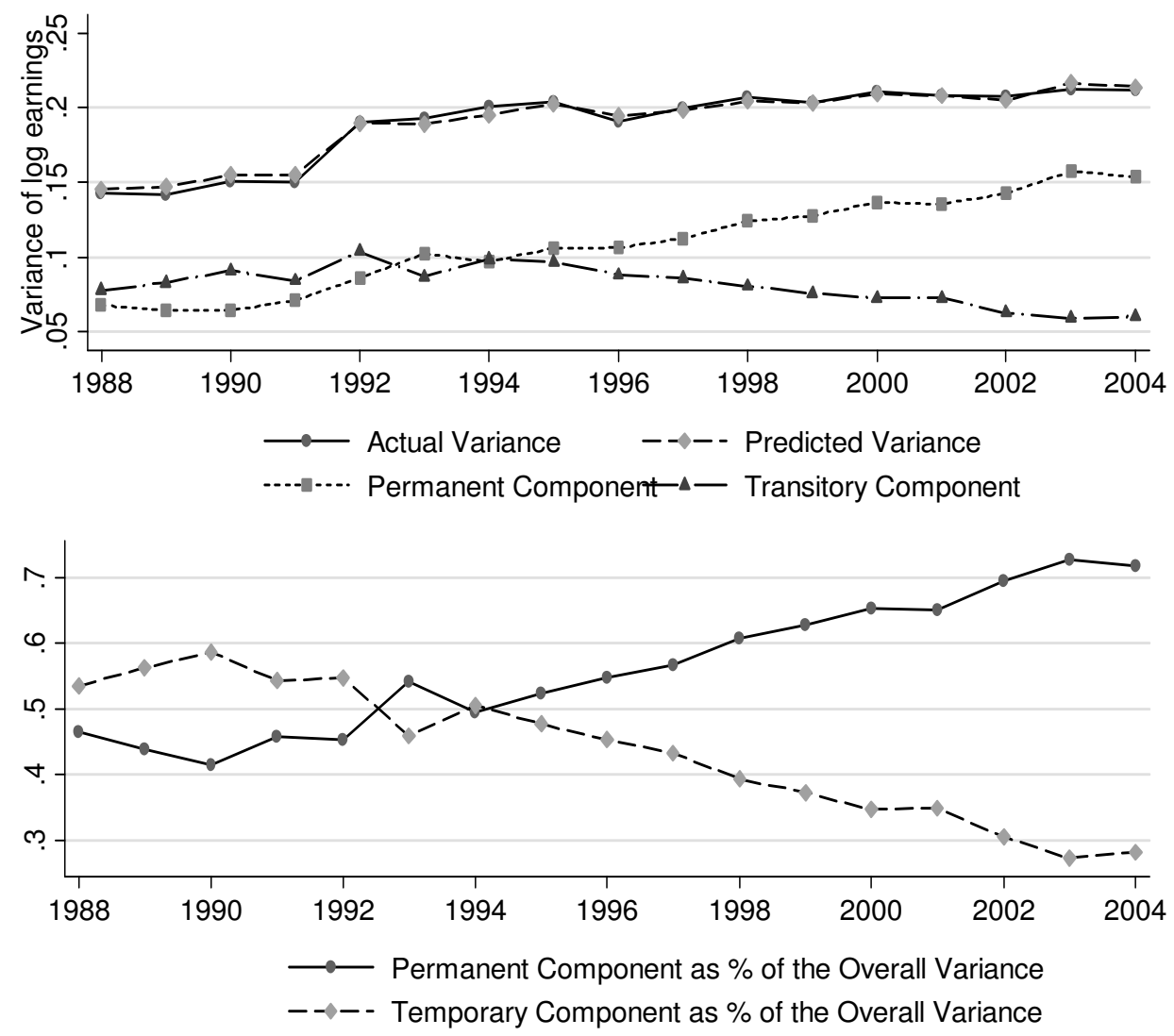

Figure 6.18. A decomposition of the variance of log hourly earnings for men, 40 years old: base model

The first thing to note is the increase in total variance, which duplicates the pattern seen in Figure 6.1. Consistent with the trends observed by cohort, the increase in the overall inequality was determined by an increase in permanent inequality. Split by sub-periods, the increase in the overall inequality between 1988 and 1992 was 
determined by an increase in both components, and by an increase in the permanent variance counteracted by a decrease in the transitory variance thereafter. Transitory inequality displays more variation compared with permanent inequality, evolving opposite to it: three spikes are observed in 1990, 1992 and 1994, followed by a monotonic decrease thereafter.

In 1988, the persistent component accounted for $46.5 \%$ of the inequality in hourly earnings. Its share decreased until 1990, increased until 1993 surpassing the transitory variance, decreased in 1994 to roughly 50\%, and increased thereafter reaching a value of over $70 \%$ in 2004 . Thus, after 1993, the permanent inequality had a dominant share in the overall inequality of men aged 40.

I also performed the decomposition for ages 30 and 50.111 The general trends are maintained, however some differences are noted. For age 50, the evolution of the two components was similar with age 40, except that for age 50 the share of the permanent component in the overall inequality was higher than for the transitory inequality for most of the period. The share of the permanent component increased from below $50 \%$ in 1990 to almost 70\% in 2004 .

For age 30, the trends display more noise compared with age 40 and 50: except for 1988-1992 and 2002, the persistent components dominated overall inequality. The share of the permanent component increased from around 40\% in 1988 to over $56 \%$ 2004. The maximum persistency for the 30-year old was reached in 1996-1997, when the share of persistent inequality was of $60 \%$. Overall, the incidence of the transitory component is higher for men aged 30 than for those aged 40 and 50.

Following the labour market structural changes, the ranking between these age groups in terms of earnings persistency changed, sign that the impact of these changes differed by age groups. In the beginning of the sample period the highest persistency was observed for men aged 50, followed by those aged 40 and 30 . In the middle of the sample period, the persistency became higher for men aged 30, followed by those aged 50 and 40. In 2004, earnings persistency was higher for age 40 , followed by age 50 and age 30 .

What are the implications for earnings mobility for these age groups over time? The answer is summarized in Figure 6.19, which plots the pattern in earnings immobility ${ }^{112}$ for these age groups. Recall, an increase in the profile implies a decrease in earnings mobility, meaning a decrease in the opportunity for low income men to improve their position in the distribution of lifetime earnings.

\footnotetext{
111 Available on request

112 Immobility = permanent variance/transitory variance
} 


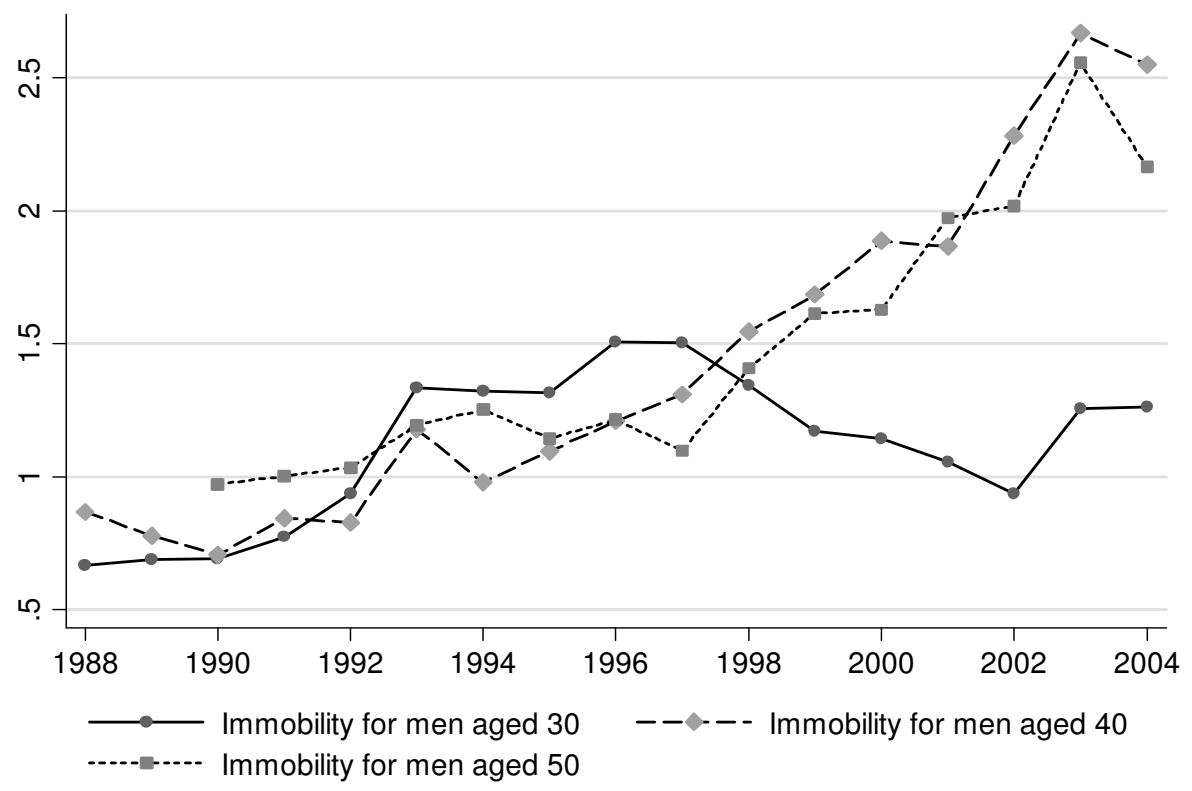

Figure 6.19. Earnings immobility for men of age 30, 40 and 50 - base model

Note: vertical axis - immobility ratio; each line plots the immobility ratio for men aged 30, 40 and 50 over time

Overall, the immobility ratio increased over the sample period, signalling decreasing earnings mobility for all age groups over the sample period. The immobility profiles over time, however, appear to differ by age groups, sign that the labour market structural changes influenced younger workers differently from older workers.

Men aged 40 and 50 exhibit similar profiles, with men aged 40 being more immobile than men aged 50 after 1996113. A turning point is observed in 1997, when both profiles intensified their increase until 2003, followed by a drop in immobility in 2004 .

A noisier trend is observed for men aged 30, for whom immobility follows a hump-shaped pattern: men aged 30 appear to be more mobile than men aged 40 and 50 over the period 1988-1991 and after 1997. 1997 appears to be a turning point also for the immobility profile of men aged 30, which record a sharp drop in

113 Except 2001 
immobility until 2002, followed by a sharp increase thereafter. Thus the factors that determined a decrease in mobility for people aged 40 and 50 after 1997, determined an increase in mobility for people aged 30 .

For comparison and to complete the picture of the impact of the labour market structural changes on earnings mobility for all age groups, I added the immobility profiles for ages 5 years apart, ranging from 20 to 55, displayed in Figure 6.20. The profile for age 20 records a slightly increasing trend over the sample period, being consistently lower than all other profiles. This suggests that the youngest group is the most mobile and the increase in immobility was much smaller compared with the other age groups.

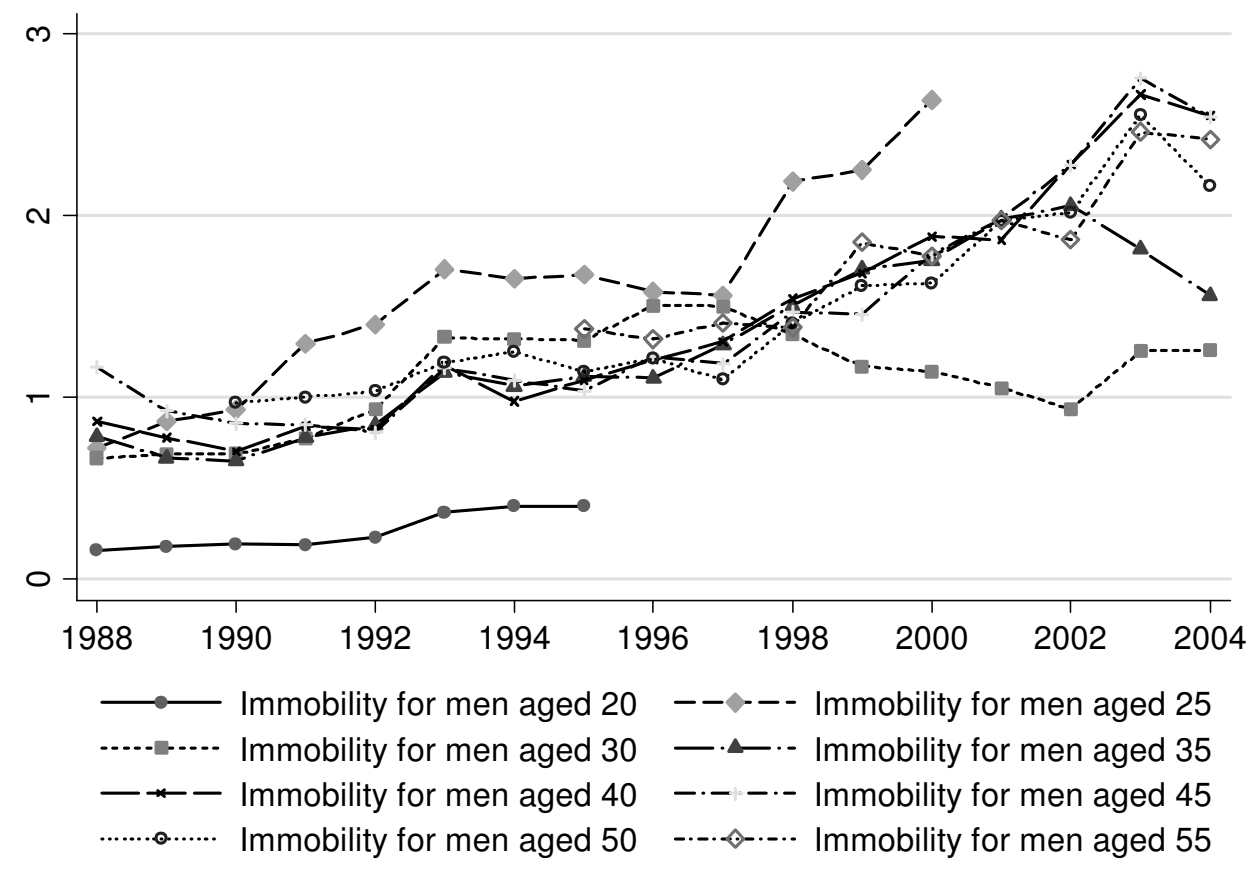

Figure 6.20. Earnings immobility for men of age 20, 25, 30, 35, 40, 45, 50, 55 - base model Note: vertical axis - immobility ratio; each line plots the immobility ratio for men aged 20, 25, 30, 35, 40, $45,50,55$ over time 
The profiles for ages 21 and 22, not shown in Figure 6.20114, evolve parallel with age 20, showing a lower mobility the older the age.

The profile for age 25 is quite surprising. Starting from slightly higher values than age 30 in 1988, it records the largest increase until 1993, then a slight decrease until 1997 followed by a sharp increase until 2000, surpassing the immobility ratios of all other profiles over the period 1991-2000. Thus the labour market structural changes increased earnings immobility for men aged 25 to a much larger extent compared with other age groups.

The profiles for ages 23-24, not shown in Figure 6.20115, evolve similar with age 25, but shifted backwards with 2 and 1 year. Thus immobility increased until 1996 for age 24, and 1995 for age 23, at a lower rate compared with age 25, and intensified their increase thereafter. Overall, for age range 20-25, earnings mobility is higher the younger the age.

The profiles for ages 26-29, not shown in Figure 6.20116, illustrate transition immobility profiles between age 25 and 30: they record a similar trend slightly lower the older the age until 1993, followed by a decrease, steeper and lasting one year longer the older the age, and finally a sharp increase parallel with the trend observed for age 25. Basically the profiles for ages 26-29 look like the profile for age 25 , lower the older the age, with a decrease after 1997 longer with one year the further we move from age 25 , followed by a similar parallel increase thereafter.

The profiles for ages 31-39 represent a transition from the profile for age 30 to the profile for age 40: they evolve similar to age 30 recording lower values than the profile for age 30 until 1997, and surpassing it thereafter, at an increasing rate the younger the cohort. Similar with the profile for age 30, they start decreasing towards the end of the sample one year later for each age group, at a decreasing rate the older the age. Thus from age 30 , the trends for each age group converges towards the profile for age 40 .

The profiles for ages 41-49 behave similar to the profile for age 40 . The profiles for ages 51-57 behave similar to the profile for age 50. Overall, the immobility around 40 s is slightly higher than for 50 s.

Thus these trends confirm the hump-shaped immobility profile observed in Figure 6.17 .

\footnotetext{
114 Provided upon request from the author.

115 Provided upon request.

116 Provided upon request.
} 
In order to see whether the estimated changes over the sample period are likely to be due to real changes in the functioning of the labour market rather than to short term fluctuations in the business cycle, I follow Baker and Solon (2003) and apply least squares to estimate time-series regressions of the persistent and transitory components and earnings immobility on a linear trend and a variable that captures the business cycle - the growth rate in real GDP ${ }^{117}$. The results are reported in Table 6.4.

The point estimates indicate a strongly significant positive trend for the permanent component and earnings immobility, and a less strong significant negative trend for the transitory component. Thus permanent variance contributes positively to the upward trend in earnings inequality, whereas the transitory variance counteracts with the increase in the permanent component. The insignificant coefficient estimates of the GDP growth rate for the permanent component and the immobility index indicate that the permanent variance and earnings mobility are insensitive to the business cycle. Hence, the estimated changes in the persistent components and earnings immobility between 1988 and 2004 are due to changes in the functioning of the labour market. The estimated coefficient of the GDP growth rate for the transitory component indicates a significant cyclical sensitivity in the transitory variance.

To conclude, the changes that occurred in the labour market in this period intensified permanent differentials and decreased transitory differentials among men, thus decreasing their earnings mobility in a lifetime perspective.

As a last step I look at the implications of estimating the restricted model displayed in Table 6.3. This model assumes away age-specific innovation variances and agerelated heteroskedasticity in the transitory shocks. The decomposition implied by the restricted model for men aged 40 is revealed in Figure 6.21.

117 The real GDP is expressed in constant prices 2004. Source: STATEC, IGSS 

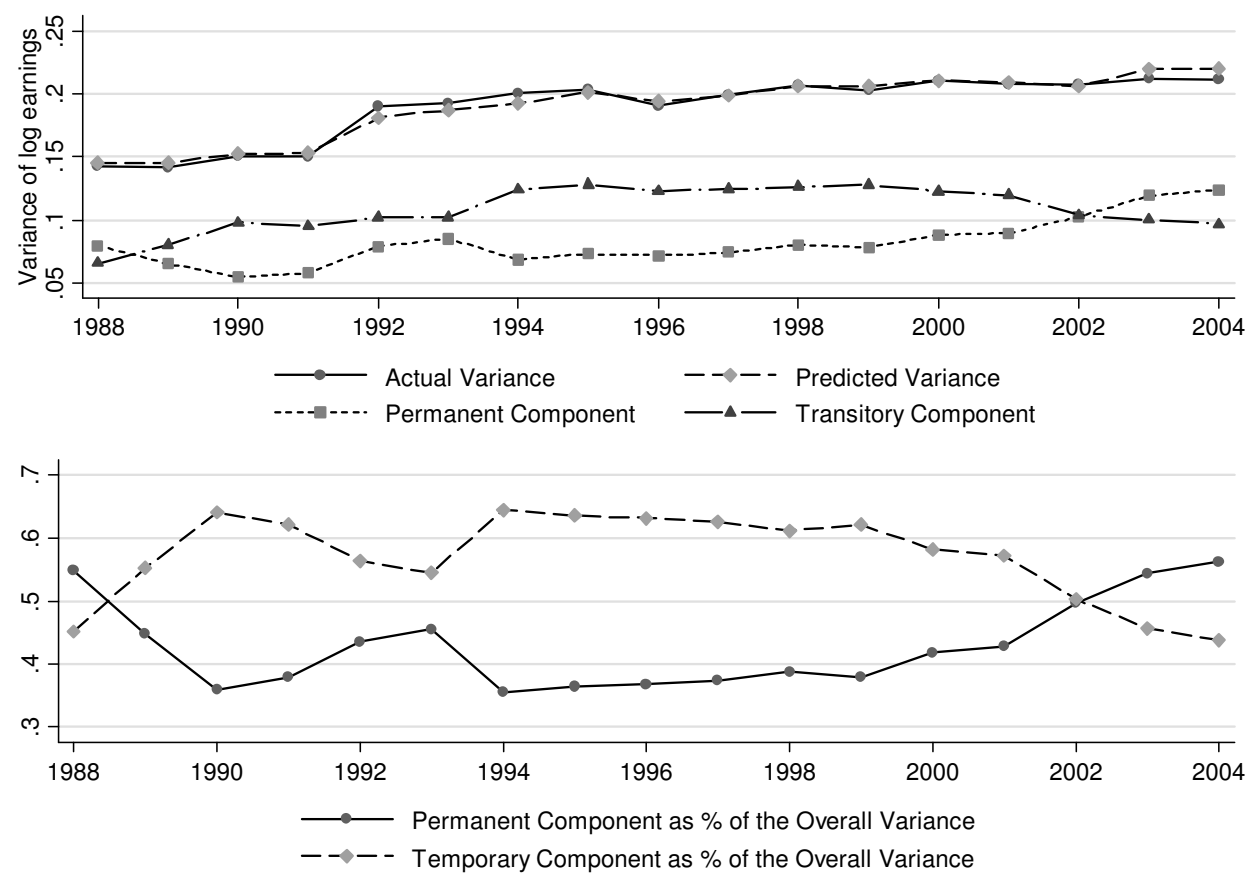

Figure 6.21. A decomposition of the variance of log hourly earnings for men, 40 years old: restricted model

Here are some major differences between Figure 6.18 and Figure 6.21. Unlike Figure 6.18, the restricted model predicts an absolute increase in both components over the sample period, with the permanent component increasing more than the transitory component. Moreover, except the beginning and the end of the sample period, the share of the transitory component is higher than the share of the permanent, with an average of over $50 \%$. The structure of inequality, however, looks similar in 2004 compared with 1988.

This information is formalized in the time-series regressions reported in Table 6.4. First, the estimates in the restricted model explain a lower share of the variation in the dependent variables and show that only the permanent variance plays a significant positive role in the trend increases in inequality. For the transitory component and earnings immobility the model predicts a positive trend, but insignificant. Moreover, none appears to be sensitive to the cyclical variations. For immobility, none of the explanatory variables are significantly different from zero. 
Therefore, while the estimates from the more general model indicates that the persistent component determines the increase in overall inequality overcoming the negative effect of the transitory component, this simpler model imposing clearly false restrictions attributes the growth in inequality to both components, albeit insignificant for the transitory component.

Table 6.4. Trend and cyclical variation of the persistent and transitory components, base and restricted model

\begin{tabular}{|c|c|c|c|c|c|}
\hline \multirow[t]{2}{*}{ Dependent Variable } & \multicolumn{2}{|c|}{ Linear trend } & \multicolumn{2}{|c|}{ Real GDP growth rate } & \multirow[t]{2}{*}{ Adjusted R } \\
\hline & Est & SE & Est & SE & \\
\hline \multicolumn{6}{|l|}{ Base Model } \\
\hline Permanent Variance & 0.0060 & 0.0003 & -0.0235 & 0.0504 & $96.80 \%$ \\
\hline Transitory Variance & -0.0022 & 0.0004 & -0.1947 & 0.0740 & $61.05 \%$ \\
\hline Immobility & 0.1217 & 0.011 & 1.8663 & 1.9257 & $88.75 \%$ \\
\hline \multicolumn{6}{|l|}{ Restricted Model } \\
\hline Permanent Variance & 0.0029 & 0.0006 & -0.0504 & 0.1106 & $58.49 \%$ \\
\hline Transitory Variance & 0.0015 & 0.0009 & -0.1193 & 0.1526 & $15.54 \%$ \\
\hline Immobility & 0.0149 & 0.013 & 0.5118 & 2.2663 & $8.72 \%$ \\
\hline
\end{tabular}

Note: OLS estimates, sample period 1988-2004 (T=16)

\subsection{Concluding remarks}

Starting with the late 1970s and intensifying after early 1990s, Luxembourg evolved from an industrial economy to an economy dominated by the tertiary sector, which relies heavily on the cross-border workforce. This paper explored the implications of these labour market structural changes for the structure of earnings inequality and earnings mobility.

Using 17 years of longitudinal earnings information drawn from the administrative data on the professional career, I decomposed Luxembourg's growth in earnings inequality into persistent and transitory components and explored the extent to which changes in cross-sectional earnings inequality in between 1988 and 2004 reflect changes in the transitory or permanent components of earnings.

My results indicate that Luxembourg's increase in earnings inequality has steamed from an increase in the permanent component of earnings variation, whereas the transitory variance recorded a decrease. Moreover, earnings immobility increased over the sample period. Thus, Luxembourg's growth in earnings inequality reflects 
increasing long-run (permanent) differentials between individuals accompanied by decreasing earnings mobility, meaning decreasing opportunity for low wage individuals of improving their income position in a lifetime perspective.

While my focus has been to extend the research on earnings dynamics at the European level and to understand the driving factors behind the increase in earnings inequality in Luxembourg in the context of the labour market structural changes that occurred starting with the late 1980s, I also tried to bring a methodological advancement in modelling earnings dynamics. Thanks to the large size of my panel, I was able to estimate a more general model that incorporates most of the features identified by the previous research on earnings mobility from the US, Canada and Europe.

First, unlike previous studies, I was able to account for cohort and age effects in a more precise way by considering cohorts formed of individuals born in one year, not several years pulled together. This is a quite unique feature in the literature given the huge data requirements. To my knowledge, only one study had the luxury of capturing the true cohort and age effect, Dickens (2000b) for the UK. Moreover, the richness of my data allowed us to incorporate cohort loading factors both on the permanent and transitory component, a feature which is not so common. Most studies used the cohort shifters only on one component.

Second, for modelling the permanent component, I extended the random walk specification to incorporate age-specific innovation variances after age 20 until age 40 , and a random effects model after age 40 with the distribution of the effects fixed at that implied by the random walk, a specification which was used previously only by Dickens (2000b). This model is consistent with the expectations steaming from many matching and human capital models, whereby human capital is accumulated for the first 20 year of labour market experiences, after which between-individual differences stop growing. I attempted to incorporate also the random growth specification, as persistent differences between individuals with respect to their human capital accumulation do exist. The specifications, however, led to identification problems in my data.

Third, for modelling the transitory component, besides allowing for cohort specific initials transitory variances to accommodate cohort heterogeneity with respect to the accumulation of the transitory process until the start of the panel, I incorporated also age-related heteroskedastic transitory innovations to accommodate the lifecycle variation in the volatility of the transitory earnings innovations. 
All these specifications, besides being economically plausible were found to be also statistically defensible. Specifying models that assume away these features when they are present in the data falsely attribute the non-stationarity that would be captured by these elements to the other sources of non-stationarity that remain in their models. Baker and Solon (2003) This statement is supported by the practical example carried out by estimating a restricted model, which imposes some restrictions that were rejected by my data. I find that imposing the restriction of no age-specific innovation variances in the random walk and no age-related heteroskedasticity in the transitory innovations exacerbates the importance of the transitory variance in explaining the trend in the overall inequality. The sensitivity of the predicted components to the different restrictions shows that when carrying out such a study one has to pay an extensive attention to the information provided by the autocovariance structure of earnings and to whether certain restrictions fit a specific data or not.

Whereas this exercise has identified the evolution of the two components over the sample period in Luxembourg, it has not identified the factors that might have triggered this evolution. This topic is extremely relevant and should be focused by future research. A good starting point is the approach taken by Sologon and O'donoghue (2009e), which tried to explain these trends in a comparative study at the EU level.

Another possible extension is to test statistically the impact of the labour market structural changes on the structure of earnings inequality and earnings mobility, by including also contextual variables, such as occupation shifters.

Another point for future research is to explore other measures of earnings mobility, as this topic is under researched at the EU level and in Luxembourg. Sologon and O'Donogue (2009c, 2009d) explored earnings mobility at the EU level and included also Luxembourg in their study. One point of interest would be to see how their results based on panel survey data compares with the results using administrative data. 


\subsection{Annex}

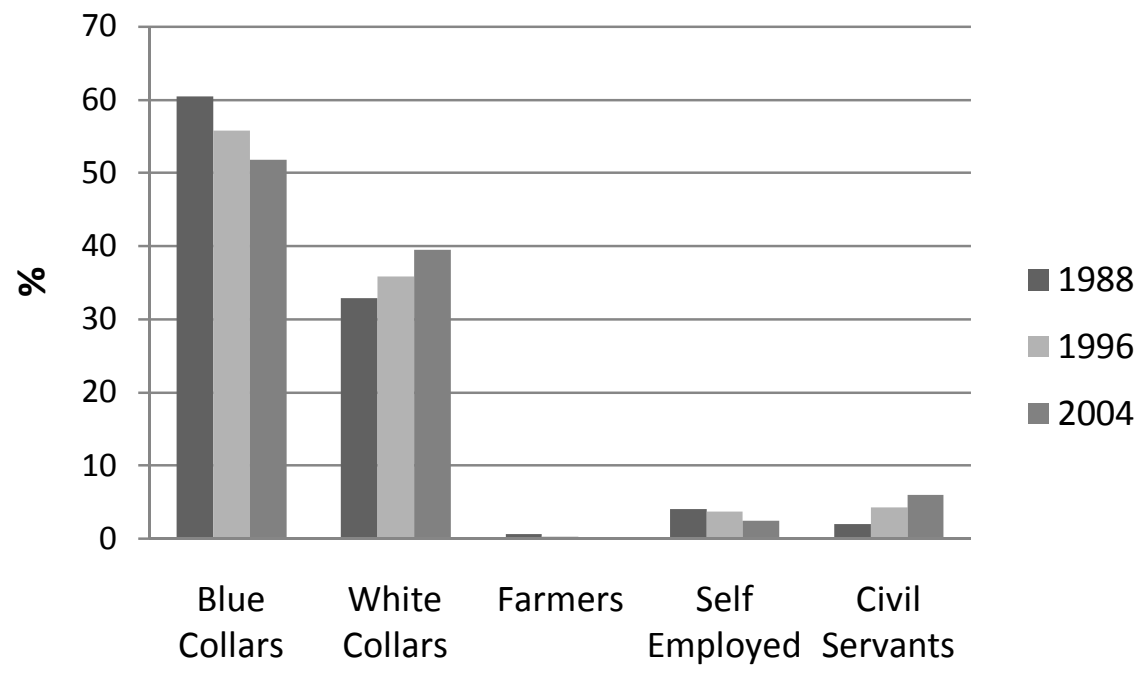

Figure 6-A- 1. The evolution of the labour market structure by occupation status in Luxembourg in 1988, 1996 and 2004.

Note: Own calculations based on IGSS data. Vertical axis - share of workers by occupation status

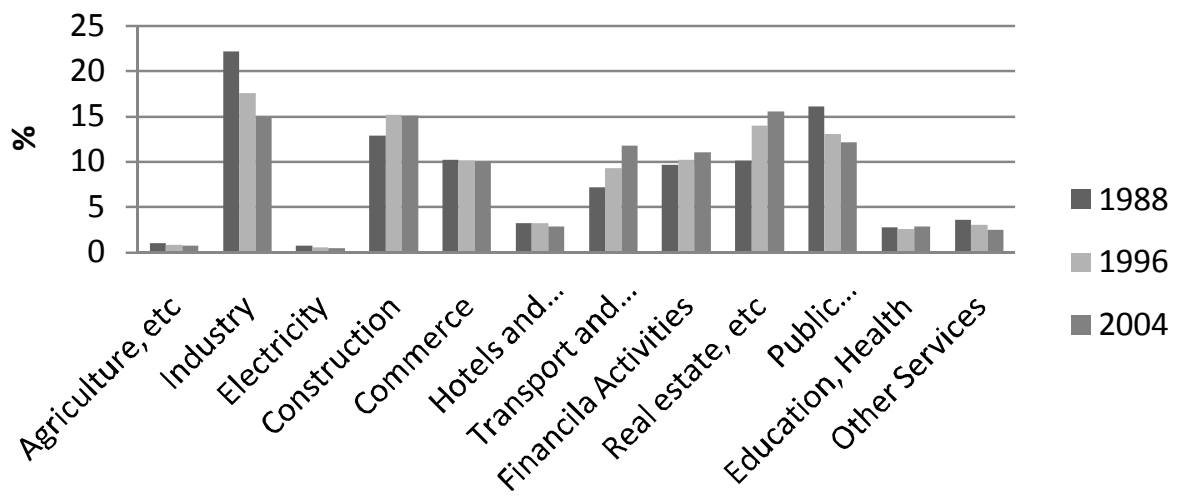

Figure 6-A-2. The evolution of the labour market structure by sector of activity status in Luxembourg in 1988, 1996 and 2004

Note: Own calculations based on IGSS data. Vertical axis - share of workers by sector of activity 


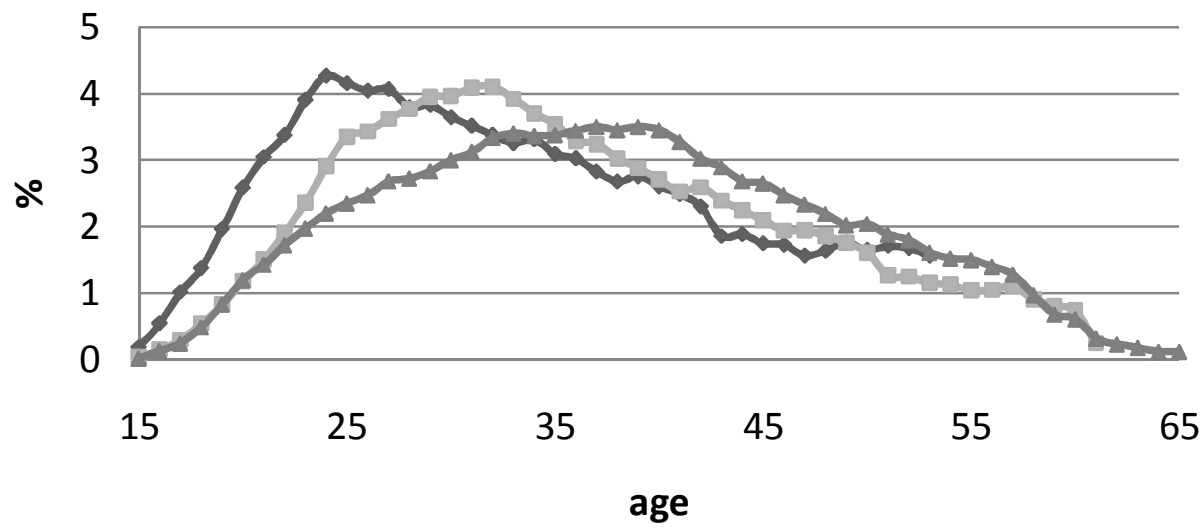

$-1988-1996$

Note: Vertical axis - share of workers by age groups

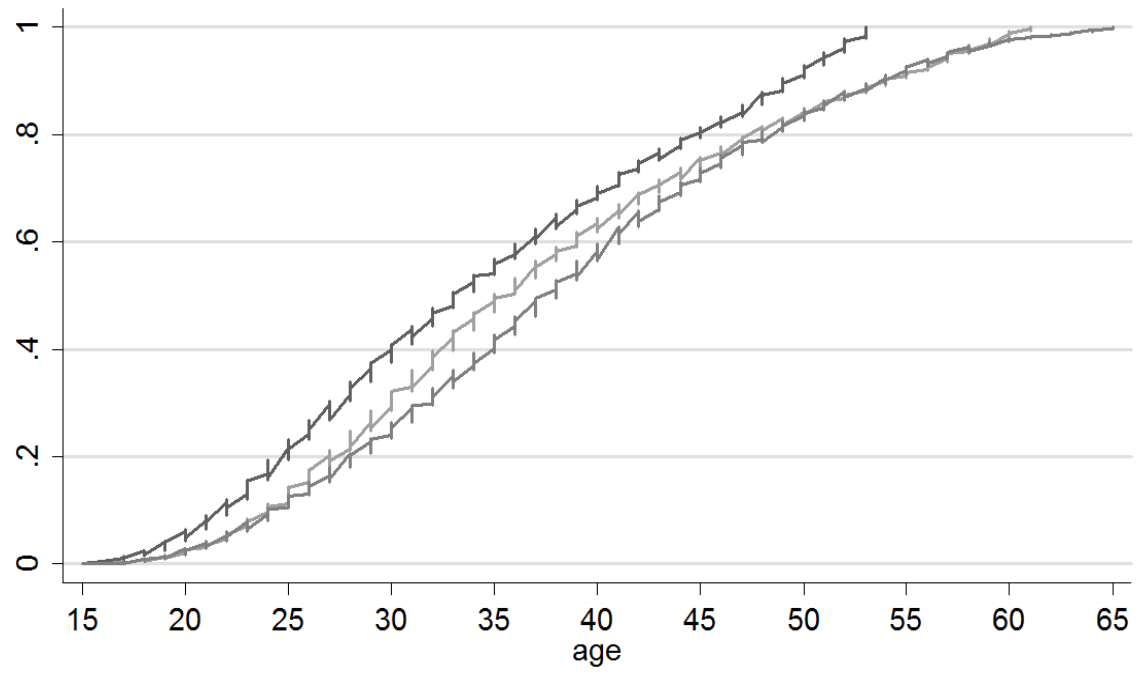

Cummulative Age Distribution 1998

Cummulative Age Distribution 1996

Cummulative Age Distribution 2004

Figure 6-A-3. The evolution of the age structure of the active population in Luxembourg Note: Own calculations based on IGSS data. Vertical axis - cumulative share of workers by age groups 
7. CONCLUSIONS AND FORWARD LOOKING 
This dissertation explores the dynamics of individual male earnings across $14 \mathrm{EU}$ countries to explain what is happening behind the changes in the distribution of labour market income across $14 \mathrm{EU}$ countries. We explore different facets of the earnings inequality-mobility story, highly relevant in the context of the labour market policy changes that occurred in Europe over the last decades. Several lessons can be drawn.

\section{Earnings Mobility and Cross-sectional Earnings Inequality}

Based on the Dickens rank mobility measure, we bring evidence that across $12 \mathrm{EU}$ countries between 1994 and 2001, the evolution of cross-sectional inequality is negatively associated with the evolution of short-term mobility.

What are the welfare implications of the cross-country trends in short-term mobility? In Netherlands, Greece, Finland, Portugal, Luxembourg, Italy, Germany, and Belgium, individuals find it harder in 2000-2001 to better their position in the earnings distribution short-term compared with the $1^{\text {st }} 2^{\text {nd }}$ wave, factor which might have contributed to the increase in earnings differentials between the $2^{\text {nd }}$ wave and 2001. Moreover, the decrease in mobility rates may signal an increase in permanent earning differentials.

In France and Austria, despite the decrease in cross-sectional earnings differentials between the $2^{\text {nd }}$ wave and 2001, individuals have a decreased opportunity in 20002001 to better their position in the earnings distribution compared with the $1^{\text {st- }} 2^{\text {nd }}$ wave. In the UK, Spain, Denmark, and Ireland individuals have an increased opportunity in 2000-2001 to improve their earnings position short-term compared with 1994-1995, which might have contributed to reduce cross-sectional differentials over time.

In 2001, the highest short-term mobility is recorded in Denmark and the lowest in Luxembourg. Thus men in Denmark observe the highest opportunity to move in the earnings distribution between 2000 and 2001.

Consistent across countries, mobility is found to be higher when measured over a longer time period, suggesting that the longer the period, the higher the opportunity to escape the initial earnings state. The highest long-term (over the sample period) mobility in terms of positional movements is found in Denmark and Ireland, and the lowest in Luxembourg. 
Overall, it appears that the higher the cross-sectional inequality in the $2^{\text {nd }}$ wave, the lower the mobility between the $1^{\text {st }}$ and $2^{\text {nd }}$ wave. Similarly, a higher long-term mobility (between the $1^{\text {st }}$ wave and 2001) is associated with a lower cross-sectional inequality in 2001. The rankings, however, have some exceptions, indicating that there are cases when (part of) earnings mobility might have a disequalizing impact on cross-sectional earnings inequality. These findings reinforce the debate that mobility is not always beneficial.

\section{Earnings Mobility and Lifetime Earnings Inequality}

If the establishment of the link between mobility and cross-sectional inequality faces problems, the implications of earnings mobility for lifetime or permanent inequality are even more cumbersome. Two approaches were used to shed some light on the potential link between earnings mobility and lifetime earnings inequality.

First, in Chapter 3 we looked at mobility as equalizer / disequalizer of longer-term earnings relative with cross-sectional inequality. Using the Fields mobility index computed over the longest observed horizon as a proxy for lifetime mobility, we bring evidence that in all countries except Portugal, mobility acts as an equalizer of lifetime/long-term differentials. The highest long-term equalizing mobility is found in Ireland and Denmark, and the only disequalizing mobility in Portugal.

Second, in Chapter 4 we decomposed the evolution in earnings inequality into permanent and transitory components to gauge their implications for long-run or lifetime earnings differentials. Earnings mobility - defined by Katz and Autor (1999) as the rate at which individuals shift positions in the earnings distribution - is closely related to the importance of the permanent and transitory components in earnings variation. A large contribution of the permanent component implies that individual earnings are highly correlated over time and individuals do not change their income position to a large extent experiencing low rates of earnings mobility. Therefore, the changes in earnings mobility are determined by the extent to which changes in cross-sectional inequality are driven by changes in the permanent or transitory inequality: the higher the incidence of the persistent differentials in the overall inequality, the lower the year-to-year mobility, thus the lower opportunity for the poor to improve their relative income position in a lifetime perspective. Thus we regard mobility as the opposite of persistency. We do not take the stand that that mobility is necessarily good, but that the lack of it is bad, as it signals a lack of opportunity to move. 
An increase in cross-sectional earnings inequality triggered by an increase in the permanent component signals an increase in lifetime earnings differentials, suggesting a worsening of the relative lifetime earnings position of the chronically poor. An increase in cross-sectional earnings differentials triggered by an increase in earnings instability signals an increase in earnings mobility, implying an increased opportunity for the poor to improve their relative income position in a lifetime perspective.

Overall earnings inequality, measured by the variance in log hourly earnings, decreased in Denmark, Belgium, France, Germany, UK, Ireland, Spain, Austria and increased in Netherlands, Luxembourg, Italy, Greece, Portugal and Finland. For all countries, both in relative and absolute terms, individual earnings inequality contains a highly permanent component for the oldest cohorts and a highly transitory component for the youngest cohort. The degree of immobility, measured by the ratio between the permanent variance and the transitory variance, is higher for older cohorts compared with younger cohorts, which suggests that the older the cohort, the lower the opportunity to improve one's position in the distribution of lifetime earnings.

Overall, the decrease in inequality resulted from a decrease in transitory differentials in Germany, France, UK and Ireland, in permanent differentials in Belgium and Spain, and in both components in Denmark and Austria. The increase in inequality reflects an increase in permanent differentials in Luxembourg, Italy, Greece and Finland, and an increase in both components in Portugal and Netherlands. The decrease in inequality was accompanied by an increase in mobility only in Denmark, Belgium and Spain. Except Netherlands and Portugal, all countries recording an increase in inequality experienced also a decrease in mobility.

What are the potential welfare implications of these trends? In Denmark, Belgium and Spain, mobility appears to be beneficial: in 2001, low wage individuals are better off both in terms of their relative wage and in terms of the opportunities to escape the low-wage trap in a lifetime perspective. Thus in a lifetime perspective, Denmark, Belgium and Spain are expected to reduce lifetime earnings differentials compared with annual differentials.

In Austria, Germany, France, UK and Ireland, in 2001, low-wage individuals are worse off in terms of the opportunity to escape the low-wage trap, but their relative position in the earnings distribution is improved compared with the $1^{\text {st }}$ wave. For these countries mobility is expected to play a decreasing role in reducing 
lifetime inequality, therefore annual differentials have a high chance of being preserved in a lifetime perspective.

Among countries recording an increase in earnings inequality, in Luxembourg, Italy, Greece, and Finland, besides the widening wages differentials, low wage individuals find it harder to better their position in the wage distribution in 2001 compared with the $1^{\text {st }}$ wave. Thus we can expect these countries to increase lifetime earnings differentials compared with annual differentials. Netherlands and Portugal record widening wages differentials accompanied by increased opportunity for low wage individuals to improve their position in the distribution of lifetime earnings. Thus, for Netherlands and Portugal, earnings mobility could either decrease or exacerbate lifetime earnings differentials compared with annual ones.

\section{Linking labour market policy and institutional factors with outcomes- permanent inequality, transitory inequality and earnings mobility}

What has caused the differential trends in long-run inequality, transitory inequality and earnings mobility across the $14 \mathrm{EU}$ countries is an important subject for continuing research. We take the first steps in this direction in Chapter 5.

The changes in the three labour market outcomes - permanent inequality, transitory inequality and wage immobility - occurred in the context of the labour market institutional and policy framework changes that characterized the EU after 1995. Given that all countries face similar macroeconomic shocks, the difference in institutions can potentially explain the differences in outcomes across countries. Thus we explored the link between the three labour market outcomes and the labour market institutional and policy factors.

The estimation results reveal a highly complex framework, where institutions interact significantly not only with each other and with the overall institutional setting, but also with the macroeconomic shocks in shaping the pattern of the three labour market outcomes. This complexity is enhanced by the endogeneity bias characterising this framework, which in the absence of reliable instruments, prevents the establishment of causality. We see our results as preliminary.

The model specifications provide clearly more a description of the data than the outcome of a tightly specified theory of interactions. But they capture the basic hypothesis, that given similar shocks, countries with worse institutions will experience worse outcomes. 
The direct effects of the institutions are mixed, depending on the interactions included in the model.

The systemic interactions reveal that the more equality/mobility-friendly the overall labour market policy and institutional framework is, the greater is the reducing impact: (i) of the union density, the degree of corporatism - a stronger reducing effect for an intermediate level than for a high level -, the tax wedge and the product market regulation on permanent inequality; (ii) of the union density and the degree of corporatism on transitory inequality; and (iii) of the union density and the degree of corporatism - a stronger reducing effect for an intermediate level than for a high level - on earnings immobility.

The findings for the effect of union density validate our hypotheses: unionization reduces persistent earnings disparities and earning instability, and enhances earnings mobility. Thus we reinforce the existing evidence that a high union density is usually associated with a low overall earnings inequality, which results from claims for high wages and earnings stability for covered workers (Card, Lemieux, Riddell, 2003; OECD, 2004).

Unions affect wage dispersion indirectly, mainly through their impact on training and minimum wage. By forcing employers to provide training to their employees, they increase the employees' human capital and adaptability to new technologies (Aghion and Williamson 2001). Thus unionization increases employees' opportunity to improve their position in the permanent earnings distribution. Hence permanent earnings inequality can be reduced at any given rate of technical change (Aghion and Williamson 2001).

However, similarly with overall inequality (Fortin and Lemieux 1997), there are potential offsetting effects. Even if unions decrease within-group earnings disparities, they may still increase both overall transitory and permanent inequality by increasing wage differentials between those unionized and nonunionized. Thus, the impact of unionization depends also on the wage gap between unionized and non-unionised workers. Our findings bring evidence that when the overall institutional framework is equality/mobility-friendly, the potential offsetting effects of unionization on wage differentials may be reduced / cancelled.

For the degree of corporatism, the findings are only partially in line with our theoretical expectations. We confirm that a high corporatism favours a lower persistent and transitory inequality compared with low corporatism. A high degree of corporatism, meaning a very centralized and coordinated bargaining system is associated with a compressed wage structure across qualification levels 
because it is expected to exclude low skilled workers from the labour market (Calmfors, 1993). A low degree of corporatism, meaning a decentralized wage bargaining at the firm level is expected to prevent excessive wage claims since this would lead to a loss of market shares to competitors with detrimental effects on employment. This implies that wages are less uniformly distributed, meaning that there is a higher dispersion in the returns to skills and in earnings variability (Bassanini and Duval 2006).

However, instead of the expected hump-shaped relationship between the degree of corporatism and persistent and transitory inequality, we find a "U-shaped" pattern with permanent inequality and a negative relationship with transitory inequality.

Consistent with our expectations, we find that an intermediate corporatism favours the highest mobility. Contrary to our expectations we find that a high corporatism favours a higher earnings mobility compared with low corporatism. The potential explanation may be that under a high corporatism, expected to exclude low skill workers from the labour market, the remaining workers have a higher opportunity to improve their lifetime earnings position.

The validity of our hypothesis that the tax wedge reduces the human capital price, and thus reduces persistent inequality is confirmed.

PMR is found to reduce persistent differentials, in line with our expecations. The effect of PMR on persistent inequality, however, depends also on the wage gap between regulated and non-regulated sectors. Our findings provide evidence that the more equality-friendly the overall framework is, the potentially offsetting effect of PMR due to the wage gap between regulated/non-regulated sectors is reduced.

Overall, our findings show that permanent inequality and transitory inequality are determined mainly by the institutional setting, which wipe out both the direct and interaction effects of the macro shocks. This suggests that the overall institutional structure manages to filter out all direct and indirect effect of the macro shocks. Hence, in shaping permanent and transitory inequality patterns, not the individual interactions between shocks and each institution count, but how institutions interact with each other in dealing with the effects of these shocks. We identified more significant institutional direct and indirect effects for permanent inequality, sign that the institutional factors play a larger role in shaping permanent than transitory inequality. The only stand-alone factor which is effective in reducing or limiting the increase of permanent inequality under in the impact of macroeconomic shocks is the high degree of corporatism. 
Earnings immobility is determined by the direct effects of institutions, macro shocks and their interactions with the institutional setting. The institutional and policy factors that amplify the positive impact of the systemic shock on wage immobility are the employment protection legislation (EPL), the union density, the product market regulation (PMR), the active labour market policies (ALMPs). The factors that decrease the impact of the systemic shock on wage immobility are the degree of corporatism, and the generosity of the unemployment benefit.

Overall, the current study appoints Denmark as the "champion country" in terms of best labour market distributional outcomes. In 2001, Denmark records the lowest average persistent inequality, one of the lowest average transitory inequalities and the highest average degree of mobility. Moreover, as seen in Chapter 2, both short (2000-2001) and long term (1994-2001), men in Denmark observe the highest opportunity to move in the earnings distribution across all countries. Additionally, as seen in Chapter 3, Denmark records among the highest long-term equalizing mobility.

Among the worst outcomes are observed in Portugal, which records the highest average persistent and transitory differentials, and one of the lowest mobility. Moreover, as found in Chapter 3, the only disequalizing mobility long-term is observed in Portugal. The potential explanation lies in the different institutional setting.

The outstanding performance of the labour market in Denmark might be due to the so-called "flexicurity approach" (OECD, 2004), which represents an interesting combination of high labour market dynamism and a relatively high social protection. It is a mix of flexibility (a high degree of job mobility thanks to low employment protection legislation), social security (a generous system of unemployment benefits) and active labour market programmes. Moreover, Denmark exhibits a high union density and degree of corporatism, a low product market regulation and a medium high tax wedge. The coupled effect of these factors appears to assure a small annual inequality - small persistent inequality and earnings volatility -, a high opportunity to low wage individuals to improve their relative position in the distribution of lifetime earnings and an earnings mobility with a strong equalizing effect on lifetime differentials.

At the opposite pole lies Portugal, with a high employment protection legislation, less generous unemployment benefits, much less developed active labour market programmes, a low union density and an intermediate corporatism, a more regulated product market, and a lower tax wedge. 
Thus we may conclude that potential complementary factors in keeping persistent inequality and earnings instability low, assuring at the same time a high degree of earnings mobility is a high union density, a high corporatism, a low EPL, developed active labour market programmes, generous unemployment benefits, deregulated product market and a relatively high tax wedge.

A high union density coupled with a high corporatism is expected to favour a compressed wage structure and earnings stability for covered workers, assuring at the same time increasing human capital and adaptability to new technologies for the covered workers through training (Aghion and Williamson 2001). Thus these coupled effects have the potential to increase the employees' opportunity to improve their position in the permanent earnings distribution.

Following Cazes and Nesporova (2003), the argument against the employment protection legislation (EPL) is its key role in generating labour market rigidity as it increases the cost of hiring and of layoffs, and consequently lowers labour turnover. Hence it may reduce total employment. Moreover, the low turnover is expected to affect mainly workers with temporary contracts, because they have a weaker protection in the labour market. Thus, the potential cost of a stricter EPL is the widening differentials between those covered by the EPL who enjoy regular jobs and those non-covered who have irregular jobs, unemployed jobseekers: the former benefit from tenure increases with age and thus decreasing likelihood of job loss, whereas the latter experience the opposite. Moreover the cost of EPL is augmented in periods of high economic volatility, when irregular jobs tend to increase at the expense of regular jobs. Under this scenario, taking into account the differentials between covered and non-covered workers, a strict EPL is expected to increase permanent inequality, transitory inequality and wage immobility, in line with our findings.

Active Labour Market Programs (ALMP), which typically consist of job placement services and labour market programmes such as job-search, vocational training or hiring subsidies may reduce permanent earnings differentials and earnings volatility, increasing at the same time the opportunity of the vulnerable groups to advance in the distribution of lifetime earnings, by improving the efficiency of the job matching process and by enhancing the work experience and skills of the most vulnerable groups. The effects of the ALMPs, however, depend on the other labour market policies and institutions: e.g. a strict EPL is expected to dampen the effect of active labour market policies aimed to reintegrate the unemployed into the labour market (Bassanini and Duval, 2006b, 2006a). Generous ALMPs increase the employability of the vulnerable groups and the low EPL facilitates their labour market reintegration. 
Hence, from a policy point of view, an increase in ALMP coupled with a low or decreasing EPL which facilitates the labour market reintegration of the vulnerable groups may be a promising path towards increasing their human capital, reducing their earnings vulnerability, and reducing lifetime earnings differentials.

Moreover, as argued by Bassanini and Duval (2006b, 2006a), developed ALMPs are expected to reduce the adverse effect of generous unemployment benefits on employment and implicit wages, thus reducing persistent and transitory differentials, assuring at the same time a high opportunity to move in the lifetime earnings distribution. More generous unemployment benefits represent incentives not to accept low-paid jobs. Thus they improve the job-matching and they increase the likelihood of a more stable employment and earnings patterns.

Product market deregulation coupled with high unionization and a high corporatism appears to favour a reduction in persistent and transitory inequality, and an increase in earnings mobility. Thus we may conclude that a high unionization and corporatism should complement the process of deregulation in order to keep persistent inequality and earnings volatility low, and to assure at the same time a high mobility.

Similarly, a high tax wedge appears to be an efficient tool in reducing persistent differentials, thus for reducing lifetime earnings differentials.

\section{Zooming in - potential consequences of dramatic labour market structural changes for the structure of earnings inequality}

As a last step, using 17 years of administrative data, I zoomed in and decomposed the growth in earnings inequality into permanent and transitory components in the EU country which underwent the most dramatic labour market structural changes during the last decades - Luxembourg. The transition from an industrial economy to one dominated by the tertiary sector which relies heavily on the cross-border workers led to an increase in earnings inequality between 1988 and 2004, which reflects increasing long-run (permanent) differentials between individuals accompanied by decreasing earnings mobility, meaning decreasing opportunity for low wage individuals of improving their income position in a lifetime perspective. Thus, in Luxembourg, cross-sectional inequality may be exacerbated in a lifetime perspective.

These results reconfirm the trends predicted in Chapter 4 for Luxembourg between 1995 and 2001, using ECHP. Besides the methodological advancements, the value added of Chapter 6 compared with Chapter 4 resides in the predicted trends before 
1995 and after 2001. 1993-1994- mark a turning point in the evolution of the inequality structure in Luxembourg. Before this turning point, transitory inequality is the dominant inequality component, recording an increasing trend, similar with persistent inequality. After 1994, persistent inequality continued to increase becoming dominant, whereas transitory inequality started to decrease. The potential explanation for the turning point around this period is the intensification of the transition from the steel sector to the financial sector.

Thus we may conclude that the transition from an industrial economy to one dominated by the tertiary sector is one of the main driver behind the dominant increase in persistent differentials, and consequently behind the increase in overall inequality in Luxembourg.

\section{Forward looking}

This dissertation has set the first steps towards several future studies.

The cross-national comparative studies on earnings mobility undertaken in Chapter $2-5$ can be extended by exploring more mobility measures and the link between the evolution of mobility and the labour market policy and institutional factors. Moreover, what has caused the differential trends in long-run inequality, transitory inequality and earnings mobility across the $14 \mathrm{EU}$ countries remains an important subject for continuing research.

The research undertaken in Chapter 4 can be continued by developing a single European earnings dynamic model, with country-specific parameters. Moreover, the model can be extended by including policy and institutional variables.

Whereas the exercise in Chapter 6 identified the evolution of the two components over the sample period in Luxembourg, it has not identified the factors that might have triggered this evolution. This topic is extremely relevant and should be focused by future research. A good starting point is the approach taken in Chapter 5. Another possible extension is to test statistically the impact of the labour market structural changes on the structure of earnings inequality and earnings mobility, by including also contextual variables, such as occupation shifters.

Additionally, the inflow of foreign-born and cross-border workers led to quite an important change in the composition of the labour force, expected to have influenced the structure of earnings inequality and earnings mobility in Luxembourg. Chapter 6 does not touch upon this issue. It would be interesting to see to what extent the results in Chapter 6 can be linked and explained by this. 
Another point for future research is to exploit the richness of the Luxembourgish data by exploring other measures of earnings mobility, as this topic is under researched at the EU level and in Luxembourg. Another point of interest is to see how the results based on panel survey data compares with the results using the administrative data.

Moreover, the richness of the administrative data in Luxembourg allows the study of annual earnings mobility going back to 1950, an amazing opportunity given the scarcity of longitudinal data.

For closure, I highlight the methodological implications of this dissertation. One unexplored area in earnings dynamics relates to the potential implications of the earnings dynamics models for improving the dynamics earnings microsimulation models. The need of a sound dynamic earnings microsimulation model can be understood in the larger context of evaluating the coherence of the national systems of social transfers. For example, evaluating the distributional outcomes of lifecycle programmes, such as the pension systems, requires data on lifetime earnings. However, in most cases, these studies target the unretired population, with incomplete lifetime earnings data. This is where the relevance of a dynamic earnings microsimulation model kicks in.

Of core importance in evaluating lifecycle programmes is the development of a dynamic earnings microsimulation model able to simulate longitudinal individual earnings profiles. And the first step towards designing a dynamic earnings microsimulation is to understand thoroughly the dynamics of earnings characterising a particular labour market, aim accomplished by this dissertation.

Thus understanding earnings dynamics in a particular labour market, leads to understanding how to model sophisticated error components structures. My next step is to utilize the earnings dynamics methodology developed in this dissertation to improve the methodology used for simulating earnings variability in a dynamic microsimulation model both internationally and in Luxembourg. The existing earnings models used for dynamic microsimulations are limited, in the sense that they rely on simple econometric models that incorporate a low degree of individual heterogeneity and neglect to a large extent the inherent dynamics in the earnings structure (O'Donoghue ,2001; Baekgaard, 2002; Zaidi, 2004).

My aim is to advance a more complex methodology which, unlike existent studies which exploit mainly the observed heterogeneity, allows incorporating also a high degree of unobserved heterogeneity by decomposing the error structure of the earnings function using various error components models. 
By improving the dynamic microsimulation of individual earnings, this methodology is particularly suitable for enhancing the performance of pension microsimulation models, thus providing a better reference for policy making. 


\section{BIBLIOGRAPHY}

Aaberge, Rolf, Bjorklund, Anders, Jantti, Markus, Palme, Marten, Pedersen, Peder J., Smith, Nina, and Wannemo, Tom. 2002. Income inequlaity and income mobility in the Scandinavian countries compared to the United States. Review of Income and Wealth, 48(4).

Abowd, John M., and Card, David. 1989. On the covariance structure of earnings and hours changes. Econometrica, 57(2), 411-445.

Aghion, Philippe, and Williamson, Jeffrey G. 2001. Growth, Inequality and Globalization: Theory, History and Policy: Cambridge University Press.

Anderson, T. W., and Hsiao, Cheng. 1982. Formulation and estimation of dynamic models using panel data. Journal of Econometrics.

Atkinson, Anthony, B., Bourguignon, Francois, and Morrisson, C. (Eds.). (1992). Empirical studies of earnings mobility: Suisse : Harwood Academic Publishers.

Baekgaard, Hans .2002. Modelling the Dynamics of the Distribution of Earned Income, NATSEM.

Baker, Michael. 1997. Growth-rate heterogeneity and the covariance structure of life-cycle earnings. Journal of Labor Economics, 15(2), 338-375.

Baker, Michael, and Solon, Gary. 2003. Earnings dynamics and inequality among Canadian men, 1976-1992: evidence from longitudinal income tax records. Journal of Labor Economics, 21(2), 289-321.

Bassanini, A., and Duval, R. 2006a. The Determinants Of Unemployment Across OECD Countries: Reassessing The Role of Policies And Institutions. OECD Economics Studies, 42.

Bassanini, A., and Duval, R. 2006b. Employment Patterns In OECD Countries: Reassessing The Role Of Policies And Institutions. OECD Economics Department Working Papers, 486.

Benabou, R, and Ok, E. A. 2001. Mobility and progressivity: ranking income processes according to equality of opportunity. NBER Working Paper, 8431.

Bertola, G., Blau, F., and Kahn, L. 2002. Labor Market Institutions and Demographic Employment Patterns. NBER Working Paper 9043. 
Blanchard, O. 1999. European unemployed: the role of shocks and institutions Paper presented at the Baffi Lecture.

Brukhauser, Richard V., Holtz-Eakin, Douglas, and Rhody, Stephen E. 1998. Mobility and inequality in the 1980s: a cross-national comparison of the Unite States and Germany. In Jenkins, Kapteyn andVan Praag (Eds.), The distribution of welfare and household production (pp. 111-175). Cambridge: Cambridge University Press.

Brukhauser, Richard V., and Poupore, John G. 1997. A cross-national comparison of permanent inequality in the United States and Germany. Review of Economics and Statistics, 79, 10-17.

Cappellari, Lorenzo. 2003. The dynamics and inequlaity of Italian men's earnings. The Journal of Human Resources, XXXIX.

Card, David, Lemieux, Thomas and Riddell, W. Craig. 2003. Unionization and Wage Inequality: A Comparative Study of The US, The UK and Canada. NBER Working paper, 9473.

Cervini, Morilla, and Ramos, Xavier. 2006. Permanent and Transitory Earnings Inequlaity in Spain, 1993-2000. Paper presented at the EALE 2006.

Cholezas, Ioannis, and Tsakloglou, Panos 2008. Earnings inequality in Europe: structure and patterns of inter-temporal changes. IZA Discussion Papers, No. 2636.

Clark, Todd E. 1996. Small sample properties of estimators of non-linear models of covariance structure. Journal of Business and Economic Statistics, 14, 367-373.

Creedy, J. 1998. The Dynamics of Inequality and Poverty. Northampton: Edward Elgar Publishing Limited.

Creedy, J., and Wilhelm, M. 2002. Income Mobility, Inequality and Social Welfare. Australian Economic Papers, 41(2), 140-150.

Daly, Mary C, and Valletta, Robert G. 2005. Cross-national trends in earnings instability and earnings inequality. Economic Letters, 99 (2), 215-219.

Dew-Becker, Ian, and Gordon, Robert J. 2008. The Role of Labour Market Changes in the Slowdown of European Productivity Growth. CEPR Discussion Papers.

Dickens, Richard. 2000a. Caught in a trap? Wage mobility in Great Britain: 19751994. Economica(67), 477-497. 
Dickens, Richard. 2000b. The evolution of individual male earnings in Great Britain: 1975-95. The Economic Journal, 110(460), 27-49.

Doris, Aedín, O'Neill, Donal, and Sweetman, Olive. 2008. Does growth affect the nature of inequality? Ireland 1994-2001. NUI Maynooth Seminar.

Duncan, Greg J., and Morgan, James N. 1981. Persistence an change in economic status and the role of changing family composition. In Hill, Hill andMorgan (Eds.), Five thousand American families: patterns of economic progress (Vol. 9, pp. 1-44). Ann Arbor: Institute for Social Resarch, University of Michigan.

EIROnline. http://www.eurofound.europa.eu/eiro/country_index.htm.

Fields, Gary S. 2008. Does income mobility equalize longer-term incomes? New measures of an old concept. Available at: http://works.bepress.com/gary_fields/23

Fields, Gary S., Leary, Jesse, and Ok, Efe. 2003. Stochastic dominance in mobility analysis. Economic Letters, 75(3), 333-339.

Fields, Gary S., and Ok, Efe. 1999. The measurement of income mobility: an introduction to the literature. In Silber (Ed.), Handbook of Income Inequality Measurement. Boston: Kluwer Academic Publishing.

Fortin, Nicole M., and Lemieux, Thomas. 1997. Institutional Changes and Rising Wage Inequality: Is there a Linkage? The Journal of Economic Perspectives, 11(2), 75-96.

Freeman, R., and Gibbons, R. 1995. Getting together and breaking appart: the decline in centralized bargaining. In Freeman andKatz (Eds.), Differences and changes in wage structures. Chicago: University of Chicago Press and NBER.

Freeman, Richard B. 1975. Overinvestment in college training? Journal of human resources, 10, 287-311.

Freeman, Richard B. 1976. The overeducated American. San Diego: Academic Press.

Freeman, Richard B., and Katz, Lawrence F. 1994. Rising wage inequality: the United States vs. other advanced countries. In Freeman (Ed.), Working under different rules (pp. 29-62). New York: Russel Sage Foundation.

Friedman, M. 1962. Capitalism and Freedom. Chicago: University of Chicago Press. 
Friedman, Milton, and Kuznets, Simon. 1954. Income from independent professional practice. New York, NBER

Fritzell, Johan. 1990. The dynamics of income distributions: economic mobility in Sweden in comparizon with the United States. Social Science Research, 1746.

Gottschalk, Peter, and Smeeding, Timothy M. 1997. Cross-national comparisons of earnings and income inequality. Journal of Economic Literature, 35(2), 633687.

Gottschalk, Peter, and Spolaore, Enrico. 2002. On the evaluation of economic mobility. Review of Economic Studies, 68, 191-208.

Gregg, Paul, and Vittori, Claudia 2008. Exploring Shorrocks Mobility Indices Using European Data. THE CENTRE FOR MARKET AND PUBLIC ORGANISATION, 08(206).

Gustavsson, Magnus. 2004a. Changes in Permanent and Transitory Earnings Inequality in Sweden: 1991:1999". In "Empirical Essays on Earnings Inequality": Ph.D. Dissertation, Uppsala University.

Gustavsson, Magnus. 2004b. Trends in the transitory variance of earnings: evidence from Sweden 1960-1990 and a comparison with the United States. Uppsala University Working Papers, No. 11.

Hause, John C. 1977. The covariance structure of earnings and on-the-job training hypothesis. Annals of Economic and Social Measurement, 335-366.

Hause, John C. 1980. The fine structure of earnings and the on-the-job training hypothesis. Econometrica, 48(4), 1013-1029.

Hofer, H., and Weber, A. 2002. Wage mobility in Austria 1986-1996? Labour Economics, 9, 563-577.

Jarvis, S., and Jenkins, S. 1998. How much income mobility is there in Britain? Economic Journal, 108(447), 428-443.

Kalwij, Adriaan, and Alessie, Rob. 2003. Permanent and transitory wage inequality of British men, 1975-2001: year, age and cohort effect. Journal of Applied Econometrics, 22, 1063-1093.

Katz, Lawrence F. 1994. Comments and discussion. Brookings Papers on Economic $\operatorname{Activity(2),~255-261.~}$ 
Katz, Lawrence F., and Autor, David H. 1999. Changes in the wage structure and earnings inequality. In Handbook of Labor Economics (Vol. 3): Elsevier Science B.V.

Layard, R., Nickell, S., and Jackman, R. 1991. Unemployment: macroeconomic performance and the labour market. Oxford: Oxford University Press.

Leamer, Edward E. 1983. Let's take the con out of econometrics. American Economic Review, 74(March), 31-43.

Lillard, Lee A. 1977. The distribution of earnings and human wealth in a life-cycle context. In Cambridge (Ed.), The Distribution of Economic Well-Being: NBER.

Lillard, Lee A., and Weiss, Y. 1979. Components of variation in panel earnings data: American scientists 1960-70. Econometrica, 47(2), 437-454.

Lillard, Lee A., and Willis, R. 1978. Dynamic aspects of earnings mobility. Econometrica, 46(5), 985-1012.

MaCurdy, Thomas E. 1981. Time series models applied to panel data. Stanford University.

MaCurdy, Thomas E. 1982. The use of time series processes to model the error structure of earnings in a longitudinal data analysis. Journal of Econometrics, 18(1), 83-114.

Mincer, Jacob. 1957. A study of income distribution. Columbia University.

Mincer, Jacob. 1958. Investment in human capital and personal income distribution. Joournal of Political Economy, 66(4), 281-302.

Mincer, Jacob. 1962. On-the-job training: costs, returns and some implications. Journal of Political Economy, 70(5, Part 2), S50-S79.

Mincer, Jacob. 1974. Schooling, experience and earnings. New York: NY: NBER.

Moffitt, Robert, and Gottschalk, Peter. 1995. Trends in the covariance structure of earnings in the United States: 1969-1987. Paper presented at the Working Papers in Economics, No. 355.

Moffitt, Robert, and Gottschalk, Peter. 1998. Trends in the variances of permanent and transitory earnings in the U.S. and their relation to earnings mobility. Boston College Working Papers, No. 444.

Moffitt, Robert, and Gottschalk, Peter. 2002. Trends in the transitory variance of earnings in the United States. The Economic Journal, 112(478), C68-C73. 
Moffitt, Robert, and Gottschalk, Peter. 2008. Trends in the transitory variance of male earnings in the U.S., 1970-2004. Boston College Working Papers, No. 697.

OECD. 1996. Earnings inequality, low paid employment and earnings mobility. In Employment Outlook (pp. 59-99). Paris: OECD.

OECD. 1997. Earnings mobility: taking a longer view. In Employment Outlook. Paris: OECD.

OECD. 2004. Chapter 2. Employment Protection Regulation and Labour Market Performance. In Employment Outlook. Paris: OECD.

OECD. 2006. Labour Market Performance since 1994 and Future Challenges. In Employment Outlook.

O'Donoghue, Cathal. 2001. Dynamic Microsimulation: A Survey, Brazilian Electronic Journal of Economics.

Pen, J. (1971). Income Distribution. Harmondsworth Mx.: Penguin Books. Pelican edition, 1974.

Ramos, Xavier. 1999. Anatomy of earnings mobility in Britain: evidence from BHPS, 1991-1995. Working Papers of the ESRC Research Centre on Micro-social Change(99-11).

Ramos, Xavier. 2003. The covariance structure of earnings in Great Britain, 19911999. Economica, vol. 70(278), 353-374.

Rodrik, Dani. 1997. Has international integration gone too far? Washington, DC.

Shorrocks, A.F. 1978. Income inequality and income mobility. Journal of Economic Theory(19), 376-393.

Sologon, Denisa M. 2009. Earnings dynamics and inequality among men in Luxembourg, 1988-2004: Evidence from administrative data. MGSOG Working Series(December).

Sologon, Denisa M., and O'Donoghue, Cathal. 2009a. Earnings dynamics and inequality among men across $14 \mathrm{EU}$ countries: evidence from ECHP. IZA Discussion Papers, No. 4012(February).

Sologon, Denisa M., and O'Donoghue, Cathal. 2009b. Earnings dynamics and inequality in EU, 1994-2001. Revised and resubmitted to Labour Economics. / SOEPpapers on Multidisciplinary Panel Data Research, No. 184. / MGSOG Working Series(December). 
Sologon, Denisa M., and O'Donoghue, Cathal. 2009c. Equalizing or disequalizing lifetime earnings differentials? Earnings mobility in the EU: 1994-2001. IZA Discussion Papers, 4642(December). / MGSOG Working Series(December). / SOEPpapers on Multidisciplinary Panel Data Research, No. 251.

Sologon, Denisa M., and O'Donoghue, Cathal. 2009g,h,i. Increased Opportunity to Move Up the Economic Ladder? Earnings Mobility in EU: 1994-2001. IZA Discussion Papers, No. 4311(July). / MGSOG Working Series(December). I SOEPpapers on Multidisciplinary Panel Data Research, No. 221.

Sologon, Denisa M., and O'Donoghue, Cathal. 2009j,k,l. Policy, Institutional Factors and Earnings Mobility. IZA Discussion Papers, No. 4151(April) / SOEPpapers on Multidisciplinary Panel Data Research, No. 183. / MGSOG Working Series(December).

Topel, Robert H. 1997. Factor Proportions and Relative Wages: The Supply-Side Determinants of Wage Inequality. The Journal of Economic Perspectives, 11(2), 55-74.

Van Kerm, Philippe. 2004. What lies behind income mobility? Reranking and distributional change in Belgium, Western Germany and the USA. Economica, 71, 223-239.

Weizsäcker, Robert K. Von. 1993. A theory of earnings distributions. New York: Cambridge University Press.

Zaidi, Asghar .2004. Estimation of earnings in the SAGE dynamic microsimulation model. SAGE Technical Note No.10. 


\section{SAMENVATTING}

Dit proefschrift onderzoekt de dynamiek van de individuele inkomens van mannen om de veranderingen in de distributie van arbeidsmarktinkomen in $14 \mathrm{EU}$ landen te verklaren. In inkomensstudies is de strategie om dynamiek te meten steeds verfijnder geworden. Dit proefschrift hanteert dezelfde strategie. Dit proefschrift heeft twee doelstellingen.

Ten eerste voer ik vier studies uit waarin ik de inkomensdynamiek tussen EUlanden vergelijk tussen 1994 en 2001. De contributie van deze studies ligt op de gebieden van ongelijkheid-mobiliteit en mobiliteit op EU niveau.

Deze studies onderzoeken de evolutie van inkomensmobiliteit, permanente en voorbijgaande ongelijkheid, en de rol van arbeidsmarktbeleiden institutionele factoren in de evolutie van deze drie arbeidsmarktresultaten in 14 EU landen. Deze vragen zijn hoogst relevant in de context van de veranderingen binnen het arbeidsmarktbeleidkader van de EU na 1995 die onder de weerslag van de OESO werkgelegenheid strategie van 1994 en de Agenda van Lissabon van 2000 plaatsvonden. De veranderingen betreffen beleid om loonflexibiliteit te verhogen, lagere niet bezoldigde loonkosten te verhogen en relatieve lonen toe te staan om individuele verschillen in productiviteit en lokale arbeidsmarktvoorwaarden beter weer te geven (OESO, 2004; Dauw-Becker en Gordon, 2008).

Voor deze studies maak ik gebruik van data uit het European Community Household Panel, van 14 EU landen tussen 1994 en 2001. In navolging van vorige studies focus ik op mannen, om problemen van selectie bias betreffende vrouwelijke inkomens te vermijden.

De eerste studie onderzoekt of de burgers van de EU een verhoogde kans hebben om hun positie in de distributie van inkomens over tijd te verbeteren. Deze vraag wordt beantwoord door loonmobiliteit te onderzoeken op korte en lange termijn. Loonmobiliteit wordt geëvalueerd door middel van twee maatstaven, die positionele bewegingen in de distributie van inkomens meten. De eerste indicator wordt afgeleid uit de overgangsmatrices aanpak tussen inkomenskwintalen, en de tweede indicator is gebaseerd op de individuele rangorde, zoals afgeleid door Dickens (2000a).

In Nederland, Griekenland, Finland, Portugal, Luxemburg, Italië, Duitsland en België was het voor individuen in 2000-2001 lastiger om hun positie op de 
inkomensverdeling te verbeteren in vergelijking met de eerste en tweede golf. 118 Dit zou kunnen hebben bijgedragen aan een toename in inkomensverschillen tussen de tweede golf en 2001. Daarnaast zou een afname in mobiliteit kunnen duiden op een toename in permanente inkomensverschillen.

Ondanks een afname in cross-sectie inkomensverschillen tussen de tweede golf en 2001, hebben individuen in Frankrijk en Oostenrijk in 2000-2001 minder kans om hun positie op de inkomensverdeling te verbeteren in vergelijking met de eerste en tweede golf. In het Verenigd Koninkrijk, Spanje, Denemarken, en Ierland hebben individuen een grotere kans om in hun inkomenspositie op korte termijn te verbeteren in vergelijking met 1994-1995. Dit zou kunnen hebben bijgedragen aan een reductie in de verschillen tussen landen over tijd.

De tweede studie onderzoekt of de burgers van de EU een verhoogde kans hebben om hun positie in de distributie van levensinkomens te verbeteren, en of de inkomensmobiliteit tot meer gelijkheid in leveninkomens leidt relatief aan ongelijkheid in de cross-sectie. Onze basisveronderstelling is dat mobiliteit, gemeten over een tijdsperiode van 8 jaar, een goede maatstaf is voor mobiliteit gedurende het arbeidsleven. Voor de beantwoording van de vragen gebruik ik indices van Shorrocks (1978) en Fields (2008). Verder onderzocht ik het effect van inkomensmobiliteit als determinant van inkomensongelijkheid op langere termijn.

Gebruik makende van de mobiliteitsindex van Fields (gemeten over de langst geobserveerde periode als proxy voor mobiliteit gedurende het arbeidsleven), vinden we bewijs dat mobiliteit in alle landen behalve Portugal tot minder verschillen in inkomensongelijkheid over het leven leidt. In Ierland en Denemarken bracht mobiliteit de meeste gelijkheid. Alleen in Portugal vonden we bewijs dat mobiliteit meer ongelijkheid bracht.

De derde studie onderzoekt de dynamische structuur van inkomens en de mate waarin veranderingen in inkomensongelijkheid in de cross-sectie op tijdelijke of permanente componenten van de individuele variatie van levensinkomens wijzen. Deze studie is wederom gebaseerd op data uit 14 EU landen. Ik maak gebruik van Equally Weighted Minimum Distance methoden om de covariantiestructuur van inkomens te schatten, om inkomensongelijkheid in een permanente en tijdelijke component te verdelen, en om gebrek aan inkomensmobiliteit te schatten.

\footnotetext{
${ }^{118}$ In de dataset zijn 12 landen geobserveerd tussen 1994-2001, 2 landen tussen 1995-2001 en 1 land tussen 1996-2001. De eerste golf is het eerste jaar dat ik het land observeer.
} 
De vermindering in ongelijkheid werd in Duitsland, Frankrijk, het Verenigd Koninkrijk, en Ierland bewerkstelligd door een vermindering in tijdelijke verschillen. In België en Spanje werd dit bewerkstelligd door permanente verschillen, en in Denemarken en Oostenrijk door zowel tijdelijke als permanente verschillen. De toegenomen ongelijkheid weerspiegelt een toename in permanente verschillen in Luxemburg, Italië, Griekenland en Finland en een toename in beide componenten in Portugal en Nederland. De afname in ongelijkheid ging alleen in Denemarken, België en Spanje gepaard met een toename in mobiliteit. In alle landen behalve Nederland en Portugal ging een toename in ongelijkheid gepaard met een afname in mobiliteit.

De vierde studie bouwt op de schattingsresultaten van de derde studie en de OECD-gegevens voor de 14 EU landen. In de vierde studie wordt de rol van arbeidsmarktfactoren onderzocht om internationale verschillen in de dynamische structuur van inkomenste verklaren. De institutionele OECD data en de voorspelde arbeidsmarktuitkomsten uit de derde studie, te weten permanente ongelijkheid, tijdelijke ongelijkheid en gebrek aan inkomensmobiliteit, worden gebruikt in een niet-lineaire least squares analyse. Deze analyse schat het verband tussen de drie arbeidsmarktresultaten, arbeidsmarktbeleid en institutionele factoren.

De resultaten laten een zeer complex raamwerk zien, waarin instituties vaak met elkaar en met overkoepelende institutionele settings samenwerken maar waarin ook macroeconomische veranderingen die het patroon van de drie arbeidsmarktuitkomsten beïnvloeden. De complexiteit wordt vergroot doordat endogeniteit een rol speelt. Zonder betrouwbare instrumenten kan causaliteit niet worden aangetoond. Onze resultaten zijn daarom preliminair.

Als tweede doelstelling van het proefschrift, bekijk en analyseer ik in de vijfde studie de inkomensdynamiek in Luxemburg, het EU land dat de meest dramatische structurele arbeidsmarktveranderingen tijdens de laatste decennia onderging. Eind jaren '70 en nog intensiever begin jaren '90, veranderde Luxemburg van een industriële economie in een service economie, die sterk afhankelijk is van grote aantallen grensoverschrijdende arbeidskrachten. Voorts groeide de actieve arbeidsmarktbevolking in Luxemburg sterk, voortkomend uit groei in zowel nationale bevolking als groei in aantal grensarbeiders. In 2004 is dit aantal meer dan verdubbeld in vergelijking met 1998. Door deze veranderingen vergrootte de cross-sectionele inkomensongelijkheid.

Bouwend op een buitengewoon uitgebreide dataset gebaseerd opadministratieve gegevens van professionele carrières, deel ik de groei van inkomensongelijkheid in 
Luxemburg in permanente en tijdelijke componenten. Tevens bestudeer ik de verandering van de inkomensongelijkheid en inkomensmobiliteit. De verandering in de structuur van de arbeidsmarkt leidde tot een grotere inkomensongelijkheid tussen 1988 en 2004. Dit weerspiegelt een groter wordende lange termijn verschillen tussen individuen, hetgeen gepaard gaat met minder inkomensmobiliteit. Dit houdt in dat individuen met lagere inkomens minder kansen hebben om hun inkomenspositie over hun leven te verbeteren. 


\section{CURRICULUM VitAE}

Name:

Denisa Maria Sologon

E-mail: denisa.sologon@maastrichtuniversity.nl

Date and place of birth: 4 March 1981, Brasov, Romania

Gender:

Female

Nationality:

Romanian

\section{Research Interests}

Themes: welfare and labour economics, applied econometrics, dynamic microsimulation

Particulars: income distribution dynamics, income mobility, estimation and projection of age-earning profiles and lifetime labour supply using panel data econometrics, lifetime intra-generational redistributive effects of public pension systems, static and dynamic microsimulation techniques

\section{Education}

January 2010: Fifth Winter School on Inequality and Collective Welfare Theory (IT5): "Inequality in a Dynamic Perspective", University of Verona, Italy

January 2009 - June 2009: Visiting Research Fellow, Harvard University, Harvard Kennedy School of Government

May 2009: IZA Summer School, Germany

July-August 2008: Essex Summer School in Econometrics, The UK

July 2007: Essex Summer School in Econometrics, The UK

June 2007: Wageningen Summer School in Economatrics, The Netherlands

February 200: Training in microsimulation, UCL, the UK

September 2005 - : PhD in European Social Protection Policy, Maastricht University, Maastricht Graduate School of Governance

September 2004 - August 2005: MSc International Master in Social Policy Analysis, Katholieke Universiteit Leuven, Leuven, Belgium.

September 2003 - January 2004: Period Abroad, Lund University, Sweden 
September 2000 - June 2004: BA in Economics, Transylvania University, Brasov, Romania

\section{Academic Awards}

September 2008 - August 2010: AFR Scholarship, National Research Fund, Luxembourg

September 2005-August 2008: Marie Curie Fellowship, Maastricht University, Netherlands

September 2004 - August 2005: IMPALLA Scholarship, CEPS/INSTEAD Luxembourg

\section{Academic Affiliations}

Research Affiliate, IZA, Bonn, 2010 -

Research Fellow, Maastricht Graduate School of Governance, Maastricht University, 2005 -

Visiting Fellow, Harvard Kennedy School of Government, Harvard University 2009

\section{Relevant Work Experience}

Netherlands (2005-2010), Marie Curie Research Fellow, Universiteit Maastricht, Maastricht, the Netherlands

\section{Relevant Project Experience}

The Netherlands and Luxembourg (2007-2010), team member and researcher in the project - "Coherence of social transfer policies and microsimulation" within the program "Living tomorrow in Luxembourg" organized by Inspection Généralé de la Securité Sociale (IGSS Luxembourg), CEPS/ INSTEAD (Luxembourg), CREPP Institute, Université de Liège, (Belgium) and Maastricht Graduate School of Governance (MGSOG), Maastricht University.

Research Interest - the lifetime intra-generational redistribution of the General Pension System in Luxembourg 
The Netherlands (2006), researcher in the EC project organized by Maastricht Graduate School of Governance in cooperation with Arcadis: "Assessment of the labour market impact of the pension reform in the Russian Federation".

Research interest: the Russian pension reform in an international perspective; retirement age around the world.

The Netherlands (2006), Content tutor for UNICEF staff, "Learning Program on Public Policy, Advocacy and Partnership for Children's Rights", Maastricht Graduate School of Governance, Maastricht University

\section{Relevant teaching experience}

Course Lecturer and Tutor: "Public Economics and Empirical Analysis", Master Program in Public Policy, Maastricht Graduate School of Governance, Maastricht University, The Netherlands $(2009,2008,2007)$

Course Lecturer and Tutor: "Introduction to Econometrics using STATA", Master Program in Public Policy, Maastricht Graduate School of Governance, Maastricht University, The Netherlands (2009)

Course Lecturer and Tutor: "Introduction to STATA", Master Program in Public Policy, Maastricht Graduate School of Governance, Maastricht University, The Netherlands $(2009,2008,2007)$

Course Lecturer: "Analysis of Policy Processes", PhD Program in Governance and Policy Analysis Dual Career, Maastricht Graduate School of Governance, Maastricht University, The Netherlands (2008)

Course Lecturer: "Essentials of Policy Analysis", PhD Program in Governance and Policy Analysis, Maastricht University, The Netherlands (2008)

Lecturer: "Theory of Insurance", Social Protection Financing Master Program, Maastricht Graduate School of Governance, Maastricht University, The Netherlands $(2008,2007,2006)$

Lecturer: "Pension reforms around the world" within the course "Comparative Analysis of Social Protection Policy", Social Protection Financing and Public Policy Master Programs, Maastricht Graduate School of Governance, Maastricht University, The Netherlands (2006)

Content tutor for UNICEF staff, "Learning Program on Public Policy, Advocacy and Partnership for Children's Rights", Maastricht Graduate School of Governance, Maastricht University, The Netherlands (2006) 
Assisting Supervision of Social Protection Financing Master Theses, Maastricht Graduate School of Governance, Maastricht University, The Netherlands (2006)

Thesis Supervision for students enrolled in the Master Program in Public Policy, Maastricht Graduate School of Governance, Maastricht University, The Netherlands (2008-2009)

\section{Selected Publications}

Sologon, Denisa M. 2010. Earnings dynamics in Europe, PhD thesis, Maastricht University.

Sologon, Denisa M., and O'Donoghue, Cathal. 2009. Earnings dynamics and inequality in EU, 1994-2001. (Revised and Resubmitted to Labour Economics); IZA Working Series, No. 4012; MGSOG Working Series(December); SOEPpapers on Multidisciplinary Panel Data Research, No. 184.

Sologon, Denisa M., and O'Donoghue, Cathal. 2009. Equalizing or disequalizing lifetime earnings differentials? Earnings mobility in the EU: 1994-2001. IZA Working Series, 4642(December), SOEPpapers on Multidisciplinary Panel Data Research, No. 251, MGSOG Working Series(December).

Sologon, Denisa M., and O'Donoghue, Cathal. 2009. Increased Opportunity to Move Up the Economic Ladder? Earnings Mobility in EU: 1994-2001. IZA Working Series, No. 4311(July); SOEPpapers on Multidisciplinary Panel Data Research, No. 221; MGSOG Working Series(December).

Sologon, Denisa M., and O'Donoghue, Cathal. 2009. Policy, Institutional Factors and Earnings Mobility. IZA Working Series, No. 4151(April); SOEPpapers on Multidisciplinary Panel Data Research, No. 183.

Sologon, Denisa M. 2009. Earnings Dynamics and Inequality among Men in Luxembourg, 1988-2004: Evidence From Administrative Data. MGSOG Working Series (December).

Li, J., Sologon, D.M. Simulating Labour Supply: A Lifetime Modelling Approach with Heterogeneity and Uncertainty Extension, MGSOG Working Paper, November 2007

Neubourg, C. and Sologon, D.M. The Russian Pension Reform in an International Perspective, mimeographed, Maastricht, September 2006

Neubourg, C. and Sologon, D.M. Retirement Age around the World, mimeographed Maastricht, September 2006 
Sologon D. M. The Governance of the General Pension Scheme in Grand-Duchy of Luxembourg, MGSOG Working Paper, January 2005

Sologon, D.M. The Redistribution Effects of Public Pension Schemes - the case of the Luxembourg General Pension Scheme, Master Thesis, KU Leuven, Belgium, July 2005

\section{Miscellaneous}

Referee for The Berkeley Electronic Journal of Economic Analysis \& Policy

Maastricht, April 15, 2010 


\section{MAASTRICHT GraduATE SCHOOL OF GOVERNANCE DISSERTATION SERIES}

Geranda Notten

Measuring and Managing Poverty Risks

Maastricht Graduate School of Governance Dissertation Series, nr. 1 (2008)

Britta Augsburg

Microfinance - Greater Good or Lesser Evil?

Maastricht Graduate School of Governance Dissertation Series, nr. 2 (2009)

Christiane Arndt

Governance Indicators

Maastricht Graduate School of Governance Dissertation Series, nr. 3 (2009)

Mirtha R. Muniz Castillo

Human Development and Autonomy in Project Aid: Experiences from four bilateral projects in Nicaragua and El Salvador

Maastricht Graduate School of Governance Dissertation Series, nr. 4 (2009)

Jessica S. Hagen-Zanker

Modest expectations: Causes and effects of migration on migrant households in source countries

Maastricht Graduate School of Governance Dissertation Series, nr. 5 (2010)

Melissa Siegel

Money and Mobility: Migration and Remittances

Maastricht Graduate School of Governance Dissertation Series, nr. 6 (2010)

Denisa Maria Sologon

Earnings Dynamics in Europe

Maastricht Graduate School of Governance Dissertation Series, nr. 7 (2010) 